Instituto de Agroquímica y Tecnología de Alimentos Consejo Superior de Investigaciones Científicas
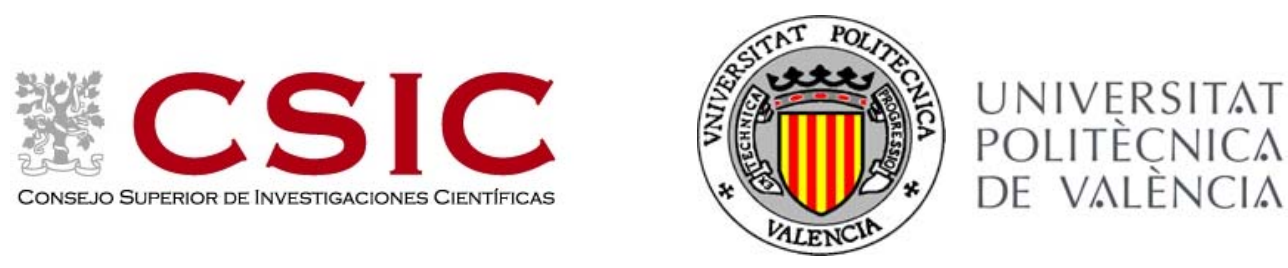

\title{
Study of short-wave ultraviolet treatments (UV-C) as a non-thermal preservation process for liquid egg products
}

\author{
DOCTORAL THESIS
}

Presented by:

Poliana Mendes de Souza

Directed by:

Avelina Fernández García

\author{
Valencia \\ July / 2012
}





\section{Dra. AVELINA FERNANDEZ GARCIA,}

HACE CONSTAR: Que el presente trabajo intitulado "Study of shortwave ultraviolet treatments (UV-C) as a non-thermal preservation process for liquid egg products" ha sido realizado bajo su dirección en el Instituto de Agroquímica y Tecnología de Alimentos del CSIC, en Valencia, por la Licenciada en Ingenieria de Alimentos y Master en Ingenieria de Alimentos POLIANA MENDES DE SOUZA para optar al grado de Doctora en Tecnología de Alimentos por la Universidad Politecnica de Valencia.

Valencia, 09 de Julio de 2012.

Dra. Avelina Fernandez Garcia

Avda. Agustín Escardino, 7 46980 PATERNA (VALENCIA). ESPAÑA 



\title{
Thesis committee
}

\author{
Maria Montserrat Ferrando Cogollos - President \\ Universitat Rovira i Virgili (Tarragona/Spain)
}

\author{
$\overline{\text { Claudia Monika Haros - Secretary }}$ \\ Instituto de Agroquímica y Tecnología de Alimentos (Paterna / Spain) \\ Bernhard Trierweiler - Vocal \\ Max Rubner-Institut (Karlsruhe / Germany) \\ Jean-Claude Laguerre - Vocal \\ Institut Polytechnique LaSalle Beauvais (Beauvais / France) \\ Pierre Picouet - Vocal \\ Institut de Recerca i Tecnologia Agroalimentàries (Monells / Spain) \\ Jordi Saldo Periago \\ Universitat Autònoma de Barcelona (Barcelona / Spain) \\ José Vicente Gil \\ Universitat de València (Paterna / Spain)
}



This thesis is dedicated

to my beloved parents,

Teide and Losé. 

This thesis is dedicated to my wonderful husband Âtrane. 

"The aim of science is not to open the door to infinite wisdom, but to set a limit to infinite error."

(Bertolt Brecht)

"A theory is something nobody believes, except the person who made it. An experiment is something everybody believes, except the person who made it."

(Albert Einstein)

"If it can't be expressed in figures, it is not science; it is opinion."

(Lazarus Long) 

Acknowledgements

This doctoral work was carried out between November/2007 and June/2012, at the Instituto de Agroquímica y Tecnología de Alimentos, Spain. It would not have been possible its realization without the help and support of some kind people around me, to only some of whom it is possible to give particular mention here.

I wish to thank the Generalitat Valenciana for its financial support through the grants BFPI/2008/230 "Progama2+2 - Becas para la Formación de Personal Investigador de Carácter Predoctoral” and BEFPI/2011/027 "Becas para Estancias Predoctorales fuera de Comunitad Valenciana". The latter has allowed me to spend part of my $\mathrm{PhD}$ studies at Max-Rubner Institut in Karlsruhe, Germany. Additionally, I would like to express my appreciation to the CSIC/IATA, in special to the Department of Conservation and Quality, for placing its facilities at my disposal.

Thanks to Dr. H. Brod, Dr. M. Poggel and Ms. M. Wübben from Bayer Technology Services, and Dr. José Salas from UVConsulting Spain for their kind support and supply of the UV-C reactor (UVivatec ${ }^{\circledR}$ ), UV chamber, and 4 lamps positive geometry reactor. 
Acknowledgements

I am thankful to my supervisor $\operatorname{Dr}^{\mathrm{a}}$. Avelina Fernandéz for her support and advice throughout this thesis. Thanks to my tutors at the university $\operatorname{Dr}^{\mathrm{a}}$. Isabel Hernando and Dr. Guillermo Palau. And thanks to Dr. Chema Lagarón, Dra ${ }^{\mathrm{a}}$. Maria José Ocio, Dr ${ }^{\mathrm{a}}$. Pilar Hernandez, Dr. Rafael Gavara, Dr. Ramon Catala and $\operatorname{Dr}^{\mathrm{a}}$. Susana Fizmann whose were responsible to bring me to Spain, and later to provide good advices and support.

I would like to express my gratitude to the revisors of the manuscript, $\mathrm{Dr}^{\mathrm{a}}$. Mariza Landgraf (USP/Brazil), Dr. Peter Butz (MRI/Germany) and Dr. Craig Leadley (Campden BRI/England). And to my thesis court, Dr $^{\mathrm{a}}$. Maria Montserrat Ferrando Cogollos (URV/Spain), Dra ${ }^{\mathrm{a}}$. Claudia Monika Haros (IATA/Spain), Dr. Bernhard Trierweiler (MRI/Germany), Dr. Jean-Claude Laguerre (LaSalle Beauvais/France), Dr. Pierre Picouet (IRTA/Spain), Dr. Jordi Saldo Periago (UAB/Spain) and Dr. José Vicente Gil (UV/Spain).

The best and worst moments of my doctoral studies journey have been shared with many people. I am indebted to my many student colleagues for providing a stimulating and fun environment in which to learn and grow. I am especially grateful to Arlette Santacruz Lopez, Carolina Dicastillo, Mari Pau Balaguer, José Pascual Cerisuelo, Laura Higueras, Marta Calatayoud, Marta Vazquez, Rene Rocha Barrasa, and Virginia Muriel Galet. Who played such important roles along the journey, as we mutually engaged in making sense of the various challenges we faced and in providing encouragement to each other at those times when it seemed impossible to continue. Thanks also to some colegues with whom I had less contact but also contributed to this thesis: Elizabeth Carrillo Alava, Laura Laguna, 
Carla Arancibia Aguilar, Bruno Motta Oliveira. Edson Pablo da Silva, Francisca Vanessa Manzanares. I also offer my special gratitude and appreciation to $\mathrm{Dr}^{\mathrm{a}}$. Gracia Carballo to have supported me through out the whole of this work providing encouragement, sound advice, good teaching and lots of good ideas.

I would like to acknowledge the assistance given to me by the IATA staff: Ali Abour Cañadas, Ana Cristina Adam Traver, Ana Lopez, Ana Veyrat Ferrerm, Caty Segura, Daniel Alberto Gómez Sanchez, Elvira Bellver Traver, Fernando Lopez Santoveña, Fran Garcia, José Francisco Fabregat Loyo, José Vicente Gimeno Alcañiz, Ignacio Galdeano Richart, Maria Dolores Gil Garcia, Mariano Rodriguez Moya and Vicente Lopez Perez, And some IATA researchers: Dr ${ }^{\mathrm{a}}$. Elvira Costell Ibañez, Dr ${ }^{\mathrm{a}}$. Ana Salvador Alcaraz, Dr ${ }^{\mathrm{a}}$. Vicenta Angela Devesa Perez, Dr ${ }^{\mathrm{a}}$. Maria Dinoraz Velez Pacios, Dr ${ }^{\mathrm{a}}$. Patricia Roig Montoya, Dr ${ }^{\mathrm{a}}$. Maria Amparo Tarrega Guillem.

During my PhD I had the great opportunity to do 6 months internship at the Max-Rubner Institut in Karlsruhe/Germany. And I would like to thank Dr. Mario Stahl for accepting me at his team and specially for his valuable friendship and technical guidance. I am also grateful to Alexandra Müller, my partner during my internship, for her help, special attention and to "take care" of me as a non german speaker in german territory.

I also would like to give my gratitude to my roommate Natalia Garrido Nuero and her entire family, for the time with laughter and mutual encouragement, and for their care. 
Finally, I wish to express my appreciation to my dearest ones. My parents, Cleide and José, who have been sources of encouragement and inspiration to me throughout the entire $\mathrm{PhD}$ period. Besides bore me, raise me, and love me, they actively supported me in my determination to find and realise my potential. My sister, Diana, who, on her way, has given me unequivocal support. And my husband, Adnane, whose dedication, love and persistent confidence in me, has taken the load off my shoulder. They have lost a lot due to my research abroad and without their encouragement and understanding it would have been impossible for me to finish this work.

Most of all, thanks to God, Who continues to make the impossible possible.

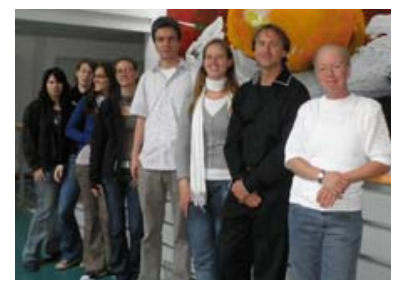

Muito obrigada !!
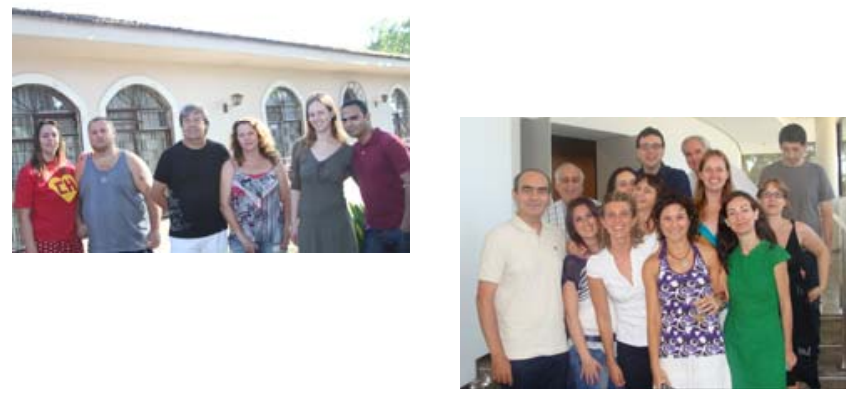
Summary, List of figures, List of tables and List of symbols 



\section{Summary}

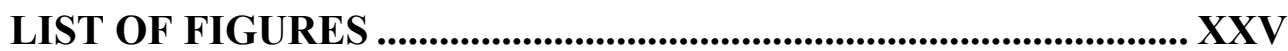

LIST OF TABLES …............................................................. XXXV

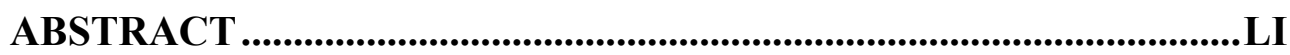

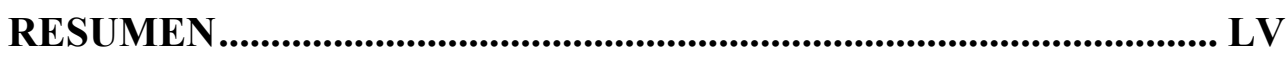

RESUM ………...........................................................................................LIX

ZUSAMMENFASSUNG ................................................................XIII

RESUME................................................................................................. LXVII

1. INTRODUCTION.........................................................................................

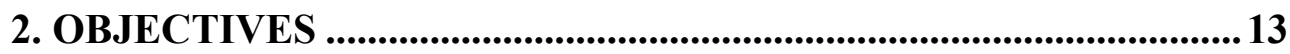

3. LITERATURE REVIEW....................................................................17

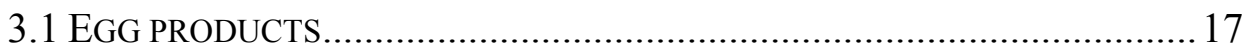

3.1.1. Structure and chemical properties .......................................... 17

3.1.1.1 Egg white .......................................................................... 18

3.1.1.2 Egg yolk …………………………………………..... 19

3.1.1.3 Liquid whole egg ……………………………………......... 20

3.1.2 Nutritive Value of Eggs ............................................................ 21

3.1.3 Functionality of Eggs ........................................................... 23

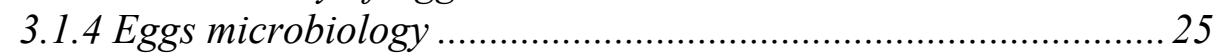

3.1.4.1 Salmonella in eggs .............................................................. 26

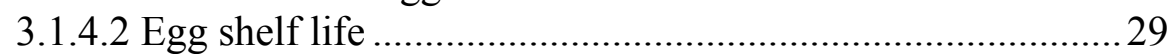

3.1.5 Manufacturing of Liquid Egg Products .......................................... 30

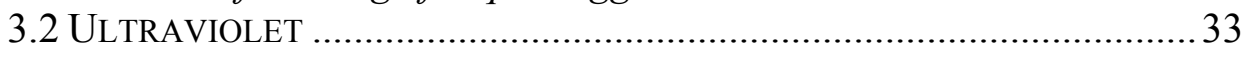

3.2.1 Definition and general concepts .................................................. 33

3.2.2 Mechanisms of UV-Light generation ............................................. 39

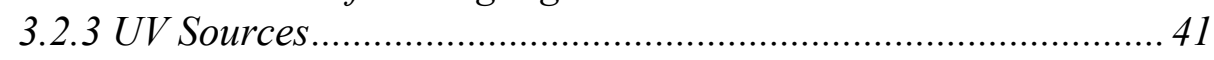

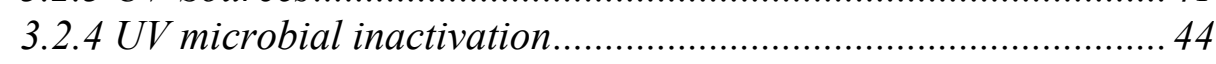

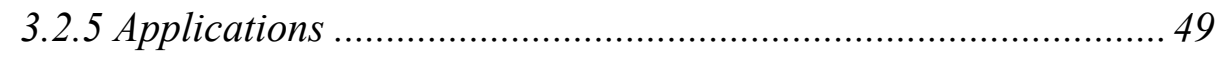

3.2.5.1 UV Systems in liquids........................................................... 51

3.2.6 Advantages and limitations of UV technology .............................57

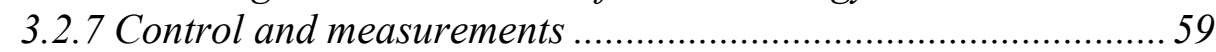

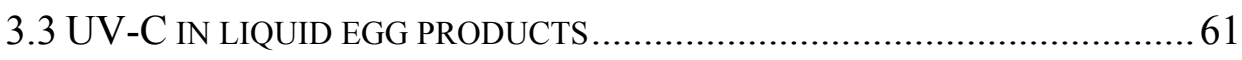




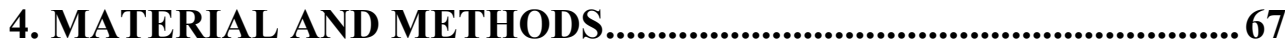

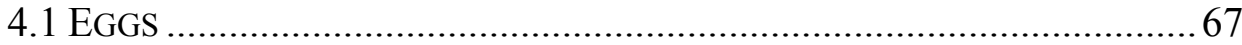

4.2 EXPERIMENTAL METHODOLOGY ....................................................... 70

4.2.1 IATA Bench scale equipment ..................................................... 74

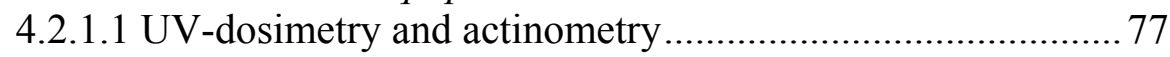

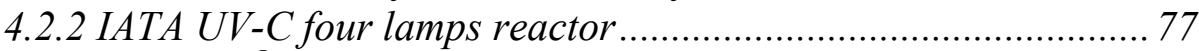

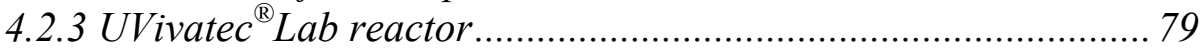

4.2.4 MRI 2010 UV-C reactor........................................................... 82

4.2.4.1 UV-C dosimetry and Dean vortex technology.................... 83

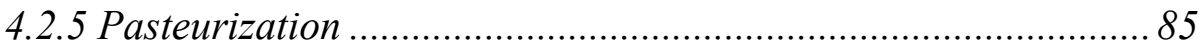

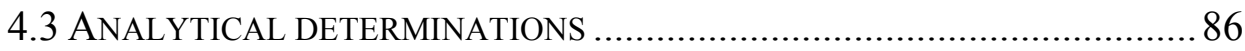

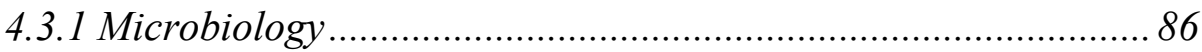

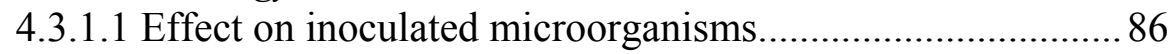

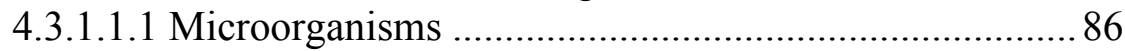

4.3.1.1.2 Effects of UV-C on the inactivation of inoculated

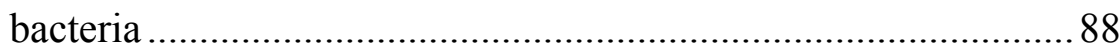

4.3.1.1.3 Fitting of kinetic data ................................................. 90

4.3.1.2 Effects of UV-C on the inactivation of spoilage-related

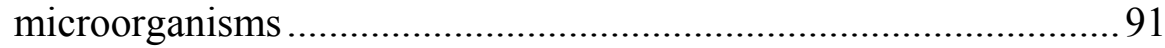

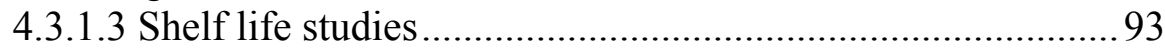

4.3.2 Physical-chemical analysis ................................................... 95

4.3.2.1 Optical properties: transmittance and absorbance............... 95

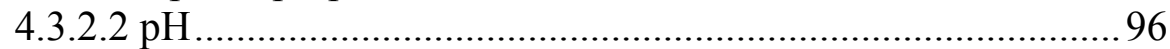

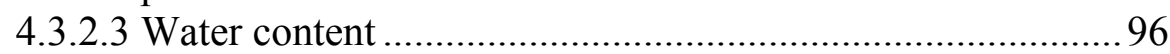

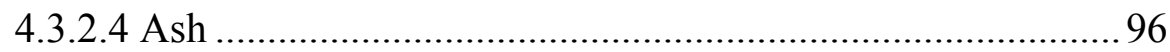

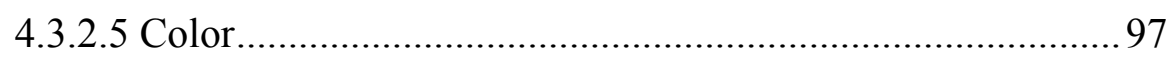

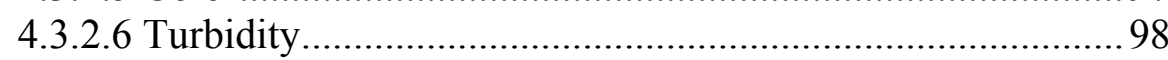

4.3.2.7 Differencial scanning calorimetry (DSC) ........................... 98

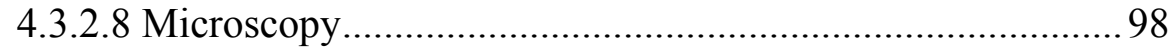

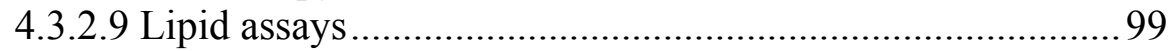

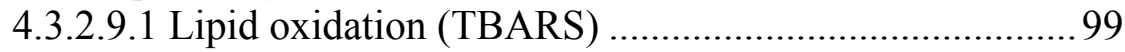

4.3.2.9.2 Peroxides value (PV) .................................................... 100

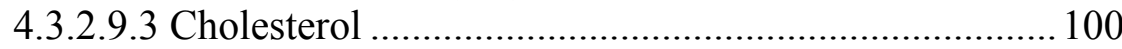

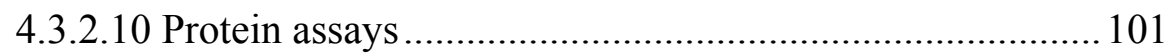

4.3.2.10.1 Total protein determination...................................... 101

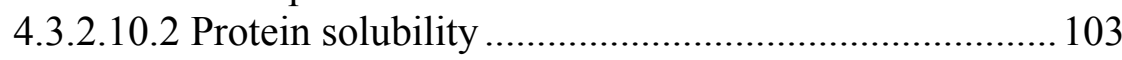

4.3.2.10.3 Protein oxidation: sulfhydryl content....................... 103

4.3.2.10.4 Electrophoresis ....................................................... 104 
4.3.2.11 Rheological properties .................................................... 105

4.3.2.11.1 Viscosity measurement as a function of shear rate ... 105

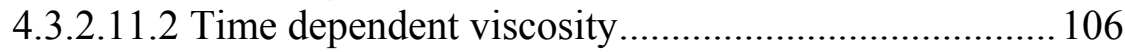

4.3.2.11.3 Temperature dependent viscosity............................. 106

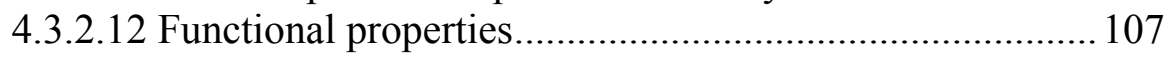

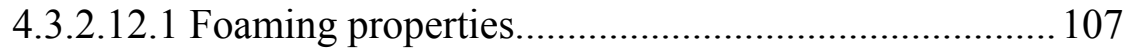

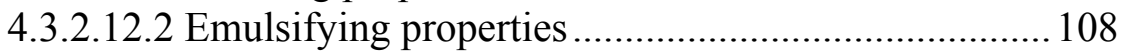

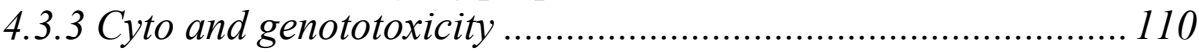

4.3.3.1 Caco-2 cell culture ......................................................... 110

4.3.3.2 Cytotoxicity in cell viability assays: Calcein assay ........... 111

4.3.3.3 Genotoxicity: Comet assay ............................................ 111

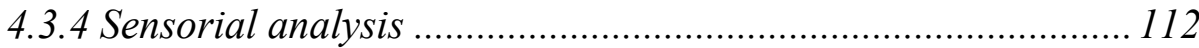

4.3.4.1 Preparation of egg-containing foods .................................. 113

4.3.4.1.1 Preparation of cooked eggs ......................................... 113

4.3.4.1.2 Preparation of mayonnaise ......................................... 113

4.3 4.1.3 Preparation of puddings ............................................ 114

4.3.4.1.4 Preparation of angel cakes ......................................... 114

4.3.4.2 Evaluation of sensory differences ..................................... 115

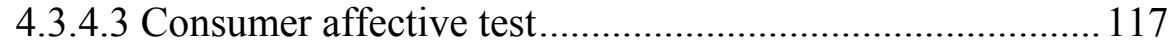

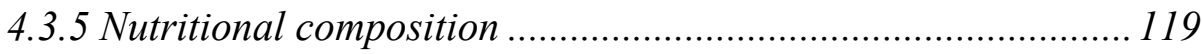

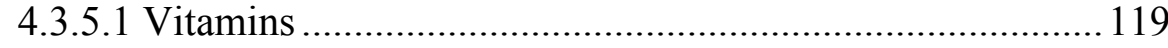

4.3.5.1.1 Ascorbic acid (vitamin C) ............................................ 119

4.3.5.1.2 Pantothenic acid (vitamin $\mathrm{B}_{5}$ ) ...................................... 119

4.3.5.1.3 Riboflavin (vitamin $\mathrm{B}_{2}$ )........................................ 120

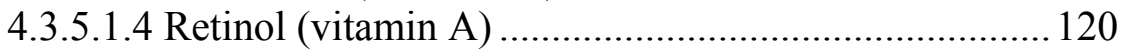

4.3.5.1.5 Tocopherol (vitamin E) ............................................... 122

4.3.5.2 Carotenoids (lutein and zeaxanthin).................................. 122

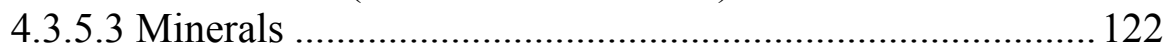

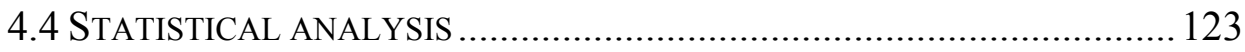

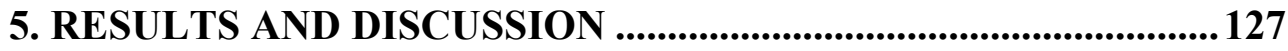

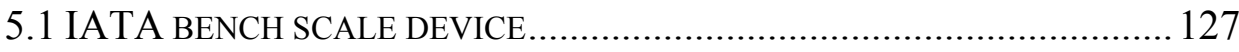

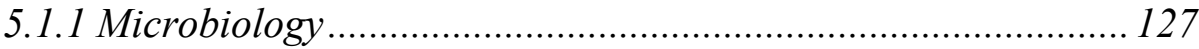

5.1.1.1 Effects on inoculated microorganisms .............................. 128

5.1.1.2 UV-C inactivation of spoilage-related microorganisms .... 140

5.1.2 Physicochemical parameters ............................................. 148

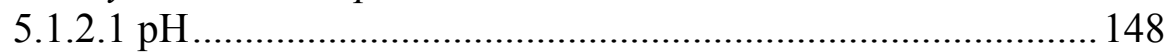

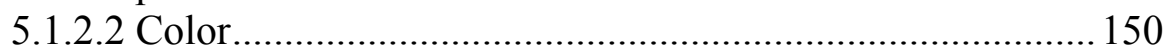

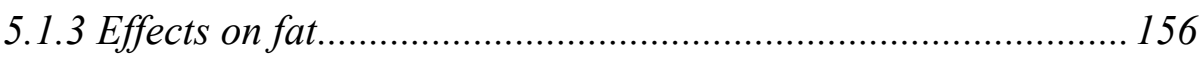




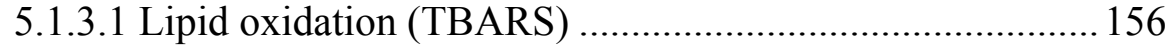

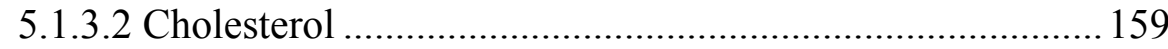

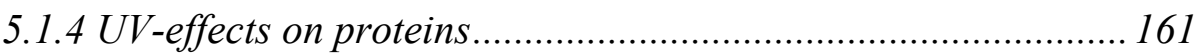

5.1.4.1 Total protein and protein solubility................................... 161

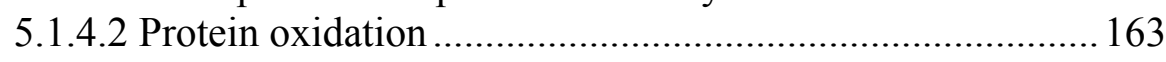

5.1.4.3 Thermodynamic properties (Differential scanning

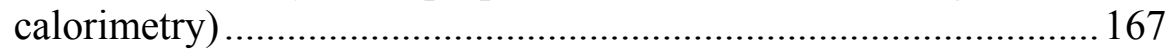

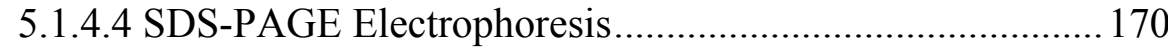

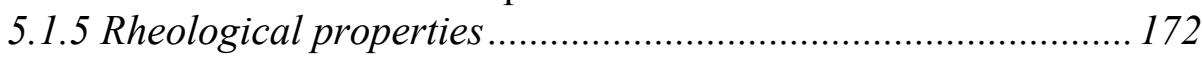

5.1.5.1 Dynamic viscosity (Shear-dependent viscosity) ................ 172

5.1.5.2 Time dependent viscosity............................................... 175

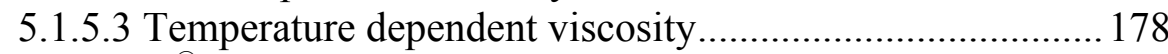

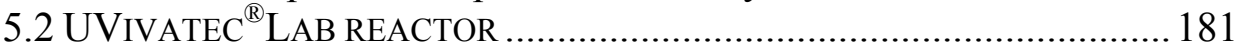

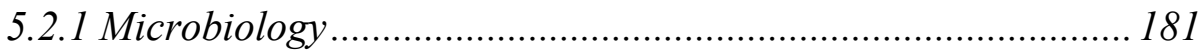

5.2.1.1 UV-C Inactivation kinetics of inoculated microorganisms 182

5.2.1.2 Effects on naturally occurring microorganisms ................. 186

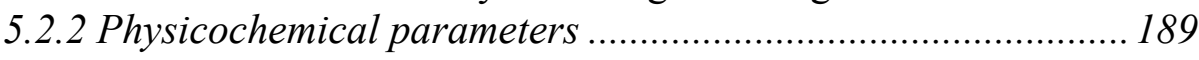

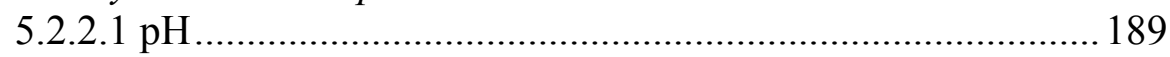

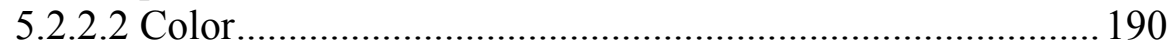

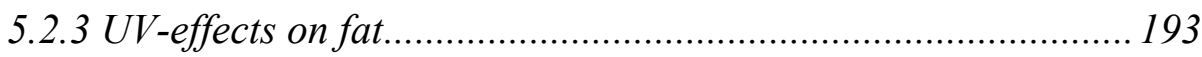

5.2.3.1 Lipid oxidation (TBARS) ................................................. 193

5.2.3.2 Peroxide value (PV) .......................................................... 196

5.2.4 UV-effects on proteins: Protein oxidation ................................ 198

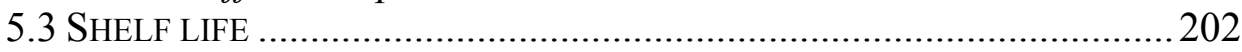

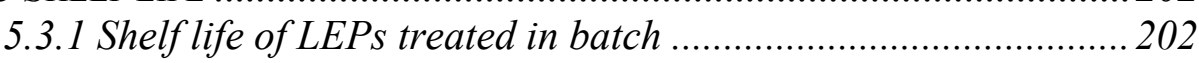

5.3.1.1 Microbiology................................................................. 203

5.3.1.2 Evolution of physicochemical parameters during shelf-life

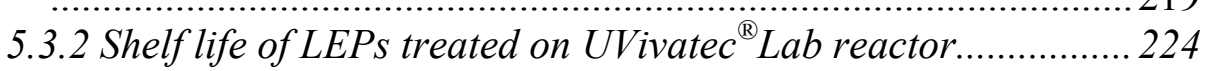

5.3.2.1 Microbiology................................................................ 224

5.3.2.2 Evolution of physicochemical parameters during shelf-life

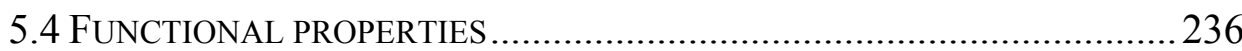

5.4.1 Foaming properties .............................................................. 236

5.4.2 Emulsifying properties .......................................................... 245

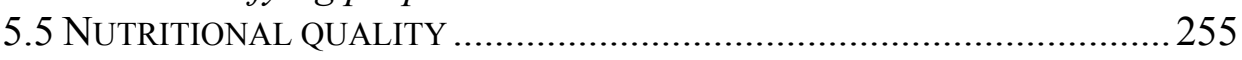

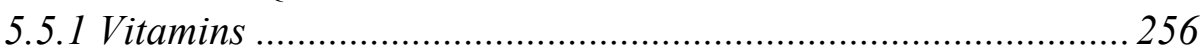

5.5.1.1 Vitamin A................................................................... 257

xxii 


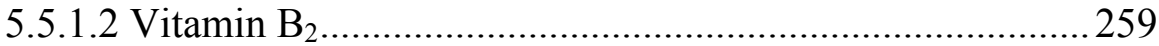

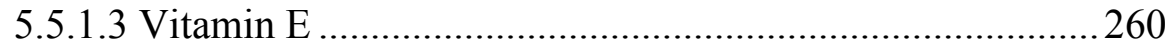

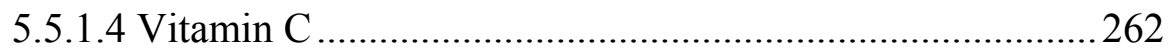

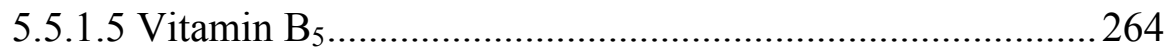

5.5.2 Carotenoids: Lutein and Zeaxanthin ..................................... 265

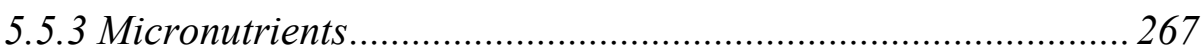

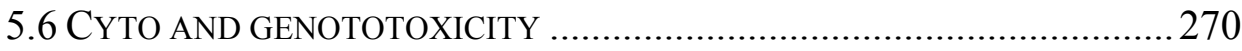

5.6.1 Effects on the vitality of the intestinal Caco-2 cells.................2270

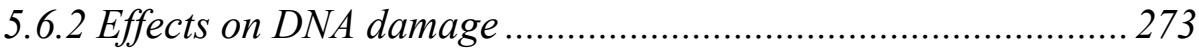

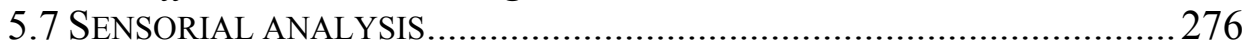

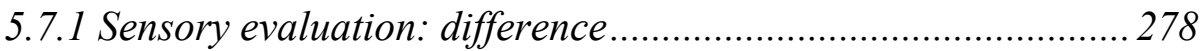

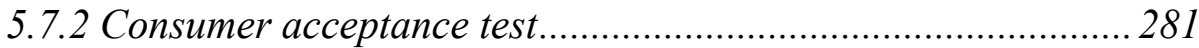

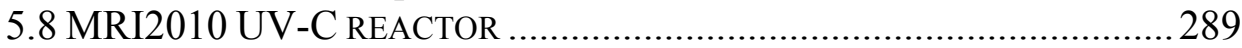

5.8.1 Microbiology: Effects on inoculated microorganisms .............. 290

6. CONCLUSIONS ................................................................................295

6.1 RECOMMENDATIONS AND FUTURE STUDIES.......................................298

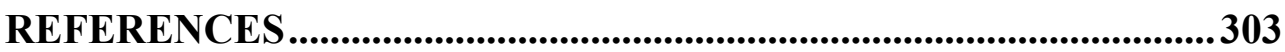

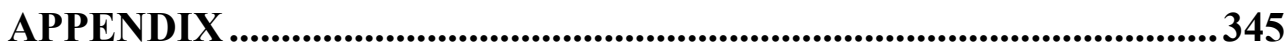

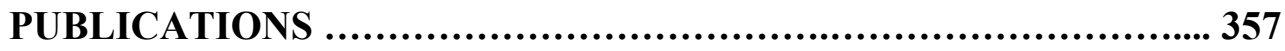





\section{List of figures}

Figure 3.1 - Egg structural components ................................................ 18

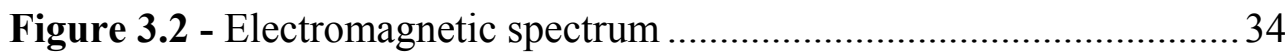

Figure 3.3 - Microbial DNA damage after UV exposure........................... 45

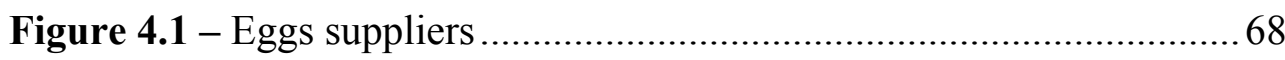

Figure 4.2 - Experimental methodology ............................................... 71

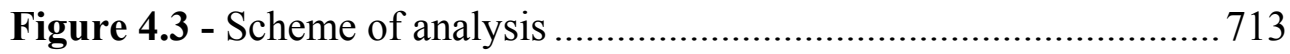

Figure 4.4 - IATA bench scale equipment scheme …........................... 75

Figure 4.5 - IATA UV-C four lamps reactor (a) Device ready to be used (b) Superior view of the treatment chamber (c) Device left view - motor detail (d) Device right view - detail of quartz tube and sample output78

Figure 4.6 - UVivatec ${ }^{\circledR} L a b$ reactor (a) Device appearance (b) Principle of

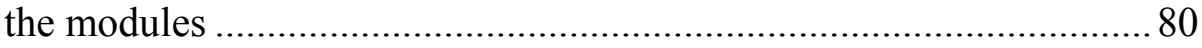

Figure 4.7 - MRI 2010 UV-C reactor (a) Device appearance (b) Principle

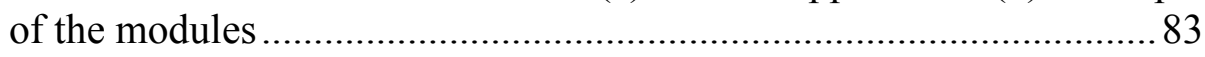

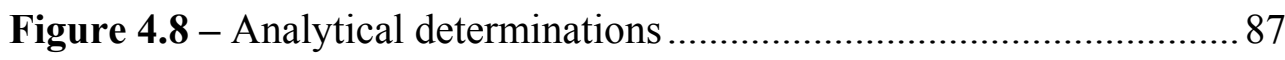

Figure 5.1 - Inactivation kinetics of Escherichia coli ATCC 11775 in (a) LEW (b) LWE and (c) LEY. Results are the mean of triplicate \pm standart deviation. 
List of figures

Figure 5.2 - Inactivation kinetics of Listeria innocua ATCC 33090 in (a) LEW (b) LWE and (c) LEY. Results are the mean of triplicate \pm standart deviation. 130

Figure 5.3 - Inactivation kinetics of Staphylococcus aureus ATCC 12600 in (a) LEW (b) LWE and (c) LEY. Results are the mean of triplicate \pm standart deviation.

Figure 5.4 - Inactivation kinetics of Salmonella enteritidis ATCC 13076 in (a) LEW (b) LWE and (c) LEY. Results are the mean of triplicate \pm standart deviation. 132

Figure 5.5 - Influence of UV-C on (a) Total Aerobic Mesophilic counts (TAM) (b) Total Anaerobic Mesophilic (TAnM) (c) Total Aerobic Psychrotrophic counts (TAP) and (d) Total Anaerobic Psychrotrophic counts (TAnP) inactivation under static or dynamic conditions on LEW. Results are the mean of triplicate \pm standart deviation. 143

Figure 5.6 - Influence of UV-C on (a) Total Aerobic Mesophilic counts (TAM) (b) Total Anaerobic Mesophilic (TAnM) (c) Total Aerobic Psychrotrophic counts (TAP) and (d) Total Anaerobic Psychrotrophic counts (TAnP) inactivation under static or dynamic conditions on LWE. Results are the mean of triplicate \pm standart deviation. 144

Figure 5.7 - Influence of UV-C on (a) Total Aerobic Mesophilic counts (TAM) (b) Total Anaerobic Mesophilic (TAnM) (c) Total Aerobic Psychrotrophic counts (TAP) and (d) Total Anaerobic Psychrotrophic counts (TAnP) inactivation under static or dynamic conditions on LEY. Results are the mean of triplicate \pm standart deviation. 145

Figure 5.8 - Natural, UV-treated and pasteurized LEW 155

Figure 5.9 - Natural, UV-treated and pasteurized LWE 155

Figure 5.10 - Natural, UV-treated and pasteurized LEY 155

Figure 5.11 - Influence of UV-C radiation on lipid oxidation of (a) LEY and (b) LWE. Results are the mean of triplicate \pm standart deviation. 
Different superscripts in each bar indicate difference statiscally significant at $95 \%$ confidence level 158

Figure 5.12 - Total and soluble proteins as affected by UV-C under dynamic and static conditions of (a) LEW (b) LWE and (c) LEY. Results are the mean of triplicate \pm standart deviation. 162

Figure 5.13 - Effect of UV-C treatment on the exposed, masked and total sulphydryl content of (a) LEW, (b) LWE and (c) LEY. Results are the mean of triplicate \pm standart deviation. 165

Figure 5.14 - Differential scanning calorimetry thermograms of (a) LEW, (b) LWE and (c) LEY. Untreated LEP (control), pasteurized, UV treated under dynamic and static conditions. Results are the mean of triplicate; standart deviation is bellow $5 \%$. 169

Figure 5.15 - SDS-PAGE analysis of (a) LEW, (b) LWE and (c) LEY. MW - Molecular weigh marker; NT - not treated sample; UV-D - UVtreated under dynamic conditions; UV-S - UV-treated under static conditions; $\mathrm{T}$ - pasteurized.

Figure 5.16 - Dynamic viscosity - share rate dependence for (a) LEW, (b) LWE and (c) LEY. Untreated LEPs (control), pasteurized, UV-C treated under dynamic conditions (UV-D), and UV-C treated under static conditions (UV-S). Results are the mean of triplicate, standart deviation is bellow $5 \%$ 174

Figure 5.17 - Flow behavior of (a) egg white, (b) whole egg and (c) egg yolk. Untreated LEPs (control), pasteurized, UV-C treated under dynamic conditions (UV-D), and UV-C treated under static conditions (UV-S). Results are the mean of triplicate, standart deviation is bellow $5 \%$. 177

Figure 5.18 - Temperature-dependent viscosity of (a) LEW, (b) LWE and (c) LEY. Untreated LEPs (control), pasteurized, UV-C treated under dynamic conditions (UV-D), and UV-C treated under static conditions (UV-S). Results are the mean of triplicate, standart deviation is bellow $5 \%$. 179 
List of figures

Figure 5.19 - UV-C inactivation of Escherichia coli DH5a, Listeria innocua WS 2258 and Salmonella subterranea DSM 16208 on (a) LEW, (b) LWE and (c) LEY as a function of the volumetric dose. Results are the mean of triplicate \pm standart deviation. 183

Figure 5.20 - Inactivation of naturally occurring microorganisms in LEPs treated by UV-C and pasteurized; (a) LEW, (b) LWE and (c) LEY. Results are the mean of triplicate \pm standart deviation. Dashed line represents detection limit $(1 \mathrm{Log})$. 187

Figure 5.21 - Natural, UV-treated and pasteurized LEW 192

Figure 5.22 - Natural, UV-treated and pasteurized LWE 192

Figure 5.23 - Natural, UV-treated and pasteurized LEY 192

Figure 5.24 - Influence of UV-C radiation on lipid oxidation of (a) LWE and (b) LEY. Results are the mean of triplicate \pm standart deviation. Different superscripts in each bar indicate difference statiscally significant at $95 \%$ confidence level 195

Figure 5.25 - Peroxide value (a) LWE (b) LEY. Results are the mean of triplicate \pm standart deviation. Different superscripts in each bar indicate difference statiscally significant at $95 \%$ confidence level .. 197

Figure 5.26 - Effect of UV-C treatment on the exposed, masked and total sulfhydryl content of (a) LEW (b) LWE and (c) LEY. Results are the mean of triplicate, standard deviation is less then $5 \%$. 200

Figure 5.27 - Changes in microorganisms of UV-C (2.088 J.mL ${ }^{-1}$ and $4.076 \mathrm{~J} . \mathrm{mL}^{-1}$ ) and heat pasteurized LEW during storage at $4{ }^{\circ} \mathrm{C}$. (a) TAM, (b) TAnM, (c) TAP, (d) TAnP, (e) LAB, (f) Yeast, (g) Pseudomonas spp. and (h) Enterobacteriacea. Results are the mean of triplicate \pm standart deviation. Dashed line represents the detection limit (1 Log). 205

Figure 5.27 (cont.) - Changes in microorganisms of UV-C (2.088 J.mL ${ }^{-1}$ and 4.076 J.mL ${ }^{-1}$ ) and heat pasteurized LEW during storage at $4{ }^{\circ} \mathrm{C}$. (a) 
TAM, (b) TAnM, (c) TAP, (d) TAnP, (e) LAB, (f) Yeast, (g) Pseudomonas spp. and (h) Enterobacteriacea. Results are the mean of triplicate \pm standart deviation. Dashed line represents the detection limit (1 Log). 206

Figure 5.28 - Changes in microorganisms of UV-C (2.088 J.mL $\mathrm{mL}^{-1}$ and 4.076 J.mL ${ }^{-1}$ ) and heat pasteurized LWE during storage at $4{ }^{\circ} \mathrm{C}$. (a) TAM, (b) TAnM, (c) TAP, (d) TAnP, (e) LAB, (f) Yeast, (g) Pseudomonas spp. and (h) Enterobacteriacea. Results are the mean of triplicate \pm standart deviation. Dashed line represents the detection limit $(1 \mathrm{Log})$. 207

Figure 5.28 (cont.) - Changes in microorganisms of UV-C $\left(2.088 \mathrm{~J} . \mathrm{mL}^{-1}\right.$ and $4.076 \mathrm{~J} . \mathrm{mL}^{-1}$ ) and heat pasteurized LWE during storage at $4{ }^{\circ} \mathrm{C}$. (a) TAM, (b) TAnM, (c) TAP, (d) TAnP, (e) LAB, (f) Yeast, (g) Pseudomonas spp. and (h) Enterobacteriacea. Results are the mean of triplicate \pm standart deviation. Dashed line represents the detection limit (1 Log). 208

Figure 5.29 - Changes in microorganisms of UV-C (2.088 J.mL ${ }^{-1}$ and 4.076 J.mL $\mathrm{mL}^{-1}$ ) and heat pasteurized LEY during storage at $4{ }^{\circ} \mathrm{C}$. (a) TAM, (b) TAnM, (c) TAP, (d) TAnP, (e) LAB, (f) Yeast, (g) Pseudomonas spp. and (h) Enterobacteriacea. Results are the mean of triplicate \pm standart deviation. Dashed line represents the detection limit (1 Log). 209

Figure 5.29 (cont.) - Changes in microorganisms of UV-C (2.088 J.mL $\mathrm{m}^{-1}$ and $4.076 \mathrm{~J} . \mathrm{mL}^{-1}$ ) and heat pasteurized LEY during storage at $4{ }^{\circ} \mathrm{C}$. (a) TAM, (b) TAnM, (c) TAP, (d) TAnP, (e) LAB, (f) Yeast, (g) Pseudomonas spp. and (h) Enterobacteriacea. Results are the mean of triplicate \pm standart deviation. Dashed line represents the detection limit (1 Log). 210

Figure 5.30 - Changes in microorganisms of UV-C $\left(2.088 \mathrm{~J}_{\mathrm{mL}} \mathrm{mL}^{-1}\right.$ and $4.076 \mathrm{~J} . \mathrm{mL}^{-1}$ ) and heat pasteurized LEW during storage at $4{ }^{\circ} \mathrm{C}$. (a) TAM, (b) TAnM, (c) TAP, (d) TAnP, (e) LAB, (f) Yeast, (g) Pseudomonas spp. and (h) Enterobacteriacea. Results are the mean of triplicate \pm standart deviation. Dashed line represents the detection limit $(1 \log )$ 
List of figures

Figure 5.30 (cont.) - Changes in microorganisms of UV-C (2.088 J.mL ${ }^{-1}$ and $4.076 \mathrm{~J} . \mathrm{mL}^{-1}$ ) and heat pasteurized LEW during storage at $4{ }^{\circ} \mathrm{C}$. (a) TAM, (b) TAnM, (c) TAP, (d) TAnP, (e) LAB, (f) Yeast, (g) Pseudomonas spp. and (h) Enterobacteriacea. Results are the mean of triplicate \pm standart deviation. Dashed line represents the detection limit $(1 \mathrm{Log})$.

Figure 5.31 - Changes in microorganisms of UV-C (2.088 J.mL $\mathrm{m}^{-1}$ and 4.076 J.mL ${ }^{-1}$ ) and heat pasteurized LWE during storage at $4{ }^{\circ} \mathrm{C}$. (a) TAM, (b) TAnM, (c) TAP, (d) TAnP, (e) LAB, (f) Yeast, (g) Pseudomonas spp. and (h) Enterobacteriacea. Results are the mean of triplicate \pm standart deviation. Dashed line represents the detection limit $(1 \mathrm{Log})$. 214

Figure 5.31 (cont.) - Changes in microorganisms of UV-C (2.088 J.mL $\mathrm{mL}^{-1}$ and $4.076 \mathrm{~J} . \mathrm{mL}^{-1}$ ) and heat pasteurized LWE during storage at $4{ }^{\circ} \mathrm{C}$. (a) TAM, (b) TAnM, (c) TAP, (d) TAnP, (e) LAB, (f) Yeast, (g) Pseudomonas spp. and (h) Enterobacteriacea. Results are the mean of triplicate \pm standart deviation. Dashed line represents the detection limit (1 Log) 215

Figure 5.32 - Changes in microorganisms of UV-C (2.088 J.mL ${ }^{-1}$ and 4.076 J.mL ${ }^{-1}$ ) and heat pasteurized LEY during storage at $4{ }^{\circ} \mathrm{C}$. (a) TAM, (b) TAnM, (c) TAP, (d) TAnP, (e) LAB, (f) Yeast, (g) Pseudomonas spp. and (h) Enterobacteriacea. Results are the mean of triplicate \pm standart deviation. Dashed line represents the detection limit $(1 \mathrm{Log})$. 216

Figure 5.32 (cont.) - Changes in microorganisms of UV-C (2.088 J.mL ${ }^{-1}$ and 4.076 J.mL ${ }^{-1}$ ) and heat pasteurized LEY during storage at $4{ }^{\circ} \mathrm{C}$. (a) TAM, (b) TAnM, (c) TAP, (d) TAnP, (e) LAB, (f) Yeast, (g) Pseudomonas spp. and (h) Enterobacteriacea. Results are the mean of triplicate \pm standart deviation. Dashed line represents the detection limit $(1 \mathrm{Log})$.

Figure 5.33 - Changes in microorganisms of UV-C (7491J.L $\left.{ }^{-1}\right)$ and heat pasteurized LEW during storage at $4{ }^{\circ} \mathrm{C}$. (a) TAM, (b) TAnM, (c) TAP, (d) TAnP, (e) LAB, (f) Yeast, (g) Pseudomonas spp. and (h) Enterobacteriacea. Results are the mean of triplicate \pm standart deviation. Dashed line represents the detection limit $(1 \mathrm{Log})$. 227 
Figure 5.33 (cont.) - Changes in microorganisms of UV-C (7491J.L $\left.{ }^{-1}\right)$ and heat pasteurized LEW during storage at $4{ }^{\circ} \mathrm{C}$. (a) TAM, (b) TAnM, (c) TAP, (d) TAnP, (e) LAB, (f) Yeast, (g) Pseudomonas spp. and (h) Enterobacteriacea. Results are the mean of triplicate \pm standart deviation. Dashed line represents the detection limit $(1 \mathrm{Log})$........... 228

Figure 5.34 - Changes in microorganisms of UV-C (7491J.L $\left.{ }^{-1}\right)$ and heat pasteurized LWE during storage at $4{ }^{\circ} \mathrm{C}$. (a) TAM, (b) TAnM, (c) TAP, (d) TAnP, (e) LAB, (f) Yeast, (g) Pseudomonas spp. and (h) Enterobacteriacea. Results are the mean of triplicate \pm standart deviation. Dashed line represents the detection limit $(1 \mathrm{Log})$. 229

Figure 5.34 (cont.) - Changes in microorganisms of UV-C (7491J.L $\left.\mathrm{L}^{-1}\right)$ and heat pasteurized LWE during storage at $4{ }^{\circ} \mathrm{C}$. (a) TAM, (b) TAnM, (c) TAP, (d) TAnP, (e) LAB, (f) Yeast, (g) Pseudomonas spp. and (h) Enterobacteriacea. Results are the mean of triplicate \pm standart deviation. Dashed line represents the detection limit $(1 \mathrm{Log})$...........230

Figure 5.35 - Changes in microorganisms of UV-C (47299J.L $\left.\mathrm{L}^{-1}\right)$ and heat pasteurized LEY during storage at $4{ }^{\circ} \mathrm{C}$. (a) TAM, (b) TAnM, (c) TAP, (d) TAnP, (e) LAB, (f) Yeast, (g) Pseudomonas spp. and (h) Enterobacteriacea. Results are the mean of triplicate \pm standart deviation. Dashed line represents the detection limit $(1 \mathrm{Log})$. 231

Figure 5.35 (cont.) - Changes in microorganisms of UV-C (47299J.L $\left.\mathrm{L}^{-1}\right)$ and heat pasteurized LEY during storage at $4{ }^{\circ} \mathrm{C}$. (a) TAM, (b) TAnM, (c) TAP, (d) TAnP, (e) LAB, (f) Yeast, (g) Pseudomonas spp. and (h) Enterobacteriacea. Results are the mean of triplicate \pm standart deviation. Dashed line represents the detection limit $(1 \mathrm{Log})$. 232

Figure 5.36 - Effect of UV irradiation on foaming ability and stability of (a) LEW (b) LWE and (c) LEY treated on the IATA bench device with continuous stirring. Results are the mean of triplicate \pm standart deviation. Different bars superscripts, for each analyse, indicate difference statiscally significant at $95 \%$ confidence level 239

Figure 5.37 - Effect of UV irradiation on foaming ability and stability of (a) LEW (b) LWE and (c) LEY treated on the IATA bench device without 
List of figures

continuous stirring. Results are the mean of triplicate \pm standart deviation. Different bars superscripts, for each analyse, indicate difference statiscally significant at $95 \%$ confidence level 240

Figure 5.38 - Effect of UV irradiation on foaming ability and stability of (a) LEW (b) LWE and (c) LEY treated on the UVivatec ${ }^{\circledR} L a b$ reactor with continuous stirring. Results are the mean of triplicate \pm standart deviation. Different bars superscripts, for each analyse, indicate difference statiscally significant at $95 \%$ confidence level. 243

Figure 5.39 - Appearance of foams prepared with (a) control untreated LEW (b) LEW UV-C treated in the IATA bench equipment -9.22 J.mL ${ }^{-1}$ (c) LEW UV-C treated on UVivatec ${ }^{\circledR}$ Lab reactor - 20133 J.L $^{-1}$ (d) control untreated LEY (e) LEY UV-C treated in the IATA bench equipment - $9.22 \mathrm{~J} . \mathrm{mL}^{-1}$ (f) LEY UV-C treated on UVivatec ${ }^{\circledR} \mathrm{Lab}$ reactor $-115619 \mathrm{~J} . \mathrm{L}^{-1}$ 244

Figure 5.40 - Effect of UV irradiation on emulsifying activity index of (a) LEW (b) LWE and (c) LEY treated the IATA bench equipment with stirring. Results are the mean of triplicate \pm standart deviation......... 246

Figure 5.41 - Effect of UV irradiation on emulsifying activity index of (a) LEW (b) LWE and (c) LEY treated the IATA bench equipment with outstirring. Results are the mean of triplicate \pm standart deviation.... 247

Figure 5.42 - Effect of UV irradiation on emulsifying activity index of (a) LEW (b) LWE and (c) LEY treated on UVivatec ${ }^{\circledR}$ Lab reactor. Results are the mean of triplicate \pm standart deviation. 252

Figure 5.43 - Influence of UV-C exposure on retinol content of LWE and LEY. Results are the mean of triplicate \pm standart deviation. 258

Figure 5.44 - Effect of UV-C irradiation on ascorbic acid (vitamin C) content of LEW and LWE. Results are the mean of triplicate \pm standart deviation. 
Figure 5.45 - Influence of UV-C exposure on Luthein and Zeaxanthin content of LWE and LEY. Results are the mean of triplicate \pm standart deviation.

Figure 5.46 - Effect of (a) LEW (b) LWE and (c) LEY UV-C treated on viability of Caco-2 cells. Control cells were incubated in medium only (EMEM). Results are the mean of triplicate \pm standart deviation. Different superscripts for each concentration and control indicate difference statiscally significant at $95 \%$ confidence level 272

Figure 5.47 - Effect of LEPs on DNA strand breaks in Caco-2 cells. LEW UV-C: 20,133 J.L ${ }^{-1}$, LWE UV-C 32,181 J.L ${ }^{-1}$ and LEY UV-C 115,619 ${\mathrm{J} . \mathrm{L}^{-1}}^{-1}$. Results are the mean of triplicate \pm standart deviation. Different superscripts for bar indicate difference statiscally significant at $95 \%$ confidence level

Figure 5.48 - Hedonic scale grades attained by (a) LEW, (b) LWE, and (c) LEY. UV-C, treated with $4.176 \mathrm{~J} . \mathrm{cm}^{-2}$; Control, natural untreated LEPs. Results are the mean of triplicate. Standart deviation is bellow 5 $\%$. 282

Figure 5.49 - Hedonic scale grades attained by (a) cooked LEW, (b) cooked LWE, and (c) cooked LEY. UV-C, treated with $4.176 \mathrm{~J} . \mathrm{cm}^{-2}$; Control, natural untreated LEPs. Results are the mean of triplicate. Standart deviation is bellow $5 \%$ 284

Figure 5.50 - Hedonic scale grades attained by (a) mayonnaise, (b) pudding,

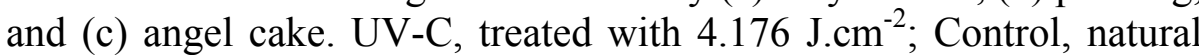
untreated LEPs. Results are the mean of triplicate. Standart deviation is bellow $5 \%$. 286

Figure 5.51 - Products prepared with LEPs. (a) (b) (c) Mayonnaise; (d) (e) (f) Pudding; (g) (h) (i) Angel cake. (a) (d) (g) Preparations with untreated LEPs; (b) (e) (h) Preparations with pasteurized LEPs; (c) (f) (i) Preparations with UV-C treated LEPs. 288

Figure 5.52 - UV-C inactivation of Escherichia coli DH5a, Listeria innocua WS 2258 and Salmonella subterranea DSM 16208 in LWE 
List of figures

treated at the MRI2010 UV-C reactor, as a function of the volumetric dose. Results are the mean of triplicate \pm standart deviation. 291

Figure A.1 - Scheme of dose calculation formulas - actinometry measurement 345

Figure A.2 - Actinometry calibration curbe 345

Figure A.3 - Inactivation kinetics of Salmonella enteritidis ATCC 13076 in LEW treated on the four lamps positive geometry device.... 355

Figure A.4 - Inactivation kinetics of Escherichia coli ATCC 11775 in LEW treated on the four lamps positive geometry device 355 


\section{List of tables}

Table 3.1 - Egg white, egg yolk and whole egg composition (per 100g of edible portion)

Table 3.2 - Functional characteristics of eggs and ovoproducts and their

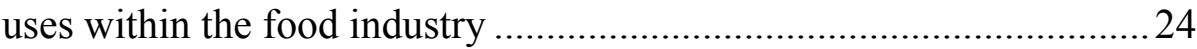

Table 3.3 - USDA Liquid egg products pasteurization requirements .........31

Table 3.4 - Ultraviolet ligh electromagnetic spectrum according to ISO 21348 standard for solar irradiances .............................................. 35

Table 3.5 - Absorption coefficient $(\alpha)$ of some liquid food at $253.7 \mathrm{~nm}$.... 38

Table 3.6 - Conventional UV lamps characteristics. 43

Table 3.7 - UV dose at $254 \mathrm{~nm}$ required to inactivate some microorganims (in $\mu$ W.s.cm ${ }^{-2}$ )

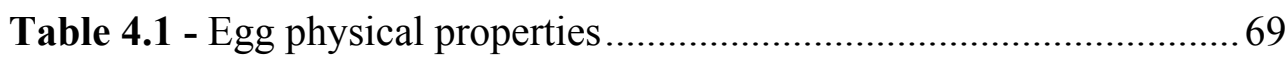

Table 4.2 - UV-C doses, Reynolds and Dean Numbers; per cycle ............. 85

Table 4.3 - Thermal pasteurization conditions ........................................ 85

Table 4.4 - Summary of the analyzed populations, together with their growth medium, plating technique and incubation conditions ............93

Table 4.5 - Legal criteria and microbiological guidelines for determining the shelf life and microbiological safety of LWE ............................... 95

Table 5.1 - Weibull fitting from inactivation kinetics of LEW ................ 135 
List of tables

Table 5.2 - Weibull fitting from inactivation kinetics of LWE................ 136

Table 5.3 - Weibull fitting from inactivation kinetics of LEY ................. 137

Table 5.4 - Dose required to reach 5D* according to the Log-linear models

Table 5.5 - Initial microbial loads of untreated LEPs

Table 5.6 - Influence of UV-C radiation on Lactic acid bacteria (LAB), Yeast and moulds (Yeast), Pseudomonas spp. (Pseud), Enterobacteriacea (Enter) and Salmonella spp. (Salm) inactivation under dynamic conditions on LEW.

Table 5.7 - Influence of UV-C radiation on Lactic acid bacteria (LAB), Yeast and moulds (Yeast), Pseudomonas spp. (Pseud), Enterobacteriacea (Enter) and Salmonella spp. (Salm) inactivation under dynamic conditions on LWE.

Table 5.8 - Influence of UV-C radiation at on Lactic acid bacteria (LAB), Yeast and moulds (Yeast), Pseudomonas spp. (Pseud), Enterobacteriacea (Enter) and Salmonella spp. (Salm) inactivation under dynamic conditions on LEY

Table 5.9 - Effects of treatment on $\mathrm{pH}$ values of LEPs 149

Table 5.10 - CIELAB L*(Brightness), a*(redness-greenness) and $b^{*}$ (yellowness-blueness) color coordinates in LEW submitted to pasteurization or UV-C.

Table 5.11 - CIELAB L*(Brightness), a*(redness-greenness) and $b^{*}$ (yellowness-blueness) color coordinates in in LWE submitted to pasteurization or UV-C.

Table 5.12 - CIELAB L*(Brightness), a*(redness-greenness) and $b^{*}$ (yellowness-blueness) color coordinates in LEY submitted to pasteurization or UV-C. 
Table 5.13 - Total color difference $\left(\Delta \mathrm{E}^{*}\right)$ and browning index $(\mathrm{BI})$ in LEPs submitted to pasteurization or UV-C.

Table 5.14 - Influence of UV-C on cholesterol contend of LWE and LEY

Table 5.15 - Peak temperatures (Td) and the enthalpy changes $(\Delta H)$, integrated between 50 and $95^{\circ} \mathrm{C}$, of LEPs.

Table 5.16 - Consistency coefficient (K) and power law index (n) of LEPs

Table 5.17 - Weibull fitting from inactivation kinetics of LEPs treated on the UVivatec ${ }^{\circledR}$ reactor 185

Table 5.18 - Effects of UV-C on the $\mathrm{pH}$ values of LEPs treated on UVivatec ${ }^{\circledR}$ Lab reactor

Table 5.19 - CIELAB L*(Brightness), a*(redness-greenness) and $b^{*}$ (yellowness-blueness) color coordinates in LEPs.

Table 5.20 - Total color difference $\left(\Delta \mathrm{E}^{*}\right)$ and browning index $(\mathrm{BI})$ in LEPs

Table 5.21 - Microbial loads of LEPs at day 0 of storage 204

Table 5.22 - Changes in physicochemical parameters of LEW treated on the IATA bench device during storage at $4{ }^{\circ} \mathrm{C}$ 221

Table 5.23 - Changes in physicochemical parameters of LWE treated on the IATA bench device during storage at $4{ }^{\circ} \mathrm{C}$ 222

Table 5.24 - Changes in physicochemical parameters of LEY treated on the IATA bench device during storage at $4{ }^{\circ} \mathrm{C}$ 223

Table 5.25 - Microbial loads of LEPs at day 0 of storage 226 
List of tables

Table 5.26 - Changes in physicochemical parameters of LEP treated on the UVivatec ${ }^{\circledR}$ Lab reactor during storage at $4{ }^{\circ} \mathrm{C}$ 234

Table 5.27 - Foam density of LEP treated in batch at the IATA bench equipment 242

Table 5.28 - Foam density of LEP treated on UVivatec $®$ Lab reactor ..... 242

Table 5.29 - Emulsifying properties of LEW treated in the IATA bench equipment 248

Table 5.30 - Emulsifying properties of LWE treated in the IATA bench equipment 249

Table 5.31 - Emulsifying properties of LEY treated in the IATA bench equipment 250

Table 5.32 - Emulsifying properties of LEW treated on UVivatec ${ }^{\circledR}$ Lab reactor 251

Table 5.33 - Emulsifying properties of LWE treated on UVivatec ${ }^{\circ}$ Lab reactor

Table 5.34 - Emulsifying properties of LEY treated on UVivatec ${ }^{\circledR L a b}$ reactor 251

Table 5.35 - Influence of UV-C exposure on riboflavin content of (a) LEW,

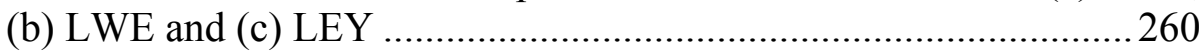

Table 5.36 - Influence of UV-C exposure on tocopherol content of LWE and LEY 262

Table 5.37 - Influence of UV-C exposure on panthotenic acid content of LEPs 265

Table 5.38 - Mineral content in UV-C treated LEPs 269 
Table 5.39 - Correct answers in a triangle test by treatment comparison at the highest UV dose $\left(4.176 \mathrm{~J}_{\mathrm{cm}} \mathrm{cm}^{-2}\right.$ or $30 \mathrm{~min}$ with fluence of 2.32 $\mathrm{mWcm}{ }^{-2}$ ).

Table 5.40 - Consumer acceptance ratings specifically for off-flavor on cooked egg white, cooked whole egg, cooked egg yolk, mayonnaise, pudding and angel cake; and overall quality calculated from the aroma, flavor, color and harmony (general acceptance).... 287

Table 5.41 - Weibull fitting from inactivation kinetics of LWE at the MRI 2010 reactor. 292

Table A.1 - Log-linear fitting from inactivation kinetics of LEW treated on the IATA bench device 346

Table A.2 - Log-linear with tail fitting from inactivation kinetics of LEW treated on the IATA bench device 347

Table A.3 - Weibull with tail fitting from inactivation kinetics of LEW treated on the IATA bench device 348

Table A.4 - Log-linear fitting from inactivation kinetics of LEW treated on IATA bench equipement 349

Table A.5 - Log-linear with tail fitting from inactivation kinetics of LWE treated on IATA bench equipement 350

Table A.6 - Weibull with tail fitting from inactivation kinetics of LWE treated on IATA bench equipement 351

Table A.7 - Log-linear fitting from inactivation kinetics of LWE treated on IATA bench equipement 352

Table A.8 - Log-linear with tail fitting from inactivation kinetics of LEY treated on the IATA bench device

Table A.9 - Weibull with tail fitting from inactivation kinetics of LEY treated on the IATA bench device 



\section{List of Sym6ols}

$a^{*}:$ Redness-greenness

A: absorbance

$A$ : aroma

$b^{*}$ : Yellowness-blueness

$\mathrm{B}_{\mathrm{O}}$ : emulsified oil in the blanck

BI: browning index

BSA: brillance salmonella agar

$c$ : speed of light $\left(2.998 \times 10^{8} \mathrm{~m} \mathrm{~s}^{-1}\right)$

$C$ : color

CFU: colony forming unit

CIELAB: international commission on illumination coordinates

d: dose $\left(\mathrm{J}^{\mathrm{cm}} \mathrm{cm}^{-2}\right)$

D: diameter of the coil

$\mathrm{D}_{\mathrm{el}}$ : electrical energy (J.L $\left.{ }^{-1}\right)$ 
List of symbols

$\mathrm{D}_{\mathrm{e}}$ : dean number

$d_{h}$ : hydraulic diameter of the tube

$\mathrm{D}_{\mathrm{S}}$ : fluence $\left({\left.\mathrm{J} . \mathrm{cm}^{-2}\right)}^{-2}\right.$

$\mathrm{D}_{\mathrm{V}}$ : ultraviolet energy output per volume $\left(\mathrm{J} . \mathrm{L}^{-1}\right)$

D.L.: detection limit

DNA: deoxyribonucleic acid

DOC: deoxycholate trichloroacetic acid

DRCM: differential reinforced clostridial agar

DTNB: 5,5-dithiobis(2-nitrobenzoic acid)

$E$ : energy $(\mathrm{J})$

$\mathrm{E}_{\mathrm{AI}}$ : emulsifying activity index

$\mathrm{E}_{\mathrm{C}}$ : emulsifying capacity

$\mathrm{E}_{\mathrm{O}}$ : emulsified oil in the sample

Enter: enterobacteriaceae count

$\mathrm{E}_{\mathrm{C}}$ : emulsifying capacity

$E_{S}$ : emulsifying stability

EDTA: ethylenediaminetetraacetic acid

EMEM: eagle's minimal essential medium 
FDA: food and drug administration

GC: gas chromatograph

$\mathrm{h}^{*}$ : tone

$H$ : harmony or overall quality

HPLC: high.performance liquid chromatograph

$k$ : kinetic rate parameter

$\mathrm{k}_{\text {mas }}$ : inacitvation rate $\left(\mathrm{cm}^{2} \mathrm{~J}^{-1}\right)$

L*: Brightness

LAB: lactic acid bacteria count

LDL: low density lipoproteins

LEPs: Liquid egg products

LEW: liquid egg white

LEY: liquid egg yolk

Log: $\log \left(\right.$ CFU.mL $\left.L^{-1}\right)$

LWE: liquid whole egg

MDA: malondialdehyde

MRS: deMann rogosa-shape agar

$\mathrm{N}_{0}$ : initial number of microorganisms $\left(\mathrm{CFU} \cdot \mathrm{mL}^{-1}\right)$

xliii 
List of symbols

$\mathrm{N}$ : number of survivors (CFU.mL ${ }^{-1}$ )

NASA: national aeronautics and space administration

NEAA: nonessential amino acids

$\mathrm{p}$ : concavity/convexity of the weibull model

$\mathrm{P}_{\mathrm{W}}$ : protein weight

PAB-CFC: pseudomonas agar base supplemented with pseudomonas CFC

PCA: plate count agar

PV: peroxide value

$Q:$ overall quality

QSRS: quarter strength ringer solution

Re: reynolds number

RCA: reinforced clostridial agar

RED: reduction equivalent dose

RMSE: root mean sum of squared total

RNA: ribonucleid acid

Salm: salmonela count

S.D.: standart deviation

SDS: sodium dodecyl sulfate

xliv 
SDS-PAGE: sodium dodecyl sulfate polyacrylamide

SH: sulphydryl groups

SS: disulfide bonds

$\mathrm{t}$ : treatment time

T: taste

TAM: total aerobic mesophilic count

TAnM: total anaerobic mesophilic count

TAnP: total anaerobic psychrotrophic count

TAnS: total anaerobic spore count

TAP: total aerobic psychrotrophic count

TAS: total aerobic spore count

TBA: thiobarbituric acid

TBARS: 2-thiobarbituric acid-reactive substance

TCA: trichloroacetic acid

Td: peak temperature

TSA: tryptone soy agar

TSB: tryptone soy broth

$u$ :velocity $\left(\mathrm{m} \mathrm{s}^{-1}\right)$ 
List of symbols

USDA: United States Drug Administration

UV: ultraviolet

UV-A: long wave ultraviolet

UV-B: medium wave ultraviolet

UV-C: short wave ultraviolet

UV-D: samples treated with ultraviolet under dynamic conditions

UV-S: samples treated with ultraviolet under static conditions

UV-VIS: visible ultraviolet

v: cinematic viscosity (Pa.s)

$v$ : frequency $\left(\mathrm{s}^{-1}\right)$

$\mathrm{V}_{\mathrm{LD}}$ : volume of liquid drainage

$\mathrm{V}_{\mathrm{OL}}$ : original volume of liquid

$\mathrm{V}_{\mathrm{PF}}$ : volume of prepared foam

VRBG: violet red bile glucose agar

Yeast: yeast and moulds count

YGC: yeast glucose chloramphenicol

$\% \mathrm{~V}$ : foaming properties

ఇ: dynamic viscosity (Pa.s) 
$\rho:$ mass density $\left(\mathrm{kg} \mathrm{m}^{-3}\right)$

$\delta$ : fluence for the first decimal reduction $\left(\mathrm{J}_{\mathrm{cm}} \mathrm{cm}^{-2}\right)$

$\lambda$ : radiation wavelenght $(\mathrm{nm})$

$h$ : Planck constant $\left(6.63 \times 10^{-34} \mathrm{~J}\right)$

$\Delta \mathrm{E}^{*}:$ total color difference

$\Delta \mathrm{H}$ : enthalpy changes

2S: treatement of samples with $2 \mathrm{~mm}$ high under static conditions

2D: treatement of samples with $2 \mathrm{~mm}$ high under dynamic conditions

5S: treatement of samples with $5 \mathrm{~mm}$ high under static conditions

5D: treatement of samples with $5 \mathrm{~mm}$ high under dynamic conditions 

Abstract, resumen, resum,

zusammenfassung and résumé 



\section{A6stract}

The viability of short-wave ultraviolet treatment (UV-C) at $254 \mathrm{~nm}$ as a non-thermal process for liquid egg products (LEPs) was evaluated from the point of view of the effects on egg quality attributes and the decontamination efficiency. The effects of UV-C on microbial loads were evaluated by kinetic studies on the inactivation of inoculated and naturally occurring microorganisms, and during shelf-life. UV-C treated egg fractions (egg white . LEW, whole egg - LWE and egg yolk LEY) were analyzed for changes in $\mathrm{pH}$, color, effects on lipids (TBARS, cholesterol and peroxide value), effects on proteins (protein oxidation, DSC, SDS-PAGE), rheological properties (dynamic viscosity, flow behavior, temperaturedependent viscosity), functional properties (emulsification and foaming), nutritional composition (vitamins, carotenoids and minerals), and citogenotoxicology. Sensory acceptability of UV-C treated LEPs and products containing UV-C treated liquid egg (mayonnaise, angel cake and pudding) was evaluated by triangle tests and bys consumer affective tests (hedonic scale).

UV-C treatment proved to be an effective alternative to heat pasteurization. Thus, a decay of 5 Log was reported in inoculated Gram(+) and Gram(-) bacteria in a commercial device UVivatec ${ }^{\circledR}$ for continuous treatments. In batch, the results also showed an important decay on the inoculated 
Abstract

microorganisms, although longer exposure times would be necessary to produce decontaminations comparable to heat pasteurizations. UV-C treated LEPs were stable during 8 weeks of storage at $4{ }^{\circ} \mathrm{C}$ (6 weeks for the LEY treated in batch), and also during 15 days at room temperature.

Contrary to heat treatments, UV-C did not affected viscosity and $\mathrm{pH}$. Browning due to Maillard was perceptible in egg yolk and whole egg at low UV-C doses, but the corresponding browning indexes were always lower than in heat pasteurized egg fractions.

Major changes were only due to lipid oxidation. TBARS values at the highest UV-C doses were larger than in pasteurized egg yolk and whole egg. Minor changes were observed in proteins. A slight protein oxidation was observed, and no changes in rheological properties were recorded. Improvement on foam ability and foam stability, and an increasing on the emulsifying activity index were also reported. The content of some vitamins, such as vitamin $\mathrm{A}$ and $\mathrm{C}$, and carotenoids (lutein and zeaxanthin) were affected by UV-C. But highly positive results were found for cito/genotoxic studies, where no cito-/genotoxic could be attributed to UV-C treatments.

Overall scores for the evaluated sensory parameters indicated an acceptability of UV-C treated egg fractions and their preparations not significantly different from that of untreated egg and they were perceived as comparable to, or, in some cases, better than the thermally pasteurized eggs. No off-flavors due to UV-C treatments were reported. This study confirms 
no adverse effects on sensory perception (consumer acceptance) of egg products processed by UV-C, with overall appearance and taste similar to the controls.

Those findings are valuable to further consider UV-C treatment of eggs as a feasible alternative to heat but indicate that new measures have to be considered to minimise the effects on some nutritional parameters and health-related attributes. 



\section{Resumen}

La viabilidad de los tratamientos con radiación ultravioleta (UV-C) a 254 $\mathrm{nm}$ como proceso no térmico para la conservación de ovoproductos líquidos fue evaluada desde el punto de vista de la eficiencia en la descontaminación y sus efectos en los atributos de calidad. Los estudios cinéticos sobre la inactivación de microorganismos inoculados y de los principales grupos de microorganismos alterantes sirvieron para discriminar los parámetros más relevantes del tratamiento con UV-C. Los estudios de vida útil sirvieron para evaluar las ventajas aportadas por esta tecnología frente a tratamientos térmicos tradicionales. Las fracciones de huevo (clara, yema y huevo entero) tratadas con UV-C fueron analizadas en cuanto a los cambios de $\mathrm{pH}$, color, estabilidad de lípidos (TBARS, colesterol y valor de peróxidos), efectos en las proteínas (oxidación proteica, DSC, SDS-PAGE), propiedades reológicas (viscosidad dinámica, comportamiento de flujo, viscosidad en función de la temperatura), propiedades funcionales (emulsionantes y espumantes), composición nutricional (vitaminas y minerales), composición

de componentes saludables (carotenoides), y cito-genotoxicologia. Finalmente, la aceptación sensorial de los ovoproductos líquidos tratados por UV-C y de productos preparados con ovoproductos líquidos tratados por UV-C (mayonesa, bizcocho y pudin) fueron evaluadas por medio de pruebas triangulares y afectivas. 
Resumen

El tratamiento con UV-C demostró ser una excelente alternativa a la pasteurización térmica. En microorganismos inoculados, se demostró una reducción de 5 Log tanto para $\operatorname{Gram}(+)$ como para $\operatorname{Gram}(-)$ en un equipo comercial para tratamientos en régimen continuo (UVivatec $\AA$ ). En tandas, los resultados también mostraron decrecimientos importantes en el recuento de microorganismos inoculados, aunque serían necesarios tiempos largos de tratamiento para producir una descontaminación comparable a la pasteurización térmica. Los ovoproductos líquidos tratados con UV-C fueron estables durante 8 semanas de almacenamiento a $4{ }^{\circ} \mathrm{C}$ ( 6 semanas en el caso de la yema tratada en lotes), y durante 15 días a temperatura ambiente.

La radiación ultravioleta no originó cambios relevantes en la viscosidad y el $\mathrm{pH}$. La reacción de Maillard produjo un oscurecimiento perceptible en la yema y en eL.huevo entero a bajas dosis de UV-C, pero los correspondientes índices de oscurecimiento estuvieron siempre por debajo de los niveles observados en las muestras pasteurizadas térmicamente.

Los principales cambios fueron debidos a la oxidación de lípidos. Los valores de TBARS en la yema y huevo entero tratados con las dosis más altas superaron los valores obtenidos en las pasteurizaciones térmicas. Cambios menores se observaron en las proteínas. Se observó una ligera oxidación de proteínas tras el tratamiento con UV-C, pero no se observó ningún cambio en las propiedades reológicas. En cambio, se observaron mejoras en la capacidad espumante y en la estabilidad de la espuma, así como un aumento en el índice de actividad emulsionante. Los contenidos de 
algunas vitaminas y compuestos saludables, como las vitaminas A y C, y la luteína y zeaxantina, se vieron considerablemente reducidos por la radiación UV-C. En cambio, no se observaron efectos cito-/genotóxicos en las muestras tratadas.

Los parámetros sensoriales evaluados mostraron una gran aceptación de los ovoproductos tratados con radiación UV-C y de sus preparados, que no eran significativamente diferentes a los que no estaban tratados. Estos productos fueron percibidos como comparables, y en algunos casos, incluso mejores, que los ovoproductos pasteurizados térmicamente. No se detectó la formación de sabores desagradables debido a los tratamientos UV-C. Por lo tanto se confirma que no existen efectos adversos en la aceptación del consumidor de los productos de huevo procesados por radiación UV-C, teniendo una apariencia general y sabor similar a los controles.

Estos hallazgos son muy valiosos ya que permiten proponer los tratamientos con UV-C como un método alternativo a los tratamientos térmicos en el tratamiento de ovoproductos líquidos, pero también nos indican que para implementar estos tratamientos a nivel industrial, hay que considerar las pérdidas que se originan en algunos nutrientes y en componentes saludables. 



\section{Resum}

La viabilitat dels tractaments amb la radiació ultravioleta (UV-C) a $254 \mathrm{~nm}$ com a procés no tèrmic per la conservació d'ovoproductes líquids es va avaluar des del punt de vista de l'eficiència en la descontaminació i el seus efectes en els atributs de qualitat. Els estudis cinètics sobre la inactivació de microorganismes inoculats i dels principals grups de microorganismes alterants van servir per discriminar els paràmetres més rellevant del tractament amb UV-C. Els estudis de vida útil van servir per avaluar les avantatges aportades per aquesta tecnologia enfront als tractaments tèrmics tradicionals. Les fraccions d'ou (clara, rovell i ou sencer) tractades amb UV$\mathrm{C}$ van ser analitzades en quant als canvis de $\mathrm{pH}$, color, estabilitat de lípids (TBARS, colesterol i valor de peròxids), efectes en les proteïnes (oxidació proteica, DSC, SDS-PAGE), propietats reològiques (viscositat dinàmica, comportament de flux, viscositat en funció de la temperatura), propietats funcionals (emulsions i espumants), composició nutricional (vitamines i minerals), composició de components saludables (carotenoides), i citogenotoxicologia. Finalment, l'acceptació sensorial dels ovoproductes líquids tractats per UV-C i de productes preparats amb ovoproductes líquids tractats per UV-C (maionesa, pa de pessic i púding) van ser avaluades mitjançant probes triangulars $\mathrm{i}$ afectives. El tractament amb UV-C demostrà ser una excel·lent alternativa a la pasteurització tèrmica. En microorganismes 
Resum

inoculats, es demostrà una reducció de 5 Log tant per a Gram(+) com a Gram(-) en un equip comercial per a tractaments en règim continu (UVivatec ${ }^{\circledR}$ ). En tandes, els resultats també mostraren decreixement importants al recompte de microorganismes inoculats, encara que seria necessari temps llargs de tractaments per a produir una descontaminació comparable a la pasteurització tèrmica. Els ovoproductes líquids tractats amb UV-C van ser estables durant 8 setmanes d' emmagatzematge a $4{ }^{\circ} \mathrm{C}$ (6 setmanes en el cas del rovell tractat en lots), i durant 15 dies a temperatura ambient.

La radiació ultravioleta no originà canvis rellevants en la viscositat $\mathrm{i}$ el $\mathrm{pH}$. La reacció de Maillard va produir un enfosquiment perceptible al rovell i a l'ou sencer a baixes dosis de UV-C, però els corresponents índexs de enfosquiment van estar sempre per baix dels nivells observats a les mostres pasteuritzades tèrmicament.

Els principals canvis van ser debuts a l'oxidació de lípids. Els valors de TBARS al rovell i a l'ou sencer tractats amb les dosis més altes superaren els valors obtinguts en la pasteurització tèrmica. Canvis menors es van observar a les proteïnes. Es va observar una lleugera oxidació de proteïnes després el tractament amb UV-C, però no es va observar cap canvi en les propietats reològiques. En canvi, es van observar millores en la capacitat espumant i en la estabilitat de l'espuma, així com un augment en l'índex d'activitat emulsionant. Els continguts d'algunes vitamines i composts saludables, com les vitamines A i C, i la luteïna i zeaxantina, es van veure 
considerablement reduïts per la radiació UV-C. En canvi, no es van observar efectes cito-/genotóxicos en les mostres tractades.

Els paràmetres sensorials avaluats mostraren una gran acceptació dels ovoproductes tractats amb radiació UV-C i de els seus preparats, que no eren significativament diferents als que no estaven tractades. Estes productes van ser percebuts com comparables, $i$ en alguns casos, fins $i$ tot millors, que els ovoproductes pasteuritzats tèrmicament. No es va detectar la formació de sabors desagradables a causa dels tractaments UV-C. Per tant es confirma que no hi ha efectes adversos en l'acceptació del consumidor dels productes d'ou processats per radiació UV-C, tenint una aparença general i sabor similar als controls.

Aquestes troballes són molt valuoses ja que permeten proposar els tractaments amb UV-C com un mètode alternatiu als tractaments tèrmics en el tractament de ovoproductes líquids, però també ens indiquen que per tenir aquests tractaments a nivell industrial, cal considerar les pèrdues que s'originen en alguns nutrients $i$ en components saludables. 



\section{Zusammenfassung}

Die Eignung einer UV-C-Behandlung kleiner Wellenlänge (UV-C) bei 254 $\mathrm{nm}$ als athermisches Verfahren für Flüssigeiprodukte wurde hinsichtlich ihre Wirkung auf Qualitätsmerkmale und Effizienz bei der Entkeimung von Ei geprüft. Durch Untersuchungen der Inaktivierungskinetiken zugesetzter und natürlich vorkommender Mikroorganismen wurde die UV-C-Wirkung auf die mikrobielle Belastung und Haltbarkeit geprüft. UV-C behandelte Eifraktionen (Eigelb, Eiweiß und Gesamtflüssigei) wurden auf Änderungen des $\mathrm{pH}-$ Wertes und der Farbe, Wirkung auf Lipide (TBARS-Werte, Cholesterin und Peroxidzahl) und Proteine (Proteinoxidation, DSC, SDSPage), rheologische Eigenschaften (dynamische Viskosität, Fließverhalten, temperaturabhängige Viskosität), funktionelle Eigenschaften (Emulgierbarkeit und Schaumbildungseigenschaften), Nährstoffzusammensetzung (Vitamine, Carotinoide und Mineralstoffe) und Zyto- bzw. Genotoxizität getestet. Die sensorische Akzeptanz UV-C behandelter Flüssigeiprodukte und daraus erzeugter Lebensmittel (Mayonnaise, Biskuitkuchen und Pudding) wurde in Triangel- und Konsumententests geprüft.

Die UV-C-Behandlung von Flüssigei erwies sich als effektive Alternative zur thermischen Pasteurisation. Hierbei wurden Reduktionen zugesetzter Gram(+) und Gram(-) Bakterien von 5 Log in einem kontinuierlichem 
Zusammenfassung

Durchflussreaktor (UVivatec ${ }^{\circledR}$ ) erreicht. Auch in chargenweiser Behandlung eigten die Ergebnisse eine beträchtliche Reduktion der zugesetzten Mikroorganismen, wenngleich hierbei längere Behandlungszeiten notwendig waren, um eine mit thermischer Pasteurisation vergleichbare Dekontamination zu erreichen. UV-C behandelte Flüssigeifraktionen waren während 8 wöchiger Lagerung bei $4{ }^{\circ} \mathrm{C}$ (6 Wochen für Flüssigeigelb chargenweise behandelt) und über 15 Tage bei Raumtemperatur haltbar.

Im Gegensatz zur Hitzebehandlung beeinflusste UV-C weder die Viskosität noch den $\mathrm{pH}$-Wert. Durch Maillardreaktion verursachte Bräunung wurde zwar in Eigelb und Gesamtflüssigei bei niedrigen UV-C-Dosen festgestellt, jedoch lagen die entsprechenden Bräunungswerte immer unter denen der pasteurisierten Eifraktionen.

Bedeutende Veränderungen waren nur bei der Lipidoxidation festzustellen. Die TBARS-Werte bei den höchsten UV-C-Dosen waren höher als in pasteurisiertem Eigelb und Gesamtflüssigei. Geringe Veränderungen wurden bei den Proteinen festgestellt. Hierbei wurde eine schwache Proteinoxidation aber keine Veränderung der rheologischen Eigenschaften beobachtet. Es wurde eine Verbesserung der Schaumfähigkeit und stabilität sowie zunehmende Emugierfähigkeit gezeigt. Der Gehalt von Vitaminen wie zum Beispiel Vitamin A und $\mathrm{C}$ sowie Lutein und Zeaxanthin wurde durch UV-C beeinflusst. Jedoch wurden sehr positive Ergebnisse in der zyto-/genotoxischen Wirkung festgestellt, welche nicht durch die UVC-Behandlung beeinflusst wurde. 
Die Gesamtauswertung der sensorischen Parameter zeigte keine signifikanten Unterschiede in der Akzeptanz der UV-C behandelten Eifraktionen oder deren Zubereitungen im Vergleich zu den unbehandelten Eifraktionen. Die UV-C behandelten Proben wurden als gleichwertig wahrgenommen oder in manchen Fällen besser eingestuft als thermisch pasteurisierte Eier. Es wurden keine durch UV-C-Behandlung verursachten Fremdaromen festgestellt. Diese Studie bestätigt keine nachteilige Wirkung auf die Konsumentenakzeptanz, da die UV-C behandelten Eiprodukte in Erscheinungsbild oder Geschmack als gleichwertig zum Kontrollprodukt ermittelt wurden.

Die hier vorliegenden Forschungsergebnisse sind nützlich, um die UV-CBehandlung von Eiern als praktikable Alternative zur Hitzebehandlung zu erwägen. Aber sie zeigen auch, dass neue Maßstäbe in Betracht gezogen werden müssen, um die Wirkung auf verschiedene ernährungsrelevante Inhaltsstoffe mit gesundheitsbezogenen Wirkungen zu minimieren. 



\section{Résumé}

La viabilité de traitements ultra-violets à ondes courtes (UV-C) à $254 \mathrm{~nm}$ comme un traitement non thermique pour les œufs-produits liquides a été évalué du point de vue des effets sur les attributs de qualité et l'efficacité de la décontamination. Les effets des UV-C sur les charges microbiennes ont été évalués par des études cinétiques d'inactivation de micro-organismes inoculés et banales, et pendant la durée de conservation. Les fractions d'œufs (jaune d'œuf, blanc d'œuf et l'œuf entier) traités par UV-C ont été analysées par les changements de $\mathrm{pH}$, couleurs, les effets sur les lipides (TBARS, cholestérol, indice de peroxyde), les effets sur les protéines (oxydation des protéines, DSC, SDS-PAGE), les propriétés rhéologiques (viscosité dynamique, comportement de l'écoulement, la viscosité dépend de la température), les propriétés fonctionnelles (émulsion et mousse), la composition nutritionnelle (vitamines, caroténoïdes et minéraux), et citogenotoxicologie. L'acceptabilité sensorielle des produits d'œufs liquides traités par UV-C et de produits contenants des œufs traités par UV-C a été évaluée dans des essais triangle et dans les tests affectifs de consommation.

Les traitements avec UV-C ont montré être une alternative efficace à la pasteurisation thermique. Ainsi, une décroissance de 5 Log a été signalé sur Gram (+) et Gram (-) micro-organismes inoculés et traités dans un réacteur commercial (UVivatec ${ }^{\circledR}$ ) pour traitements en régime continu. Dans les 
Résumé

essais en lot, les résultats ont également montré une décroissance importante dans les micro-organismes inoculés, bien que les doses plus hautes soient nécessaires pour produire des décontaminations comparables à la pasteurisation par l'application de chaleur. Les LEP traités par UV-C se sont maintenus stables pendant 8 semaines de stockage à $4{ }^{\circ} \mathrm{C}(6$ semaines pour le LEY traités en batch), et aussi pendant 15 jours à température ambiante. Contrairement aux traitements thermiques, UV-C n'a pas impacté la viscosité et le $\mathrm{pH}$. Le brunissement était perceptible en raison de la réaction de Maillard dans le jaune d'œuf et l'œuf entier déjà à des faibles doses UV$\mathrm{C}$, mais les indices correspondants de brunissement étaient toujours inférieurs à ceux des fractions d'œufs pasteurisés par l'emploi de la chaleur.

Les changements majeurs ont été seulement dus à l'oxydation des lipides. Les valeurs de TBARS aux doses UV-C plus haute étaient plus grandes que dans le jaune d'œuf et œuf entier pasteurisé. Des modifications mineures ont été observées dans les protéines. Une légère oxydation des protéines et aucun changement dans les propriétés rhéologiques ont été observés. Une amélioration de la capacité de la mousse et la stabilité de la mousse, et une augmentation de l'indice de l'activité d'émulsification ont également été signalé. Le contenu de certaines vitamines comme la vitamine $\mathrm{A}$ et $\mathrm{C}$, et les caroténoïdes lutéines et zéaxanthine ont été touchées par l'UV-C. Mais des résultats très positifs ont été trouvés pour les effets cito-/geno-toxique, qui ne pouvaient pas être attribués aux traitements avec UV-C.

Les scores globaux pour les paramètres sensoriels évalués indiquent que l'acceptabilité des fractions d'œufs traités avec UV-C, ou de leurs 
préparations, ne diffèrent pas significativement de celle des non traités et ils ont été aperçus comme comparables à, ou, dans certains cas, mieux que les œufs pasteurisés thermiquement. Également l'étude montre qu'il n'y a pas de changement de saveurs dus au traitement avec UV-C. Cette étude ne confirme pas d'effets néfastes sur l'acceptation des consommateurs des produits d'œufs traités par UV-C, avec l'apparence générale ou de goût semblable à celle des contrôles.

Ces résultats sont précieux pour poursuivre l'examen de traitement des œufs par UV-C comme une alternative possible à la chaleur, mais ils indiquent aussi que de nouvelles mesures doivent être subies afin de minimiser les effets sur certains paramètres nutritionnels et les attributs liés à la santé. 

1. Introduction 



\section{Introduction}

Hen's egg products are a significant farm commodity worldwide. The term "egg products" refers to eggs that are removed from their shells for processing (breaking, filtering, mixing, stabilizing, blending, pasteurizing, cooling, freezing or drying, and packaging). In this category are included whole eggs, egg whites, egg yolks and various blends - with or without non-egg ingredients - that are processed and pasteurized and may be available in liquid, frozen, or dried forms. World egg production was of 1.182 billion eggs in 2010 (Watt Executive Guide to World Poultry, 2010), China alone is responsible for $38 \%$ of that total, while USA, Brazil and Europe represented respectively $8.9,3.5$ and $7 \%$. In the same year the average egg consumption was 300 units per person in China, 250 in USA, 135 in Brazil (Watt Executive Guide to World Poultry, 2010), and in Europe the consumption falled between 150 and 300 eggs per capita.

Eggs are one of the most complete foods. Their composition includes all essential amino acids, and several vitamins and minerals, including retinol (vitamin A), tocopherol (vitamin E), riboflavin (vitamin $\mathrm{B}_{2}$ ), pantothenic acid (vitamin $\mathrm{B}_{5}$ ) and even ascorbic acid (vitamin $\mathrm{C}$ ), in concentrations that can change as a function of hen's feeding and age. Remarkably, egg is one of the few foodstuffs naturally containing vitamin D. Despite the nutritional 
Introduction

value of eggs, there are some potentiaL.health issues arising from egg quality, storage, and individual allergies.

As a consequence of being a vitamin rich-nutritious foodstuff, eggs are also an excellent medium for microbial growen. The liquid egg products (LEPs) initial microflora is composed of a mixture of bacteria similar to the indigenous microflora of shell-eggs, since the shell is typically the contamination source (ICMSF, 2005). Strains commonly involved on egg deterioration include Acinetobacter spp., Proteus spp., Aeromonas spp., Alcaligenes spp., Escherichia spp., Micrococcus spp., Serratia spp., Enterobacter spp. and Flavobacterium spp. And the main associated pathogens are Salmonella spp., Staphylococcus spp., Campylobacter jejuni, Listeria monocytogenes and Yersinia enterocolitica (Ricke, Birklold and Gast, 2001), being Salmonella spp. the most relevant group of pathogens and the microorganism used as reference on pasteurisation process.

Egg associated salmonellosis is one of the most important public health concerns. The Salmonella enterica Serovar Enteritidis shows no clinical signs in hens and can not be observed by the naked eye in the shell egg. Like many other species of Salmonella, the Salmonella enteritidis can live in the hen intestinal tract and contaminate the egg through exposure to faeces. However, due to the strict government regulations adopted in the 1970's, this type of transmission has become increasingly rare. It is possible, though, that the hens ovaries could become contaminated and the Salmonella enteritidis passed into the shell egg before the shell is formed (CDC, 2005). If not correctly processed LEP can cause disease outbreaks, 
specially food-borne disease outbreaks involving Escherichia coli O157:H7 and Salmonella enteritidis in liquid egg products are the major public health concern (Lee et al. 2001, Mañas et al. 2003). In the United States it is estimated that 2.3 million shell eggs or 1 out of every 20,000 eggs may be contaminated with the pathogen, Salmonella enteritidis (Ebel and Schlosser, 2000). If the contaminated eggs are subsequently temperature abused, there is a potential for significant bacterial growth that would pose a serious health risk for people who consume these eggs raw or undercooked. Based on Centers for Disease Control and Prevention (CDC) surveillance data, an estimated 174,356 illnesses, 1,440 hospitalizations, and 75 deaths a year are attributed to Salmonella enteritidis-contaminated eggs only in USA (USDAFSIS, 2005). In Europe the number of cases was around 108,000 in 2009 (EFSA, 2010).

As a result, egg products must be processed in sanitary installations and devices under continuous inspection and pasteurized before distribution for consumption. In the production of ready to use and shelf stable LEPs, pasteurization is the fundamental process to eliminate pathogenic microorganisms. The most commonly used pasteurization methods for LEPs are thermal treatments, where microorganisms are inactivated after the application of heat for certain periods of time (Muriana, 1997) usually in plate or tube heat exchangers (Lai, 2006). The temperature/time binomials stipulated by the USDA are $56.6^{\circ} \mathrm{C} / 3.5 \mathrm{~min}$ for albumen, $60{ }^{\circ} \mathrm{C} / 3.5 \mathrm{~min}$ for whole egg and $61.1^{\circ} \mathrm{C} / 3.5 \mathrm{~min}$ for egg yolk (USDA-ARS 74-48, 1969; Stadelman and Cotteril, 1990; Muriana, 1997). However under those conditions heat resistant microorganisms, such as Bacillus spp. and 
Introduction

Micrococcus spp., might survive and spoil LEPs even under refrigeration. The European Union does not specify pasteurisation conditions, but has implemented microbial standards for the finished products. European Regulation CEE 1441/2007 requires that the finished product must be free of Salmonella (absence in $25 \mathrm{~g}$ ) and contain no more than $100 \mathrm{CFU} \mathrm{g}^{-1}$ of Enterobacteriaceae.

Thermal pasteurization still represents the most available and best understood technique. Although heat induces the oxidation of egg proteins leading to changes in the sulphydryl content, and specifically the unfolding of ovalbumin and livetins, resulting in the modification of the functional properties of egg proteins and later, in coagulation (Van der Plancken et al., 2003; Van der Plancken et al., 2004; Van der Plancken, Van Loey and Hendrickx, 2006; Lai et al., 2010). Therefore, heat pasteurizations may alter the foaming and emulsifying properties, and therefore degrade the quality and functional properties (both technological and nutritive) of egg products (Gongora-Nieto et al., 2003; Hermawan et al., 2004). In particular, after the typical pasteurization conditions, the egg albumen appears cloudier, more viscous, and requires longer whipping times (Li-Chan et al., 1995; Hou et al., 1996; Schuman et al.., 1997). Those changes, if significant, may determine the final consumer acceptability and reduce the purchase expectations of egg products.

The low thermo stability of egg proteins, the short shelf life and the consumers preference for minimally processed and preservative-free products, make crucial the search for non-thermal pasteurisation alternative 
technologies, which do not compromise product quality. The egg industry would thus greatly benefit from innovative solutions that not only produce safe eggs but also overcome the limitations seen with current thermal pasteurization technology.

Alternative LEPs pasteurization methods that do not use heat or combine heat with other techniques have been developed in the last two decades: irradiation (Alvarez et al., 2007), biopreservation (Ponce et al., 1998; Boziaris et al., 1998; Calderon-Miranda et al., 1999; Lee et al., 2003), pulsed electric fields (Amiali et al., 2004; Bazhal et al., 2006; Jin et al., 2009), high hydrostatic pressure (Lee et al., 2001), hydrostatic pressure pulsing (Bari et al., 2008), and ultra high pressure homogenisation (Velazquez-Estrada et al., 2008), combination of high hydrostatic pressure with high ultra sound treatment (Lee et al., 2003), hydrogen peroxide treatment (Isiker et al., 2003), and pH-adjusted pasteurisation (Schuman and Sheldon, 2003), among others. All these methods are focused on the elimination of pathogens like Salmonella spp., Listeria monocytogenes, E. coli $\mathrm{O} 157: \mathrm{H} 7$ or Bacillus cereus. And most of them cause substantial changes in the structure of LEPs by causing coagulation and denaturation of proteins.

In response to these limitations, UV-C radiation can be an alternative nonthermal process for LEPs in order to achieve microbiologically safe and shelf stable products (Bintsis et al., 2000). UV-C radiation does not only eliminate the harmful effects of thermal treatment but also decreases the high operating and separation cost of the other pasteurization methods 
Introduction

(Garibaldi et al., 2003), and has already been approved by the US-FDA (2002) to treat food surfaces and clear fruit juices.

Light in the UV-C region (between 100 and $280 \mathrm{~nm}$ ) is lethal and mutagenic for a variety of organisms, including bacteria. When DNA is exposed to UV light, electrons within specific bases become energized, which leads to formation of hydrogen bonds between adjacent bases. The structural damage caused by the formation of these dimmers inhibits the formation of new DNA, resulting in the inactivation of the affected microorganism (Bank et al., 1990; Miller et al., 1999; Bintsis et al., 2000). Other lesions, such as DNA strand breaks are also induced by UV-C treatments. However, the efficiency of UV-C radiation depends on the UV-C absorption: increasing the amount of solids, large suspended particles or microbial populations will reduce the penetration of UV-C (Lopez-Malo and Palou, 2002; GuerreroBeltran and Barbosa-Canovas, 2004; Koutchma, Parisi and Patazca, 2007).

A number of works have been carried out on the efficiency of the UV-C light at germicide wavelengths on microorganism reduction by using either bench top collimated beam apparatus or continuous flow reactors (Sommer et al., 1998; Lage et al., 2003). Most of these works were conducted with drinking and wastewater samples, being the microbial inactivation achieved in those studies considerably better than the one achieved in liquid foods with similar doses. UV-C light treatment has also been used in the food industry for air sanitation in the meat and vegetable processing, reduction of pathogen microorganisms in red meat, poultry and fish processing (Wong et al., 1998; Liltved and Landfald, 2000); and to packaging decontamination 
(Bintsis et al., 2000). Processing equipment, medical devices, and many other surfaces are also UV-light sterilised (Barbosa-Cánovas et al., 1998).

Concerning studies in eggs, the investigations are focused on the sanitization of the shell (Reu et al., 2006; Szablewski et al., 2009; Sommers et al., 2010), being efforts in the last years also concentrated in the inactivation of LEPs, specially LEW (Ngati, Smith and Cayouette, 2003; Ünlütürk et al., 2008; Geveke, 2008; Ünlütürk et al., 2010; Ünlütürk, Baysal and Atilgan, 2010). Interest for UV-C treatments in LEPs comes from 1964, when Ijichi et al. (1964) used UV-C to treat liquid egg white (LEW) in a centrifilmer at a feed rate of $100 \mathrm{~mL} \min ^{-1}$; counts of Salmonella typhimurium and Salmonella seftenberg were reduced by 6-7 Log. Ngadi, Smith, and Cayouette (2003) worked on the inactivation of E. coli O157:H7 in LEW under a stainless steel tube, sample was agitated during treatment and a reduction of 5 Log was achieved when sample depth was $0.1 \mathrm{~cm}$ and fluence was $5 \mathrm{~mW}$ min $\mathrm{cm}^{-2}$. Ünlütürk et al. (2007) used a flat black collimated beam to evaluate the efficiency of UV-C as a non-thermal process for LEP fractions against the Escherichia coli (ATCC 8739) UV-C resistant strain, among others. The best reduction $(>2 \mathrm{Log})$ for this highly UV-C resistant strain was achieved in LEW, at $0.153 \mathrm{~cm}$ fluid depth and $1.314 \mathrm{~mW} \mathrm{~cm}^{-2} \mathrm{UV}-\mathrm{C}$ intensity. But under similar conditions, maximum inactivation ranged $0.675 \mathrm{Log}$ in LEY, and $0.316 \mathrm{Log}$ in LWE. Furthermore, Geveke (2008) reported an effective UV-C treatment of E. coli K12 (ATCC 23716) in LEW, using a continuous process with a lowpressure mercury lamp surrounded by UV transparent tubing and a silicon 
Introduction

rubber tape. In that work, the population of E. coli was reduced by $4.3 \mathrm{Log}$ after being exposed to UV-C at $50{ }^{\circ} \mathrm{C}$ during 160 s.

Short-wave ultraviolet treatments appear as an emerging non-thermal process with enormous potential for food decontamination. This technology might provide safe products, minimizing the effects of heat on food quality attributes. In this context, the use of UV-C radiation for the treatment of LEPs would have a clear advantage if compared with available treatments, or the use of preservatives. Previous to the industrial implementation, however, UV-C effects on LEPs have to be characterized. First, basic information concerning the decontamination under UV-C of relevant spoilage-related and pathogen microorganisms has to be recorded, and the minimum energy required under continuous treatments to achieve pasteurization has to be determined. Secondly, the UV-C induced changes in relevant quality parameters (nutritional, functional, sensorial) needs to be investigated instrumentally and from the point of view of consumer acceptability. Finally, the optimal processing parameters in continuous devices ought to be determined. 
2. Objectives 



\section{Objectives}

Egg is a versatile, thermo-sensitive, and high nutritive food that could benefit from ultraviolet treatments. UV technology is proposed as a promising alternative technology that will produce a superior quality egg acceptable by both consumers and the egg industry. The application of UV$\mathrm{C}$ radiations at germicide wavelengths is intended to lessen the thermal effects on heat-sensitive proteins. However, the process involves exposing eggs to light with subsequent potential oxidations. The UV-C effects on egg quality are still unknown and also there a lack of data about consumer acceptance/perception of UV-C treated LEPs.

The main objective of this Thesis is to investigate the suitability of UV-C radiation at $254 \mathrm{~nm}$ as a non-thermal preservation process for liquid egg products to produce shelf-stable, natural, highly nutritious, safe, and sensory acceptable liquid egg products.

To achieve this main objective the following partial objectives have been raised:

1. Determination of treatment parameters relevant for the effectiveness of UV-C processing at $254 \mathrm{~nm}$ on the inactivation of egg food-borne pathogens and pathogen surrogates, and on the inactivation of the egg's endogenous microflora, especially spoilage-related microorganisms; 
Objectives

2. Evaluation of the improvement in the shelf-life of liquid egg products achieved under optimal UV-C processing conditions determined in the previous objectives;

3. Assessment of the impact of UV-C treatments at $254 \mathrm{~nm}$ on the main physicochemical quality parameters -instrumental color, $\mathrm{pH}$ - of liquid egg products, effects on lipids - lipid oxidation and cholesterol -, and on egg protein quality attributes, based on protein oxidation and rheological study dynamic viscosity, flow behavior, temperature dependent-viscosity -, thermal and electrophoretical properties;

4. Evaluation of the impact of UV-C treatements at $254 \mathrm{~nm}$ on egg's functional properties - foaming and emulsifying.

5. Determination of the impact of UV-C treatments at $254 \mathrm{~nm}$ on the content of relevant nutritional and health-related compounds, and on the cito-/genotoxic effects of liquid egg products.

6. Assessment of the impact of UV-C treatments at $254 \mathrm{~nm}$ on the organoleptic attributes of liquid egg products and products containing UV-C treated liquid egg products as ingredient, on the base of discrimination tests and consumer acceptance studies. 


\section{Literature Review}





\section{Literature Review}

\subsection{Egg products}

\subsubsection{Structure and chemical properties}

Egg can be described as the food source developed from most poultry animals, when the term "egg" is used alone it refers to chicken eggs, if the egg comes from another bird it is necessary to follow the word egg by the bird specie. Eggs are one of the most important foods in the diet of human beings due to their high protein content, low cost and large availability in most of the countries (Kusunoki, 1983; Hamid-Samimi and Swartzel, 1985; Punidadas and McKellar, 1999). They are highly versatile and are used throughout the kitchen, both by serving alone or by using as ingredients in a prepared meal in order to provide texture, flavor, structure, moisture and nutritive value for many prepared foods (Punidadas and McKellar, 1999). In addition to the domestic use, egg products have great importance in the food industry due to their functional properties. The egg white is an excellent foaming agent, while the yolk has the property of viscosity control and the 
whole egg is used to adjust the volume and texture (Forsyre, 1970 cited in Hamid-Samimi et al., 1984). It takes approximately $26 \mathrm{~h}$ for a hen to lay one egg. Each part of the egg is formed in a separate section of the hen's reproductive tract, which is made up of the ovary and the oviduct. In the ovary, an ovum matures by accumulating yolk, thereby, growing in size. Typically, the largest most mature ovum breaks away from a stem connecting it to the ovary and enters the oviduct. The oviduct is the tube where the structures necessary to complete the egg are applied,in sucession the oviduct secretes the albumen, the two shell membranes, and the shell. Hen's natural egg is composed of three main parts: shell (11\%), yolk (31\%) and white (58\%), the egg structure is detailed on Figure 3.1.

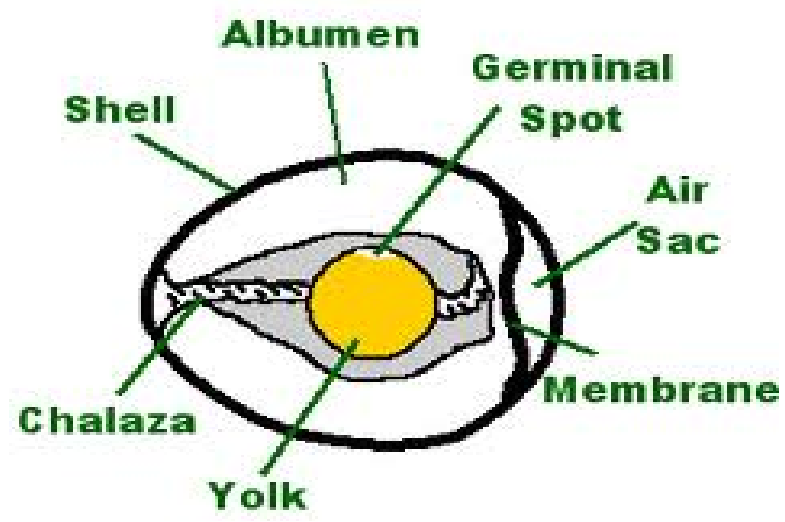

Figure 3.1 - Egg structural components.

\subsubsection{Egg white}

Egg white (also known as albumen) constitutes most of an egg's liquid weight, and correspond to $58 \%$ of the whole egg (USDA, 2000). Albumen is 
made up of approximately forty different kinds of proteins, which are the responsibles for its functional and antimicrobial characteristics. Ovalbumin, ovotransferrin, avidin, lysozyme, conalbumin, and ovomucoid are some examples of the proteins found in albumen. Eggs contain four layers of albumen: an inner thin layer, a thick layer, an outer thin layer, and the chelazaferous (inner thick).

Carbon dioxide makes the structure cloudy, and tends to disappear in aged eggs, causing a more transparent structure of albumen in old eggs than on fresh eggs. When egg albumen is beaten vigorously, it foams and increases in 6 to 8 times volume. Egg foams are essential to make several meals such as soufflés, meringues, puffy omelets, and angel food and sponge cakes (Foregeding et al., 2006). The albumen is opalescent until it is beaten or cooked, when it becomes white (American Egg Board, 2007).

The egg white is composed primarily of water, about $88 \%$ (Stadelman and Weinheim, 1988), is low in fat but rich in protein. The denaturation of egg white occurs at temperatures above $58^{\circ} \mathrm{C}$ (Németh et al., 2010).

\subsubsection{Egg yolk}

The yolk is defined as the yellow part of the egg and is located in the centre of a freshly laid egg, inside the egg white, it makes up to $31 \%$ of the egg (USDA, 2000), and includes three fourths of the calories. Major components of the yolk are proteins and lipids; nearly all the lipids, vitamins, and 
Literature review

minerals found in eggs are located in the yolk. The yolk material is contained in a thin membrane known as the vitelline membrane, which is a clear membrane composed mostly of protein (USDA, 2000), and that gives the yolk its shape. The yolk protein lecithin is the compound responsible for emulsification of products such as hollandaise sauce and mayonnaise (TelisRomero et al., 2006).

Although the color of a yolk may vary depending on the chicken's feed, color does not affect egg quality or nutritional value. The egg yolk is a very important ingredient in the food industry because it has the ability to reduce the interfacial tension between oleic and liquid phases, and is mainly used as emulsifier (Telis-Romero et al., 2006).

The yolk has about $50 \%$ water (Ohata, 2000) and its denaturation occurs at temperatures above $62.5^{\circ} \mathrm{C}$ (Németh et al., 2010).

\subsubsection{Liquid whole egg}

The liquid whole egg is composed of egg white (approximately 65.2\%) and egg yolk (approximately $34.8 \%$ ), and combines the technological properties of whites and yolks, like coagulation power, foaming capacity, gelling and emulsifying properties (Mine, 1995). It has around $75 \%$ of water. Whole egg proteins denature at an intermediate temperature between egg white and egg yolk coagulations temperature (Németh et al., 2010), sugar or salt can 
be mixed with the liquid whole egg during production, to increase its stability.

\subsubsection{Nutritive Value of Eggs}

Eggs are nutrient-dense, one single egg (category large) provides 13 essentials nutrients, $12.6 \%(6.3 \mathrm{~g})$ of the adulte recommended daily protein intake , $5 \mathrm{~g}$ of fat (mainly mono and polyunsaturated fats), and only 72 calories (USDA-ARS, 2007). The nutritional composition of each egg component is show in Table 3.1. Eggs are considered an "excellent" source of choline and selenium and a "good" source of vitamin $\mathrm{B}_{12}$, phosphorus and riboflavin. Eggs are considered one of the highest quality proteic food available and are used as the standard to compare protein quality in other foods. The protein found in eggs is highly digestible with a biological value of $94 \%$; comparable values are $84.5 \%$ for milk, $76 \%$ for fish, and $74.3 \%$ for beef (Ovobel, 2012).

The egg yolk contains all the eggs triglycerides, phospholipids, and sterols and is the major source of eggs calories and nutrients. It is a source of unsaturated fatty acids (linoleic and oleic) and fat-soluble vitamins (Watkins, 1995), and contains vitamins A, D, E, and K as well as folic acid, pantothenic acid and zinc (ENC, 2004). 
Table 3.1 - Egg white, egg yolk and whole egg composition (per 100g of edible portion).

\begin{tabular}{|c|c|c|c|}
\hline Constituents (per $100 \mathrm{~g}$ of edible portion) & Egg white & Whole egg & Egg yolk \\
\hline Energy value (kcal) & 44 & 50 & 64 \\
\hline Water $(\mathrm{g})$ & 87.3 & 74.7 & 50 \\
\hline Protein $(g)$ & 11.1 & 12.5 & 16.1 \\
\hline Available carbohydrates (g) & 0.70 & 0.70 & 0.30 \\
\hline Glucose (mg) & 410 & 340 & 210 \\
\hline Fat $(\mathrm{g})$ & 0.03 & 11.4 & 31.9 \\
\hline Cholesterol (mg) & - & 396 & 1260 \\
\hline Phospholipids (g) & - & 3.51 & 10.3 \\
\hline Minerals $(\mathrm{g})$ & 0.70 & 0.94 & 1.70 \\
\hline Sodium (mg) & 170 & 144 & 51 \\
\hline Potassium (mg) & 254 & 147 & 108 \\
\hline Magnesium (mg) & 12 & 11 & 16 \\
\hline Calcium (mg) & 11 & 51 & 140 \\
\hline Manganese $(\mu \mathrm{g})$ & 40 & 71 & 125 \\
\hline Iron (mg) & 0.2 & 1.8 & 7.2 \\
\hline Zinc (mg) & 0.02 & 1.3 & 3.8 \\
\hline Phosphorus (mg) & 21 & 210 & 590 \\
\hline Chloride (mg) & - & 180 & 180 \\
\hline Fluoride $(\mu \mathrm{g})$ & - & 110 & 30 \\
\hline \multicolumn{4}{|l|}{ Vitamins } \\
\hline Vitamin A $(\mu \mathrm{g})$ & - & 276 & 914 \\
\hline Carotenoids $(\mu \mathrm{g})$ & - & 13 & 29 \\
\hline$\beta$-Carotene $(\mu \mathrm{g})$ & - & 13 & 29 \\
\hline Vitamin D $(\mu \mathrm{g})$ & - & 2.9 & 5.6 \\
\hline Tocopherols (mg) & - & 2.3 & 6.5 \\
\hline Vitamin $\mathrm{K}(\mu \mathrm{g})$ & - & 8.9 & - \\
\hline Vitamin B2 $(\mu \mathrm{g})$ & 320 & 408 & 400 \\
\hline Nicotinamide $(\mu \mathrm{g})$ & 90 & 83 & 65 \\
\hline Pantothenic acid (mg) & 0.14 & 1.6 & 3.7 \\
\hline Vitamin B6 $(\mu \mathrm{g})$ & 12 & 77 & 300 \\
\hline Biotin $(\mu \mathrm{g})$ & 7.0 & 25 & 53 \\
\hline Folic acid $(\mu \mathrm{g})$ & 9.2 & 67 & 162 \\
\hline Vitamin B12 $(\mu \mathrm{g})$ & 0.1 & 1.9 & 2.0 \\
\hline Vitamin $\mathrm{C}(\mu \mathrm{g})$ & 300 & - & - \\
\hline \multicolumn{4}{|l|}{ Fatty acids } \\
\hline Palmitic acid (mg) & - & 2580 & 6897 \\
\hline Stearic acid (mg) & - & 723 & 2010 \\
\hline Palmitoleic acid (mg) & - & 442 & 1173 \\
\hline Oleic acid (mg) & - & 4280 & 11700 \\
\hline Linoleic acid (mg) & - & 1660 & 3750 \\
\hline
\end{tabular}




\subsubsection{Functionality of Eggs}

Eggs are also popular as ingredients in dishes due to its multifunctional properties like coagulation, foaming, emulsification, and contribution to disches color and flavor (Yang and Baldwin, 1995). Some examples of food containing eggs and the corresponding egg functional properties needed for its preparation are resumed on Table 3.2.

There are four alternating composing the albumen (chalaziferous or inner thick white, inner thin white, outer thick white and outer thin layer) and it is the quantity and viscosity of the thick layers that determines eggs foaming (Stadelman, 1995). When the albumen is beaten vigorously, foam is created, increasing the volume up to eight times (American Egg Board, 2007). The protein ovomucin makes up the majority of the thick layers and when heated, forms insoluble films which are able to stabilize foams (Froning et al., 2001; Zeidler, 2002). Dishes such as meringues, sponge cakes, angel food cakes, soufflés, fluffy omelets, and confectioneries rely on the structure provided by the foams to attain the desired volume and stability (Ziedler, 2002). In confectionaries, egg whites are also used to prevent sugar crystallization (Froning et al., 2001).

Storage conditions affect egg's quality. As the storage time and temperature increases, carbon dioxide and moisture diffuses out through the eggshell's pores causing the rise of the albumen $\mathrm{pH}$. When the $\mathrm{pH}$ rises to around 8.8, the albumen begins to thin and viscosity decreases (Stadelman, 1995; Froning et al., 2001). 
Table 3.2 - Functional characteristics of eggs and ovoproducts and their uses within the food industry.

\begin{tabular}{|c|c|c|c|c|}
\hline Capacities & $\begin{array}{l}\text { Responsible } \\
\text { agents }\end{array}$ & Variation factor & $\begin{array}{l}\text { Products of } \\
\text { substitution }\end{array}$ & $\begin{array}{l}\text { Industrial } \\
\text { application }\end{array}$ \\
\hline $\begin{array}{l}\text { Aromatic } \\
\text { (entire) }\end{array}$ & $\begin{array}{l}\text { numerous } \\
\text { volatile } \\
\text { compounds }\end{array}$ & $\begin{array}{l}\text { chicken diet, storage } \\
\text { condition }\end{array}$ & - & all food industries \\
\hline $\begin{array}{l}\text { Coulorant } \\
\text { (yellow) }\end{array}$ & $\begin{array}{l}\text { xantophylls, } \\
\text { caratenoids }\end{array}$ & $\begin{array}{l}\text { chicken diet, light, } \\
\text { presence of salt, drying }\end{array}$ & coulourants & $\begin{array}{l}\text { biscuit industry, } \\
\text { baking industry, } \\
\text { desserts and pasta }\end{array}$ \\
\hline $\begin{array}{l}\text { Coagulant } \\
\text { (entire) }\end{array}$ & $\begin{array}{l}\text { coagulatablet } \\
\text { proteins }\end{array}$ & $\begin{array}{l}\text { time/temperature, } \mathrm{pH}, \\
\text { ionic strenght, presence of } \\
\text { sugars, dilution, } \\
\text { technological processes }\end{array}$ & $\begin{array}{l}\text { carrageenan, } \\
\text { alginates, } \\
\text { modified } \\
\text { starches }\end{array}$ & $\begin{array}{l}\text { biscuit industry, } \\
\text { baking industry, } \\
\text { processed meats }\end{array}$ \\
\hline $\begin{array}{l}\text { Binder } \\
\text { (entire) }\end{array}$ & proteins & $\begin{array}{c}\text { additives increasing } \\
\text { viscosity, technological } \\
\text { processes }\end{array}$ & $\begin{array}{l}\text { polysaccharides, } \\
\text { pectin, gelatin, } \\
\text { gums, proteins }\end{array}$ & $\begin{array}{l}\text { ice-cream, pasta, } \\
\text { processed meats }\end{array}$ \\
\hline $\begin{array}{l}\text { Anti } \\
\text { crystallizer } \\
\text { (white) }\end{array}$ & proteins & $\begin{array}{c}\text { presence of yolk, presence } \\
\text { of cation, tehnological } \\
\text { properties }\end{array}$ & polysaccharides & confectionery \\
\hline $\begin{array}{l}\text { Foamer } \\
\text { (white) }\end{array}$ & $\begin{array}{l}\text { globulins, } \\
\text { lysozyme, } \\
\text { ovomucin, } \\
\text { ovalbumin }\end{array}$ & $\begin{array}{l}\text { homogenisation, beating } \\
\text { conditions, } \mathrm{pH} \text {, dilution, } \\
\text { presence of salt or sugars, } \\
\text { presence of yolk, } \\
\text { technological processes }\end{array}$ & $\begin{array}{l}\text { caseins, } \\
\text { caseinates, whey } \\
\text { proteins }\end{array}$ & $\begin{array}{l}\text { biscuit industry, } \\
\text { baking industry, } \\
\text { confectionery, } \\
\text { ready-made meals }\end{array}$ \\
\hline $\begin{array}{l}\text { Emulsifier } \\
\text { (yelow) }\end{array}$ & $\begin{array}{l}\text { lecitihins, } \\
\text { lipoproteins } \\
\text { and } \\
\text { cholesterol }\end{array}$ & $\begin{array}{l}\text { beating conditions, } \mathrm{pH}, \\
\text { dilution, presence of salt } \\
\text { or sugars, presence of } \\
\text { white, technological } \\
\text { processes }\end{array}$ & $\begin{array}{l}\text { Soya lecithins } \\
\text { and daily } \\
\text { proteins }\end{array}$ & $\begin{array}{l}\text { Biscuit industry, } \\
\text { baking } \\
\text { industry,processed } \\
\text { meats (croquettes), } \\
\text { emulsified sauces }\end{array}$ \\
\hline
\end{tabular}

Heat treatment during pasteurization could cause quality changes to the egg components, as some of egg proteins undergo denaturation, the functional properties associated to proteins, like coagulation, foaming, and emulsification, are affected (Hou et al., 1996).

Phospholipids, lecithin and other lipoproteins present in the egg yolk are important emulsifiers, and are the componend needed on mayonnaises, salad 
dressing and other dishes preparation. Specifically, the lipovitellin, livetin, and lipovitellenin act as surface active agents to stabilize films around oil globules in order to form an emulsion (Froning et al., 2001). The yolk is also used for its coagulating abilities by providing structure to custards, and color in foods such as egg noodles and breads (Zeidler, 2002).

The yolk yellow-orange color is derived from the fat-soluble carotenoids called xanthophylls, specifically, lutein and zeaxanthin. The color varies according to the nutrient composition of the hen's diet (Li-Chan et al, 1995). Hens fed with yellow corn or alfalfa will lay eggs with medium yellow yolks, while hens fed with wheat or barley produces eggs with lighter-colored yolks (American Egg Board, 2007).

\subsubsection{Eggs microbiology}

Despite the egg's many microbial barriers, bacteria are still able to penetrate the shell and membranes. Factors that improve bacteria survival on the shell surface, reducing the egg's antimicrobial defense system, include the physical condition of the cuticle and underlying shell (Sparks and Board, 1984); the presence of water on the shell (Board et al., 1979); and the concentration of iron in water that comes into contact with the egg (Board et al., 1986). If the cuticle is damaged or washed away, the pores are exposed, and there is a greater susceptibility to microbial entry into the contents (Board, 1966; Wang and Slavik, 1998). The diameters of pores range from 9-35 $\mu \mathrm{m}$ (Romanoff and Romanoff, 1949), which is significantly larger than 
Literature review

most microorganisms (which are typically 1-5 $\mu \mathrm{m}$ ). Salmonella species, for example, range from 0.7-1.5 $\mu \mathrm{m}$ wide and 2.0-5.0 $\mu \mathrm{m}$ long (Bell and Kyriakides, 2002). Because pores are larger in size, Salmonella spp. and other bacteria found on the shell can move through them into the liquid portion and cause spoilage.

Microorganisms found in egg shells are capable of breaching the shell's microbial barriers. These microorganisms are mainly $\operatorname{Gram}(+)$ bacteria derived from dust, soil and faeces (Haines, 1939; Zasgaevsky and Lutikova, 1944; Board, 1964; Board, 1966), especially cocci and bacillus such as Micrococcus and Arthrobacter (Hutchinson et al., 2003).

Once the shell's microbial barriers have been breached, Gram(-) bacteria are more capable of withstanding the antimicrobials present in the albumen (Board, 1966; Jones et al., 2004); therefore, the internal contaminants of eggs are commonly Gram(-) organisms such as Alcaligenes spp., Achromobacter spp., Pseudomonas fluorescens, Salmonella spp., and Escherichia spp. (Hutchinson et al., 2003).

\subsubsection{Salmonella in eggs}

Salmonella spp. are gram(-), non spore-forming, rod-shaped facultative aerobes belonging to the family Enterobacteriaceae, which are naturally found in the intestinal tract of humans and animals. They can be spread from animal to animal and from animal to humans by poor food-handling 
practices and consumption of raw or undercooked foods of animal origin (Banwart, 1989). There are more than 2500 serotypes of Salmonella spp. but Salmonella enterica serotype Enteritidis is of primary concern with poultry and eggs. It is the most prevalent serotype implicated in egg-borne illness in humans (CDC, 2008).

The association between eggs and Salmonella enteritidis was first reported in 1988 and was based on epidemiological studies of outbreaks during the years 1976-1986 (St. Louis et al., 1988). The researchers determined 77 \% of the reported outbreaks with an identified food vehicle were caused by grade A shell eggs or dishes containing eggs. More recently, Braden (2006) studied 997 reported Salmonella enteritidis infection outbreaks in the United States from 1985-2003 and reported that among the outbreaks with a confirmed food vehicle, $75 \%$ were still associated primarily with eggs or egg containing dishes. Therefore, the proportion of outbreaks associated with eggs remains steady. In 2006, S. enteritidis was the second most common serotype identified in all Salmonella outbreaks and has remained in the top four since 1995 (CDC, 2008). Using data from FoodNet, Schroeder et al. (2000) developed a risk model to estimate the number of shell eggassociated Salmonella enteritidis illnesses that occurred in 2000 in United States. It was estimated that the consumption of Salmonella enteritidiscontaminated eggs caused 182,060 illnesses, 2,000 hospitalizations, and 70 deaths (Schroeder et al., 2005). This is similar to the FSIS estimate of 174,356 illnesses, 1,440 hospitalizations, and 75 deaths based on surveillance data and the Joint Expert Meetings on Microbiological Risk Assessment (JEMRA) risk model to estimate illness from exposure (USDA- 
Literature review

FSIS, 2005). Salmonella enteritidis has been recovered from the shells, albumens, and yolks of intact shell eggs from naturally infected and artificially inoculated hens (Humphrey et al., 1989; Gast and Beard, 1990; Humphrey et al., 1991; Humphrey, 1994; Keller et al., 1995; Gast and Holt, 2001), researchers artificially inoculated pathogen-free flocks with Salmonella enteritidis and were able to recover Salmonella from both the albumen and yolk from the infected hen's eggs in greater percentages than from the shell surface (Gast and Holt, 2001). Previously, it was thought the main bacterial transmission route was through the shell. However, a lack of correlation between shell surface contamination and internal contamination led researchers to propose a transovarian route as the primary route of Salmonella enteritidis internal contamination. By this route, the eggs are contaminated prior to shell formation by the hen's infected reproductive system (Humphrey, 1994). To support this theory, Keller et al. (1995) found $73 \%$ of Salmonella enteritidis-positive forming eggs from artificially inoculated hens were associated with colonized ovarian tissue or upper oviduct tissue. The incidence of freshly laid eggs being positive for Salmonella enteritidis was only $0-0.6 \%$ in their study which indicated some intrinsic factor of the egg that prevented survival and growth of the bacteria.

If contamination occur in the nutrient-rich yolk, it would be reasonable to expect the presence of pathogens in high numbers as seen by Saeed and Koons (1993) when they inoculated yolks with Salmonella (20 CFU per egg) and reported significant growth $\left(10^{9} \mathrm{CFU} \mathrm{mL} \mathrm{m}^{-1}\right.$ of egg $)$ within 2-3 days when stored at $23{ }^{\circ} \mathrm{C}$. Schoeni et al. (1995) also reported a 3-5 Log increase in Salmonella enteritidis after $24 \mathrm{~h}$ when artificially-inoculated yolks were stored 
at $25{ }^{\circ} \mathrm{C}$. When stored at $10{ }^{\circ} \mathrm{C}$, growth occurred at a slower rate and at $4{ }^{\circ} \mathrm{C}$ there was only sporadic growth (Schoeni et al., 1995). Instead, the number of Salmonella enteritidis in internally contaminated eggs has been reported as less than 10-40 cells per contaminated egg (Humphrey et al., 1989; Humphrey et al., 1991; Hope et al., 2002). This provided more evidence of the albumen or the vitelline membrane being the main site of contamination. However, a small number of cases were reported where eggs were found to contain high Salmonella counts $\left(10^{4}-10^{5} \mathrm{CFU}\right.$ per egg), so yolk-contamination should not be ruled out completely (Humphrey et al., 1991). Regardless of the site of contamination, internal contamination is still a greater concern because Salmonella spp. survives the cleaning and disinfection process.

\subsubsection{Egg shelf life}

The shelf life of eggs ranges from a few hours, weeks, up to some months and years, depending on the form and the temperature at which they are stored. Eggs have excellent keeping quality; the type of egg (brown, organic, etc) does not affect shelf life. When kept in the egg carton and properly refrigerated, clean eggs free from cracks will keep for up to 4-5 weeks without significant loss of quality. Raw egg whites can be refrigerated up to four days. Unbroken raw yolks covered in water in a tightly sealed container can be refrigerated up to two days. Hard-cooked yolks can be kept four to five days when well drained, stored and refrigerated in a tightly sealed container. Hard-cooked eggs in the shell last 
Literature review

up to one week when properly refrigerated. Since eggs have pores in the shell, they can pick up odors from other foods.

\subsubsection{Manufacturing of Liquid Egg Products}

Although shelled table eggs make up a large proportion of the egg industry, pasteurized egg products are in high demand. According to the FSIS, approximately $30 \%$ of the 76 billion eggs consumed in 2007 were in the form of egg products, or eggs that have been removed from the shell and pasteurized (USDA-FSIS, 2007). From the baking industry to specialty products, pasteurized products are developed utilizing whole egg mixtures, as well as separated yolk and albumen components. Many consumers favor these products because they are perceived as safer than shelled eggs since they are processed. There are several processes that take an egg from its shelled form to packaged liquid product found in grocery stores, this includes: selection, breaking, fractions separation, homogenization, filtering, pasteurization, packing.

For pasteurization, certain specific times and temperatures must be used to maintain safety. According to the Code of Federal Regulations (Title 9, volume $2,590.570,2005)$ every portion of the product must be heated quickly to the required temperature and held at that respective temperature for at least the minimum holding time. Table 3.3 shows USDA pasteurization requirements for LEPs pasteurization (Froning et al., 2002). 
Table 3.3 - USDA Liquid egg products pasteurization requirements.

\begin{tabular}{ccc}
\hline Liquid egg product & $\begin{array}{c}\text { Minimun } \\
\text { temperature }\left({ }^{\mathbf{o}} \mathbf{C}\right)\end{array}$ & $\begin{array}{c}\text { Minimun holding } \\
\text { time (min) }\end{array}$ \\
\hline Albumen (without chemicals) & $56.7-55.6$ & $3.5-6.2$ \\
Whole egg & 60.0 & 3.5 \\
Whole egg blends & $61.1-60.0$ & $3.5-6.2$ \\
Fortified Whole egg and blends & $62.2-61.1$ & $3.5-6.2$ \\
Salted whole egg & $63.3-62.2$ & $3.5-6.2$ \\
Sugared whole egg & $61.1-60.0$ & $3.5-6.2$ \\
Plain yolk & $61.1-60.1$ & $3.5-6.2$ \\
Sugared yolk & $63.3-62.2$ & $3.5-6.2$ \\
Salted yolk & $63.3-62.2$ & $3.5-6.2$ \\
\hline
\end{tabular}

Instead of traditionally produced and marketed shell eggs, processed liquid egg products have been increasingly consumed. Since processed LEPs are handled easily in distribution to the food manufacturing processes and marketing, egg processing plays a fundamental role in addition to the high shelf life and safety.

Processing of LEPs constitutes several steps to achieve high quality and safe products with long shelf life until consuming. Before processing, shell eggs are usually held under refrigeration no longer than 7-10 days (USDA, 2000). In the production line, shell eggs are holded and classified according to their size and shape and divided into quality groups, then washed and rinsed completely to remove outer faeces coming from hen. This section is essential since a great amount of foodborne microorganisms are sourced from faeces after ovulation. Shell eggs are sanitized by spraying highly 
Literature review

diluted chemicals. In order to determine and remove the imperfections, shell eggs are then candled by quartz halogen light (USDA, 2000).

Shells are broken and liquid eggs are either separated to produce egg white and yolk, or later mixed to form whole egg. Whole or separated eggs are mixed uniformly to homogenize and filtered to remove shell fragments, membranes, and chalaza. Egg products are sent to the pasteurization unit to inactivate foodborne pathogens. All pasteurized LEPs must contain less than $10^{3} \mathrm{CFU} \mathrm{g}{ }^{-1}$. Moreover, only Salmonella-negative products are allowed to be sold (USDA, 2000). Pasteurized egg products are finally refrigerated, dried or salted according to the consumers' needs before packaging. In the production of ready to use and shelf stable liquid egg products, pasteurization is the most important process in order to inactivate harmful microorganisms and undesirable enzymes to prevent health risk in human body (Muriana, 1997; Gut et al., 2005; Daugrthy et al., 2005). Main pathogen microorganisms, which cause several foodborne illnesses associated to LEPs are Salmonella enteritidis, Salmonella seftenberg, Listeria monocytogenes and Escherichia coli (Ferreira et al., 1998; Lee et al., 2001; Ngadi et al., 2003). Most common pasteurization method is defined as thermal pasteurization, having the principle of inactivation of microorganisms at proper temperature and residence time without affecting the main quality and characteristics of products. In this technique, heat is directly applied to LEPs in a plate heat exchanger, consequently, heat sensitive food pathogenic microorganisms are inactivated. Moreover, the process parameters are to be designed for the desired level of thermal treatment with minimum damage to the lipoprotein ingredients of the LEPs 
(Gut et al., 2005). Since thermal treatment has the potential to degrade the nutritive quality and functional properties of egg products, negative effects of high temperature, as denaturation of protein structure should be eliminated (Gongora-Nieto et al., 2003; Hermawan et al., 2004). Two main parameters of LEPs are fundamental for thermal pasteurization processes: pasteurization temperature and residence time, which depend directly on the flow type (laminar or turbulent) (Pottier et al., 2006; Schuerger et al., 2005). USDA requires liquid egg pasteurization (as a conventional processing) to be conducted on a critical temperature-time condition where egg protein coagulation may not occur (FDA, 2009).

Instead of thermal treatments, several pasteurization methods have been evaluated for LEPs, such as ultrasonic wave treatment (Wrigley and Llorca, 1992), high electric field pulses (Ma et al., 1997), high hydrostatic pressure (Ponce et al., 1998) or irradiation (Alvarez et al., 2006).

\subsection{Ultraviolet}

\subsubsection{Definition and general concepts}

The discovery of UV radiation was associated with the observation that silver salts darkened when exposed to sunlight. In 1801, the german 
physicist Johann Wilhelm Ritter made the hallmark observation that invisible rays just beyond the violet end of the visible spectrum darkened silver chloride-soaked paper more quickly than violet light itself. He called them "oxidizing rays" to emphasize chemical reactivity and to distinguish them from "heat rays" at the other end of the visible spectrum. The simpler term "chemical rays" was adopted shortly thereafter, and it remained popular throughout the 19th century. The terms chemical and heat rays were eventually dropped in favor of ultraviolet and infrared radiation, respectively (Beeson and Mayer, 2008).

Ultraviolet light can be described as a spectrum of light, remaining below the range visible to the human eye (Sosnin et al., 2006; Shama, 2007). The electromagnetic spectrum is presented on Figure 3.2.

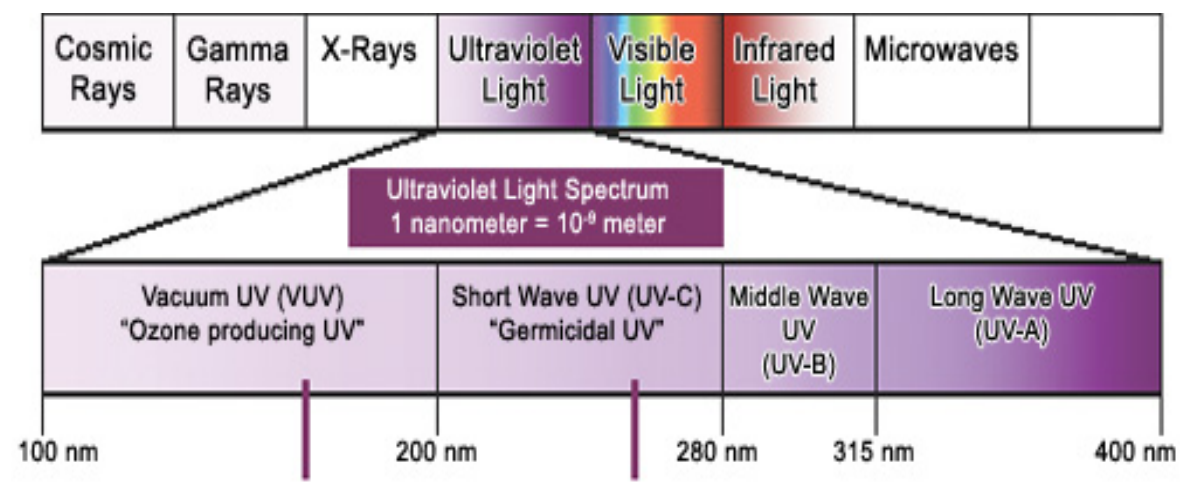

Figure 3.2 - Electromagnetic spectrum.

UV light can be divided into four distinct spectral areas up to their effectiveness, such as Vacuum UV (100-200 nm), UV-C (200-280 nm), 
UV-B (280-315 nm), and UV-A (315-400 nm). The part of an electromagnetic spectrum, which is responsible for germicidal effect to microbial structure is located between 200 and $300 \mathrm{~nm}$, is called UV-C (Shama, 2007). The ISO-DIS-21348 standard for solar irradiances (Space Environment Technologies, 2004) describes the ranges presented on Table 3.4 .

Table3.4 - Ultraviolet ligh electromagnetic spectrum according to ISO 21348 standard for solar irradiances.

\begin{tabular}{lccc}
\hline \multicolumn{1}{c}{ Name } & Abbreviation & $\begin{array}{c}\text { Wavelength } \\
\text { range (nm) }\end{array}$ & $\begin{array}{c}\text { Energy per } \\
\text { photon (eV) }\end{array}$ \\
\hline $\begin{array}{l}\text { Before UV spectrum } \\
\text { Ultraviolet A, long wave, or }\end{array}$ & Visible light & $>400$ & $<3.10$ \\
black light & UVA & $400-315$ & $3.10-3.94$ \\
Near & NUV & $400-300$ & $3.10-4.13$ \\
Ultraviolet B or medium & & & \\
wave & UVB & $315-280$ & $3.94-4.43$ \\
Middle & MUV & $300-200$ & $4.13-6.20$ \\
Ultraviolet C, short wave, or & & & \\
germicidal & UVC & $280-100$ & $4.43-12.4$ \\
Far & FUV & $200-122$ & $6.20-10.2$ \\
Vacuum & VUV & $200-100$ & $6.20-12.4$ \\
Low & LUV & $100-88$ & $12.4-14.1$ \\
Super & SUV & $150-10$ & $8.28-124$ \\
Extreme & EUV & $121-10$ & $10.2-124$ \\
Beyond UV range & X-rays & $<10$ & $>124$ \\
\hline
\end{tabular}

In photolithography and laser technology, the term "deep ultraviolet" refers to wavelengths below $300 \mathrm{~nm}$. Extreme Ultraviolet stands here for discrete 
Literature review

spectral ranges of around $13.5 \mathrm{~nm}$ of about $2 \%$ bandwidth. In fields like analytics and life sciences, the acronym "XUV" is used for Extreme Ultraviolet (EUV) for characterizing the broader spectral range, such as to distinguish from EUV. XUV is separated from x-rays and vaccum ultraviolet (VUV), by the fact that the photoelectron ionization of innershell electrons is the - by orders of magnitudes - dominating photon-matter interaction effect. This is in contrast to x-rays, where scatter is relevant and VUV where the interaction is mainly with outer ("chemical active") electrons of the atoms and molecules.

"Vacuum UV" is so named because it is absorbed strongly by air and is, therefore, used in a vacuum. In the long-wave limit of this region, roughly $150-200 \mathrm{~nm}$, the principal absorber is the oxygen in air. Work in this region can be performed in an oxygen-free atmosphere, pure nitrogen being commonly used, which avoids the need for a vacuum chamber.

The UV-C spectrum $(200-280 \mathrm{~nm})$ is the most lethal range of wavelengths for microorganisms. The germicidal effect of ultraviolet radiation was first detected in 1878, but the first processing units were built only in 1955 in Switzerland and Austria (Aguiar et al., 2002). UV-C treatment is described as a non thermal disinfection method having no undesirable effect on the organoleptic and nutritional properties of drinkable water (Bintsis et al., 2000).

Ultraviolet radiation has biological and biochemical effects, with several applications in food processing. It was first applied to the treatment of water 
and then spread also to juices treatment. Advances in studies led to approval by the Food and Drug Administration, in 1999, of the UV-C light as an alternative treatment to thermal pasteurization of fresh juice products. In 2000, the FDA amended the food additive regulations combined to UV irradiation to reduce pathogens and other microorganisms in juice products.

The technology of UV irradiation is applied, since 1930 in United States, on air and surfaces, in sterile environments like hospitals. Then it was adapted for packaging sterilization, such as bottle caps from high density polyethylene and paperboard for liquid products, yogurt containers, plastic cups and aluminum lids, besides the surface of fruits and vegetables to increase tissue resistance to spoilage microorganisms (Bintsis et al., 2000).

The efficiency of the UV process will depend on several factors like fluence, intensity, absorption coefficient, flow rate, turbidity and sample depth. The fluence is the amount of UV light exuded from the germicidal bulb and will depend on light intensity and exposure time. The intensity is an inherent characteristic of the lamp, but the intensity arising to the sample is conditioned to the bulb strength and geometry of the reactor (distance between UV source and sample). The absorption coefficient delineates how much light is lost as it passes through a medium, and is defined by the Lambert-Beer law (Equation 3.1):

$$
\mathrm{A}=\varepsilon . \mathrm{d} . \mathrm{c}
$$


Where $\mathrm{A}$ is the absorbance, $\varepsilon$ is the molar extinction coefficient, $\mathrm{d}$ is pathlenght in $\mathrm{cm}$, and $\mathrm{c}$ is the molar concentration.

High concentrations of absorbent substances, strong colors or high turbidities increase the absorption coefficient, which implies less light penetration through the system. Table 3.5 shows the absorption coefficients $(\alpha)$ of some liquid foods. About the flow rate, as higher the flow rate, the shorter the hydraulic detention time, therefore the smaller the dose received by the treated product.

The UV irradiation intensity is expressed as irradiance or intensity flux $\left(\mathrm{W} \cdot \mathrm{m}^{-2}\right)$. The dose is a function of the intensity and the exposure time, expressed as radiant exposure or dose (J.m ${ }^{-2}$ ) (Giese, 1964 cited in Bintsis et al., 2000).

Table 3.5 - Absorption coefficient $(\alpha)$ of some liquid food at $253.7 \mathrm{~nm}$.

\begin{tabular}{cc}
\hline Liquid food & Absorption coefficient $\left(\mathbf{c m}^{-\mathbf{1}}\right)$ \\
\hline Potable water & $0.02-0.10$ \\
Waste water & 14 \\
Liquid sucrose & 4.5 \\
Clear sauces & $2.0-5.0$ \\
Dark sauces & $20.0-50.0$ \\
White wine & 10 \\
Red wine & 30 \\
Coca-cola, bottled & 31 \\
Beer & $10.0-20.0$ \\
Apple cider & 40 \\
Clear apple juice & 15 \\
Orange juice & 100 \\
Milk & 300 \\
Egg white & 104 \\
Egg yolk & 630.7 \\
Whole egg & 807.5 \\
\hline Source: Shama (1999), Ünlütürk (2008) and Koutchma (2009)
\end{tabular}




\subsubsection{Mechanisms of UV-Light generation}

Atoms and ions emit light when they change from a higher to a lower energy state. An atom and most ions consist of electrons orbiting a nucleus of protons and neutrons. The electrons in each orbital occupy a unique energy state, with the electrons closest to the nucleus having a lower energy and the electrons further away having a higher energy. When electrons make a transition from a higher energy to a lower energy a discrete amount of energy is released as photons of light. Max Planck theorized that energy was transferred in chunks known as quanta, equal to h.v. The variable $h$ is a constant equal to $6.63 \times 10^{-34} \mathrm{~J}$.s and the variable $v$ represents the frequency in $\mathrm{s}^{-1}$. This equation allows calculating the energy of photons, given their frequency. If the wavelength is given, the energy can be determined by the wave equation (Equation 3.2)

$$
\mathrm{c}=\lambda \mathrm{x} v
$$

Where $c$ is the speed of light $\left(2.998 \times 10^{8} \mathrm{~m} \cdot \mathrm{s}^{-1}\right)$, and $\lambda$ is the wavelength of radiation $(\mathrm{nm})$. As first stated by Planck, each photon carries an energy $E(\mathrm{~J})$ described by equation 3.3 .

$$
E=\frac{h \times c}{\lambda}
$$

Energy levels of a given atom or ion are unique, arising from the number of electrons, protons, and neutrons within that atom or ion and their interaction with external force fields. As such, each element emits a unique spectrum of 
Literature review

light. If the difference between energy levels is appropriate, the light emitted is UV.

A transition from a lower to a higher energy state requires an energy input. This energy may be derived from the collision of the atom with a photon of light or by collision with other atoms, ions, or electrons. Energy transferred to the atom may result in an increase in the atom's kinetic energy, the transfer of an electron to a higher energy level, or the removal of an electron from the atom. Removal of an electron from the atom is named ionization and results in a positively charged cation and a negatively charged free electron. Recombination of a free electron and a cation may result in the emission of light. Since the free electron and cation may have a range of kinetic energies, the wavelength of emitting light will vary over continuous or range.

For expressing the energy of a single photon, the unit of joules $(\mathrm{J})$ is rather large employed. Other units used like electronvolt $(\mathrm{eV}$, defined as the energy gained by an electron in passing through a potential difference of 1 V), kcal per Einstein (used usually for photochemical purposes).

The photon may be viewed as the smallest discrete unit of radiation energy. Corresponding photon energies exist across the electromagnetic spectrum in a wide range of wavelengths. Radiation of UV light and the adjacent visible (VIS) spectral range, as well as other less-energetic types are called nonionizing radiation, as opposed to ionizing radiation. Absorption of 
nonionizing radiation, however, leads to electronic excitation of atoms and molecules.

\subsubsection{UV Sources}

There are two main classes of UV sources: natural, mainly coming from the sun; and artificial sources, such as low pressure mercury lamps.

The sun is the primary natural source of UV radiation. Though the sun emits all of the different kinds of electromagnetic radiation, $99 \%$ of its rays are in the form of visible light, ultraviolet rays, and infrared rays (also known as heat). UV-C is the most energetic and most harmful; UV-A is the least energetic and least harmful. UV-C rays do not reach the earth's surface because of the ozone layer. UV-C is completely absorbed in the upper and middle atmosphere by the ozone and molecular oxygen (Bintsis et al., 2000). When UV-C rays meet the ozone molecules at high layers of the atmosphere, the energy inherent in them is enough to break apart the bond of the molecule and absorb the energy. Therefore, no UV-C rays from the sun ever come into contact with life on earth. UV radiation (A and B), originating from the Sun, has been an important factor in controlling the growth of most microorganisms, except for photosynthetic bacteria (Guedes, 2009).

Shortwave UV lamps, mercury lamps projected to produce energy at the germicidal region (peak of emission at about $254 \mathrm{~nm}$ ), are electrically 
Literature review

identical to the fluorescent lamps, except for the absence of the phosphorous covering. Lamps can be constructed with glass or quartz, which allows the transmission of UV-C. Ordinary glass is partially transparent to UV-A but is opaque to shorter wavelengths, whereas silica or quartz glass, depending on quality, can be transparent even to vacuum UV wavelengths. Ordinary window glass passes about $90 \%$ of the light above $350 \mathrm{~nm}$, but blocks over $90 \%$ of the light below $300 \mathrm{~nm}$ (PGO, 2011).

Those lamps emit ultraviolet light with two peaks, at $253.7 \mathrm{~nm}$ and $185 \mathrm{~nm}$, due to the peak emission of the mercury within the bulb. $73 \%$ of the UV produced is at $253.7 \mathrm{~nm}$, while only $19 \%$ is at $185 \mathrm{~nm}$, and $8 \%$ are produced as a series of 313, 365, 405, 436 and $546 \mathrm{~nm}$ (Lucas, 2003). Germicidal lamps use quartz (glass) doped with an additive to block the $185 \mathrm{~nm}$ wavelength. With the addition of a phosphorescent coating, they can be modified to produce a UV-A, UV-B, or visible light spectrum (all fluorescent tubes used for domestic and commercial lighting are mercury UV emission bulbs at heart).

Such low-pressure mercury lamps are used extensively for disinfection, and in standard form have an optimum operating temperature of about $30{ }^{\circ} \mathrm{C}$. Use of a mercury amalgam allows operating temperature to rise to $100{ }^{\circ} \mathrm{C}$, and UV-C emission to about double or triple per unit of light-arc length. These low-pressure lamps have a typical efficiency of approximately 30-35 $\%$, meaning that for every $100 \mathrm{~W}$ of electricity consumed by the lamp, it will produce approximately $30-35 \mathrm{~W}$ of total UV output. UV-A/UV-B 
emitting bulbs are also sold for other special purposes, such as reptilekeeping.

The electric field can also be generated by microwaves. In this system, lamps do not heat up over time and there is the possibility of producing ozone and UV to achieve synergistic effect. The electric field generated by microwaves is transverse, so the UV light emitted reaches higher intensities (Lucas, 2003). The low-pressure UV lamps are considered in decontamination kinetic studies. Some features of UV lamps are presented on Table 3.6.

Table 3.6 - Conventional UV lamps characteristics.

\begin{tabular}{ccccc}
\hline $\begin{array}{c}\text { Wavelengh } \\
(\mathbf{n m})\end{array}$ & $\begin{array}{c}\text { Lamp } \\
\text { power (W) }\end{array}$ & $\begin{array}{c}\text { Electic } \\
\text { current }(\mathbf{A})\end{array}$ & $\begin{array}{c}\text { UV Power } \\
(\mathbf{W})\end{array}$ & $\begin{array}{c}\text { UV Irradiance } \\
\left(\boldsymbol{\mu} \mathbf{W} \mathbf{c m}^{-\mathbf{2}}\right)\end{array}$ \\
\hline 212 & 10 & 425 & 2.9 & 24 \\
287 & 14 & 425 & 3.9 & 35 \\
436 & 23 & 425 & 7.0 & 69 \\
793 & 37 & 425 & 12.8 & 131 \\
\hline
\end{tabular}

Source: Lucas (2003)

The efficiency of low-pressure UV lamps is directly related to the pressure of mercury (saturated), which depends on the lowest temperature detected in the lamp (Philips, 2006). These lamps have greater utility in the decontamination of surfaces and can be installed in the roof as on the floor for decontamination of air. To be submerged in liquid, the UV lamp must be protected by quarts or other material transparent to UV-C. The shelf life of 
Literature review

the low pressure mercury bulbs depends on the electrode geometry, the gas filling, the frequency of on/off launched, the ambient temperature and electrical circuits (Philips, 2006).

\subsubsection{UV microbial inactivation}

Photochemical damage to nucleic acids in cellular structure is the main result of the absorption of germicidal UV-C light. The DNA of most living organisms is double stranded, including the adenine in one strand opposite to thymine in the other, and linked by one hydrogen bond, and guanine is paired with cytosine (Bank, 1990; Moan, 1998; Miller, 1999; Bintsis, 2000; Tornaletti, 2005; Cadet et al., 2005). The purine and pyrimidine combinations are called base pairs. When UV light of a germicidal wavelength is absorbed by the pyrimidine bases, the hydrogen bond is disruptured (Cieminis et al., 1987; Tornaletti, 2005), and new bonds between adjacent nucleotides are structured. This phenomena creates double molecules or dimers (Tornaletti, 2005), shown in Figure 3.3.

Dimerization of adjacent pyrimidine molecules is the most common photochemical damage, resulting from UV-C irradiation, but, cytosinecytosine, cytosine-thymine, and uracil dimerization can also be identified. Hence, cell replication is interrupted by formation of numerous dimers in the microbial DNA and RNA structure (Ball, 2007), which with the effect of other types of damage, such as crosslinking of nucleic acids and proteins, results on cell death (Tornaletti, 2005). 
As the composition of DNA varies among species, it is considered that the absorption peak of UV-C is in the range $260-265 \mathrm{~nm}$ (very close to the main emission wavelength of low pressure mercury lamps and to the higher efficiency of this light source in the inactivation of microorganisms). Wavelengths longer than $300 \mathrm{~nm}$ do not have any lethal effect on microorganisms. The amount of cell damage depends on the dose of UV energy absorbed by the microorganisms and their resistance to UV. The resistance of different micro-organisms to ultraviolet radiation varies considerably, the approximate doses of UV at $254 \mathrm{~nm}$ required for the inactivation of various microorganisms are shown on Table 3.7. The sensitivity of microorganisms can be summarized as follows: vegetative bacteria $>$ yeasts $>$ bacterial spores $>$ fungi $>$ virus.
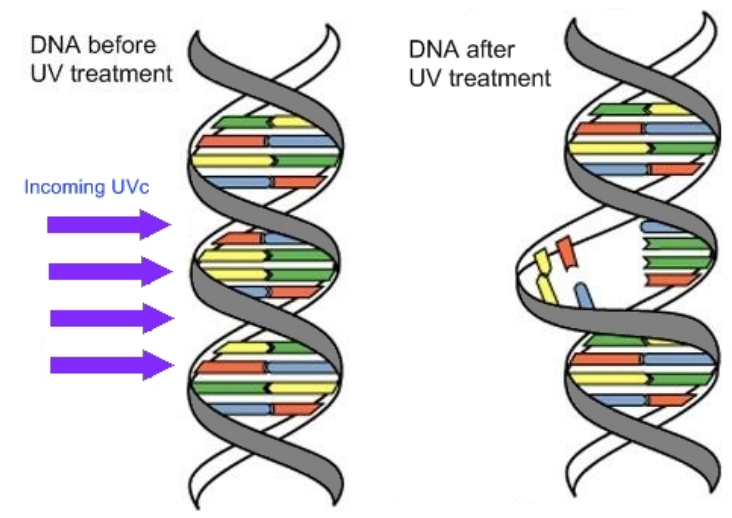

Figure 3.3 - Microbial DNA damage after UV exposure.

It is necessary to take into account also the fact that microbial sporulate forms are high UV resistant, and that sublethal doses can stimulate microorganisms growth instead of inhibiti. The UV-C processing is limited 
Literature review

by its low penetration power, to be inactivated microorganisms should be directly exposed to radiation, ie, should not be protected by solid particles (López-Malo and Palou, 2005). Among the factors that affect the efficiency of UV-C treatment are: presence of other microflora (Wright et al., 2000), soluble and insoluble solids, pH (Koutchma et al., 2004), microorganism growth phase, temperature of the low pressure mercury lamp (when less than $25{ }^{\circ} \mathrm{C}$, the formation of thymine dimmers will be faster and the UV dose required will be lower) (Severin et al., 1983 cited in Tran and Farid, 2004).

Several works report the efficiency of UV light into the inactivation of different microorganisms by using either bench top collimated beam apparatus or continuous flow reactors (Sommer, 1998; Lage, 2003), what lead to the approval since November $29^{\text {th }}, 2000$, by the Food and Drug Administration (FDA) of the UV irradiation to inactivate foodborne pathogens and other microorganisms in juice products.

UV disinfection is mainly used in air and water purification, and sewage treatment of food and beverages (Blume and Neis, 2004; Chmiel et al., 2002; Green et al., 1995; Hassen et al., 2000), processing of drinking water (Peldszus et al., 2003; Lehtola et al., 2004), and it is potentially useful for milk and fruit juice production (Koutchma, 2004; Matak, 2005).

Chmiel et al. (2002) determined the reduction of highly contaminated spent process water of food and beverage industries using the combination of a membrane bioreactor, UV pre-disinfector and UV disinfection apparatus. 
Table 3.7 - UV dose at $254 \mathrm{~nm}$ required to inactivate some microorganims (in $\mu$ W.s.cm ${ }^{-2}$ ).

\begin{tabular}{|c|c|c|}
\hline Organisms & $90 \%$ (1 Log reduction) & 99\% (2 Log reduction) \\
\hline \multicolumn{3}{|c|}{ Bacteria } \\
\hline Bacillus anthracis - Anthrax & 4.520 & 8.700 \\
\hline Bacillus paratyphusus & 3.200 & 6.100 \\
\hline Bacillus subtilis & 5.800 & 11.000 \\
\hline Clostridium tetani & 13.000 & 22.000 \\
\hline Escherichia coli & 3.000 & 6.600 \\
\hline Microccocus candidus & 6.050 & 12.300 \\
\hline Mycobacterium tuberculosis & 6.200 & 10.000 \\
\hline Proteus vulgaris & 3.000 & 6.600 \\
\hline Pseudomonas aeruginosa & 5.500 & 10.500 \\
\hline Pseudomonas fluorescens & 3.500 & 6.600 \\
\hline Salmonella enteritidis & 4.000 & 7.600 \\
\hline Salmonela paratyphi - Enteric fever & 3.200 & 6.100 \\
\hline Salmonella typhosa - Typhoid fever & 2.150 & 4.100 \\
\hline Salmonella typhimurium & 8.000 & 15.200 \\
\hline Shigella dyseteriae - Dysentery & 2.200 & 4.200 \\
\hline Shigella flexneri - Dysentery & 1.700 & 3.400 \\
\hline Shigella paradysenteriae & 1.680 & 3.400 \\
\hline Staphylococcus aureus & 2.600 & 6.600 \\
\hline Staphylococcus hemolyticus & 2.160 & 5.500 \\
\hline Staphylococcus lactis & 6.150 & 8.800 \\
\hline Streptococcus viridans & 2.000 & 3.800 \\
\hline Vibrio comma - Cholera & 3.375 & 6.500 \\
\hline \multicolumn{3}{|c|}{ Molds } \\
\hline Aspergillius flavus & 60.000 & 99.000 \\
\hline Aspergillius niger & 132.000 & 330.000 \\
\hline Oospora lactis & 5.000 & 11.000 \\
\hline Penicillium roqueforti & 13.000 & 26.400 \\
\hline Penicillium digitatum & 44.000 & 88.000 \\
\hline Rhisopus nigricans & 111.000 & 220.000 \\
\hline \multicolumn{3}{|c|}{ Protozoa } \\
\hline Chlorella vulgaris & 13.000 & 22.000 \\
\hline Nematode Eggs & 45.000 & 92.000 \\
\hline Paramecium spp. & 11.000 & 20.000 \\
\hline \multicolumn{3}{|c|}{ Virus } \\
\hline Infectious Hepatitis & 5.800 & 8.000 \\
\hline Influenza & 3.400 & 6.600 \\
\hline Poliovirus - Poliomyelitis & 3.150 & 6.600 \\
\hline \multicolumn{3}{|c|}{ Yeast } \\
\hline Brewers yeast & 3.300 & 6.600 \\
\hline Common yeast cake & 6.000 & 13.200 \\
\hline Saccharomyces carevisiae & 6.000 & 13.200 \\
\hline Saccharomyces spores & 8.000 & 17.600 \\
\hline
\end{tabular}


Literature review

Sommer and Cabaj (1993) calculate the effective dose in UV-reactors using B. subtilis (ATCC 6633) spores suspended in potable water (3-80\% of transmission; thickness of $1.0 \mathrm{~cm}$ ), the data resulted in an individual diagram of efficiency, and also was show that this procedure is suitable for the evaluation of the disinfection capacity of UV plants and the estimation of the field of application depending upon transmission and flow rate of the water being irradiated.

On surface disinfection, Wong et al. (1998) determined the $>5$ Log reduction of E.coli on the surface of tryptic soy agar with doses of $>12$ $\mathrm{mW} . \mathrm{cm}^{-2}$. Summer et al. (1995) achieved 7 Log reduction of Salmonella typhimurium on brain heart infusion agar plates with doses of $36 \mathrm{~mW} . \mathrm{cm}^{-2}$. Yaun et al. (1999) defined the UV light treatment and reduced the numbers of multistrain cocktails of Salmonella spp. and E.coli O157:H7 on agar surfaces using a one $\mathrm{m}$ long UV chamber with peak of emission at $253.7 \mathrm{~nm}$ wavelength and dose of $100 \mathrm{~mW} . \mathrm{s}_{\mathrm{cm}} \mathrm{cm}^{-2}$, then achieved 5 Log reduction under $14.5 \mathrm{~mW} . \mathrm{cm}^{-2}$ irradiance average.

Wright et al. (2000) studied UV inactivation of E.coli $\mathrm{O} 157: \mathrm{H} 7$ in apple cider in continuous flow reactor in the dose range of 9.4-61 mW.s.cm ${ }^{-2}, \mathrm{UV}$ pathogen treatment achieved a mean reduction of 3.81 Log. Matak (2005) achieved a more remarkable 5 Log reduction of L. monocytogenes in milk

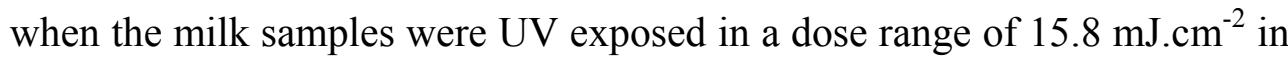
a continuos flow reactor. 
Tosa and Hirata (1999) determined the susceptibility of enterohemorrhagic E.coli $\mathrm{O} 157: \mathrm{H} 7$ to $\mathrm{UV}$ radiation at $254 \mathrm{~nm}$ and investigated the photoreactivation in a batch disinfection device at 1.5 and $3.0 \mathrm{~mW} . \mathrm{s}^{\mathrm{cm}} \mathrm{cm}^{-2}$ UV dose. Giese and Darby (2000) defined the responses of three coliform bacteria species (Citrobacter diversus, Citrobacter freundii and Klebsiella pneumoniae) to three wavelengths of UV light (254, 280 and $301 \mathrm{~nm})$ with a collimated beam apparatus having medium pressure UV lamps at 29 to $575 \mathrm{~s}$ under 2.3-39 mW.s.cm ${ }^{-2}$ and achieved 3 Log inactivation level. Hence, germicidal efficiency determined for one species of bacteria or virus may be used to represent the relative responses of all bacteria and viruses to medium pressure UV irradiation (Giese and Darby, 2000).

\subsubsection{Applications}

UV can be used in a wide range of applications. For example, $13.5 \mathrm{~nm}$ can be used in extreme ultraviolet lithography; $230-365 \mathrm{~nm}$ is used on label tracking and barcodes; $230-400 \mathrm{~nm}$ is used in optical sensors; $250-300 \mathrm{~nm}$ is used in forensic analysis and drug detection; $270-300 \mathrm{~nm}$ is the wavelength used for protein analysis and DNA sequencing; etc.

On the field of UV-C, Pottier (2006) applied the two-flux approach to the Chlamydomonas reinhardtii growth in a photobioreactor of torus shape using daylight fluorescent tubes. Instead of the destruction of pathogens, the aim of this study was to promote the grown of microorganisms of interrest. It can be predicted that UV light could be also applied on the growth of 
Literature review

organisms in biotechnology. Schuerger (2005) improved the UV simulations in order to create an inactivation model for spore-forming Bacillus species, used as the benchmark for assessing the cleanliness of spacecraft surfaces prior to launch, on sun exposed surfaces of spacecraft on Mars. Li and Logan (2004) studied on the prevention of biofouling on glass and quartz surfaces with photocatalytical materials, like active metal oxides. Fauquet et al. (2004) determined the inactivation procedure for foodborne pathogens in blood used in clinical operations from unknown donors.

Disinfection using UV radiation is commonly used in wastewater treatment and is finding an increased usage in drinking water treatment. New York City has approved the construction of a 2.2 billion US gallon per day ultraviolet drinking water disinfection facility, which must be online in 2012 (Trojan UV, 2012). There are also several facilities under construction and several in operation that treat wastewater with several stages of filters, hydrogen peroxide, and UV light to bring the water up to drinking standards. One such facility exists in Orange County, California, which is designed to treat wastewater and convert it into high-quality water for Indirect Potable Reuse. The NASA has examined the use of this technology, using titanium dioxide as catalyst, for breaking down harmful products in spacecraft waste water (Antoniou and Dionysius, 2007). Triassi et al. (2005) studied ultraviolet disinfection of 30 environmental Legionella strains from the pediatric and cardiac surgery units in hospital environment, hospital water supply and medical devices to prevent Legionnaries' disease. UV-C treatment has also been applied to prolong shelf life of wrapped partially 
baked baguettes to minimize post baking contamination (Doulia et al., 2000).

Lyon et al. (2007) reported that raw broiler breast fillets were subjected to UV-C light $\left(1000 \mu \mathrm{W} . \mathrm{cm}^{-2}\right.$ for $\left.5 \mathrm{~min}\right)$ to evaluate its potential to reduce Listeria monocytogenes loads in the raw product. Boneless and skinless breast fillets were inoculated with four different strains of $L$. monocytogenes 5 min before treatment. After the UV-C treatment, breast fillets were stored at $4{ }^{\circ} \mathrm{C}$ for $24 \mathrm{~h}$. An approximate $2 \mathrm{Log}$ reduction in viable $L$. monocytogenes was observed with all four strains on UV-treated breast fillets as compared with the nontreated controls.

The effect of UV-C light has been evaluateded on the microbial population and quality of fresh-cut watermelon (Fonseca and Rushing, 2006) and cantaloupe melon (Beaulieu, 2007; Lamikanra et al., 2005) and for surface disinfection of apples, kiwifruit, lemons, nectarines, oranges, peaches, pears, raspberries, and grapes (Lagunas-Solar et al., 2006). The results reported by Fonseca and Rushing (2006) showed that exposing packaged watermelon

cubes to UV light at $4.1 \mathrm{~kJ} . \mathrm{m}^{-2}$ produced more than a 1 Log reduction in microbial populations without affecting juice leakage, color, and overall visual quality.

\subsubsection{UV Systems in liquids}

The simplest way to build a UV-C system for treating liquid foods is using concentric tubing systems with a UV-C lamp, containers for the liquids, 
Literature review

plastic tubing or sanitary pipes, refrigeration systems, and pumps. An ultraviolet lamp surrounded by a sleeve made of quartz (Shama, 1999), as in a heat exchanger system, may be placed inside the concentric system. The liquid will flow through the annular part. The UV-C lamp standing in the centre of the system will provide the amount of light dose required for disinfection. Thus, the jacket requires tubing connectors at the ends of the system to be used as the circulation system. The liquid passing through the system can be re-circulated or treated continuously through the annular part to achieve the required germicidal effect. However, more than one concentric tubing system can be connected in a series array to increase the germicidal effect on the liquid food without being re-circulated. A refrigeration system at the inlet or outlet of the concentric system can be attached to cool the liquid food before or after UV light treatment. Pumps can control the flow rate of the liquid. Mixing devices are needed before and after the UV-C unit to ensure the appropriate mixing of microorganisms.

In fluid treatment systems a phenomenon called "fouling" can occur. Basically it means that there is a progressive decline in the efficiency of inactivation with time due to the accumulation of deposits on the flowing/transfer surfaces. This has been considered an important factor limiting the efficiency of conventional UV reactors, mainly due to insufficient mixing and high temperatures inside the reactor.

UV-C light is considered a promising technology to reduce the levels of microbial contamination for a wide range of liquid foods and beverages. These liquids include juices, brines, liquid sugars, pharmaceuticals, process 
lubricants, and other semitransparent and opaque ingredients or foods. Due to the presence of color compounds, organic solutes, and suspended matter, liquid foods usually transmit relatively little UV light, and this low transmission lowers the performance efficiency of the UV pasteurization processes.

Several arrangements have been used for UV-C liquid treatments. For example, water disinfection supplier companies throughout the world have built UV-C disinfection units for drinking water. However, most liquid fruit products are neither transparent nor colorless. This means that some specific characteristics are needed when applying UV as a disinfection technology to liquid food products. The most common approach for disinfecting liquids by UV-C light is by running the liquid through an annulus, as in those used for drinking water disinfection. However, the disinfection may not be effective if the thickness of the layer of liquid is not small enough, since UV penetration depends on the liquid absorbance (Shama, 1992). Thin films of liquids are recommended to increase the effectiveness of UV-C penetration and ensure a lethal dose against bacteria (Shama, 1992).

Shama (1992) and Shama et al. (1996) developed a thin film photoreactor that had a nozzle with a special design that could spray the liquid by forming a liquid bell. The equipment had a UV-C lamp positioned axially inside the falling liquid bell and four UV-C lamps circumferentially located outside of the product to improve the UV germicidal effect. Each lamp was held at a distance of $10 \mathrm{~cm}$ from the liquid bell. 
Shama et al. (1996) recirculated $32 \mathrm{~L}$ of E. coli $\left(1.2 \times 10^{7}\right.$ CFU.mL $\left.{ }^{-1}\right)$ suspended in water or humic acid at a rate of $13.5 \mathrm{~L} \cdot \mathrm{min}^{-1}$. They found that the initial load was reduced to survival fractions of $1.88 \times 10^{5}$ and $1.84 \times 10^{4}$ CFU. $\mathrm{mL}^{-1}$ for absorptivities of $0.18 \mathrm{~cm}^{-1}$ (water) and $4.0 \mathrm{~cm}^{-1}$ (humic acid), respectively, after $30 \mathrm{~min}$ of treatment. The dosage delivered was between $20.3 \mathrm{~J} . \mathrm{m}^{-2}$ and $48.4 \mathrm{~J} . \mathrm{m}^{-2}$ for one and five sources, respectively (GuerreroBeltrán and Barbosa-Canóvas, 2004).

Koutchma et al. (2002) examined individual physical and chemical factors in a model fluid that simulated $\mathrm{pH},{ }^{\circ} \mathrm{Brix}$, and the range of absorbancies of apple juice and cider for their effects on the efficacy of UV light on the destruction of E. coli $\mathrm{K} 12$ bacteria using laminar and turbulent-flow treatment systems. A thin-film flowthrough laboratory UV-C unit (CiderSure Model 1500, FPE Inc., Macedon, NY) and a UV-C reactor (Aquionics, Hanovia Ltd., Slough, England) were used in the study. Factors unique to juice, such as ${ }^{\circ}$ Brix and $\mathrm{pH}$, did not exhibit a large effect over the range tested when examined individually. The single factor found to consistently affect the efficacy of UV-light inactivation in juice was absorbance.

Wright et al. (2000) examined the efficacy of UV-C light for reducing $E$. coli $\mathrm{O} 157: \mathrm{H} 7$ in apple cider. For their studies, a model CIDER-10uv (IdeaL.horizons, Poultney, VT) was used to deliver dosages ranging from

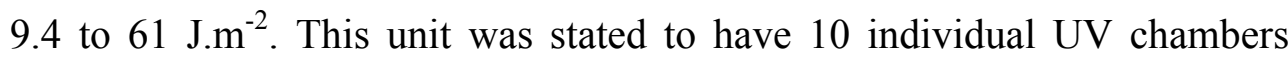
connected in series through which the apple cider was pumped as a thin film. UV-C treatments significantly reduced the pathogen counts, with a 
mean reduction of $3.81 \mathrm{Log}$. Geveke (2005) processed apple cider with a single-lamp UV apparatus surrounded by a coil of UV-transparent Chemfluor tubing. Escherichia coli $\mathrm{K} 12$ and L. innocua were used for inoculation of apple cider. The population of E. coli K12 was reduced by 3.4 Log after being exposed for $19 \mathrm{~s}$ to a $15 \mathrm{~W}$ low-pressure mercury lamp. The population of $L$. innocua was more resistant to UV and was reduced by 2.5 Log after being exposed for $58 \mathrm{~s}$. The energy for the process was calculated as the ratio of lamp power to the flow rate and was equal to 34 J.mL ${ }^{-1}$. The comparison of the average energy cost with heat treatments showed that energy consumption and cost for UV-C and heat treatments were in the same range.

For juice, the FDA requires the application of a Reduction Equivalent Dose

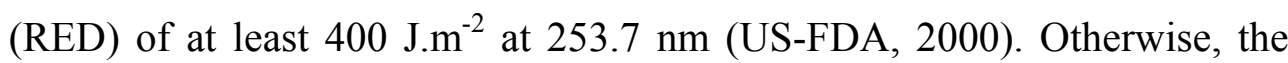
phenomenon of photoreactivation may take place, which makes the organisms more resistant to UV-C than non-reactivated (Guerrero-Beltrán and Barbosa-Canovas, 2004). Hanes et al. (2002) determined the inactivation of Cryptosporidium parvum oocysts in fresh apple cider using a CiderSure 3500A (FPE Inc., Rochester, NY) device. Harrington and Hills (1968) treated juice at $14.32 \mathrm{~mJ} . \mathrm{cm}^{-2}$ for 1.2 to $1.9 \mathrm{~s}$, this level of treatment successfully reduced oocysts from $106 \mathrm{~mL}^{-1}$ to below the lower limit of detection, which was 23 oocysts $\mathrm{mL}^{-1}$.

Müller et al. (2011) tested the potential to inactivate spoilage microorganisms in cloudy fruit juices of a laboratory-scale UV-C treatment device based on Dean Vortex technology. A 5 and 6 Log reductions were 
Literature review

achieved on Lactobacillus plantarum (BFE 5092) and Escherichia coli DH5 $\alpha$ in naturally cloudy apple juice at 1.9 and 7.7 kJ.L ${ }^{-1}$, respectively. A treatment with $9.6 \mathrm{~kJ} . \mathrm{L}^{-1}$ led to an approximately 4 Log inactivation of Saccharomyces cerevisiae DSM 70478 and Alicyclobacillus acidoterrestris DSM 2498. An increasing flow rate and the consequently higher Dean number clearly improved the efficacy of the UV-C treatment. Thus, the inactivation of L. plantarum in blood orange juice could be enhanced by an approximately $2.5 \mathrm{Log}$ reduction by increasing the Dean number from 32 to 256 at $7.7 \mathrm{~kJ} . \mathrm{L}^{-1}$.

Guerrero-Beltran and Barbosa-Canovas (2005) studied the inactivation of Saccharomyces cerevisiae, E. coli, and L. innocua by UV-C light in apple juice. Two annular single-lamp reactors from Atlantic UV Co. were connected in series using a low pressure mercury lamp of $25 \mathrm{~W}$. The apple juice was recirculated in the system, Re numbers indicated that only laminar flow was achieved during trials. Reductions of 1.34, 4.29, and 5.10 Log after $30 \mathrm{~min}$ of UV treatment were reported for S. cerevisiae, E. coli, and $L$. innocua, respectively. An incident UV fluence of $450 \mathrm{~kJ} . \mathrm{m}^{-2}$ was reported in this study. Guerrero-Beltran and Barbosa-Canovas (2006) processed mango nectar with UV light and examined inactivation of $S$. cerevisiae and polyphenoloxidase using the same lab-scale UV reactors described above. The maximum 3 Log reduction was achieved after treatment for $30 \mathrm{~min}$. In addition, shelf-life extension up to 20 days for mango nectar was reported.

Regarding UV treatment of milk, Matak et al. (2005) reported more than a 5 Log reduction in Listeria monocytogenes numbers in goat's milk by 
exposure to a cumulative UV dose of $15.8-1.6 \mathrm{~mJ} . \mathrm{cm}^{-2}$ with the use of a CiderSure 3500 UV apparatus (FPE Inc., Macedon, NY). Reinemann et al. (2006) reported that UV treatment (dose of $15 \mathrm{~kJ} . \mathrm{L}^{-1}$ ) achieved a $3 \mathrm{Log}$ reduction in total bacteria counts in raw cow's milk, with coliforms showing the greatest reduction, and spore formers showing only a modest reduction. UV-light inactivation of Mycobacterium avium subsp. paratuberculosis in Middlebrook $7 \mathrm{H} 9$ broth and whole and semi-skim milk was investigated by Altic et al. (2007) using a laboratory-scale UV unit that consisted of four UV lamps surrounding a UV-penetrable flow tube and incorporated static mixers within UV-penetrable pipes. UV-C treatments proved to be less effective in killing M. avium subsp. paratuberculosis suspended in milk (0.5 to $1.0 \mathrm{Log}$ reduction per $1000 \mathrm{~mJ} . \mathrm{mL}^{-1}$ ) than that suspended in Middlebrook $7 \mathrm{H} 9$ broth (2.5 to $3.3 \mathrm{Log}$ reduction per $\left.1000 \mathrm{~mJ} . \mathrm{mL}^{-1}\right)$.

\subsubsection{Advantages and limitations of UV technology}

The UV-C was show on the previous sections to be effective for microbiological decontamination. UV systems are universally accepted disinfection processes especially in surface and water disinfection (Guedes, 2009). Although it is also know that is limited to the surface decontamination or liquids with a low absorption coefficient.

Another advantage of the UV processing demonstrated in water processing is that it does not contain nor create any residuals, or byproducts, in contrast with chemical decontamination methods. In fact, UV is sometimes used to 
Literature review

remove residuals, and disinfection by-products, such as chlorine, peroxide, ozone, and trihalomethanes, that result from other purification processes. Besides, UV-C systems can be operated automatically without special attention, what do not require highly specialized skills, and reinstallations are not highly demanding (Tchobanoglous et al., 1996; Lazarova et al., 1998; Elyasi and Taghipour, 2006). Depending on the food matrices, treatment process may be immediately operated without any holding tanks or long retention times (Oppenheimer et al., 1993; Masschelein et al., 1989). UV operations are extremely economical and a large amount of food matrices may be treated for a little operating cost with low power consumption (Green et al., 1995). Comparing the thermal treatment, no or hardly any change in taste, odor, $\mathrm{pH}$ or conductivity is differentiated in water. And also, UV-C systems may be used as a compatible device with other treatment attempting to obtain a synergistic effect (Blume and Neis, 2004; Koivunen and Heinonen-Tanski, 2005). However UV processing was not completely studied and some effects on food matrix are still not well understood. UV light is not only harmful to microorganisms, but it is also dangerous to humans. In this respect, UV light may cause skin irritation, conjunctivitis, erythema and severe eye damage if maximum limit of exposure to UV-C is exceed (Philips, 2006). Conventional UV systems are not effective against cysts like Cryptosporidium; obligating the products to be filtered before UV disinfection (nevertheless, some advanced UV systems address this problem by using a stainless steel screen with $2 \mu \mathrm{m}$ openings to capture the cysts). Disinfection is not appropriate for treatment of products with high levels of suspended solids, turbidity, color, or soluble 
organic matter (substances can react with UV radiation and also decrease the purification efficacy).

\subsubsection{Control and measurements}

The ultraviolet light intensity emitted by mercury lamps may change during operation. UV-C lamps are useful for an average of 10,000 hours. This limited lifespan is the main reason why the UV-C lamp's intensity needs to be measured constantly, and this will ensure that the lamp delivers the correct dose during processing. For this purpose, UV-C sensors (called radiometers), chemical actinometers, or bio-dosimeters can be used to address this problem.

Radiometers can be either thermal or photonic and measure UV irradiance. There are several radiometer models on the market that provide various types of information. A radiometer should be chosen to fit the application and the information required. Functions range from simple intensity and simple dosage to sophisticated mapping devices. The wavelength to measure is also a matter of choice. Most radiometry typically involves measuring UV dosage in $\mathrm{mJ} . \mathrm{cm}^{-2}$, while more sophisticated measurements involve measuring peak UV intensity in addition to dosage.

A chemical actinometer or dosimeter is a chemical system (fluid, gas, solid, or a microheterogeneous environment) that undergoes a light-induced reaction (at a certain wavelength) for which the quantum yield is accurately 
Literature review

known. Measuring the reaction rate allows the calculation of the absorbed photon flux. Actinometers can measure concentrations of products with well-characterized energies delivered from photochemical reactions. The concentration of those products is related to the UV light absorbed by the treated product (Shama, 1999). In a chemical actinometer, photochemical conversion is directly related to the number of photons absorbed because the chemical action of light means reversible or irreversible chemical change, i.e., destruction or build-up of molecules and, consequently, of their properties such as spectra (Kuhn, Braslavsky and Schmidt, 2004). The importance of chemical actinometers is extremely high for the development of UV-C applications, being also used for the standardization of UV-C sensors (Sastry et al., 2000).

A third common option to measure UV dose is the biodosimetry. The biological effect of microorganism inactivation exposed to UV allows the plotting of survival curves that are used as calibration curves. As "biodosemeters" can be used, for example, bacteria spores or virus (Cabaj and Sommer, 2000). In this method the dose-response behavior to UV-C of microbial flora is first obtained and then the fractional survival is determined under conditions where it is desired to estimate the UV-C dose. Doses may then be computed from the dose-response curve. Spores of Bacillus subtilis have frequently been used for this purpose owing to the fact that they are non pathogenic (Gardner and Shama, 1999). 


\subsection{UV-C in liquid egg products}

UV light has been documented to be effective in reducing various bacterial populations on eggshell surfaces, including total aerobic plate count (Chavez et al., 2002), S. typhimurium and E. coli (Coufal et al. 2003), and Yersinia enterocolitica (Favier et al., 2001).

Kuo et al. (1997) reported UV inactivation of aerobic bacteria and molds in addition to S. typhimurium, and a $99 \%$ reduction of CFU of aerobic bacteria per egg was observed for all UV treatments $(0,15$, and $30 \mathrm{~min})$ at an intensity of $0.62 \mathrm{~mJ} . \mathrm{cm}^{-2}$. Mold CFU per egg was either 0 or 1 for all treatments.

Ünlütürk et al. (2008) explored the efficacy of UV radiation as a nonthermal pasteurization process for LEPs using E. coli (ATCC 8739) as the target microorganism. For this purpose, the effects of depth of liquid food medium, applied UV intensity (incident), and exposure time on the inactivation of $E$. coli (ATCC 8739) were explored in three LEPs, namely liquid egg yolk, liquid egg white, and liquid whole egg. UV irradiation of samples was conducted using a collimated beam apparatus as described by Bolton and Linden (2003). The apparatus consisted of a low-pressure mercury UV lamp with peak radiation at $254 \mathrm{~nm}$ wavelength. The UV radiation was collimated with a flat-black painted tube that was the same size as a Petri dish. Samples were placed in 6-cm diameter Petri dishes directly below the collimated UV beam and stirred continuously during the 
Literature review

irradiation with a vortex mixer. Absorption coefficients of liquid egg products were reported to be 104,807 , and $630 \mathrm{~cm}^{-1}$ for liquid egg white, whole egg, and egg yolk, respectively. Turbidity of the liquid egg product was in the range from 398 NTU for liquid egg white to 8400 NTU for liquid whole egg and yolk. The kinetic rate parameters $(k)$ were reported based on the first-order reaction for the different fluid-medium depths and UV intensities. Maximum inactivation obtained was 0.675 Log in LEY and 0.316 Log in LWE. On the other hand, 2 Log reduction of E. coli (ATCC 8739) was achieved in liquid egg white. It was concluded that UV light may not be the feasible inactivation process for liquid whole egg and liquid egg yolk. Considering the lower treatment costs of UV systems compared with thermal pasteurization methods, it was suggested that UV-light treatment can be used as a pretreatment process or alternative method when combined either with mild heat treatment or non-thermal technologies to reduce the initial microbial load as well as the adverse effects of thermal pasteurization of liquid egg products. It may also be used in combination with other preventive methods, such as good manufacturing practices and sanitizing treatments of egg shells, as part of an approved hazard analysis and critical control point plan (US-FDA, 2001).

Ngadi et al. (2003) reported effects of $\mathrm{pH}$, depth of food medium, and UVlight dose on the inactivation of $E$. coli $\mathrm{O} 157: \mathrm{H} 7$ in UV-opaque products such as apple juice ( $\mathrm{pH} 3.5)$ and egg white $(\mathrm{pH}$ 9.1). The applied UV dose ranged from 0 to $6.5 \mathrm{~mW} \cdot \mathrm{min} . \mathrm{cm}^{-2}$, while the depths of the medium were 1 , $3.5,5$, and $10 \mathrm{~mm}$. The $\mathrm{pH}$ of the medium did not affect the inactivation of E coli $\mathrm{O} 157: \mathrm{H} 7$, since similar inactivation characteristics were obtained for 
both apple juice and liquid egg white. More than a 5 Log reduction was obtained when the fluid depth and UV dose were $1 \mathrm{~mm}$ and 6.5 $\mathrm{mW} . \min . \mathrm{cm}^{-2}$, respectively. However, less than 1 Log reduction was obtained when the fluid depth was $10 \mathrm{~mm}$. The visual appearance of the treated apple juice and egg white did not show any discoloration changes during 4 weeks of storage at ambient temperature $\left(25^{\circ} \mathrm{C}\right)$.

Geveke (2008) reported an effective UV treatment of E. coli K12 (ATCC 23716) in LEW, using a continuous process with a low-pressure mercury lamp surrounded by UV transparent tubing and a silicon rubber tape. In that work, the population of $E$. coli was reduced by 4.3 Log after being exposed to $\mathrm{UV}$ at $50^{\circ} \mathrm{C}$ for $160 \mathrm{~s}$.

Despite the urgent need to improve egg safety and the demonstrated UVlight inactivation efficiency, the UV-C treatment of eggs has not yet been commercially implemented. 



\section{Material and}

methods 



\section{Material and methods}

\subsection{Eggs}

Preliminary studies were done with powder egg (egg white, egg yolk and whole egg), which was reconstituted before assays with sterile water. But this kind of preparation was discarded since the UV-C effects could be masked due to the previous processing already suffered by the samples. Viscosity and color were visibly different from natural eggs.

Experiments were performed in three different locations. Raw in shell freshly laid eggs, from cage hens, were purchased in each location to ensure freshness, and had approximately the same external characteristics: yellow shell and weight between 55 and $61 \mathrm{~g}$. After reception eggs were inspected for shell integrity and broken or defective eggs were discarded. Approved eggs were stored in the reception box in a refrigerated chamber $\left(8 \pm 2{ }^{\circ} \mathrm{C}\right)$ for no longer than 2 weeks before analysis. On the day of assays, eggs were removed from the storage chamber and allowed to reach the room temperature (around $20{ }^{\circ} \mathrm{C}$ ). Just before experiments were carried out, the egg content (separately, egg whites and egg yolks) was removed under 
Material and methods

aseptic conditions, and collected in sterile containers. The chalaza was removed and the separated egg fractions were then homogenized.

The $\mathrm{pH}$ of the samples was measured before proceeding with the experiments and eggs were considered to be fresh when $\mathrm{pH}$ were around 7.2 $( \pm 0.2)$ for egg white, and $6.2( \pm 0.2)$ for egg yolk. To prepare the whole egg samples, $13.3 \mathrm{~mL}$ of egg yolk were mixed with $26.7 \mathrm{~mL}$ of egg white. Figure 4.1 show a resume of eggs suppliers with the corresponding device where the egg from each supplie was used. And Table 4.1 presents the physical parameters of eggs from each supplier.

\section{Eggs suppliers}

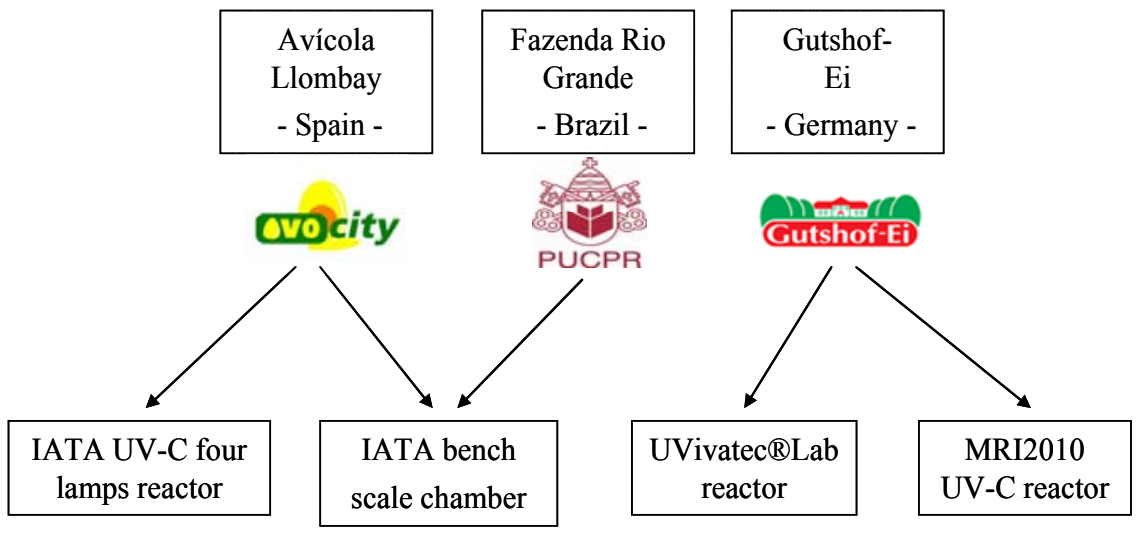

Figure 4.1 - Eggs suppliers.

Devices

In Spain experiments were performed at the IATA bench scale device and IATA 4 lamps reactor. The eggs were purchased from Avícola Llombay (Valencia, Spain). And the homogeneization was performed for 1 min using a vortex (MS3 Digital, IKA ${ }^{\circledR}$, USA), at the maximum speed (3000 rpm). 
Material and methods

In Germany the experiments were carried out on UVivatec ${ }^{\circledR}$ Lab reactor and on the MRI2010 UV-C reactor, both based on Dean vortex technology. Eggs were purchased from Gutshof-Ei GmbH (Schackendorf, Germany). For the homogeneization step, a commercial blender was used (31BL44, Waring, USA) at maximum speed for $3 \mathrm{~min}$.

In Brazil, the sensory experiments were performed at the IATA bench scale device. Eggs used were purchased from Fazenda Rio Grande (Curitiba, Brazil) and the homogenization was carried out using a vortex (QL901, Biomixer, Brazil), at $3000 \mathrm{rpm}$ for $1 \mathrm{~min}$.

Table 4.1 - Egg physical properties.

\begin{tabular}{|c|c|c|c|c|}
\hline & & Lgg & Whole & Egg \\
\hline \multirow{4}{*}{ 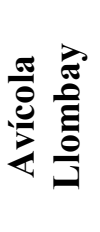 } & & & $337.6 \pm 28.5$ & 6 \\
\hline & Turbidity (NTU) & 6 & 6 & 9 \\
\hline & Pa.s) & 1 & & 99 \\
\hline & Dens & 041 & 1.04 & 002 \\
\hline \multirow{4}{*}{ 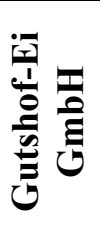 } & Optic & $42.03 \pm 3.67$ & & \\
\hline & & 6 & 5 & 36 \\
\hline & a.s) & $3.90 \pm$ & .04 & 86.95 \\
\hline & & 1.04 & 1.03 & 1.0 \\
\hline \multirow{4}{*}{ 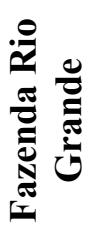 } & pre & 1 & 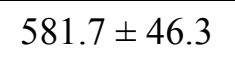 & 89 \\
\hline & $\mathrm{Tu}$ & $291.0 \pm 14$. & 8814 & $10712 \pm 257$ \\
\hline & Viscosit & $4.15 \pm 0.16$ & $9.22 \pm 0.64$ & $70.62 \pm 7.28$ \\
\hline & Density $\left(\mathrm{g} . \mathrm{cm}^{-3}\right)$ & $1.031 \pm 0.015$ & $1.040 \pm 0.030$ & $1.051 \pm 0.020$ \\
\hline
\end{tabular}




\subsection{Experimental methodology}

Just before experiments were carried out, the egg content was removed under aseptic conditions, $\mathrm{pH}$ was check to ensure freshness, egg fractions were homogenised and the LWE was reconstituted. Control samples without any treatment, and control pasteurized samples were prepared as need.

Samples were treated in four UV-C devices. First, to determine the suitability of the UV-C technology to treat LEPs, a bench-scale device in batch feed was used; secondly, the study was carried out in a lab-scale reactor provided with $4 \mathrm{UV}-\mathrm{C}$ lamps with manually feeding, and in a lab scale commercial prototype with continuous feeding; and finally, a "scale up" was carried out with optimized prototype under continuous flow. The general scheme of the experimental methodology is presented on Figure 4.2.

The sensitivity of a food to UV-C light is a function of intrinsic factors such as the chemical composition and the absorption coefficient of particles in suspension, and of external factors such as the UV light intensity, the available oxygen and temperature. Therefore to identify new target food matrices it is firstly relevant to analyze the effects of UV on microbial inactivation and food quality attributes. For this, lab scale bench equipments and equipments with laminar flows are providing reliable information in liquid and solid foods (Bolton and Linden, 2003; Guerrero-Beltran and Barbosa-Canovas, 2004; Noci et al., 2008). 

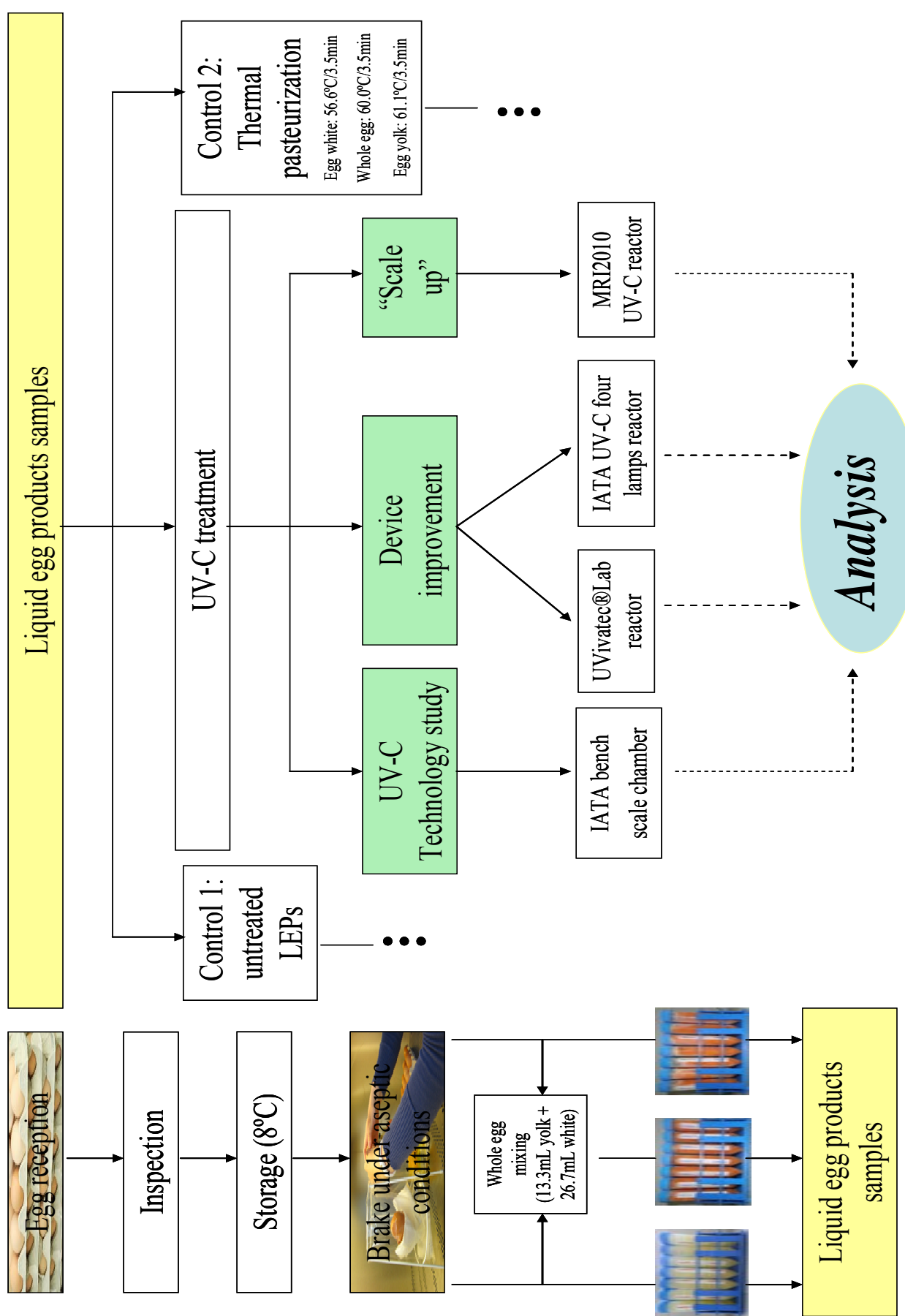

Figure 4.2 - Experimental methodology. 
Material and methods

An initial attempt to determine the suitability of UV-C for the decontamination of LEPs, taking into account the changes induced in the main quality attributes was performed in the IATA bench-scale equipment provided with one low pressure mercury lamp. The bench scale equipment allows the study of the technology with a static feeding, under static and dynamic conditions. The fluence and the speed of mixing can be easily controlled. Althought, the samples treated in this device are exposed directly to the ozone generated during the process and to the environment oxygen, which may be also contributing for the product quality deterioration. Faces to this, 2 improved devices were also object of study.

The first device proposed as an improuvement to the IATA bench-scale equipment is a novel UV-C reactor, so called IATA UV-C four lamps reactor. This reactor is provided with four low pressure mercury lamps and flow based on a positive geometry. The reactor was specially designed for the treatment of highly viscous food. It was very versatile and allowed the treatment with 1 to 4 lamps independently, although the residence time was not adequate for industrial purposes, and the flow was hard to control due to the manual feeding. Therefore, the investigations with this prototype were aborted, and the results produced are show only on the Appendix.

The second device proposed as an improuvement to the IATA bench-scale equipment is the UVivatec ${ }^{\circledR} \mathrm{Lab}$ reactor. This is a commercially available device optimized to decontaminate blood plasma. The reactor, based on a Dean vortex technology is provided with one low pressure mercury lamp, the feeding is done by a peristaltic pump and the flow is vertical, being the 
way out situated at the top. Different quality parameters of LEPs were investigated after continuous treatment. The flow on the UVivatec ${ }^{\circledR} \mathrm{Lab}$ reactor was limited by the egg viscosity. If the flow of $2.58 \mathrm{~L} \cdot \mathrm{h}^{-1}$ for LEY, 9.48 L.h ${ }^{-1}$ for LWE and $14.48 \mathrm{~L} . \mathrm{h}^{-1}$ for LEW was exceed an overpressure was produced and the device was not able to work properly.

Aiming to improve the process, the effectiveness of a pilot-scale MRI2010 UV-C reactor also based on Dean Vortex technology was investigated.

A resume of the analysis done in each device is presented on Figure 4.3.

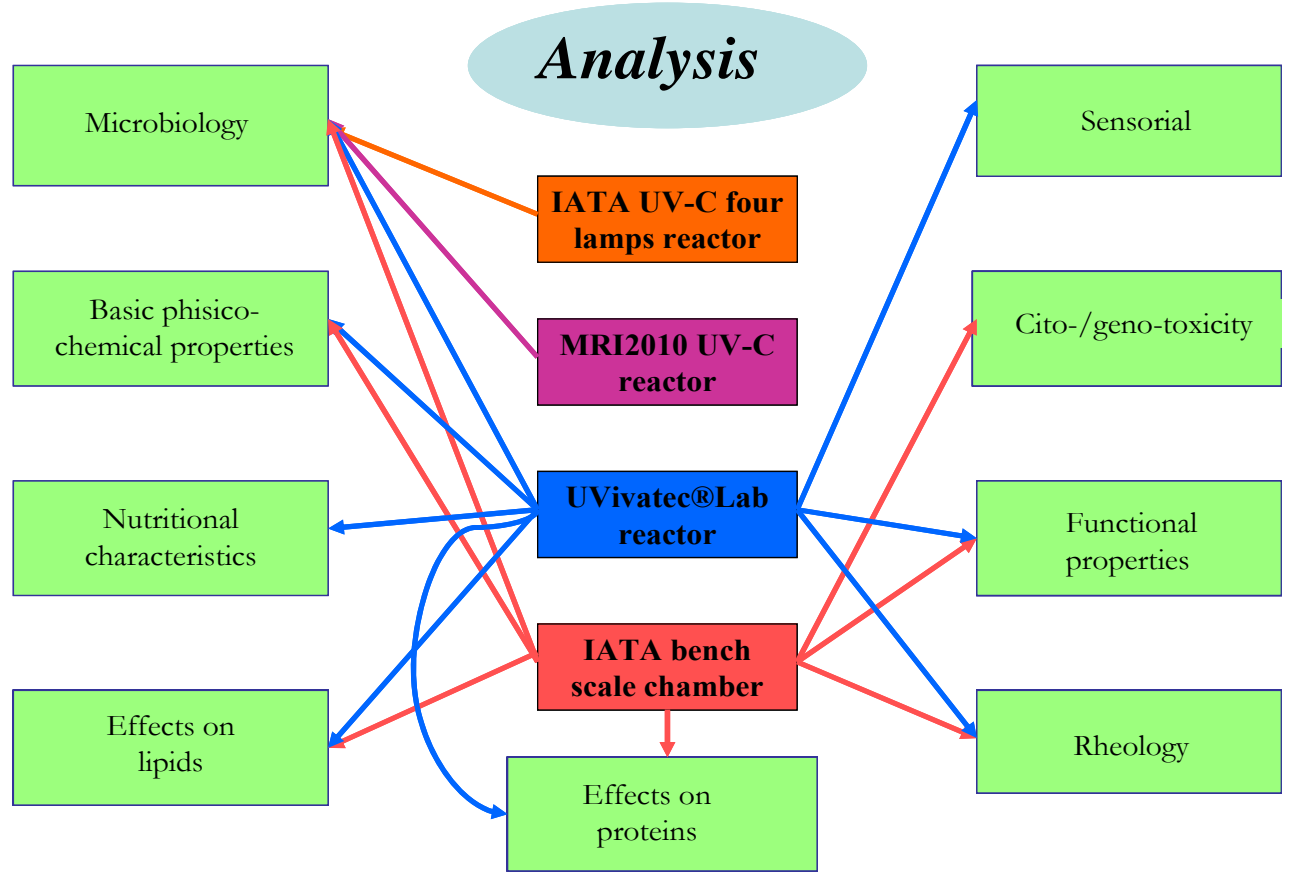

Figure 4.3 - Scheme of analysis. 
Material and methods

\subsubsection{IATA Bench scale equipment}

The IATA bench scale equipment was constructed by UV-Consulting Peschl $^{\circledR}$ Spain (Burjassot, Valencia, Spain). The treatment chamber was made of stainless-steel and provided with one low pressure mercury lamp with 9 W output (Heraeus Noblelight GmbH, Hanau, Germany) with maximum peak radiation at $253.7 \mathrm{~nm}$. Chamber dimensions were $60 \mathrm{x} 40 \mathrm{x}$ $40 \mathrm{~cm}$, the inner surface was flat black painted to avoid light reflection in the walls; to enhance the amount of light incinding into samples an aluminium reflector was placed on the plafond inside the chamber. The distance between the lamp and the device floor was adjustable, from 25 up to $50 \mathrm{~cm}$; and the sample could be placed in any hight between the floor and the lamp, for the experiments the distance of $10 \mathrm{~cm}$ between the samples and the lamps was chosed. After stabilization of UV-C emission, the lamp remained on. A shutter between the lamp and the exposition chamber was used to protect the operator without disturbing the operational conditions of the lamp. The excess of heat was dissipated by a ventilator installed on the upper part of the chamber.

A magnetic stirrer (Ovan MBG15, Barcelona, Spain) was positioned at the central part of the lamp. Samples $(12 \mathrm{~mL}$ volume and $0.2 \mathrm{~cm}$ height; or 30 $\mathrm{mL}$ volume and $0.5 \mathrm{~cm}$ height $)$ were placed in polystyrene Petri dishes $(60.3$ $\mathrm{cm}^{2}$ ) and they were treated in batch, under static or dynamic conditions. For the dynamic treatment, samples were continuously stirred during irradiation. A scheme of the equipment is represented in Figure 4.4. 


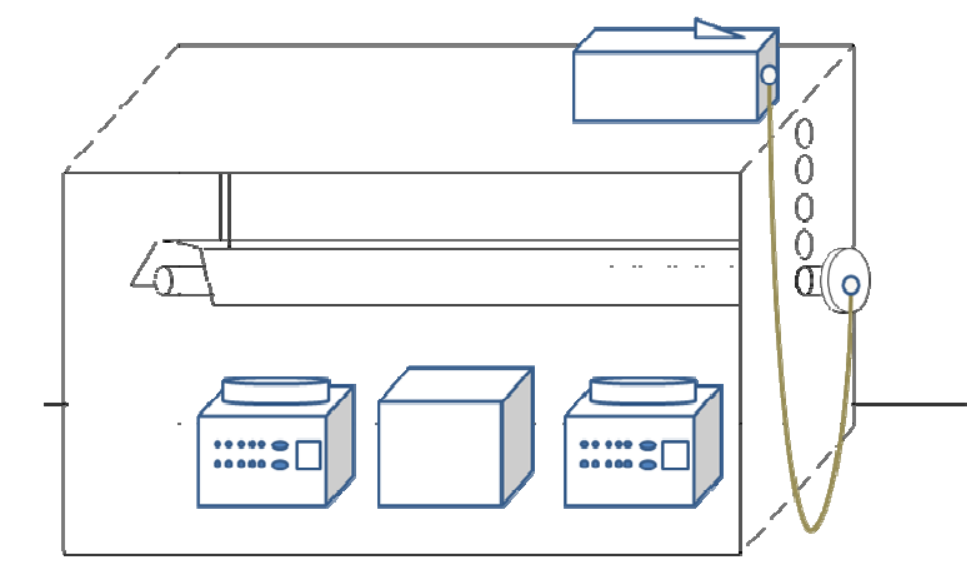

Figure 4.4 - IATA bench scale equipment scheme.

Before each test, the apparatus was cleaned and sanitized with commercial liquid soap and alcool $70^{\circ}$. The experiments were run in a acclimatised room (temperature around $21^{\circ} \mathrm{C}$ ), and the temperature in the chamber was never above $27{ }^{\circ} \mathrm{C}$, the temperature of untreated samples were around $21{ }^{\circ} \mathrm{C}$ and presented an increase on the temperature lower than $0.5{ }^{\circ} \mathrm{C}$ during the treatment.

The study on this device was divided on:

1) Determination of the inactivation kinetics of inoculated microorganisms. Trials were carried out with Escherichia coli ATCC 11775, Staphylococcus aureus ATCC 12600, Listeria innocua ATCC 33090 and Salmonella enterica subsp. enterica Ser. Enteritidis ATCC 13076 in dynamic and static conditions, with 2 and $5 \mathrm{~mm}$ sample height. (From these trials, the optimal sample position inside the device was determined). 
Material and methods

2) Determination of the inactivation kinetics of naturally occurring egg spoilage-related microorganisms' inactivation, including 11 microorganisms groups.

3) Evaluation of shelf-life of LEPs treated with UV-C at the optimal dose determined on the inactivation kinetics.

4) Characterisation of the influence of UV-C treatments on physicochemical parameters, including protein/lipid oxidation. For this, $\mathrm{pH}$, color, protein oxidation (effects on sulphydryl groups) and lipid oxidation (formation of thio-barbituric acid reactive substances) and cholesterol content were evaluated.

5) Study of the effects of UV-C treatments on the rheological properties and the protein technological quality. Differences in the dynamic viscosity, the flow behavior, the temperature-dependent viscosity, and the thermal and electrophoretic properties were analyzed as an indication of protein denaturation or protein coagulation.

6) Functional properties, including foaming and emulsifying properties, were studied.

7) Sensory evaluation of the impact of short-wave ultraviolet treatments on key organoleptic attributes of LEPs and products containing UV-C treated LEPs as ingredient (mayonnaise, pudding and angel cake). For this analysis, consumers were asked to distinguish between samples in triangle tests, and to score the degree of liking of such products in acceptance tests. 
Material and methods

\subsubsection{UV-dosimetry and actinometry}

The average UV-C radiation intensity (total UV-C output units $(\mathrm{mW})$ per area $\left.\left(\mathrm{cm}^{-2}\right)\right)$ arising the sample surface on the IATA bench scale equipment was quantified using chemical actinometry. For this, the iodide/iodate method was carried out in bi-distilled water under continuous agitation, as proposed by Rahn (1997a, 1997b), in an area equivalent to the treatment surface. The incident photons were calculated by assuming that, at defined concentrations where the mixture is opaque below $290 \mathrm{~nm}$, all the incident photons are absorbed by the solution (Rahn, 1997a). Thus, the estimated fluence rate of the lamps at the position chosen ranged between 2.32 and $3.94 \mathrm{~mW} \cdot \mathrm{cm}^{-2}$.

\subsubsection{IATA UV-C four lamps reactor}

The IATA four lamps reactor was designed by our lab in cooperation with the UV-Consulting Peschl ${ }^{\circledR}$ Spain (Burjassot, Spain), in an attempt to achieve a continuous treatment for highly viscous samples. This device is represented on Figure 4.5.

The reactor consists of a horizontal cylindrical aluminum chamber of $33 \mathrm{~cm}$ diameter and $50 \mathrm{~cm}$ long. In the center of the chamber there is a quartz tube of $25 \mathrm{~mm}$ diameter, $65 \mathrm{~cm}$ long, and $1 \mathrm{~mm}$ wall. Inside the quartz glass there is a Teflon ${ }^{\circledR}$ helicoid with spirals every $2 \mathrm{~mm}$. The helicoid is connected to the shaft of an engine, responsible for the flow. And the engine 
Material and methods

is connected by a perforated stainless steeL.head to the device carcass. The sample flow rate is controlled by the rotation of the helicoids, the lower flow is $2.5 \mathrm{~mL} \cdot \mathrm{min}^{-1}$ and the maximum flow is $5.0 \mathrm{~mL} \cdot \mathrm{min}^{-1}$.
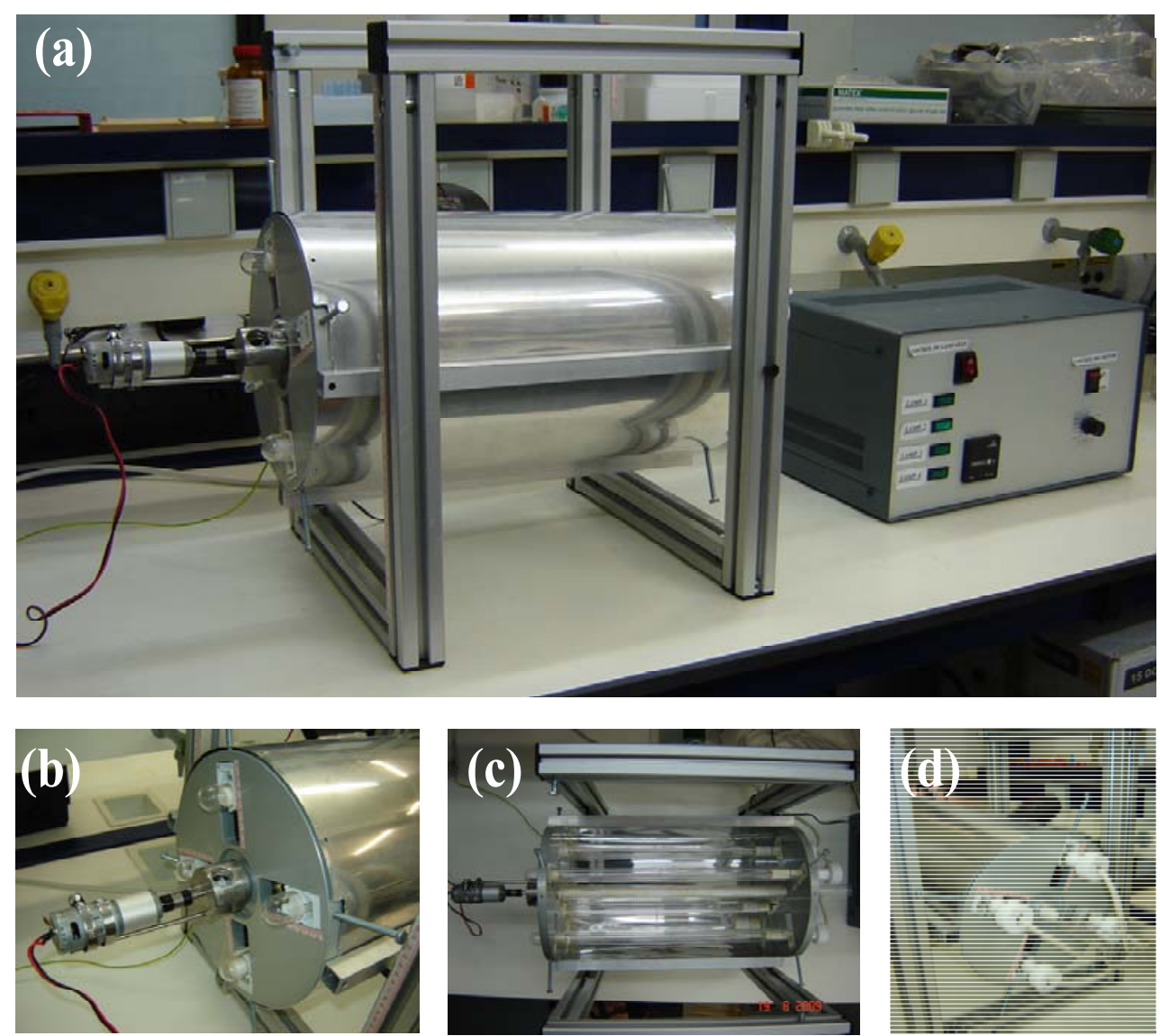

Figure 4.5 - IATA UV-C four lamps reactor (a) Device ready to be used (b) Superior view of the treatment chamber (c) Device left view - motor detail (d) Device right view - detail of quartz tube and sample output.

The chamber is equipped with 4 lamps UV low pressure mercury vapor, with emission peak of $254 \mathrm{~nm}$ (Heraeus, Hanau, Germany). The lamps are 
equidistant between them and have independent switches. The distance of the lamps to the central quartz tube is adjustable (minimum distance of $5 \mathrm{~cm}$ and a maximum of $8.5 \mathrm{~cm}$ ), and independently in each lamp. For safety, it has also installed a master switch for the lighting of the lamps.

The inclination of the device is adjustable and can vary from 0 to $90^{\circ}$ on the sample output side. On the top shell of the device it was installed a fan (Evercool, SB-A EC, Taiwan) in order to dissipate the heat generated by the lamps. The lamps are protected by a quartz tube, enabling the use of the device under refrigerated conditions to simulate clean room treatments. This device reach Reynolds numbers lower than 2 for LEPs.

\subsubsection{UVivatec ${ }^{\circledR} \mathrm{Lab}$ reactor}

For laboratory scale UV-C continuous treatment the UVivatec ${ }^{\circledR}$ Lab reactor (Bayer Technology Services GmbH, Leverkusen, Germany), described, among others, by Schmidt and Kauling (2007) and Müller et al. (2011) was used. The basic design of the UVivatec ${ }^{\circledR}$ Lab reactor based on Dean Vortex technology system consists of a helical channel tube formed with the semicircular outer side consisting of Teflon ${ }^{\circledR}$ and the straight inner side of quartz glass.

Figure 4.6 present the device and the working principle of the modules. The helical channel can be irradiated from the inside to the outside by a rod- 
Material and methods

shape UV light source placed inside the quartz glass which is wrapped around by a Teflon ${ }^{\circledR}$ helicoid (Figure 4.6 b) (Poggel et al., 2008).

(a)

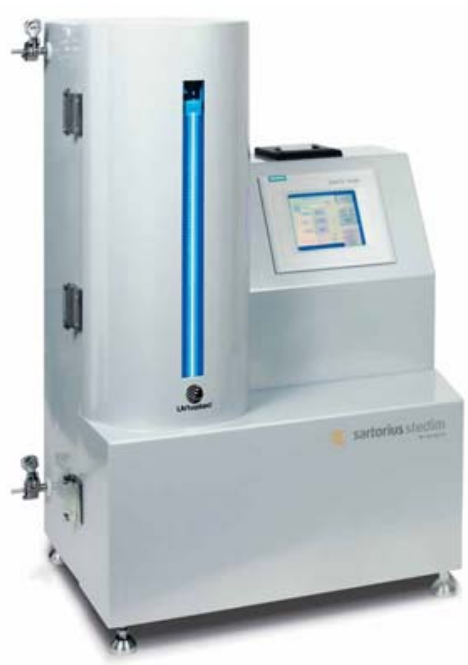

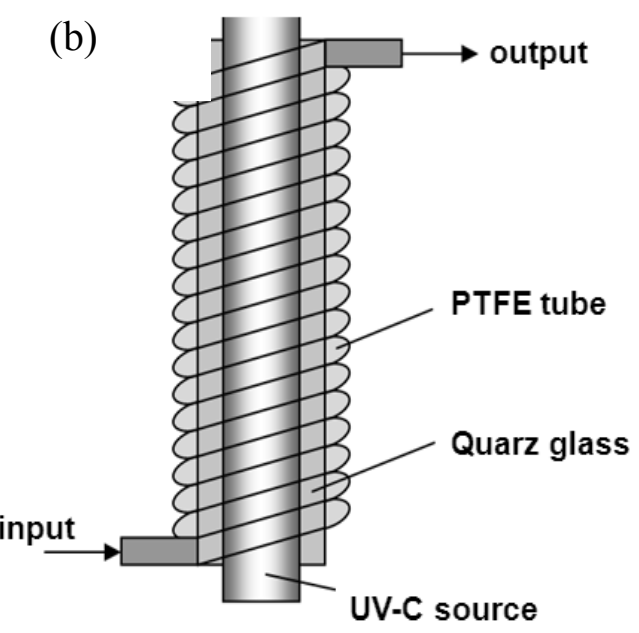

Figure 4.6 - UVivatec ${ }^{\circledR} L a b$ reactor (a) Device appearance (b) Principle of the modules.

The light source on this device is a $9 \mathrm{~W}$ low-pressure mercury lamp (UVP, Type CPQ-7731) which generates UV at $253.7 \mathrm{~nm}$. Hydraulic spiral flow around an irradiation source induces Dean Vortices in a fluid stream. These vortices provide highly efficient mixing in a fluid stream and optimize microorganism (vitamins or other solid suspedend on the sample) exposure to the light source. As a consequence, high doses of UV-C irradiation can be delivered uniformly throughout the solution. Thus, the required residence times in the irradiation chamber are extremely short and the UV-C treatment can be accurately controlled. 
The liquids can be pumped through the device at flow rates between 2 and 20 L.h $^{-1}$ by a peristaltic pump. Although viscous foods can cause overpressure and the uper flow limit must be diminished. For the experiments carried out on this device the flow was experimentally determined as the highest flow supported by the peristaltic pump without cause overpressure, and was equal to $2.58 \mathrm{~L}^{-1}{ }^{-1}$ for egg yolk, $9.48 \mathrm{~L} . \mathrm{h}^{-1}$ for whole egg and $14.48 \mathrm{~L} . \mathrm{h}^{-1}$ for egg white. The parameters investigated here are the following:

1) Determination of the inactivation kinetics of inoculated $s$. microorganismTrials were carried out with Salmonella subterranea DSM 16208, Listeria innocua WS 2258 and Escherichia coli DH5a.

2) Determination of the inactivation kinetics of naturally occurring egg spoilage-related microorganisms inactivation, including 11 microorganisms groups.

3) Shelf-life evaluation of LEPs treated with continuous UV-C.

4) Characterisation of the influence of continuous short-wave ultraviolet treatments on physicochemical parameters, including protein/lipid oxidation. For this, $\mathrm{pH}$, color, protein oxidation (effects on sulphydryl groups) and lipid oxidation (formation of thio-barbituric acid reactive substances) were evaluated.

5) Study of the effects of continuous short-wave ultraviolet treatments on protein technological quality, including foaming and emulsifying properties. 
Material and methods

6) Characterisation of the effects of a continuous short-wave ultraviolet treatment on key nutritional aspects. To validate the feasibility of continuous UV-C, key indicators of nutritional quality in eggs were investigated: retinol, tocopherol, riboflavin, ascorbic acid and pantothenic acid; calcium, potassium, magnesium and zinc; lutein and zeaxanthin.

7) In vitro evaluation of cyto- and genotoxic activity on intestinal epithelial cells after UV-C treatments. To ensure that the irradiation with short-wave ultraviolet does not generate cyto or genotoxic residues in food matrices, two different in vitro assays were carried out, the Calcein and the Comet assay.

\subsubsection{MRI 2010 UV-C reactor}

The Dean Flow reactor MRI 2010 was developed by the Max RubnerInstitut (Karlsruhe, Germany). The main component is a module which consists of a FEP envelope with a diameter of $3 \mathrm{~mm}$ (Adtech Polymer Engineering Ldt., Stroud, UK) which is wound around a $30 \mathrm{~W}$ low pressure mercury lamp with maximum peak radiation at $253.7 \mathrm{~nm}$ (UVN 30, uv technik Speziallampen GmbH, Wümbach, Germany). The liquids can be pumped through the device at flow rates between 4 and $40 \mathrm{~L}^{-1} \mathrm{~h}^{-1}$ by a peristaltic pump (Pumpdrive Pd 5206, Heidolph, Schwabach, Germany). Figure 4.7 present the device and the working principle of the modules. 
Material and methods

(a)

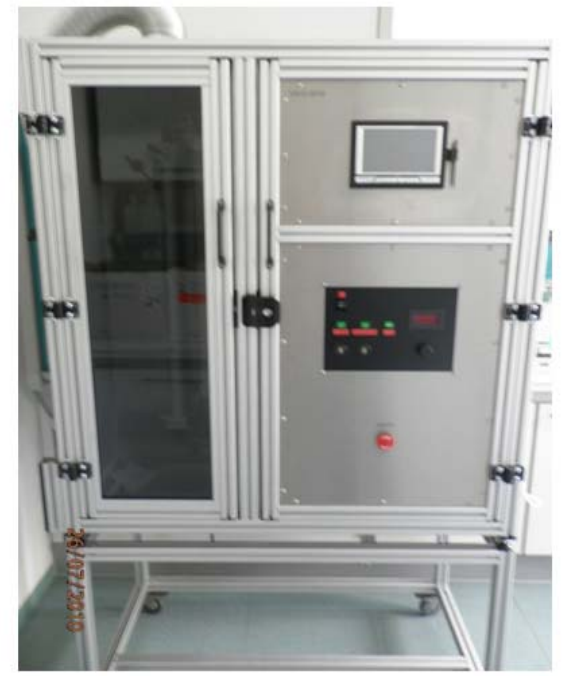

(b)

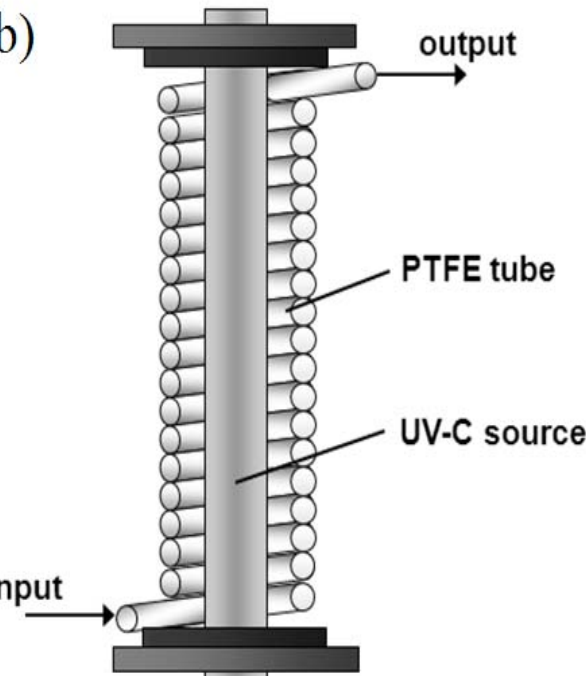

Figure 4.7 - MRI 2010 UV-C reactor (a) Device appearance (b) Principle of the modules.

On this device, the inactivation kinetics of inoculated microorganisms Salmonella subterranea DSM 16208, Listeria innocua WS 2258 and Escherichia coli DH5 $\alpha$, were studied in whole egg samples at a flow rate of $20{\mathrm{~L} . \mathrm{h}^{-1}}^{\text {. }}$

\subsubsection{UV-C dosimetry and Dean Vortex technology}

Several methods are used to compare the efficacy of UV-C treatments. The first method relied on the fluence $\left(D_{s}\right.$ in $\left.\mathrm{J}_{\mathrm{cm}} \mathrm{cm}^{-2}\right)$ defined as the constant fluence rate multiplied by the exposure time in seconds referring to the available treatment surface (Bolton and Linden, 2003). The UV dosage per Litre $\left(D_{v}\right.$, in $\left.J . L^{-1}\right)$ of treated liquid for a reactor with continuous flow is calculated as the UV-C output of the lamp (W) per flow rate $\left(\mathrm{L} . \mathrm{s}^{-1}\right)$ (Keyser 
Material and methods

et al., 2008) and used as dose definition for this research project. To compare the inactivation method with other based on relevant energy imput $\left(D_{e l}\right.$, in J.L $\left.{ }^{-1}\right)$, the third method relied on the necessary electrical energy imput of the lamp (W) per flow rate (L.s ${ }^{-1}$ ) (Müller et al., 2011). In this study, the UV-C treatment devices are based on liquid flow in a coiled tube that causes secondary eddy flow effects (Dean Vortices), also known as the Dean effect (Dean, 1927; Schmidt and Kauling, 2007).

The Dean vortices created by the UV reactors were calculated using the Reynolds number (Re) and Dean number (De) which depend on the geometric data $\left(d_{h}\right.$ and D) of the helically wound tube.

$$
\begin{gathered}
\operatorname{Re}=\frac{u \times d_{h}}{v}=\frac{u \times d_{h} \times \rho}{\eta} \\
D e=\operatorname{Re} \sqrt{\frac{d_{h}}{D}}
\end{gathered}
$$

where $d_{h}$ is the hydraulic diameter of the tube, $D$ is the diameter of the coil, $u$ is the velocity $\left(\mathrm{m} . \mathrm{s}^{-1}\right), v$ is the kinematic viscosity $\left(\mathrm{m}^{2} \cdot \mathrm{s}^{-1}\right), \eta$ is the dynamic viscosity (Pa.s) and $\rho$ is the mass density $\left(\mathrm{kg} \cdot \mathrm{m}^{-3}\right)$.

Table 4.2 gives an overview of the different dose values, Reynolds and Dean Numbers used in this study, for the UVivatec ${ }^{\circledR}$ Lab reactor and MRI 2010 UV-C reactor. 
Table 4.2 - UV-C doses, Reynolds and Dean Numbers; per cycle.

\begin{tabular}{|c|c|c|c|c|c|c|c|}
\hline Device & $\begin{array}{c}\text { Egg } \\
\text { fraction }\end{array}$ & $\begin{array}{l}\text { Flow } \\
\text { rate } \\
\left(\mathbf{L} \cdot h^{-1}\right)\end{array}$ & $\begin{array}{c}\text { Electrical } \\
\text { energy } \\
\left(J^{-1} L^{-1}\right)\end{array}$ & $\begin{array}{c}\text { Surface } \\
\text { dose } \\
\left.(\mathbf{m J . c m})^{-2}\right)\end{array}$ & $\begin{array}{l}\text { UV-C energy } \\
\text { output per } \\
\left.\text { volume (J.L }{ }^{-1}\right)\end{array}$ & $\operatorname{Re}$ & De \\
\hline \multirow{3}{*}{$\begin{array}{l}\text { UVivatec } \\
{ }^{\circledR} \mathrm{Lab}\end{array}$} & LEW & 14.48 & 2238 & 43.3 & 467.96 & 432.3 & 159.2 \\
\hline & LWE & 9.48 & 3417 & 66.1 & 715.13 & 129.6 & 47.7 \\
\hline & LEY & 2.58 & 12558 & 243.0 & 2626.38 & 2.6 & 0.9 \\
\hline $\begin{array}{l}\text { MRI } \\
2010 \\
\end{array}$ & LWE & 20.0 & 5400 & 149.4 & 1269.7 & 256.3 & 70.4 \\
\hline
\end{tabular}

\subsubsection{Pasteurization}

Aiming at a comparison with conventional pasteurizations, $1 \mathrm{~mL}$ ampoules of the analyzed egg fractions were treated using a thermostatic bath. The conditions for pasteurisation were chosen in conformity with the requirements of the USDA (USDA ARS 74-48, 1969). The holding time used for the three fractions was $3.5 \mathrm{~min}$ when the coldest point of the sample attained the pasteurization temperature. Table 4.3 presents the complete information about time, temperatures and devices used for thermal pasteurization.

Table 4.3 - Thermal pasteurization conditions.

\begin{tabular}{ccccc}
\hline \multirow{2}{*}{ Egg supplier } & Thermostatic bath & \multicolumn{3}{c}{ Pasteurization conditions } \\
\cline { 3 - 5 } & & $\begin{array}{c}\text { Egg } \\
\text { white }\end{array}$ & $\begin{array}{c}\text { Whole } \\
\text { egg }\end{array}$ & $\begin{array}{c}\text { Egg } \\
\text { yolk }\end{array}$ \\
\hline Avícola Llombay & Unitronic OR, Selecta, Spain & & & \\
Gutshof-Ei GmbH & - & $56.6^{\circ} \mathrm{C} /$ & $60.0^{\circ} \mathrm{C} /$ & $61.1^{\circ} \mathrm{C} /$ \\
$3.5 \mathrm{~min}$ & $3.5 \mathrm{~min}$ & $3.5 \mathrm{~min}$ \\
Fazenda Rio Grande & TBA23, SP Labor, Brazil & & \\
\hline
\end{tabular}




\subsection{Analytical determinations}

The analytical determinations are grouped on 5 main categories: microbiology, physical-chemical analysis, sensorial evaluation, nutritional characteristics and cyto-/genotoxicity. And each category is subdivided according to the analytical determinations performed. The analytical determinations performed are resumed on Figure 4.8. All experiments were done in triplicate and the results are expressed as the average \pm standart deviation, if not specified.

\subsubsection{Microbiology}

\subsubsection{Effect on inoculated microorganisms}

\subsection{Microorganisms}

For the experiments in the IATA bench scale equipment and IATA UV-C four lamps ractor non pathogenic substitutes and pathogenic LEP important were used. Escherichia coli ATCC 11775, Staphylococcus aureus ATCC 12600, Listeria innocua ATCC 33090 and Salmonella enterica subsp. enterica Ser. Enteritidis ATCC 13076 were obtained from the Spanish Type Culture Collection (Valencia, Spain). Strains were stored in Tryptone Soy Broth (TSB) with $20 \%$ glycerol at $-80{ }^{\circ} \mathrm{C}$. Stock cultures were kept by regular subculture on agar Tryptone Soy Agar (TSA) slants at $4{ }^{\circ} \mathrm{C}$. 


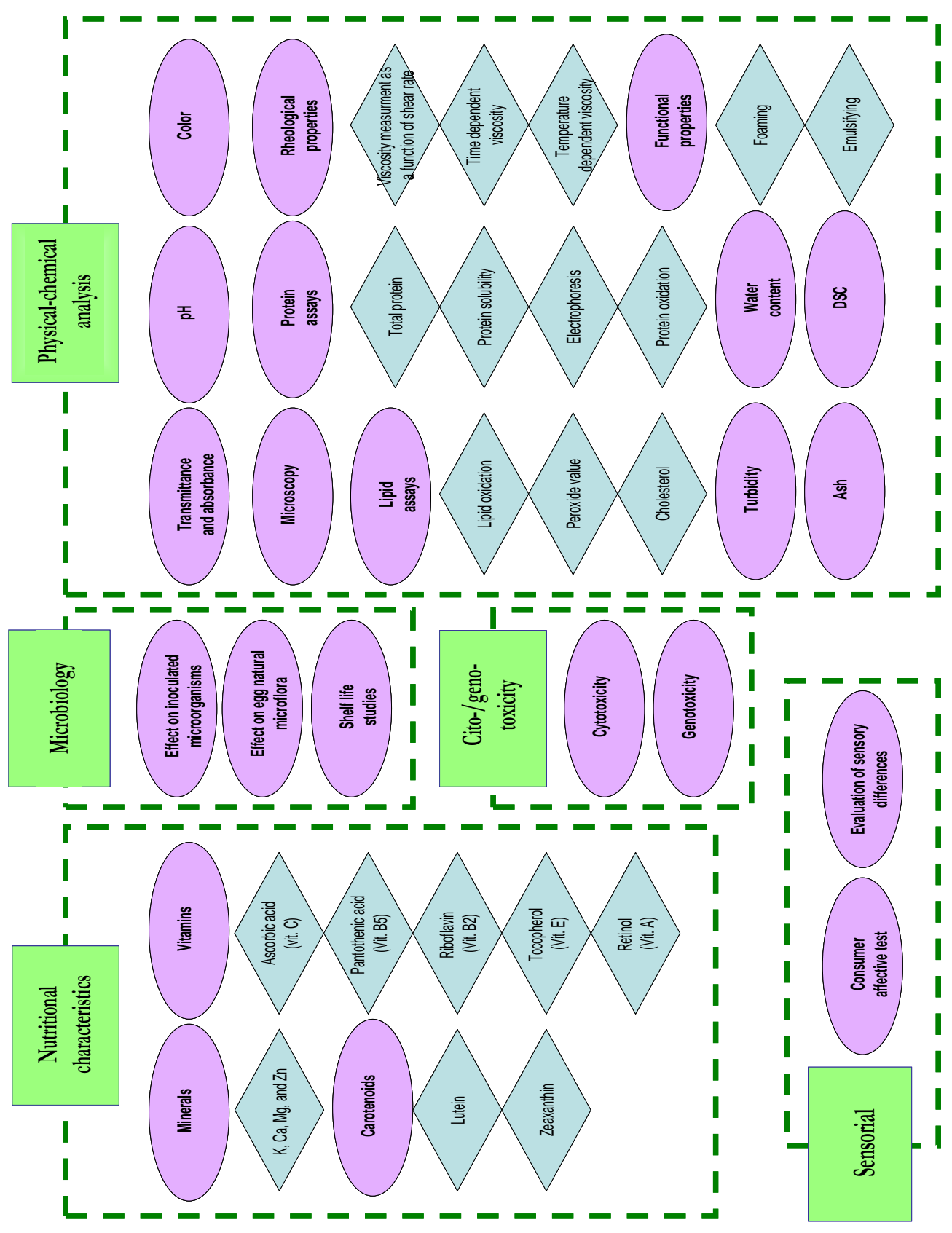

Figure 4.8 - Analytical determinations. 
Material and methods

Prior to inoculation of egg fractions, an overnight culture was prepared. A loopful of the bacteria strain was transferred to Tryptone Soy Broth (TSB) and incubated at $37^{\circ} \mathrm{C}$ for $18 \mathrm{~h}$ to obtain early-stationary phase cells.

For the experiments in the UVivatec ${ }^{\circledR} \mathrm{Lab}$ and the MRI2010 UV-C reactors based on Dean Vortex technology, non pathogenic substitutes for pathogenic LEP important strains were used. Salmonella subterranea DSM 16208 is a non-pathogenic salmonella strain (risk group 1, classification of DSMZ) isolated from uranium contaminated subsurface sediment (Shelobolina et al., 2004) and selected for this study as a substitute of the pathogenic strain Salmonella enterica subsp. enterica Ser. Enteritidis ATCC 13076. Listeria innocua WS 2258 isolated by Weihenstephan (Freising, Germany) was used in this study as substitute for cold-tolerant food spoilage microorganisms. Escherichia coli DH5a, a common K12-derived laboratory strain, was also used for the inactivation studies.

Strains were stored in Standard I Broth with $20 \%$ glycerol at $-80{ }^{\circ} \mathrm{C}$. Stock cultures were kept by regular subculture on Standard I Broth. Prior to inoculation of egg fractions, an overnight culture was prepared with $5 \mathrm{~mL}$ of the subculture in $500 \mathrm{~mL}$ of Standard I and incubated at $37^{\circ} \mathrm{C}$ for $18 \mathrm{~h}$.

\subsection{Effects of UV-C on the inactivation of inoculated bacteria}

For inactivation trials on the bench-scale equipment and the continuous UVC four lamp reactor with positive geometry, the overnight prepared as 
described on section 4.3.1.1.1 was homogenised and distributed in $1 \mathrm{~mL}$ Eppendorf tubes that were centrifuged at $1000 \mathrm{rpm}$ for $2 \mathrm{~min}$ at ambient temperature. The supernatant phase was discarded and the decanted was spread on $50 \mathrm{~mL}$ of fresh LEPs, to obtain a concentration of cells around 7 to $8 \mathrm{Log}\left(\mathrm{CFU} \cdot \mathrm{mL}^{-1}\right)$. Afterwards, for the UV-C lamp chamber inactivation tests, 12 or $30 \mathrm{~mL}$ of the homogenized mixture were transferred to standard Petri-dishes (equivalent to 0.2 and $0.5 \mathrm{~cm}$ height). For enumeration, decimal dilutions were made with $0.1 \%$ peptone water and samples were surface plated in duplicate on Trypticase Soy Agar (TSA, Scharlau, Germany).

For inactivation trials on the UVivatec ${ }^{\circledR}$ Lab and the MRI 2010 UV-C reactors, the overnight culture was centrifuged at 9,512 x $g$ during $10 \mathrm{~min}$ at $4{ }^{\circ} \mathrm{C}$ and the pellet was resuspended in quarter strength ringer solution (QSRS) until the optical density equivalent to 8 to 9 Log $\left(\mathrm{CFU} \cdot \mathrm{mL}^{-1}\right)$ was obtained. The suspension of microorganisms was decimal diluted in fresh egg samples, to obtain a concentration of cells around 7 to $8 \mathrm{Log}$ $\left(\right.$ CFU.mL $\left.{ }^{-1}\right)$. For enumeration, decimal dilutions of the samples were made in QSRS and surface plated in duplicate on Standard I Agar (Merck, Germany). The plates were incubated at $37^{\circ} \mathrm{C}$ for $24 \mathrm{~h}$ and counted.

All experimental conditions were tested in triplicate. 
Material and methods

\subsection{Fitting of kinetic data}

Microbial inactivation data were analyzed by GInaFIT tool according to Geeraerd et al. (2005). GInaFIT is a freeware tool to assess non-log-linear microbial survivor curves. All these models were developed as function of time. For the purpose of this application, the classical term " $t$ " (treatment time) was substituted by d (dose, ${\mathrm{J} . \mathrm{cm}^{-2}}^{-}$. The tested models as described in the GInaFIT tool but adapted as function of fluence are as follow,

The log-linear model (Bigelow and Esty, 1920) is:

$$
\log (\mathrm{N})=\log \left(\mathrm{N}_{0}\right)-\mathrm{k}_{\max } \times \mathrm{F} / \operatorname{Ln} 10
$$

where $N\left(\mathrm{CFU} \cdot \mathrm{mL}^{-1}\right)$ is the number of survivors, $N_{0}\left(\mathrm{CFU} \cdot \mathrm{mL}^{-1}\right)$ is the initial number of microorganisms, and $k_{\max }$ is the dosimetric inactivation rate $\left(\mathrm{cm}^{2}\right.$ $\left.\mathrm{J}^{-1}\right)$. It is worth explaining the meaning of the units of the term $k_{\max }$. Its classical unit is $\left(\mathrm{min}^{-1}\right)$, that means that one min of treatment is required to achieve " $x$ " logarithmic reduction in microbial count. In the present context,

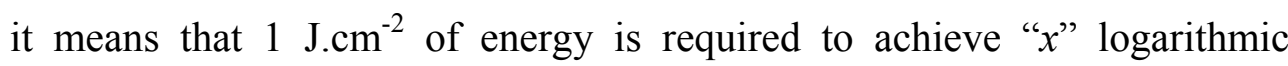
reduction in microbial count.

The Weibull model as presented by Mafart et al. (2002) is as follows:

$$
\log (\mathrm{N})=\log \left(\mathrm{N}_{0}\right)-\mathrm{p}(\mathrm{F} / \delta)
$$


where $\delta\left(\mathrm{J} . \mathrm{cm}^{-2}\right)$ is the fluence for the first decimal reduction, and $p$ (dimensionless) is a parameter describing concavity or convexity of the curve.

The Log-linear and tail model by Geeraerd et al. (2000) is as follows:

$$
\log (N)=\log \left(\left(10^{\log \left(N_{0}\right)}-10^{\log \left(N_{\text {res }}\right)}\right) \times e^{\left(-k_{\max } \times F\right)}+10^{\log \left(N_{\text {res }}\right)}\right)
$$

where $k_{\max }$ is the dosimetric inactivation rate $\left(\mathrm{cm}^{2} \mathrm{~J}^{-1}\right)$ of the log-linear part of the curve. The Weibull and tail model as presented by Albert and Mafart et al. (2005) is as follows:

$$
\log (\mathrm{N})=\log \left(\left(10^{\log \left(\mathrm{N}_{0}\right)}-10^{\log \left(\mathrm{N}_{\mathrm{res}}\right)}\right) \times 10^{(-\mathrm{t} / \delta)^{\mathrm{p}}}+10^{\log \left(\mathrm{N}_{\mathrm{res}}\right)}\right)
$$

The models were constructed using means from 3 data sets; individual data were used for validation.

\subsubsection{Effects of $U V-C$ on the inactivation of egg natural microflora}

The egg natural occurring microbial groups analyzed in this study are total aerobic mesophiles, total anaerobic mesophiles, total aerobic psychrotrophiles, total anaerobic psychrotrophiles, total aerobic spores, total anaerobic spores, lactic acid bacteria, yeasts, moulds, Pseudomonas spp., 
Material and methods

Enterobacteriaceae and Salmonella spp. For the trials in the UV-C bench scale equipment, $12 \mathrm{~mL}$ of the LEPs homogenate were transferred to standard Petri-dishes (equivalent to $0.2 \mathrm{~cm}$ height).

For enumeration, decimal dilutions were made with $0.1 \%$ peptone water and samples were plated following the instructions of Gonzales et al. (2009). For the UVivatec ${ }^{\circledR}$ Lab reactor the LEP were treated immediately after breaking and homogenization. For enumeration, decimal dilutions of the samples were made in QSRS and surface plated in duplicate following an adaptation of the instructions of Gonzales et al. (2009).

All experimental conditions were tested in triplicate. PCA, plate count agar; MRS, deMann-Rogosa-Sharpe agar; RCA, reinforced clostridial agar; YGC, yeast glucose chloramphenicol, were puschased from Scharlau (Barcelone, Spain). VRBG, violet red bile glucose agar; King A, King A medium (Pseudomonas $\mathrm{P}$ agar) and Salmonella chromogenic agar were puschased from Conda Pronadisa (Madrid, Spain). Standard I Agar; DRCM, Differential Reinforced Clostridial Medium; PAB-CFC, pseudomonas agar base supplemented with pseudomonas CFC; and BSA, brilliance salmonella agar were purchased from Merck (Madrid, Spain). Anaerobic conditions were attained with a top layer of the same medium. Spores enumeration was done with tenfold diluted sample that was first pasteurized at $80{ }^{\circ} \mathrm{C}$ for 10 min to inactivate vegetative cells. Anaerobic conditions were attained with top layer of the same medium. Table 4.4 presents the growth media, plate technique and the incubation conditions used in this work. 
Table 4.4 - Summary of the analyzed populations together with their growth medium, plating technique and incubation conditions.

\begin{tabular}{|c|c|c|c|c|c|}
\hline \multirow[b]{2}{*}{ Populations } & \multirow[b]{2}{*}{ Symbol } & \multicolumn{2}{|c|}{ Grown media } & \multirow[b]{2}{*}{$\begin{array}{l}\text { Tech- } \\
\text { nique }\end{array}$} & \multirow{2}{*}{$\begin{array}{l}\text { Incubation } \\
\text { condition }\end{array}$} \\
\hline & & $\begin{array}{l}\text { Avícola } \\
\text { Llombay }\end{array}$ & $\begin{array}{l}\text { Gutshof- } \\
\text { Ei GmbH }\end{array}$ & & \\
\hline $\begin{array}{l}\text { Total aerobic } \\
\text { mesophilic count }\end{array}$ & TAM & PCA & Standart I & $\begin{array}{l}\text { Pour } \\
\text { plate }\end{array}$ & $\begin{array}{c}30^{\circ} \mathrm{C}, 3 \text { days, } \\
\text { aerobic }\end{array}$ \\
\hline $\begin{array}{l}\text { Total anaerobic } \\
\text { mesophilic count }\end{array}$ & TAnM & PCA & DRCM & $\begin{array}{l}\text { Pour } \\
\text { plate }\end{array}$ & $\begin{array}{c}30^{\circ} \mathrm{C}, 3 \text { days, } \\
\text { anaerobic }\end{array}$ \\
\hline $\begin{array}{l}\text { Total aerobic } \\
\text { psychrotrophic count }\end{array}$ & TAP & PCA & Standart I & $\begin{array}{l}\text { Pour } \\
\text { plate }\end{array}$ & $\begin{array}{c}22^{\circ} \mathrm{C}, 5 \text { days } \\
\text { aerobic }\end{array}$ \\
\hline $\begin{array}{l}\text { Total anaerobic } \\
\text { psychrotrophic count }\end{array}$ & TAnP & PCA & DRCM & $\begin{array}{l}\text { Pour } \\
\text { plate }\end{array}$ & $\begin{array}{c}22^{\circ} \mathrm{C}, 5 \text { days, } \\
\text { anaerobic }\end{array}$ \\
\hline Total aerobic spores & TAS & PCA & Standart I & $\begin{array}{l}\text { Pour } \\
\text { plate }\end{array}$ & $\begin{array}{c}30^{\circ} \mathrm{C}, 3 \text { days, } \\
\text { aerobic }\end{array}$ \\
\hline Total anaerobic spores & TAnS & PCA & DRCM & $\begin{array}{l}\text { Pour } \\
\text { plate }\end{array}$ & $\begin{array}{c}30^{\circ} \mathrm{C}, 3 \text { days, } \\
\text { anaerobic }\end{array}$ \\
\hline Lactic acid bacteria & LAB & MRS & MRS & $\begin{array}{l}\text { Pour } \\
\text { plate }\end{array}$ & $\begin{array}{c}30^{\circ} \mathrm{C}, 3 \text { days, } \\
\text { anaerobic }\end{array}$ \\
\hline Yeast and moulds & Yeast & YGC & YGC & $\begin{array}{l}\text { Spread } \\
\text { plate }\end{array}$ & $\begin{array}{c}30^{\circ} \mathrm{C}, 3 \text { days, } \\
\text { aerobic }\end{array}$ \\
\hline Pseudomonas spp. & Pseud & King A & PAB-CFC & $\begin{array}{l}\text { Spread } \\
\text { plate }\end{array}$ & $\begin{array}{c}30^{\circ} \mathrm{C}, 2 \text { days, } \\
\text { aerobic }\end{array}$ \\
\hline Enterobacteriaceae & Enter & VRBG & VRBG & $\begin{array}{l}\text { Spread } \\
\text { plate }\end{array}$ & $\begin{array}{c}37^{\circ} \mathrm{C}, 1 \text { day } \\
\text { aerobic }\end{array}$ \\
\hline Salmonella spp. & Salm & $\begin{array}{l}\text { Chromo- } \\
\text { genic }\end{array}$ & BSA & $\begin{array}{l}\text { Spread } \\
\text { plate }\end{array}$ & $\begin{array}{c}37^{\circ} \mathrm{C}, 1 \text { day } \\
\text { aerobic }\end{array}$ \\
\hline
\end{tabular}

\subsubsection{Shelf life studies}

Shelf life studies were performed to evaluate the effect of ultraviolet processing on microbial growth during refrigerated and room-temperature storage, taking heat pasteurized liquid whole egg as a reference. All 
Material and methods

fractions were treated at room temperature using the optimal doses identified in the kinetics study. Immediately after processing, the samples were aseptically transferred to sterile flasks and aerobically stored at 4 and $20^{\circ} \mathrm{C}$.

Samples were stored at $4{ }^{\circ} \mathrm{C}$, on weekly basis samples were aseptically withdrawn from the stored samples for microbial enumeration. Studies were conducted over a storage period of 8 weeks for these samples to ensure that the 5 weeks shelf life currently applied for heat pasteurized LWE was satisfied (Gonzales et al., 2009).

The accelerated shelf-life was carried out with samples stored at room temperature $\left(20^{\circ} \mathrm{C}\right)$, the sampling was proceed each 3 days during 15 days. The European Regulation 2073/2005 only limits the number of Enterobacteriaceae (target after production of $1 \mathrm{Log}$, and tolerance after production of 2 Log, and Salmonella spp. (absent in 25g). The Salmonella assays were carried out as for the other microorganisms, and at the last day of assays $25 \mathrm{~g}$ were plated to accomplish the regulation of "absence of Salmonella in 25 g”. In this study additional microbial guidelines were used following the recommendations of Gonzales et al. (2009) and are described on Table 4.5.

Target and tolerance are the guide values that are relevant immediately after production. "Target" represents the guide value that should be reached in good hygienic conditions. In such cases "tolerance" represents the upper limit. When the total aerobic psychrotrophic count (TAP) at the end of the 
shelf-life exceeds the guide value of $10^{6} \mathrm{CFU} \cdot \mathrm{mL}^{-1}$, the product can only be rejected when it has been shown that the bacteria concerned are different from (homo-fermentative) LAB.

Table 4.5 - Legal criteria and microbiological guidelines for determining the shelf life and microbiological safety of LWE.

\begin{tabular}{|c|c|c|c|}
\hline $\begin{array}{l}\text { Microbiological } \\
\text { parameters }\end{array}$ & $\begin{array}{c}\text { Target } \\
\text { Log }\left(\text { CFU.mL }{ }^{-1}\right)\end{array}$ & $\begin{array}{c}\text { Tolerance } \\
\text { Log }\left(\text { CFU.mL }{ }^{-1}\right)\end{array}$ & $\begin{array}{l}\text { End of shelf life } \\
\left.\text { Log (CFU.mL } L^{-1}\right)\end{array}$ \\
\hline $\begin{array}{l}\text { Total aerobic } \\
\text { psychrotrophic count }^{\mathrm{a}}\end{array}$ & 3 & 4 & 6 \\
\hline Lactic acid bacteria $^{a}$ & 2 & 3 & 7 \\
\hline Yeasts and moulds ${ }^{\mathrm{a}}$ & 2 & 3 & 5 \\
\hline Enterobacteriaceae $^{\mathrm{b}}$ & 1 & 2 & Not applicable \\
\hline Salmonella spp. ${ }^{\mathrm{c}}$ & Absent in $25 \mathrm{~g}$ & Absent in $25 \mathrm{~g}$ & Absent in $25 \mathrm{~g}$ \\
\hline
\end{tabular}

\subsubsection{Physical-chemical analysis}

\subsubsection{Optical properties: transmittance and absorbance}

The transmittance and absorbance were measured on a UV-VIS spectrophotometer (Agilent, St. Claire, USA) adjusted to the wavelength of $254 \mathrm{~nm}$. The transmission rate was measured for the optical path of 1 and 10 $\mathrm{mm}$, for the samples diluted with distilled sterile water as convenience. Aiming to determine the average UV irradiance over the 2 and $5 \mathrm{~mm}$ depth 
Material and methods

of the LEPs Petri plate was calculated with the (Morowitz, 1950) equation:

$$
\bar{G}=\frac{G}{K(\lambda) z}\left(1-\mathrm{e}^{-K(\lambda) z}\right)
$$

where $G$ is the depth averaged total irradiance $\left(\mathrm{MJ} \cdot \mathrm{m}^{-2} \cdot \mathrm{s}^{-1}\right)$ and $z$ is the depth of the product $(0.002 \mathrm{~m}$ and $0.005 \mathrm{~m}) . K(\lambda)\left(\mathrm{m}^{-1}\right.$, denotes wavelength).

\subsubsection{2 $\mathrm{pH}$}

The determination of $\mathrm{pH}$ was undertaken in triplicate with a calibrated Consort C830 pH meter (Consort, CE, Belgium). Samples were tempered for $45 \mathrm{~min}$ at $20^{\circ} \mathrm{C}$ in a thermostated room before analysis.

\subsubsection{Water content}

The dry matter and water content determination was done by drying in an estufe (Typ UT 12, Heraeus Instruments, Germany) at $105{ }^{\circ} \mathrm{C}$ according to AOAC (method 33.2.09/A, AOAC, 1995).

\subsubsection{Ash}

The samples were calcinated at $580-600{ }^{\circ} \mathrm{C}$ over $10-12 \mathrm{~h}$, until the decomposition of all the organic material. 


\subsubsection{Color}

Color changes were quantified through the CIELAB color space coordinates (L*, a*, and $\mathrm{b}^{*}$ ) obtained by a spectrocolorimeter (Hunter Labscan II, Minolta, Tokyo, Japan), equipped with D65 as the light source, and using an observation angle of $10^{\circ}$. The spectrocolorimeter was calibrated with standard black and white tiles. The spectrocolorimeter is equipped with a Color Data Software CM-S100w Spectra magic NX (Konica Minolta, Tokyo, Japan).

From L* (Brightness), a* (redness-greenness) and $b^{*}$ (yellowness-blueness) coordinates, the values of $\mathrm{C}^{*}$ (chroma), $\mathrm{h}^{*}$ (hue) were directly calculated, while $\Delta \mathrm{E}^{*}$ (CIE total color difference), and $\mathrm{BI}$ (browning index) were calculated using equations 4.8 and 4.9, respectively (Palou et al., 1999). The base-line for the $\Delta \mathrm{E}^{*}$ calculations were the CIE coordinates of the untreated LEPs (used as controls). Triplicate measurements were carried out for each experiment.

$$
\Delta \mathrm{E}^{*}=\left(\Delta \mathrm{L}^{* 2}+\Delta \mathrm{a}^{* 2}+\Delta \mathrm{b}^{* 2}\right)^{1 / 2}
$$

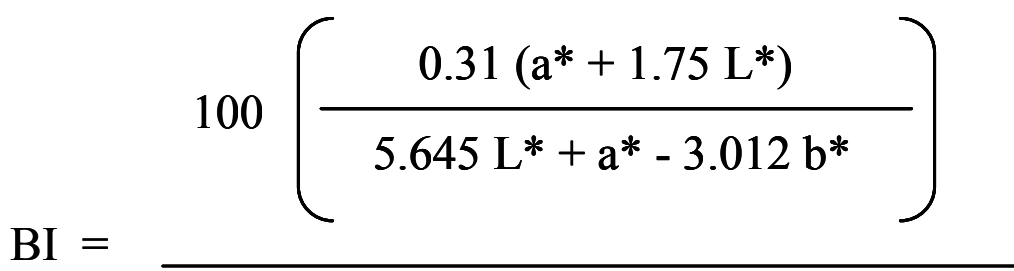

\subsection{2}


Material and methods

\subsubsection{Turbidity}

The determination of turbidity was undertaken in triplicate with a calibrated Turbidimeter TurbiQuant 3000 IR (Merck, Germany). Samples were tempered for $45 \mathrm{~min}$ at $20^{\circ} \mathrm{C}$ in a thermostated room before analysis.

\subsubsection{Differencial scanning calorimetry (DSC)}

Changes in the thermodynamic parameters were measured according to Zhao et al. (2009) and Van der Plancken et al. (2007). Thermal properties of liquid egg products were determined using a differential scanning calorimeter (Mettler Toledo, model 821e, Columbus, OH). $25 \mu \mathrm{L}$ of egg samples were placed in aluminium DSC pans. The pans were hermetically sealed, and the samples were scanned from 15 to $100{ }^{\circ} \mathrm{C}$ at a heating rate of $10{ }^{\circ} \mathrm{C} \cdot \mathrm{min}^{-1}$. An empty pan was used as a reference. The denaturation enthalpy $(\Delta \mathrm{H})$ was calculated from the peak area of the thermogram (between 50 and $95{ }^{\circ} \mathrm{C}$ ) using the Origin 8.5 software (Origin Lab, Northampton, MA), the denaturation temperatures (Td) were also determined. Triplicate samples of each condition were analyzed.

\subsubsection{Microscopy}

Images were captured using a Nikon-Eclipse-90i microscope (Nikon) provided with a refrigerated digital color microphotography camera and with an Image-Pro AMS version 6.0 software. 
Material and methods

\subsubsection{Lipid assays}

\subsection{Lipid oxidation (TBARS)}

To evaluate the extent of lipid oxidation of the samples, the determination of the amount of the formed 2-thiobarbituric acid-reactive substances (TBARS) was undertaken, according to Vinckel (1970) and Ramanathan and Das (1992). Before TBARS analysis was conducted, treated egg samples were freeze-dried in a Genesis Freeze Dryer (SP Virtis, 35EL Genesis SQEL85, New York, USA). Then $2.5 \mathrm{~g}$ of the dry samples were mixed with $17 \mathrm{~mL}$ of $7.5 \%(\mathrm{w} / \mathrm{v})$ trichloroacetic acid (TCA).

The samples were allowed to mix up for $10 \mathrm{~min}$, and were filtered with a cellulose filter in a $10 \mathrm{~mL}$ volumetric flash. Volume (up to $10 \mathrm{~mL}$ ) was filled up with $7.5 \%$ TCA solution if necessary. $5 \mathrm{~mL}$ of the filtered solution were then mixed with $5 \mathrm{~mL}$ of $0.02 \mathrm{M}$ thiobarbituric acid (TBA) thoroughly with a vortex mixer, and heated in a boiling water bath (Unitronic OR, Selecta, Spain) for $40 \mathrm{~min}$. Afterwards samples were allowed to cool down to room temperature. TBARS index was estimated at $530 \mathrm{~nm}$ in a spectrophotometer (Agilent, St. Claire, USA) by comparison with a blank sample containing only TCA/TBA reagent.

Concentrations of TBARS were determined using a standard curve prepared using malondialdehyde (MDA) and expressed as mgMDA. $\mathrm{kg}^{-1}$ of dry sample. 
Material and methods

\subsection{Peroxides value (PV)}

Initial peroxide value of egg yolk and whole egg was determined by using a modified ferrous iron method as described by Wang et al. (2005). In brief, the egg sample was accurately weighed between 50 and $400 \mathrm{mg}$ into a 10 $\mathrm{mL}$ volumetric flask and diluted with ethanol/benzene (80:20). Next, $50 \mu \mathrm{L}$ ammonium thiocyanate solution $(3.75 \mathrm{M})$ and $100 \mu \mathrm{L}$ ferrous chloride solution (approx. $0.014 \mathrm{M}$ ) were added to the flask and mixed. After $10 \mathrm{~min}$, the absorbance was measured at $515 \mathrm{~nm}$ with a Unicam UV/VIS spectrometer UV2 (Tokyo, Japan), and the PV was calculated based on a standard curve. The standard curve was established as a linear plot of the absorbance of a series of dilutions of an oxidized oil sample against the microequivalents of hydroperoxide in each tube. The PV of the original oxidized oil was determined by using AOCS Official Method Cd 8-53 (1994).

\subsection{Cholesterol}

The determination of cholesterol in LEPs was carried out by a method based on direct saponification of the samples with methanolic $\mathrm{KOH}$ solution (Fletouris et al., 1998). A $0.3 \mathrm{~g}$ sample of egg was accurately weighed into a sample preparation vial and $5 \mathrm{~mL}$ of $0.5 \mathrm{M} \mathrm{KOH}$ methanolic solution were added, followed by $40 \mu \mathrm{L}$ of a hexanolic solution of $5 \alpha$-cholestane as the internal standard. The vial was closed tightly and vortexed for $15 \mathrm{~s}$. The vial was then immersed in a $75^{\circ} \mathrm{C}$ bath under agitation for $25 \mathrm{~min}$. Several vials 
with different samples could be handled conveniently by placing them in a wire basket. Following heating, the vials were cooled to room temperature, $1 \mathrm{~mL}$ of water and $5 \mathrm{~mL}$ of hexane were added, and the contents were vortexed vigorously for $1 \mathrm{~min}$ and then centrifuged for $3 \mathrm{~min}$ at $1500 \mathrm{rpm}$. An aliquot of the upper phase was injected for GC analysis. The cholesterol concentration was determined in a fused capillary column $(30 \mathrm{~m} \times 0.22 \mathrm{~mm}$ x $0.22 \mathrm{~mm}$ ) model TRB-STEROL (Teknokroma S. Coop. C. Ltda., Barcelona, Spain) using an HP 5890 gas chromatograph (Agilent Technologies, Barcelona, Spain) equipped with a flame ionization detector. The chromatographic conditions were as follows: He carrier gas, $4 \mu \mathrm{L}$ sample injection volume, $1 / 20$ split ratio, isothermal running at $285{ }^{\circ} \mathrm{C}$ for $15 \mathrm{~min}$, injection port temperature $300^{\circ} \mathrm{C}$, and flame ionization detector temperature $300{ }^{\circ} \mathrm{C}$. The cholesterol was quantified through a 5 point calibration curve with $5 \alpha$-cholestane as the internal standard. A linear peak area/concentration response $(r=0.998)$ was observed within the tested range (1-300 mg. $\left.\mathrm{L}^{-1}\right)$. The cholesterol in the control/blank samples was determined for each batch of test samples.

\subsubsection{Protein assays}

\subsection{Total protein determination}

Quantification of protein concentrations in LEPs was carried out using a modification of the micro-Lowry technique (protein assay kit; Sigma). In 
Material and methods

the Lowry assay (Lowry et al., 1951) a copper-protein complex is formed in alkaline solution. This complex reduces a phosphomolybdicphosphotungstic reagent (Folin-Ciocalteu reagent), to produce a purple-blue color, which is quantified spectrophotometrically at $562 \mathrm{~nm}$. In the Peterson modification (Peterson, 1977) sodium dodecyl sulfate is added, so as more completely to dissolve lipids and lipoproteins as well as to alleviate possible nonionic and cationic detergent interferences. A deoxycholatetrichloroacetic acid (DOC) precipitation step is used to decrease nonprotein interference.

Experimentally, samples were diluted to $1 \mathrm{~mL}$ with destilated water. To eliminate ampholyte interference sodium chloride were add to a concentration of $0.1 \mathrm{M}$. Then $0.1 \mathrm{~mL}$ of DOC solution were add to each tube and were well mixed and allow to stand at room temperature for 10 min. After that, $0.1 \mathrm{~mL}$ of TCA solution was add to each test tube and was well mixed. The tubes were centrifuged during $10 \mathrm{~min}$ at $5000 \mathrm{rpm}$ to pellet the precipitates. The samples were allowed to decant and the supernatants were blot away. The pellets were dissolved in $1 \mathrm{~mL}$ of Lowry reagent solution. Samples were transferred to another tube, and $1 \mathrm{~mL}$ of water was used for rinse. Solutions were allowed to stay at room temperature for 20 minutes. With rapid and immediate mixing, $0.5 \mathrm{~mL}$ of the Folin and Ciocalteau's phenol reagent working solution was added. Color was allowed to develop during $30 \mathrm{~min}$. The absorbance of the samples was measured at $562 \mathrm{~nm}$. The protein content was determined by comparison with a standard curve using bovine serum albumin. 
Material and methods

\subsection{Protein solubility}

The soluble fraction was defined as the supernatant after centrifugation of a 10 -fold diluted sample (in water) (i.e., $1 \% \mathrm{v} / \mathrm{v}$ ) at 15,000 $\mathrm{g}$ and $4{ }^{\circ} \mathrm{C}$ during $15 \mathrm{~min}$. The protein content of the supernatant was determined using a modification of the micro-Lowry technique (protein assay kit; Sigma) as described on section 4.3.2.10.1. The protein content was determined by comparison with a standard curve using bovine serum albumin.

\subsection{Protein oxidation: sulfhydryl content}

The concentration of sulfhydryl (SH) groups of the egg fractions was determined using Ellman's reagent (5,5-dithiobis (2-nitrobenzoic acid), DTNB) following the method described by Van der Plancken et al. (2005) adapted from Beveridge et al. (1974).

For the determination of exposed SH groups a $100 \mu \mathrm{L}$ of sample was diluted 10 times with Tris-glycine-buffer. Then a $10 \mu \mathrm{L}$ of Ellman's reagent (4 mg.mL ${ }^{-1}$ DTNB in Tris-glycine-buffer) was added and after incubation for $15 \mathrm{~min}$ at room temperature, the reaction mixture was centrifuged (Biofuge pico, hereaus, Kendro Laboratory Products $\mathrm{GmbH}$, Osterode, Germany) at $15,000 \mathrm{~g}$ for $15 \mathrm{~min}$. Finally, the absorbance of the supernatant was measured at $412 \mathrm{~nm}$ against a reagent blank. A blank sample in which DTNB was substituted by Tris-glycinebuffer was carried through in parallel. 
Material and methods

For the determination of total SH groups before the addition of the DTNB the sample was diluted 10 times with SDS-Tris-glycine and kept at $40{ }^{\circ} \mathrm{C}$ in a water bath for $15 \mathrm{~min}$ to allow the protein to unfold and all sulfhydryl groups to be accessible to DTNB. A molar extinction coefficient of 13,600 $\mathrm{M}^{-1} \cdot \mathrm{cm}^{-1}$ at $412 \mathrm{~nm}$ was used to calculate the amount of exposed and total sulfhydryl groups (Beveridge et al., 1974).

The amount of buried sulfhydryl groups was calculated by subtracting the amount of exposed SH groups from the total amount of SH groups and the sulfhydryl contents are expressed as the percentage of total sulfhydryl groups present in the untreated egg solution.

\subsection{Electrophoresis}

Sodium dodecyl sulfate-polyacrylamide gel electrophoresis (SDS-PAGE) were carried out at a constant current $(20 \mathrm{~mA})$ in a Mini-Protean Tetra systerm with PowerPac Basic Power Supply (Bio-Rad Laboratories, Inc., Richmond, CA) according to the method of Laemmli (1970). Because of the low voltage, the produced heat was not significant. SDS-PAGE was performed using $12.5 \%$ polyacrylamide gels. Stacking and resolving.gels contained $0.1 \%$ sodium dodecyl sulphate (SDS). LEPs were mixed with a reductive sample buffer containing 2\% SDS and 5\% mercaptoethanol. The sample solution was boiled for $3 \mathrm{~min}$ and centrifuged at 1,500 $\mathrm{g}$ for $10 \mathrm{~min}$ to remove the insoluble fractions. From each sample, $10 \mu \mathrm{L}$ were casted in each lane. After running the electrophoresis, proteins were stained with 
Coomassie Brilliant Blue R-25. A molecular weight marker S8445 (SigmaAldrich, St. Louis, MO), was used as standard.

\subsubsection{Rheological properties}

\subsection{Viscosity measurement as a function of shear rate}

Viscosity measurements as a function of shear rate were carried out following the method described by Severa, Nedomova and Buchr (2010). Apparent viscosity, which is the ratio of shear stress and shear rate (Steffe, 1996), of LEPs was measured using a rheometer (Rheostress RS100, Haake, Karlsruhe, Germany), equipped with a parallel-plate measuring system (rotor 222-1223, $35 \mathrm{~mm}$ radius, $1.0 \mathrm{~mm}$ gap). Samples were examined at room temperature $\left(\sim 20^{\circ} \mathrm{C}\right)$. Measurements were carried out with an increasing shear rate 0.17 to $68 \mathrm{~s}^{-1}$. The duration of the experiment was set up to $10 \mathrm{~min}$.

Data were adjusted to the power-law model:

$$
\eta=K \dot{\gamma}^{n-1}
$$

where $\eta$ is the viscosity, $\dot{\gamma}$ is the shear rate, $K$ is the consistency coefficient and $n$ is the Power Law Index. 
Material and methods

\subsection{Time dependent viscosity}

Rheological measurements were made as described by Lee, Heinz and Knorr (1999), in a rheometer (Rheostress RS100, Haake, Karlsruhe, Germany), equipped with a parallel-plate measuring system (rotor 222$1223,35 \mathrm{~mm}$ radius, $1.0 \mathrm{~mm}$ gap), which was controlled to be $20^{\circ} \mathrm{C}$ by a Thermo Haake C25P refrigerated bath (Karlsruhe, Germany). Samples were sheared for $5 \mathrm{~min}$ at a fixed rotational speed of $55 \mathrm{rpm}$ (corresponding to a Newtonian shear rate of $300 \mathrm{~s}^{-1}$ ). During the shear, torque was recorded every second by the data acquisition software Rheowin Pro (v. 3.61, Haake, Karlsruhe, Germany). The excess work of structure breakdown $(\Delta \mathrm{W})$, or degree of coagulation, is proportional to the area under the stress overshoot peak:

$$
\Delta \mathrm{W}=\dot{\gamma} \cdot \int\left(\tau-\tau_{\mathrm{e}}\right) \mathrm{dt}
$$

where $\dot{\gamma}_{\text {is }}$ the shear rate, $\tau$ is the shear stress, $\tau_{\mathrm{e}}$ is the equilibrium shear stress.

\subsection{Temperature dependent viscosity}

The temperature dependent viscosity measurements were carried out using a rheometer (Rheostress RS100, Haake, Karlsruhe, Germany), equipped with a parallel-plate measuring system (rotor 222-1223, $35 \mathrm{~mm}$ radius, $1.0 \mathrm{~mm}$ 
gap) and a Thermo Haake C25P refrigerated bath (Karlsruhe, Germany), which allows an accurate temperature control of the plate.

The temperature-dependent viscosity behavior was determined, according to the method of Jaekel and Ternes (2009), by placing the sample in the rheometer, then equilibrating for $10 \mathrm{~min}$ and increasing the temperature linearly from $18{ }^{\circ} \mathrm{C}$ up to $95{ }^{\circ} \mathrm{C}$ using a temperature gradient of $1{ }^{\circ} \mathrm{C} \cdot \mathrm{min}^{-1}$, and measuring the viscosity at a constant shear rate of $26 \mathrm{~s}^{-1}$. Low-viscosity silicon oil was chosen as a sealing fluid for all the measurements in order to avoid coagulation of the egg protein and to prevent moisture loss during heating.

\subsubsection{Functional properties}

\subsection{Foaming properties}

Foaming properties were determined by using the method described by Song et al. (2009) with some modifications described by Kuan, Bath and Karim (2011). Briefly, a volume of $30 \mathrm{~mL}$ of $1 \% \mathrm{w} / \mathrm{v}$ sample solution was added into a $100 \mathrm{~mL}$ cylinder. Aeration was performed by using an UltraTurrax T25 basic (Ika-Works, Germany) at 12,000 rpm for $1 \mathrm{~min}$ at $25^{\circ} \mathrm{C}$. The foaming activity ( $\%$ volume) was measured in terms of volume of the liquid. Foam stability (\% volume) was expressed as percent liquid drainage 
Material and methods

in relation to initial liquid volume as a function of standing time for $30 \mathrm{~min}$. Both foaming ability and foaming stability were calculated from the following equation:

$$
\% \mathrm{~V}=\left(\mathrm{V}_{\mathrm{PF}}-\mathrm{V}_{\mathrm{LD}}\right) / \mathrm{V}_{\mathrm{OL}} \times 100 \%
$$

Where $\mathrm{V}_{\mathrm{PF}}$ is the volume of prepared foam; $\mathrm{V}_{\mathrm{LD}}$ is the volume of liquid drainage; $\mathrm{V}_{\mathrm{OL}}$ is the original volume of liquid.

\subsection{Emulsifying properties}

For determining the emulsifying capacity $\left(E_{C}\right)$, the method of Vuillemard et al. (1990) adapted by Bizzotto, Capobiango and Silvestre (2005) was used. $50 \mathrm{~mL}$ of egg protein solution were homogenized using a mixer (Fisher, mod. 14057-5) at the highest speed. Corn oil (Mazzola) was added continuously during the emulsification process from a funnel into the mixture at a rate of $25 \mathrm{~mL} \cdot \mathrm{min}^{-1}$. During emulsification, the temperature was maintained at $22 \pm 3{ }^{\circ} \mathrm{C}$ by immersing the reaction vessel in an ice bath. The emulsifying capacity was determined by the interruption of the electric current detected by a $120 \mathrm{~V}$ lamp. The $\mathrm{E}_{\mathrm{C}}$ was calculated using equation 4.13:

$$
E_{C}=\frac{E_{O}-B_{O}}{P_{W}} \times 100
$$


Material and methods

where $E_{O}$ and $B_{O}$ are the amount of emulsified oil in the sample and in the blank respectively. Blank is the buffer solution with no emulsifying agent.

The method of Pearce and Kinsella (1978), with the modifications described by Bizzotto, Capobiango and Silvestre (2005) was used for determining the emulsifying activity index $\left(\mathrm{E}_{\mathrm{AI}}\right)$. The emulsion was formed by transferring $1.0 \mathrm{~mL}$ of sunflower oil into $3.0 \mathrm{~mL}$ of $0.1 \% \mathrm{w} / \mathrm{v}$ sample solution in 100 $\mathrm{mM}$ sodium phosphate buffer at $\mathrm{pH}$ 7.4. The mixture was then homogenized in an Ultra-Turrax T25 basic (Ika-Works, Germany) at 12,000 $\mathrm{g}$ for $1 \mathrm{~min}$ at $25{ }^{\circ} \mathrm{C}$. A $100 \mu \mathrm{L}$ aliquot of the emulsion sample was taken from the bottom of the test tube at $0,1,2,3,5,10,20$ and $30 \mathrm{~min}$ and immediately diluted with $5 \mathrm{~mL}$ of $0.1 \%$ SDS solution (prepared with $100 \mathrm{mM}$ sodium phosphate buffer at $\mathrm{pH}$ 7.4). The absorbance (A) of the diluted emulsion was determined at $500 \mathrm{~nm}$ by using an UVvisible spectrophotometer (UV2, Unicam, Germany). At a path length of $1 \mathrm{~cm}$, the emulsifying activity index $\left(\mathrm{E}_{\mathrm{AI}}\right)$ is calculated from the sample turbidity:

$$
\mathrm{E}_{\mathrm{AI}}=4.606 \times \mathrm{A} \times \mathrm{P}_{\mathrm{W}}
$$

Where $\mathrm{A}$ is the absorbance and $\mathrm{P}_{\mathrm{W}}$ is the protein weight on the sample.

The method of Chobert et al. (1988), as modified by Bizzotto, Capobiango and Silvestre (2005) was used for determining the emulsion stability. The stock emulsions prepared above were held at $20{ }^{\circ} \mathrm{C}$ for $24 \mathrm{~h}$. After stirring, aliquots were diluted in $0.1 \%$ SDS and turbidity was measured as described above. The $24 \mathrm{~h}$ - old emulsions were then heated at $80{ }^{\circ} \mathrm{C}$ for $30 \mathrm{~min}$. After 
Material and methods

the aliquots were cooled to room temperature and stirred, the turbidity was again measured as described above. The $\mathrm{E}_{\mathrm{S}}$ was calculated by the Eq. 4.15:

$$
\mathrm{E}_{\mathrm{S}}=\frac{\left(\mathrm{E}_{\mathrm{AImax}}-\mathrm{E}_{\mathrm{AImin}}\right)}{\mathrm{E}_{\mathrm{AImax}}} \times 100
$$

where $\mathrm{E}_{\mathrm{AImax}}$ is the maximum value obtained just after emulsion formation, and $\mathrm{E}_{\mathrm{AImin}}$ is the lowest value obtained for the aliquots after $24 \mathrm{~h}$ storage and $80{ }^{\circ} \mathrm{C}$ heating.

\subsubsection{Cyto and genototoxicity}

\subsubsection{Caco-2 cell culture}

The human colon adenocarcinoma cell line Caco- 2 was obtained from the German Collection of Microorganisms and Cell Cultures (Braunschweig, Germany). Cells were routinely cultivated in $75 \mathrm{~cm}^{2}$ cell culture flasks from Corning (Corning, USA) in EMEM containing $10 \%$ (v/v) FCS, $1 \%$ NEAA, $1 \%$ glutamine, 50 units. $\mathrm{mL}^{-1}$ penicillin $\mathrm{G} / 50 \mu \mathrm{g} \cdot \mathrm{mL}^{-1}$ streptomycin. Cells were maintained in a humidified atmosphere with $5 \% \mathrm{CO}_{2}$ at $37{ }^{\circ} \mathrm{C}$. Cell culture medium was replaced three times a week. 
Material and methods

\subsubsection{Cytotoxicity in cell viability assays: Calcein assay}

Caco-2 cells were seeded into 96-well cell culture plates (4500 cells/well) and grown in EMEM containing $10 \%(\mathrm{v} / \mathrm{v})$ FCS, $1 \%$ NEAA, 1\%

glutamine, 50 units. $\mathrm{mL}^{-1}$ penicillin $\mathrm{G} / 50 \mu \mathrm{g} \cdot \mathrm{mL}^{-1}$ streptomycin until they reached confluence. Subsequently, cells were incubated during $24 \mathrm{~h}$ in a 96well plate (in a humidified atmosphere with $5 \% \mathrm{CO}_{2}$ at $37^{\circ} \mathrm{C}$ ) with LEPs diluted to: $2.5 \%, 5 \%, 10 \%$ and $20 \%(\mathrm{v} / \mathrm{v})$ with cell culture medium. The effect of LEPs on cell viability was determined by the calcein assay.

According to the manufacturer's protocol cells were incubated in the presence of calcein-AM ( $4 \mu \mathrm{M})$ for $45 \mathrm{~min}$. Thereafter, the fluorescence was measured at $485 \mathrm{~nm}$ (extinction) and $535 \mathrm{~nm}$ (emission) using a microplate reader (SpectraFluor Plus, Tecan Deutschland GmbH, Crailsheim, Germany). Incubation of cells with hydrochloric acid/methanol in the medium for 30 min was used as positive control.

\subsubsection{Genotoxicity: Comet assay}

DNA strand breaks were determined by the Comet assay (single cell gel electrophoresis assay) as described by Singh et al. (1988). Caco-2 cells were seeded into a 6-well cell culture plates $\left(10^{5}\right.$ cells/well) and grown in EMEM containing $10 \%(\mathrm{v} / \mathrm{v})$ FCS, $1 \%$ NEAA, $1 \%$ glutamine, 50 units. $\mathrm{mL}^{-1}$ penicillin G/50 $\mu \mathrm{g} \cdot \mathrm{mL}^{-1}$ streptomycin until they reached confluence. Thereafter, cells were incubated for $24 \mathrm{~h}$ with LEPs diluted to $5 \%(\mathrm{v} / \mathrm{v})$ 
Material and methods

with cell culture medium. Control cells were incubated in medium only. Incubation of cells with hydrogen peroxide $(30 \mu \mathrm{M})$ for 60 min was used as positive control. After treatment, the cells were washed with PBS, trypsinized, and viability was determined microscopically by the trypan blue exclusion method.

Cells $\left(2 \times 10^{5}\right)$ were mixed with $85 \mu \mathrm{L}$ low melting point agarose and placed between two layers of agarose on a microscopic slide. After lysis (lysis solution: $100 \mathrm{mM} \mathrm{Na} 2 \mathrm{EDTA}, 1$ \% Triton X 100, $2.5 \mathrm{mM} \mathrm{NaCl}, 1 \%$ (w/V) lauroyl sarcosine sodium salt, $10 \mathrm{mM}$ Tris, $10 \%$ DMSO) followed electrophoresis for $1 \mathrm{~h}$ (gel: Geltray, Renner; eletrophoreris buffer: $1 \mathrm{mM}$ $\mathrm{Na}_{2}$ EDTA, $300 \mathrm{mM} \mathrm{NaOH}, \mathrm{pH}$ 13; $\left.25 \mathrm{~V}, 300 \mathrm{~mA}, 40 \mathrm{~min}\right)$. DNA was stained with $100 \mu \mathrm{L}$ ethidium bromide solution $\left(20 \mu \mathrm{g} \cdot \mathrm{mL}^{-1}\right)$. The percentage of fluorescence in the tail (tail intensity, \%) was assessed fluorimetrically (DM 400 B, Leica Microsystems) and then quantified using the imaging software of Perceptive Instruments (Halstead, UK).

\subsubsection{Sensorial analysis}

Ingredients required to prepare egg containing food products (angel cake, pudding and mayonnaise) were acquired in a local supermarket. Components requiring low temperatures were preserved in a refrigerator until experiments were carried out. Samples were treated at room temperature $\left(20{ }^{\circ} \mathrm{C}\right)$ and untreated controls were kept under similar conditions without irradiation. UV-samples were prepared in batches and 
stored under refrigeration until the necessary amount of product was treated; sensory evaluation of fresh LEPs was carried out immediately thereafter. Untreated samples and pasteurized samples were kept under the same conditions. For the cooked eggs and egg-containing products, the egg preparation was the same as for the fresh product, and the cooking or product preparing was done immediately after the necessary amount of sample was collected.

\subsubsection{Preparation of egg-containing foods}

\subsection{Preparation of cooked eggs}

Untreated, pasteurized or UV treated egg whites, whole eggs and egg yolks samples were homogenised in an electric mixer (Eletronic filter, Britânia, Brazil) for one minute and disposed in aluminium capsules $(10 \mathrm{~cm}$ length, 4 $\mathrm{cm}$ diameter) until they were completely filled. The capsules were boiled in a water bath for $10 \mathrm{~min}$ and then allowed to cool down to room temperature. The cooked eggs were extracted from the capsules and cut into one $\mathrm{cm}$ thick slices.

\subsection{Preparation of mayonnaise}

Mayonnaise was prepared with the treated (UV-C or heat pasteurized) or untreated whole eggs using the following formula: egg (30\%), sunflower 
Material and methods

oil (67\%), salt (2\%) and lemon juice (1\%). The mixing of ingredients was performed using an electric mixer (Eletronic Filter, Britânia, Brazil). Oil was added slowly to the egg under continuous mixing to form the emulsion; after oiL.had been added, mixing continued for $5 \mathrm{~min}$. This was followed by the addition of the lemon juice and salt, and mixing for an additional $5 \mathrm{~min}$. The mayonnaise was kept refrigerated at $10{ }^{\circ} \mathrm{C}$ until sensory analysis was carried out.

\subsection{1.3 Preparation of puddings}

Puddings containing untreated, pasteurized or UV treated whole eggs were prepared using the following formula: egg (20\%), condensed milk (40\%) and whole milk (40\%). The mixing of ingredients was performed using an electric mixer (Eletronic filter, Britânia, Brazil) for $10 \mathrm{~min}$. The mixture was transferred to a non-stick aluminium pan with centraL.hole and baked in a boiling water bath for $1 \mathrm{~h}$. The pudding was put in a refrigerator and was allowed to cool down in the mould until $10{ }^{\circ} \mathrm{C}$ were achieved.

\subsection{Preparation of angel cakes}

Angel food cake was prepared with the treated (UV-C or heat pasteurized) or untreated egg whites using the following formula: egg white $(57.7 \%)$, sugar $(24.2 \%)$, flour $(13.4 \%)$, corn starch $(3.4 \%)$, tartar cream $(0.9 \%)$ and 
Material and methods

salt $(0.4 \%)$. A planetary mixer (SX80, Arno, Brazil) was used to prepare the cakes. First, egg whites were mixed with the salt and tartar cream for 10 min while the other ingredients were hand mixed. The handmade mixture was slowly added to the mixer. The preparation was instrumentally mixed for 10 min prior to baking. The cake flour was sifted, combined, and mixed at low speed with the remaining sugar for at least $20 \mathrm{~s}$. Baking took place at $175{ }^{\circ} \mathrm{C}$ for $45 \mathrm{~min}$. Cakes were cooled in an inverted position at room temperature.

\subsubsection{Evaluation of sensory differences}

Triangle tests were carried out in order to evaluate the differences between untreated, UV-C or pasteurized LEPs and products containing untreated, UV-C or pasteurized LEPs. For the experiments three samples were served to each member of the panel, two of these samples were equal, and one different, and the panel was asked to identify which of the samples was the different (Dutcosky, 1996; ASTM, 1968). The panel was composed by 50 not trained members, screened for basic abilities to identify salt/sweet/bitter/sour flavors, volunteers, from both sexes, aging between 18 and 50 years old, who had reported the habit of consuming eggs. The test runs were grouped as follows: UV-C treated-pasteurized; without treatmentUV-C treated; and without treatment-pasteurized. Tests between ultraviolet treated and pasteurized samples proceeded with the highest UV-C doses. Tests to identify differences between the ultraviolet treated and the non- 
Material and methods

treated samples started with the lowest UV-C doses. The experiments were carried out in 3 steps: first, the evaluation of the natural LEPs without preparation or cooking; second, the evaluation of the cooked products; and third, the evaluation of egg preparations.

On the first step, three $30 \mathrm{~mL}$ samples were served in white cups randomly numbered, and panellists were asked to identify the different sample from the group without any indication about which sensorial parameter should be analyzed. These experiments were repeated asking the jury to focus on the color, and later on the aroma. The products analyzed here were LEPs natural, pasteurized or UV-C treated.

On the second step, three samples of 3 slices of $1 \mathrm{~cm}$ (height) $\mathrm{x} 4 \mathrm{~cm}$ (diameter) of the cooked egg products were served to the panel in white plates randomly numbered, and panellists were asked to identify the different sample from the group. The products analyzed here were cooked egg fractions natural, pasteurized or UV-C treated.

On the third step, triangular tests were used in order to evaluate if consumers were able to identify differences between the products based on UV-C treated eggs from the products using non treated eggs, or pasteurized eggs. Pudding and mayonnaise were prepared with whole eggs and angel cakes were prepared with egg whites treated for $30 \mathrm{~min}$ (highest UV-C dose \left. used in this study, $4.176{\mathrm{~J} . \mathrm{cm}^{-2}}^{-2}\right) .25 \mathrm{~mL}$ of mayonnaise were tempered up to $15^{\circ} \mathrm{C}$ and served to the panel in white plastic cups randomly numbered. Pieces of approximately $5 \times 5 \times 1 \mathrm{~cm}$ of pudding were tempered up to $15^{\circ} \mathrm{C}$ 
and served on plastic white dishes randomly numbered. And pieces of the angel cake of approximately $6 \times 6 \times 4 \mathrm{~cm}$ were served to the panel also in white plastic dishes randomly numbered at ambient temperature.

\subsubsection{Consumer affective test}

To verify the acceptability of the products prepared with UV treated eggs compared to natural and pasteurized eggs a 9-point hedonic scale was used, as described by Dutcosky (1996).

Evaluations were performed by 50 untrained sensory panellists between 18 and 50 years old. Panellists were volunteers pre-screened for potential food allergies and on the basis of being egg and egg products consumers. Panellists were provided with an instruction/score sheet with specific instructions for evaluating the samples. Samples were offered to panellists on odorless plastic plates or cups coded by three-digit random numbers at room temperature. The order of serving was determined by random permutation. Questionnaires were provided with samples. Panellists were instructed to use unsalted crackers and mineral water to cleanse their palate before tasting the samples and any time during the test, as needed.

The panellists evaluated the food preparations on a 9-point hedonic scale to determine degree of liking $(9=$ like extremely, $5=$ neither like nor dislike, 1 $=$ dislike extremely). Angel cake samples were rated for color, flavor, 
Material and methods

aroma, sponginess, humidity, after flavor, appearance and overall acceptability using this scale.

Mayonnaise samples were rated for color, flavor, aroma, texture, creaminess, firmness, after flavor, appearance and overall acceptability. And pudding samples were rated for color, flavor, aroma, texture, after flavor, appearance and overall acceptability.

The panellists were also asked to evaluate the presence of off flavors on each preparation using a 9-point hedonic scale where $9=$ presence of good off flavor, $5=$ no presence of off flavor, $1=$ presence of bad off flavor.

The panel received the differently treated samples (cooked using LEPs

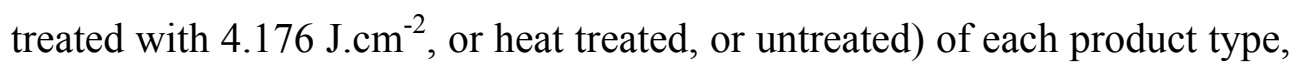
randomly numbered. Mayonnaise samples were served at $15^{\circ} \mathrm{C}$; pieces of approximately $5 \times 5 \times 1 \mathrm{~cm}$ of pudding were served at $15^{\circ} \mathrm{C}$; and pieces of angel cake of approximately $6 \times 6 \times 4 \mathrm{~cm}$ were served at ambient temperature.

The consumer overall quality $Q$ was calculated using the following equation (Garci et al., 2001):

$$
Q=\frac{(3 \times C)+(5 \times A)+(8 \times T)+(4 \times H)}{20}
$$

Where: $C=$ color; $A=$ aroma; $T=$ taste; $H=$ harmony, or overall acceptability. 
Material and methods

\subsubsection{Nutritional composition}

\subsubsection{Vitamins}

\subsection{Ascorbic acid (vitamin C)}

The determinations of the vitamin $\mathrm{C}$ were done as described by the European Pharmacopeia (2005a). In brief, $0.15 \mathrm{~g}$ of egg samples were dissolved in $10 \mathrm{~mL}$ of sulphuric acid and $80 \mathrm{~mL}$ of distillate water, than 1 $\mathrm{mL}$ of starch solution was added. The mixture was titrated with $0.05 \mathrm{M}$ of iodine until a persistent violet-blue color was obtained. $1 \mathrm{ml}$ of $0.05 \mathrm{M}$ iodine is equivalent to $8.81 \mathrm{mg}$ of ascorbic acid.

\subsection{Pantothenic acid (vitamin $\left.B_{5}\right)$}

The determinations of the vitamin $\mathrm{B}_{5}$ were done as described by the European Pharmacopeia (2005b). In brief, $0.18 \mathrm{~g}$ of egg samples were dissolved in $50 \mathrm{~mL}$ of anhydrous acetic acid. The solution was titrated with $0.1 \mathrm{M}$ perchloric acid determining the end-point potentiometrically. $1 \mathrm{ml}$ of $0.1 \mathrm{M}$ perchloric acid is equivalent to $23.83 \mathrm{mg}$ of calcium panthotenate or $21.83 \mathrm{mg}$ of panthotenic acid. 
Material and methods

\subsection{Riboflavin (vitamin $B_{2}$ )}

The assays for the determination of riboflavin were carried out in subdued light. In a brown glass $65 \mathrm{mg}$ of the sample was suspended in $5 \mathrm{~mL}$ of water, ensuring that it is completely wetted, and dissolved in $5 \mathrm{~mL}$ of $2 \mathrm{~N}$ sodium hydroxide solution. $2.5 \mathrm{~mL}$ of glacial acetic acid were added. The solution was diluted to $500 \mathrm{~mL}$ with distillate water. $20 \mathrm{~mL}$ of this solution was placed in another brown volumetric flask and $3.5 \mathrm{~mL}$ of $1.4 \% \mathrm{w} / \mathrm{v}$ sodium acetate were added. The final solution was diluted to $200 \mathrm{~mL}$ with water and the absorbance (A) was recorded at $444 \mathrm{~nm}$. (European Pharmacopoeia, 2005c). To calculate the concentration of riboflavin the following equation was used:

$$
\text { Riboflavin }(\mathrm{g})=0.2872 \times \mathrm{A}
$$

\subsection{Retinol (vitamin A)}

Extraction and HPLC analysis was performed as described previously by Mayer-Miebach et al. (2003) for carotenoids samples.

LWE and LEY samples were extracted twice. $2 \mathrm{~g}$ were mixed with $20 \mathrm{~mL}$ of ice-cold acetone containing $0.1 \%(\mathrm{w} / \mathrm{v})$ butylated hydroxytoluene (Acros Organics/VWR, Darmstadt, Germany) under continuous stirring and homogenised (Ultra Turrax, IKA-Werke, Staufen, Germany). After incubation for $30 \mathrm{~min}$ at about $4{ }^{\circ} \mathrm{C}$, the extraction mixture was re-extracted 
Material and methods

with petroleum ether until colorless (as checked visually) and discarded. The organic phase was washed with water, dried overnight at $8{ }^{\circ} \mathrm{C}$ using anhydrous sodium sulphate, and filtered. The total retinol content was determined by spectral photometric measurement (Lambda 40, Perkin Elmer, Connecticut, USA) (325 nm). Finally, samples were evaporated to dryness at $40{ }^{\circ} \mathrm{C}$ under reduced pressure (Rotavapor R-205, Büchi, Essen, Germany), flushed with nitrogen gas and stored at $-86{ }^{\circ} \mathrm{C}$ untiL.hPLCanalysis. All experiments were carried out under subdued light to prevent photo-degradation and isomerisation.

For HPLC analysis, dry extracts were re-dissolved in tetrahydrofuran containing $0.1 \%(\mathrm{w} / \mathrm{v})$ butylated hydroxytoluene and measured twice according to a modified method described by Emenhiser et al. (1995) using an HPLC equipment (LaChrom Elite, VWR/Hitachi, Darmstadt, Germany) consisting of a quarternary pump, an auto-sampler, a column oven and a photodiode array detector combined with a software for controlling data acquisition and analysis (EZChrom Elite, VWR/Hitachi, Darmstadt). Retinol was separated on a C30 reversed phase column (250 mm x $4.6 \mathrm{~mm}$; $5 \mu \mathrm{m}$ ) (YMC Europe, Dinslaken, Germany) at $27{ }^{\circ} \mathrm{C}$ using a linear gradient of methyl t-butyl ether (MTBE) in methanol for 20 min (starting phase composition: $81 \%$ methanol, $15 \%$ MTBE, $4 \%$ water; end phase composition: $64 \%$ methanol, $32 \% \mathrm{MTBE}, 4 \%$ water) at a flow rate of 1 $\mathrm{mL} \cdot \mathrm{min}^{-1}$. Retinol, was identified based on standards (Fluka/Sigma-Aldrich, Taufkirchen, Germany), which was also used as calibration standards for quantification. All chemicals used for extraction and HPLC analysis were purchased from Merck/VWR, Darmstadt, Germany, except otherwise stated. 
Material and methods

\subsection{Tocopherol (vitamin E)}

Extraction and HPLC analysis was performed as described by MayerMiebach et al. (2003) for carotenoids; and previously detailed in Section 4.3.4.1.4. The total tocopherol content was determined by spectral photometric measurement (Lambda 40, Perkin Elmer, Connecticut, USA) (292 nm). Tocopherol was identified based on standards (Fluka/SigmaAldrich), which was also used as calibration standards for quantification.

\subsubsection{Carotenoids (lutein and zeaxanthin)}

Extraction and HPLC analysis was performed as described by MayerMiebach et al. (2003) for carotenoids; and previously detailed in Section 4.3.4.1.4. The total carotenoids content was determined by spectral photometric measurement (Lambda 40, Perkin Elmer, Connecticut, USA) (445 nm). Lutein was identified based on standards (CaroteNature, Lupsingen, Switzerland), which was also used as calibration standards for quantification. Zeaxanthin was identified retention time and specific absorption spectra (Britton, 1995) and quantified as lutein equivalents.

\subsubsection{Minerals}

$1 \mathrm{~g}$ of sample was digested with $25 \mathrm{~mL}$ of $37 \%$ hypochlorite acid and $5 \mathrm{~min}$ heating at $95^{\circ} \mathrm{C}$. Samples were filtered and the minerals were quantified on 
Material and methods

a Perkin Elmer 2100 (California, USA) atomic absorption spectrometer following the device manufacture instructions. Merck (Madrid, Spain) standards were used to build the calibration curves. The wavelengths used for $\mathrm{K}, \mathrm{Ca}, \mathrm{Mg}$, and $\mathrm{Zn}$ were 766.5, 422.6, 285.2 and $213.8 \mathrm{~nm}$ respectively.

\subsection{Statistical analysis}

One-way analysis of variance (ANOVA) was performed with the software XLSTAT-270 Pro (Win) 7.5.3 (Addinsoft, NY). Statistical analysis was run with a confidence level of $95 \%$. Comparisons between treatments were evaluated with the Tukey test. 

5. Results and

\author{
discussion
}





\section{Results and discussion}

\subsection{IATA bench scale device}

UV-C light treatment has been used in the food industry for different purposes. One important point to be considered for the treatments is the device design; an ideal UV reactor would be able to provide a uniform dosage of photons to the fluid and would be able to provide a uniform dosage on a continuous basis to large volumes of fluid. These objectives are particularly difficult when the absorbance of the fluid is high, as is the case for LEPs.

The suitability of UV-C for the decontamination of LEPs was initially determined in bench-scale equipment provided with one low pressure mercury lamp, also taking into account the changes in key egg quality attributes. Results were explained in five main sections: microbiology, basic quality study ( $\mathrm{pH}$ and color), effects on lipids, effects on proteins and characterization of rheological attributes.

\subsubsection{Microbiology}


Results and discussion

\subsubsection{Effects on inoculated microorganisms}

The inactivation kinetics of Salmonella enteritidis ATCC 13076, Escherichia coli ATCC 11775, Staphylococcus aureus ATCC 12600 and Listeria innocua ATCC 33090 populations inoculated in liquids egg white, whole egg and egg yolk were studied after UV-C irradiation under static or dynamic conditions. Based on the counts after decimal serial dilutions, semilogarithmic survivor curves are represented in Figures 5.1, 5.2, 5.3 and 5.4 respectively for E. coli, L.innocua, S. aureus and S. enteritidis relating the viable populations $\left(\mathrm{Log}\left(\mathrm{CFU} \cdot \mathrm{mL}^{-1}\right)\right)$ to the UV-C dose $\left(\mathrm{J}_{\mathrm{cm}}{ }^{-2}\right)$ under static or dynamic conditions.

Microbial inactivation under UV-C and under dynamic conditions was more accurately described by the Weibull distribution (similar $\mathrm{R}^{2}$ also were observed for the modified Weibull described by Albert and Manfart) than by linear models, meaning that data presented a certain tailing in all LEPs. This can be mainly attributed to low light transmittance of LEPs, which protects the bacterial cells during irradiation. The estimated parameters describing the UV-C inactivation under dynamic and static conditions at 2 and $5 \mathrm{~mm}$ are recorded on Tables 5.1 to 5.3 for the Weibull distribution, and Table 5.4 presented the expected doses to reach 5 Log inactivation calculated by the Log linear model, since was not possible to integrate all data from the tail models. 
Results and discussion
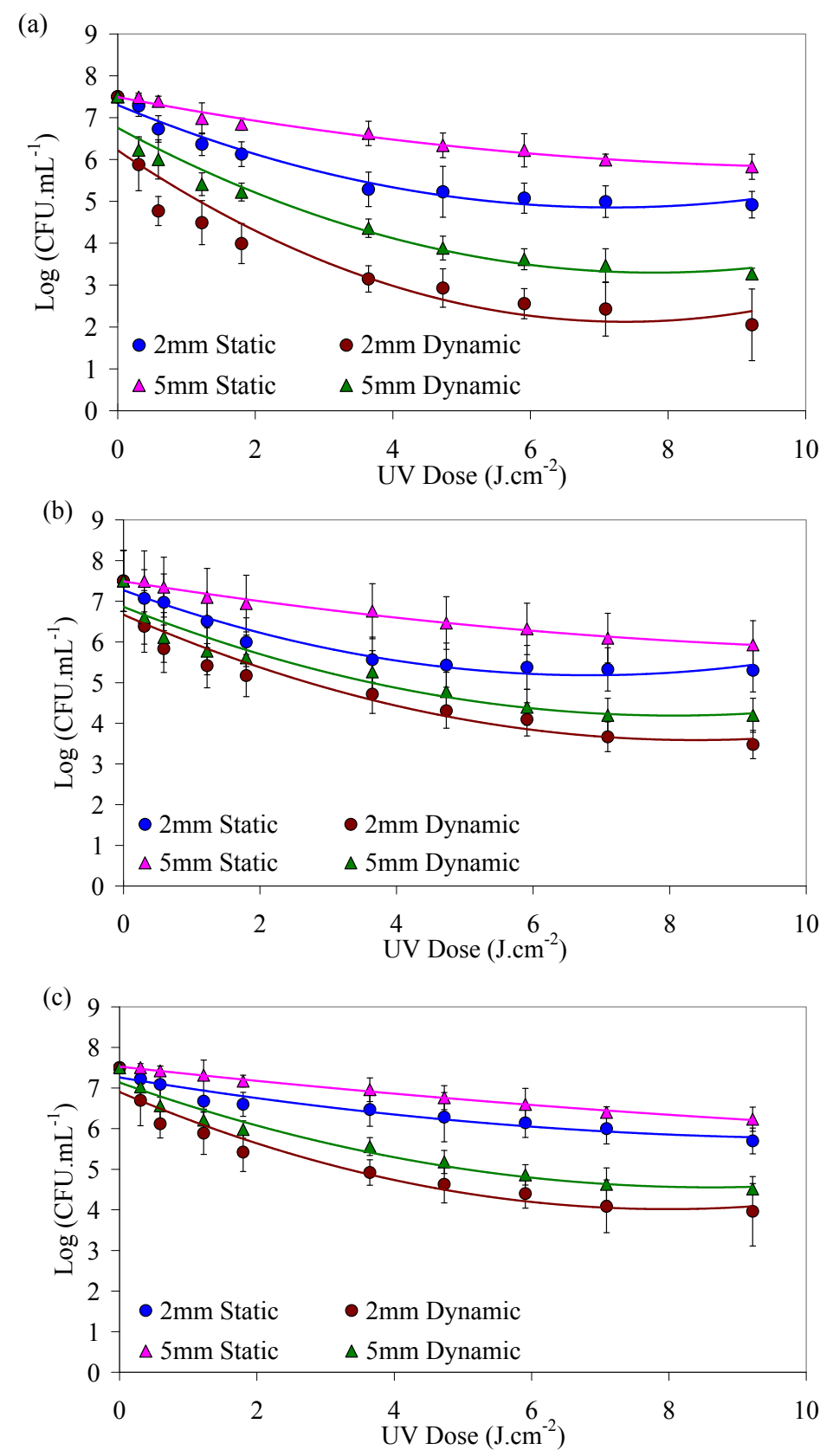

Figure 5.1 - Inactivation kinetics of Escherichia coli ATCC 11775 in (a) LEW (b) LWE and (c) LEY. Results are the mean of triplicate \pm standart deviation. 
Results and discussion
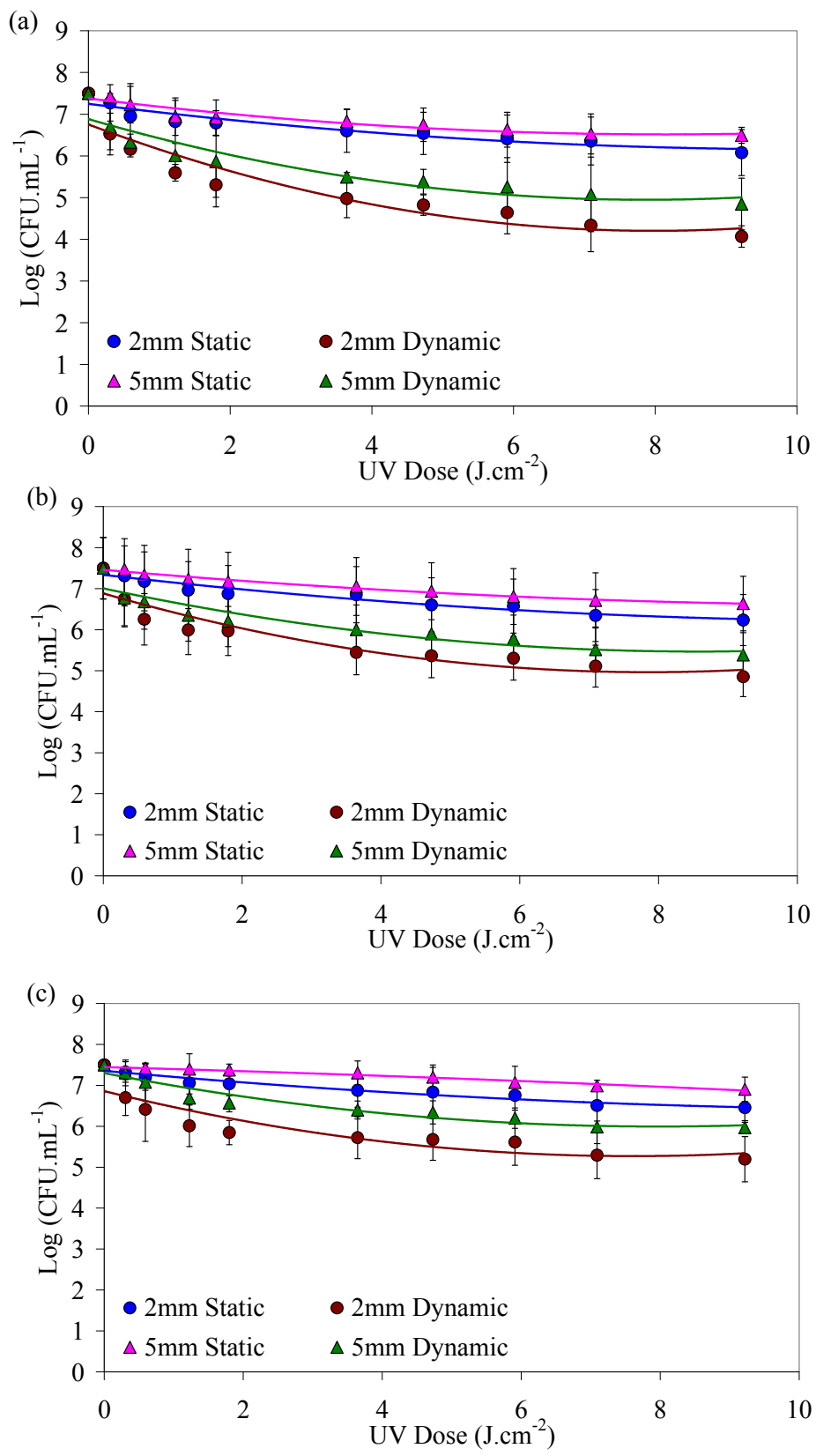

Figure 5.2 - Inactivation kinetics of Listeria innocua ATCC 33090 in (a) LEW (b) LWE and (c) LEY. Results are the mean of triplicate \pm standart deviation. 
Results and discussion
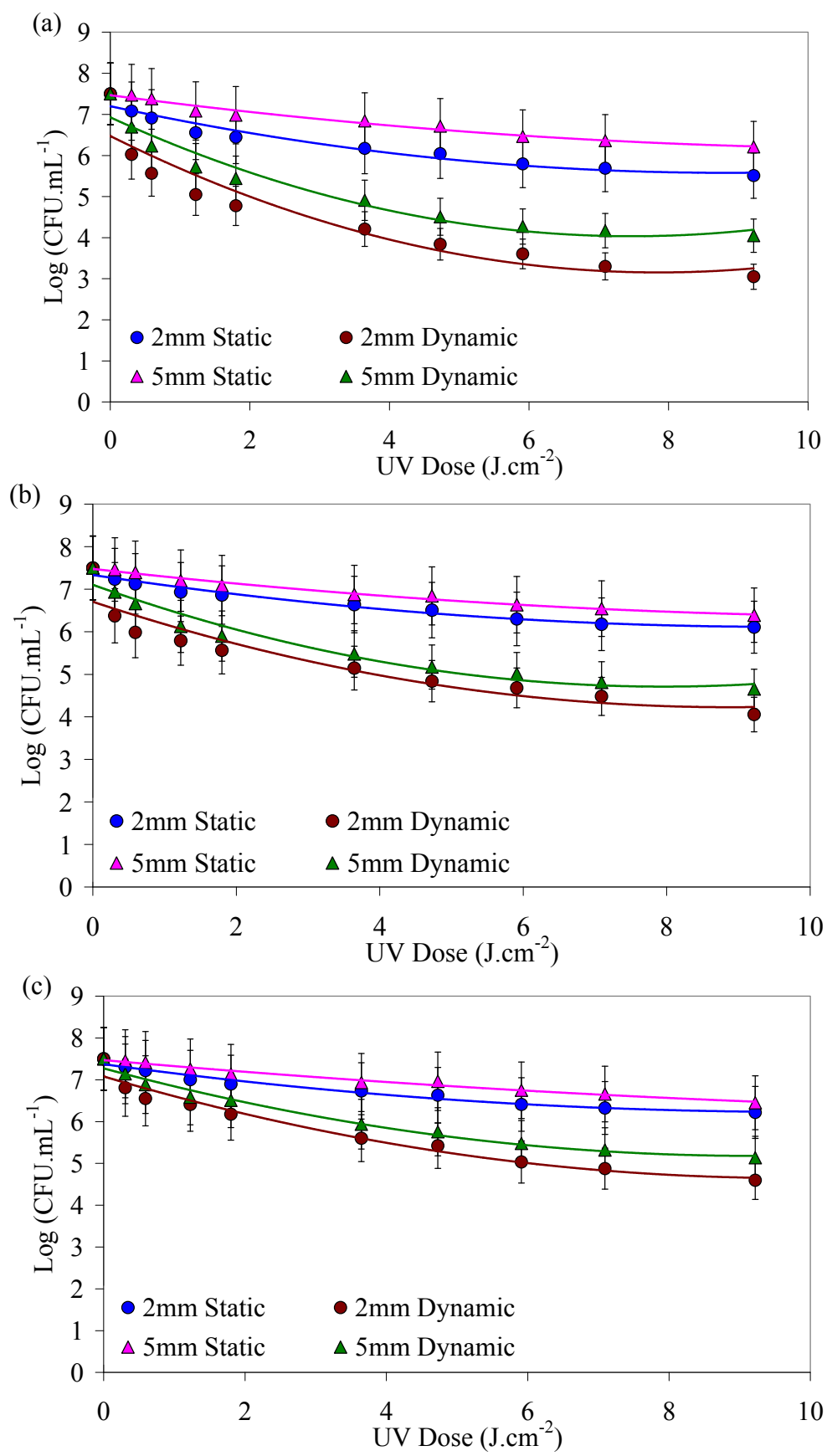

Figure 5.3 - Inactivation kinetics of Staphylococcus aureus ATCC 12600 in (a) LEW (b) LWE and (c) LEY. Results are the mean of triplicate \pm standart deviation. 
Results and discussion
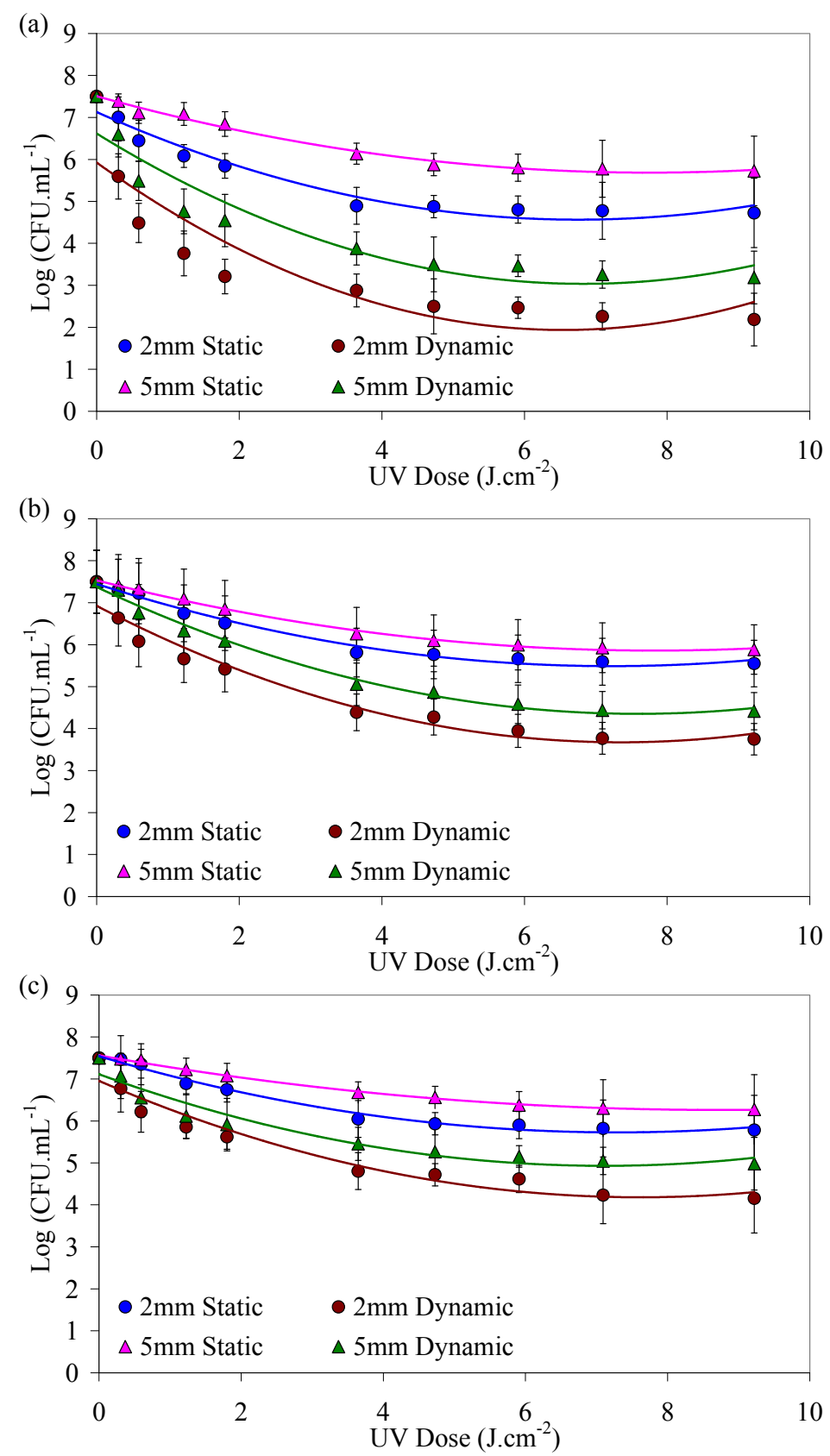

Figure 5.4 - Inactivation kinetics of Salmonella enteritidis ATCC 13076 in (a) LEW (b) LWE and (c) LEY. Results are the mean of triplicate \pm standart deviation. 
An effective reduction of $5.2 \log$ of $S$. enteritidis was achieved when samples with $2 \mathrm{~mm}$ high were subjected to the highest UV-C doses (9.2

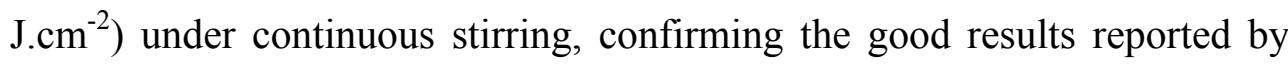
Geveke (2008) and Ngadi et al. (2003). Under similar conditions the reduction attained by E. coli, S. aureus and L. innocua in LEW were 5.45, 4.45 and 3.43 Log respectively.

The matrix characteristics had a significant influence on the inactivation. In particular, in LEY, a reduction of $3.34 \log$ of $S$. enteritidis was achieved when the samples with $2 \mathrm{~mm}$ high were subjected to the $9.2 \mathrm{~J} . \mathrm{cm}^{-2}$ under dynamic conditions. And the reduction attained with inoculated E. coli, $S$. aureus and L. innocua were 3.54, 2.90 and $2.30 \mathrm{Log}$, respectively, which are considerably lower than for LEW samples at the same conditions. And in LWE, a reduction of $3.75 \mathrm{Log}$ of $S$. enteritidis was achieved when $2 \mathrm{~mm}$ samples were subjected to $9.2 \mathrm{~J} . \mathrm{cm}^{-2}$ with stirring. Log reductions of $E$. coli, S. aureus and L. innocua inoculated on LWE were 4.02, 3.44 and 2.65, respectively.

Absorbance coefficients, as calculated applying the Beer-Lambert law explain the effectiveness of the treatments (egg white $>$ whole egg $>$ egg yolk). Absorbance coefficients accounted $130 \mathrm{~cm}^{-1}$ for LEW, $337 \mathrm{~cm}^{-1}$ for LWE and $620 \mathrm{~cm}^{-1}$ for LEY, being this absorbances in the range recently commented by Ünlütürk et al. (2008) for similar products. Consequently, the dose required to achieve the inactivation of inoculated microorganisms in LEPs is relatively high, if compared to dose requirements in clarified

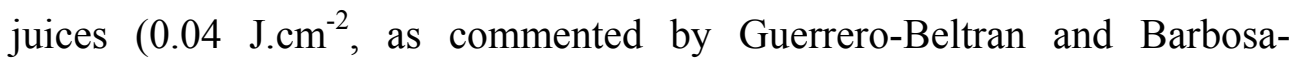


Results and discussion

Canovas, 2004) or on chicken breast $\left(0.5 \mathrm{~J}_{\mathrm{cm}} \mathrm{cm}^{-2}\right.$, as commented by Chun et al., 2010), for example. But results here are presented as a function of the average fluence rate as calculated by actinometry, which is higher than the

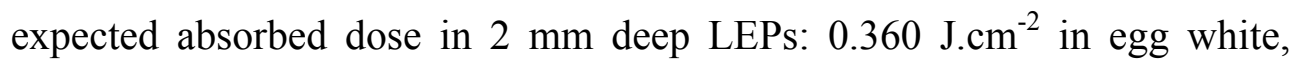
$0.075 \mathrm{~J} . \mathrm{cm}^{-2}$ in egg yolk, and $0.140 \mathrm{~J} . \mathrm{cm}^{-2}$ in whole egg, estimated following Morowitz (1950).

Among all the microorganisms investigated, E. coli and S. enteritidis exhibited similar resistance to UV-C irradiation (Figures 5.1 and 5.4), and attained a higher reduction with the same dose if compared to $S$. aureus and L. innocua. In a similar work, Guerrero-Beltrán and Barbosa-Cánovas (2004) also observed that the Gram(+) L. innocua (ATCC 51742) had higher resistance to UV-C radiation than the Gram(-) E. coli (ATCC 11775) when suspended in apple juice, which could be attributed to the differential characteristics of the cell wall in both types of microorganisms. Stirring was also a non-negligible factor accelerating cell inactivation by enhancing the contact of the microbial cells and the UV-C beam.

Stirring at $400 \mathrm{~min}^{-1}$ significantly improved the UV-C inactivation efficiency and was therefore chosen as an optimum condition for the subsequent shelf-life study.

Several variables (fluid depth, optical density, microorganism grow phase, fluence, etc) influence the inactivation of microorganisms by UV-C, consequently, a comparison of UV-C sensibility with results for other microorganisms in similar systems is difficult. 
Table 5.1 - Weibull fitting from inactivation kinetics of LEW.

\begin{tabular}{|c|c|c|c|c|}
\hline \multirow[b]{2}{*}{ Parameters } & \multicolumn{4}{|c|}{ Weibull } \\
\hline & $\begin{array}{c}2 \mathrm{~mm} \\
\text { Dynamic }\end{array}$ & $\begin{array}{l}2 \mathrm{~mm} \\
\text { Static }\end{array}$ & $\begin{array}{c}5 \mathrm{~mm} \\
\text { Dynamic }\end{array}$ & $\begin{array}{l}5 \mathrm{~mm} \\
\text { Static }\end{array}$ \\
\hline \multicolumn{5}{|l|}{ Salmonella enteritidis } \\
\hline $\mathrm{RMSE}^{\mathrm{a}}$ & 0.5233 & 0.4646 & 0.5071 & 0.3837 \\
\hline $\mathrm{R}^{2}$ & 0.9129 & 0.8245 & 0.8927 & 0.7723 \\
\hline $\log \mathrm{N}_{0}\left(\mathrm{CFU} \cdot \mathrm{mL}^{-1}\right)^{\mathrm{b}}$ & $7.18 \pm 0.30$ & $7.60 \pm 0.26$ & $7.57 \pm 0.29$ & $7.61 \pm 0.21$ \\
\hline$\delta\left(\mathrm{J}^{\mathrm{cm}} \mathrm{cm}^{-2}\right)^{\mathrm{c}}$ & $0.02 \pm 0.02$ & $0.37 \pm 0.28$ & $0.06 \pm 0.05$ & $2.28 \pm 1.06$ \\
\hline $\mathrm{p}(-)^{\mathrm{d}}$ & $0.28 \pm 0.04$ & $0.36 \pm 0.07$ & $0.31 \pm 0.05$ & $0.54 \pm 0.14$ \\
\hline \multicolumn{5}{|l|}{ Escherichia coli } \\
\hline $\mathrm{RMSE}^{\mathrm{a}}$ & 0.4938 & 0.3623 & 0.2704 & 0.2306 \\
\hline $\mathrm{R}^{2}$ & 0.9231 & 0.8757 & 0.9641 & 0.8762 \\
\hline $\log \mathrm{N}_{0}\left(\mathrm{CFU} \cdot \mathrm{mL}^{-1}\right)^{\mathrm{b}}$ & $7.19 \pm 0.28$ & $7.63 \pm 0.23$ & $7.44 \pm 0.15$ & $7.58 \pm 0.12$ \\
\hline$\delta\left(\mathrm{J} \mathrm{cm}^{-2}\right)^{\mathrm{c}}$ & $0.07 \pm 0.05$ & $0.70 \pm 0.36$ & $0.20 \pm 0.07$ & $3.58 \pm 0.84$ \\
\hline $\mathrm{p}(-)^{\mathrm{d}}$ & $0.34 \pm 0.04$ & $0.42 \pm 0.07$ & $0.38 \pm 0.03$ & $0.63 \pm 0.12$ \\
\hline \multicolumn{5}{|l|}{ Staphylococcus aureus } \\
\hline $\mathrm{RMSE}^{\mathrm{a}}$ & 0.4033 & 0.4596 & 0.5581 & 0.2840 \\
\hline $\mathrm{R}^{2}$ & 0.9220 & 0.6648 & 0.8150 & 0.7248 \\
\hline $\log \mathrm{N}_{0}\left(\mathrm{CFU} \cdot \mathrm{mL}^{-1}\right)^{\mathrm{b}}$ & $7.51 \pm 0.23$ & $7.51 \pm 0.26$ & $7.55 \pm 0.32$ & $7.54 \pm 0.15$ \\
\hline$\delta\left(\mathrm{J}^{\mathrm{cm}} \mathrm{cm}^{-2}\right)^{\mathrm{c}}$ & $0.07 \pm 0.05$ & $1.70 \pm 1.23$ & $0.26 \pm 0.22$ & $5.66 \pm 1.54$ \\
\hline $\mathrm{p}(-)^{\mathrm{d}}$ & $0.31 \pm 0.04$ & $0.42 \pm 0.13$ & $0.37 \pm 0.08$ & $0.64 \pm 0.19$ \\
\hline \multicolumn{5}{|l|}{ Listeria innocua } \\
\hline $\mathrm{RMSE}^{\mathrm{a}}$ & 0.3589 & 0.4469 & 0.4686 & 0.3165 \\
\hline $\mathrm{R}^{2}$ & 0.8980 & 0.4738 & 0.7508 & 0.5467 \\
\hline $\log \mathrm{N}_{0}\left(\mathrm{CFU} \cdot \mathrm{mL}^{-1}\right)^{\mathrm{b}}$ & $7.52 \pm 0.20$ & $7.50 \pm 0.25$ & $7.51 \pm 0.27$ & $7.54 \pm 0.18$ \\
\hline$\delta\left(\mathrm{J} \cdot \mathrm{cm}^{-2}\right)^{\mathrm{c}}$ & $0.20 \pm 0.13$ & $4.45 \pm 3.20$ & $0.38 \pm 0.36$ & $7.60 \pm 3.58$ \\
\hline $\mathrm{p}(-)^{\mathrm{d}}$ & $0.32 \pm 0.05$ & $0.39 \pm 0.18$ & $0.30 \pm 0.07$ & $0.42 \pm 0.17$ \\
\hline
\end{tabular}

${ }^{a}$ RMSE: Root mean sum of squared error.

${ }^{\mathrm{b}} \log \left(\mathrm{N}_{0}\right)$ : predicted logarithm of initial count.

${ }^{\mathrm{c}} \delta$ : fluence for the first decimal reduction.

${ }^{\mathrm{d}} \mathrm{p}$ : dimensionless parameter describing concavity or convexity of the curve. 
Results and discussion

Table 5.2 - Weibull fitting from inactivation kinetics of LWE.

\begin{tabular}{|c|c|c|c|c|}
\hline \multirow[b]{2}{*}{ Parameters } & \multicolumn{4}{|c|}{ Weibull } \\
\hline & $\begin{array}{c}2 \mathrm{~mm} \\
\text { Dynamic }\end{array}$ & $\begin{array}{l}2 \mathrm{~mm} \\
\text { Static }\end{array}$ & $\begin{array}{c}5 \mathrm{~mm} \\
\text { Dynamic }\end{array}$ & $5 \mathrm{~mm}$ Static \\
\hline \multicolumn{5}{|l|}{ Salmonella enteritidis } \\
\hline $\mathrm{RMSE}^{\mathrm{a}}$ & 0.4564 & 0.3834 & 0.4130 & 0.4108 \\
\hline $\mathrm{R}^{2}$ & 0.8910 & 0.7973 & 0.8915 & 0.7142 \\
\hline $\log \mathrm{N}_{0}\left(\mathrm{CFU} \cdot \mathrm{mL}^{-1}\right)^{\mathrm{b}}$ & $7.55 \pm 0.26$ & $7.63 \pm 0.21$ & $7.67 \pm 0.23$ & $7.62 \pm 0.22$ \\
\hline$\delta\left(\mathrm{J} \mathrm{cm}^{-2}\right)^{\mathrm{c}}$ & $0.23 \pm 0.15$ & $1.51 \pm 0.80$ & $0.64 \pm 0.32$ & $2.74 \pm 1.34$ \\
\hline $\mathrm{p}(-)^{\mathrm{d}}$ & $0.38 \pm 0.06$ & $0.47 \pm 0.11$ & $0.48 \pm 0.08$ & $0.55 \pm 0.17$ \\
\hline \multicolumn{5}{|l|}{ Escherichia coli } \\
\hline $\mathrm{RMSE}^{\mathrm{a}}$ & 0.2599 & 0.4160 & 0.2437 & 0.2161 \\
\hline $\mathrm{R}^{2}$ & 0.9595 & 0.7938 & 0.9523 & 0.8750 \\
\hline $\log \mathrm{N}_{0}\left(\mathrm{CFU} \cdot \mathrm{mL}^{-1}\right)^{\mathrm{b}}$ & $7.45 \pm 0.15$ & $7.60 \pm 0.23$ & $7.51 \pm 0.14$ & $7.55 \pm 0.11$ \\
\hline$\delta\left(\mathrm{J} \mathrm{cm}^{-2}\right)^{\mathrm{c}}$ & $0.19 \pm 0.08$ & $0.81 \pm 0.54$ & $0.30 \pm 0.12$ & $4.37 \pm 0.85$ \\
\hline $\mathrm{p}(-)^{\mathrm{d}}$ & $0.36 \pm 0.03$ & $0.39 \pm 0.09$ & $0.36 \pm 0.04$ & $0.69 \pm 0.13$ \\
\hline \multicolumn{5}{|l|}{ Staphylococcus aureus } \\
\hline $\mathrm{RMSE}^{\mathrm{a}}$ & 0.5069 & 0.4708 & 0.3852 & 0.3609 \\
\hline $\mathrm{R}^{2}$ & 0.8019 & 0.4982 & 0.8622 & 0.5451 \\
\hline $\log \mathrm{N}_{0}\left(\mathrm{CFU} \cdot \mathrm{mL}^{-1}\right)^{\mathrm{b}}$ & $7.45 \pm 0.29$ & $7.50 \pm 0.26$ & $7.55 \pm 0.22$ & $7.54 \pm 0.18$ \\
\hline$\delta\left(\mathrm{J}^{\mathrm{cm}}{ }^{-2}\right)^{\mathrm{c}}$ & $0.24 \pm 0.22$ & $4.45 \pm 2.72$ & $0.60 \pm 0.35$ & $7.31 \pm 2.33$ \\
\hline $\mathrm{p}(-)^{\mathrm{d}}$ & $0.32 \pm 0.07$ & $0.49 \pm 0.23$ & $0.40 \pm 0.07$ & $0.66 \pm 0.30$ \\
\hline \multicolumn{5}{|l|}{ Listeria innocua } \\
\hline $\mathrm{RMSE}^{\mathrm{a}}$ & 0.4666 & 0.5635 & 0.3113 & 0.3424 \\
\hline $\mathrm{R}^{2}$ & 0.7503 & 0.3418 & 0.8083 & 0.4425 \\
\hline $\log \mathrm{N}_{0}\left(\mathrm{CFU} \cdot \mathrm{mL}^{-1}\right)^{\mathrm{b}}$ & $7.51 \pm 0.27$ & $7.50 \pm 0.31$ & $7.49 \pm 0.18$ & $7.52 \pm 0.18$ \\
\hline$\delta\left(\mathrm{J} \mathrm{cm}^{-2}\right)^{\mathrm{c}}$ & $0.39 \pm 0.37$ & $6.03 \pm 4.21$ & $0.94 \pm 0.59$ & $10.87 \pm 3.75$ \\
\hline $\mathrm{p}(-)^{\mathrm{d}}$ & $0.30 \pm 0.07$ & $0.50 \pm 0.32$ & $0.32 \pm 0.07$ & $0.63 \pm 0.35$ \\
\hline
\end{tabular}

${ }^{a} \mathrm{RMSE}$ : Root mean sum of squared error.

${ }^{\mathrm{b}} \log \left(\mathrm{N}_{0}\right)$ : predicted logarithm of initial count.

${ }^{\mathrm{c}} \delta$ : fluence for the first decimal reduction.

${ }^{\mathrm{d}} \mathrm{p}$ : dimensionless parameter describing concavity or convexity of the curve. 
Table 5.3 - Weibull fitting from inactivation kinetics of LEY.

\begin{tabular}{|c|c|c|c|c|}
\hline \multirow[b]{2}{*}{ Parameters } & \multicolumn{4}{|c|}{ Weibull } \\
\hline & $\begin{array}{c}2 \mathrm{~mm} \\
\text { Dynamic }\end{array}$ & $\begin{array}{l}2 \mathrm{~mm} \\
\text { Static }\end{array}$ & $\begin{array}{c}5 \mathrm{~mm} \\
\text { Dynamic }\end{array}$ & $5 \mathrm{~mm}$ Static \\
\hline \multicolumn{5}{|l|}{ Salmonella enteritidis } \\
\hline $\mathrm{RMSE}^{\mathrm{a}}$ & 0.3669 & 0.4714 & 0.4136 & 0.3636 \\
\hline $\mathrm{R}^{2}$ & 0.9038 & 0.6883 & 0.8184 & 0.6536 \\
\hline $\log \mathrm{N}_{0}\left(\mathrm{CFU} \cdot \mathrm{mL}^{-1}\right)^{\mathrm{b}}$ & $7.55 \pm 0.21$ & $7.66 \pm 0.26$ & $7.58 \pm 0.23$ & $7.60 \pm 0.19$ \\
\hline$\delta\left(\mathrm{J}^{\mathrm{cm}} \mathrm{cm}^{-2}\right)^{\mathrm{c}}$ & $0.31 \pm 0.17$ & $2.08 \pm 1.26$ & $0.52 \pm 0.37$ & $4.92 \pm 1.79$ \\
\hline $\mathrm{p}(-)^{\mathrm{d}}$ & $0.37 \pm 0.05$ & $0.51 \pm 0.16$ & $0.36 \pm 0.07$ & $0.62 \pm 0.22$ \\
\hline \multicolumn{5}{|l|}{ Escherichia coli } \\
\hline $\mathrm{RMSE}^{\mathrm{a}}$ & 0.4414 & 0.2871 & 0.2463 & 0.1822 \\
\hline $\mathrm{R}^{2}$ & 0.8756 & 0.7945 & 0.9453 & 0.8682 \\
\hline $\log \mathrm{N}_{0}\left(\text { CFU.mL } \mathrm{mL}^{-1}\right)^{\mathrm{b}}$ & $7.49 \pm 0.25$ & $7.51 \pm 0.16$ & $7.54 \pm 0.14$ & $7.54 \pm 0.08$ \\
\hline$\delta\left(\mathrm{J} \mathrm{cm}^{-2}\right)^{\mathrm{c}}$ & $0.33 \pm 0.21$ & $2.81 \pm 0.14$ & $0.71 \pm 0.23$ & $6.46 \pm 0.77$ \\
\hline $\mathrm{p}(-)^{\mathrm{d}}$ & $0.39 \pm 0.07$ & $0.46 \pm 0.11$ & $0.45 \pm 0.05$ & $0.85 \pm 0.17$ \\
\hline \multicolumn{5}{|l|}{ Staphylococcus aureus } \\
\hline $\mathrm{RMSE}^{\mathrm{a}}$ & 0.4274 & 0.3660 & 0.2354 & 0.2851 \\
\hline $\mathrm{R}^{2}$ & 0.8281 & 0.5846 & 0.9227 & 0.6113 \\
\hline $\log \mathrm{N}_{0}\left(\mathrm{CFU} \cdot \mathrm{mL}^{-1}\right)^{\mathrm{b}}$ & $7.47 \pm 0.24$ & $7.51 \pm 0.20$ & $7.53 \pm 0.13$ & $7.51 \pm 0.14$ \\
\hline$\delta\left(\mathrm{J} \mathrm{cm}^{-2}\right)^{\mathrm{c}}$ & $0.92 \pm 0.53$ & $5.40 \pm 2.40$ & $1.51 \pm 0.46$ & $8.67 \pm 1.94$ \\
\hline $\mathrm{p}(-)^{\mathrm{d}}$ & $0.46 \pm 0.10$ & $0.51 \pm 0.20$ & $0.50 \pm 0.07$ & $0.72 \pm 0.29$ \\
\hline \multicolumn{5}{|l|}{ Listeria innocua } \\
\hline $\mathrm{RMSE}^{\mathrm{a}}$ & 0.4582 & 0.3910 & 0.5195 & 0.2491 \\
\hline $\mathrm{R}^{2}$ & 0.6951 & 0.4197 & 0.5075 & 0.3809 \\
\hline $\log \mathrm{N}_{0}\left(\mathrm{CFU} \cdot \mathrm{mL}^{-1}\right)^{\mathrm{b}}$ & $7.51 \pm 0.26$ & $7.49 \pm 0.21$ & $7.55 \pm 0.29$ & $7.44 \pm 0.09$ \\
\hline$\delta\left(\mathrm{J} \mathrm{cm}^{-2}\right)^{\mathrm{c}}$ & $0.37 \pm 0.41$ & $9.01 \pm 4.32$ & $2.66 \pm 2.23$ & $14.71 \pm 5.35$ \\
\hline $\mathrm{p}(-)^{\mathrm{d}}$ & $0.26 \pm 0.07$ & $0.50 \pm 0.27$ & $0.40 \pm 0.18$ & $1.22 \pm 0.74$ \\
\hline
\end{tabular}


Results and discussion

Table 5.4 - Dose required to reach 5D* according to the Log-linear models

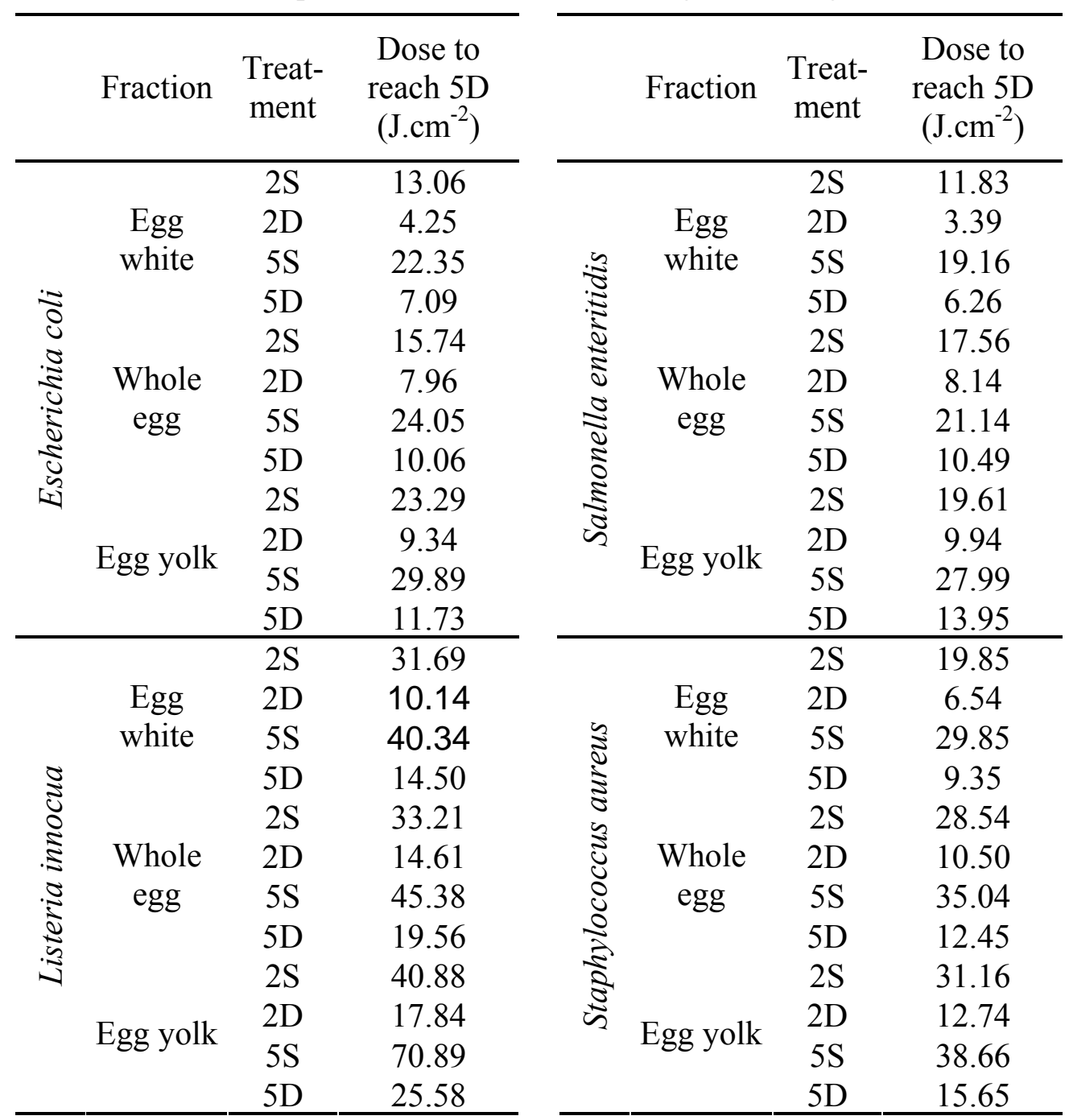

2S - $2 \mathrm{~mm}$ static; $2 \mathrm{D}-2 \mathrm{~mm}$ dynamic; $5 \mathrm{~S}-5 \mathrm{~mm}$ static; $5 \mathrm{D}-5 \mathrm{~mm}$ dynamic $5 \mathrm{D} *$ is $5 \mathrm{Log}$ cycles reduction (pasteurization requirements)

Ünlütürk et al. (2008) described the kinetic results under collimated beams for E. coli ATCC 8739 in egg products using a first order approximation. Using their fit, a decimal reduction time of $10 \mathrm{~min}$ is expected in LEW for 
that microorganism treated with $0.383 \mathrm{~mW} . \mathrm{cm}^{-2}$, which is considerably larger than the decimal reduction time found in this work for S. enteritidis for samples with $2 \mathrm{~mm}$ heigh treated with continuos stirring. In food systems, S.enteritidis is known to be a highly UV-C resistant microorganism (Chevrefils et al., 2006; Yaun et al., 2003). But, UV-C intensity, being considerably higher in the system tested here, might play a non-negligible role in the inactivation of microorganisms under UV-C. Consequently, models able to accurately describe the microorganism inactivation under UV-C will have to consider the largest amount of operational variables influencing the system efficiency.

UV-C is already used to decontaminate egg shells since it lowers remarkably the concentration of $S$. enteritidis (Rodriguez-Romo and Yousef, 2005). And, although treatment parameters are not fully comparable, lower inactivation rates than the ones reported here for UV-C decontamination have been recorded in LEPs treated with other non-thermal technologies. For example, energy levels up to $250 \mathrm{~J} \cdot \mathrm{mL}^{-1}$ could be required to achieve a pasteurization of LEW with pulsed electric fields (Monfort et al., 2010), and lower energy levels seem to be ineffective against $S$. enteritidis even if applied at $55{ }^{\circ} \mathrm{C}$; furthermore, high pressure cycles (between 500 and $800 \mathrm{MPa}$ ) achieved only 2 Log reduction around $20{ }^{\circ} \mathrm{C}$ (Huang, Mittal and Griffiths, 2006).

The influence of other variables in UV-C, specially the fluence rate, or the combination with heat or antimicrobials remains to be investigated. 
Results and discussion

\subsubsection{UV-C inactivation of spoilage-related microorganisms}

Albumin contains natural antimicrobials like ovotransferrin and lysozyme, besides the presence of antiproteases. However their antimicrobial activity is not enough to fully inhibit the contamination of the product against microorganisms coming either from the environment, or from the contact with the digestive tract during egg laying. To decrease the risks associated to contamination, egg shell integrity and the correct collection and handling are essential. Egg yolks are protected from contamination by the egg white enveloping, however, as egg ages, the egg white thins and the yolk membrane weakens, making it possible for the spoilage related microorganisms to reach the nutrient-dense egg yolk.

Heat pasteurization is the key process to eliminate pathogenic microorganisms during the production of ready-to-use and shelf-stable LEPs. For the pasteurization of LEPs, temperature-time combinations of $56.6{ }^{\circ} \mathrm{C} / 3.5 \mathrm{~min}$ for albumen, $60{ }^{\circ} \mathrm{C} / 3.5 \mathrm{~min}$ for whole egg and 61.1 ${ }^{\circ} \mathrm{C} / 3.5 \mathrm{~min}$ for egg yolk are required (USDA-ARS 74-48, 1969; Muriana, 1997). Under those conditions, however, heat resistant microorganisms such as Bacillus and Micrococcus spp. might survive and spoil LEPs, even under refrigeration. Thus, disease outbreaks involving Salmonella enterica Ser. Enteritidis in LEPs continue to be a major public health concern (Little et al., 2007). Initial microbial loads of untreated LEW, LWE and LEY are presented in Table 5.5. Legal criteria for whole egg stablish that the microbial load (total aerobic counts) should be below 6 Log to be 
acceptable for human consumption, and this same criteria was used for LEW and LEY.

Table 5.5 - Initial microbial loads of untreated LEPs.

\begin{tabular}{cccc}
\hline Micro- & \multicolumn{3}{c}{ Counts (Log CFU.mL ${ }^{-1}$ )) } \\
organism & Egg white & Whole egg & Egg yolk \\
\hline TAM & $4.77 \pm 0.25$ & $4.87 \pm 0.22$ & $5.02 \pm 0.18$ \\
TAnM & $4.68 \pm 0.19$ & $4.60 \pm 0.18$ & $4.95 \pm 0.22$ \\
TAP & $4.70 \pm 0.14$ & $4.92 \pm 0.20$ & $5.06 \pm 0.24$ \\
TAnP & $4.40 \pm 0.17$ & $4.47 \pm 0.21$ & $4.68 \pm 0.17$ \\
TAS & $<$ D.L. & $<$ D.L. & $<$ D.L. \\
TAnS & $<$ D.L. & $<$ D.L. & $<$ D.L. \\
LAB & $4.45 \pm 0.22$ & $4.67 \pm 0.23$ & $4.72 \pm 0.21$ \\
Yeast & $2.51 \pm 0.26$ & $2.78 \pm 0.25$ & $2.78 \pm 0.24$ \\
Pseud & $3.86 \pm 0.23$ & $4.00 \pm 0.19$ & $4.13 \pm 0.18$ \\
Enter & $4.56 \pm 0.16$ & $4.60 \pm 0.16$ & $4.83 \pm 0.19$ \\
Salm & $1.71 \pm 0.18$ & $2.11 \pm 0.17$ & $1.98 \pm 0.14$ \\
\hline
\end{tabular}

Results are the mean of triplicate \pm standard deviation. D.L.: Detection limit

The albumen used in this work presented average initial counts of approximately $4.71 \mathrm{Log}\left(\mathrm{CFU} \cdot \mathrm{mL}^{-1}\right)$. The counts of lactic acid bacteria (4.45 Log) and yeast and moulds $(2.51 \mathrm{Log})$ were also below the maximum permitted levels. However, counts of $1.71 \mathrm{Log}$ of Salmonella spp. were found, contrary to the desirable absence in $25 \mathrm{~g}$. In egg yolk, average initial counts of total mesophilic (5.07 Log), counts of lactic acid bacteria (4.72 Log) and yeast and moulds $(2.78 \mathrm{Log})$ were also below the maximum regulated levels. But, again, 1.98 Log of Salmonella spp. were found. 
Results and discussion

In egg yolk samples, the presence of Enterobacter spp. could be indicating faecal contamination. Aspergillus niger and Mucor spp. have been noted for their ability to survive in fatty liquids by producing lipases (Adams and Moss, 1999). The ability of fungi to produce spores would help them to survive the anaerobic nature of the yolk. As for the inoculated bacteria, microbial inactivation was also studied using spoilage-related microorganisms as target. The kinetics for total aerobic (TAM) and anaerobic (TanM) mesophilic counts and total aerobic (TAP) and anaerobic (TAnP) psychotrophic counts are shown in Figures 5.5 to 5.7.

Again, it was evidenced that the UV-C treatments under dynamic conditions promoted a higher exposure of the microorganisms to the UV-C light, resulting in considerably higher reductions. The inactivation curves at the investigated doses have a rather linear shape, without shoulders or tailing. The inactivation results for lactic acid bacteria, yeast and moulds, Pseudomonas spp., Enterobacteriacea and Salmonella spp. attained under continuous stirring are represented on Tables 5.6 to 5.8.

In LEW, Salmonella spp. counts, after relatively low UV-C doses (1.392

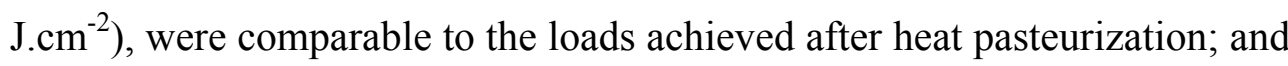
after $3.480 \mathrm{~J} . \mathrm{cm}^{-2}$, the results for all microbial groups were below the detection limit of $1 \log \left(\mathrm{CFU} \cdot \mathrm{mL}^{-1}\right)$, also in the same range than pasteurized samples. In contrast, in LEY, only the highest UV-C doses used in this study $\left(4.176{\left.\mathrm{~J} . \mathrm{cm}^{-2}\right)}^{2}\right.$ allowed to achieve a similar level than in heat pasteurized samples (except for Salmonella spp., which was controlled at

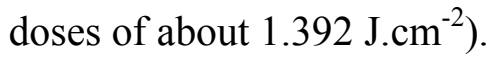




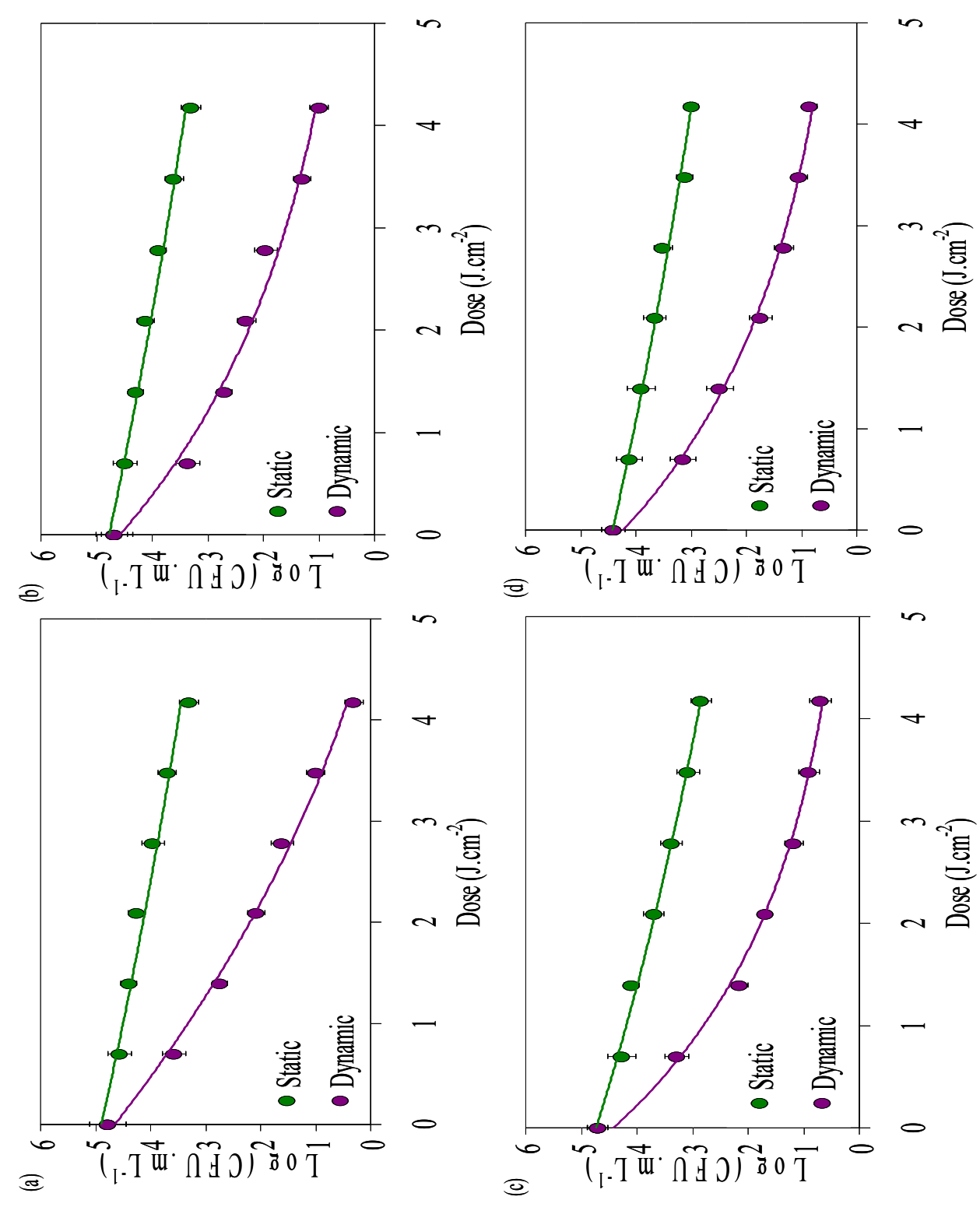

Figure 5.5 - Influence of UV-C on (a) Total Aerobic Mesophilic counts (TAM) (b) Total Anaerobic Mesophilic (TAnM) (c) Total Aerobic Psychrotrophic counts (TAP) and (d) Total Anaerobic Psychrotrophic counts (TAnP) inactivation under static or dynamic conditions on LEW. Results are the mean of triplicate \pm standart deviation. 

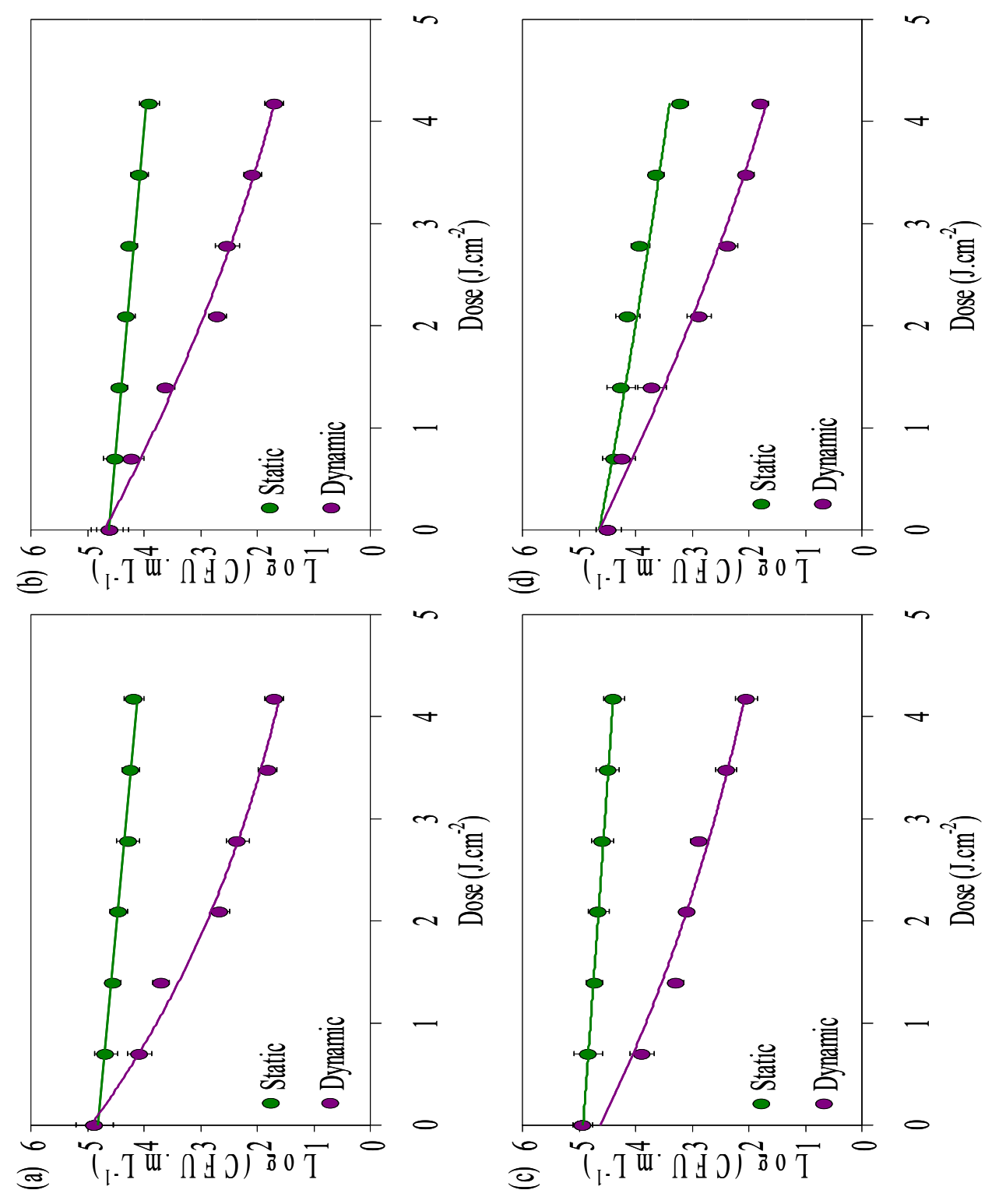

Figure 5.6 - Influence of UV-C on (a) Total Aerobic Mesophilic counts (TAM) (b) Total Anaerobic Mesophilic (TAnM) (c) Total Aerobic Psychrotrophic counts (TAP) and (d) Total Anaerobic Psychrotrophic counts (TAnP) inactivation under static or dynamic conditions on LWE. Results are the mean of triplicate \pm standart deviation. 


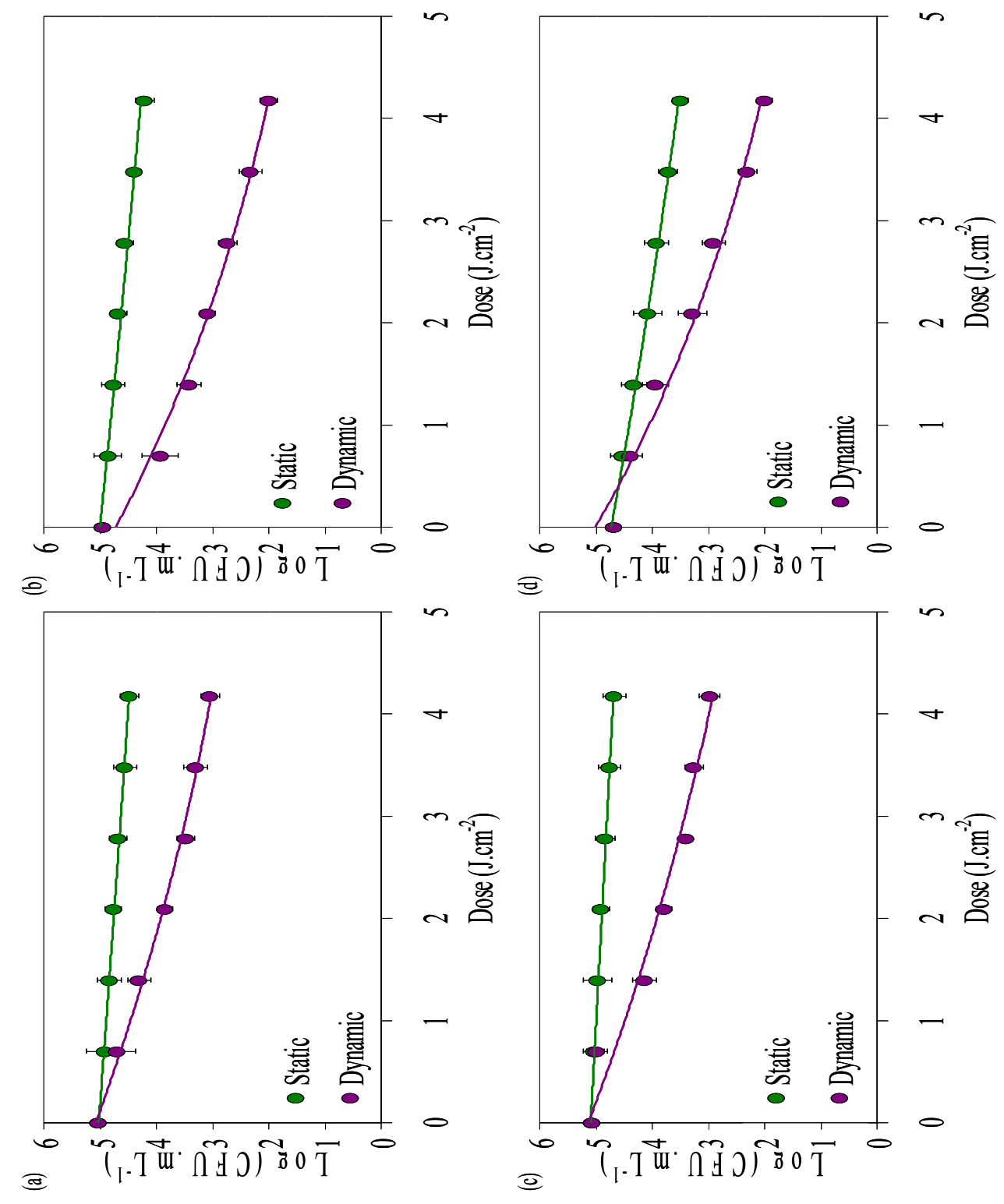

Figure 5.7 - Influence of UV-C on (a) Total Aerobic Mesophilic counts (TAM) (b) Total Anaerobic Mesophilic (TAnM) (c) Total Aerobic Psychrotrophic counts (TAP) and (d) Total Anaerobic Psychrotrophic counts (TAnP) inactivation under static or dynamic conditions on LEY. Results are the mean of triplicate \pm standart deviation. 
Results and discussion

Table 5.6 - Influence of UV-C radiation on Lactic acid bacteria (LAB), Yeast and moulds (Yeast), Pseudomonas spp. (Pseud), Enterobacteriacea (Enter) and Salmonella spp. (Salm) inactivation under dynamic conditions on LEW.

\begin{tabular}{|c|c|c|c|c|c|c|}
\hline \multirow{2}{*}{\multicolumn{2}{|c|}{ Treatment }} & \multicolumn{5}{|c|}{ Counts $\left(\log \left(\right.\right.$ CFU.mL $\left.\left.{ }^{-1}\right)\right)$} \\
\hline & & LAB & Yeast & Pseud & Enter & Salm \\
\hline \multicolumn{2}{|c|}{ Untreated } & $4.45^{\mathrm{a}} \pm 0.21$ & $2.51^{\mathrm{a}} \pm 0.24$ & $3.86^{\mathrm{a}} \pm 0.17$ & $4.56^{\mathrm{a}} \pm 0.19$ & $1.71^{\mathrm{a}} \pm 0.14$ \\
\hline \multirow{6}{*}{ 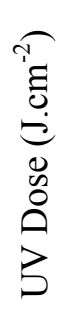 } & 0.696 & $3.04^{\mathrm{b}} \pm 0.16$ & $1.55^{\mathrm{b}} \pm 0.21$ & $2.70^{b} \pm 0.12$ & $3.40^{\mathrm{b}} \pm 0.14$ & $0.60^{\mathrm{b}} \pm 0.12$ \\
\hline & 1.392 & $1.96^{\mathrm{c}} \pm 0.18$ & $1.08^{\mathrm{c}} \pm 0.19$ & $1.48^{\mathrm{c}} \pm 0.11$ & $2.10^{\mathrm{c}} \pm 0.11$ & $<$ D.L. \\
\hline & 2.088 & $1.18^{\mathrm{d}} \pm 0.13$ & $<$ D.L. & $1.04^{\mathrm{d}} \pm 0.24$ & $1.18^{\mathrm{d}} \pm 0.13$ & $<$ D.L. \\
\hline & 2.784 & $<$ D.L. & $<$ D.L. & $<$ D.L. & $1.04^{\mathrm{d}} \pm 0.10$ & $<$ D.L. \\
\hline & 3.480 & $<$ D.L. & $<$ D.L. & $<$ D.L. & $<$ D.L. & $<$ D.L. \\
\hline & 4.176 & $<$ D.L. & $<$ D.L. & $<$ D.L. & $<$ D.L. & $<$ D.L. \\
\hline \multicolumn{2}{|c|}{ Pasteurized } & $<$ D.L. & $<$ D.L. & $<$ D.L. & $<$ D.L. & $<$ D.L. \\
\hline
\end{tabular}

*Different superscripts in each column indicate difference statiscally significant at $95 \%$ confidence level Results are the mean of triplicate \pm standart deviation.

D.L.: Detection limit

Table 5.7 - Influence of UV-C radiation on Lactic acid bacteria (LAB), Yeast and moulds (Yeast), Pseudomonas spp. (Pseud), Enterobacteriacea (Enter) and Salmonella spp. (Salm) inactivation under dynamic conditions on LWE.

\begin{tabular}{|c|c|c|c|c|c|c|}
\hline \multirow{2}{*}{\multicolumn{2}{|c|}{ Treatment }} & \multicolumn{5}{|c|}{ Counts (Log $\left(\right.$ CFU.mL $\left.\left.L^{-1}\right)\right)$} \\
\hline & & LAB & Yeast & Pseud & Enter & Salm \\
\hline \multicolumn{2}{|c|}{ Untreated } & $4.67^{\mathrm{a}} \pm 0.21$ & $2.78^{\mathrm{a}} \pm 0.24$ & $4.00^{\mathrm{a}} \pm 0.17$ & $4.60^{\mathrm{a}} \pm 0.19$ & $2.11^{\mathrm{a}} \pm 0.14$ \\
\hline \multirow{6}{*}{ 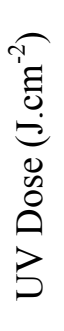 } & 0.696 & $4.08^{b} \pm 0.16$ & $2.48^{\mathrm{a}} \pm 0.21$ & $3.70^{\mathrm{b}} \pm 0.12$ & $3.36^{\mathrm{b}} \pm 0.14$ & $1.90^{\mathrm{a}} \pm 0.12$ \\
\hline & 1.392 & $3.67^{\mathrm{c}} \pm 0.18$ & $2.06^{\mathrm{b}} \pm 0.19$ & $3.08^{\mathrm{c}} \pm 0.11$ & $3.18^{\mathrm{b}} \pm 0.11$ & $<$ D.L. \\
\hline & 2.088 & $2.83^{\mathrm{d}} \pm 0.13$ & $1.85^{\mathrm{bc}} \pm 0.20$ & $2.02^{\mathrm{d}} \pm 0.24$ & $2.57^{\mathrm{c}} \pm 0.13$ & $<$ D.L. \\
\hline & 2.784 & $2.52^{\mathrm{de}} \pm 0.21$ & $1.60^{\mathrm{cd}} \pm 0.21$ & $1.94^{\mathrm{d}} \pm 0.23$ & $2.34^{\mathrm{c}} \pm 0.10$ & $<$ D.L. \\
\hline & 3.480 & $2.19^{\mathrm{e}} \pm 0.16$ & $1.30^{\mathrm{de}} \pm 0.22$ & $1.86^{\mathrm{d}} \pm 0.16$ & $2.06^{\mathrm{d}} \pm 0.08$ & $<$ D.L. \\
\hline & 4.176 & $1.86^{\mathrm{f}} \pm 0.17$ & $1.00^{\mathrm{e}} \pm 0.23$ & $1.85^{\mathrm{d}} \pm 0.10$ & $1.90^{\mathrm{d}} \pm 0.12$ & $<$ D.L. \\
\hline \multicolumn{2}{|c|}{ Pasteurized } & $1.11^{\mathrm{g}} \pm 0.14$ & $1.15^{\mathrm{de}} \pm 0.24$ & $1.04^{\mathrm{e}} \pm 0.09$ & $1.08^{\mathrm{e}} \pm 0.07$ & $<$ D.L. \\
\hline
\end{tabular}

* Different superscripts in each column indicate difference statiscally significant at $95 \%$ confidence level Results are the mean of triplicate \pm standart deviation.

D.L.: Detection limit 
Table 5.8 - Influence of UV-C radiation at on Lactic acid bacteria (LAB), Yeast and moulds (Yeast), Pseudomonas spp. (Pseud), Enterobacteriacea (Enter) and Salmonella spp. (Salm) inactivation under dynamic conditions on LEY.

\begin{tabular}{|c|c|c|c|c|c|c|}
\hline \multirow{2}{*}{\multicolumn{2}{|c|}{ Treatment }} & \multicolumn{5}{|c|}{ Counts (Log $\left(\right.$ CFU.mL $\left.\left.L^{-1}\right)\right)$} \\
\hline & & LAB & Yeast & Pseud & Enter & Salm \\
\hline \multicolumn{2}{|c|}{ Untreated } & $4.72^{\mathrm{a}} \pm 0.21$ & $2.78^{\mathrm{a}} \pm 0.24$ & $4.13^{a} \pm 0.17$ & $4.83^{\mathrm{a}} \pm 0.19$ & $1.98^{\mathrm{a}} \pm 0.14$ \\
\hline \multirow{6}{*}{ 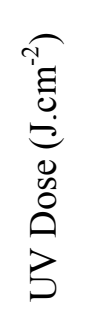 } & 0.696 & $3.43^{b} \pm 0.16$ & $2.41^{\mathrm{ab}} \pm 0.21$ & $3.81^{b} \pm 0.12$ & $3.75^{\mathrm{b}} \pm 0.14$ & $1.30^{\mathrm{b}} \pm 0.12$ \\
\hline & 1.392 & $3.10^{\mathrm{bc}} \pm 0.18$ & $2.15^{\mathrm{bc}} \pm 0.19$ & $2.54^{\mathrm{c}} \pm 0.11$ & $2.95^{\mathrm{c}} \pm 0.11$ & $<$ D.L. \\
\hline & 2.088 & $2.81^{\mathrm{c}} \pm 0.13$ & $2.02^{\mathrm{c}} \pm 0.20$ & $2.06^{\mathrm{d}} \pm 0.24$ & $2.63^{\mathrm{d}} \pm 0.13$ & $<$ D.L. \\
\hline & 2.784 & $2.45^{\mathrm{d}} \pm 0.21$ & $2.01^{\mathrm{c}} \pm 0.21$ & $2.02^{\mathrm{d}} \pm 0.23$ & $2.33^{\mathrm{e}} \pm 0.10$ & $<$ D.L. \\
\hline & 3.480 & $2.10^{\mathrm{e}} \pm 0.16$ & $2.01^{\mathrm{c}} \pm 0.22$ & $2.01^{\mathrm{d}} \pm 0.16$ & $2.23^{\mathrm{ef}} \pm 0.08$ & $<$ D.L. \\
\hline & 4.176 & $2.00^{\mathrm{e}} \pm 0.17$ & $2.00^{\mathrm{c}} \pm 0.23$ & $2.00^{\mathrm{d}} \pm 0.10$ & $2.18^{\mathrm{ef}} \pm 0.12$ & $<$ D.L. \\
\hline \multicolumn{2}{|c|}{ Pasteurized } & $2.10^{\mathrm{e}} \pm 0.14$ & $2.10^{c} \pm 0.24$ & $2.10^{\mathrm{d}} \pm 0.09$ & $2.10^{\mathrm{f}} \pm 0.07$ & $<$ D.L. \\
\hline
\end{tabular}

* Different superscripts in each column indicate difference statiscally significant at $95 \%$ confidence level Results are the mean of triplicate \pm standart deviation.

D.L.: Detection limit

No literature references were found on the effects of UV-C irradiation on egg-spoilage related microorganisms. The available data focus mainly on fruit juices, water, or surface decontamination, especially for meat and frankfurters.

In apple juice, Franz et al. (2009) reported the reduction from $10^{5}$ (CFU.mL ${ }^{-1}$ ) of yeast, $10^{4}\left(\mathrm{CFU} \cdot \mathrm{mL}^{-1}\right)$ of lactic acid bacteria, $10^{4}$ CFU.mL ${ }^{-1}$ ) of total mesophilic aerobic counts, and $10^{3}\left(\mathrm{CFU} \cdot \mathrm{mL}^{-1}\right)$ of Gram (-) bacteria to levels below the detection limit after treatments using a novel lab-scale continuous UV-C device, with an irradiation intensity of $60 \mathrm{~W} \cdot \mathrm{m}^{-2}$. 
Results and discussion

Guevara et al. (2011) treated guava and passion fruit nectars with UV-C up to 24 and $11 \mathrm{~J} . \mathrm{mL}^{-1}$, respectively, in an annular reactor. The effects of this process on microbial inactivation were evaluated by assessing the aerobic mesophilic counts, and yeast and moulds. In that device, microbial inactivation increased with fluence, and was strongly dependent on the optical parameters of the samples. In particular, reductions of 0.51 and 1.36 Log were achieved for aerobic mesophilic counts of guava and passion fruit nectars, respectively, and yeast and mould were reduced by about $0.53 \mathrm{Log}$.

\subsubsection{Physicochemical parameters}

\subsubsection{1 pH}

LEW and LEY are used by the food industry as food ingredients because of their excellent functional properties, such as foaming, emulsifying and gelling. Among others, $\mathrm{pH}$ is an essential attribute to achieve adequate functional properties. Treatments with UV-C of the homogenized samples have not caused an effect on $\mathrm{pH}$ directly after treatment.

UV-C treated LEY $\mathrm{pH}$ was not significantly different $(\mathrm{P}>0.05)$ to the untreated control on the dose range studied, under static or dynamic conditions (Table 5.9). Functional properties of LEY are highly dependent on $\mathrm{pH}$, and around $\mathrm{pH} 6.0$, an acceptable solubility of the yolk proteins can be achieved (Chang and Chen, 2000). 
Table 5.9 - Effects of treatment on $\mathrm{pH}$ values of LEPs.

\begin{tabular}{|c|c|c|c|c|}
\hline \multirow{2}{*}{\multicolumn{2}{|c|}{ Process }} & \multicolumn{3}{|c|}{ Egg fraction } \\
\hline & & LEW & LWE & LEY \\
\hline \multicolumn{2}{|c|}{ Natural } & $7.81^{\mathrm{a}} \pm 0.10$ & $6.22^{\mathrm{a}} \pm 0.09$ & $7.28^{\mathrm{a}} \pm 0.04$ \\
\hline \multicolumn{2}{|c|}{ NaturaL.homogenized } & $9.22^{b} \pm 0.09$ & $6.22^{\mathrm{a}} \pm 0.17$ & $7.85^{b} \pm 0.10$ \\
\hline \multicolumn{2}{|c|}{ Pasteurized } & $9.90^{c} \pm 0.09$ & $6.58^{\mathrm{b}} \pm 0.16$ & $8.56^{\mathrm{c}} \pm 0.10$ \\
\hline \multirow{8}{*}{ 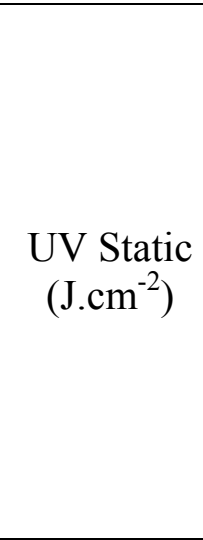 } & 0.304 & $9.14^{\mathrm{b}} \pm 0.10$ & $6.22^{\mathrm{a}} \pm 0.07$ & $7.77^{b} \pm 0.13$ \\
\hline & 0.591 & $9.09^{b} \pm 0.23$ & $6.21^{\mathrm{a}} \pm 0.20$ & $7.73^{b} \pm 0.12$ \\
\hline & 1.224 & $9.04^{\mathrm{b}} \pm 0.19$ & $6.12^{\mathrm{a}} \pm 0.11$ & $7.66^{b} \pm 0.14$ \\
\hline & 3.645 & $9.12^{b} \pm 0.26$ & $6.19^{\mathrm{a}} \pm 0.15$ & $7.75^{\mathrm{b}} \pm 0.17$ \\
\hline & 4.728 & $9.13^{\mathrm{b}} \pm 0.22$ & $6.21^{\mathrm{a}} \pm 0.20$ & $7.67^{b} \pm 0.15$ \\
\hline & 5.910 & $9.18^{\mathrm{b}} \pm 0.16$ & $6.09^{\mathrm{a}} \pm 0.19$ & $7.75^{\mathrm{b}} \pm 0.18$ \\
\hline & 7.090 & $9.20^{\mathrm{b}} \pm 0.19$ & $6.25^{\mathrm{a}} \pm 0.29$ & $7.81^{b} \pm 0.14$ \\
\hline & 9.219 & $9.14^{\mathrm{b}} \pm 0.23$ & $6.28^{\mathrm{a}} \pm 0.15$ & $7.84^{b} \pm 0.21$ \\
\hline \multirow{8}{*}{$\begin{array}{c}\text { UV } \\
\text { Dynamic } \\
\left({\left.\mathrm{J} . \mathrm{cm}^{-2}\right)}^{-2}\right.\end{array}$} & 0.304 & $9.16^{\mathrm{b}} \pm 0.18$ & $6.17^{\mathrm{a}} \pm 0.15$ & $7.79^{b} \pm 0.17$ \\
\hline & 0.591 & $9.20^{\mathrm{b}} \pm 0.21$ & $6.11^{\mathrm{a}} \pm 0.12$ & $7.77^{b} \pm 0.12$ \\
\hline & 1.224 & $9.18^{b} \pm 0.13$ & $6.33^{\mathrm{a}} \pm 0.21$ & $7.88^{b} \pm 0.22$ \\
\hline & 3.645 & $9.00^{\mathrm{b}} \pm 0.14$ & $6.14^{\mathrm{a}} \pm 0.11$ & $7.65^{b} \pm 0.08$ \\
\hline & 4.728 & $9.12^{b} \pm 0.21$ & $6.25^{\mathrm{a}} \pm 0.15$ & $7.79^{b} \pm 0.14$ \\
\hline & 5.910 & $9.16^{\mathrm{b}} \pm 0.14$ & $6.23^{\mathrm{a}} \pm 0.18$ & $7.78^{b} \pm 0.12$ \\
\hline & 7.090 & $9.18^{\mathrm{b}} \pm 0.25$ & $6.24^{\mathrm{a}} \pm 0.16$ & $7.74^{b} \pm 0.13$ \\
\hline & 9.219 & $9.24^{\mathrm{b}} \pm 0.17$ & $6.21^{\mathrm{a}} \pm 0.13$ & $7.81^{b} \pm 0.16$ \\
\hline
\end{tabular}

*Results are the mean of five repetitions \pm standart deviation.

Different superscripts in each column indicate difference statiscally significant at $95 \%$ confidence level

The effects of homogenization were evident only in the $\mathrm{pH}$ of LEW and LWE. The $\mathrm{pH}$ of the UV-C treated samples was not significantly different $(\mathrm{P}>0.05)$ to the homogenized products (Table 5.9). But contrary to the 
Results and discussion

negligible effects of UV-C radiation on the $\mathrm{pH}$, the $\mathrm{pH}$ of the LEPs was significantly $(\mathrm{P}<0.05)$ impacted by the thermal pasteurization for all fractions.

\subsubsection{Color}

Customers may not accept discoloration and the change in the shade caused by UV radiation or thermal treatments, considering the eggs as being of low-quality. Color perception highly depends on the chemical and physical properties of the egg components (Min et al., 2005). The raw CIELAB L*, $a^{*}$ and $b^{*}$ coordinates are represented in Tables 5.10 to 5.12 , the calculated $\mathrm{BI}$ and the $\Delta \mathrm{E}^{*}$ are recorded in Table 5.13. Figures 5.8 to 5.10 show the sample appearance. In general, the browning index increased as a function of the UV-C dose in all the studied fractions, and $\Delta \mathrm{E}^{*}$ values also increased as a consequence of the UV treatment. Remarkably, differences from the untreated controls were more evident when the samples were submitted to static UV-C treatments, suggesting a certain dissipation of the oxidative effects during mixing, probably due to the radical scavenging capacity of the available antioxidants.

In UV treated LEW, there was a slight but not statistically significant tendency of the coordinate $b^{*}$ to increase, and a significant decrease in $L^{*}$ at the higher doses $(p<0.05)$. Regarding the parameter $a^{*}$, which reflects the changes in the red region of the spectrum (i.e. +120 , red color), UV treated egg whites showed a small tendency to increase, if compared with untreated 
controls. The slight increase in the browning index led to perceptible changes in samples treated under static conditions. But dynamic treatments up to $3.645 \mathrm{~J} . \mathrm{cm}^{-2}$ in LEW caused $\Delta \mathrm{E}^{*}$ values, which were not expected to be detectable by the naked eye $\left(\Delta \mathrm{E}^{*}<3\right)$ (Torrico et al., 2011).

Table 5.10 - CIELAB L*(Brightness), a*(redness-greenness) and $b^{*}$ (yellowness-blueness) color coordinates in LEW submitted to pasteurization or UV-C.

\begin{tabular}{|c|c|c|c|c|}
\hline \multirow{2}{*}{\multicolumn{2}{|c|}{ Process }} & \multicolumn{3}{|c|}{ CIELAB coordinates } \\
\hline & & $\mathbf{L}^{*}$ & $a^{*}$ & $\mathbf{b}^{*}$ \\
\hline \multicolumn{2}{|c|}{ Natural } & $42.33^{\mathrm{a}} \pm 1.66$ & $0.77^{\mathrm{a}} \pm 0.18$ & $32.45^{\mathrm{a}} \pm 1.45$ \\
\hline \multicolumn{2}{|c|}{ Pasteurized } & $30.16^{\mathrm{b}} \pm 1.37$ & $1.22^{b} \pm 0.14$ & $33.95^{\mathrm{a}} \pm 0.52$ \\
\hline \multirow{5}{*}{$\begin{array}{l}\text { UV Static } \\
\left(\mathrm{J} \cdot \mathrm{cm}^{-2}\right)\end{array}$} & 0.591 & $39.90^{\mathrm{ab}} \pm 1.49$ & $0.84^{\mathrm{a}} \pm 0.15$ & $32.96^{\mathrm{a}} \pm 1.39$ \\
\hline & 1.224 & $39.25^{\mathrm{ab}} \pm 2.16$ & $0.85^{\mathrm{a}} \pm 0.13$ & $33.04^{\mathrm{a}} \pm 1.40$ \\
\hline & $\begin{array}{l}3.645 \\
5.910\end{array}$ & $\begin{array}{c}38.32^{\mathrm{abc}} \pm 2.90 \\
37.19^{\mathrm{bc}} \pm 2.91\end{array}$ & $\begin{array}{c}0.88^{\mathrm{a}} \pm 0.19 \\
0.91^{\mathrm{ab}} \pm 0.20\end{array}$ & $\begin{array}{l}33.23^{\mathrm{a}} \pm 2.73 \\
33.34^{\mathrm{a}} \pm 1.55\end{array}$ \\
\hline & 7.090 & $36.77^{b c} \pm 2.92$ & $0.93^{\mathrm{ab}} \pm 0.17$ & $33.46^{\mathrm{a}} \pm 2.16$ \\
\hline & 9.219 & $35.92^{c} \pm 2.93$ & $0.97^{\mathrm{ab}} \pm 0.14$ & $33.59^{\mathrm{a}} \pm 1.81$ \\
\hline \multirow{6}{*}{ 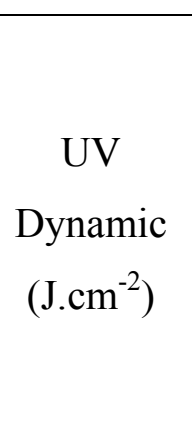 } & 0.591 & $41.07^{\mathrm{a}} \pm 0.68$ & $0.83^{\mathrm{a}} \pm 0.13$ & $32.93^{\mathrm{a}} \pm 0.41$ \\
\hline & 1.224 & $38.05^{\mathrm{ac}} \pm 0.72$ & $0.85^{\mathrm{a}} \pm 0.19$ & $33.04^{\mathrm{a}} \pm 0.97$ \\
\hline & 3.645 & $35.90^{\mathrm{c}} \pm 1.19$ & $0.87^{\mathrm{a}} \pm 0.18$ & $33.18^{\mathrm{a}} \pm 2.31$ \\
\hline & 5.910 & $32.13^{b c} \pm 0.79$ & $0.88^{\mathrm{a}} \pm 0.22$ & $33.31^{\mathrm{a}} \pm 1.15$ \\
\hline & 7.090 & $30.22^{\mathrm{b}} \pm 0.88$ & $0.90^{\mathrm{a}} \pm 0.16$ & $33.74^{\mathrm{a}} \pm 1.25$ \\
\hline & 9.219 & $29.53^{\mathrm{b}} \pm 0.92$ & $0.91^{\mathrm{a}} \pm 0.18$ & $33.92^{\mathrm{a}} \pm 2.28$ \\
\hline
\end{tabular}

*Results are the mean of triplicate, and each sample was measured in five different positions \pm standart deviation. Different superscripts in each column indicate difference statiscally significant at $95 \%$ confidence level 
Results and discussion

Table 5.11 - CIELAB L*(Brightness), $a^{*}\left(\right.$ redness-greenness) and $b^{*}$ (yellowness-blueness) color coordinates in in LWE submitted to pasteurization or UV-C.

\begin{tabular}{|c|c|c|c|c|}
\hline \multirow{2}{*}{\multicolumn{2}{|c|}{ Process }} & \multicolumn{3}{|c|}{ CIELAB coordinates } \\
\hline & & $\mathbf{L}^{*}$ & $a^{*}$ & $\mathbf{b}^{*}$ \\
\hline \multirow{2}{*}{\multicolumn{2}{|c|}{$\begin{array}{c}\text { Natural } \\
\text { Pasteurized }\end{array}$}} & $59.28^{\mathrm{a}} \pm 1.27$ & $27.40^{\mathrm{a}} \pm 0.57$ & $69.87^{\mathrm{a}} \pm 5.90$ \\
\hline & & $50.76^{\mathrm{b}} \pm 0.78$ & $30.65^{b} \pm 1.86$ & $81.60^{\mathrm{ab}} \pm 5.98$ \\
\hline \multirow{6}{*}{$\begin{array}{l}\text { UV Static } \\
\left(\mathrm{J} \mathrm{cm}^{-2}\right)\end{array}$} & 0.591 & $57.14^{\mathrm{c}} \pm 0.46$ & $28.32^{\mathrm{ab}} \pm 1.33$ & $78.96^{b} \pm 2.41$ \\
\hline & 1.224 & $54.22^{\mathrm{cd}} \pm 2.18$ & $29.45^{\mathrm{ab}} \pm 1.09$ & $79.53^{b} \pm 1.55$ \\
\hline & 3.645 & $53.55^{\mathrm{abd}} \pm 4.53$ & $30.15^{\mathrm{b}} \pm 1.84$ & $80.13^{b} \pm 3.82$ \\
\hline & 5.910 & $51.19^{\mathrm{bd}} \pm 3.15$ & $31.18^{\mathrm{b}} \pm 2.23$ & $80.66^{\mathrm{b}} \pm 4.77$ \\
\hline & 7.090 & $50.92^{\mathrm{bd}} \pm 2.57$ & $32.02^{\mathrm{b}} \pm 1.77$ & $81.12^{b} \pm 2.33$ \\
\hline & 9.219 & $50.01^{\text {bd }} \pm 2.88$ & $32.88^{\mathrm{b}} \pm 1.94$ & $81.92^{b} \pm 3.39$ \\
\hline \multirow{6}{*}{ 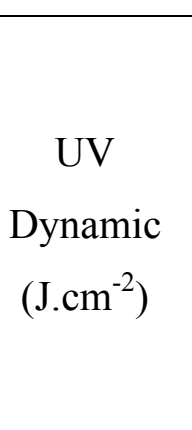 } & 0.591 & $57.62^{\mathrm{ab}} \pm 2.75$ & $28.11^{\mathrm{ab}} \pm 0.77$ & $78.79^{\mathrm{ab}} \pm 4.41$ \\
\hline & 1.224 & $56.33^{\mathrm{ab}} \pm 4.16$ & $28.86^{\mathrm{ab}} \pm 2.14$ & $79.27^{\mathrm{ab}} \pm 4.14$ \\
\hline & 3.645 & $55.16^{\mathrm{ab}} \pm 5.89$ & $29.52^{\mathrm{ab}} \pm 1.47$ & $79.83^{\mathrm{ab}} \pm 7.56$ \\
\hline & 5.910 & $54.19^{\mathrm{ab}} \pm 3.14$ & $30.15^{b} \pm 2.03$ & $80.15^{\mathrm{ab}} \pm 5.16$ \\
\hline & 7.090 & $53.67^{\mathrm{ab}} \pm 4.15$ & $30.94^{\mathrm{b}} \pm 2.14$ & $80.71^{b} \pm 4.32$ \\
\hline & 9.219 & $52.92^{\mathrm{ab}} \pm 2.19$ & $31.62^{\mathrm{b}} \pm 1.66$ & $81.55^{\mathrm{b}} \pm 4.60$ \\
\hline
\end{tabular}

*Results are the mean of triplicate, and each sample was measured in five different positions \pm standart deviation. Different superscripts in each column indicate difference statiscally significant at $95 \%$ confidence level

In accordance to the results obtained for LEW, also the parameter $\mathrm{a}^{*}$ of LWE and LEY increased slightly after treatment with UV-C lamps, showing a tendency upon more reddish tones. But in LEY and LWE, the parameter $\mathrm{b}^{*}$ (yellow color, +120 ; blue-violet color, -80 ) is predominant due to the 
presence of carotenoids. In those samples, the parameter $b^{*}$ increased some what after treatments with UV-C, although differences were not significant.

Table 5.12 - CIELAB L*(Brightness), a*(redness-greenness) and $b^{*}$ (yellowness-blueness) color coordinates in LEY submitted to pasteurization or UV-C.

\begin{tabular}{ccccc}
\hline \multirow{2}{*}{ Process } & \multicolumn{3}{c}{ CIELAB coordinates } \\
\cline { 2 - 5 } Natural & $63.32^{\mathrm{a}} \pm 0.56$ & $19.72^{\mathrm{a}} \pm 1.23$ & $47.13^{\mathrm{a}} \pm 1.01$ \\
Pasteurized & $53.11^{\mathrm{b}} \pm 2.11$ & $23.29^{\mathrm{b}} \pm 2.06$ & $52.24^{\mathrm{b}} \pm 2.80$ \\
\hline & 0.591 & $60.89^{\mathrm{ac}} \pm 2.81$ & $20.21^{\mathrm{a}} \pm 0.73$ & $47.86^{\mathrm{a}} \pm 1.03$ \\
& 1.224 & $59.15^{\mathrm{c}} \pm 2.14$ & $20.74^{\mathrm{ab}} \pm 1.52$ & $48.52^{\mathrm{a}} \pm 1.15$ \\
UV Static & 3.645 & $57.71^{\mathrm{c}} \pm 1.30$ & $21.25^{\mathrm{ab}} \pm 1.73$ & $49.05^{\mathrm{ab}} \pm 1.88$ \\
$\left({\left.\mathrm{~J} . c m^{-2}\right)}^{2}\right)$ & 5.910 & $56.93^{\mathrm{bc}} \pm 2.76$ & $22.06^{\mathrm{ab}} \pm 1.14$ & $49.62^{\mathrm{ab}} \pm 2.10$ \\
& 7.090 & $55.14^{\mathrm{bc}} \pm 2.99$ & $22.51^{\mathrm{ab}} \pm 1.88$ & $50.15^{\mathrm{ab}} \pm 1.55$ \\
& 9.219 & $54.88^{\mathrm{bc}} \pm 3.14$ & $22.97^{\mathrm{ab}} \pm 2.05$ & $50.98^{\mathrm{ab}} \pm 2.52$ \\
\hline & 0.591 & $61.45^{\mathrm{ac}} \pm 1.30$ & $20.18^{\mathrm{ab}} \pm 1.48$ & $47.71^{\mathrm{a}} \pm 1.05$ \\
UV & 1.224 & $60.55^{\mathrm{ac}} \pm 1.66$ & $20.52^{\mathrm{ab}} \pm 2.06$ & $48.12^{\mathrm{ab}} \pm 2.02$ \\
Dynamic & 3.645 & $59.34^{\mathrm{c}} \pm 1.30$ & $20.74^{\mathrm{a}} \pm 0.34$ & $48.64^{\mathrm{ab}} \pm 2.17$ \\
$\left(\mathrm{~J} . c m^{-2}\right)$ & 5.910 & $58.71^{\mathrm{c}} \pm 1.14$ & $21.17^{\mathrm{ab}} \pm 0.96$ & $49.15^{\mathrm{ab}} \pm 2.63$ \\
& 7.090 & $57.60^{\mathrm{c}} \pm 1.22$ & $21.66^{\mathrm{ab}} \pm 2.19$ & $49.74^{\mathrm{b}} \pm 1.55$ \\
& 9.219 & $56.14^{\mathrm{bc}} \pm 2.01$ & $22.14^{\mathrm{ab}} \pm 2.14$ & $50.16^{\mathrm{b}} \pm 1.60$
\end{tabular}

*Results are the mean of triplicate, and each sample was measured in five different positions \pm standart deviation. Different superscripts in each column indicate difference statiscally significant at $95 \%$ confidence level 
Results and discussion

Table 5.13 - Total color difference $\left(\Delta \mathrm{E}^{*}\right)$ and browning index $(\mathrm{BI})$ in LEPs submitted to pasteurization or UV-C.

\begin{tabular}{|c|c|c|c|c|c|c|c|}
\hline \multirow{2}{*}{\multicolumn{2}{|c|}{ Process }} & \multicolumn{2}{|c|}{ LEW } & \multicolumn{2}{|c|}{ LWE } & \multicolumn{2}{|c|}{ LEY } \\
\hline & & $\Delta \mathbf{E}^{*}$ & BI & $\Delta \mathbf{E}^{*}$ & BI & $\Delta \mathbf{E}^{*}$ & BI \\
\hline \multicolumn{2}{|c|}{ Natural } & 0 & 126.25 & 0 & 322.74 & 0 & 142.42 \\
\hline \multicolumn{2}{|c|}{ Pasteurized } & 12.27 & 273.35 & 14.86 & 792.52 & 11.97 & 227.55 \\
\hline \multirow{6}{*}{ 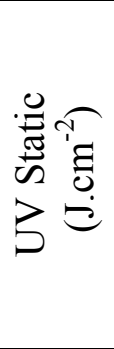 } & 0.591 & 2.48 & 143.78 & 9.38 & 479.68 & 2.58 & 155.11 \\
\hline & 1.224 & 3.14 & 148.72 & 11.1 & 572.94 & 4.51 & 166.24 \\
\hline & 3.645 & 4.09 & 157.06 & 12.07 & 610.35 & 6.12 & 176.4 \\
\hline & 5.91 & 5.22 & 167.21 & 14.01 & 729.24 & 7.25 & 184.5 \\
\hline & 7.09 & 5.65 & 172.1 & 14.76 & 759.14 & 9.16 & 198.42 \\
\hline & 9.219 & 6.51 & 181.59 & 16.16 & 842.49 & 9.83 & 205.85 \\
\hline \multirow{6}{*}{ 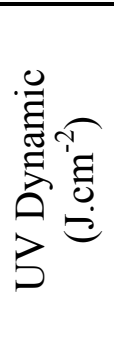 } & 0.591 & 1.36 & 136.64 & 9.1 & 465.71 & 2.01 & 152.21 \\
\hline & 1.224 & 4.32 & 157.4 & 9.96 & 505.28 & 3.05 & 158.04 \\
\hline & 3.645 & 6.47 & 177.26 & 10.99 & 549.33 & 4.38 & 165.99 \\
\hline & 5.91 & 10.24 & 225.05 & 11.8 & 587.56 & 5.24 & 171.97 \\
\hline & 7.09 & 12.18 & 267.34 & 12.71 & 619.18 & 6.58 & 181.19 \\
\hline & 9.219 & 12.88 & 286.98 & 13.95 & 672.25 & 8.16 & 192.12 \\
\hline
\end{tabular}

$\Delta \mathrm{E}^{*}<2$, minimum differences; $\Delta \mathrm{E}^{*}$ between 2 and 3, acceptable differences; $\Delta \mathrm{E}^{*}$ between 3 and 5 , almost unacceptable; $\Delta \mathrm{E}^{*}>5$, unacceptable differences.

That increase is generally associated to the formation of Maillard products, which are evident during egg processing or storage (Caboni et al., 2005; Badr, 2006). As in LEW, the effects of the treatment were more evident under static conditions, indicating a buffering effect of the available antioxidants during mixing. 


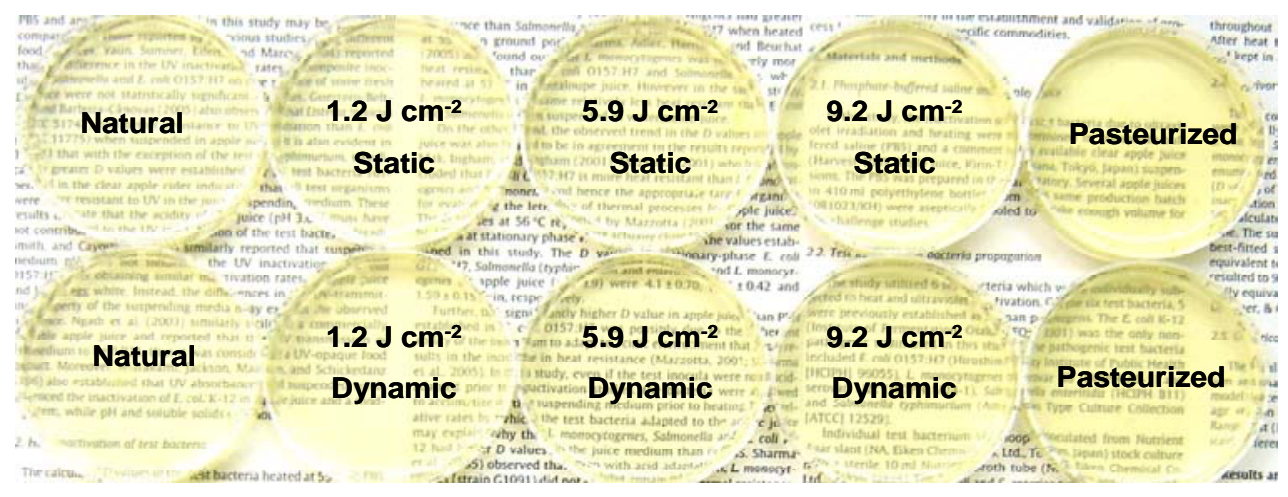

Figure 5.8 - Natural, UV-treated and pasteurized LEW.

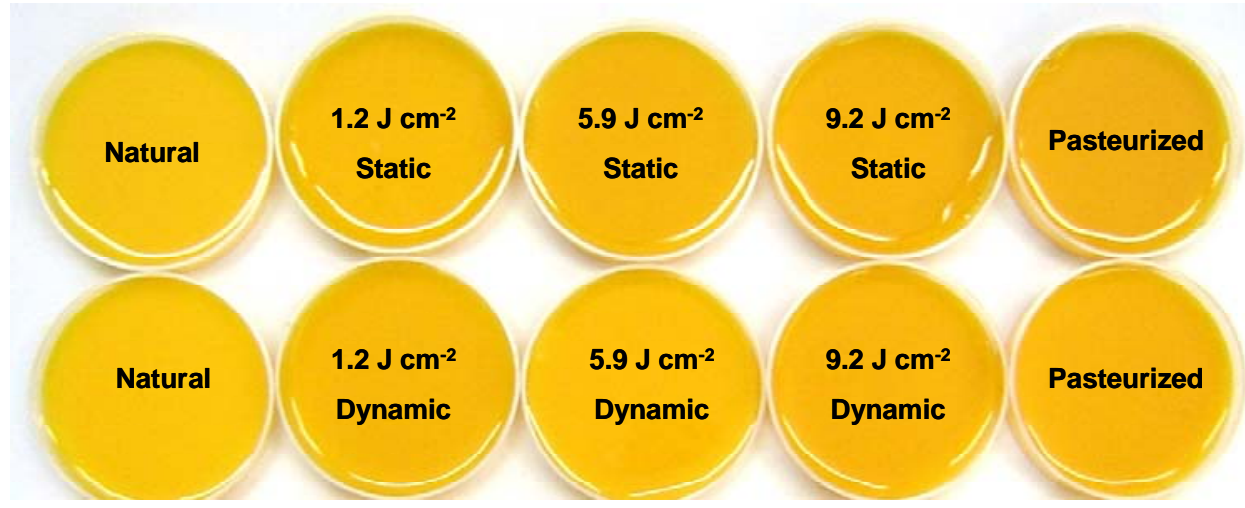

Figure 5.9 - Natural, UV-treated and pasteurized LWE.

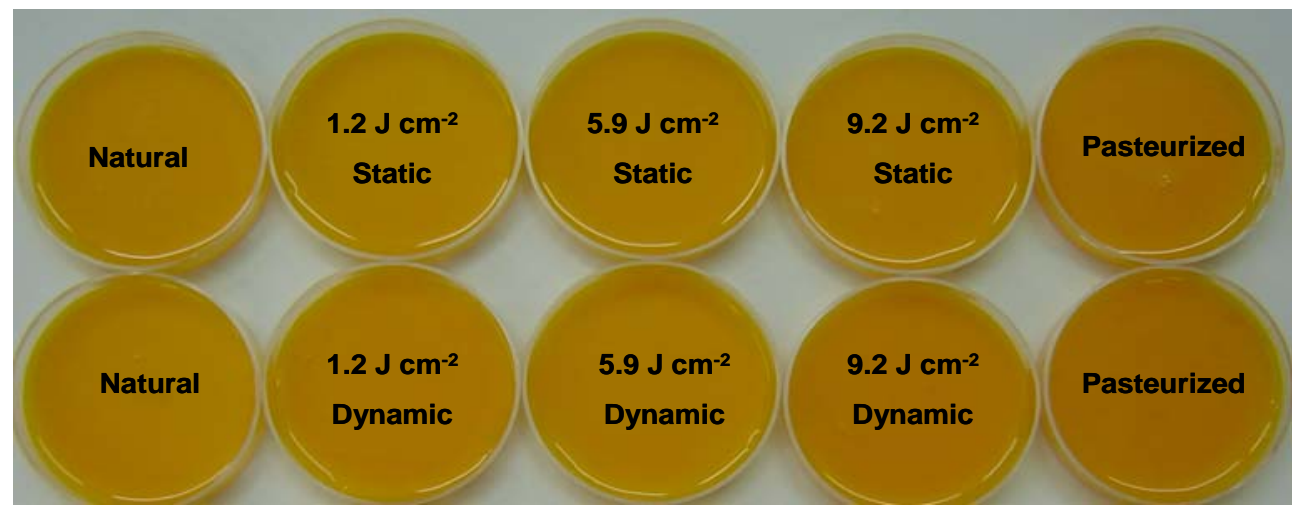

Figure 5.10 - Natural, UV-treated and pasteurized LEY. 
Results and discussion

The increase in the browning index of the egg yolk was perceptible at the lowest doses applied, since $\Delta \mathrm{E}^{*}$ values were above 3 . But in LWE, the presence of the egg white minimized the changes in color, and $3.645 \mathrm{~J}_{\mathrm{cm}} \mathrm{cm}^{-2}$ were not enough to cause a detectable value change with naked eyes $\left(\Delta \mathrm{E}^{*}<\right.$ 3) under dynamic conditions. The changes observed in UV irradiated samples are opposite to the generally reported for ionizing radiation, where a discoloration (regarding a significant decrease in $\mathrm{L}^{*}, \mathrm{a}^{*}$ and $\mathrm{b}^{*}$ ) of the yolk towards a more pale tone has been reported at doses above $2.5 \mathrm{kGy}$ (Dvorak et al., 2005).

Heat treatments accelerated the production of brown Maillard products. All UV-C LEPs had lower $\Delta \mathrm{E}^{*}$ than heat pasteurized. Compared to UV-C, the loss in lightness, and the increment in the parameters $\mathrm{a}^{*}$ and $\mathrm{b}^{*}$ were more evident in heat pasteurized samples, pointing out for a more extensive effect of heat on the color of the LEPs. Those results confirmed a tendency towards more reddish/brownish tones of the heat pasteurized LEP.

\subsubsection{Effects on fat}

\subsubsection{Lipid oxidation (TBARS)}

In eggs, quality deterioration due to oxidative processes in cholesterol and unsaturated fatty acids might be originated by $\mathrm{UV}$, since radiation at short wavelengths is an effective promoter of the lipid peroxidation (Spikes, 1981). But natural antioxidants, such as tocopherols, carotenoids and 
phosvitin, and the structure of the yolk low density lipoproteins (LDLs) might contribute to decelerate the oxidative processes. The evaluation of the presence of the thiobarbituric acid-reactive substances provides a first estimation of the lipid oxidation extention originated by UV-C wavelengths decontamination. The TBARS values of fresh eggs after homogenization ranged were 0.594 and $0.791 \mathrm{mgMDA} . \mathrm{kg}^{-1}$, respectively for LWE and LEY. The TBARS values obtained in this study are comparable to those obtained by other authors for whole egg (Ren, 2009), showing that the undertaken agitation step has not caused a considerable increase in the concentration of secondary products of the lipid oxidation.

The TBARS values for UV-C treated LEPs are reported in Figures 5.11, as well as the values obtained for thermally treated egg samples and for the untreated homogenized samples. Contrary to the fair stability of TBARS in chicken breasts shown by Chun et al. (2010) submitted to UV-C radiation, the TBARS values of LEP increased as a function of the UV dose, with

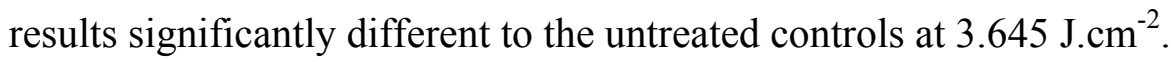

Pasteurized LEY also showed a significant increment, and was more similar to UV-C samples than to the untreated controls. Few studies deal with the effects of egg processing on TBARS values. Thermal processing of eggs originated a remarkable increase in the TBARS (Liu et al., 2005; Ren, 2009). Formation of hydroperoxides was also accelerated in egg yolk powder submitted to ionizing radiation, with the subsequent degradation of carotenoids (Katusin-Razem, Mihaljevic and Razem, 1992). And spraydrying of LWE originated the formation of furosine through Maillard, and 
Results and discussion

the oxidation of cholesterol (Caboni et al., 2005). In this study, both processes (UV and thermal) significantly increased the TBARS values in all egg fractions, which could have consequences in the organoleptic characteristics. After the short heat treatments, thermally treated LEPs presented TBARS values 2-3 fold higher than the untreated controls, but the treatment with UV-C at the highest doses tested seems to be more oxidizing than heat.
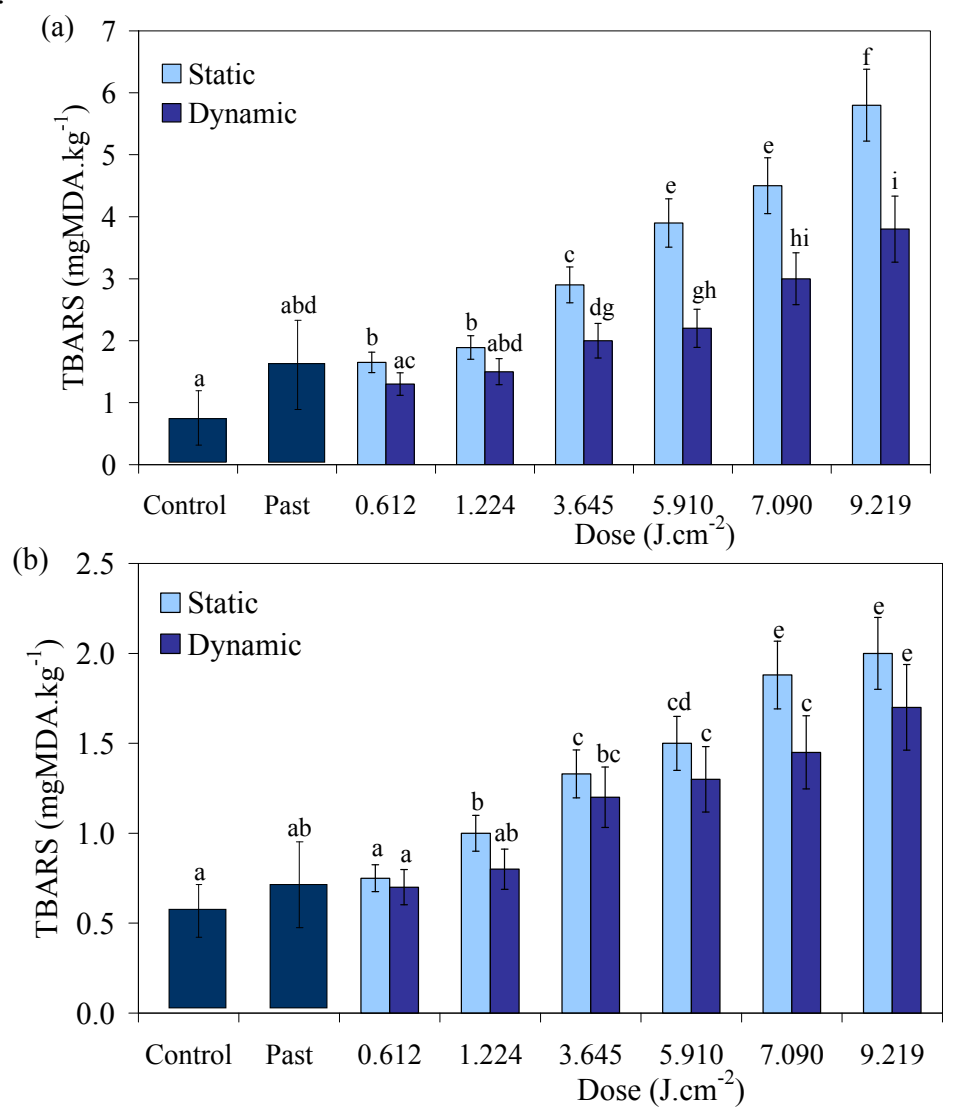

Figure 5.11 - Influence of UV-C radiation on lipid oxidation of (a) LEY and (b) LWE. Results are the mean of triplicate \pm standart deviation. Different superscripts in each bar indicate difference statiscally significant at $95 \%$ confidence level. 


\subsubsection{Cholesterol}

Eggs are an important single food, and an important raw material for the food industry, however they show high levels of cholesterol. Cholesterol may be oxidized during processing and/or storage to cholesterol oxides which are toxic; but UV radiation is able to generate the vitamin $\mathrm{D}_{3}$ from its precursor 7-dehydrocholesterol. The stability of cholesterol from LEPs to UV-C processing is show on Table 5.14.

The presence of cholesterol was significantly lower in samples treated with doses higher than $5.910 \mathrm{~J} . \mathrm{cm}^{-2}$. The most noticeable variation was that

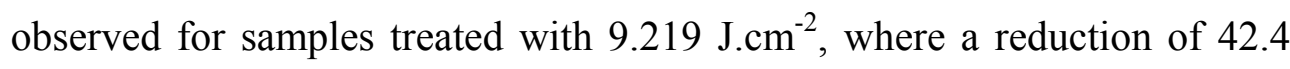
for LWE and $31.9 \%$ for LEY were obtained. The cholesterol seems to be oxidised by the UV-light. Further assays are necessary to identify the oxidation products, but a production of vitamin $\mathrm{D}_{3}$ cannot be discarded. Verardo et al. (2010) showed that egg coproducts (pasteurized eggs obtained from hens bred with organic methods, conventional breeding and spraydried eggs obtained from conventional breeding) exposed to light had a significantly higher oxidation than samples stored in the dark.

Contrarily to the phenomena observed in UV-C LEPs, the concentration of cholesterol in the pasteurized samples remained at the same level of the untreated control. Vicenti, Sampaio and Ferrari (2012) explained that pure cholesterol is rather resistant to oxidation during heating. Kim and Nawar (1993) showed that in the range $110-120^{\circ} \mathrm{C}$, less than $10 \%$ of cholesterol was oxidized after $80 \mathrm{~h}$ of heating. At $125^{\circ} \mathrm{C}$, less than $10 \%$ was already 
Results and discussion

oxidized after $20 \mathrm{~h}$ of heating, whereas in the range $135-180^{\circ} \mathrm{C}$, oxidation was very severe and more than $80 \%$ was already oxidized after 1 hour of heating. At normal cooking temperature $\left(90-100{ }^{\circ} \mathrm{C}\right)$, none or very low amounts of cholesterol is oxidized, whereas frying or roasting temperatures $\left(120-180{ }^{\circ} \mathrm{C}\right)$ are sufficient to extensively oxidize cholesterol (Vicenti, Sampaio and Ferrari, 2012).

Table 5.14 - Influence of UV-C on cholesterol contend of LWE and LEY.

\begin{tabular}{|c|c|c|c|}
\hline \multirow{2}{*}{\multicolumn{2}{|c|}{ Process }} & \multicolumn{2}{|c|}{$\begin{array}{c}\text { Cholesterol concentration } \\
\text { (mg per } 100 \mathrm{~g} \text { of edible portion) }\end{array}$} \\
\hline & & LWE & LEY \\
\hline \multicolumn{2}{|c|}{ Natural } & $396.5^{\mathrm{a}} \pm 34.8$ & $1260.3^{\mathrm{a}} \pm 124.8$ \\
\hline \multicolumn{2}{|c|}{ Pasteurized } & $371.2^{\mathrm{a}} \pm 43.2$ & $1198.3^{\mathrm{a}} \pm 139.6$ \\
\hline \multirow{6}{*}{ 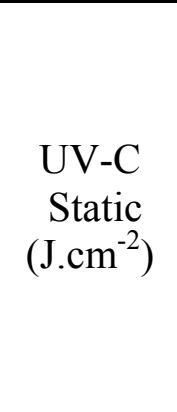 } & 0.591 & $385.1^{\mathrm{a}} \pm 15.3$ & $1207.6^{\mathrm{a}} \pm 112.5$ \\
\hline & 1.224 & $379.8^{\mathrm{a}} \pm 12.9$ & $1175.8^{\mathrm{a}} \pm 99.3$ \\
\hline & 3.645 & $348.2^{\mathrm{a}} \pm 17.6$ & $1048.7^{\mathrm{a}} \pm 88.5$ \\
\hline & 5.910 & $311.0^{b} \pm 16.3$ & $889.8^{b} \pm 81.3$ \\
\hline & 7.090 & $295.3^{b} \pm 22.1$ & $826.2^{\mathrm{b}} \pm 79.5$ \\
\hline & 9.219 & $269.8^{\mathrm{b}} \pm 21.4$ & $725.4^{\mathrm{b}} \pm 63.4$ \\
\hline \multirow{6}{*}{$\begin{array}{c}\text { UV-C } \\
\text { Dynamic } \\
\left({\left.\mathrm{J} . \mathrm{cm}^{-2}\right)}^{2}\right.\end{array}$} & 0.591 & $381.4^{\mathrm{a}} \pm 26.3$ & $1223.4^{\mathrm{a}} \pm 104.3$ \\
\hline & 1.224 & $369.1^{\mathrm{a}} \pm 19.5$ & $1207.5^{\mathrm{a}} \pm 81.2$ \\
\hline & 3.645 & $332.8^{\mathrm{a}} \pm 22.5$ & $1105.8^{\mathrm{a}} \pm 77.4$ \\
\hline & 5.910 & $284.6^{\mathrm{b}} \pm 20.6$ & $985.1^{b} \pm 66.7$ \\
\hline & 7.090 & $254.3^{b c} \pm 17.1$ & $937.4^{\mathrm{bc}} \pm 55.1$ \\
\hline & 9.219 & $228.3^{\mathrm{c}} \pm 15.6$ & $858.0^{c} \pm 60.5$ \\
\hline
\end{tabular}

*Results are the mean of triplicate \pm standart deviation.

Different superscripts in each column indicate difference statiscally significant at $95 \%$ confidence level 


\subsubsection{UV-effects on proteins}

\subsubsection{Total protein and protein solubility}

The total protein content and protein solubility on the UV-C treated samples were investigated, in comparison with the heat pasteurized process. It is known from literature that the heat treatment of liquid egg white can result in a major loss of solubility, depending on the $\mathrm{pH}$ and salt content (Croguennec, Nau and Brulé, 2002).

In Figure 5.12 the UV-induced reductions of the total and soluble proteins of the liquid egg products are shown. On egg yolk, aggregates formed due to UV treatment were less soluble than on the egg white. From the figures it can be observed that insolubilization of egg fractions proteins occurs follows a cuasi-linear behavior. Also the total protein content reduction pursues a zero order kinetic. Protein oxidation is the responsible for the reduction of protein content, and also to a possible drying of the sample during processing.

Zabielski et al. (1984) gamma-irradiated chicken meat and observed a decrease in solubility of the protein fractions after irradiation. It was found that the relative protein extractability fell in a linear manner with increase in the radiation dose that was coincident with increase in free water content, and fall in water holding capacity and water retention capacity. 
Results and discussion
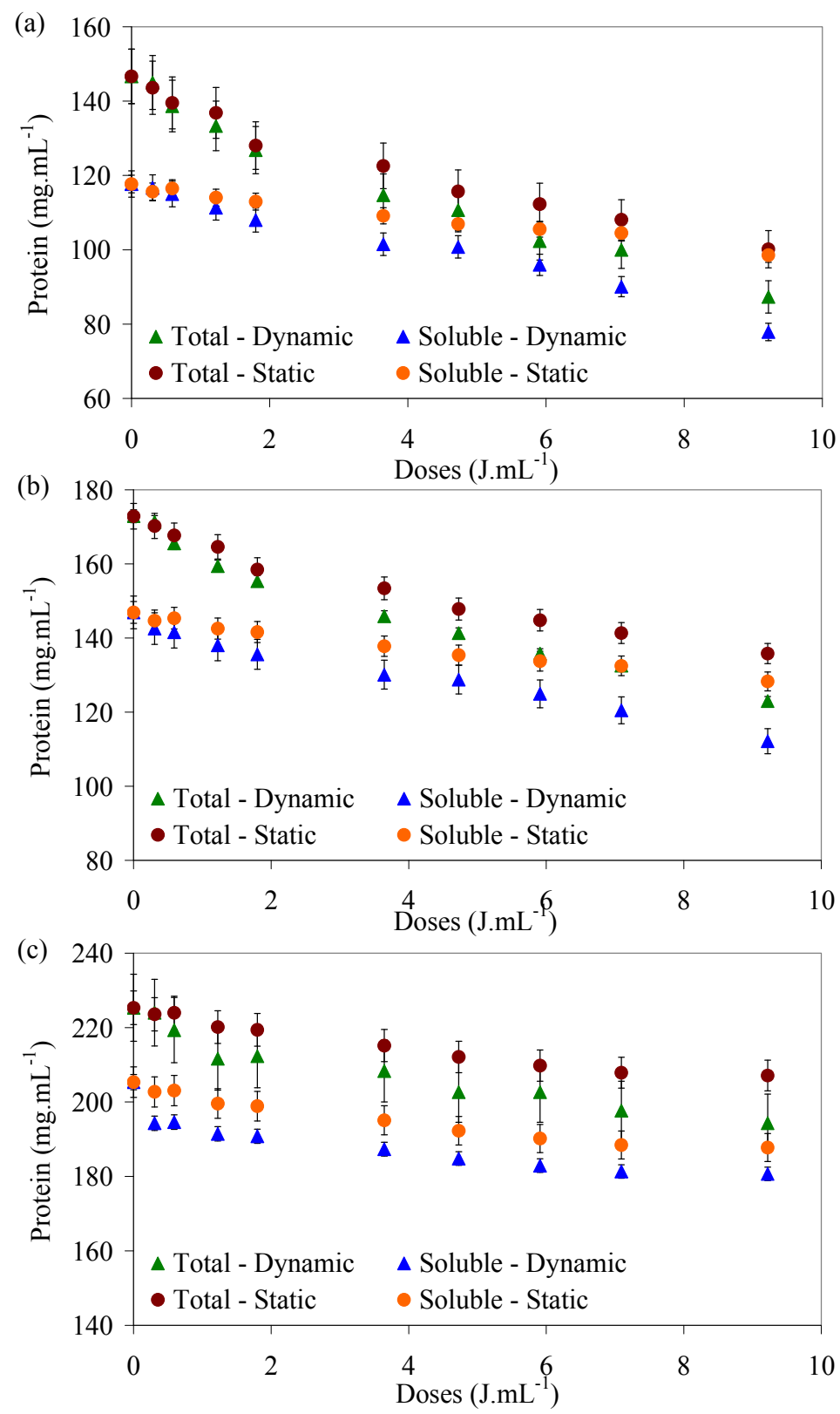

Figure 5.12 - Total and soluble proteins as affected by UV-C under dynamic and static conditions of (a) LEW (b) LWE and (c) LEY. Results are the mean of triplicate \pm standart deviation. 
Afify et al. (2011) studied the proteins properties of three oil seeds (soybean, peanut and sesame) were investigated following $\gamma$-irradiation $(0.0$, $0.5,1.0,2.0,3.0,5.0$ and $7.5 \mathrm{kGy})$. The effect of $\gamma$-radiation on total protein solubility, albumin, globulin and SDS-ME fractions were studied using SDS-polyacrylamide gel electrophoresis. The results showed that solubility of total protein were decreased and reached to the maximum decrease using irradiation dose of $7.5 \mathrm{kGy}$ compared to control. The interesting phenomena are that albumin and globulin fractions decreased in its solubility while the SDS-ME fraction increased. These phenomena may be due to the effect of gamma radiation on the protein, which may dissociate this fraction to small subunits, and rearrangement to form a complex protein even high or small molecular weight proteins solubilized only in SDS-ME fraction. The changes in protein profile were depended even on radiation dose and on the nature of oil seeds; soybean, peanut and sesame.

\subsubsection{Protein oxidation}

Disulfide (SS) bonds and sulphydryl (SH) groups play an important role in protein gelation. Inaccesible thiol groups become exposed during heating, which is related to the generation of covalent SS linkages. Ultraviolet is a highly oxidizing agent, and could also generate a loss in sulphydryl content. In the untreated egg white, a total amount of SH groups of $60.5 \mu \mathrm{M} \mathrm{SH.g}{ }^{-1}$

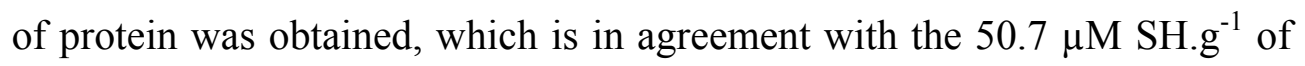


Results and discussion

dry weight observed by Beveridge et al. (1974) and the value of $58.5 \mu \mathrm{M}$ SH.g ${ }^{-1}$ presented by Van der Plancken et al. (2005).

Before treatments, these $\mathrm{SH}$ groups were mainly buried in the protein core and therefore inaccessible for DTNB when no denaturant (SDS) was applied, as shown by the low exposed SH content on the untreated sample. Ovalbumin, the major protein in egg white, is the only egg white protein to contain (four) free sulfhydryl groups, which are buried in the protein core (Powrie and Nakai, 1986).

As can be observed from Figure 5.13, UV-C heat-induced unfolding of the LEW proteins resulting in the exposure of buried sulfhydryl groups (calculated from the difference between total and exposed sulfhydryl groups), which was more pronounced at the higher doses. This was demonstrated by an increase in the proportion of exposed against buried SH.

These exposed sulfhydryl groups are rather reactive at neutral or alkaline $\mathrm{pH}$ and therefore they can be expected to be involved in further interactions that can lead to protein aggregation. One feasible mechanism for such further reaction is the sulfhydryl-disulfide exchange reaction, in which the exposed $\mathrm{SH}$ groups from ovalbumin react with the molecules owning disulfide bonds, or with another ovalbumin molecule, or even with another SScontaining egg white protein. This can result in the formation of a protein network and, depending on the protein, salt concentration and $\mathrm{pH}$, in a gel (Croguennec, Nau and Brulé, 2006). 

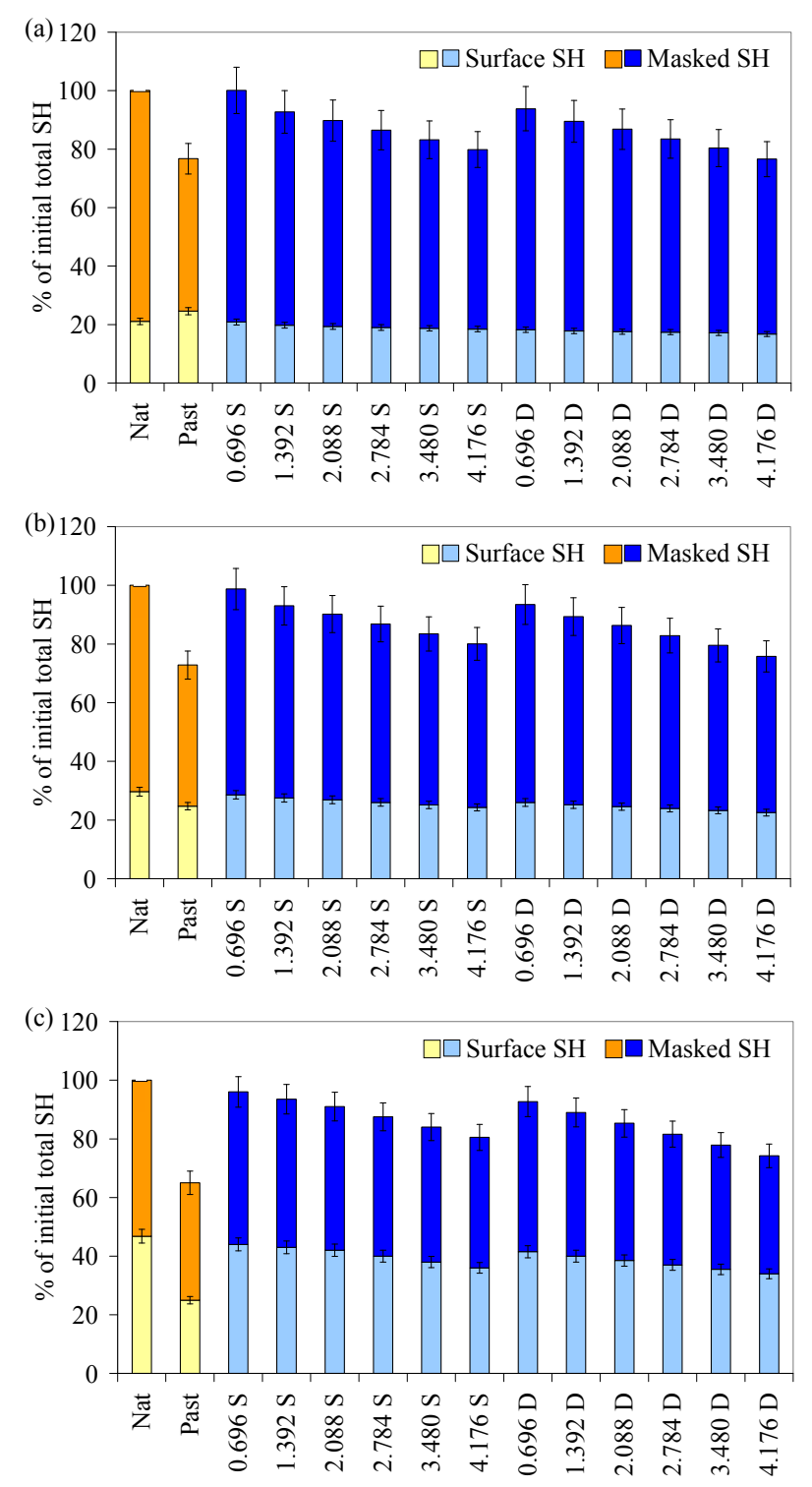

Figure 5.13 - Effect of UV-C treatment on the exposed, masked and total sulphydryl content of (a) LEW, (b) LWE and (c) LEY. Results are the mean of triplicate \pm standart deviation. 
Results and discussion

When the sulfhydryl-disulfide exchange reaction is the sole reaction involving exposed sulfhydryl groups, no change in the total $\mathrm{SH}$ content should be expected, as the free SH group merely shifts from one position to another. However, after the UV-C and heat treatment of LEPs, a gradual but limited decrease of total SH content could be observed. This indicates that some of the exposed $\mathrm{SH}$ groups were oxidized to form new disulfide bonds.

On the case of heat pasteurization the same observations are valid, and the oxidative effect is even more pronounced. Heat-induced denaturation of ovalbumin results in exposure of these sulfhydryl groups, accompanied by a decrease in total sulfhydryl content, due to oxidation of $\mathrm{SH}$ groups to disulfide bonds (Beveridge and Arntfield, 1979; Rumbo et al., 1996).

It has been demonstrated that in oxygen containing egg white solutions, heat treatment induces a rapid decrease in total $\mathrm{SH}$ content, while no clear decrease in these groups can be observed when heat treatment is performed on nitrogen flushed solutions (Beveridge and Arntfield, 1979).

In this study the UV-C treatments were carried out in an open container, and the samples were exposed to the air oxygen, so sulfhydryl oxidation to disulfide bonds could be expected. Such results are in good agreement with the decrease in protein solubility previously reported which would point to a certain degree of protein aggregation after UV-C. 
Results and discussion

\subsubsection{Thermodynamic properties (Differential scanning calorimetry)}

The denaturation enthalpy of proteins correlates well with the content of ordered structures. Thermograms of LEPs obtained by differential scanning calorimetry are represented in Figures 5.14. Net values of peak maxima and enthalpy changes are shown in Table 5.15. Data are a combination of endothermic reactions, such as the disruption of hydrogen bonds, and exothermic processes, such as the disruption of hydrophobic interactions; therefore enthalpy change is an indication of structure loss (Van der Plancken et al., 2006).

Untreated and UV-C treated egg whites exhibit the typical four main thermal transitions due to protein denaturation: at $59.5^{\circ} \mathrm{C}$, corresponding to conalbumin, at $68{ }^{\circ} \mathrm{C}$ due to lysozyme, and a double peak at 78.8 and $83{ }^{\circ} \mathrm{C}$ due to ovalbumin and S-ovalbumin. The increase of viscosity at $63{ }^{\circ} \mathrm{C}$ (later reported on section 5.1.5.3) might be interpreted as the beginning of the exothermic peak of the DSC thermograms, corresponding to conalbumin denaturation (Ferreira et al., 1997). Thermograms and denaturation enthalpies of egg white correlated well with the results obtained by Perez and Pilosof (2004).

Ferreira et al. (1997) also observed a comparable behavior corresponding to protein denaturation, and could distinguish 4 main peaks, at 60, 67, 78 and $82{ }^{\circ} \mathrm{C}$. Ibanoglu and Erçelebi (2007) obtained higher enthalpies for dehydrated samples. The preceding pasteurization at mild temperatures caused however a certain extent of protein unfolding, confirming the 
Results and discussion

changes in the rheological properties (section 5.1.5). This is recognizable as a decrease in the denaturation enthalpies of LEW proteins (Figure 5.13 a), affecting specially the proteins between 50 and $65^{\circ} \mathrm{C}$, probably conalbumin.

Table 5.15 - Peak temperatures (Td) and the enthalpy changes $(\Delta \mathrm{H})$, integrated between 50 and $95^{\circ} \mathrm{C}$, of LEPs.

\begin{tabular}{|c|c|c|c|c|c|}
\hline & & \multirow{2}{*}{ Untreated } & \multicolumn{2}{|c|}{ Ultraviolet } & \multirow{2}{*}{ Pasteurized } \\
\hline & & & Dynamic & Static & \\
\hline \multirow{5}{*}{$\begin{array}{c}\text { Egg } \\
\text { white }\end{array}$} & $\mathrm{Td}_{1}\left({ }^{\circ} \mathrm{C}\right)$ & 59.5 & $59.3 \pm 0.4$ & $59.4 \pm 0.6$ & - \\
\hline & $\mathrm{Td}_{2}\left({ }^{\circ} \mathrm{C}\right)$ & $68.2 \pm 0.5$ & $68.0 \pm 0.5$ & $68.1 \pm 0.7$ & $68.3 \pm 0.6$ \\
\hline & $\mathrm{Td}_{3}\left({ }^{\circ} \mathrm{C}\right)$ & $78.8 \pm 0.4$ & $78.6 \pm 0.5$ & $78.7 \pm 0.8$ & $78.9 \pm 0.7$ \\
\hline & $\mathrm{Td}_{4}\left({ }^{\circ} \mathrm{C}\right)$ & $83.1 \pm 0.7$ & $82.9 \pm 0.5$ & $83.3 \pm 0.6$ & $83.1 \pm 0.8$ \\
\hline & $\Delta H\left({\mathrm{~J} . \mathrm{g}^{-1}}^{-1}\right.$ & $2.16 \pm 0.22$ & $2.14 \pm 0.18$ & $2.10 \pm 0.17$ & $1.63 \pm($ \\
\hline \multirow{3}{*}{$\begin{array}{c}\text { Whole } \\
\text { egg }\end{array}$} & $\mathrm{Td}_{1}\left({ }^{\circ} \mathrm{C}\right)$ & $60.0 \pm 0.9$ & $60.5 \pm 0.10$ & $60.2 \pm 0.08$ & - \\
\hline & $\mathrm{Td}_{2}\left({ }^{\circ} \mathrm{C}\right)$ & $80.5 \pm 0.11$ & $80.5 \pm 0.08$ & $80.5 \pm 0.10$ & - \\
\hline & $\mathrm{Td}_{3}\left({ }^{\circ} \mathrm{C}\right)$ & $85.5 \pm 0.04$ & $85.1 \pm 0.11$ & $85.2 \pm 0.12$ & $86.1 \pm 0.07$ \\
\hline \multirow{2}{*}{$\begin{array}{l}\text { Egg } \\
\text { yolk }\end{array}$} & $\Delta \mathrm{H}\left({\left.\mathrm{J} . \mathrm{g}^{-1}\right)}^{-1}\right.$ & $2.16 \pm 0.16$ & $2.15 \pm 0.18$ & $2.17 \pm 0.24$ & $1.88 \pm 0.19$ \\
\hline & $\mathrm{Td}_{1}\left({ }^{\circ} \mathrm{C}\right)$ & $85.0 \pm 0.12$ & $85.1 \pm 0.14$ & $85.3 \pm 0.15$ & $84.6 \pm 0.16$ \\
\hline
\end{tabular}

*Results are the mean of triplicate \pm standart deviation.

A single peak was observed for LEY, being composed by HDL, phosphitin and LDL denaturation enthalpies (Ibanoglu and Erçelebi, 2007). Transition temperatures of egg yolks were obtained at about $85{ }^{\circ} \mathrm{C}$ for all yolk treatments and not treated control, and the residual denaturation enthalpies were slightly influenced by the thermal pasteurization (Table 5.15). 

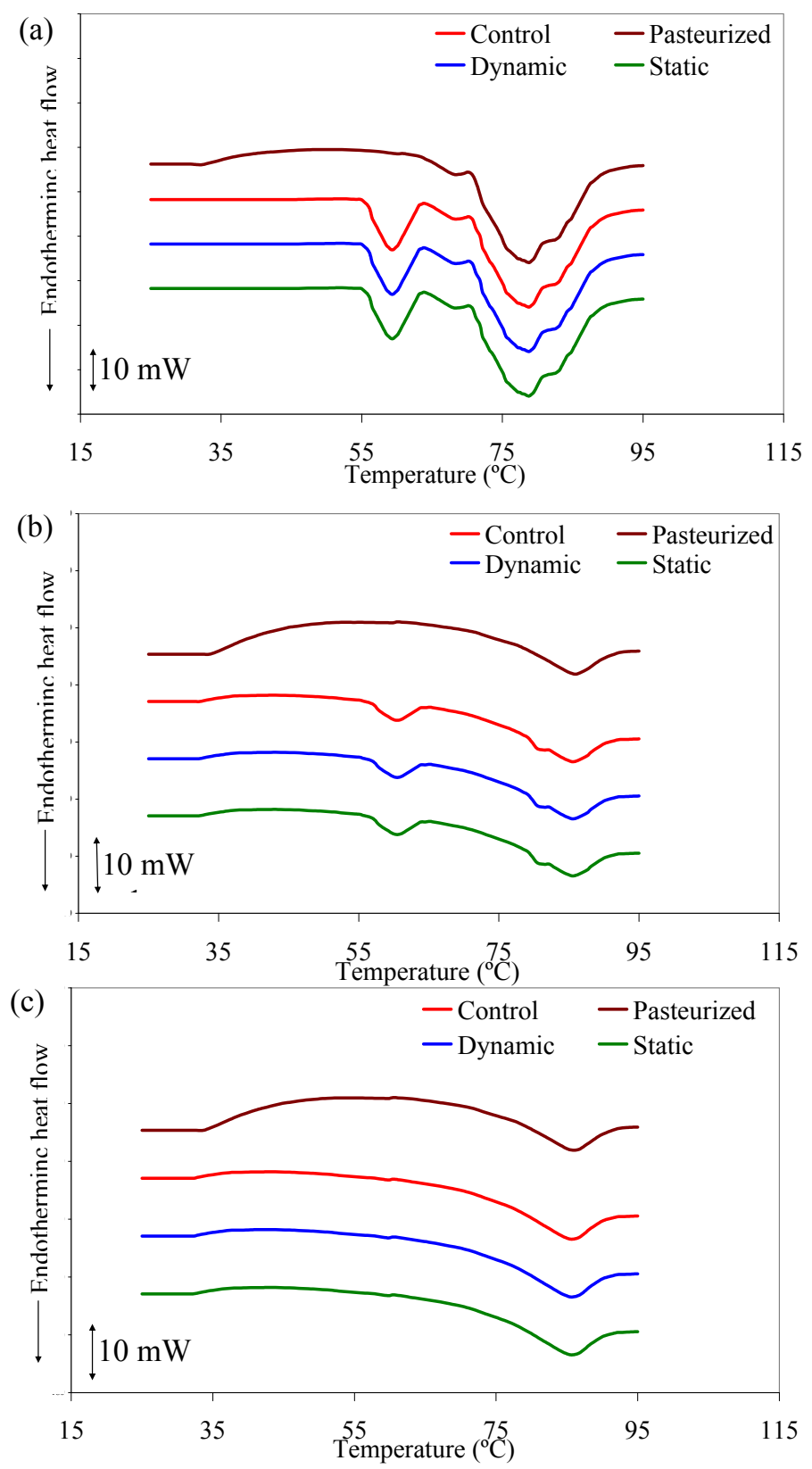

Figure 5.14 - Differential scanning calorimetry thermograms of (a) LEW, (b) LWE and (c) LEY. Untreated LEP (control), pasteurized, UV treated under dynamic and static conditions. Results are the mean of triplicate; standart deviation is bellow $5 \%$. 
Results and discussion

Ibanoglu and Erçelebi (2007) obtained similar unfolding temperatures for the pure proteins of egg yolk granulates (HDL and phosphitin) and egg yolk plasma (LDL).

Concerning the heat denaturation of LWE, a composition of the effects observed in LEY and LEW has been recorded. Two main peaks can be distinguished at 60 and $85^{\circ} \mathrm{C}$, corresponding to the main unfolding peaks of egg white and egg yolk proteins. Again minimal effects could be attributed to UV-C treatments, contrary to the pasteurization, which generated a considerable loss in denaturation enthalpy.

\subsubsection{SDS-PAGE Electrophoresis}

Polyacrylamide gel electrophoresis discriminates proteins by size. On the protein patterns, presented on Figure 5.15, six main bands are unambiguously identified in untreated LEW; ten bands are identified in untreated LWE; and 13 bands are identified in untreated LEY.

Egg white bands probably match with lysozyme, avidin, flavoprotein, ovomucoid, ovalbumin and ovotransferin. In egg white, ovomucoid, ovotransferrin, and ovalbumin represent approximately $80 \%$ of the protein content (54, 13, and 11\%, respectively) (Desert et al., 2001), showing highest intensities in the gels, especially ovalbumin at 45.0 kDa. In LEY, 13 bands were identified: apolipoprotein CII, apolipoprotein CII apovitellenin $\mathrm{I}$, apovitellenin I, apovitellin 8 , $\beta$-livetin, $\beta$-livetin, R-livetin/apovitellenin 
III, apovitellenin IIIa/ apovitellenin IV, apovitellin $5+6 /$ apovitellenin V, apovitellenin $\mathrm{Vb}$, apovitellin $3+4$ and apovitellenin $\mathrm{Va}$, in accordance to Guilmineau, Krause and Kulozik (2005). The main protein components of egg whites and yolks could be identified also in LWE.
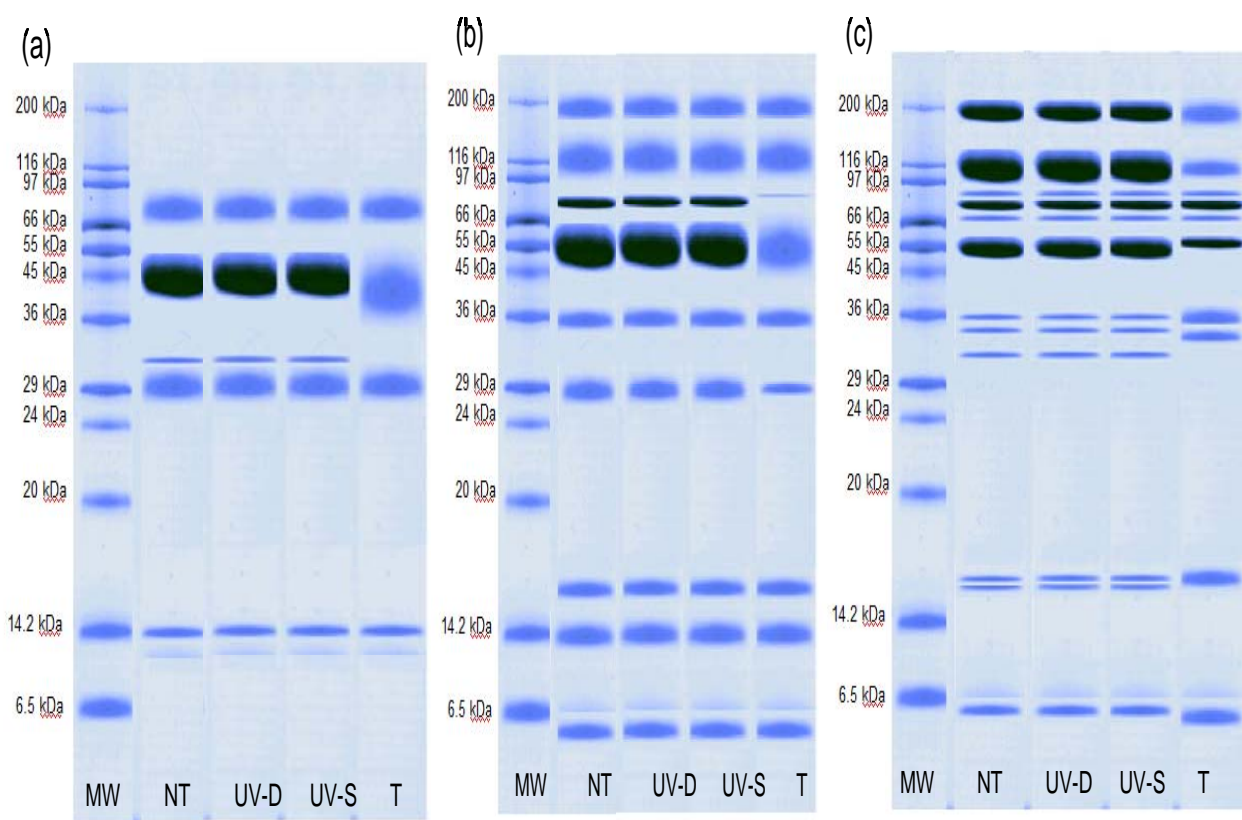

Figure 5.15 - SDS-PAGE analysis of (a) LEW, (b) LWE and (c) LEY. MW - Molecular weigh marker; NT - not treated sample; UV-D - UV-treated under dynamic conditions; UV-S - UV-treated under static conditions; T pasteurized.

The size and relative volume of the individual bands was used to compare the effects of processing. At the view of the results, UV-C treatments have not altered the migration pattern of the protein components of LEW, LWE or LEY to a significant extent. Similarly, Huang, Herald and Mueller (1997) 
Results and discussion

reported negligible effects of electron beam radiation on the electrophoretic patterns of soluble proteins and delipidized LDL from egg yolk.

On the contrary, mild heat pasteurization treatments of LEPs induced a certain degree of protein aggregation, mainly affecting the high molecular weight bands in egg white and egg yolk. In LEW, the bands corresponding to ovalbumin and ovomucoid vanished after the thermal treatment. Vanishing of ovomucoid and R-livetin/apovitellenin was also observed on pasteurized LEY and LWE, indicating protein unfolding or aggregation. All the samples were centrifuged, and consequently insoluble deposits were not casted. Therefore, heat treatments originated insoluble deposits.

The low effects of UV-C on the different parameters investigated in this work demonstrate that UV-C treatments do not alter important qualityrelated protein properties of LEPs. In this sense, UV-C treatments prevent the aggregation of egg white and egg yolk proteins and could be more convenient that heat pasteurization.

\subsubsection{Rheological properties}

\subsubsection{Dynamic viscosity (Shear-dependent viscosity)}

The effects of UV-C and pasteurization on the apparent viscosity of LEPs are recorded on Figure 5.16, and on Table 5.16. LEPs are known as shearthinning fluids (Severa et al., 2010) with the apparent viscosity showing a 
typical dependence of the shear rate and the Power Law Index $0<n<1$. According to Tang, Munro and McCarthy (1993), this behavior could be attributed to combined effects of the breakdown of weak linkages between proteins. If the network is broken, shear thinning will occur, and the apparent viscosity will decrease. As a result, the molecules are arranged in the direction of the shear, decreasing the resistance to flow.

On LEY and LWE, this effect can also be attributed to changes in the structure of fat globules. In accordance, the pseudoplastic behavior in LEPs is confirmed after UV-C treatments and pasteurizations, since the apparent viscosity decreases as the shear stress increases, and the power law index (n) is below 1 .

However, heat pasteurization influenced more than UV-C on the flow behavior of the LEPs. Heat treatments were a non negligible factor to increase the viscosity values, being however the main shear-thinning properties still retained after the pasteurization conditions (Table 5.16).

On the contrary, UV-C treatments have not affected $(\mathrm{P}>0.05)$ the apparent viscosity of the LEPs, being recorded values more similar to the untreated controls than in heat treated samples. These results are in good agreement with the data of Gosset, Rizvi, and Baker (1983) on egg white, and Severa et al. (2010) on egg yolk, and corroborate the expected shear-thinning behavior of LEPs. 
Results and discussion
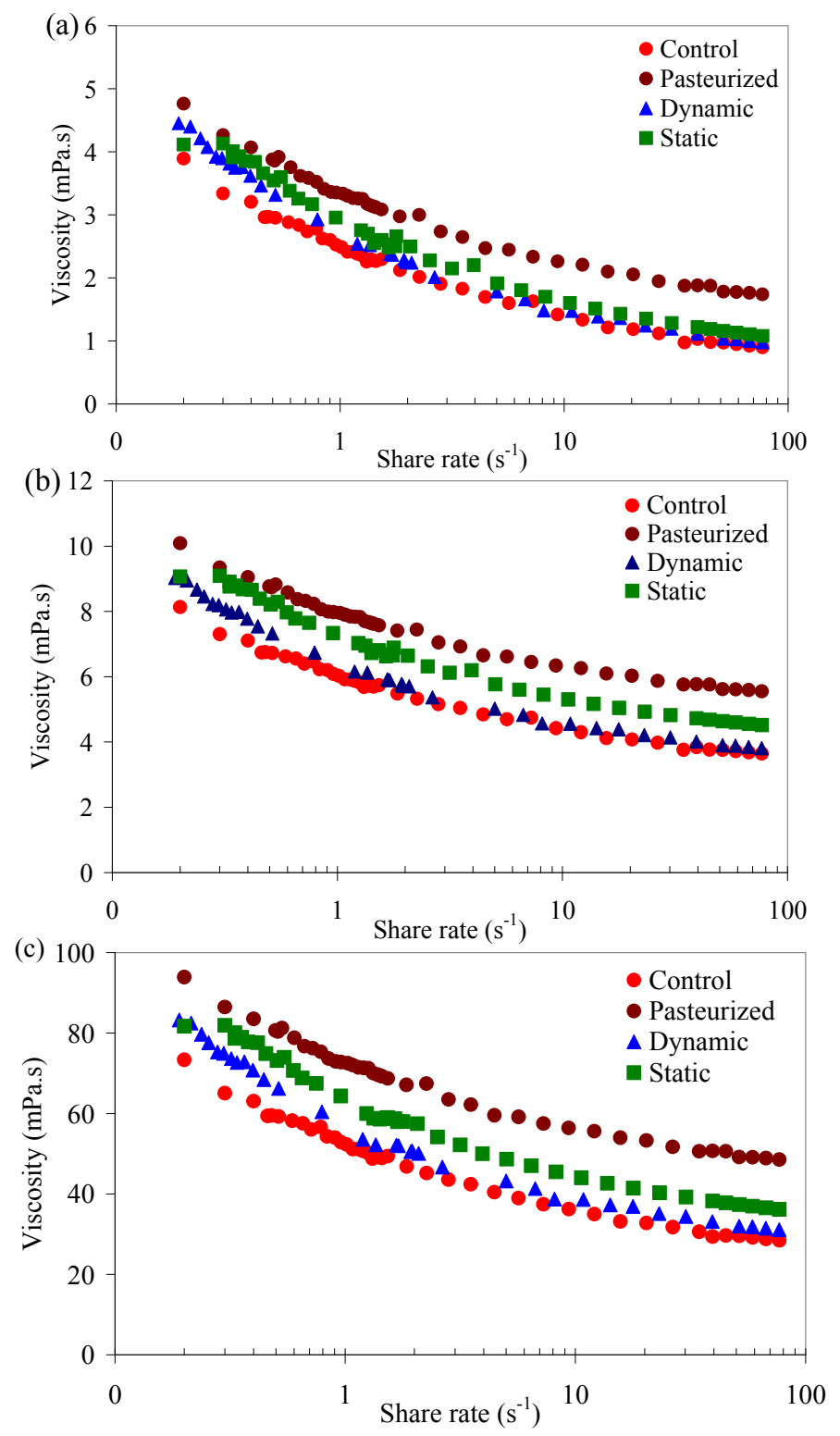

Figure 5.16 - Dynamic viscosity - share rate dependence for (a) LEW, (b) LWE and (c) LEY. Untreated LEPs (control), pasteurized, UV-C treated under dynamic conditions (UV-D), and UV-C treated under static conditions (UV-S). Results are the mean of triplicate, standart deviation is bellow $5 \%$. 
Table 5.16 - Consistency coefficient (K) and power law index (n) of LEPs.

\begin{tabular}{cccccc}
\hline & & & & & \multicolumn{2}{c}{ Control } & Pasteurized & \multicolumn{2}{c}{ Diolet } \\
& & & & Dynamic & Static \\
Egg & $\mathrm{K}$ & 2.5013 & 3.376 & 2.7935 & 2.9476 \\
white & $\mathrm{n}$ & 0.7543 & 0.8348 & 0.7426 & 0.7565 \\
& $\mathrm{R}^{2}$ & 0.9963 & 0.9892 & 0.9943 & 0.9941 \\
\hline \multirow{2}{*}{ Whole } & $\mathrm{K}$ & 6.0851 & 8.0381 & 6.6711 & 7.3935 \\
egg & $\mathrm{n}$ & 0.8703 & 0.9051 & 0.8537 & 0.873 \\
& $\mathrm{R}^{2}$ & 0.9858 & 0.9769 & 0.9768 & 0.9786 \\
\hline \multirow{2}{*}{ Egg } & $\mathrm{K}$ & 52.728 & 73.342 & 59.348 & 64.669 \\
yolk & $\mathrm{n}$ & 0.845 & 0.8946 & 0.833 & 0.8513 \\
& $\mathrm{R}^{2}$ & 0.9893 & 0.9791 & 0.9793 & 0.9813 \\
\hline
\end{tabular}

\subsubsection{Time dependent viscosity}

Structure breakdown of partially coagulated egg proteins is a timedependent process. Characterization of the structure breakdown is possible by the measurement of the stress decay at a constant shear rate (Lee, Heinz and Knorr, 1999). In the steady shear analysis, the total strain is rather large, if compared to that of dynamic shear measurements (Elliot and Ganz, 1975; Lee, Heinz and Knorr, 1999). Consequently coagulated structures might be broken due to the strong mechanical stress, being possible the identification of coagulated structures. In Figure 5.17 the flow behavior of LEPs is represented. In all the three fractions, the controls and samples treated with UV-C show no coagulation when placed at a constant shear rate $\left(300 \mathrm{~s}^{-1}\right)$. Equilibrium values of about 7.0 $\mathrm{Pa}$ for LEW, 10.9 $\mathrm{Pa}$ for LWE and 11.1 $\mathrm{Pa}$ 
Results and discussion

for LEY are reached early on the untreated control and UV-C treated samples.

The retarded response to shear of egg fractions might result from the combination of viscous and elastic properties, which seems not to be modified due to UV-C irradiation, but is indeed sharply modified by other non-thermal technologies, such as high pressure (Lee, Heinz and Knorr, 1999). Remarkably, the observed decrease in SH content could be related to any relevant effect in the flow behavior of UV-C treated LEPs.

On the other hand, in the pasteurized samples, a structure breakdown occurred, visualized as the stress overshoot on the first seconds of shear. As a consequence of torque, the coagulated structures breakdown and the equilibrium is achieved within a few minutes, depending on the degree of coagulation.

The excess work of structure breakdown, explained as the area below the overshoot peak, is proportional to the protein content (Lee, Heinz and Knorr, 1999). Thus, the numerical solution of Eq. 4.11 shows that the excess work of structure breakdown is above 0 in pasteurized samples (estimated $827 \mathrm{~kJ} . \mathrm{m}^{-3}$ in LEW; $510 \mathrm{~kJ} . \mathrm{m}^{-3}$ in LWE, and $330 \mathrm{~kJ} \cdot \mathrm{m}^{-3}$ in LEY), while it vanishes in UV-C treated samples under the same conditions.

Furthermore, the average steady shear stress in heat treated samples is higher than in controls and in UV-C treated: about 14.6 Pa for egg white, 15.0 $\mathrm{Pa}$ for whole egg and 14.8 Pa for egg yolk. 

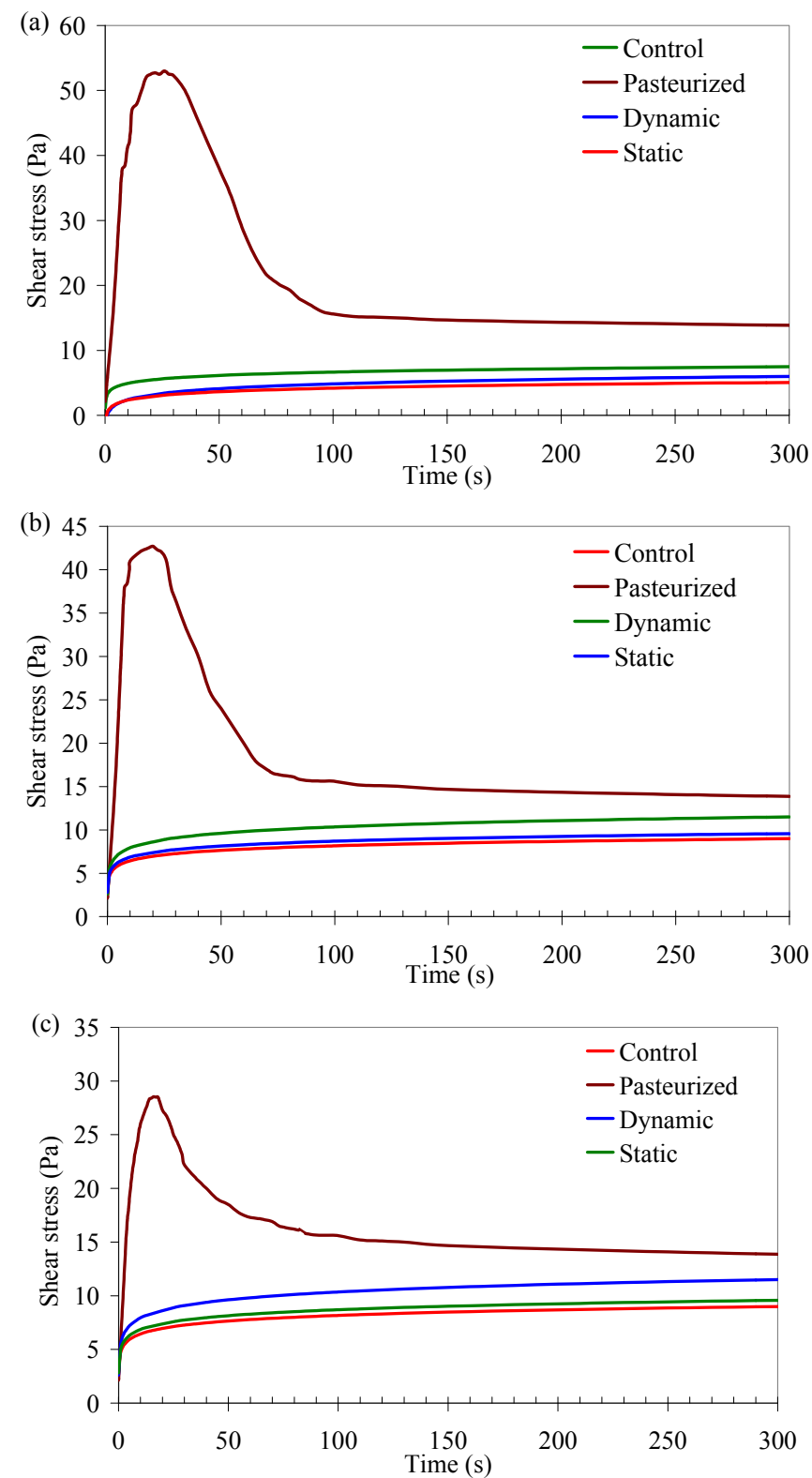

Figure 5.17 - Flow behavior of (a) egg white, (b) whole egg and (c) egg yolk. Untreated LEPs (control), pasteurized, UV-C treated under dynamic conditions (UV-D), and UV-C treated under static conditions (UV-S). Results are the mean of triplicate, standart deviation is bellow $5 \%$. 
Results and discussion

\subsubsection{Temperature dependent viscosity}

Processing and thermal treatments (spray-drying, freezing, pasteurization) have a large influence on the rheological properties of LEPs (Jaekel and Ternes, 2009). Functional changes of egg rheological behavior from fresh, UV-C and thermally treated eggs are represented in Figure 5.18. In LEW, a sudden increase in viscosity takes place at $63{ }^{\circ} \mathrm{C}$, indicating the initial formation of egg albumen aggregates. In LEY, a peak could be observed at $75^{\circ} \mathrm{C}$. Hsieh and Regenstein (1992) determined $60{ }^{\circ} \mathrm{C}$ as the phase transition temperature in LEW. That viscosity increase is coincident with the denaturation of conalbumin (Ferreira, Hofer, and Raemy, 1997). The investigated UV-C processing parameters seem not to compromise egg white functional properties and the denaturation of conalbumin is evident in the figures representing the temperature dependent viscosity. On the contrary, the mild thermal conditions applied to pasteurize were sufficient to originate perceptible changes in egg white proteins, being the peak at $63{ }^{\circ} \mathrm{C}$ considerably smaller.

In egg yolk, the heat-induced gelation is a multistage mechanism (Cordobés, Partal and Guerrero, 2004). The temperature-dependent flow behavior of egg yolk showed a viscosity minimum at approximately $65{ }^{\circ} \mathrm{C}$ (Figure 5.18 c) in accordance with data from Jaekel and Ternes (2009), followed by a viscosity maximum at about $73^{\circ} \mathrm{C}$. The viscosity maximum could be due to the interaction of the unfolded livetins and the partially denatured LDL (Ternes and Werlein, 1987), which seems not to be altered by UV-C. 

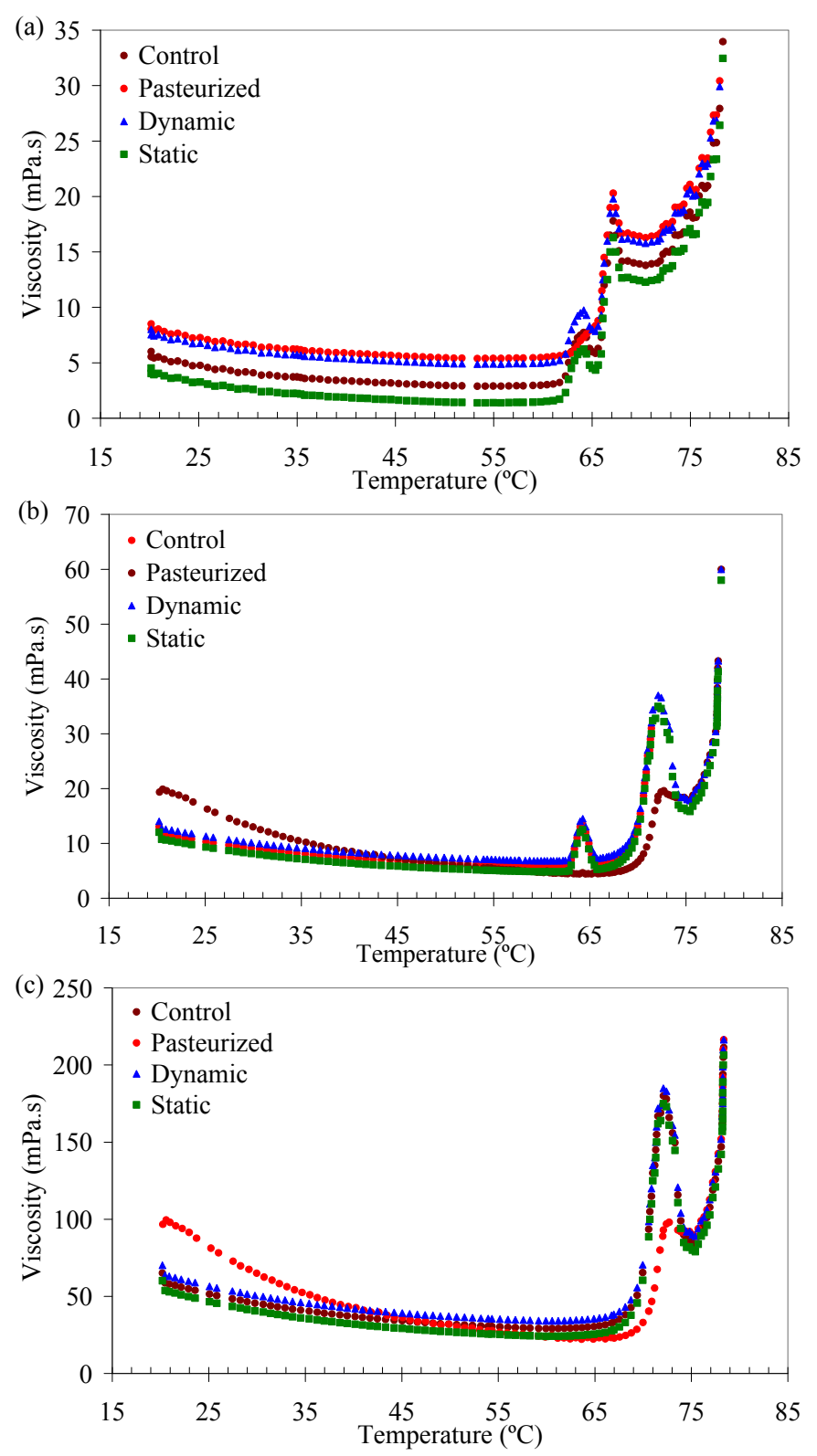

Figure 5.18 - Temperature-dependent viscosity of (a) LEW, (b) LWE and (c) LEY. Untreated LEPs (control), pasteurized, UV-C treated under dynamic conditions (UV-D), and UV-C treated under static conditions (UV$\mathrm{S})$. Results are the mean of triplicate, standart deviation is bellow $5 \%$. 
Results and discussion

Only heat treated samples showed a slightly different behavior than the untreated controls, probably due to a certain degree of LDL denaturation resulting in less extensive LDL/LPC complexes, as reported by Jaekel and Ternes (2009).

Accordingly, the differential pattern observed for pasteurized LWE (Figure $5.18 \mathrm{~b}$ ) seems to be driven by the effects observed in LEY and LEW components, such as the reported unfolding of conalbumin and the effects on LDL complexes. 


\subsection{UVivatec ${ }^{\circledR}$ Lab reactor}

On chapter 5.1 the suitability of UV-C on the decontamination of LEPs was determined in bench-scale equipment. Although the system worked in batch and the treatment capacity was small. For the egg-food industry would be interesting to increase the production, and also to be able to treat the products under continuous flow.

In this section the UVivatec ${ }^{\circledR}$ Lab reactor was tested and proposed as an improvement of the IATA bench scale equipement. The basic idea of the

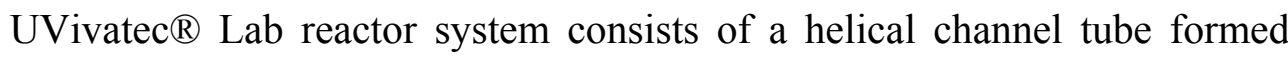
with the semicircular outer side consisting of Teflon and the straight inner side of quartz glass. The helical channel can be irradiated from the inside to the outside by a rod-shape UV-C light source placed inside the quartz glass. Novel hydraulic spiral flow around an irradiation source induces Dean vortices in a fluid stream, providing highly efficient mixing.

The purpose of the present study was to examine the efficacy of UV-C irradiation using UVivatec ${ }^{\circledR}$ system in the inactivation of egg-related microorganisms and the effects on main quality atttibutes. Results are explained in five main sections: microbiology, basic quality study $(\mathrm{pH}$ and color), effects on lipids and effects on proteins.

\subsubsection{Microbiology}


Results and discussion

\subsubsection{UV-C Inactivation kinetics of inoculated microorganisms}

The inactivation of microorganisms inoculated in LEPs, in continous flow UV-C systems, was evaluated. Semilogarithmic survivor curves of Salmonella subterranea DSM 16208, Escherichia coli DH5a and Listeria innocua WS 2258 inoculated in LEW, LWE and LEY are represented in Figure 5.19 and relate the viable microorganism population (in $\log \left(\mathrm{N}^{-} \mathrm{N}_{0}{ }^{-}\right.$ $\left.{ }^{1}\right)$ ) to the volumetric UV-C dose.

An effective reduction of $5 \log$ for all investigated microorganisms were obtained for LEW around 11,000 J.L $\mathrm{L}^{-1}$ and around 14,000 J.L $\mathrm{L}^{-1}$ for LWE. 4.8 Log was obtained for LEY at doses of $61,000 \mathrm{~J} . \mathrm{L}^{-1}$. The inactivation curves with UV-C show upward concavity, with fast decline at low doses, followed by a tail at the end of processing (Peleg, 2000). In this study, $n$ is less than 1 for all the microorganisms tested, both $\operatorname{Gram}(+)$ and $\operatorname{Gram}(-)$, in all LEPs.

Microbial inactivation with UV-C under dynamic conditions was more accurately described by the Weibull distribution (similar $\mathrm{R}^{2}$ also were observed for the modified Weibull described by Albert and Manfart) than by linear models, meaning that data presented a certain tailing in all LEPs. As on the IATA bench equipement, this behavior can be mainly attributed to low light transmittance of LEPs, which protect the bacterial cells during irradiation. The estimated parameters describing the UV-C inactivation at the UVivatec ${ }^{\circledR}$ reactor are recorded on Table 5.17. 

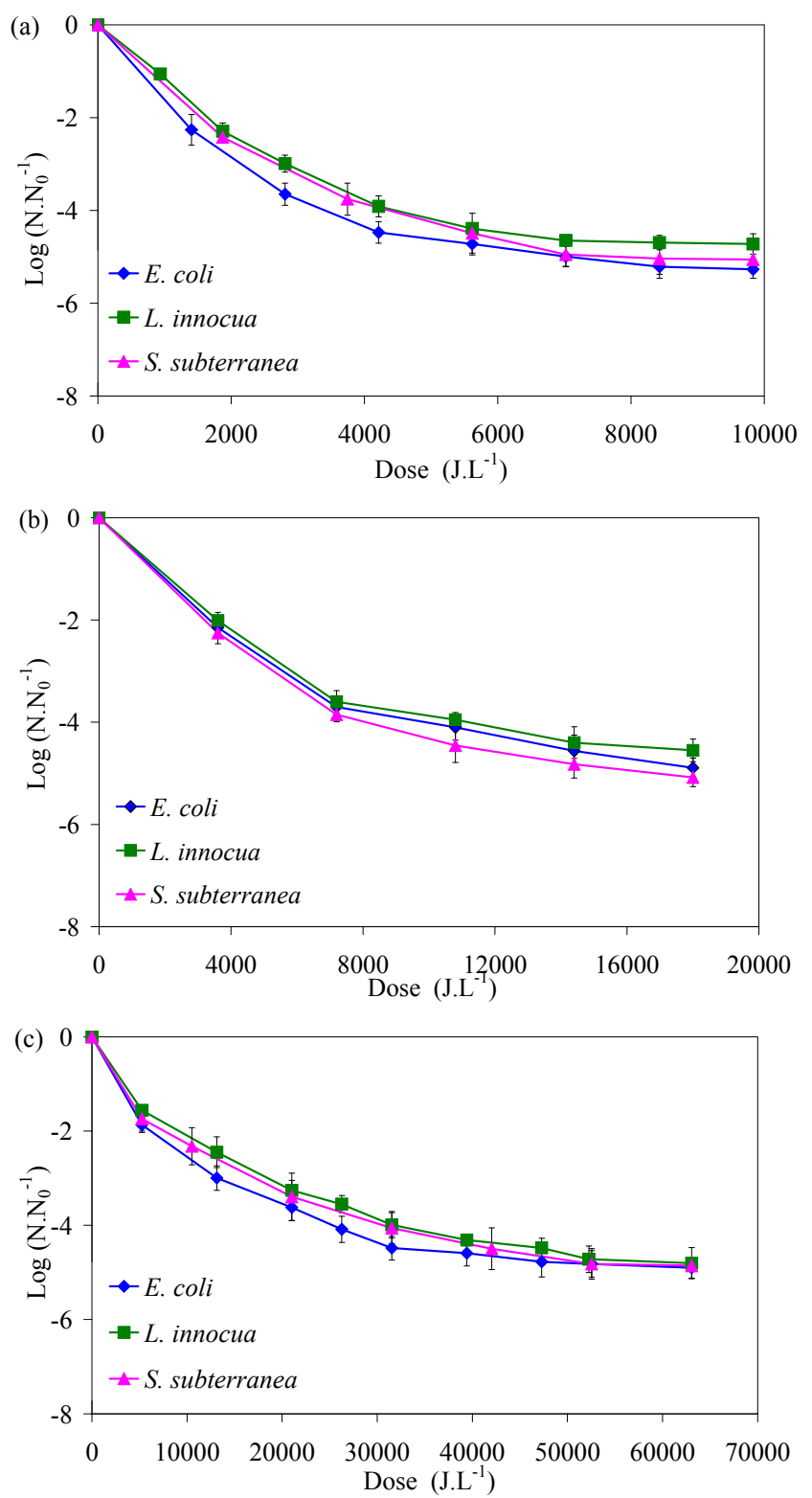

Figure 5.19 - UV-C inactivation of Escherichia coli DH5a, Listeria innocua WS 2258 and Salmonella subterranea DSM 16208 on (a) LEW, (b) LWE and (c) LEY as a function of the volumetric dose. Results are the mean of triplicate \pm standart deviation. 
Results and discussion

Reynolds numbers above 2,300 are considered turbulent, and were achieved in LEW. Additionally Dean Vortices causes secondary eddy flow effects facilitating the microorganism exposure to the light. But even under turbulent flows, the most limiting factor is the LEPs optical density. The optical densities at $254 \mathrm{~nm}$ of LEW $\left(42 \mathrm{~cm}^{-1}\right)$, LWE $\left(630 \mathrm{~cm}^{-1}\right)$ and LEY $\left(1,266 \mathrm{~cm}^{-1}\right)$ explain the effectiveness of the treatments (egg white $>$ whole egg $>$ egg yolk) in the Dean Vortex device as well as in the bench scale equipment.

In general, the efficacy of UV-C inactivation of microorganisms decreases with increasing of the optical density (Koutchma et al., 2004; Murakami et al., 2006; Müller et al., 2011). Consequently, the dose required to achieve a satisfactory inactivation in LEPs are higher when compared to fruit juices. For example, in apple juice, Ngati et al. (2006) obtained 5 Log reduction on the inactivation of Escherichia coli O157:H7 when the fluid depth and UV$\mathrm{C}$ dose were $1 \mathrm{~mm}$ and $390 \mathrm{~mJ} . \mathrm{cm}^{-2}$. And in water, McKinney et al. (2009) related the decrease to below the detection limit $\left(1 \log \left(\mathrm{CFU} \cdot \mathrm{mL}^{-1}\right)\right)$ of $L$. monocytogenes counts at doses $>33.2 \mathrm{~mJ} . \mathrm{cm}^{-2}$.

Due to the good UV-C penetration obtained in the apple juice it is usually used as model on UV-C decontamination studies. After the juice exposure to $1377{\mathrm{~J} . \mathrm{L}^{-1}}^{-1} 7.42 \mathrm{Log}$ reduction of the E. coli K12 was obtained (Keyser et al., 2008). In this same study the endogenous spoilage-related microorganisms were inactivated at doses around 230 J.L ${ }^{-1}$ in apple juice $<$ $1377{\mathrm{~J} . \mathrm{L}^{-1}}^{-1}$ guava juice $<2066 \mathrm{~J} . \mathrm{L}^{-1}$ in strawberry and mango nectar, 
showing again the influence of the optical density (absorbance or transmisttance) on microorganisms' inactivation.

Table 5.17 - Weibull fitting from inactivation kinetics of LEPs treated on the UVivatec ${ }^{\circledR}$ reactor.

\begin{tabular}{|c|c|c|c|}
\hline \multirow{2}{*}{ Parameters } & \multicolumn{3}{|c|}{ Weibull } \\
\hline & LEW & LWE & LEY \\
\hline \multicolumn{4}{|l|}{ Salmonella enteritidis } \\
\hline $\mathrm{RMSE}^{\mathrm{a}}$ & 0.6716 & 0.7934 & 0.7406 \\
\hline $\mathrm{R}^{2}$ & 0.9146 & 0.8593 & 0.8691 \\
\hline $\log \mathrm{N}_{0}\left(\text { CFU.mL } L^{-1}\right)^{b}$ & 7.33 & 6.41 & 6.80 \\
\hline $4 \mathrm{D}\left(\mathrm{J} . \mathrm{L}^{-1}\right)$ & 7865.73 & 16739.52 & 62429.4 \\
\hline$\delta\left(\mathrm{J} \mathrm{L}^{-1}\right)^{\mathrm{c}}$ & 1162.15 & 3141.21 & 12933.08 \\
\hline$p(-)^{d}$ & 0.73 & 0.83 & 0.88 \\
\hline \multicolumn{4}{|l|}{ Escherichia coli } \\
\hline $\mathrm{RMSE}^{\mathrm{a}}$ & 0.9312 & 0.7701 & 0.786 \\
\hline $\mathrm{R}^{2}$ & 0.7439 & 0.8281 & 0.811 \\
\hline $\log \mathrm{N}_{0}\left(\mathrm{CFU} \cdot \mathrm{mL}^{-1}\right)^{\mathrm{b}}$ & 6.28 & 6.15 & 5.93 \\
\hline 4D $\left({\left.\mathrm{J} . \mathrm{L}^{-1}\right)}^{-1}\right.$ & 9242.23 & 17088.26 & $93526.02 *$ \\
\hline$\delta\left(\mathrm{J} \cdot \mathrm{L}^{-1}\right)^{\mathrm{c}}$ & 1874.49 & 3366.76 & 11915.13 \\
\hline$p(-)^{d}$ & 0.87 & 0.86 & 0.78 \\
\hline \multicolumn{4}{|l|}{ Listeria innocua } \\
\hline $\mathrm{RMSE}^{\mathrm{a}}$ & 0.4311 & 0.6235 & 0.6289 \\
\hline $\mathrm{R}^{2}$ & 0.9387 & 0.9004 & 0.8735 \\
\hline $\log \mathrm{N}_{0}\left(\mathrm{CFU} \cdot \mathrm{mL}^{-1}\right)^{\mathrm{b}}$ & 7.71 & 2209.95 & 6.44 \\
\hline 4D $\left({\left.\mathrm{J} . \mathrm{L}^{-1}\right)}^{-1}\right.$ & 5702.65 & 15840.01 & 62429.4 \\
\hline$\delta\left(\mathrm{J}^{\prime} \mathrm{L}^{-1}\right)^{\mathrm{c}}$ & 359.02 & 2209.95 & 13128.63 \\
\hline $\mathrm{p}(-)^{\mathrm{d}}$ & 0.5 & 0.71 & 0.89 \\
\hline
\end{tabular}


Results and discussion

From the inoculated bacteria kinetics were determined the optimal dose for each LEP treatment. This doses correspond to the points were the $5 \log$ reduction were achieved. Other important point observed on the kinetics is the beginning of tail, which correspond to $6,277 \mathrm{~J} . \mathrm{L}^{-1}$ on LEW; $6,780 \mathrm{~J} . \mathrm{L}^{-1}$ on LWE, and 40,677 J.L -1 $^{-1}$ LEY.

\subsubsection{Effects on spoilage-related microorganisms}

Inactivation after UV-C treatments at the optimal conditions, determined by inoculated bacteria inactivation kinetics, was evaluated on the endogenous microflora of LEPs, using heat pasteurized samples as control. Results are represented in Figure 5.20.

The initial loads were similar in all fresh LEPs, and accounted up to 4.85 Log for total aerobic mesophilic microorganisms, $4.92 \mathrm{Log}$ for total anaerobic mesophiles, $5.02 \mathrm{Log}$ for total aerobic psychrotrophic microorganisms, and 4.65 Log for total anaerobic psychrotrophes. Hereof, about 4.69 Log were lactic acid bacteria, about 2.75 Log yeast and moulds, about 4.10 Log Pseudomonadaceae, 4.80 Log Enterobacteriaceae and 1.95 Log Salmonella spp. Spores were not detected in any of the fresh egg fractions. The initial counts presented here are in accordante to the not treated LWE counts reported by González et al. (2009), and to the inicial counts from the eggs from Avicola Llombay used on the studies with the IATA bench device. 

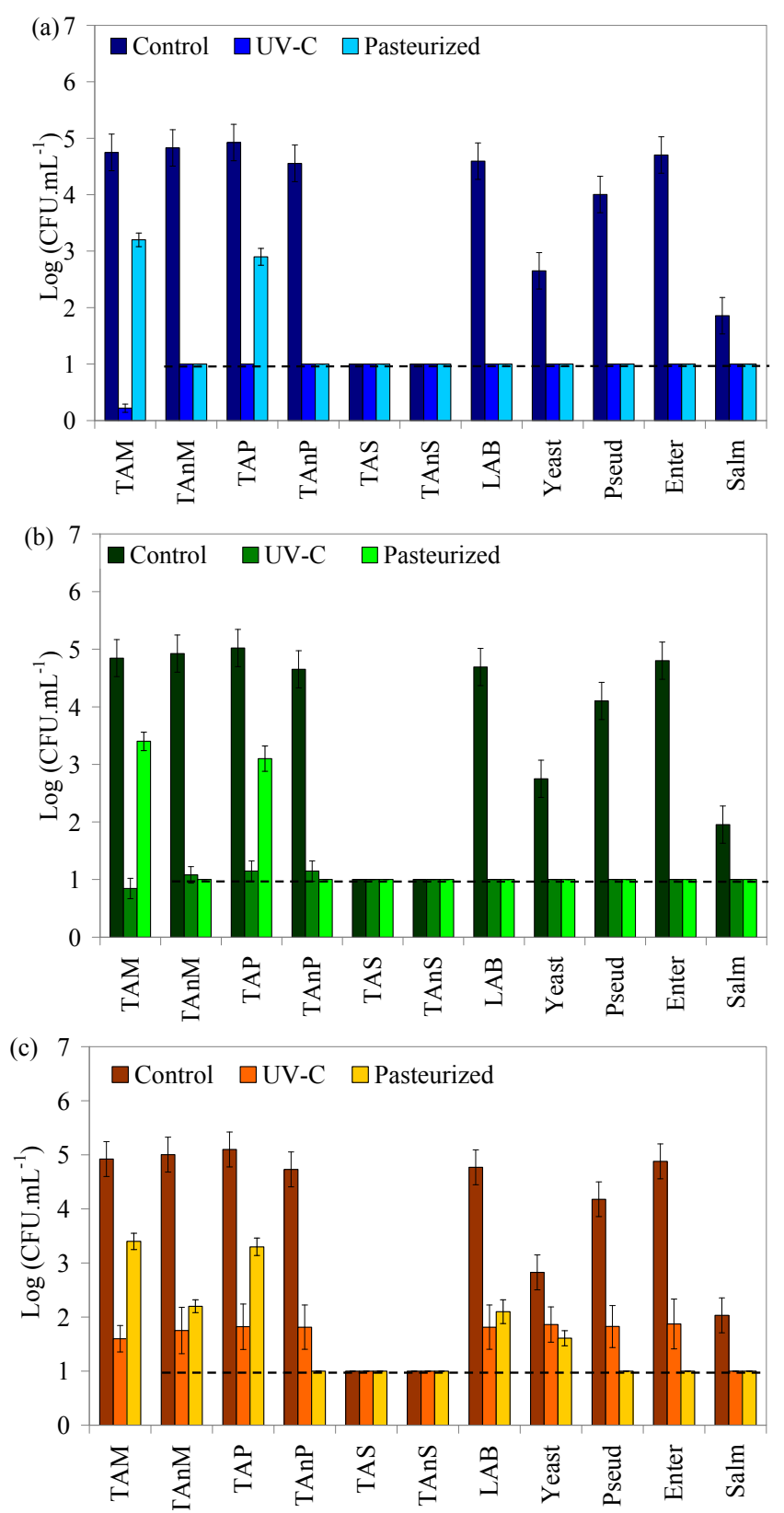

Figure 5.20 - Inactivation of naturally occurring microorganisms in LEPs treated by UV-C and pasteurized; (a) LEW, (b) LWE and (c) LEY. Results are the mean of triplicate \pm standart deviation. Dashed line represents detection limit $(1 \mathrm{Log})$. 
Results and discussion

UV-C treatments achieved higher reductions if compared to conventional thermal pasteurizations in all egg fractions for most of the analysed microbial groups. Remarkably, in LEW counts after UV-C treatments of TAM were of $0.2 \mathrm{Log}$, and below the detection limit $(1 \mathrm{Log})$ for all the other microbial groups. Contrarily, in pasteurized LEW samples counts of 3.20 Log of TAM and 2.93 Log of TAP remained. On UV-C treated LWE TAM, TAnM, TAP and TAnP loads accounted approximately 1 Log $\left(\mathrm{CFU} \cdot \mathrm{mL}^{-1}\right)$, and all the other microorganisms were below the detection limit. Again, as for the LEW, on LWE pasteurized samples counts of 3.35 Log of TAM and 3.08 Log of TAP were detected. And for LEY, counts after UV-C processing ranged around 1.5 Log, while counts around 2-3 Log of TAM, TAnM and TAP were found. In all assays, absence of Salmonella spp. in $25 \mathrm{~g}$ could be confirmed after UV-C treatments and pasteurizations.

The resistance of the microorganisms to UV-C is determined principally by the cell complexity and the ability to repair the DNA damage, in general the resistance to UV is known to be: $\operatorname{Gram}(-)<\operatorname{Gram}(+)<$ yeast $<$ spores $<$ moulds $<$ virus (Almazora, 2007). In the UVivatec ${ }^{\circledR}$ Lab reactor, the fluence rate is very high, compared to the bench scale approach, and resulted in comparable inactivation rates for all microbial groups under investigation. Only yeast and moulds were confirmed to be more resistant, with a considerably lower inactivation compared to the other microbial groups. Yeast and moulds are eukaryotic microorganisms responsible for food spoilage, and their presence in LEPs could be related to decrease in shelflife. 


\subsubsection{Physicochemical parameters}

\subsubsection{1 pH}

$\mathrm{pH}$, among other properties, is an essential attribute to achieve adequate functional properties. As for the treatments done with bench scale equipment, the treatments done on the UVivatec ${ }^{\circledR} \mathrm{Lab}$ reactor did not caused any effect on LEPs $\mathrm{pH}$ after treatment. UV-C treated LEW, LWE and LEY $\mathrm{pH}$ were not significantly different $(\mathrm{P}>0.05)$ to the homogenized control at any of the investigated doses (Table 5.18).

Table 5.18 - Effects of UV-C on the $\mathrm{pH}$ values of LEPs treated on UVivatec ${ }^{\circledR}$ Lab reactor.

\begin{tabular}{|c|c|c|c|c|c|}
\hline \multicolumn{2}{|c|}{ LEW } & \multicolumn{2}{|c|}{ LWE } & \multicolumn{2}{|c|}{ LEY } \\
\hline Treatment & $\mathbf{p H}$ & Treatment & pH & Treatment & pH \\
\hline Control & $7.96^{\mathrm{a}} \pm 0.35$ & Control & $7.24^{\mathrm{a}} \pm 0.60$ & Control & $6.36^{\mathrm{a}} \pm 0.41$ \\
\hline $\begin{array}{l}\text { Homoge- } \\
\text { nized }\end{array}$ & $8.92^{\mathrm{b}} \pm 0.20$ & $\begin{array}{l}\text { Homoge- } \\
\text { nized }\end{array}$ & $7.54^{\mathrm{a}} \pm 0.42$ & $\begin{array}{l}\text { Homoge- } \\
\text { nized }\end{array}$ & $6.43^{\mathrm{a}} \pm 0.34$ \\
\hline Pasteurized & $9.92^{\mathrm{c}} \pm 0.25$ & Pasteurized & $7.90^{\mathrm{a}} \pm 0.61$ & Pasteurized & $7.91^{\mathrm{b}} \pm 0.39$ \\
\hline 4214 J.L $\mathrm{L}^{-1}$ & $8.90^{\mathrm{b}} \pm 0.30$ & 7151 J.L L $^{-1}$ & $7.50^{\mathrm{a}} \pm 0.39$ & 31533 J.L $^{-1}$ & $6.45^{\mathrm{a}} \pm 0.33$ \\
\hline $7491 \mathrm{~J} . \mathrm{L}^{-1}$ & $8.93^{b} \pm 0.29$ & $14303 \mathrm{~J} . \mathrm{L}^{-1}$ & $7.51^{\mathrm{a}} \pm 0.29$ & 47299 J.L $\mathrm{L}^{-1}$ & $6.49^{\mathrm{a}} \pm 0.39$ \\
\hline 14982 J.L $\mathrm{L}^{-1}$ & $8.93^{b} \pm 0.23$ & $28606 \mathrm{~J} . \mathrm{L}^{-1}$ & $7.53^{\mathrm{a}} \pm 0.38$ & 94598 J.L $\mathrm{L}^{-1}$ & $6.51^{\mathrm{a}} \pm 0.21$ \\
\hline 20133 J.L $\mathrm{L}^{-1}$ & $8.92^{\mathrm{b}} \pm 0.33$ & $32181 \mathrm{~J} . \mathrm{L}^{-1}$ & $7.52^{\mathrm{a}} \pm 0.29$ & 115619 J.L ${ }^{-1}$ & $6.48^{\mathrm{a}} \pm 0.34$ \\
\hline
\end{tabular}


Results and discussion

\subsubsection{Color}

As was commented on section 5.1.2.2, customers may not accept discoloration and/or changes in the shade of LEPs caused by UV radiation or by thermal treatments, considering these LEPs as being of low-quality.

The CIELAB L*, a* and $b^{*}$ coordinates are represented on Table 5.19 and the calculated $\mathrm{BI}$ and $\Delta \mathrm{E}^{*}$ are recorded on Table 5.20. And Figures 5.21 to 5.23 show the samples general appearance. In all LEPs browning index increased as a function of the UV-C dose, this could be mainly attributed to to Maillard reaction, which is also reflected on the increasing of $\Delta \mathrm{E}^{*}$. However, $\triangle \mathrm{E}^{*}$ of UV-C LEPs was always bellow 3 indicating that the differentes instrumentally observed can not be identified by the human naked eye.

In LEW UV-C treated the $\mathrm{a}^{*}$ and $\mathrm{b}^{*}$ values remained inalterated, while the $\mathrm{L}^{*}$ coordinate significantly increased with the increasing doses, acquiring a darker color without any change on the tone. In LWE UV-C, the samples the $\mathrm{b}^{*}$ and $\mathrm{L}^{*}$ coordinate showed a decrease while the $\mathrm{a}^{*}$ increased with the augmentation of doses, tending to present darker color, with more pronounced yellow-red tones when compared to the control. And on LEY, the $\mathrm{L}^{*}$ and $\mathrm{a}^{*}$ increased and $\mathrm{b}^{*}$ decreased with the higher doses, tending to present lighter color, with more pronounced blue-red tones. Althought the differences were significant, they were always lower than on the case of thermal pasteurized controls.

Heat treatments accelerated the production of Maillard products. Compared 
to UV-C, the loss in lightness, and the increment in the parameters a* and $b^{*}$ were more evident in heat pasteurized samples, pointing out for a more extensive effect of heat on the color of the LEPs. Those results confirmed the results already observed observed for the IATA bench equipment.

Table 5.19 - CIELAB L*(Brightness), $\mathrm{a}^{*}$ (redness-greenness) and $\mathrm{b}^{*}$ (yellowness-blueness) color coordinates in LEPs

\begin{tabular}{|c|c|c|c|c|c|}
\hline & & ss & $\mathbf{L}^{*}$ & $a^{*}$ & $\mathbf{b}^{*}$ \\
\hline \multirow{6}{*}{$\begin{array}{c}\text { Egg } \\
\text { white }\end{array}$} & \multicolumn{2}{|c|}{ Natural } & $63.89^{\mathrm{a}} \pm 0.43$ & $4.79^{\mathrm{a}} \pm 0.32$ & $8.23^{\mathrm{a}} \pm 0.34$ \\
\hline & \multicolumn{2}{|c|}{ Pasteurized } & $60.15^{\mathrm{b}} \pm 0.66$ & $6.89^{b} \pm 0.26$ & $8.99^{\mathrm{a}} \pm 0.26$ \\
\hline & \multirow{4}{*}{$\begin{array}{l}\text { Dose } \\
\left(J^{-} L^{-1}\right)\end{array}$} & 4214 & $63.93^{\mathrm{a}} \pm 0.23$ & $4.89^{\mathrm{a}} \pm 0.27$ & $8.61^{\mathrm{a}} \pm 0.27$ \\
\hline & & 7491 & $63.38^{\mathrm{ab}} \pm 0.74$ & $4.80^{\mathrm{a}} \pm 0.34$ & $8.71^{\mathrm{a}} \pm 0.74$ \\
\hline & & 14982 & $62.12^{\mathrm{b}} \pm 0.90$ & $4.73^{\mathrm{a}} \pm 0.19$ & $8.23^{\mathrm{a}} \pm 0.79$ \\
\hline & & 20133 & $63.03^{\mathrm{b}} \pm 0.80$ & $4.88^{\mathrm{a}} \pm 0.36$ & $8.32^{\mathrm{a}} \pm 0.60$ \\
\hline \multirow{6}{*}{$\begin{array}{c}\text { Whole } \\
\text { egg }\end{array}$} & \multicolumn{2}{|c|}{ Natural } & $63.21^{\mathrm{a}} \pm 0.61$ & $0.05^{\mathrm{a}} \pm 0.02$ & $47.04^{\mathrm{a}} \pm 1.25$ \\
\hline & \multicolumn{2}{|c|}{ Pasteurized } & $52.28^{\mathrm{d}} \pm 0.25$ & $1.07^{\mathrm{e}} \pm 0.14$ & $58.55^{\mathrm{c}} \pm 1.70$ \\
\hline & \multirow{4}{*}{$\begin{array}{c}\text { Dose } \\
\left(\mathrm{J} . \mathrm{L}^{-1}\right)\end{array}$} & 7151 & $63.12^{\mathrm{ab}} \pm 0.26$ & $0.07^{\mathrm{b}} \pm 0.03$ & $47.27^{\mathrm{a}} \pm 0.71$ \\
\hline & & 14303 & $62.79^{\mathrm{abc}} \pm 0.81$ & $0.10^{\mathrm{bc}} \pm 0.05$ & $47.04^{\mathrm{ab}} \pm 0.35$ \\
\hline & & 28606 & $62.72^{\mathrm{bc}} \pm 0.47$ & $0.14^{\mathrm{c}} \pm 0.08$ & $46.82^{\mathrm{ab}} \pm 0.48$ \\
\hline & & 32181 & $62.32^{c} \pm 0.14$ & $0.20^{\mathrm{d}} \pm 0.07$ & $46.28^{\mathrm{b}} \pm 1.63$ \\
\hline \multirow{6}{*}{$\begin{array}{l}\text { Egg } \\
\text { yolk }\end{array}$} & \multicolumn{2}{|c|}{ Natural } & $67.69^{\mathrm{a}} \pm 0.24$ & $1.27^{\mathrm{a}} \pm 0.16$ & $57.29^{\mathrm{a}} \pm 2.64$ \\
\hline & \multicolumn{2}{|c|}{ Pasteurized } & $55.20^{\mathrm{d}} \pm 0.56$ & $3.58^{\mathrm{e}} \pm 0.33$ & $64.18^{\mathrm{c}} \pm 2.77$ \\
\hline & \multirow{4}{*}{$\begin{array}{l}\text { Dose } \\
\left(\mathrm{J}^{-L^{-1}}\right)\end{array}$} & 31 & $67.52^{\mathrm{ab}} \pm 0.57$ & $1.35^{\mathrm{ab}} \pm 0.34$ & $57.57^{\mathrm{a}} \pm 2.78$ \\
\hline & & 47299 & $67.43^{\mathrm{ab}} \pm 0.38$ & $1.53^{\mathrm{bc}} \pm 0.34$ & $57.99^{\mathrm{a}} \pm 3.30$ \\
\hline & & 94598 & $66.98^{\mathrm{bc}} \pm 0.19$ & $1.60^{\mathrm{cd}} \pm 0.12$ & $58.85^{\mathrm{a}} \pm 0.55$ \\
\hline & & 115619 & $66.51^{\mathrm{c}} \pm 1.23$ & $1.84^{\mathrm{d}} \pm 0.20$ & $69.11^{\mathrm{b}} \pm 0.97$ \\
\hline
\end{tabular}

* Results are the mean of triplicate, and each sample was measured in five different positions \pm standart deviation. Different superscripts in each column indicate difference statiscally significant at $95 \%$ confidence level 
Results and discussion

Table 5.20 - Total color difference $\left(\Delta \mathrm{E}^{*}\right)$ and browning index $(\mathrm{BI})$ in LEPs.

\begin{tabular}{|c|c|c|c|c|}
\hline & \multicolumn{2}{|c|}{ Process } & $\Delta \mathbf{E}^{*}$ & BI \\
\hline \multirow{6}{*}{$\begin{array}{c}\text { Egg } \\
\text { white }\end{array}$} & \multicolumn{2}{|c|}{ Natural } & 0 & 126.25 \\
\hline & \multicolumn{2}{|c|}{ Pasteurized } & 11.05 & 266.41 \\
\hline & \multirow{4}{*}{$\begin{array}{l}\text { Dose } \\
\left(\mathrm{J} . \mathrm{L}^{-1}\right)\end{array}$} & 4214 & 0.39 & 140.42 \\
\hline & & 7491 & 0.71 & 151.53 \\
\hline & & 14982 & 0.77 & 177.31 \\
\hline & & 20133 & 0.87 & 197.84 \\
\hline \multirow{6}{*}{$\begin{array}{l}\text { Whole } \\
\text { egg }\end{array}$} & \multirow{2}{*}{\multicolumn{2}{|c|}{$\begin{array}{c}\text { Natural } \\
\text { Pasteurized } \\
\end{array}$}} & 0 & 292.46 \\
\hline & & & 15.21 & 905.02 \\
\hline & \multirow{4}{*}{$\begin{array}{c}\text { Dose } \\
\left(\mathrm{J}^{-L^{-1}}\right)\end{array}$} & 7151 & 0.55 & 252.81 \\
\hline & & 14303 & 1.07 & 373.03 \\
\hline & & 28606 & 1.9 & 418.04 \\
\hline & & 32181 & 2.75 & 526.11 \\
\hline \multirow{6}{*}{$\begin{array}{l}\text { Egg } \\
\text { yolk }\end{array}$} & \multirow{2}{*}{\multicolumn{2}{|c|}{$\begin{array}{c}\text { Natural } \\
\text { Pasteurized } \\
\end{array}$}} & 0 & 160.2 \\
\hline & & & 10.88 & 213.66 \\
\hline & \multirow{4}{*}{$\begin{array}{l}\text { Dose } \\
\left(\mathrm{J}^{-L^{-1}}\right)\end{array}$} & 31533 & 0.36 & 183.1 \\
\hline & & 47299 & 0.4 & 197.52 \\
\hline & & 94598 & 1.98 & 216.98 \\
\hline & & 115619 & 1.91 & 241.24 \\
\hline
\end{tabular}

Natural $\quad 4214 \mathrm{JL}^{-1} \quad 4214 \mathrm{JL}^{-1} \quad 4214 \mathrm{JL}^{-1} \quad 4214 \mathrm{JL}^{-1} \quad$ Pasteurized

Figure 5.21 - Natural, UV-treated and pasteurized LEW.

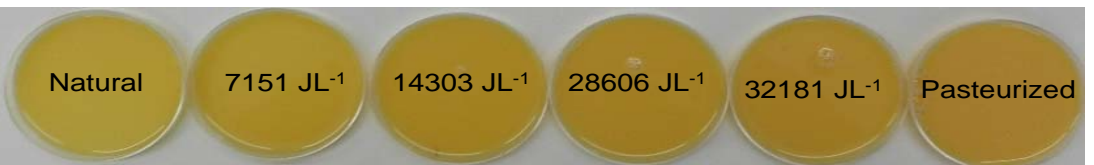

Figure 5.22 - Natural, UV-treated and pasteurized LWE.

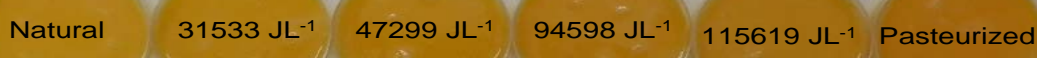

Figure 5.23 - Natural, UV-treated and pasteurized LEY. 


\subsubsection{UV-effects on fat}

\subsubsection{Lipid oxidation (TBARS)}

A large number of toxic by-products are formed during lipid oxidation and they can have effects at a site away from their generation area. The intermediate and end products of lipid peroxidation may also be mutagenic and carcinogenic (Marnett, 1999), and UV-C radiation is known to be an effective promotor of lipid peroxidation. UV-C treatment of LEPs can cause quality deterioration due to oxidation of unsaturated fatty acids and cholesterol. The evaluation of the formation of TBARS provides an estimation of the lipid oxidation extention originated by UV-C processing.

The TBARS values of LEPs controlsb were 0.567 mgMDA. $\mathrm{kg}^{-1}$ for LWE and 0.737 mgMDA. $\mathrm{kg}^{-1}$ for LEY. Tests with LEW was not performed since lipids on this fraction will be only due contamination with LEY during braking. The TBARS values obtained in this study are comparable to those obtained with eggs from Avícola Llombay that were used on the studies on the IATA bench device prouving that the sample preparation steps did not affect the quality of the initial product.

Contrarily to the results pointed with the UV-C processing, Caboni et al. (2005) found that the spray-drying led to the formation of furosine (a product of Maillard reaction) and the oxidation of cholesterol. 
Results and discussion

The TBARS values for UV-C treated LEPs are shown in Figure 5.24. UV-C induced a slight not statistically significant TBARS increase in LWE. But a statistically significant increase in LEY was already observed at the lowest dose studied $\left(31,533 \mathrm{~J} \cdot \mathrm{L}^{-1}\right)$. It seems that the egg white proteins are able to protect the lipid fraction of the yolk against oxidation.

At the highest applied doses $\left(32,181 \mathrm{~J} . \mathrm{L}^{-1}\right.$, or $2.976 \mathrm{~J} . \mathrm{cm}^{-2}$, for LWE and $115,619 \mathrm{~J} . \mathrm{L}^{-1}$, or $10.693 \mathrm{~J} . \mathrm{cm}^{-2}$, for LEY) TBARS values increased from 0.567 to 0.705 mgMDA. $\mathrm{kg}^{-1}$ on LWE, and from 0.737 to 1.077 mgMDA. $\mathrm{kg}^{-1}$ on LEY. These values are lower than those reported on section 5.1.3.1 by using a bench UV apparatus and operating in continous and in static systems with doses up to $3.645 \mathrm{~J} . \mathrm{cm}^{-2}$.

The continuous mixing system and the fact that the samples are protected of the oxygen by the quartz glass can contribute to lower formation of ROS (reactive oxygen nitrogen species) and lower lipid peroxidation in the Dean vortex system, although between the cycles the samples get in touch with the oxygen and probably due to this process defect a slight increase on the TBARS is observed.

There are only few reports in the literature about the effects of the treatments on the TBARS values of eggs. But it is known that the thermal treatment of eggs caused a remarkable increase in the TBARS, e.g., scrambling and boiling.generated 2 times higher TBARS levels in fresh eggs (Ren, 2009). TBARS values also increased considerably in heat processed commercial egg samples, the values jumped from 0.17 
mgMDA. $\mathrm{kg}^{-1}$ of oil to $2.24 \mathrm{mgMDA} \mathrm{kg}{ }^{-1}$, as studied in the work of Liu et al. (2005). A control sample which was pumped through the device, the same numbers of cycles need to reach the doses of $31,181 \mathrm{~J}^{-L^{-1}}$ on LWE and $115,619 \mathrm{~J}^{-\mathrm{L}^{-1}}$ on LEY, without UV-C showed TBARS values of 0.601 and $0.799 \mathrm{mg}$ MDA. $\mathrm{kg}^{-1}$ respectively to LWE and LEY, which are higher than the natural untreated control.
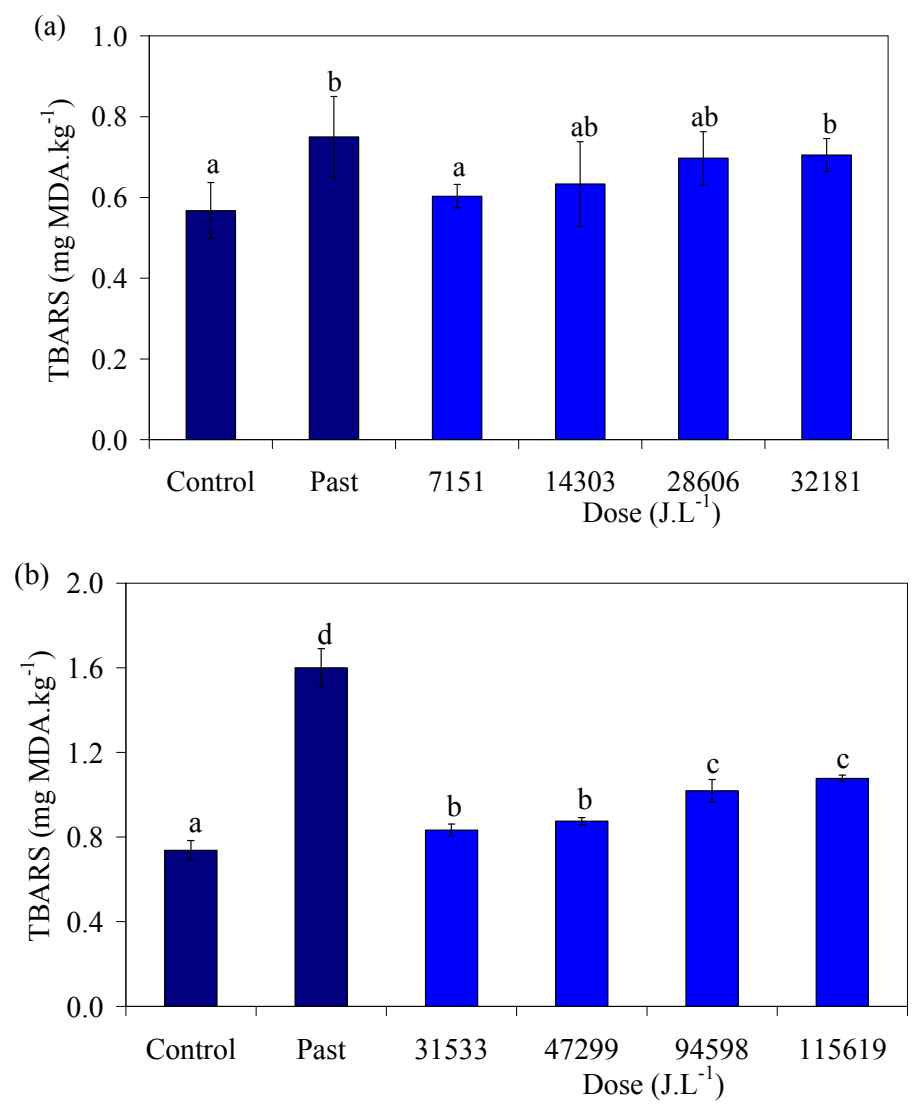

Figure 5.24 - Influence of UV-C radiation on lipid oxidation of (a) LWE and (b) LEY. Results are the mean of triplicate \pm standart deviation. Different superscripts in each bar indicate difference statiscally significant at $95 \%$ confidence level. 
Results and discussion

In this study the TBARS values increased in all fat-LEPs, but the values were statistically significant only in the yolk fraction. Although, the attained values are still lower than the values measured after heat treatment presented on section 5.1.3.1 for the IATA bench devic. The treatment of LEY at $61.1{ }^{\circ} \mathrm{C}$ for $3.5 \mathrm{~min}$, indicate by the USDA (1969) for egg yolk pasteurization, increased the TBARS from 0.7 to $1.6 \mathrm{mgMDA} \cdot \mathrm{kg}^{-1}$, and on LWE, the treatement at $60{ }^{\circ} \mathrm{C}$ during 3.5 min increased the TBARS from 0.6 to 0.8 mgMDA.kg ${ }^{-1}$.

\subsubsection{Peroxide value (PV)}

Lipid hydroperoxides are intermediates of lipid peroxidation derived from unsaturated fatty acids, phospholipids, glycolipids, cholesterol esters and cholesterol itself. Their formation occurs in enzymatic or non-enzymatic reactions by reactive oxygen or nitrogen species (ROS/RNS). The toxicity of lipid peroxides is well known and the absence of an endogenous antioxidant enzyme such as glutathione peroxidase, which is responsible for reduction of lipid hydroperoxides, in mice leads to death of animals indicating that the removal of lipid hydroperoxides is essential for mammalian life (Muller et al., 2007).

To assess the effects of the UV-C treatments on the oxidative stability of liquid egg products the peroxide value was measured as an indirect measure of primary oxidation products (Figure $5.25 \mathrm{a}$ and $\mathrm{b}$ ). The maximum level for peroxide value of refined oil is 10 meq $\mathrm{O}_{2} \cdot \mathrm{kg}^{-1}$ (Joint FAO/WHO, 1989). 

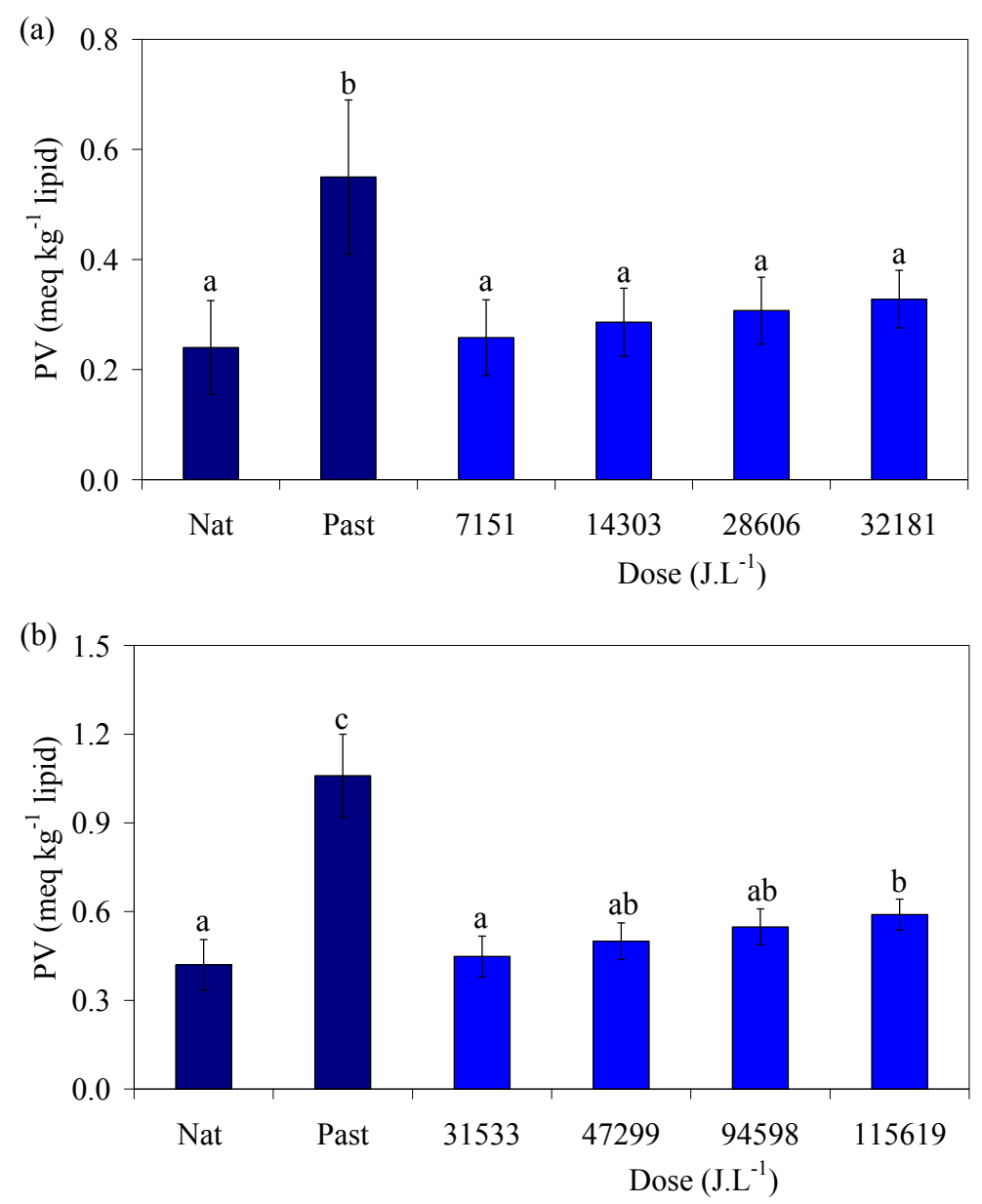

Figure 5.25 - Peroxide value (a) LWE (b) LEY. Results are the mean of triplicate \pm standart deviation. Different superscripts in each bar indicate difference statiscally significant at $95 \%$ confidence level.

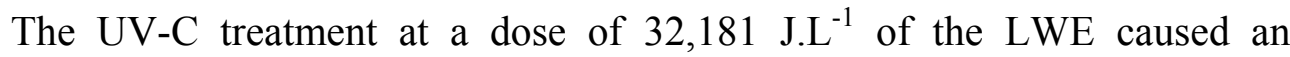
increase from $0.24 \mathrm{meqO} \mathrm{Fg}^{-1}$ before irradiation to $0.33 \mathrm{meqO} \mathrm{kg}^{-1}$ after treatment, and 115,619 J.L ${ }^{-1}$ increased the PV of LEY from 0.42 to 0.59 meqO $\mathrm{O}_{2} \cdot \mathrm{kg}^{-1}$. The observed differences were not statistically significant in 
Results and discussion

comparison to a control sample which was pumped through the device without UV-C exposure.

The tendency of PV values confirms the results of TBARS. UV-C treatment caused a slight but statistically significant increase of TBARS while non statistically significant increase of the peroxides values was registrated. Primary oxidation processes in oil mainly form hydroperoxides, which are measured by the PV. In general, the lower the PV, better the quality of the oil. However PV decreases as secondary oxidation products appear, while the TBARS value is a method to investigate secondary oxidative aldehyde products, usually in PUFA (polyunsaturated fatty acids).

\subsubsection{UV-effects on proteins: Protein oxidation}

Protein oxidation plays a phytopathological role and may affect protein functions relevant in pathological processes, besides LEPs tecnological functional properties. Mainly methionine residues are oxidized, being also important the oxidation of cysteines because of the physiological and phytopathological role of those amininoacids. For example, oxidative modification of enzymes has been shown to inhibit a wide array of enzyme activities (Fucci et al., 1983; Stadtman, 1990). Oxidative modification of enzymes can have either mild or severe effects on the cellular or systemic metabolism, depending on the amount of modified molecules and the chronicity of the modification (Shacter, 2000). Changes in the antioxidative activity of enzymes such as superoxide dismutase might induce oxidative 
stress and increase the risks associated to pathologies. One of the most commonly measured markers of protein oxidation in biological samples is the decrease in the sulfhydryl $(\mathrm{SH})$ content.

The concentration of total SH groups in LEW was $68 \mu \mathrm{M} \cdot \mathrm{g}^{-1}$. This value is

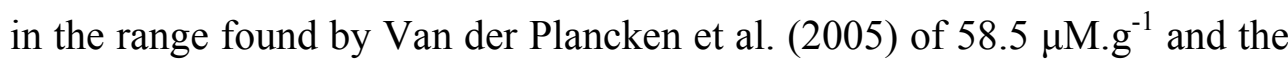
value of $50.7 \mu \mathrm{M} . \mathrm{g}^{-1}$ dry weight observed by Beveridge et al. (1974). In the

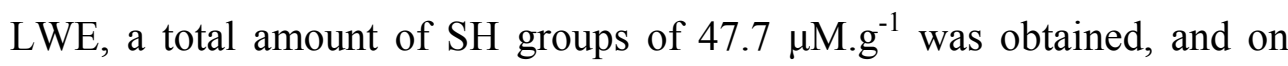

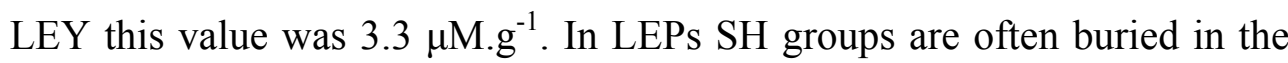
protein core and therefore inaccessible for 5,5'-dithio-bis(2-nitrobenzoic acid) (DTNB) as shown by the low content of exposed SH groups for the untreated samples. As happed with heat treatment (Beveridge and Arntfield, 1979), UV-C treatment resulted in a slight decrease of total $\mathrm{SH}$ concentration. The relative values decreased to $80.19 \%$ in LEW, $91.39 \%$ in LWE and 95.04 \% in LEY at the highest doses studied (Figure 5.26).

The amount of exposed SH groups increased slightly in all fractions, with differences more pronounced after the application of higher doses. Only in LEW and for doses above 20,133 J.L $\mathrm{L}^{-1} \mathrm{SH}$ oxidation were statistically significant.

In LEW, buried SH groups also decreased slightly due to UV-C treatments likely due to a certain protein unfolding and the subsequent increase in exposed SH groups. The possible mechanism for the further reaction of exposed SH groups is the sulfhydryl-disulfide (SS) exchange reaction was already enumerated on section 5.1.4.2. 


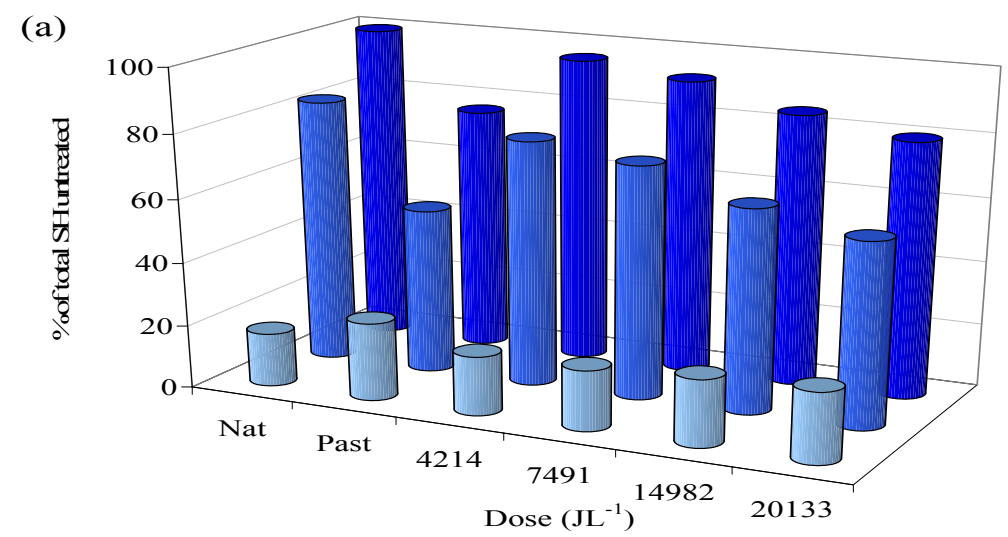

(b)

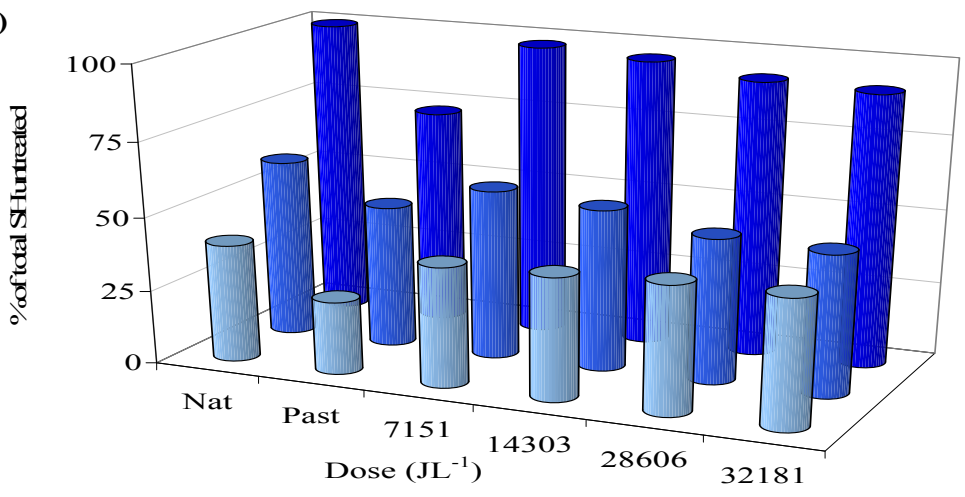

(c)

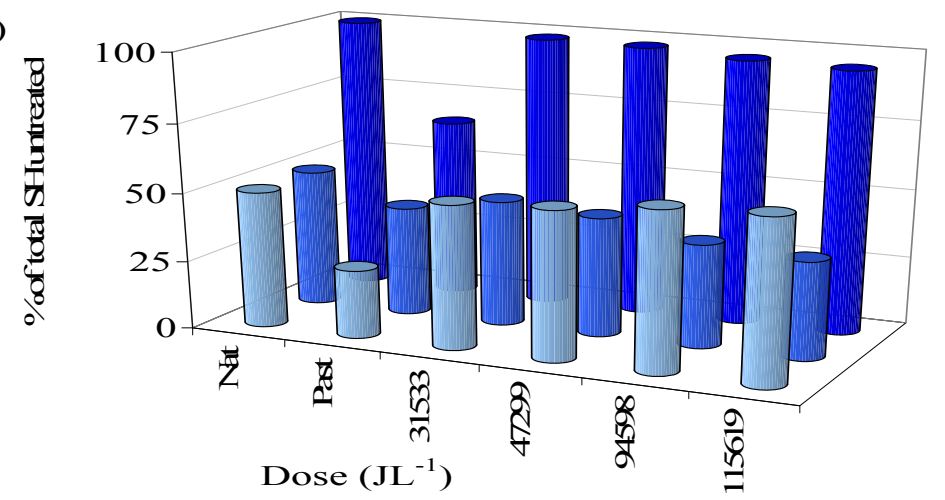

Figure 5.26 - Effect of UV-C treatment on the exposed $(\square)$, masked ( $\square$ ) and total $\square$ sulfhydryl content of (a) LEW (b) LWE and (c) LEY. Results are the mean of triplicate, standard deviation is less then $5 \%$. 
Changes induced by UV-C in the concentration of buried and exposed $\mathrm{SH}$ groups are minimal if compared to the ones typically observed for heat or pressure treated ovalbumin (Van der Plancken et al., 2005). Consequently, UV-C treatments at microbiological reduction levels equivalent to heat pasteurizations (data show on section 5.2.1.1 and 5.2.1.2) are relatively mild for protein oxidation. As on the LEW, the SH groups from the LWE and LEY were mainly buried in the protein core and therefore inaccessible for DTNB when no denaturant (SDS) was applied. The UV-C induced unfolding of the whole egg and egg yolk proteins, also resulting in an increased exposure of buried sulfhydryl groups (Figure $5.26 \mathrm{~b}$ and c) which also may take part of SH-SS exchanges.

In general, UV-C induced small changes in $\mathrm{SH}$ groups (total, exposed, and buried) in LEPs, and changes were more pronounced in LEW, being the characteristic composition (lipides) of the egg yolk able to reduce the impact of UV-C in egg proteins. Under those conditions, no gel formation occurred; only turbid suspensions of protein aggregates were obtained after treatment at the highest doses, probably due to a certain degree of protein aggregation induced by the exposed SH groups. UV-C induced lower protein oxidation levels than the traditional pasteurization method employed. 


\subsection{Shelf life}

Shelf life is an important property of any food and is of interest to everyone in the food chain, from producer to consumer. No single factor may determine the shelf life of a food but the most important to be considered in shelf life studies is the microbiological changes. In the case of eggs, they are high in protein and are highly vulnerable to bacterial growth in a short span of time. The egg has a natural protective coating that provides protection for small contamination of bacteria like Escherichia, Klebsiella, Yersinia and Salmonella, although this protection is not enough for eggs high contaminated or that were not handled correctly.

On this section the shelf life of UV-treated eggs is discussed. Egg fractions were treated in batch to get a first approach of the shelf life behavior of UVtreated eggs under refrigerated storage and at room temperature (advanced shelf life). Secondly the experiment was repeated for the LEPs treated on the UVivatec ${ }^{\circledR}$ Lab reactor based on dean vortex technology aiming an approximation of an industrial process. The dose used on this part of the study was determined by the previous microbiological studies using pathogens and naturally occurring microorganisms, already presented on sections 5.1.1, 5.1.2, 5.3.1 and 5.3.2.

\subsubsection{Shelf life of LEPs treated in batch}




\subsubsection{Microbiology}

Optimal UV-C treatment conditions were selected on the basis of the results obtained with inoculated bacteria and the inactivation of the naturally occurring micro flora. The evolution of the microbial load of LEPs was evaluated in samples stored under refrigeration $\left(4 \pm 2{ }^{\circ} \mathrm{C}\right)$ for up to 8 weeks, and at room temperature $\left(20{ }^{\circ} \mathrm{C}\right)$ over 15 days. Conventional heat pasteurized samples, as stated in the Materials and Methods section, were used as a reference. Microbial loads of UV-C and pasteurized samples at day 0 of storage are shown on Table 5.21.

Changes in microbial loads in the UV-C and heat processed LEPs during storage at 4 and $20{ }^{\circ} \mathrm{C}$ are shown in Figures 5.27, 5.28 and 5.29 for LEW, LWE and LEY respectively. In those figures, data are presented as the mean of three independent experiments \pm standard deviation.

The effects of UV-C are significant for all investigated microbial groups, a resume of the data provide the following observations. Total aerobic mesophilic counts presented a quasi-linear growth during 8 weeks of refrigerated storage in all liquid egg products, and even at the end of the 8 weeks storage growth still had not reached the exponential phase. Total aerobic psychrotrophic counts remained stable during the first 4 weeks, presenting subsequently an exponential growth. 
Results and discussion

Table 5.21 - Microbial loads of LEPs at day 0 of storage.

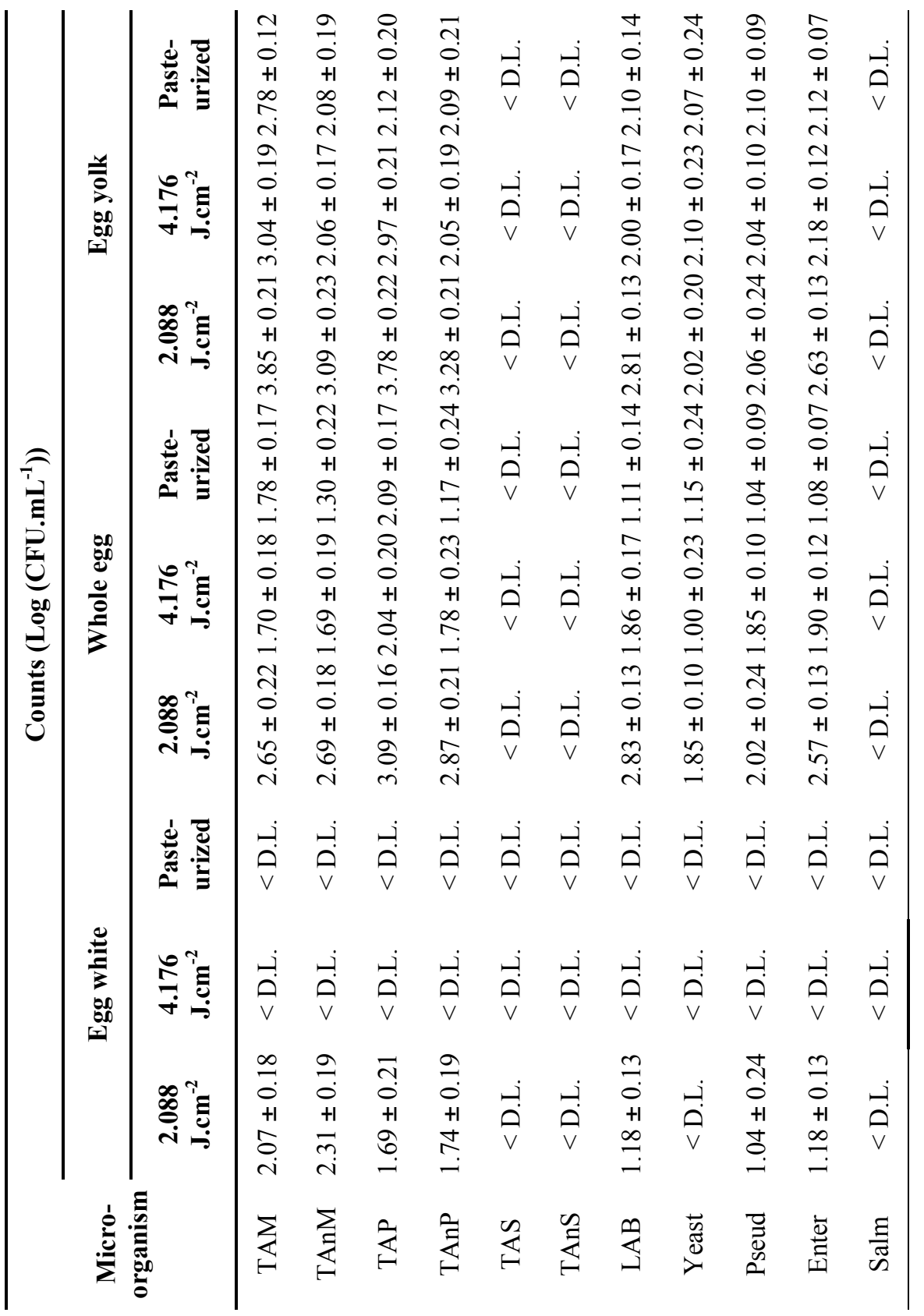

Results are the mean of triplicate \pm standart deviation.

D.L.: Detection limit (1Log) 

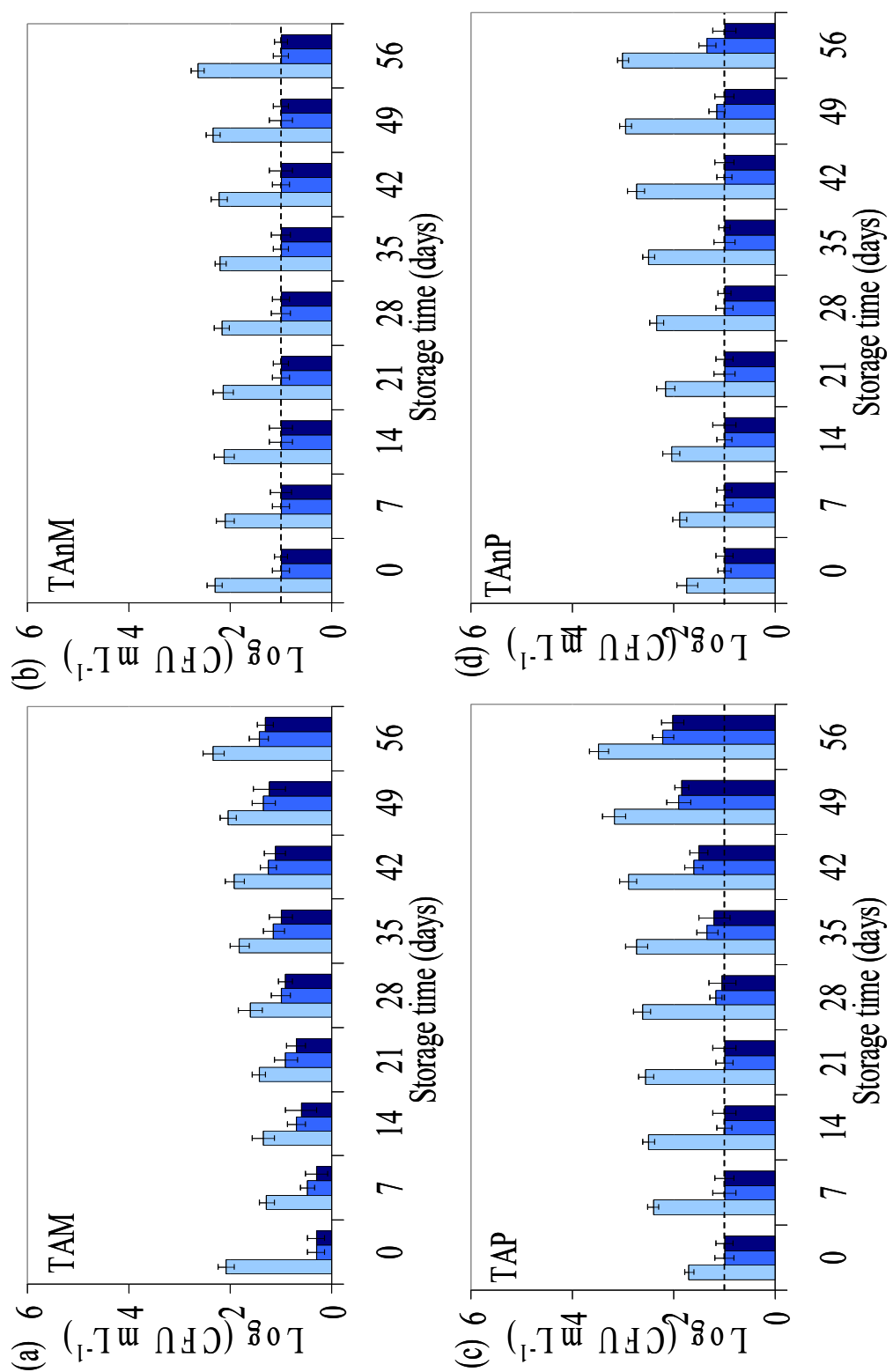

Figure 5.27 - Changes in microorganisms of UV-C ( $\square 2.088{\mathrm{~J} . m L^{-1}}^{2}$ and $\square$ 4.076 J.mL ${ }^{-1}$ ) and heat pasteurized $\square$ LEW during storage at $4{ }^{\circ} \mathrm{C}$. (a) TAM, (b) TAnM, (c) TAP, (d) TAnP, (e) LAB, (f) Yeast, (g) Pseudomonas spp. and (h) Enterobacteriacea. Results are the mean of triplicate \pm standart deviation. Dashed line represents the detection limit $(1 \mathrm{Log})$. 

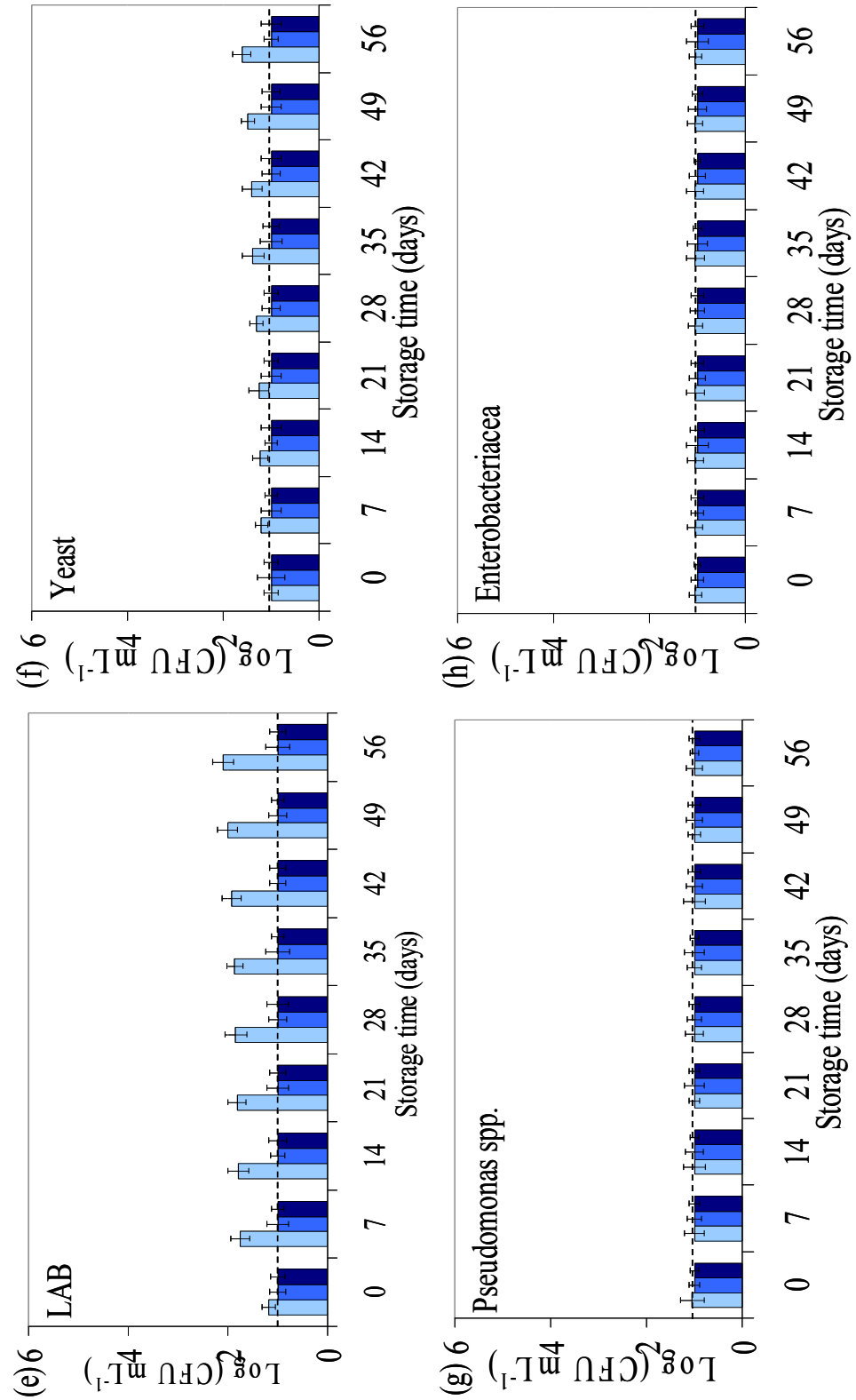

Figure 5.27 (cont.) - Changes in microorganisms of UV-C ( $\square 2.088 \mathrm{~J}^{\mathrm{m}} \mathrm{mL}^{-1}$ and $\square 4.076 \mathrm{~J} . \mathrm{mL}^{-1}$ ) and heat pasteurized $(\square) \mathrm{LEW}$ during storage at $4{ }^{\circ} \mathrm{C}$. (a) TAM, (b) TAnM, (c) TAP, (d) TAnP, (e) LAB, (f) Yeast, (g) Pseudomonas spp. and (h) Enterobacteriacea. Results are the mean of triplicate \pm standart deviation. Dashed line represents the detection limit (1 $\log )$. 


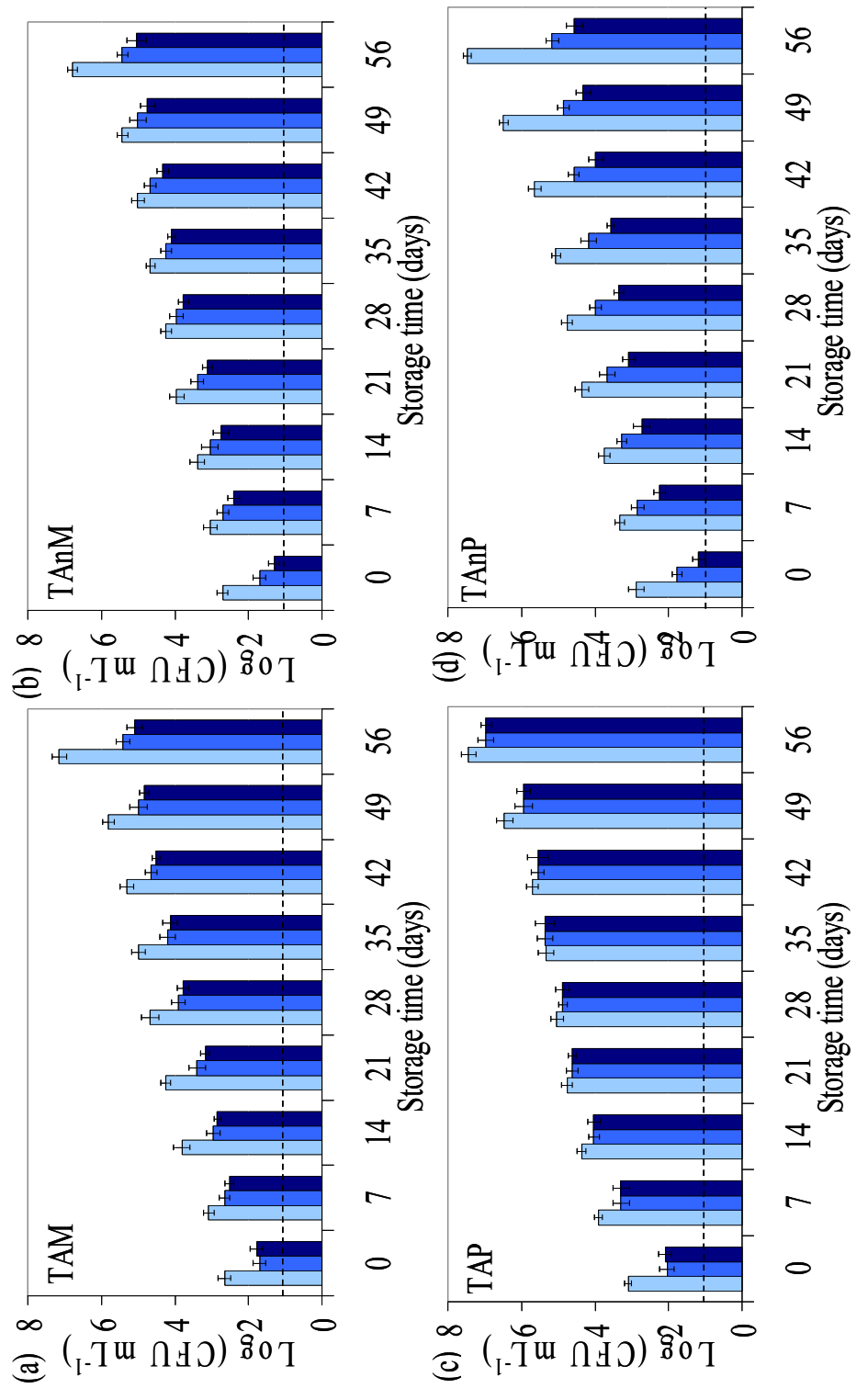

Figure 5.28 - Changes in microorganisms of UV-C ( $\square 2.088 \mathrm{~J}^{-\mathrm{mL}^{-1}}$ and $\square$ 4.076 J.mL $\mathrm{mL}^{-1}$ ) and heat pasteurized $\square$ LWE during storage at $4{ }^{\circ} \mathrm{C}$. (a) TAM, (b) TAnM, (c) TAP, (d) TAnP, (e) LAB, (f) Yeast, (g) Pseudomonas spp. and (h) Enterobacteriacea. Results are the mean of triplicate \pm standart deviation. Dashed line represents the detection limit $(1 \mathrm{Log})$. 
Results and discussion
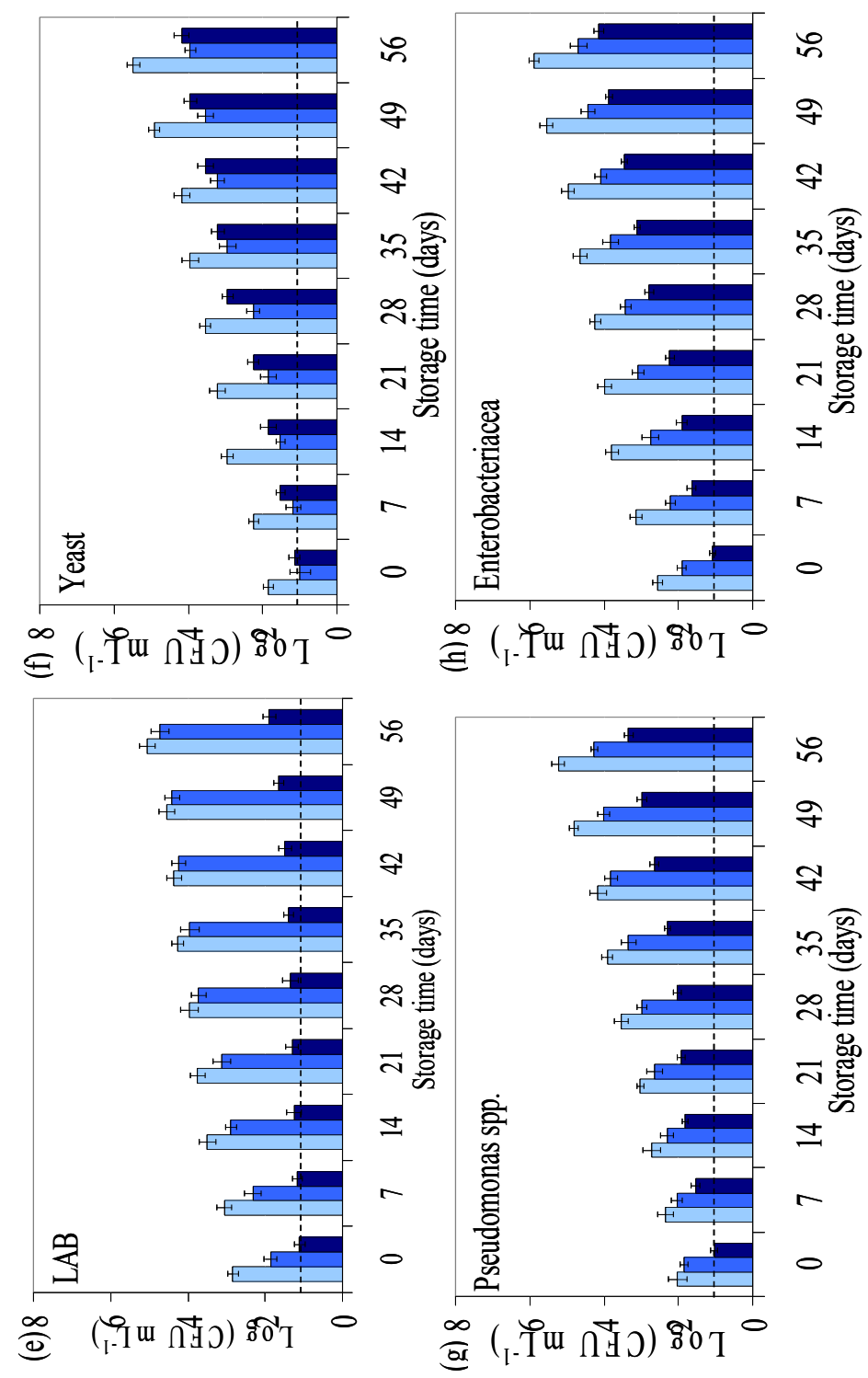

Figure 5.28 (cont.) - Changes in microorganisms of UV-C ( $\square 2.088 \mathrm{~J} . \mathrm{mL}^{-1}$ and $\square$ 4.076 J.mL ${ }^{-1}$ ) and heat pasteurized $(\square)$ LWE during storage at $4{ }^{\circ} \mathrm{C}$. (a) TAM, (b) TAnM, (c) TAP, (d) TAnP, (e) LAB, (f) Yeast, (g) Pseudomonas spp. and (h) Enterobacteriacea. Results are the mean of triplicate \pm standart deviation. Dashed line represents the detection limit (1 $\log )$. 

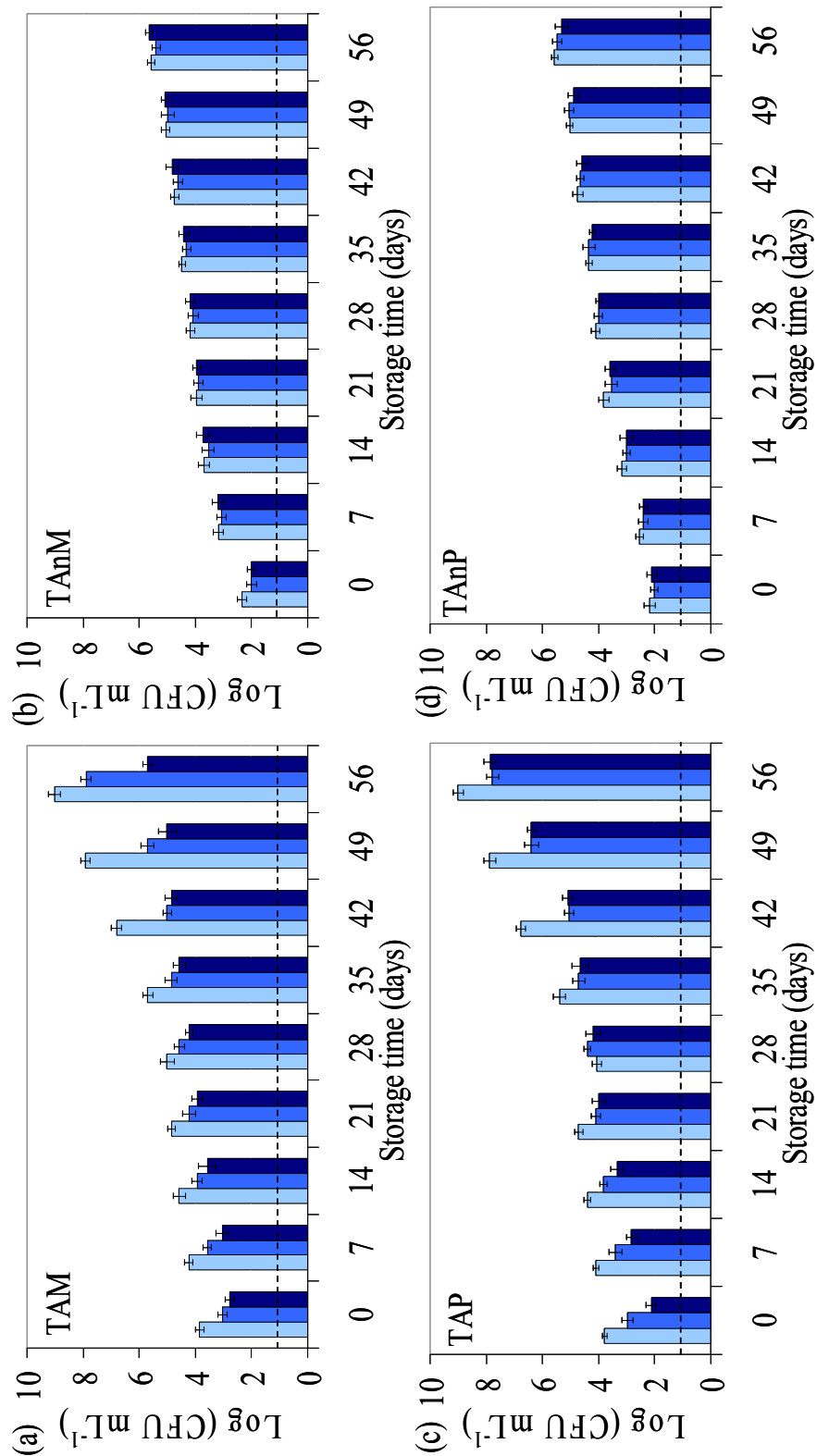

Figure 5.29 - Changes in microorganisms of UV-C ( $\square$ 2.088 J.mL $\mathrm{m}^{-1}$ and $\square$ 4.076 J.mL ${ }^{-1}$ ) and heat pasteurized ( $\square$ ) LEY during storage at $4{ }^{\circ} \mathrm{C}$. (a) TAM, (b) TAnM, (c) TAP, (d) TAnP, (e) LAB, (f) Yeast, (g) Pseudomonas spp. and (h) Enterobacteriacea. Results are the mean of triplicate \pm standart deviation. Dashed line represents the detection limit $(1 \mathrm{Log})$. 
Results and discussion
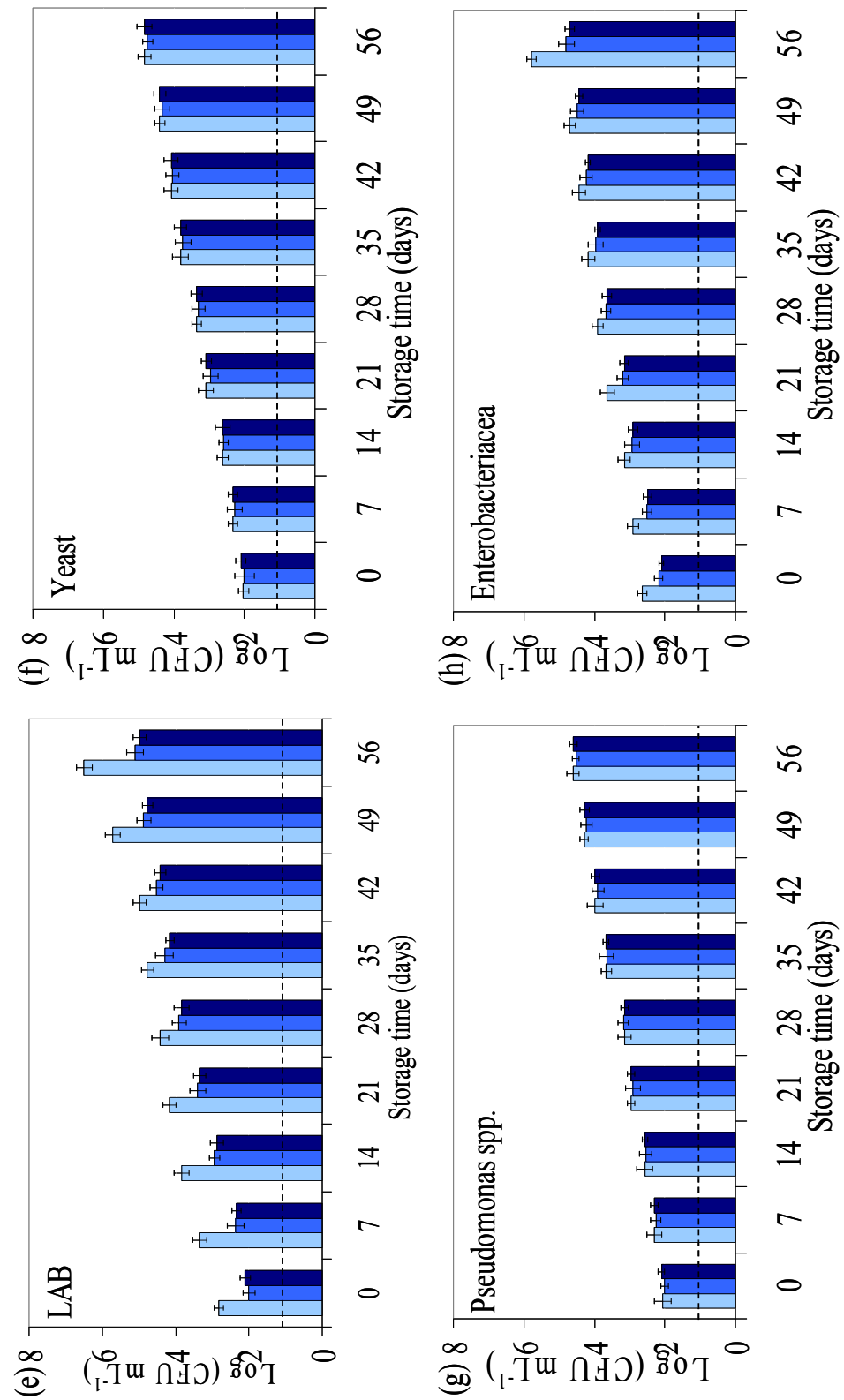

Figure 5.29 (cont.) - Changes in microorganisms of UV-C ( $\square 2.088 \mathrm{~J}^{-\mathrm{mL}^{-1}}$ and $\square 4.076 \mathrm{~J} . \mathrm{mL}^{-1}$ ) and heat pasteurized ( $\square$ ) LEY during storage at $4{ }^{\circ} \mathrm{C}$. (a) TAM, (b) TAnM, (c) TAP, (d) TAnP, (e) LAB, (f) Yeast, (g) Pseudomonas spp. and (h) Enterobacteriacea. Results are the mean of triplicate \pm standart deviation. Dashed line represents the detection limit (1 $\log )$. 
In LEW, relatively low UV-C doses and heat pasteurization treatments provided remarkable effects on the total anaerobic psychrotrophic counts, while the samples treated with doses below $3 \mathrm{~J} . \mathrm{cm}^{-2}$ showed a linear growth. In egg whites at $4{ }^{\circ} \mathrm{C}$, microbial loads of all other spoilage-related groups remained stable during 8 weeks shelf-life, and the counts of the UV-C LEW treated with $4.176 \mathrm{~J} . \mathrm{cm}^{-2}$ were comparable to the counts of heat pasteurized samples.

Even at the end of the storage period at $4{ }^{\circ} \mathrm{C}$, the counts had not reached the recommended maximum. In particular, the number of LAB, Pseudomonas spp., Enterobacteriaceae and yeasts were inactivated to undetectable levels, and remained below the detection level during the entire shelf-life. All the treated albumen samples were free of Salmonella spp., spores and moulds. However, the UV-C treatment below $3{\mathrm{~J} . \mathrm{cm}^{-2}}^{-}$exhibited a lower initial inactivation efficacy, which was also reflected on the evolution of the microbial load during refrigerated storage.

Similar observations were made for the accelerated study at $20{ }^{\circ} \mathrm{C}$ (Figure 5.30, 5.31 and 5.32 for LEW, LWE and LEY respectively).

UV-C treatment at doses above $4 \mathrm{~J} . \mathrm{cm}^{-2}$ was as effective as heat pasteurization since both treatments achieved comparable initial inactivation degrees and assured microbial stability during the entire storage period. Regarding Pseudomonas spp. and Enterobacteriaceae, no viable cells were detected during the entire storage period for both UV treatments as well as for the heat pasteurized sample. 
Results and discussion

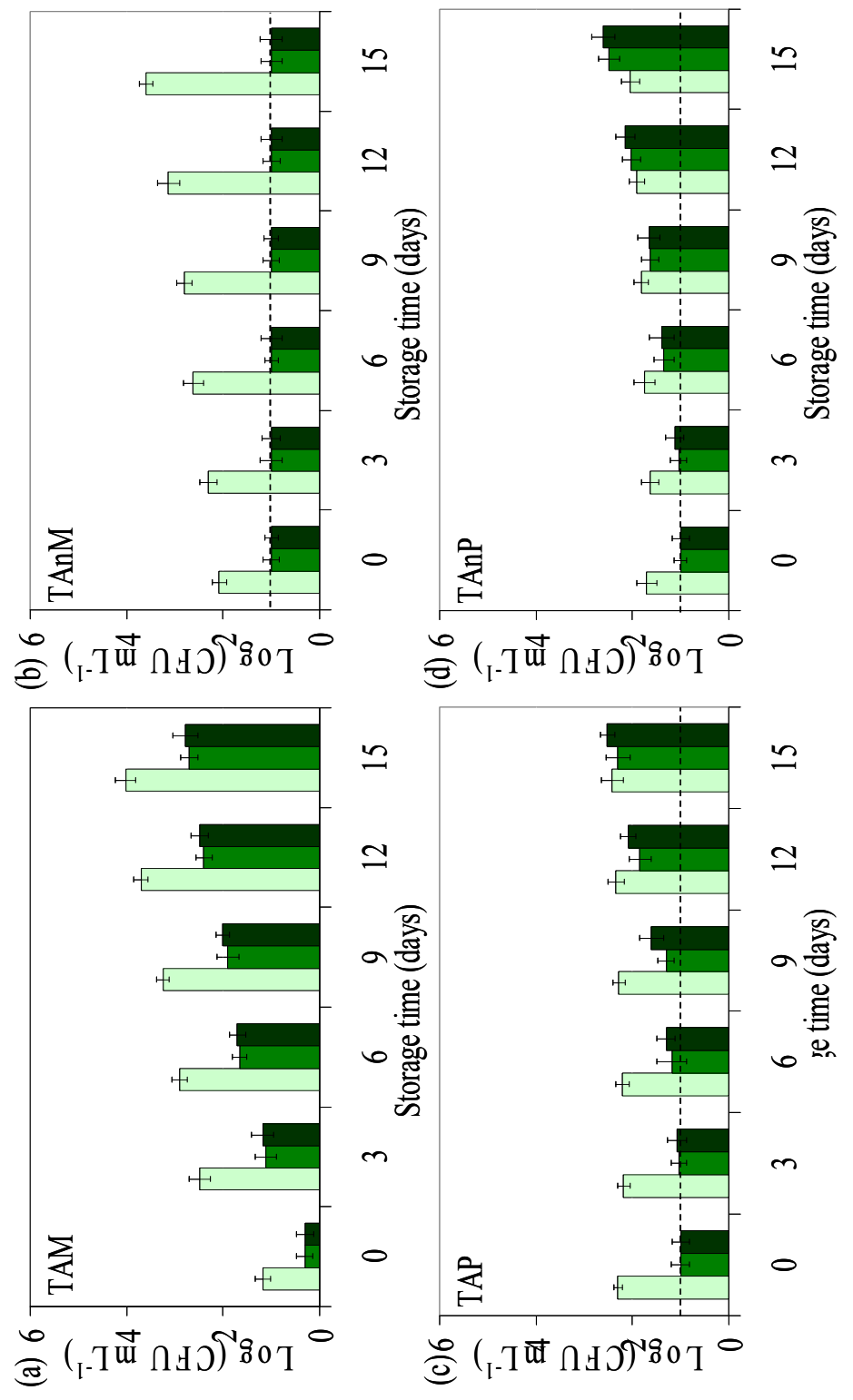

Figure 5.30 - Changes in microorganisms of UV-C ( $\square 2.088 \mathrm{~J}_{\mathrm{mL}} \mathrm{m}^{-1}$ and $\square 4.076 \mathrm{~J} . \mathrm{mL}^{-1}$ ) and heat pasteurized ( $\square$ LEW during storage at $20{ }^{\circ} \mathrm{C}$. (a) TAM, (b) TAnM, (c) TAP, (d) TAnP, (e) LAB, (f) Yeast, (g) Pseudomonas spp. and (h) Enterobacteriacea. Results are the mean of triplicate \pm standart deviation. Dashed line represents the detection limit $(1 \mathrm{Log})$. 

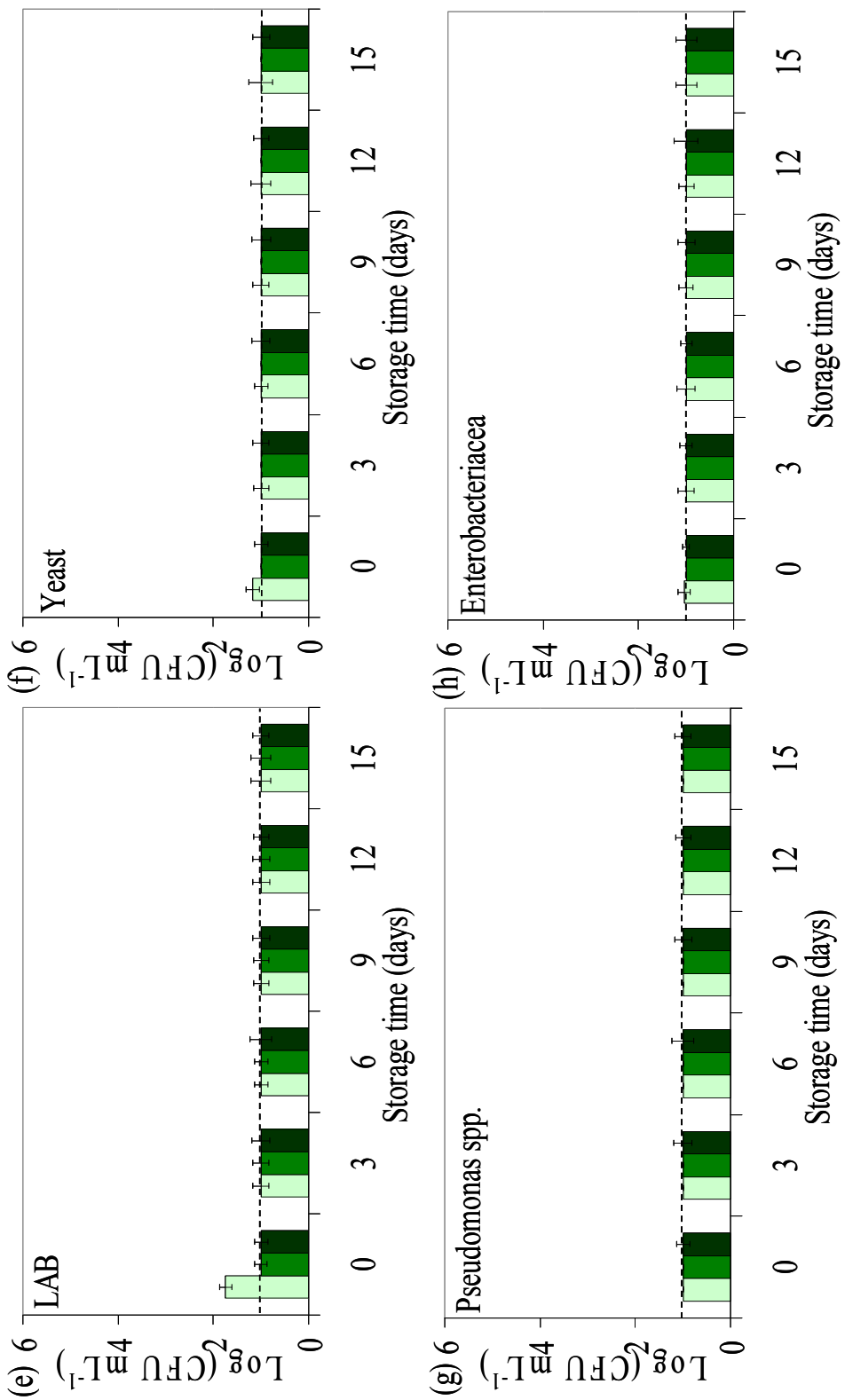

Figure 5.30 (cont.) - Changes in microorganisms of UV-C ( $\square 2.088$ J.mL ${ }^{1}$ and $\square 4.076 \mathrm{~J} . \mathrm{mL}^{-1}$ ) and heat pasteurized ( $\square$ ) LEW during storage at 20 ${ }^{\circ}$ C. (a) TAM, (b) TAnM, (c) TAP, (d) TAnP, (e) LAB, (f) Yeast, (g) Pseudomonas spp. and (h) Enterobacteriacea. Results are the mean of triplicate \pm standart deviation. Dashed line represents the detection limit (1 $\log )$. 


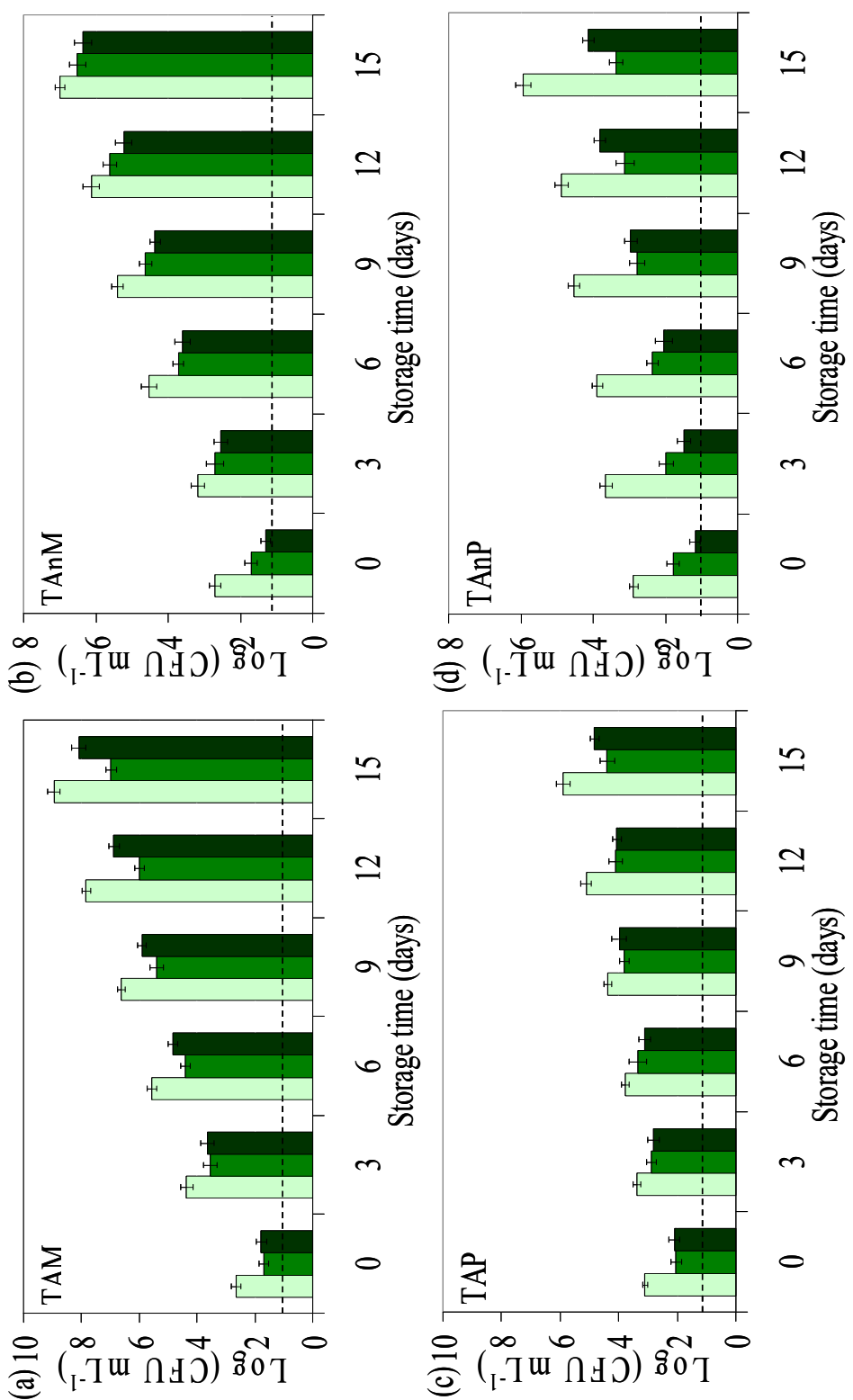

Figure 5.31 - Changes in microorganisms of UV-C ( $\square 2.088 \mathrm{~J} . \mathrm{mL}^{-1}$ and $\square$ 4.076 J.mL ${ }^{-1}$ ) and heat pasteurized ( $\square$ ) LWE during storage at $20{ }^{\circ} \mathrm{C}$. (a) TAM, (b) TAnM, (c) TAP, (d) TAnP, (e) LAB, (f) Yeast, (g) Pseudomonas spp. and (h) Enterobacteriacea. Results are the mean of triplicate \pm standart deviation. Dashed line represents the detection limit (1 Log). 


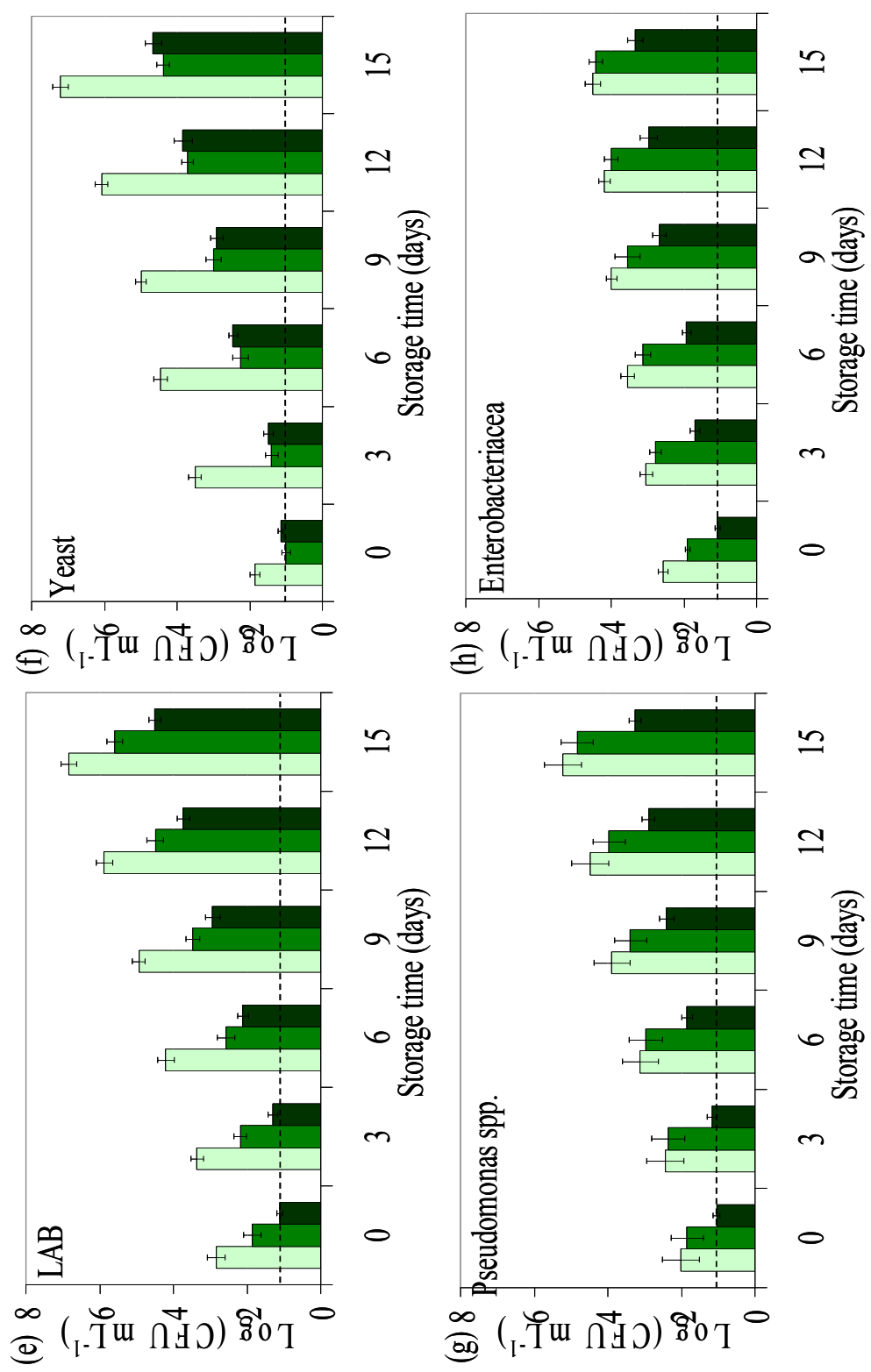

Figure 5.31 (cont.) - Changes in microorganisms of UV-C ( $\square 2.088 \mathrm{~J} . \mathrm{mL}^{-1}$ and $\square 4.076 \mathrm{~J} . \mathrm{mL}^{-1}$ ) and heat pasteurized $(\square) \mathrm{LWE}$ during storage at $20^{\circ} \mathrm{C}$. (a) TAM, (b) TAnM, (c) TAP, (d) TAnP, (e) LAB, (f) Yeast, (g) Pseudomonas spp. and (h) Enterobacteriacea. Results are the mean of triplicate \pm standart deviation. Dashed line represents the detection limit (1 $\log )$. 
Results and discussion

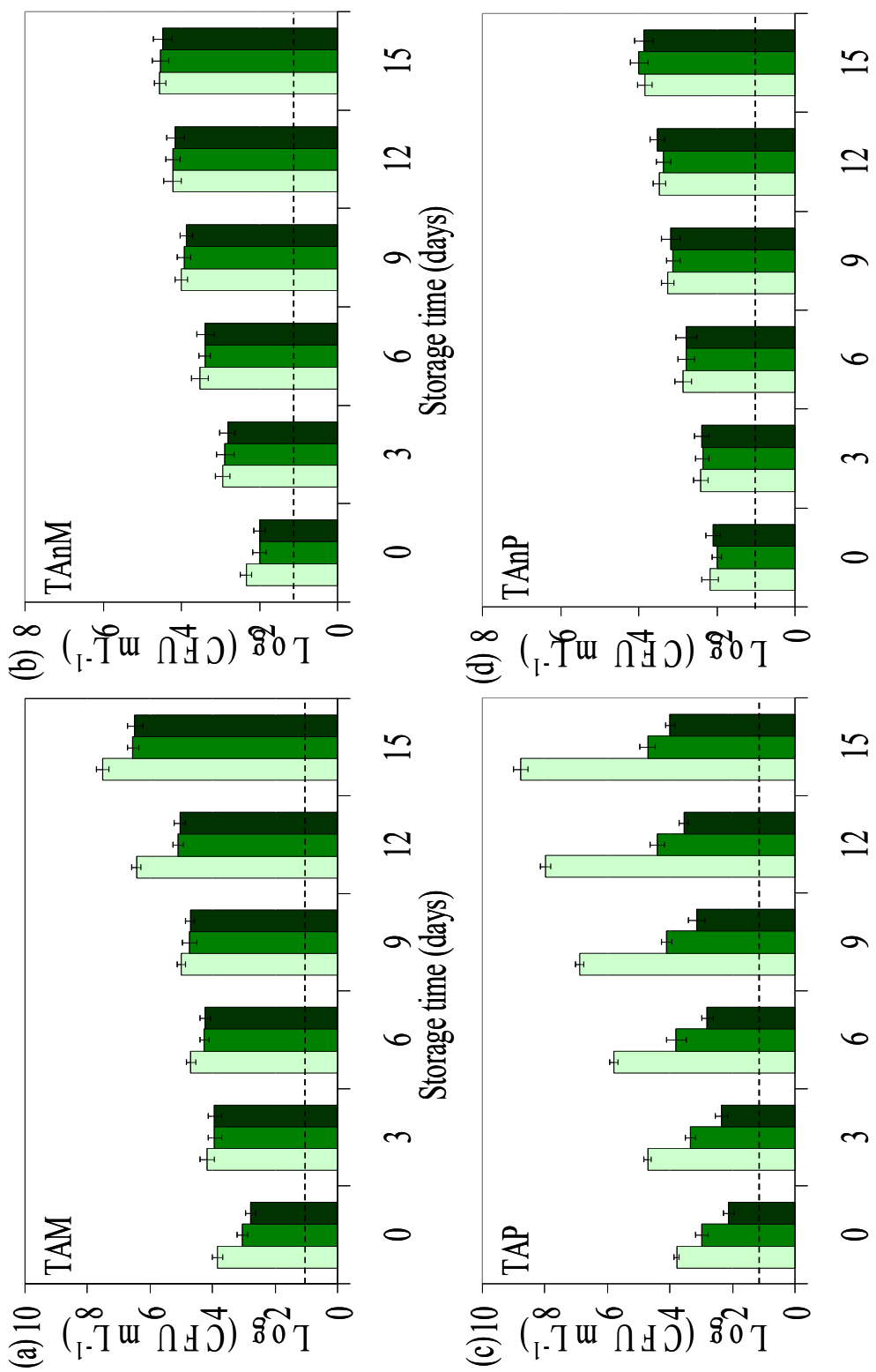

Figure 5.32 - Changes in microorganisms of UV-C ( $\square$ 2.088 J.mL $\mathrm{m}^{-1}$ and $\square$ 4.076 J.mL ${ }^{-1}$ ) and heat pasteurized ( $\square$ ) LEY during storage at $20{ }^{\circ} \mathrm{C}$. (a) TAM, (b) TAnM, (c) TAP, (d) TAnP, (e) LAB, (f) Yeast, (g) Pseudomonas spp. and (h) Enterobacteriacea. Results are the mean of triplicate \pm standart deviation. Dashed line represents the detection limit $(1 \mathrm{Log})$. 


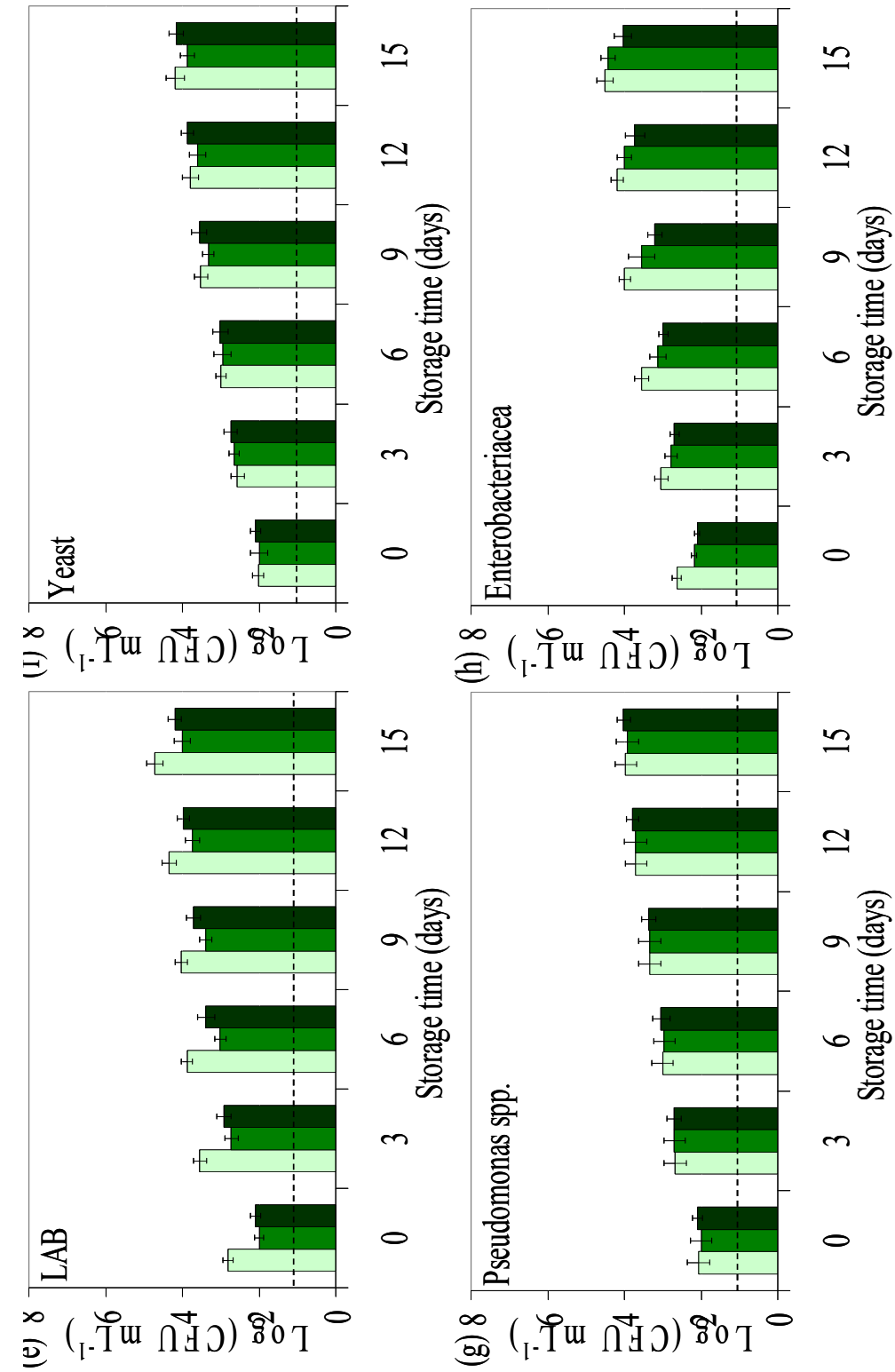

Figure 5.32 (cont.) - Changes in microorganisms of UV-C ( $\square 2.088{\mathrm{~J} . \mathrm{mL}^{-1}}^{-1}$ and $\square 4.076 \mathrm{~J} . \mathrm{mL}^{-1}$ ) and heat pasteurized ( $\square$ ) LEY during storage at $20^{\circ} \mathrm{C}$. (a) TAM, (b) TAnM, (c) TAP, (d) TAnP, (e) LAB, (f) Yeast, (g) Pseudomonas spp. and (h) Enterobacteriacea. Results are the mean of triplicate \pm standart deviation. Dashed line represents the detection limit (1 $\log )$. 
Results and discussion

The psychrotrophic bacterial maximum limit $(<6 \mathrm{Log})$ was not exceeded neither at the end of the storage study and samples were thus microbiologically acceptable for consumption even after 15 days of storage at room temperature. All the heat treated samples were shelf-stable throughout the shelf-life study. In untreated LEY, all the investigated microbial groups show a quasi-linear growth during 8 weeks of refrigerated storage without reaching the exponential phase of growth. The counts of the medium UV-C doses were comparable to the counts after heat pasteurizations. However, UV-C treatment at doses below $3 \mathrm{~J} . \mathrm{cm}^{-2}$ exhibited a considerably lower initial inactivation efficiency, which was also reflected during storage. Entering the seventh week of storage, UV-C treated egg yolks reached the end of shelf-life, since the total aerobic counts exceeded the value of $6 \mathrm{Log}$. However for the low UV-C doses, the end of the shelflife was already reached by the sixth week.

Noteworthy is the fact that all the UV-C or heat treated LEY were free of Salmonella spp. and spores. Indeed, during storage, the detection limit of Salmonella was set to $1 \mathrm{Log}$, but after 8 weeks the egg yolk samples were specially analysed to discard the presence of Salmonella in $25 \mathrm{~g}$, and indeed no Salmonella contamination was found. Similar observations could be made for the accelerated storage study at $20{ }^{\circ} \mathrm{C}$. UV-C treatments at doses above $4{\mathrm{~J} . \mathrm{cm}^{-2}}$ were as effective as heat pasteurizations since initial inactivation was comparable and ensured microbial stability during the entire storage period. The authorized limit for psychrotrophic bacteria was not exceeded at the end of the storage $(<6 \mathrm{Log})$, and samples were thus microbiologically acceptable for consumption against this critera even after 
15 days of storage at room temperature. In a similar way to LEW, all the heat treated samples were shelf-stable throughout the shelf-life study. The increase in shelf-life observed in this study is remarkable, if compared to data reported by other authors. For example, Boyer and McKinney (2009) cited by Tiersky (2009) pointed out a shelf-life of 2-4 days for natural egg white under refrigeration, 3 days for pasteurized eggs in an open container, and only one week for pasteurized egg in a closed container. In this work, the pasteurization process extended the shelf-life of the LEPs, in a similar range than the UV-C. And UV-C treatments were also adequate to increase the storage possibilities at room temperature.

Only few studies report on the evolution of microbial loads during the shelflife of a UV-C treated liquid products. Torkamani and Niakousari (2011) evaluated the counts of total aerobic counts and molds and yeasts in orange juice, and concluded that the shelf-life could be extended for at least 7 days after being exposed to UV-C light. Corrales et al. (2012) evaluated the increase in shelf-life of a UV-C treated tiger nuts milk beverage and found an improvement of 2 to 4 days in a beverage with $\mathrm{pH}$ near 7.0.

\subsubsection{Evolution of physicochemical parameters during shelf-life}

The evolution of the main physicochemical parameters for each fraction was analyzed during shelf-life. Table 5.22 presents the results of $\mathrm{pH}$, free sulfhydryl content, and apparent viscosity for heat pasteurized and UV-C treated LEW, during storage at $4{ }^{\circ} \mathrm{C}$. The $\mathrm{pH}$ of egg albumen is strongly 
Results and discussion

related to the egg aging process, being $\mathrm{CO}_{2}$ exchanged through the shell over the storage period, this process increases considerably the $\mathrm{pH}$ values. In contrast, yolk $\mathrm{pH}$ is not influenced by the $\mathrm{CO}_{2}$ concentration and remains almost unchanged during aging. Thus, the relatively low $\mathrm{pH}$ values found throughout this study proved for egg freshness. Among other physicochemical attributes, $\mathrm{pH}$ is an essential attribute to achieve adequate albumen functional properties. The effects of homogeneization were evident in LEW, with an increase in $\mathrm{pH}$.

Treatments with UV-C of the homogenized samples did not caused an effect on $\mathrm{pH}$ directly after treatment. With the progress of storage, $\mathrm{pH}$ values showed a tendency to decrease, probably due to microbial activity, moving to slightly more acidic $\mathrm{pH}$ values. The sulfrydryl content, which would express the protein oxidation during aging, was not affected. But the changes in $\mathrm{pH}$ probably affected egg thinning during storage, and the viscosity showed a tendency to decrease, reaching values of $7.18 \mathrm{mPa} . \mathrm{s}$ in UV-C treated samples. In comparison, pasteurized samples showed an initial increase in the viscosity, in accordance with the data presented in Section 5.1.4 while again $\mathrm{pH}$ changes provoked a continuous decrease in viscosity.

Results on $\mathrm{pH}$, TBARS (thiobarbituric reactive substances, lipid oxidation index) and viscosity of UV-C treated and heat pasteurized whole egg and egg yolk samples during storage at $4{ }^{\circ} \mathrm{C}$ are recorded on Tables 5.23 and 5.24. $\mathrm{pH}$ of homogenized samples was situated within the expected standard conditions (around 6.2), and a small tendency to more acidic pHs could be 
observed during storage, although this was not statistically significant $(\mathrm{P}>0.05)$. Functional properties of the egg yolk are highly dependent on $\mathrm{pH}$, and around $\mathrm{pH} 6$, an acceptable solubility of the yolk proteins can be achieved (Chang and Chen, 2000).

Table 5.22 - Changes in physicochemical parameters of LEW treated on the IATA bench device during storage at $4{ }^{\circ} \mathrm{C}$.

\begin{tabular}{|c|c|c|c|c|}
\hline & & $\mathbf{p H}$ & $\begin{array}{l}\text { Free sulphydryl } \\
\text { group }\left(\mathrm{g} \cdot \mathrm{kg}^{-1}\right)\end{array}$ & $\begin{array}{l}\text { Viscosity } \\
\text { (mPa.s) }\end{array}$ \\
\hline \multirow{2}{*}{\multicolumn{2}{|c|}{$\begin{array}{c}\text { Not homogeneised } \\
\text { Control }\end{array}$}} & $7.2^{\mathrm{a}} \pm 0.1$ & - & - \\
\hline & & $9.2^{\mathrm{b}} \pm 0.2$ & $44.7^{\mathrm{a}} \pm 2.2$ & $8.83^{\mathrm{a}} \pm 0.44$ \\
\hline \multirow{4}{*}{$\begin{array}{c}\text { Heat } \\
\text { Pasteurized }\end{array}$} & 0 & $9.2^{b} \pm 0.4$ & $44.5^{\mathrm{a}} \pm 2.6$ & $19.53^{b} \pm 1.49$ \\
\hline & 7 & $9.0^{\mathrm{b}} \pm 0.5$ & $44.4^{\mathrm{a}} \pm 3.1$ & $18.72^{b} \pm 2.53$ \\
\hline & 14 & $8.7^{\mathrm{b}} \pm 0.7$ & $44.8^{\mathrm{a}} \pm 3.8$ & $18.52^{b} \pm 1.25$ \\
\hline & 21 & $8.6^{b} \pm 0.5$ & $43.3^{\mathrm{a}} \pm 2.9$ & $18.61^{b} \pm 2.18$ \\
\hline \multirow{5}{*}{$\begin{array}{c}\text { Time of } \\
\text { storage } \\
\text { (days) }\end{array}$} & 28 & $8.4^{\mathrm{bc}} \pm 0.4$ & $44.6^{\mathrm{a}} \pm 2.5$ & $17.52^{\mathrm{b}} \pm 1.51$ \\
\hline & 35 & $8.1^{\mathrm{c}} \pm 0.4$ & $45.5^{\mathrm{a}} \pm 3.6$ & $17.21^{\mathrm{b}} \pm 2.74$ \\
\hline & 42 & $7.7^{\mathrm{cd}} \pm 0.8$ & $44.9^{\mathrm{a}} \pm 3.3$ & $17.77^{b} \pm 1.83$ \\
\hline & 49 & $7.3^{\mathrm{cd}} \pm 0.7$ & $42.8^{\mathrm{a}} \pm 2.1$ & $17.98^{\mathrm{b}} \pm 1.91$ \\
\hline & 56 & $6.9^{\mathrm{d}} \pm 0.6$ & $44.5^{\mathrm{a}} \pm 2.5$ & $17.15^{\mathrm{b}} \pm 2.95$ \\
\hline \multirow{4}{*}{$\begin{array}{c}\text { UV-C } \\
4.176 \mathrm{~J} . \mathrm{cm}^{-2}\end{array}$} & 0 & $9.2^{b} \pm 0.4$ & $44.7^{\mathrm{a}} \pm 3.6$ & $8.75^{\mathrm{a}} \pm 0.49$ \\
\hline & 7 & $9.0^{\mathrm{b}} \pm 0.6$ & $44.3^{\mathrm{a}} \pm 3.4$ & $8.21^{\mathrm{a}} \pm 0.56$ \\
\hline & 14 & $8.6^{\mathrm{bc}} \pm 0.9$ & $44.5^{\mathrm{a}} \pm 3.1$ & $8.16^{\mathrm{a}} \pm 0.58$ \\
\hline & 21 & $8.5^{b c} \pm 0.8$ & $46.3^{\mathrm{a}} \pm 3.3$ & $8.03^{\mathrm{ac}} \pm 0.65$ \\
\hline \multirow{5}{*}{$\begin{array}{c}\text { Time of } \\
\text { storage } \\
\text { (days) }\end{array}$} & 28 & $8.2^{b c} \pm 0.6$ & $45.6^{\mathrm{a}} \pm 2.8$ & $7.78^{\mathrm{ac}} \pm 0.71$ \\
\hline & 35 & $8.0^{\mathrm{cd}} \pm 0.7$ & $45.8^{\mathrm{a}} \pm 3.2$ & $7.53^{c} \pm 0.62$ \\
\hline & 42 & $7.5^{\mathrm{cd}} \pm 0.9$ & $44.8^{\mathrm{a}} \pm 3.9$ & $7.41^{c} \pm 0.66$ \\
\hline & 49 & $7.1^{\mathrm{cd}} \pm 0.5$ & $45.8^{\mathrm{a}} \pm 4.1$ & $7.35^{\mathrm{c}} \pm 0.72$ \\
\hline & 56 & $6.5^{\mathrm{cd}} \pm 0.8$ & $44.9^{\mathrm{a}} \pm 3.1$ & $7.18^{c} \pm 0.53$ \\
\hline
\end{tabular}

*Results are the mean of triplicate \pm standart deviation.

Different superscripts in each column indicate difference statiscally significant at $95 \%$ confidence level 
Results and discussion

Table 5.23 - Changes in physicochemical parameters of LWE treated on the IATA bench device during storage at $4{ }^{\circ} \mathrm{C}$.

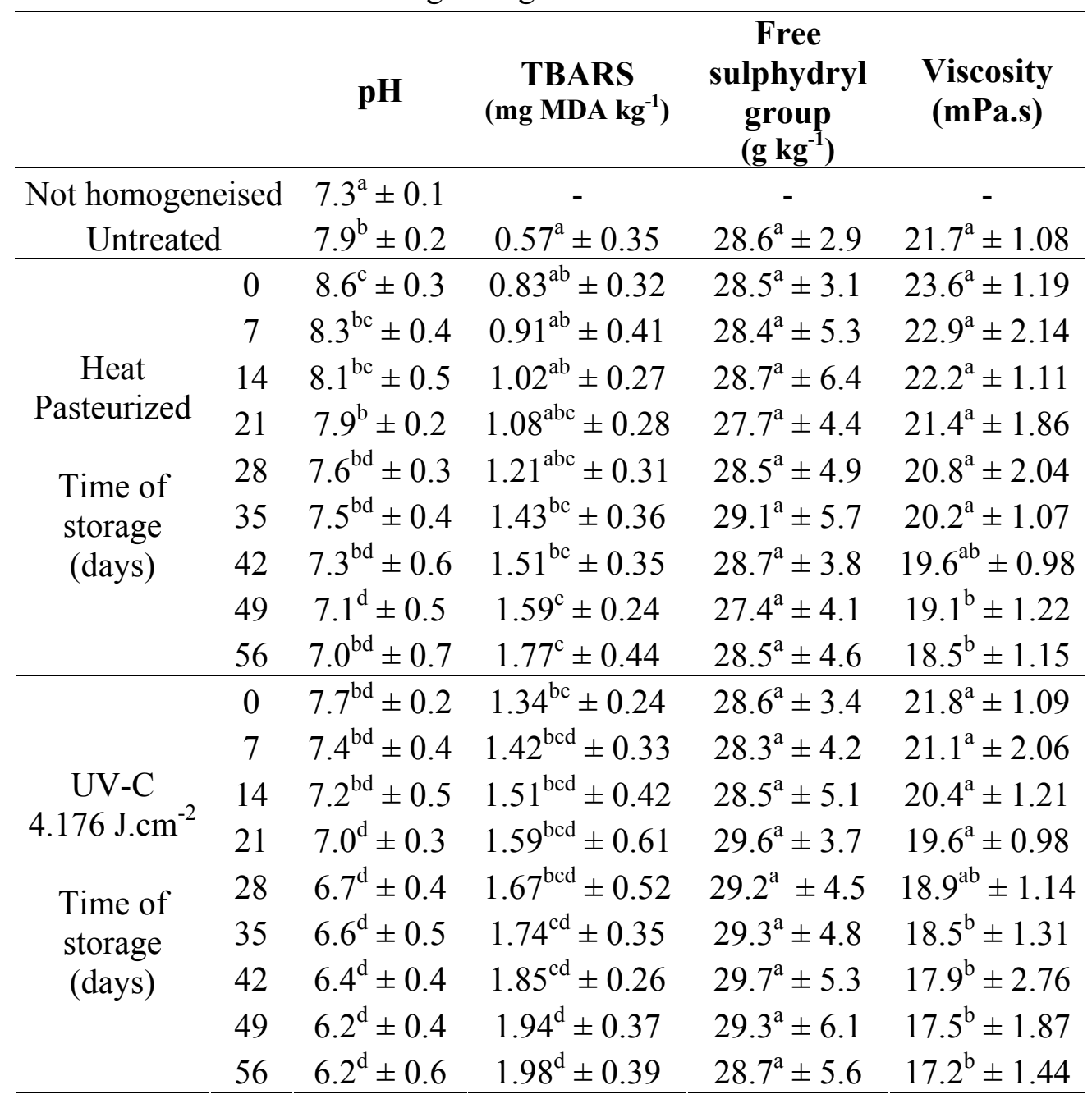

*Results are the mean of triplicate \pm standart deviation.

Different superscripts in each column indicate difference statiscally significant at $95 \%$ confidence level

But in eggs, quality deterioration due to oxidative processes in cholesterol and unsaturated fatty acids might also be originated by UV-C, since radiation at short wavelengths is an effective promoter of lipid peroxidation 
Table 5.24 - Changes in physicochemical parameters of LEY treated on the IATA bench device during storage at $4{ }^{\circ} \mathrm{C}$.

\begin{tabular}{|c|c|c|c|c|}
\hline & & pH & $\begin{array}{c}\text { TBARS } \\
\left(\mathrm{mg} \mathrm{MDA} \mathrm{kg}{ }^{-1}\right)\end{array}$ & $\begin{array}{l}\text { Viscosity } \\
\text { (mPa.s) }\end{array}$ \\
\hline \multirow{2}{*}{\multicolumn{2}{|c|}{$\begin{array}{c}\text { Not homogeneised } \\
\text { Untreated }\end{array}$}} & $6.2^{\mathrm{a}} \pm 0.1$ & - & - \\
\hline & & $6.2^{\mathrm{a}} \pm 0.2$ & $0.91^{\mathrm{a}} \pm 0.09$ & $86.9^{\mathrm{a}} \pm 3.4$ \\
\hline \multirow{4}{*}{$\begin{array}{c}\text { Heat } \\
\text { Pasteurized }\end{array}$} & 0 & $6.6^{\mathrm{b}} \pm 0.2$ & $1.65^{\mathrm{b}} \pm 0.30$ & $94.3^{b} \pm 5.8$ \\
\hline & 7 & $6.5^{\mathrm{abc}} \pm 0.4$ & $1.82^{\mathrm{b}} \pm 0.41$ & $91.5^{\mathrm{bc}} \pm 6.3$ \\
\hline & 14 & $6.4^{\mathrm{bc}} \pm 0.3$ & $2.03^{\mathrm{bcd}} \pm 0.37$ & $88.7^{\mathrm{abcd}} \pm 7.1$ \\
\hline & 21 & $6.2^{\mathrm{abc}} \pm 0.4$ & $2.16^{\mathrm{bcd}} \pm 0.46$ & $85.4^{\mathrm{abcd}} \pm 5.2$ \\
\hline \multirow{5}{*}{$\begin{array}{c}\text { Time of } \\
\text { storage } \\
\text { (days) }\end{array}$} & 28 & $6.0^{\mathrm{ac}} \pm 0.2$ & $2.41^{\mathrm{bcd}} \pm 0.51$ & $83.2^{\mathrm{acde}} \pm 4.5$ \\
\hline & 35 & $5.9^{\mathrm{abc}} \pm 0.5$ & $2.65^{\mathrm{cde}} \pm 0.32$ & $80.9^{\text {acdef }} \pm 6.7$ \\
\hline & 42 & $6.0^{\mathrm{abc}} \pm 0.6$ & $2.81^{\mathrm{ce}} \pm 0.23$ & $78.5^{\mathrm{cdef}} \pm 8.2$ \\
\hline & 49 & $5.8^{\mathrm{abc}} \pm 0.5$ & $3.04^{\mathrm{ce}} \pm 0.55$ & $76.3^{\mathrm{def}} \pm 7.0$ \\
\hline & 56 & $6.0^{\mathrm{abc}} \pm 0.6$ & $3.18^{\mathrm{ce}} \pm 0.68$ & $74.1^{\mathrm{def}} \pm 9.4$ \\
\hline \multirow{4}{*}{$\begin{array}{c}\mathrm{UV}-\mathrm{C} \\
4.176 \mathrm{~J} . \mathrm{cm}^{-2}\end{array}$} & 0 & $6.1^{\mathrm{a}} \pm 0.1$ & $2.18^{d} \pm 0.15$ & $87.1^{\mathrm{abcd}} \pm 6.3$ \\
\hline & 7 & $6.0^{\mathrm{a}} \pm 0.2$ & $2.31^{\mathrm{d}} \pm 0.26$ & $84.2^{\text {abcde }} \pm 7.1$ \\
\hline & 14 & $5.9^{\mathrm{a}} \pm 0.4$ & $2.45^{\mathrm{de}} \pm 0.44$ & $81.5^{\text {abcdef }} \pm 8.5$ \\
\hline & 21 & $5.7^{\mathrm{a}} \pm 0.5$ & $2.57^{\mathrm{de}} \pm 0.68$ & $78.3^{\mathrm{def}} \pm 4.6$ \\
\hline \multirow{5}{*}{$\begin{array}{c}\text { Time of } \\
\text { storage } \\
\text { (days) }\end{array}$} & 28 & $5.6^{\mathrm{a}} \pm 0.6$ & $2.70^{\mathrm{de}} \pm 0.59$ & $75.6^{\mathrm{def}} \pm 7.5$ \\
\hline & 35 & $5.8^{\mathrm{a}} \pm 0.5$ & $2.82^{\mathrm{de}} \pm 0.88$ & $73.9^{\mathrm{ef}} \pm 6.8$ \\
\hline & 42 & $5.7^{\mathrm{a}} \pm 0.7$ & $3.01^{\mathrm{de}} \pm 0.74$ & $71.4^{\mathrm{f}} \pm 5.9$ \\
\hline & 49 & $5.7^{\mathrm{a}} \pm 0.4$ & $3.14^{\mathrm{e}} \pm 0.52$ & $69.8^{\mathrm{f}} \pm 4.4$ \\
\hline & 56 & $5.6^{\mathrm{a}} \pm 0.9$ & $3.19^{\mathrm{e}} \pm 0.56$ & $68.7^{\mathrm{f}} \pm 6.5$ \\
\hline
\end{tabular}

*Results are the mean of triplicate \pm standart deviation.

Different superscripts in each column indicate difference statiscally significant at $95 \%$ confidence level

(Spikes, 1981). Here, the TBARS values, as an index of the extent of lipid oxidation during storage, significantly increased for the UV-C treated samples, in a similar range that in the heat pasteurized. Such results are 
Results and discussion

typical in UV-C treated products and also in products subjected to ionizing radiations, with the subsequent degradation in carotenoids (Katusin-Razem, Mihaljevic and Razem, 1992). The observed changes in $\mathrm{pH}$ and the acceleration in the oxidation of unsaturated fatty acdis have influenced slightly the apparent viscosity. Thus a slight decrease was recorded, reaching values of $74.1 \mathrm{mPa} . \mathrm{s}$ in heat pasteurized yolks, and $68.7 \mathrm{mPa} . \mathrm{s}$ in UV-C treated samples.

\subsubsection{Shelf life of LEPs treated on UVivatec ${ }^{\circledR}$ Lab reactor}

\subsubsection{Microbiology}

Optimal UV-C treatment conditions were selected on the basis of the results obtained with inoculated bacteria and the inactivation of the naturally occurring microflora. The evolution of the microbial load of liquid egg products was evaluated in samples stored under refrigeration (about $4{ }^{\circ} \mathrm{C}$ ) for up to 8 weeks. Conventional heat pasteurized samples, as stated in the Materials and Methods section, were used as a reference. Microbial loads of UV-C and pasteurized samples at day 0 are shown in Table 5.25.

In LEW, no growth was observed for the TAnM after UV-C treatment or pasteurization during 8 weeks of storage (Figure 5.33). After UV-C treatments, TAM showed a small and constant increase which has not 
exceeded the regulated $2 \log$ during storage, whereas the counts of TAM in pasteurized egg white increased from week 3 to week 6 up to $7.5 \mathrm{Log}$. The TAnP counts started to increase on the $4^{\text {th }}$ and $7^{\text {th }}$ week of shelf life after pasteurization and UV-C treatment, respectively. UV-C treated TAP presented logarithmic growth after the fourth week of storage up to 2.18 Log, whereas the counts after pasteurization showed a fast increase up to 7.6 Log in week 6. For the LAB counts, no increase was detected for the samples treated with UV. The pasteurized egg showed a considerable increase of lactic acid bacteria after the $5^{\text {th }}$ week.

In whole egg, no growth was observed in the UV-C treated samples for the TAnM and LAB (Figure 5.34). The TAM showed a small and constant increase which has not exceeded the 2 Log CFU. $\mathrm{mL}^{-1}$ during storage.

The TAnP counts grew after to $6^{\text {th }}$ week. After UV-C treatment, TAP showed a logarithmic growth after the $4^{\text {th }}$ week of storage, up to $1.80 \mathrm{Log}$. In pasteurized whole egg, the counts of TAM, TAP, TAnP and LAB increase after the $4^{\text {th }}$ week. However, no growth was detected for TAnM counts after pasteurization.

UV treated egg yolk no growth was observed for the TAnM, LAB, during 8 weeks of storage (Figure 5.35). 
Table 5.25 - Microbial loads of LEPs at day 0 of storage.

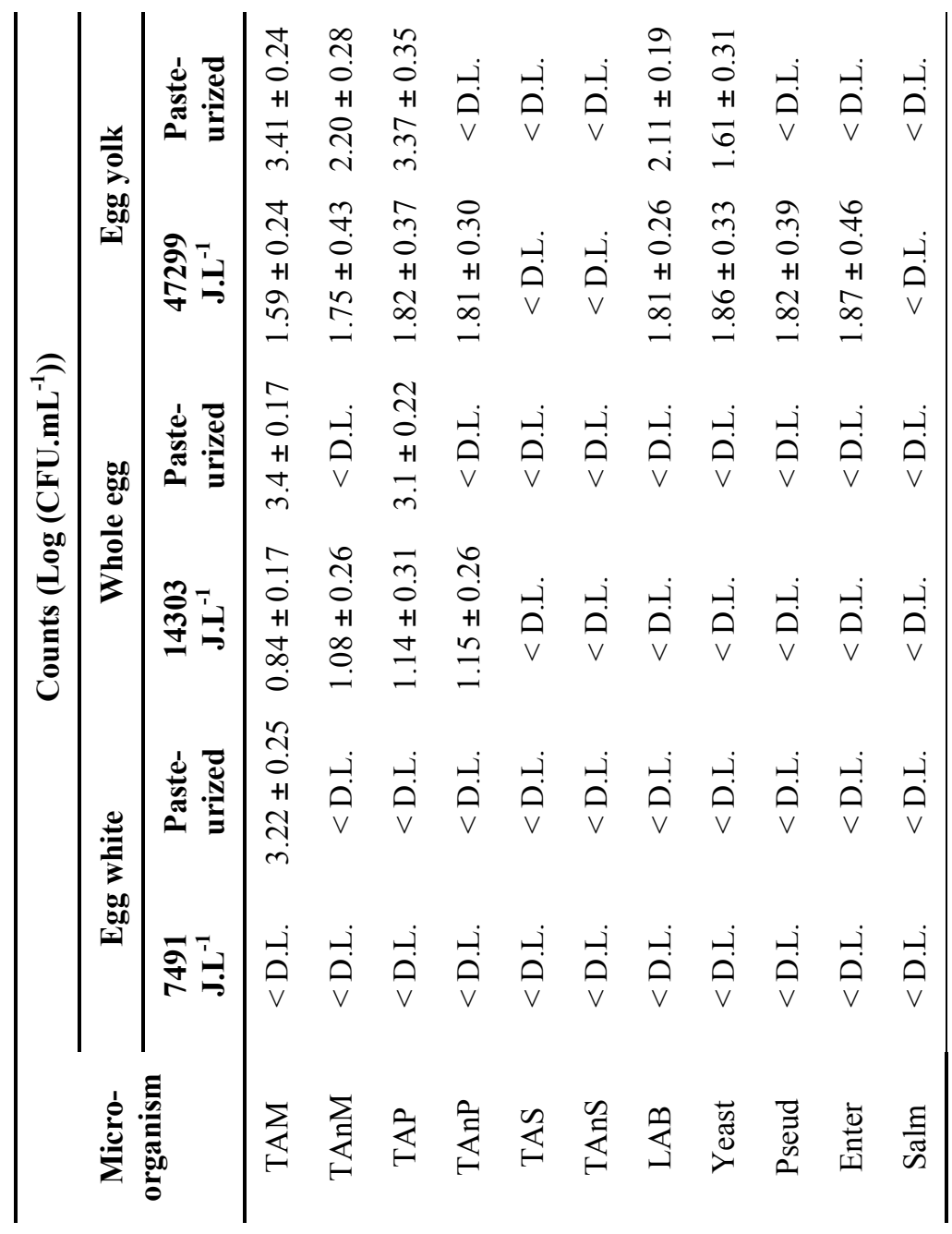

Results are the mean of triplicate \pm standart deviation.

D.L.: Detection limit (1 Log) 


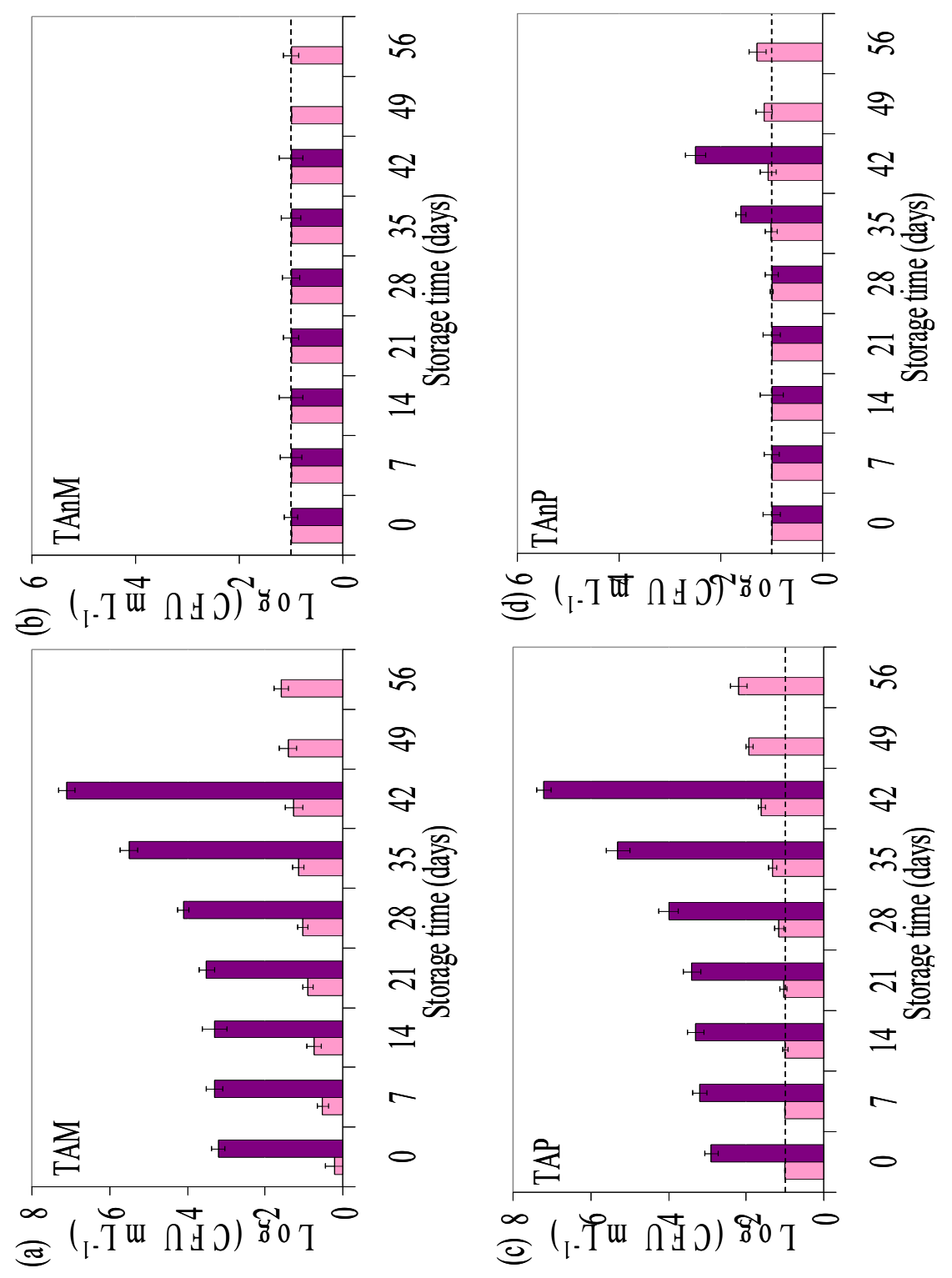

Figure 5.33 - Changes in microorganisms of UV-C ( $\square$ 7491J.L $\left.{ }^{-1}\right)$ and heat pasteurized ( $\square$ ) LEW during storage at $4{ }^{\circ} \mathrm{C}$. (a) TAM, (b) TAnM, (c) TAP, (d) TAnP, (e) LAB, (f) Yeast, (g) Pseudomonas spp. and (h) Enterobacteriacea. Results are the mean of triplicate \pm standart deviation. Dashed line represents the detection limit $(1 \mathrm{Log})$. 

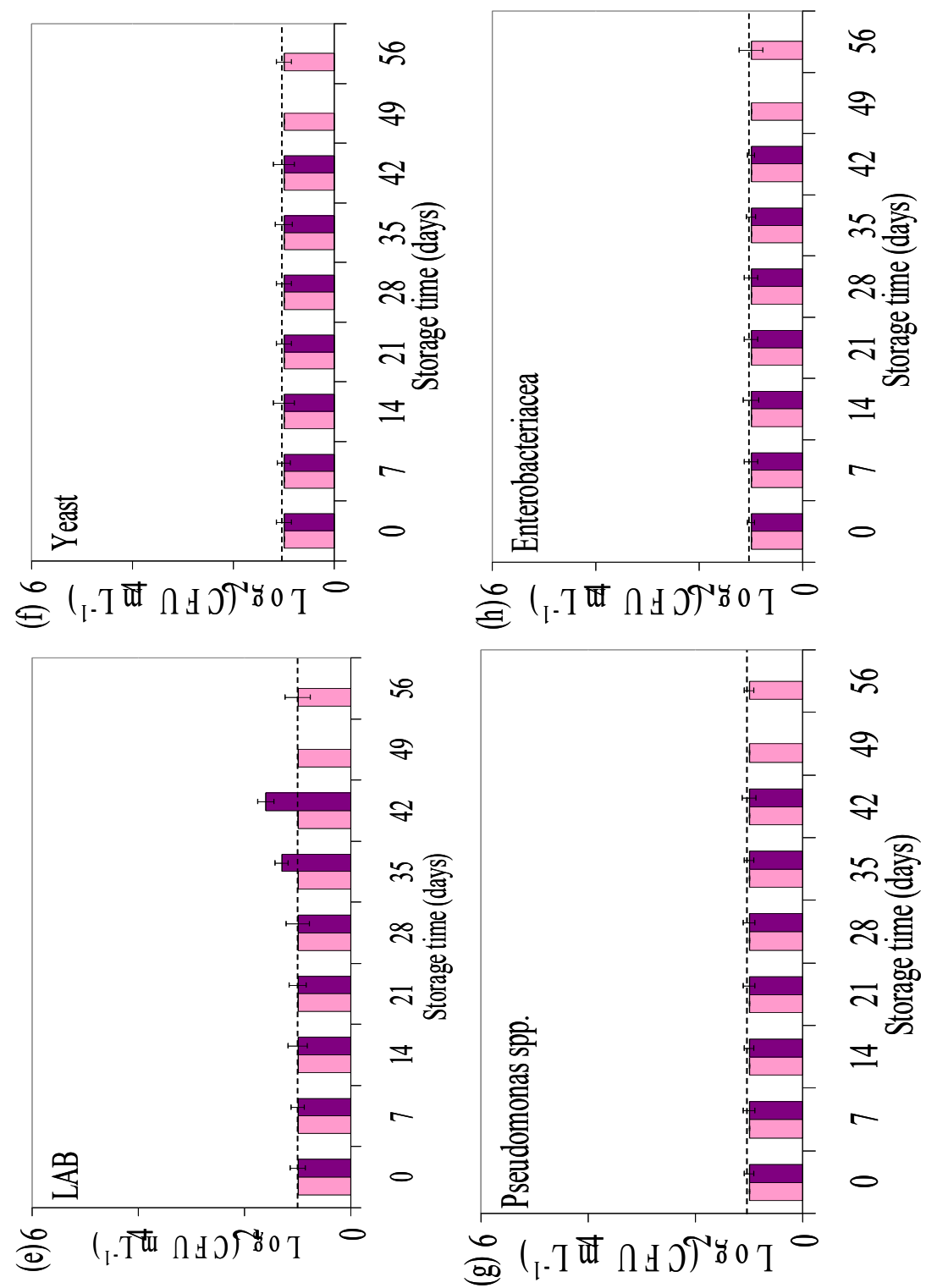

Figure 5.33 (cont.) - Changes in microorganisms of UV-C ( $\square$ 7491J.L $\left.{ }^{-1}\right)$ and heat pasteurized $(\square) \mathrm{LEW}$ during storage at $4{ }^{\circ} \mathrm{C}$. (a) TAM, (b) TAnM, (c) TAP, (d) TAnP, (e) LAB, (f) Yeast, (g) Pseudomonas spp. and (h) Enterobacteriacea. Results are the mean of triplicate \pm standart deviation. Dashed line represents the detection limit $(1 \mathrm{Log})$. 


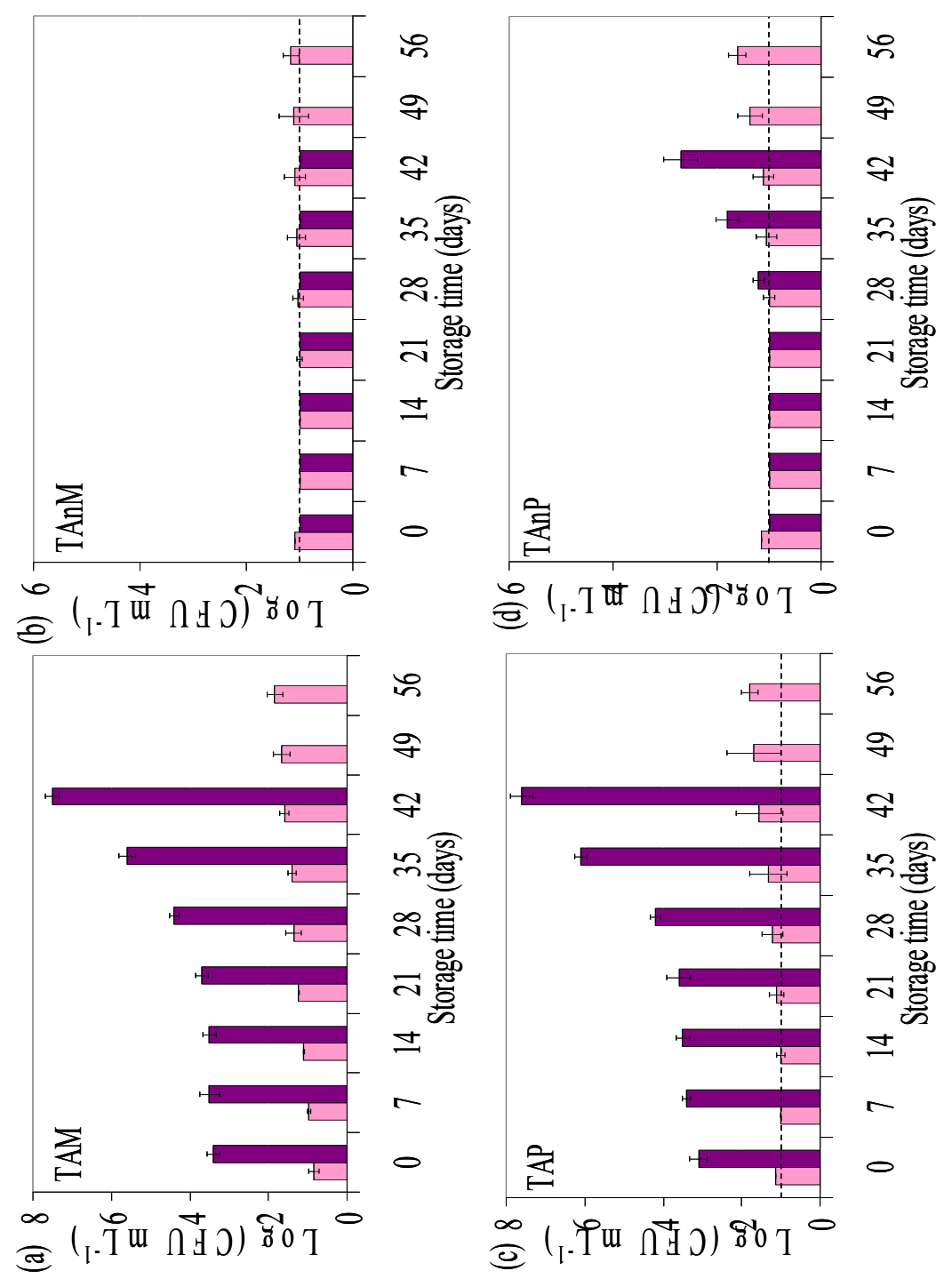

Figure 5.34 - Changes in microorganisms of UV-C ( $\square$ 7491J.L $\left.{ }^{-1}\right)$ and heat pasteurized $(\square)$ LWE during storage at $4{ }^{\circ} \mathrm{C}$. (a) TAM, (b) TAnM, (c) TAP, (d) TAnP, (e) LAB, (f) Yeast, (g) Pseudomonas spp. and (h) Enterobacteriacea. Results are the mean of triplicate \pm standart deviation. Dashed line represents the detection limit (1 Log). 

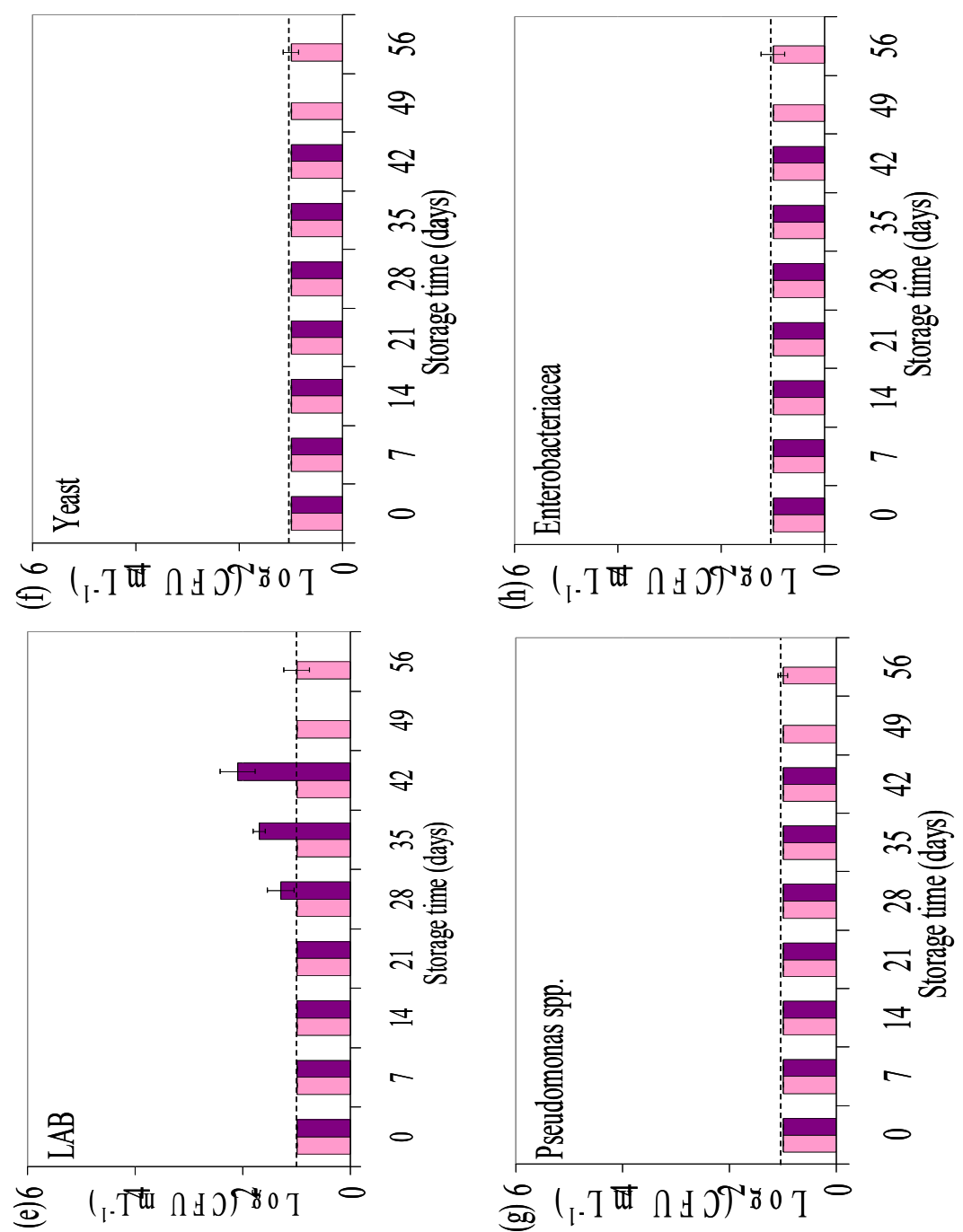

Figure 5.34 (cont.) - Changes in microorganisms of UV-C ( $\square$ 7491J.L ${ }^{-1}$ ) and heat pasteurized $(\square)$ LWE during storage at $4{ }^{\circ} \mathrm{C}$. (a) TAM, (b) TAnM, (c) TAP, (d) TAnP, (e) LAB, (f) Yeast, (g) Pseudomonas spp. and (h) Enterobacteriacea. Results are the mean of triplicate \pm standart deviation. Dashed line represents the detection limit $(1 \mathrm{Log})$. 


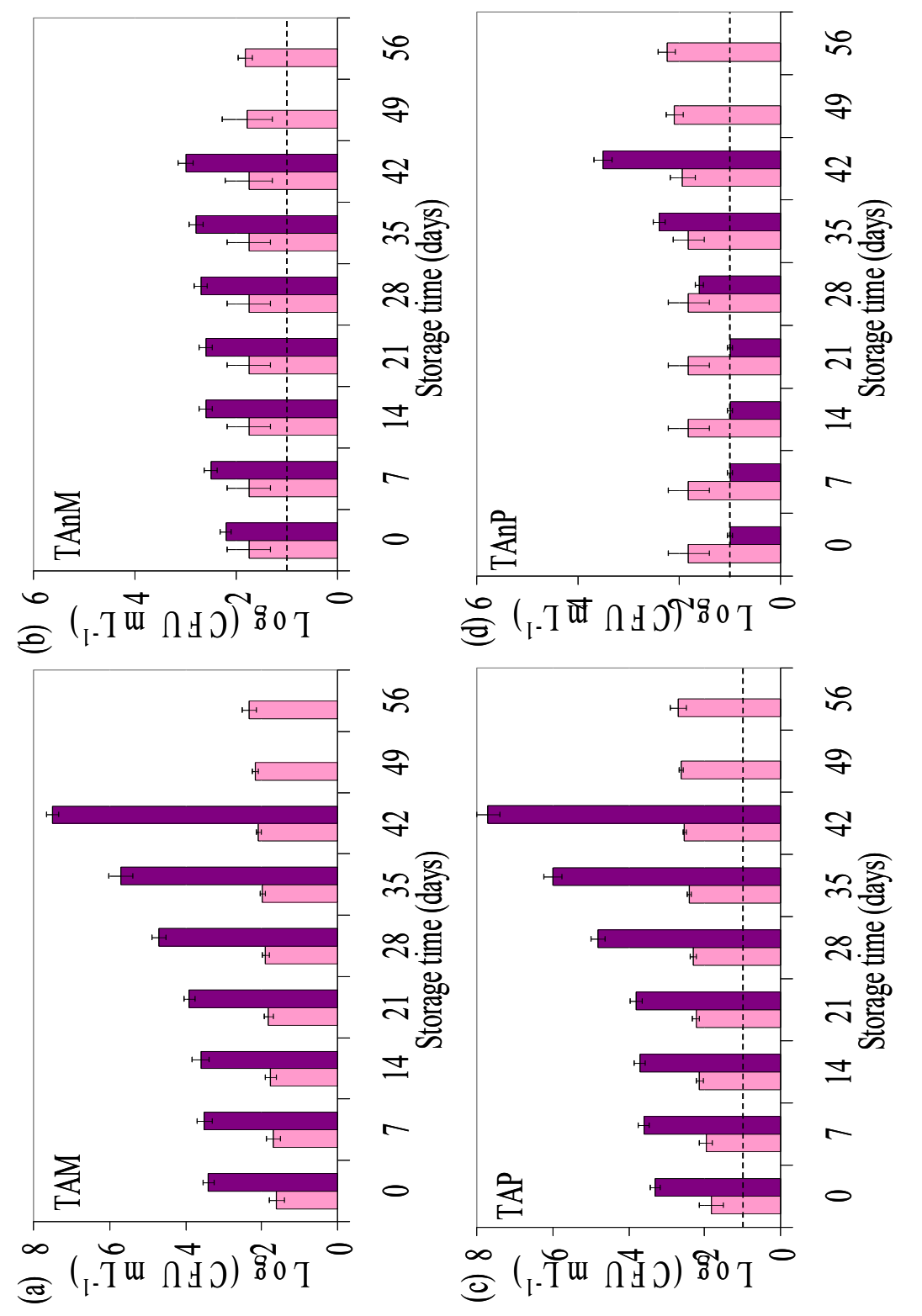

Figure 5.35 - Changes in microorganisms of UV-C ( $\square$ 47299J.L $\left.{ }^{-1}\right)$ and heat pasteurized ( $\square$ ) LEY during storage at $4{ }^{\circ} \mathrm{C}$. (a) TAM, (b) TAnM, (c) TAP, (d) TAnP, (e) LAB, (f) Yeast, (g) Pseudomonas spp. and (h) Enterobacteriacea. Results are the mean of triplicate \pm standart deviation. Dashed line represents the detection limit $(1 \mathrm{Log})$. 

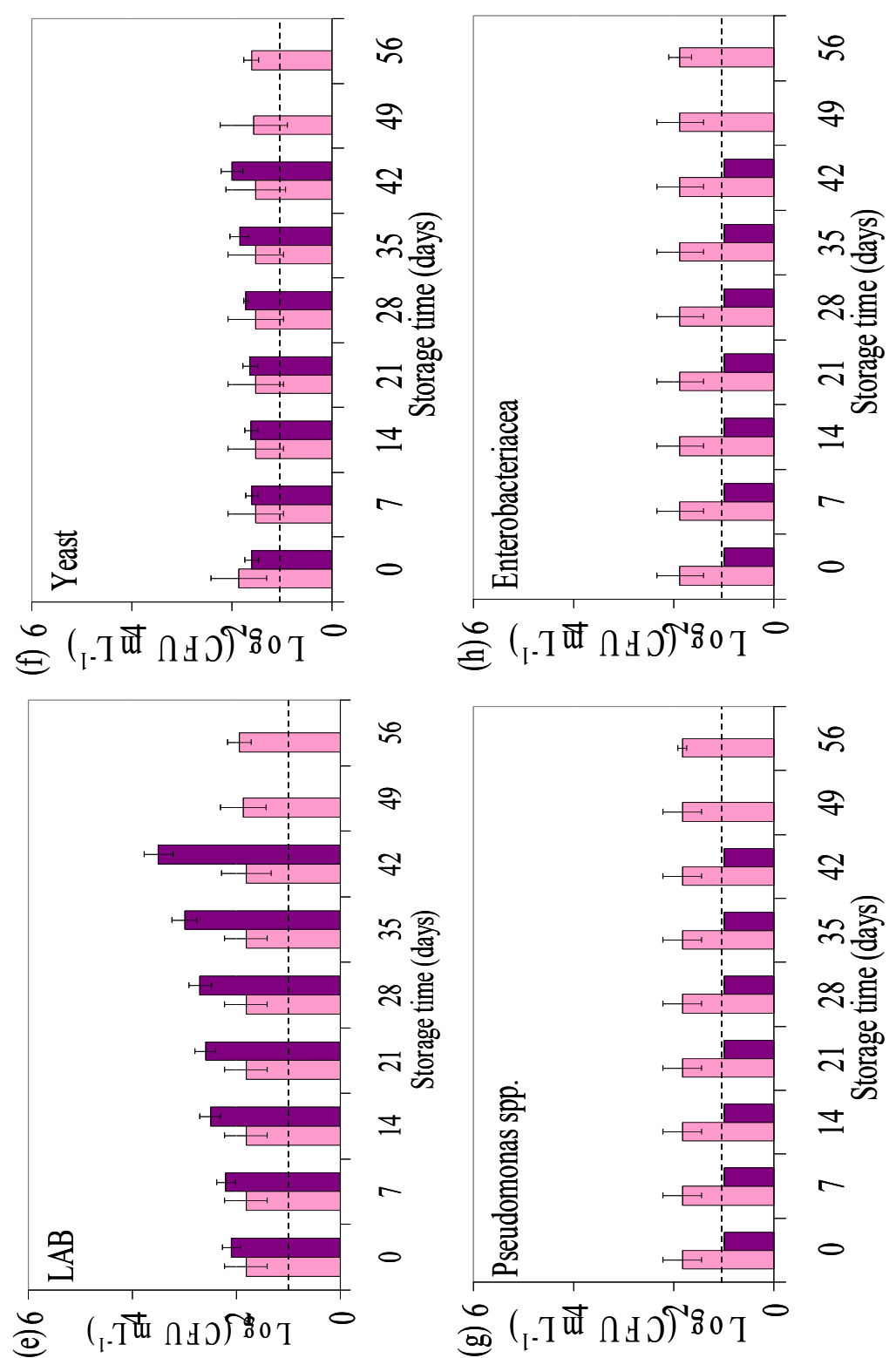

Figure 5.35 (cont.) - Changes in microorganisms of UV-C ( $\square$ 47299J.L ${ }^{-1}$ )

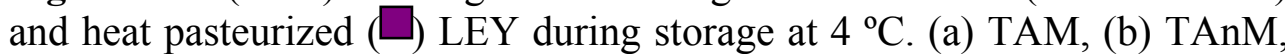
(c) TAP, (d) TAnP, (e) LAB, (f) Yeast, (g) Pseudomonas spp. and (h) Enterobacteriacea. Results are the mean of triplicate \pm standart deviation. Dashed line represents the detection limit (1 Log). 
TAM showed a small and constant increasing in UV-C treated egg yolk and the TAnP counts started to have a small increase on the $6^{\text {th }}$ week of shelf life (Figure $5.35 \mathrm{a}$ and g). TAP presented a linear growing after the first week and attained 2.70 Log at the end of the storage time. In pasteurized egg yolk, the counts of TAM, TAP and TAnP increased after the $4^{\text {th }}$ week. However, the counts of TAnM and LAB showed a slight but constant increase during storage. In all pasteurized and UV-C treated egg fractions no increase of YM, Pseudomonas spp., Enterobacteriaceae and Salmonella spp. TAS, TAnS were detected during 8 weeks of storage (data not shown). Remarkably, the critical counts signalizing the end of shelf life have not been reached during the 8 weeks storage for the UV-C treated samples. In contrast, in thermally treated eggs, the values were already critical after 5 weeks. The TAP counts were 5.3 Log for the egg white, 6.1 Log for whole egg and 6 Log for egg yolk. In the $6^{\text {th }}$ week, the TAP counts exceeded the shelf life criteria $(6 \mathrm{Log})$, and the experiments for the heat treated samples were interrupet.

\subsubsection{Evolution of physicochemical parameters during shelf-life}

The evolution of the main physicochemical parameters for each fraction was analyzed during shelf-life also for the UVivatec ${ }^{\circledR}$ Lab reactor based on dean vortex technology. Table 5.26 presents the evolution of the physicochemical parameters of LEPs during storage at $4{ }^{\circ} \mathrm{C}$. 
Results and discussion

Table 5.26 - Changes in physicochemical parameters of LEP treated on the UVivatec $₫$ Lab reactor during storage at $4{ }^{\circ} \mathrm{C}$.

\begin{tabular}{|c|c|c|c|c|c|c|}
\hline & & & $\begin{array}{c}\text { Free } \\
\text { sulphydryl } \\
\left(\mathrm{g} . \mathrm{kg}^{-1}\right)\end{array}$ & $\begin{array}{c}\text { Lipid } \\
\text { oxidation } \\
\left.(\mathbf{m g ~ M D A . k g})^{-1}\right)\end{array}$ & pH & $\begin{array}{c}\text { Viscosity } \\
\text { (m.Pas) }\end{array}$ \\
\hline \multirow{10}{*}{ 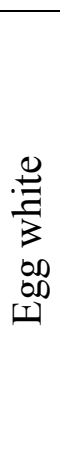 } & \multicolumn{2}{|c|}{ control } & $44.47^{\mathrm{a}} \pm 2.20$ & - & $9.10^{\mathrm{a}} \pm 0.02$ & $3.750^{\mathrm{a}} \pm 0.150$ \\
\hline & & 0 & $45.55^{\mathrm{a}} \pm 5.39$ & - & $9.07^{\mathrm{ab}} \pm 0.07$ & $3.640^{\mathrm{a}} \pm 0.150$ \\
\hline & $\overbrace{2}^{\infty}$ & 7 & $46.14^{\mathrm{a}} \pm 1.85$ & - & $9.04^{\mathrm{abc}} \pm 0.04$ & $3.623^{\mathrm{a}} \pm 0.229$ \\
\hline & 吾 & 14 & $44.43^{\mathrm{a}} \pm 4.18$ & - & $9.02^{\mathrm{abc}} \pm 0.04$ & $3.610^{\mathrm{a}} \pm 0.227$ \\
\hline & $\underset{\infty}{\infty}$ & 21 & $44.51^{\mathrm{a}} \pm 3.40$ & - & $8.99^{\mathrm{abc}} \pm 0.06$ & $3.600^{\mathrm{a}} \pm 0.239$ \\
\hline & 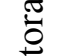 & 28 & $46.21^{\mathrm{a}} \pm 4.10$ & - & $8.98^{b c} \pm 0.06$ & $3.598^{\mathrm{a}} \pm 0.135$ \\
\hline & & 35 & $45.15^{\mathrm{a}} \pm 2.06$ & - & $8.93^{b c} \pm 0.08$ & $3.583^{\mathrm{a}} \pm 0.307$ \\
\hline & & 42 & $44.53^{\mathrm{a}} \pm 3.35$ & - & $8.85^{\mathrm{cd}} \pm 0.14$ & $3.577^{\mathrm{a}} \pm 0.310$ \\
\hline & 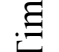 & 49 & $45.61^{\mathrm{a}} \pm 4.68$ & - & $8.84^{\mathrm{cd}} \pm 0.08$ & $3.570^{\mathrm{a}} \pm 0.121$ \\
\hline & & 56 & $45.04^{\mathrm{a}} \pm 2.85$ & - & $8.79^{\mathrm{d}} \pm 0.05$ & $3.560^{\mathrm{a}} \pm 0.485$ \\
\hline \multirow{10}{*}{$\begin{array}{l}0,0 \\
0.0 \\
0 \\
0 \\
0 \\
0 \\
3\end{array}$} & \multicolumn{2}{|c|}{ control } & $29.75^{\mathrm{a}} \pm 1.51$ & $0.57^{\mathrm{a}} \pm 0.09$ & $7.58^{\mathrm{a}} \pm 0.11$ & $8.174^{\mathrm{a}} \pm 0.043$ \\
\hline & & 0 & $30.40^{\mathrm{a}} \pm 3.08$ & $0.63^{\mathrm{ab}} \pm 0.13$ & $7.57^{\mathrm{a}} \pm 0.14$ & $8.150^{\mathrm{a}} \pm 0.080$ \\
\hline & $\sum_{2}^{\infty}$ & 7 & $30.74^{\mathrm{a}} \pm 1.24$ & $0.69^{\mathrm{bc}} \pm 0.02$ & $7.52^{\mathrm{ab}} \pm 0.10$ & $8.053^{\mathrm{ab}} \pm 0.045$ \\
\hline & हृ & 14 & $29.71^{\mathrm{a}} \pm 2.71$ & $0.70^{\mathrm{bc}} \pm 0.01$ & $7.39^{b c} \pm 0.15$ & $7.910^{\mathrm{bc}} \pm 0.070$ \\
\hline & 8 & 21 & $29.79^{\mathrm{a}} \pm 2.08$ & $0.78^{\mathrm{cd}} \pm 0.03$ & $7.34^{\mathrm{c}} \pm 0.07$ & $7.777^{\mathrm{cd}} \pm 0.057$ \\
\hline & 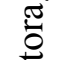 & 28 & $30.75^{\mathrm{a}} \pm 2.59$ & $0.85^{\mathrm{d}} \pm 0.02$ & $7.32^{\mathrm{c}} \pm 0.11$ & $7.658^{\mathrm{d}} \pm 0.154$ \\
\hline & & 35 & $30.16^{\mathrm{a}} \pm 1.41$ & $0.95^{\mathrm{e}} \pm 0.05$ & $7.31^{\mathrm{c}} \pm 0.14$ & $7.447^{\mathrm{e}} \pm 0.126$ \\
\hline & $=$ & 42 & $29.85^{\mathrm{a}} \pm 1.77$ & $0.98^{\mathrm{e}} \pm 0.02$ & $7.30^{c} \pm 0.03$ & $7.279^{f} \pm 0.089$ \\
\hline & $\Xi$ & 49 & $30.36^{\mathrm{a}} \pm 2.93$ & $1.09^{\mathrm{f}} \pm 0.05$ & $7.28^{c} \pm 0.09$ & $7.123^{\mathrm{fg}} \pm 0.085$ \\
\hline & & 56 & $30.08^{\mathrm{a}} \pm 1.87$ & $1.20^{\mathrm{g}} \pm 0.06$ & $7.28^{\mathrm{c}} \pm 0.08$ & $7.020^{\mathrm{g}} \pm 0.125$ \\
\hline \multirow{10}{*}{ 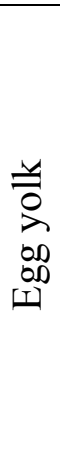 } & \multicolumn{2}{|c|}{ control } & - & $0.74^{\mathrm{a}} \pm 0.06$ & $6.34^{\mathrm{a}} \pm 0.09$ & $86.95^{\mathrm{a}} \pm 4.63$ \\
\hline & & 0 & - & $0.88^{\mathrm{b}} \pm 0.02$ & $6.35^{\mathrm{a}} \pm 0.11$ & $84.78^{\mathrm{ab}} \pm 8.94$ \\
\hline & $\gtrsim$ & 7 & - & $0.99^{c} \pm 0.02$ & $6.37^{\mathrm{a}} \pm 0.08$ & $83.10^{\mathrm{ab}} \pm 9.34$ \\
\hline & త్ & 14 & - & $1.01^{\mathrm{c}} \pm 0.01$ & $6.38^{a} \pm 0.09$ & $82.71^{\mathrm{abc}} \pm 5.63$ \\
\hline & 8 & 21 & - & $1.12^{\mathrm{d}} \pm 0.04$ & $6.41^{\mathrm{a}} \pm 0.07$ & $80.81^{\mathrm{abc}} \pm 9.59$ \\
\hline & \pm & 28 & - & $1.21^{\mathrm{e}} \pm 0.04$ & $6.43^{\mathrm{a}} \pm 0.07$ & $79.66^{\mathrm{abc}} \pm 5.63$ \\
\hline & 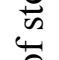 & 35 & - & $1.36^{\mathrm{f}} \pm 0.07$ & $6.43^{\mathrm{a}} \pm 0.05$ & $78.68^{\mathrm{abc}} \pm 7.14$ \\
\hline & 0 & 42 & - & $1.41^{\mathrm{f}} \pm 0.03$ & $6.44^{\mathrm{a}} \pm 0.11$ & $75.92^{\mathrm{abc}} \pm 4.22$ \\
\hline & $\Xi$ & 49 & - & $1.56^{\mathrm{g}} \pm 0.07$ & $6.45^{\mathrm{a}} \pm 0.05$ & $73.38^{\mathrm{bc}} \pm 6.55$ \\
\hline & & 56 & - & $1.71^{\mathrm{h}} \pm 0.09$ & $6.45^{\mathrm{a}} \pm 0.07$ & $71.11^{c} \pm 6.16$ \\
\hline
\end{tabular}

*Results are the mean of triplicate \pm standart deviation.

Different superscripts in each column, for each LEPS, indicate difference statiscally significant at $95 \%$ confidence level

Control: untreated LEPs 
The low $\mathrm{pH}$ values found throughout this study proved for egg freshness. As observed for samples treated in batch, treatments with UV-C have not caused an effect on $\mathrm{pH}$ directly after treatment. With the progress of storage, $\mathrm{pH}$ values of LEW and LWE showed a tendency to decrease, probably due to microbial activity, moving to slightly more acidic $\mathrm{pH}$ values. The $\mathrm{pH}$ of LEY showed a non significant approximation to neutrality. The sulfrydryl content, which would express the protein oxidation during aging, was not affected. But the changes in $\mathrm{pH}$ probably affected egg thinning during storage, and the viscosity of LWE and LEY showed a tendency to decrease, reaching values of $7.02 \mathrm{mPa}$.s and $71.11 \mathrm{mPas}$, respectively, in UV-C treated samples. 


\subsection{Functional properties}

Eggs extraordinary technological properties give rise to the use of LEPs as an ingredient in the food industry. Egg white proteins are renowned for their gelling, foaming and emulsifying properties, and egg yolk is a colorant and also an emulsifying agent. Here we focus on the effects of short-wave ultraviolet treatments on the functional properties of LEPs. Heating of LEPs is often required to ensure microbial safety or to achieve the desired organoleptic attributes. Heat treatments will however affect the physicochemical properties of the egg proteins due to protein denaturation, and thus, may impair their functionality (Hou et al., 1996). These adverse changes could lead to a stage where the pasteurized eggs are no longer suitable for their use as an ingredient in certain food products. Here, a comparative study is performed taking classic pasteurization treatments and untreated controls as reference. In an initial stage, eggs were treated in a bench scale equipment to get an insight into the effects of short-wave ultraviolet treatments on the protein functional quality, and afterwards, eggs were treated in the UVivatec ${ }^{\circledR} \mathrm{Lab}$ reactor, aiming at a first approximation to a continous industrial process.

\subsubsection{Foaming properties}

Foam is a 2-phase system in which gas is the dispersed phase and water makes the continuous phase. Foaming ability is related to the rate at which 
the surface tension of the air-water interface decreases (Liu et al., 2009). The foaming ability was determined for fresh foams after whipping, whereas the foam stability was determined 30 min after whipping. The foam density of control, UV-irradiated and pasteurized samples treated in batch are presented on Table 5.27 and the foaming ability and foaming stability for the same samples are presented on Figures 5.36 and 5.37. Remarkably, UV-C treatments enhanced especially the foaming ability of egg whites and whole eggs. Other properties were not affected by UV-C treatments. Thus, no significant changes were appreciated in the foam density of LEPs or in the foaming ability of the egg yolk. The predominant lipid fraction disrupted the formation of the foam from egg yolks, minimizing the positive effects of UV-C treatments on the protein fraction. Furthermore, the foam stability of all UV-C treated egg products remained at the same level than the untreated control. Several authors pointed out for a certain positive effect of irradiation on functional egg white properties due to changes in the protein structure, which might partially explain the effects observed after UV-C treatments.

Irradiation with ionizing sources or even UV-C generally induces an oxidative atmosphere that makes possible an increment in free radicals. Radicals cause protein changes still not well understood, which are attributed to protein fragmentation (Liu et al., 2009), or even crosslinking (Ali et al., 2011). Clark et al. (1992) reported on the improved functional properties in gamma-irradiated spray-dried egg white while Ma et al. (1990) reported an increase in surface hydrophobicity in egg white upon $\gamma$ irradiation. Ali et al. (2011) indicated that the polymerization and cross- 
Results and discussion

linking of proteins could improve the foaming properties due to the improved interfacial protein network. The high molecular weight and the crosslinked structures could be more resistant to the denaturation induced by homogenization. Kuan, Bath and Karim, (2011) also suggest that UV-C induces protein crosslinking, which improves the foaming ability of egg white. Liu et al. (2009) pointed out that a certain protein denaturation increases the foam stability, which they attributed to protein scission based on 2D-gel electrophoresis. None of the works related the phenomena to the oxidation of proteins, and for example, Liu et al. (2009) found minimal changes in free SH and SS groups of gamma-irradiated egg whites, similarly to our results for the UV-C treated.

The egg yolk FA was lower than the FA of egg white, and FA of whole egg had an intermediate value between both. A similar observation is valid for the FS. As commented above, many factors have been reported to affect the foam stability, but in egg products, mainly the fatty acids are important. Thus, Forsythe (1957) indicated that small amounts of fat in the sample decreased the FA and FS of eggs, and the yolk contains around 30-40 \% of lipids on a solids basis (Marion, Woodroof and Cook, 1965; Chung and Stadelman, 1965).

Foam density, ability and stability attained by samples treated under static conditions were slightly higher than the ones prepared under stirring at 400 rpm. Although the difference is not statistically significant, it might be considered as an indication of excess radiation accelerating the denaturing effects typically responsible for the improvement in the foaming ability. 

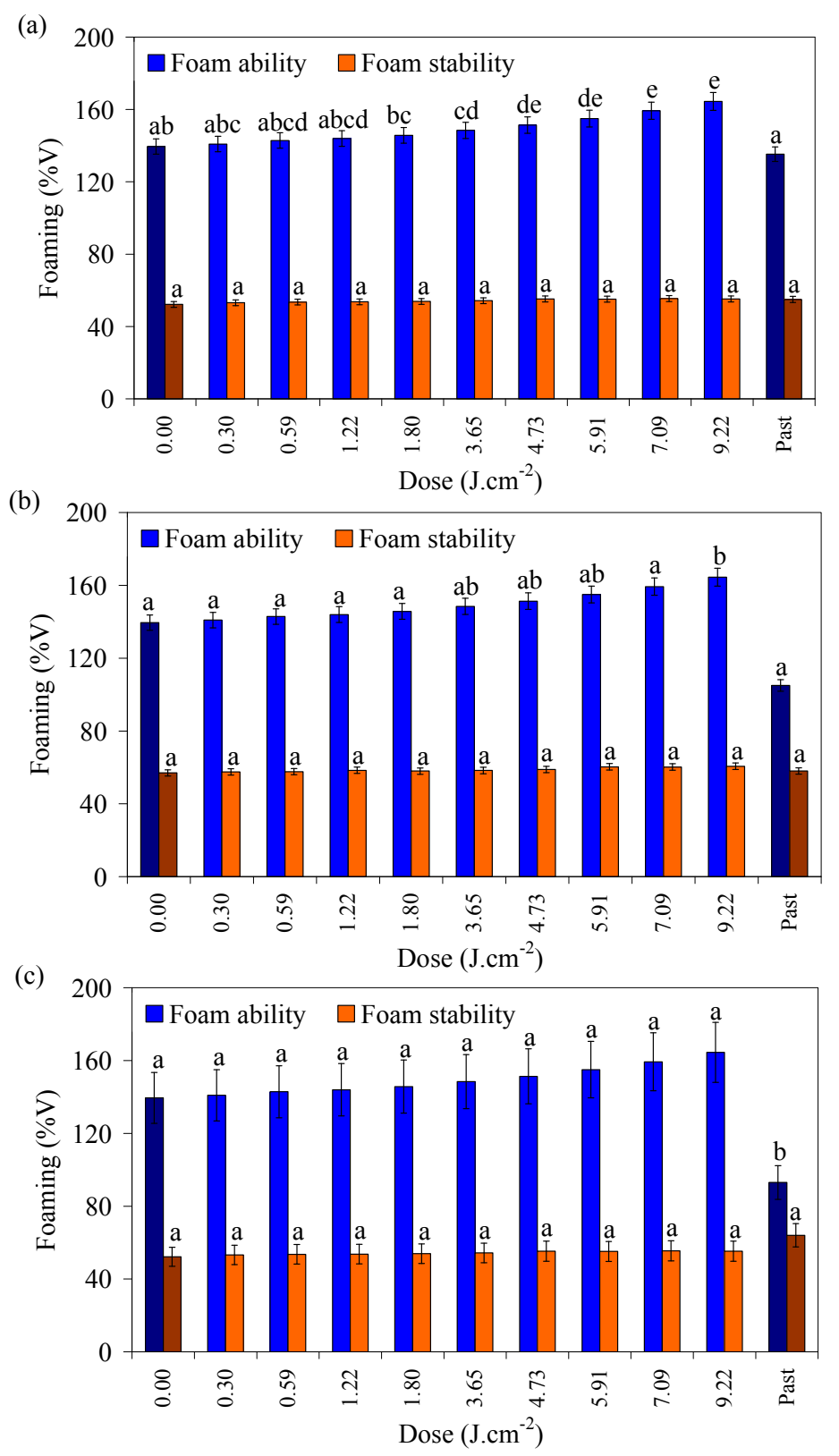

Figure 5.36 - Effect of UV irradiation on foaming ability and stability of (a) LEW (b) LWE and (c) LEY treated on the IATA bench device with continuous stirring. Results are the mean of triplicate \pm standart deviation. Different bars superscripts, for each analyse, indicate difference statiscally significant at $95 \%$ confidence level. 
Results and discussion
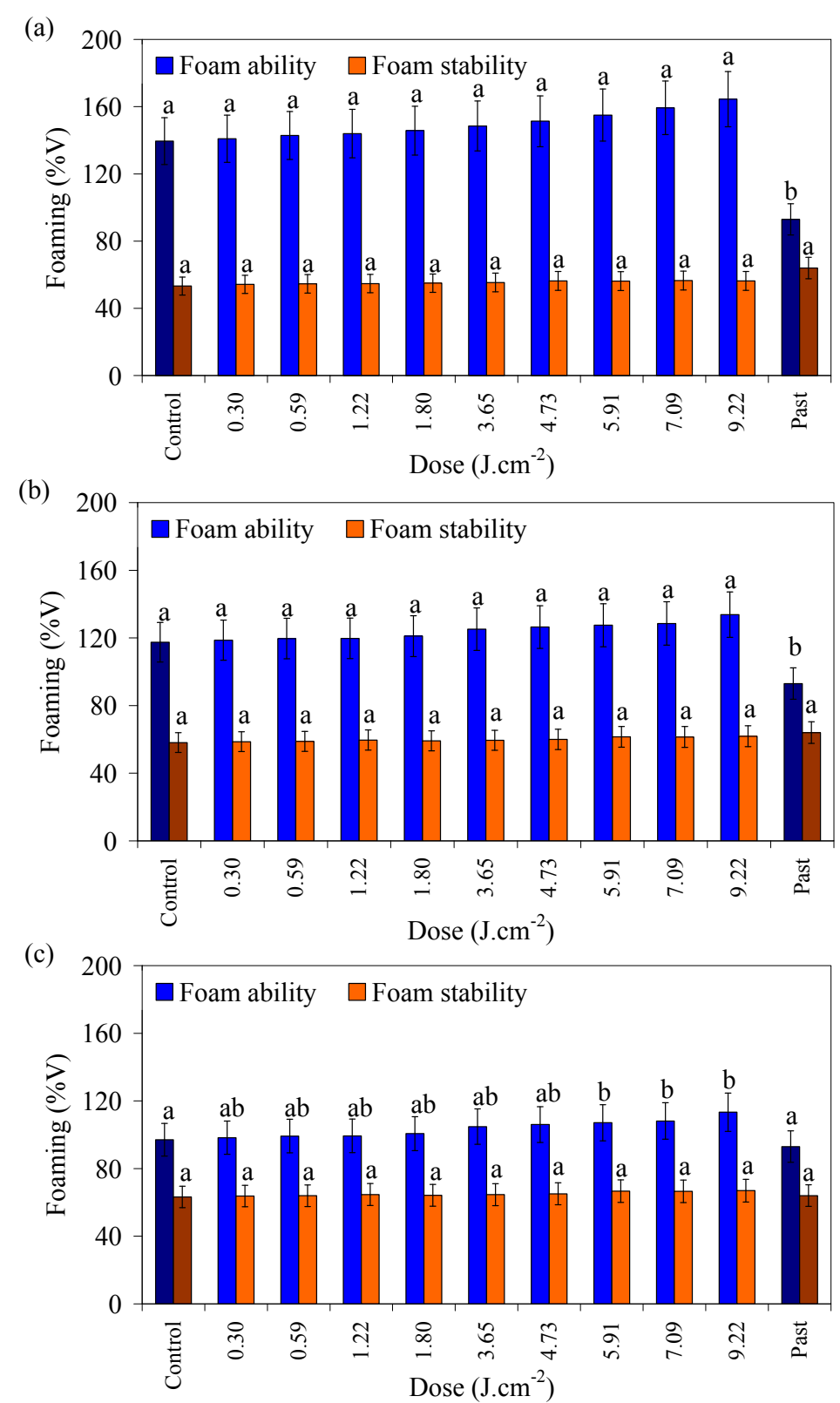

Figure 5.37 - Effect of UV irradiation on foaming ability and stability of (a) LEW (b) LWE and (c) LEY treated on the IATA bench device without continuous stirring. Results are the mean of triplicate \pm standart deviation. Different bars superscripts, for each analyse, indicate difference statiscally significant at $95 \%$ confidence level. 
A second study of the LEPs foaming properties was carried out with a continous treatment in the UVivatec ${ }^{\circledR} \mathrm{Lab}$ reactor. The foam density of control, UV-irradiated and pasteurized samples treated with this device is presented on Table 5.28 and the foaming ability and foaming stability for the same samples are presented on Figure 5.38.

Similarly to the previous results, no changes in the foam density could be attributed to UV-C treatments. And again the foaming ability of the egg white increased significantly with increasing the UV dose, while the foaming ability of egg yolk remained with a similar value to untreated LEY. Results for the whole egg were also comparable to the untreated control. On the other hand, the foaming stability of all egg products increased with increasing of UV irradiation exposure time. The higher doses attained in the continous treatment chamber gave rise to protein denaturation and possibly protein crosslinking. The increased foam stability could be then due to an increase in the apparent viscosity caused by protein crosslinking, and to the formation of more elastic foam networks at the air-water interfaces.

Foams of egg white and egg yolk prepared with UV-C LEPS resulted in a moist and creamy appearance, contrasting with the crispy and dry appearance of the foams prepared from untreated eggs. These foams were sticky and resembled clotted cream. No changes in color of the foams could be observed with the naked eye. Changes on bubbles size were only expressive on egg yolk, where both pasteurized and UV-C treated samples presented more and bigger bubbles (Figure 5.39). 
Results and discussion

Table 5.27 - Foam density of LEP treated in batch at the IATA bench equipment.

\begin{tabular}{|c|c|c|c|c|c|}
\hline \multirow{2}{*}{\multicolumn{3}{|c|}{ Treatment }} & \multicolumn{3}{|c|}{ Foam density $\left(\mathrm{g} \cdot \mathrm{mL}^{-1}\right)$} \\
\hline & & & egg white & whole egg & egg yolk \\
\hline \multirow{2}{*}{\multicolumn{3}{|c|}{$\begin{array}{c}\text { untreated } \\
\text { pasteurized }\end{array}$}} & $0.0954^{\mathrm{a}} \pm 0.0048$ & $0.3605^{\mathrm{a}} \pm 0.0180$ & $0.5215^{\mathrm{a}} \pm 0.0261$ \\
\hline & & & $0.0985^{\mathrm{a}} \pm 0.0048$ & $0.3630^{\mathrm{a}} \pm 0.0182$ & $0.5214^{\mathrm{a}} \pm 0.0261$ \\
\hline \multirow{18}{*}{ 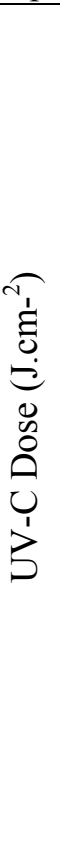 } & \multirow{9}{*}{ 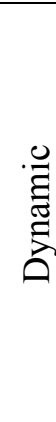 } & 0.30 & $0.0953^{\mathrm{a}} \pm 0.0051$ & $0.3694^{\mathrm{a}} \pm 0.0185$ & $0.4961^{\mathrm{a}} \pm 0.0248$ \\
\hline & & 0.59 & $0.0960^{\mathrm{a}} \pm 0.0056$ & $0.3526^{\mathrm{a}} \pm 0.0176$ & $0.5116^{\mathrm{a}} \pm 0.0259$ \\
\hline & & 1.22 & $0.0933^{\mathrm{a}} \pm 0.0047$ & $0.3570^{\mathrm{a}} \pm 0.0179$ & $0.5023^{\mathrm{a}} \pm 0.0251$ \\
\hline & & 1.80 & $0.0970^{\mathrm{a}} \pm 0.0049$ & $0.3586^{\mathrm{a}} \pm 0.0194$ & $0.5184^{a} \pm 0.0259$ \\
\hline & & 3.65 & $0.0933^{\mathrm{a}} \pm 0.0048$ & $0.3563^{\mathrm{a}} \pm 0.0177$ & $0.5204^{\mathrm{a}} \pm 0.0260$ \\
\hline & & 4.73 & $0.0960^{\mathrm{a}} \pm 0.0054$ & $0.3536^{\mathrm{a}} \pm 0.0183$ & $0.5012^{\mathrm{a}} \pm 0.0251$ \\
\hline & & 5.91 & $0.0926^{\mathrm{a}} \pm 0.0051$ & $0.3480^{\mathrm{a}} \pm 0.0176$ & $0.5061^{\mathrm{a}} \pm 0.0253$ \\
\hline & & 7.09 & $0.0953^{\mathrm{a}} \pm 0.0044$ & $0.3510^{\mathrm{a}} \pm 0.0184$ & $0.5178^{\mathrm{a}} \pm 0.0255$ \\
\hline & & 9.22 & $0.0976^{\mathrm{a}} \pm 0.0049$ & $0.3683^{\mathrm{a}} \pm 0.0192$ & $0.5066^{\mathrm{a}} \pm 0.0249$ \\
\hline & \multirow{9}{*}{ 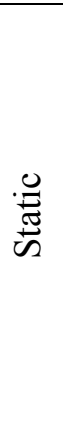 } & 0.30 & $0.0956^{\mathrm{a}} \pm 0.0044$ & $0.3878^{\mathrm{a}} \pm 0.0188$ & $0.5357^{\mathrm{a}} \pm 0.0268$ \\
\hline & & 0.59 & $0.0963^{\mathrm{a}} \pm 0.0049$ & $0.3702^{\mathrm{a}} \pm 0.0175$ & $0.5525^{\mathrm{a}} \pm 0.0276$ \\
\hline & & 1.22 & $0.0936^{\mathrm{a}} \pm 0.0051$ & $0.3748^{\mathrm{a}} \pm 0.0184$ & $0.5424^{\mathrm{a}} \pm 0.0271$ \\
\hline & & 1.80 & $0.0973^{\mathrm{a}} \pm 0.0055$ & $0.3765^{\mathrm{a}} \pm 0.0191$ & $0.5598^{\mathrm{a}} \pm 0.0280$ \\
\hline & & 3.65 & $0.0936^{\mathrm{a}} \pm 0.0056$ & $0.3741^{\mathrm{a}} \pm 0.0172$ & $0.5620^{\mathrm{a}} \pm 0.0281$ \\
\hline & & 4.73 & $0.0963^{\mathrm{a}} \pm 0.0060$ & $0.3712^{\mathrm{a}} \pm 0.0199$ & $0.5378^{a} \pm 0.0269$ \\
\hline & & 5.91 & $0.0929^{\mathrm{a}} \pm 0.0056$ & $0.3654^{\mathrm{a}} \pm 0.0182$ & $0.5465^{\mathrm{a}} \pm 0.0273$ \\
\hline & & 7.09 & $0.0956^{\mathrm{a}} \pm 0.0058$ & $0.3685^{\mathrm{a}} \pm 0.0184$ & $0.5592^{\mathrm{a}} \pm 0.0280$ \\
\hline & & 9.22 & $0.0979^{\mathrm{a}} \pm 0.0055$ & $0.3867^{\mathrm{a}} \pm 0.0193$ & $0.5471^{\mathrm{a}} \pm 0.0274$ \\
\hline
\end{tabular}

*Results are the mean of triplicate \pm standart deviation.

Different superscripts in each column indicate difference statiscally significant at $95 \%$ confidence level

Table 5.28 - Foam density of LEP treated on UVivatec ${ }^{\circledR} L a b$ reactor.

\begin{tabular}{|c|c|c|c|c|c|}
\hline \multicolumn{2}{|c|}{ egg white } & \multicolumn{2}{|c|}{ whole egg } & \multicolumn{2}{|c|}{ egg yolk } \\
\hline $\begin{array}{c}\text { Dose } \\
\left(\text { J.L } \mathbf{L}^{-1}\right)\end{array}$ & $\begin{array}{l}\text { Foam density } \\
\qquad\left(\mathrm{g} \cdot \mathrm{mL}^{-1}\right)\end{array}$ & $\begin{array}{c}\text { Dose } \\
\left(J^{-} L^{-1}\right)\end{array}$ & $\begin{array}{l}\text { Foam density } \\
\left(\mathrm{g} \cdot \mathrm{mL}^{-1}\right)\end{array}$ & $\begin{array}{c}\text { Dose } \\
\left(J^{-1} \mathbf{L}^{-1}\right)\end{array}$ & $\begin{array}{l}\text { Foam density } \\
\left(\mathrm{g} \cdot \mathrm{mL}^{-1}\right)\end{array}$ \\
\hline untreated & $0.0921^{\mathrm{a}} \pm 0.0046$ & untreated & $0.3628^{a} \pm 0.0181$ & untreated & $0.5515^{\mathrm{a}} \pm 0.0276$ \\
\hline 4214 & $0.0916^{\mathrm{a}} \pm 0.0045$ & 7151 & $0.3690^{\mathrm{a}} \pm 0.0185$ & 31533 & $0.5592^{\mathrm{a}} \pm 0.0280$ \\
\hline 7491 & $0.0902^{\mathrm{a}} \pm 0.0047$ & 14303 & $0.3692^{\mathrm{a}} \pm 0.0192$ & 47299 & $0.5516^{\mathrm{a}} \pm 0.0274$ \\
\hline 14982 & $0.0903^{\mathrm{a}} \pm 0.0053$ & 28606 & $0.3714^{\mathrm{a}} \pm 0.0182$ & 94598 & $0.5423^{\mathrm{a}} \pm 0.0271$ \\
\hline 20133 & $0.0922^{\mathrm{a}} \pm 0.0054$ & 32181 & $0.3723^{\mathrm{a}} \pm 0.0177$ & 115619 & $0.5561^{\mathrm{a}} \pm 0.0278$ \\
\hline pasteurized & $0.0944^{\mathrm{a}} \pm 0.0056$ & pasteurized & $0.3812^{\mathrm{a}} \pm 0.0202$ & pasteurized & $0.5688^{\mathrm{a}} \pm 0.0294$ \\
\hline
\end{tabular}



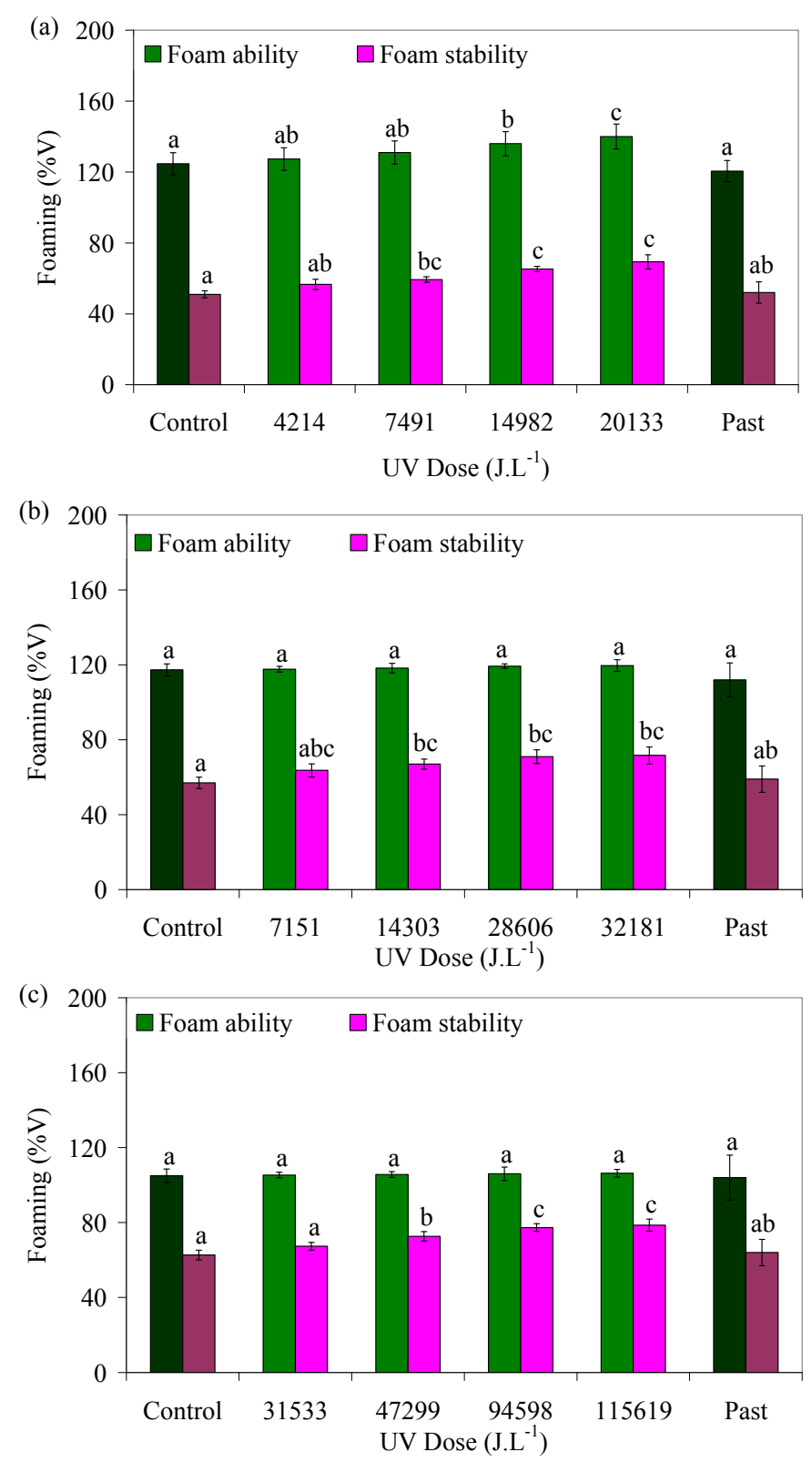

Figure 5.38 - Effect of UV irradiation on foaming ability and stability of (a) LEW (b) LWE and (c) LEY treated on the UVivatec ${ }^{\circledR} L a b$ reactor with continuous stirring. Results are the mean of triplicate \pm standart deviation. Different bars superscripts, for each analyse, indicate difference statiscally significant at $95 \%$ confidence level. 

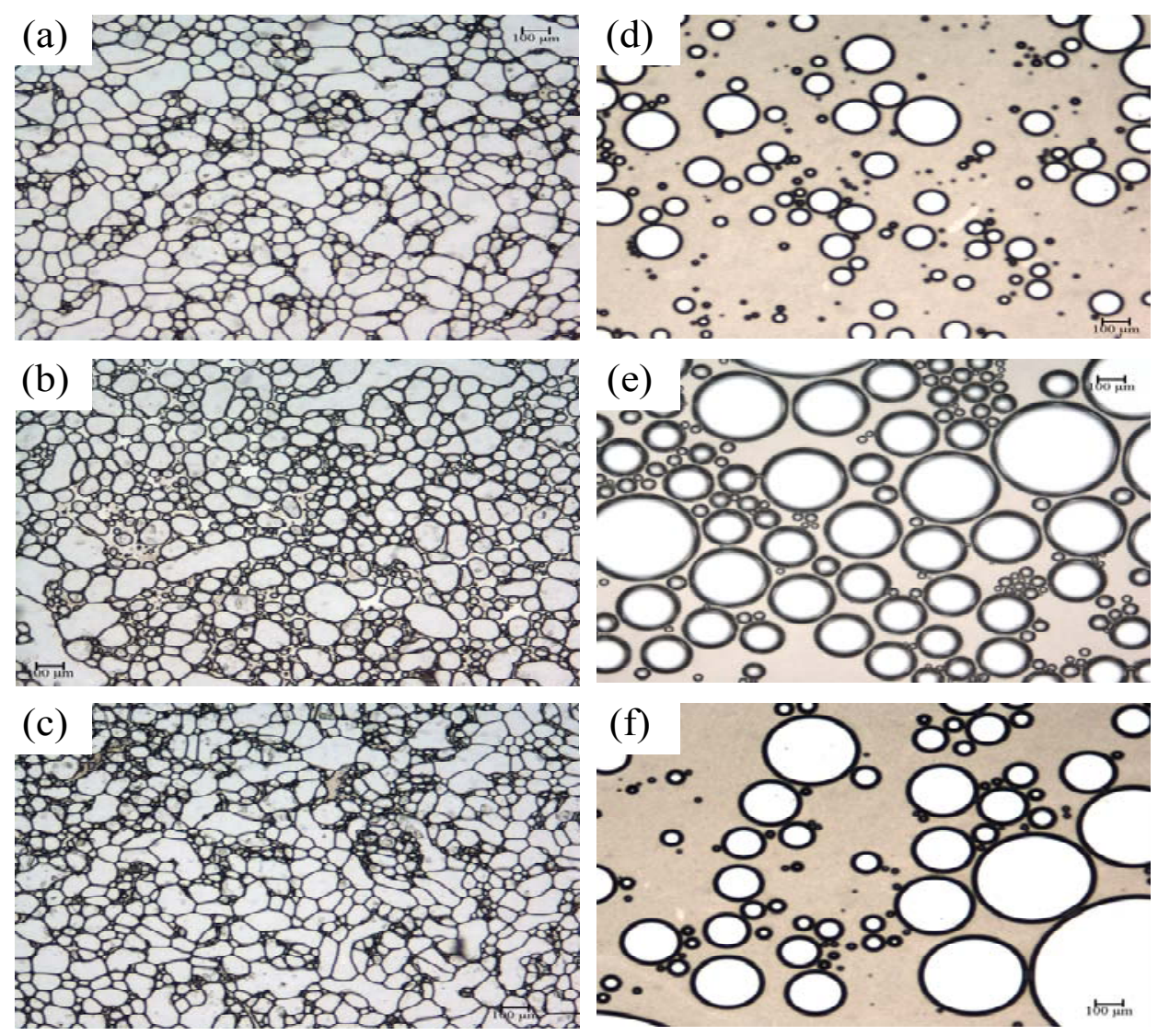

Figure 5.39 - Appearance, observed on microscope, of foams prepared with (a) control untreated LEW (b) LEW UV-C treated in the IATA bench equipment - 9.22 J.mL ${ }^{-1}$ (c) LEW UV-C treated on UVivatec ${ }^{\circledR}$ Lab reactor 20133 J.L $^{-1}$ (d) control untreated LEY (e) LEY UV-C treated in the IATA bench equipment - 9.22 J.mL ${ }^{-1}$ (f) LEY UV-C treated on UVivatec ${ }^{\circledR}$ Lab reactor -115619 J.L ${ }^{-1}$.

No significant changer were observed on rheological studies (section 5.1.5), and only small changes were observed on protein oxidation (sections 5.1.4.1 and 5.2.4), although when foaming is been formed additional denaturalization occurs. This can led to formation of new disulfide bonds, especially if a cross-linking or cleavage had occurred previously. 


\subsubsection{Emulsifying properties}

Emulsifying ability and emulsion stability are the parameters describing the emulsifying properties of proteins in food emulsion systems. The emulsifying ability of a protein emulsifier depends on its ability to form adsorption films around the oil globules and to lower the interfacial tension at the oil-water interface. Emulsion stability is the capacity of emulsion droplets to remain dispersed without separation by creaming, coalescing, and flocculation (Zayas, 1997). Figure 5.40 and 5.41 and Tables 5.29, 5.30 and 5.31 shows a tendency of the emulsifying activity index to improve after UV-C, with an increase in the emulsification capacity and stability. Those differences were not statistically significant, and higher UV-C doses would be required to produce noticeable differences. Values for the $\mathrm{E}_{\mathrm{AI}}, \mathrm{E}_{\mathrm{S}}$ and $E_{C}$ for the samples treated under dynamic static conditions are higher than to the samples without stirring during the UV-C exposure. The differences are about $3.5 \%, 3.8 \%$ and $4.4 \%$ for the LEW, LWE and LEY treated with $9.22{\mathrm{~J} . \mathrm{cm}^{-2}}^{-}$

The tendency observed in batch is confirmed at higher UV-C doses, as observed after treatments in the UVivatec ${ }^{\circledR} \mathrm{Lab}$ reactor. Figure 5.42, and Tables 5.32, 5.33 and 5.34 show rotworthy improvements in the emulsifying activity index with an increase in the emulsification capacity and stability in UV-C treated egg fractions. UV-C treatments improve considerably the results obtained with heat, and seem to have a certain beneficial effect on the protein technological quality. 
Results and discussion
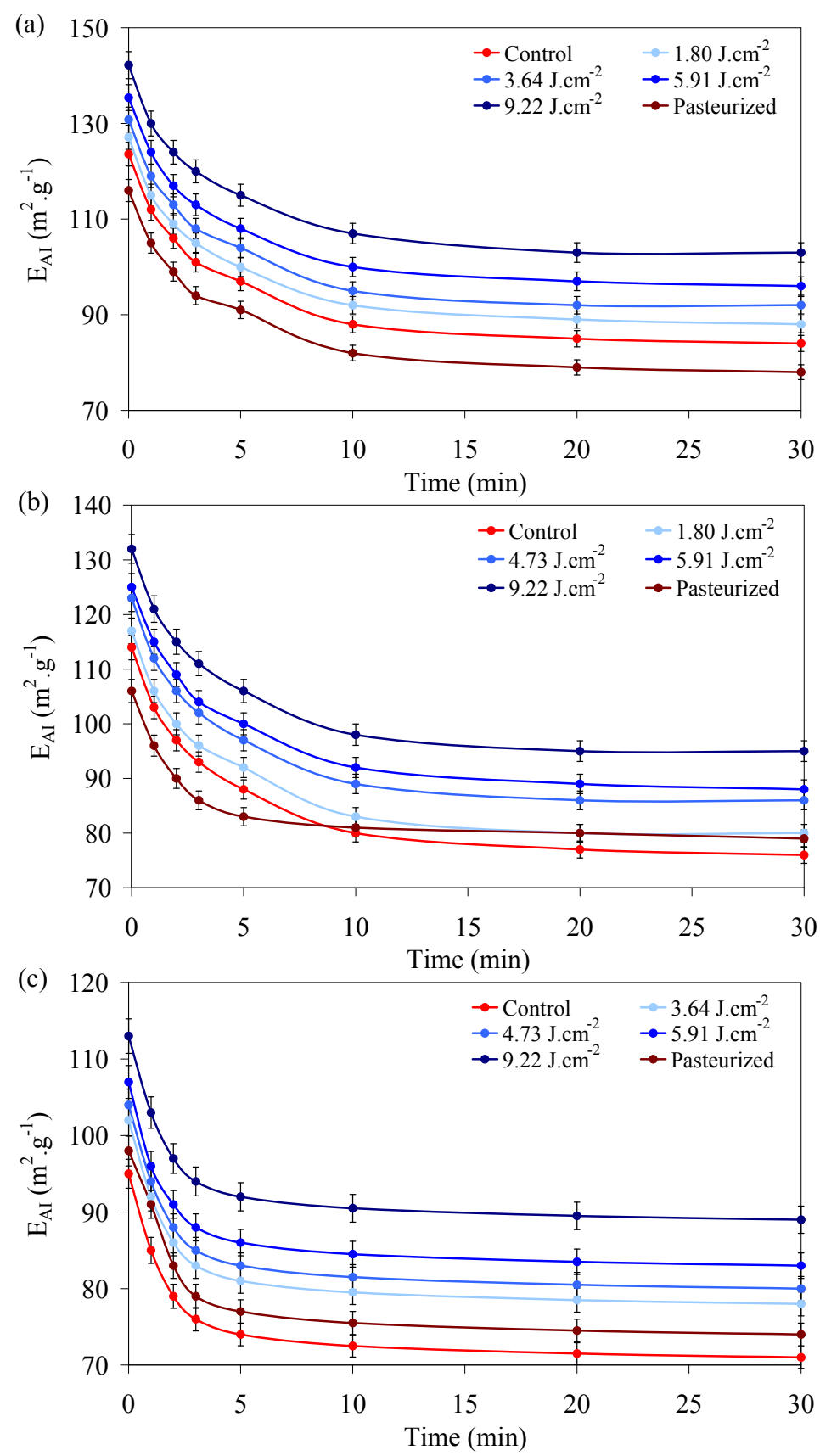

Figure 5.40 - Effect of UV irradiation on emulsifying activity index of (a) LEW (b) LWE and (c) LEY treated the IATA bench equipment with stirring. Results are the mean of triplicate \pm standart deviation. 

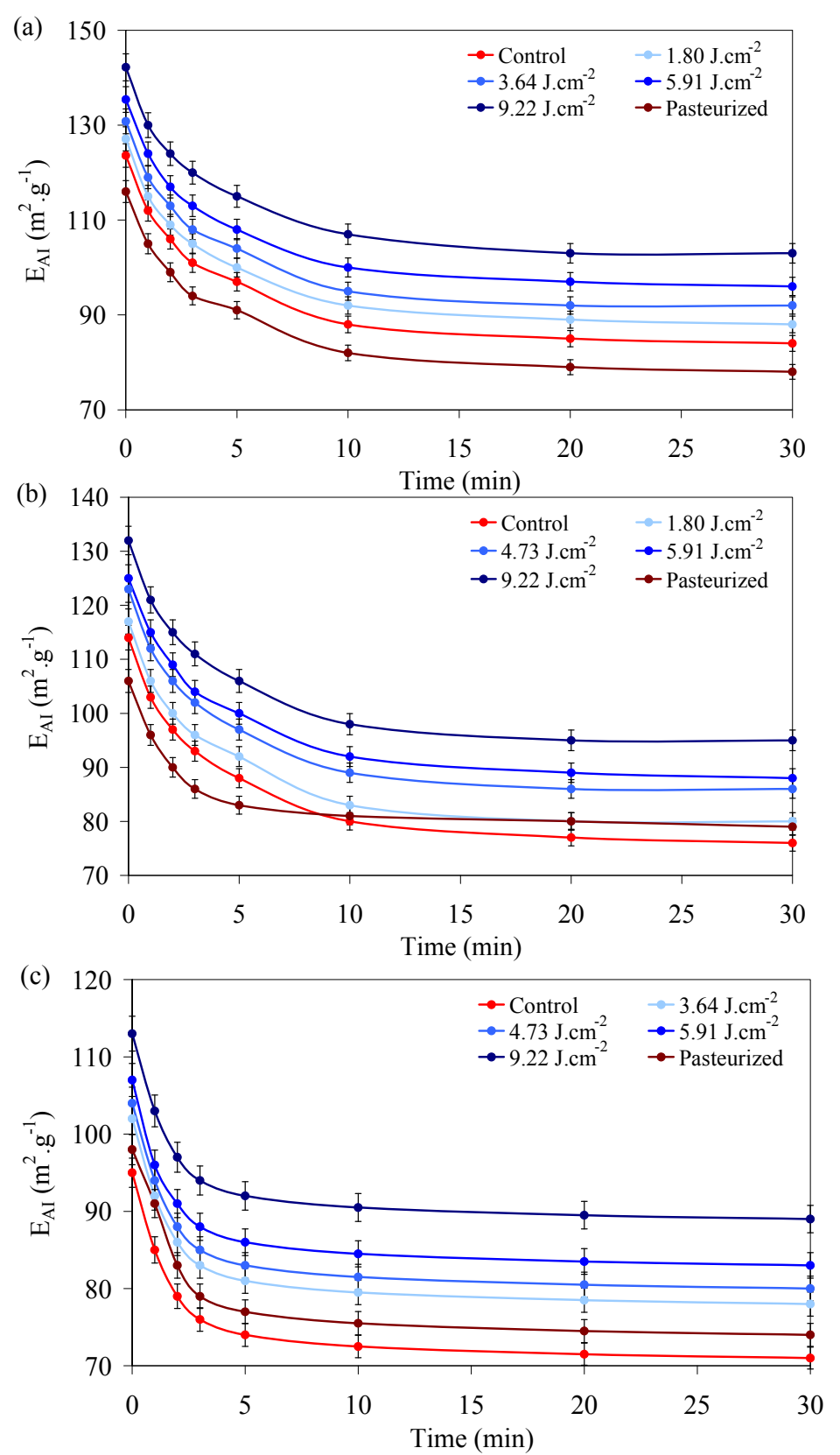

Figure 5.41 - Effect of UV irradiation on emulsifying activity index of (a) LEW (b) LWE and (c) LEY treated the IATA bench equipment with outstirring. Results are the mean of triplicate \pm standart deviation. 
Results and discussion

Table 5.29 - Emulsifying properties of LEW treated in the IATA bench equipment.

\begin{tabular}{|c|c|c|c|c|}
\hline \multicolumn{2}{|c|}{ Treatment } & $\begin{array}{l}\text { Emulsifying } \\
\text { activity index }\end{array}$ & $\begin{array}{c}\text { Emulsifying capacity } \\
\text { (g of oil per mg of }\end{array}$ & $\begin{array}{c}\text { Emulsion } \\
\text { stability (\%) }\end{array}$ \\
\hline \multicolumn{2}{|c|}{ Control } & $123.6^{\mathrm{a}} \pm 14.6$ & $0.80^{\mathrm{a}} \pm 0.08$ & $67.2^{\mathrm{a}} \pm 4.3$ \\
\hline \multirow{18}{*}{ 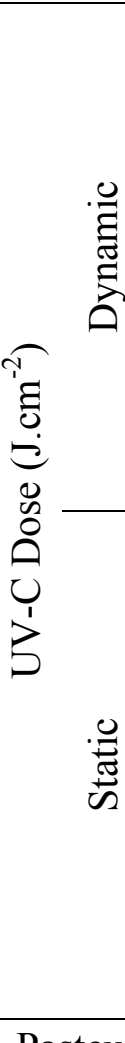 } & 0.30 & $124.2^{\mathrm{a}} \pm 18.4$ & $0.82^{\mathrm{a}} \pm 0.09$ & $67.6^{\mathrm{a}} \pm 5.1$ \\
\hline & 0.59 & $124.7^{\mathrm{a}} \pm 17.4$ & $0.82^{a} \pm 0.07$ & $67.4^{\mathrm{a}} \pm 4.7$ \\
\hline & 1.22 & $126.0^{\mathrm{a}} \pm 11.9$ & $0.83^{\mathrm{a}} \pm 0.11$ & $68.3^{\mathrm{a}} \pm 4.5$ \\
\hline & 1.80 & $127.1^{\mathrm{a}} \pm 18.3$ & $0.86^{\mathrm{a}} \pm 0.07$ & $68.5^{\mathrm{a}} \pm 4.8$ \\
\hline & 3.64 & $130.8^{\mathrm{a}} \pm 17.6$ & $0.89^{\mathrm{a}} \pm 0.06$ & $69.6^{\mathrm{a}} \pm 5.0$ \\
\hline & 4.73 & $133.0^{\mathrm{a}} \pm 14.7$ & $0.91^{\mathrm{a}} \pm 0.08$ & $69.9^{\mathrm{a}} \pm 5.0$ \\
\hline & 5.91 & $135.4^{\mathrm{a}} \pm 15.4$ & $0.92^{\mathrm{a}} \pm 0.10$ & $70.2^{\mathrm{a}} \pm 4.2$ \\
\hline & 7.09 & $137.4^{\mathrm{a}} \pm 17.8$ & $0.93^{\mathrm{a}} \pm 0.09$ & $70.6^{a} \pm 4.6$ \\
\hline & 9.22 & $142.2^{\mathrm{a}} \pm 19.5$ & $0.95^{\mathrm{a}} \pm 0.08$ & $71.7^{\mathrm{a}} \pm 5.2$ \\
\hline & 0.30 & $124.2^{\mathrm{a}} \pm 21.3$ & $0.80^{\mathrm{a}} \pm 0.10$ & $66.3^{a} \pm 6.1$ \\
\hline & 0.59 & $124.7^{\mathrm{a}} \pm 13.9$ & $0.80^{\mathrm{a}} \pm 0.09$ & $65.9^{\mathrm{a}} \pm 4.4$ \\
\hline & 1.22 & $126.0^{\mathrm{a}} \pm 16.6$ & $0.81^{\mathrm{a}} \pm 0.13$ & $66.9^{\mathrm{a}} \pm 4.3$ \\
\hline & 1.80 & $127.1^{\mathrm{a}} \pm 15.7$ & $0.82^{\mathrm{a}} \pm 0.15$ & $67.8^{\mathrm{a}} \pm 6.0$ \\
\hline & 3.64 & $130.8^{\mathrm{a}} \pm 12.0$ & $0.83^{\mathrm{a}} \pm 0.08$ & $68.4^{\mathrm{a}} \pm 5.3$ \\
\hline & 4.73 & $133.0^{\mathrm{a}} \pm 16.5$ & $0.85^{\mathrm{a}} \pm 0.10$ & $68.8^{\mathrm{a}} \pm 5.5$ \\
\hline & 5.91 & $135.4^{\mathrm{a}} \pm 14.4$ & $0.88^{\mathrm{a}} \pm 0.13$ & $69.0^{\mathrm{a}} \pm 5.6$ \\
\hline & 7.09 & $137.4^{\mathrm{a}} \pm 19.1$ & $0.87^{\mathrm{a}} \pm 0.15$ & $69.5^{\mathrm{a}} \pm 4.9$ \\
\hline & 9.22 & $142.2^{\mathrm{a}} \pm 15.8$ & $0.91^{\mathrm{a}} \pm 0.09$ & $70.7^{\mathrm{a}} \pm 4.7$ \\
\hline \multicolumn{2}{|c|}{ Pasteurized } & $116.1^{\mathrm{a}} \pm 13.1$ & $0.77^{\mathrm{a}} \pm 0.09$ & $66.4^{\mathrm{a}} \pm 4.4$ \\
\hline
\end{tabular}

*Results are the mean of triplicate \pm standart deviation.

Different superscripts in each column indicate difference statiscally significant at $95 \%$ confidence level

Emulsifying activity is related to the capacity of surface active molecules (proteins or phospholipids) to cover the oil/water interface created by mechanical homogenization. 
Table 5.30 - Emulsifying properties of LWE treated in the IATA bench equipment.

\begin{tabular}{|c|c|c|c|c|}
\hline \multicolumn{2}{|c|}{ Treatment } & \multirow{2}{*}{$\begin{array}{r}\begin{array}{r}\text { Emulsifying } \\
\text { activity index } \\
\left(\mathbf{m}^{\mathbf{2}} \cdot \mathbf{g}^{-1}\right)\end{array} \\
114.1^{\mathrm{a}} \pm 15.2 \\
\end{array}$} & \multirow{2}{*}{$\begin{array}{c}\begin{array}{c}\text { Emulsifying capacity } \\
\text { (g of oil per mg of } \\
\text { protein) }\end{array} \\
0.71^{\mathrm{a}} \pm 0.09 \\
\end{array}$} & \multirow{2}{*}{$\begin{array}{c}\begin{array}{c}\text { Emulsion } \\
\text { stability (\%) }\end{array} \\
65.8^{\mathrm{a}} \pm 4.8 \\
\end{array}$} \\
\hline Con & & & & \\
\hline \multirow{18}{*}{ 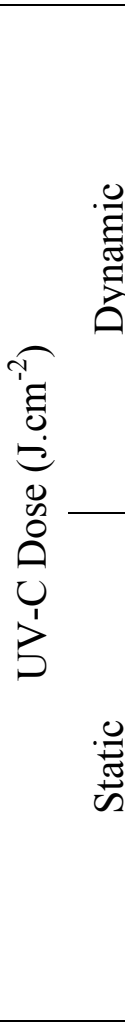 } & 0.30 & $114.2^{a} \pm 14.7$ & $0.72^{\mathrm{a}} \pm 0.10$ & $66.7^{\mathrm{a}} \pm 4.6$ \\
\hline & 0.59 & $115.2^{a} \pm 15.8$ & $0.73^{\mathrm{a}} \pm 0.12$ & $66.1^{\mathrm{a}} \pm 4.0$ \\
\hline & 1.22 & $116.4^{\mathrm{a}} \pm 17.3$ & $0.73^{\mathrm{a}} \pm 0.10$ & $67.2^{\mathrm{a}} \pm 5.2$ \\
\hline & 1.80 & $117.8^{a} \pm 19.5$ & $0.74^{\mathrm{a}} \pm 0.11$ & $67.5^{\mathrm{a}} \pm 5.6$ \\
\hline & 3.64 & $121.6^{\mathrm{a}} \pm 18.3$ & $0.76^{\mathrm{a}} \pm 0.10$ & $67.8^{\mathrm{a}} \pm 4.4$ \\
\hline & 4.73 & $123.6^{\mathrm{a}} \pm 20.6$ & $0.77^{\mathrm{a}} \pm 0.09$ & $69.1^{\mathrm{a}} \pm 4.8$ \\
\hline & 5.91 & $125.2^{a} \pm 19.1$ & $0.79^{\mathrm{a}} \pm 0.08$ & $69.6^{\mathrm{a}} \pm 4.3$ \\
\hline & 7.09 & $128.4^{\mathrm{a}} \pm 18.9$ & $0.81^{\mathrm{a}} \pm 0.07$ & $69.5^{\mathrm{a}} \pm 4.7$ \\
\hline & 9.22 & $132.2^{\mathrm{a}} \pm 17.4$ & $0.84^{\mathrm{a}} \pm 0.12$ & $71.2^{\mathrm{a}} \pm 5.2$ \\
\hline & 0.30 & $114.0^{\mathrm{a}} \pm 20.3$ & $0.70^{\mathrm{a}} \pm 0.12$ & $64.2^{\mathrm{a}} \pm 4.9$ \\
\hline & 0.59 & $114.2^{\mathrm{a}} \pm 19.4$ & $0.71^{\mathrm{a}} \pm 0.13$ & $65.1^{\mathrm{a}} \pm 4.3$ \\
\hline & 1.22 & $115.1^{\mathrm{a}} \pm 20.5$ & $0.72^{\mathrm{a}} \pm 0.10$ & $64.6^{\mathrm{a}} \pm 5.2$ \\
\hline & 1.80 & $116.0^{\mathrm{a}} \pm 21.9$ & $0.72^{\mathrm{a}} \pm 0.09$ & $65.8^{\mathrm{a}} \pm 6.1$ \\
\hline & 3.64 & $117.3^{\mathrm{a}} \pm 17.7$ & $0.73^{\mathrm{a}} \pm 0.12$ & $66.0^{\mathrm{a}} \pm 5.0$ \\
\hline & 4.73 & $121.2^{\mathrm{a}} \pm 19.8$ & $0.74^{\mathrm{a}} \pm 0.15$ & $66.3^{\mathrm{a}} \pm 4.9$ \\
\hline & 5.91 & $123.5^{\mathrm{a}} \pm 20.5$ & $0.76^{\mathrm{a}} \pm 0.10$ & $67.8^{\mathrm{a}} \pm 5.3$ \\
\hline & 7.09 & $125.8^{a} \pm 21.1$ & $0.78^{\mathrm{a}} \pm 0.08$ & $68.3^{\mathrm{a}} \pm 5.5$ \\
\hline & 9.22 & $127.2^{a} \pm 22.1$ & $0.80^{\mathrm{a}} \pm 0.14$ & $68.4^{\mathrm{a}} \pm 4.7$ \\
\hline \multicolumn{2}{|c|}{ Pasteurized } & $106.9^{a} \pm 22.3$ & $0.69^{\mathrm{a}} \pm 0.13$ & $73.6^{\mathrm{a}} \pm 5.0$ \\
\hline
\end{tabular}

*Results are the mean of triplicate \pm standart deviation.

Different superscripts in each column indicate difference statiscally significant at $95 \%$ confidence level

All constituents of the yolk (HDL, LDL, phosvitin and livetin) can adsorb at the oil/water interface (Garland, 1973; Shenton, 1979; Kiosseoglou and Sherman 1983; Chung and Ferrier, 1992; Davey et al., 1969). 
Results and discussion

Table 5.31 - Emulsifying properties of LEY treated in the IATA bench equipment.

\begin{tabular}{|c|c|c|c|c|c|}
\hline \multicolumn{3}{|c|}{ Treatment } & $\begin{array}{l}\text { Emulsifying } \\
\text { activity index }\end{array}$ & $\begin{array}{l}\text { Emulsifying capacity } \\
\text { (g of oil per mg of }\end{array}$ & $\begin{array}{c}\text { Emulsion } \\
\text { stability (\%) }\end{array}$ \\
\hline \multicolumn{3}{|c|}{ Control } & $95.2^{a} \pm 15.3$ & $0.56^{\mathrm{a}} \pm 0.09$ & $73.7^{\mathrm{a}} \pm 3.9$ \\
\hline \multirow{18}{*}{ 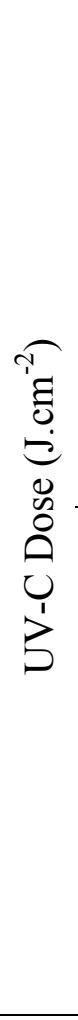 } & \multirow{9}{*}{$\begin{array}{l}.0 \\
\text { อే } \\
\text { อే }\end{array}$} & 0.30 & $95.2^{a} \pm 16.7$ & $0.57^{\mathrm{a}} \pm 0.10$ & $73.8^{\mathrm{a}} \pm 4.1$ \\
\hline & & 0.59 & $96.2^{\mathrm{a}} \pm 19.5$ & $0.58^{\mathrm{a}} \pm 0.11$ & $74.0^{\mathrm{a}} \pm 4.6$ \\
\hline & & 1.22 & $97.4^{\mathrm{a}} \pm 20.6$ & $0.59^{\mathrm{a}} \pm 0.10$ & $74.2^{\mathrm{a}} \pm 3.6$ \\
\hline & & 1.80 & $98.8^{\mathrm{a}} \pm 19.5$ & $0.60^{\mathrm{a}} \pm 0.09$ & $74.5^{\mathrm{a}} \pm 3.8$ \\
\hline & & 3.64 & $102.6^{\mathrm{a}} \pm 18.4$ & $0.62^{\mathrm{a}} \pm 0.06$ & $75.5^{\mathrm{a}} \pm 4.2$ \\
\hline & & 4.73 & $104.5^{\mathrm{a}} \pm 17.3$ & $0.64^{\mathrm{a}} \pm 0.07$ & $76.0^{\mathrm{a}} \pm 4.3$ \\
\hline & & 5.91 & $107.0^{\mathrm{a}} \pm 18.4$ & $0.66^{\mathrm{a}} \pm 0.09$ & $76.6^{\mathrm{a}} \pm 4.6$ \\
\hline & & 7.09 & $109.3^{a} \pm 19.2$ & $0.67^{\mathrm{a}} \pm 0.08$ & $77.1^{\mathrm{a}} \pm 4.7$ \\
\hline & & 9.22 & $113.6^{\mathrm{a}} \pm 18.8$ & $0.70^{\mathrm{a}} \pm 0.08$ & $77.9^{\mathrm{a}} \pm 4.5$ \\
\hline & \multirow{9}{*}{$\stackrel{0}{\stackrel{0}{\pi}}$} & 0.30 & $95.0^{a} \pm 17.6$ & $0.56^{\mathrm{a}} \pm 0.12$ & $72.2^{\mathrm{a}} \pm 5.1$ \\
\hline & & 0.59 & $95.1^{\mathrm{a}} \pm 18.4$ & $0.55^{\mathrm{a}} \pm 0.15$ & $72.3^{\mathrm{a}} \pm 4.7$ \\
\hline & & 1.22 & $96.3^{\mathrm{a}} \pm 19.3$ & $0.57^{\mathrm{a}} \pm 0.13$ & $72.5^{\mathrm{a}} \pm 4.8$ \\
\hline & & 1.80 & $97.2^{\mathrm{a}} \pm 18.4$ & $0.58^{\mathrm{a}} \pm 0.16$ & $72.8^{\mathrm{a}} \pm 5.2$ \\
\hline & & 3.64 & $98.6^{\mathrm{a}} \pm 17.8$ & $0.58^{\mathrm{a}} \pm 0.18$ & $73.1^{\mathrm{a}} \pm 4.6$ \\
\hline & & 4.73 & $102.9^{\mathrm{a}} \pm 18.6$ & $0.59^{a} \pm 0.14$ & $74.2^{\mathrm{a}} \pm 4.4$ \\
\hline & & 5.91 & $104.7^{\mathrm{a}} \pm 19.5$ & $0.60^{a} \pm 0.10$ & $74.7^{\mathrm{a}} \pm 4.3$ \\
\hline & & 7.09 & $107.1^{\mathrm{a}} \pm 20.9$ & $0.62^{a} \pm 0.12$ & $75.5^{\mathrm{a}} \pm 5.0$ \\
\hline & & 9.22 & $109.0^{\mathrm{a}} \pm 19.6$ & $0.63^{\mathrm{a}} \pm 0.09$ & $75.9^{\mathrm{a}} \pm 5.5$ \\
\hline \multicolumn{3}{|c|}{ Pasteurized } & $98.0^{\mathrm{a}} \pm 16.1$ & $0.61^{\mathrm{a}} \pm 0.11$ & $74.5^{\mathrm{a}} \pm 4.1$ \\
\hline
\end{tabular}

*Results are the mean of triplicate \pm standart deviation.

Different superscripts in each column indicate difference statiscally significant at $95 \%$ confidence level

In emulsions prepared with egg white, the contribution of proteins to emulsifying activity is higher than that of egg yolk (Kiosseoglou and Sherman, 1983; Mizutani and Nakamura, 1984, 1985; Bringe et al., 1996). 
Table 5.32 - Emulsifying properties of LEW treated on UVivatec ${ }^{\circledR} L a b$ reactor.

\begin{tabular}{|c|c|c|c|}
\hline Treatment & $\begin{array}{l}\text { Emulsifying activity } \\
\text { index }\left(\mathrm{m}^{2} \cdot \mathrm{g}^{-1}\right)\end{array}$ & $\begin{array}{l}\text { Emulsifying capacity (g of } \\
\text { oil per mg of protein) }\end{array}$ & $\begin{array}{c}\text { Emulsion } \\
\text { stability (\%) }\end{array}$ \\
\hline Control & $148.6^{a} \pm 2.2$ & $1.06^{\mathrm{a}} \pm 0.08$ & $73.2^{\mathrm{a}} \pm 4.4$ \\
\hline 4214 & $150.1^{\mathrm{ab}} \pm 2.9$ & $1.12^{\mathrm{ab}} \pm 0.07$ & $83.1^{b} \pm 3.1$ \\
\hline คิ 7491 & $152.1^{\mathrm{bc}} \pm 2.5$ & $1.19^{\mathrm{ab}} \pm 0.12$ & $85.9^{\mathrm{bc}} \pm 2.9$ \\
\hline 14982 & $155.5^{\mathrm{c}} \pm 2.8$ & $1.42^{\mathrm{b}} \pm 0.14$ & $87.3^{b c} \pm 3.6$ \\
\hline 20133 & $163.1^{\mathrm{d}} \pm 2.1$ & $1.71^{\mathrm{c}} \pm 0.09$ & $92.3^{\mathrm{bc}} \pm 4.2$ \\
\hline Pasteurized & $141.1^{\mathrm{e}} \pm 2.3$ & $0.95^{\mathrm{a}} \pm 0.08$ & $72.3^{\mathrm{a}} \pm 4.8$ \\
\hline
\end{tabular}

*Results are the mean of triplicate \pm standart deviation.

Different superscripts in each column indicate difference statiscally significant at $95 \%$ confidence level

Table 5.33 - Emulsifying properties of LWE treated on UVivatec ${ }^{\circledR} L a b$ reactor.

\begin{tabular}{|c|c|c|c|}
\hline Treatment & $\begin{array}{l}\text { Emulsifying activity } \\
\text { index }\left(\mathrm{m}^{2} \cdot \mathrm{g}^{-1}\right)\end{array}$ & $\begin{array}{l}\text { Emulsifying capacity (g of } \\
\text { oil per mg of protein) }\end{array}$ & $\begin{array}{c}\text { Emulsion } \\
\text { stability (\%) }\end{array}$ \\
\hline Control & $139.1^{\mathrm{a}} \pm 2.7$ & $0.84^{\mathrm{a}} \pm 0.12$ & $72.3^{\mathrm{a}} \pm 4.1$ \\
\hline 7151 & $140.6^{\mathrm{ab}} \pm 3.8$ & $0.90^{\mathrm{a}} \pm 0.13$ & $82.6^{\mathrm{ab}} \pm 4.6$ \\
\hline 14303 & $142.5^{\mathrm{ab}} \pm 5.4$ & $0.95^{\mathrm{a}} \pm 0.14$ & $85.3^{\mathrm{b}} \pm 5.2$ \\
\hline$\perp_{>}^{1} \Xi 28606$ & $145.8^{\mathrm{b}} \pm 1.7$ & $1.06^{\mathrm{a}} \pm 0.15$ & $86.9^{\mathrm{b}} \pm 3.9$ \\
\hline $5 \quad 32181$ & $153.2^{\mathrm{c}} \pm 4.5$ & $1.09^{\mathrm{a}} \pm 0.16$ & $92.0^{\mathrm{b}} \pm 3.1$ \\
\hline Pasteurized & $131.9^{\mathrm{d}} \pm 7.8$ & $0.84^{\mathrm{a}} \pm 0.12$ & $78.5^{\mathrm{a}} \pm 4.4$ \\
\hline
\end{tabular}

*Results are the mean of triplicate \pm standart deviation.

Different superscripts in each column indicate difference statiscally significant at $95 \%$ confidence level

Table 5.34 - Emulsifying properties of LEY treated on UVivatec $®$ Lab reactor.

\begin{tabular}{|c|c|c|c|}
\hline Treatment & $\begin{array}{l}\text { Emulsifying activity } \\
\text { index }\left(\mathrm{m}^{2} \cdot \mathrm{g}^{-1}\right)\end{array}$ & $\begin{array}{c}\text { Emulsifying capacity (g of } \\
\text { oil per mg of protein) }\end{array}$ & $\begin{array}{c}\text { Emulsion } \\
\text { stability (\%) }\end{array}$ \\
\hline Control & $120.2^{\mathrm{a}} \pm 4.4$ & $0.70^{\mathrm{a}} \pm 0.08$ & $83.1^{\mathrm{a}} \pm 4.0$ \\
\hline 7151 & $121.6^{\mathrm{a}} \pm 3.7$ & $0.82^{\mathrm{ab}} \pm 0.09$ & $83.3^{\mathrm{a}} \pm 4.2$ \\
\hline 14303 & $123.4^{\mathrm{a}} \pm 4.8$ & $0.91^{b} \pm 0.10$ & $84.0^{\mathrm{a}} \pm 3.6$ \\
\hline 28606 & $126.5^{\mathrm{ab}} \pm 4.1$ & $1.02^{\mathrm{b}} \pm 0.11$ & $85.8^{\mathrm{a}} \pm 4.1$ \\
\hline D $\quad 32181$ & $133.3^{\mathrm{b}} \pm 5.2$ & $1.08^{b} \pm 0.12$ & $90.9^{\mathrm{a}} \pm 4.4$ \\
\hline Pasteurized & $123.0^{\mathrm{a}} \pm 2.8$ & $0.70^{\mathrm{a}} \pm 0.08$ & $82.1^{\mathrm{a}} \pm 4.8$ \\
\hline
\end{tabular}

*Results are the mean of triplicate \pm standart deviation.

Different superscripts in each column indicate difference statiscally significant at $95 \%$ confidence level 
Results and discussion
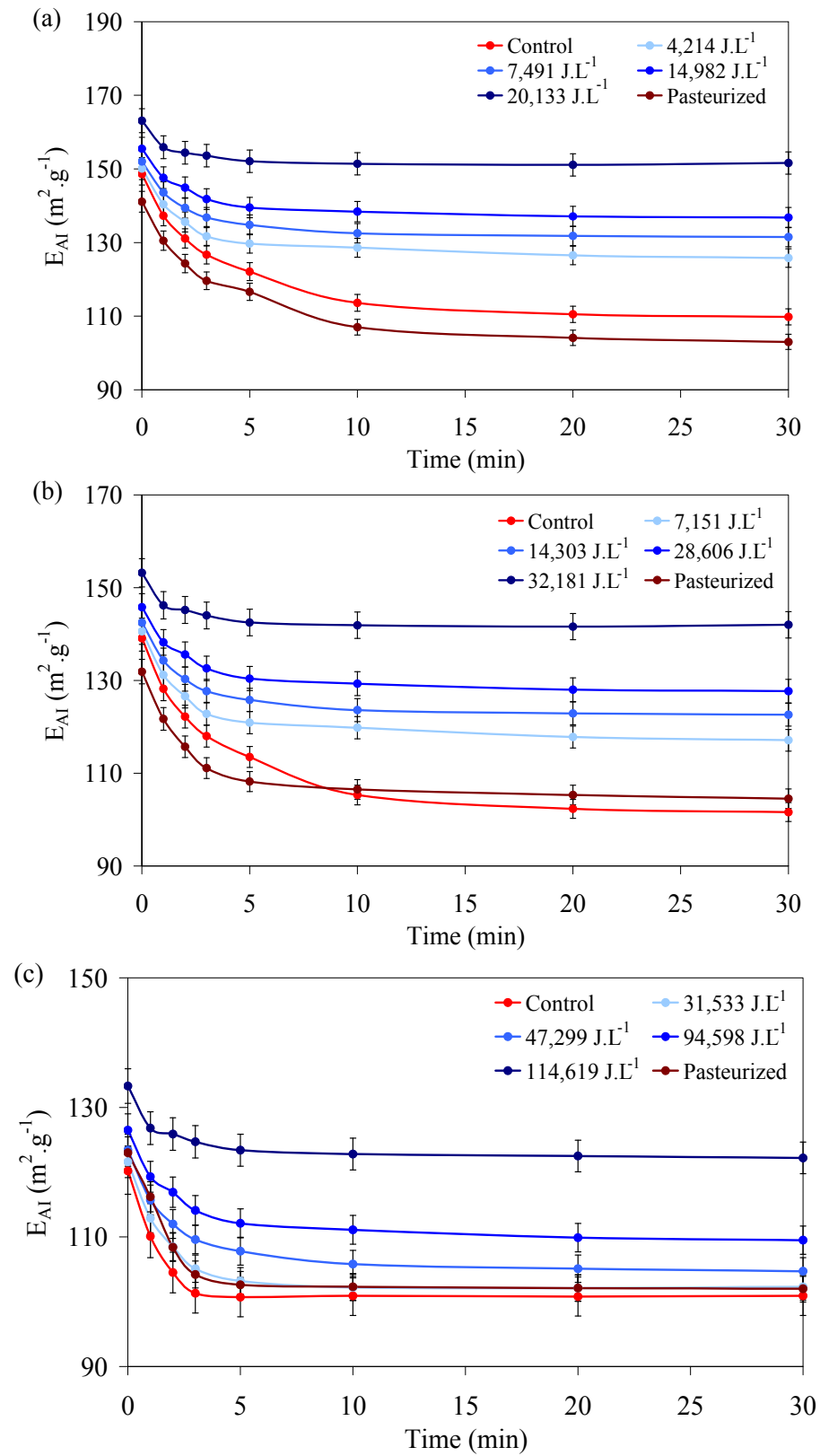

Figure 5.42 - Effect of UV irradiation on emulsifying activity index of (a) LEW (b) LWE and (c) LEY treated on UVivatec $\AA$ Lab reactor. Results are the mean of triplicate \pm standart deviation. 
Among yolk proteins, the apoproteins exhibit a higher adsorbing capacity than globular proteins (like phosvitin and livetin) because they have a more flexible structure and a greater surface hydrophobicity (Shenton, 1979; Kiosseoglou and Sherman, 1983). The proposed hypothesis for the mechanism that lipoproteins break down at the interface and then apoproteins adsorb at the interface, whereas neutral lipids coalesce with oil droplets (Shenton, 1979; Kiosseoglou and Sherman, 1983).

Emulsions are thermodynamically instable systems because of the unfavourable interactions between polar and nonpolar phases. These systems have the tendency to minimize the contact area between the two opposing phases by merging smaller droplets into larger ones. Eventually, the phases will separate, causing the emulsion to be "broken" (Dickinson, 1992). Emulsion instability can be caused by molecular, as well as supramolecular mass transport mechanisms (Weiss, 1999).

A better emulsion stability was observed for UV-irradiated samples. Emulsion stability indicates the capacity to avoid flocculation, creaming and/or coalescence. When the interfacial area is completely covered, additional proteins surround the interfacial film and form multilayers (Graham and Phillips, 1979; Phillips, 1981). Such additional layers stabilize emulsions by forming a steric or an electrostatic barrier which prevents contact between oil droplets, decreasing flocculation and consequently creaming (Phillips, 1981; Dickinson, 1986). The improved emulsion stability could be due to a diminution in the droplet size after UV-C irradiation. This implies that there was a significant flocculation and 
Results and discussion

coalescence of the control sample, leading to increased oil droplet size and emulsion destabilization.

The improved emulsifying properties of LEPs could be attributed to changes in the conformational and surface properties of protein structures upon treatment with UV-C. According to Jambrak et al. (2009), slight changes in protein surface hydrophobicity would subsequently lead to a better adsorption of the oil-in-water emulsion system. Kuan, Bhat and Karim (2011) presented similar results for egg white proteins and sodium caseinate. Those authors concluded that UV-C induced a certain protein cross-linking and conformational changes, at the view of the results obtained from formol titration, SDS-PAGE, and FTIR. These results suggest that significant conformational changes on the surface properties of LEPs upon UV irradiation would give rise to an improvement in the emulsifying properties, conferring these products with enhanced technological attributes. 


\subsection{Nutritional quality}

Egg is a nutritional complete food, and is one of the few foods containing all essential amino acids and other relevant nutrients (proteins, lipids, and minerals). Each egg constituent possesses peculiar physical and chemical characteristics responsible for its own functional properties. Environmental conditions ( $\mathrm{pH}$, ionic strength, competition) and preservative treatment (heating, freezing, and drying) can influence and modulate all these properties. Thermal technologies are the most widely applied to achieve egg microbial safety, although these treatments might have a negative impact on some food components, nutritional or functional, and may alter the sensory properties, color and texture (Falguera et al., 2011).

Non-thermal technologies are an alternative to thermal treatments. They are being studied in order to obtain a better final product sensory quality, but without neglecting microbial safety. In this context, these technologies are expected to produce safe foods with low chemical risks, but also decreasing the amount of additives. UV-C technologies constitute an emerging challenge aiming at reducing deleterious effects of heat, and yielding safe and less perishable products. But still there is a lack of data on literature about the effect of this technology on technological and nutritional attributes. In this section the changes caused by UV-C in vitamins $\left(A, B_{2}\right.$, $\mathrm{B}_{5}, \mathrm{C}$ and $\mathrm{E}$ ), secondary metabolites (carotenoids: zeaxanthin and lutein), and micronutrients $(\mathrm{K}, \mathrm{Ca}, \mathrm{Mg}$ and $\mathrm{Zn}$ ) of liquid egg products were evaluated. 
Results and discussion

The liposoluble vitamins A and E were measured by HPLC only in egg yolk and whole eggs. Vitamin C content was measured only in egg white and whole egg, this vitamin is present in small amounts in egg white but can still be used to observe the effect of the UV-C light on its content. Other vitamins were measured in all fractions.

The UV-C doses used on this study were determined according to inactivation kinetics presented on section 5.2.1.1 and 5.2.1.2, and correspond to the doses where a tail phenomenon started to be observed, required dose to reach pasteurization levels and the double of the doses required for pasteurization.

The water content of eggs was $88.07 \%, 75.33 \%$ and $43.60 \%$ respectively for egg white, whole egg, and egg yolk, these data agree with the values presented by Moran and Hale (1935) for egg white (87.8\%) and egg yolk (47.3\%). The content of water was the same of the fresh eggs after the UV$\mathrm{C}$ treatment, showing that no evaporation occurred.

\subsubsection{Vitamins}

Several factors will influence the nutritional content of the food and the type and level of losses due to processing. The effect of food processing on nutrient content will depend on the sensitivity of the nutrient to the various conditions prevailing during the process, such as heat, oxygen, $\mathrm{pH}$ and light. A slight change in the molecular structure of a nutrient can render it 
biologically ineffective. The nutrient retention may vary with a combination of conditions, such as the characteristics of the food and the concentration of the nutrient.

\subsubsection{Vitamin A}

Vitamin A, or retinol, plays a role in a variety of functions throughout the body, such as vision, immune function, skin and cellular health and antioxidant activity. The recommended daily intake of vitamin A for adults is between 600-900 $\mu \mathrm{g}$ (USDA, 2010). Thus, due to its high content of retinol egg yolk is an important source of this vitamin. The content of retinol in untreated whole egg and egg yolk were $2.53 \mu \mathrm{g}^{-\mathrm{g}^{-1}}$ and $9.15 \mu \mathrm{g} . \mathrm{g}^{-}$ ${ }^{1}$, respectively. These values are similar to the values of 2.76 and $9.14 \mu \mathrm{g} . \mathrm{g}^{-1}$ of edible fraction presented by Souci, Fachmann and Kraut (2008).

When submitted to UV-C light, the level of retinol in the samples significantly decreased $(\mathrm{P}<0.05)$ in the whole egg samples, and an even more pronounced effect was observed in the egg yolk. At the highest studied doses, 32,181 J.L $\mathrm{L}^{-1}$ on the whole egg, the final values of retinol decreased by $43 \%$ reaching the final value of $1.42 \mu \mathrm{g}^{-\mathrm{g}^{-1}}$. In egg yolk, the retinol content decreased by $85 \%$ to $1.30 \mu \mathrm{g} . \mathrm{g}^{-1}$ upon treatment with $115,619 \mathrm{~J} . \mathrm{L}^{-1}$.

Retinol is not sensitive to thermal pasteurization, but showed to be extremely photosensitive. Photochemical damage of retinoids in organic matrices is a well-known event and will lead to the destruction of the 
activity of the compounds (Moussern-Canet, 1979; Sands, 1981). The polyunsaturated side chain of vitamin $\mathrm{A}$ is particularly sensitive to irradiation. Isomerisation and disruption of double bonds results in a range of decomposition products with different chemical characteristics (Moussern-Canet, 1979; McCormick, 1980).

Whited et al. (2002) studied the effect of light on the retinol content of skimmed, semi-skimmed and whole milk, concluding that fat had a protective effect on the degradation of this vitamin. In accordance with those data, in egg products, fat also seems to play a major role, since the relative degradation of retinol in egg yolk is considerably lower than in whole egg at comparable doses (Figure 5.43).

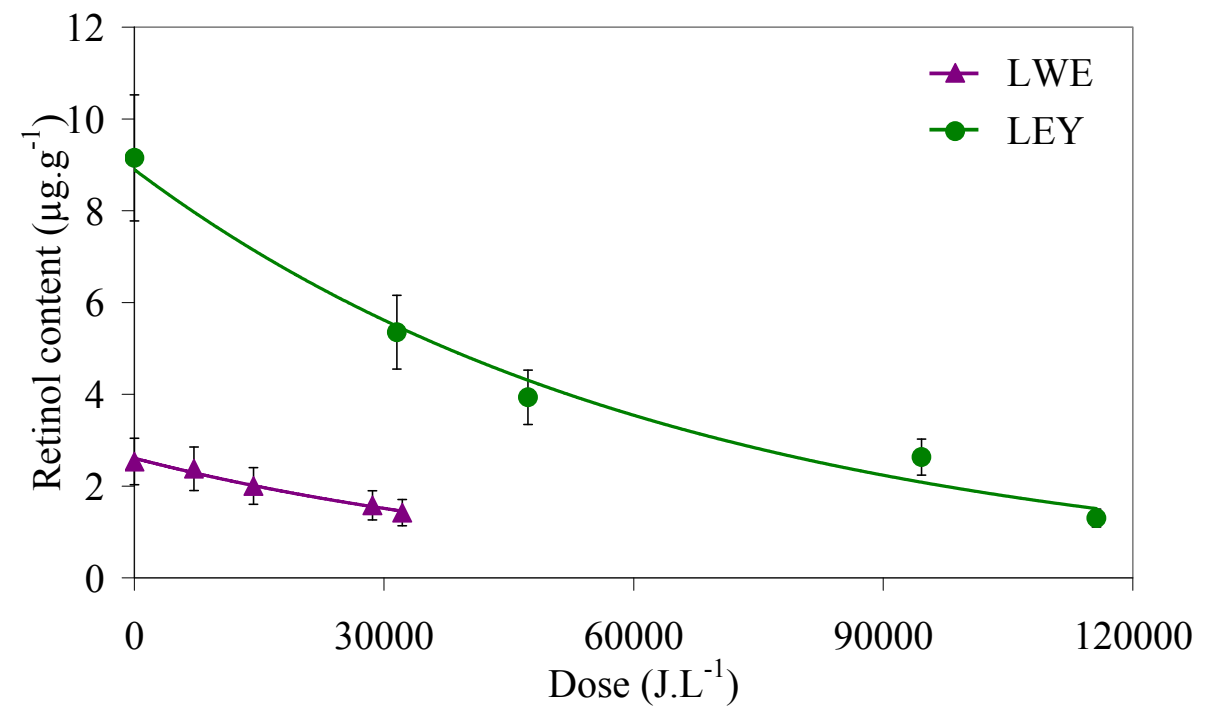

Figure 5.43 - Influence of UV-C exposure on retinol content of LWE and LEY. Results are the mean of triplicate \pm standart deviation. 


\subsubsection{Vitamin $B_{2}$}

Vitamin $\mathrm{B}_{2}$, or riboflavin, is required for a wide variety of cellular processes. It plays a key role in energy metabolism, and for the metabolism of fats, ketone bodies, carbohydrates, and proteins. The daily recommended intake of vitamin $B_{2}$ in adults is between 0.9-1.0 $\mathrm{mg}$ (USDA, 2010). In our study the effect of UV-C on vitamin $\mathrm{B}_{2}$ was evaluated. The contents of riboflavin in untreated LEW, LWE and LEY were 3.66, 3.95 and 4.15 $\mu \mathrm{g} . \mathrm{g}^{-1}$, respectively. These values are close to the values of $3.20,4.08$, and $4.00 \mu \mathrm{g} . \mathrm{g}^{-1}$ presented by Souci, Fachmann and Kraut (2008). The effect of UV-C on the vitamin $\mathrm{B}_{2}$ content is illustrated on Table 5.35.

Riboflavin is a well known photosentisizer, but is only present at low concentrations in egg. Here, riboflavin proved to be rather stable to UVlight in all the matrices, also in the presence of the lipid fraction. In the lipid fraction, tocopherol and carotenoids could be expected to protect other compounds from oxidation by acting as radical scavengers. In the egg white, ascorbic acid may act as a stabiliser for riboflavin. Additionally, tocopherol can deactivate the excited triplet state of riboflavin thus acting as photoprotector (Cardoso et al., 2007). In a similar work, Rivas et al. (2007) also remarked that the content of vitamin $B_{2}$ in beverages containing orange juice and milk was stable after treatment with pulsed electric fields.

Furaya, Warthesen, and Labuza (1984) studied the photodegradation of riboflavin in macaroni, skimmed milk powder, and buffer solutions. In 
Results and discussion

liquid systems these authors found first order photodegradation kinetics, while in solid food systems a two-step mechanism was observed.

Table 5.35- Influence of UV-C exposure on riboflavin content of (a) LEW, (b) LWE and (c) LEY.

\begin{tabular}{|c|c|c|c|c|c|c|}
\hline \multicolumn{7}{|c|}{ Riboflavin ( $\mu{\left.\mathrm{g} . \mathrm{g}^{-1}\right)}^{-1}$} \\
\hline \multicolumn{3}{|c|}{ Egg white } & \multicolumn{2}{|c|}{ Whole egg } & \multicolumn{2}{|c|}{ Egg yolk } \\
\hline & eatment & Vit. $B_{2}$ & Treatment & Vit. $B_{2}$ & Treatment & Vit. $B_{2}$ \\
\hline \multicolumn{2}{|c|}{ Control } & $3.66^{\mathrm{a}} \pm 0.27$ & Control & $3.95^{\mathrm{a}} \pm 0.32$ & Control & $4.15^{\mathrm{a}} \pm 0.27$ \\
\hline \multirow{4}{*}{ 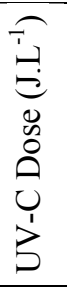 } & 4214 & $3.71^{\mathrm{a}} \pm 0.30$ & 䒠 7151 & $4.01^{\mathrm{a}} \pm 0.37$ & કب 31533 & $4.17^{\mathrm{a}} \pm 0.42$ \\
\hline & 7491 & $3.63^{\mathrm{a}} \pm 0.29$ & Е & $3.96^{\mathrm{a}} \pm 0.14$ & $\begin{array}{l}\text { ¿ } \\
\infty\end{array}$ & $4.23^{\mathrm{a}} \pm 0.22$ \\
\hline & 14982 & $3.57^{\mathrm{a}} \pm 0.20$ & @ُ 28606 & $3.99^{\mathrm{a}} \pm 0.21$ & @ُ 94598 & $4.15^{\mathrm{a}} \pm 0.34$ \\
\hline & 20133 & $3.62^{\mathrm{a}} \pm 0.22$ & B 32181 & $3.97^{\mathrm{a}} \pm 0.18$ & B 115619 & $4.10^{\mathrm{a}} \pm 0.33$ \\
\hline \multicolumn{2}{|c|}{ Pasteurized } & $3.51^{\mathrm{a}} \pm 0.17$ & Pasteurized & $3.88^{\mathrm{a}} \pm 0.22$ & Pasteurized & $4.06^{\mathrm{a}} \pm 0.29$ \\
\hline
\end{tabular}

* Results are the mean of triplicate \pm standart deviation.

Different superscripts in each column indicate difference statiscally significant at $95 \%$ confidence level

\subsubsection{Vitamin E}

Tocopherol is a main antioxidant, and also takes part in providing cells with nutrients, strengthens blood vessel walls and protects erythrocytes against premature decomposition. The recommended daily intake of vitamin $\mathrm{E}$ for adults is $15 \mathrm{mg}$ (USDA, 2010). The content of tocopherol in untreated whole egg and egg yolk were $2.3 \mu \mathrm{g} \cdot \mathrm{g}^{-1}$ and $5.32 \mu \mathrm{g} \cdot \mathrm{g}^{-1}$ of edible fraction, respectively. These values are close to the reference values of 2.3 and 6.5 $\mu \mathrm{g} . \mathrm{g}^{-1}$ (Souci, Fachmann and Kraut, 2008). 
Tocopherols are known to be unstable in the presence of oxygen, light and some unsaturated fats (Nelis et al., 1985). Thus, Murcia et al. (1999) studied the tocopherol levels of egg yolk in raw eggs and after different cooking processes: boiling for 3 and $10 \mathrm{~min}$, heating in a microwave oven, and frying; and observed that the tocopherols were reduced during commercial cooking by up to $50 \%$ in omelettes and microwave treatments. Fuhrmann et al. (2010) reported that the ozonation of egg yolk homogenates caused a significant reduction on vitamin $\mathrm{E}$ content only after treatment with the higher ozone dose, while in intact egg the effect could already be noticed with medium ozone doses.

For the contrary, tocopherol was stable to UV-C in egg yolk and in whole egg in the present study (Table 5.36). Here, the protection due to the matrix components, the low exposure to oxygen during treatments (limited by the flow throw the quartz tube), the degree of mixing, and adequate residence times achieved during processing seem to have protected the content of $\alpha$ tocopherol in liquid egg products. Interactions between tocopherol and ascorbic acid are well known, and ascorbic acid may protect tocopherol from oxidation as demonstrated in liposomes (Huang, 2004). This mechanism cannot apply, however, in egg yolk due to the absence of ascorbic acid, and the tocopherol in this fraction is possibly being protected by the presence of retinol or carotenoids (Wrona et al., 2003). 
Results and discussion

Table 5.36 - Influence of UV-C exposure on tocopherol content of LWE and LEY.

\begin{tabular}{|c|c|c|c|c|c|c|}
\hline \multicolumn{7}{|c|}{ Tocopherols $\left(\mu \mathrm{g} . \mathrm{g}^{-1}\right)$} \\
\hline \multicolumn{4}{|c|}{ Whole egg } & \multicolumn{3}{|c|}{ Egg yolk } \\
\hline \multicolumn{2}{|c|}{ Treatment } & $\begin{array}{c}\alpha- \\
\text { Tocopherol } \\
\end{array}$ & $\begin{array}{c}\text { Total } \\
\text { tocopherol }\end{array}$ & Treatment & $\begin{array}{c}\alpha- \\
\text { Tocopherol } \\
\end{array}$ & $\begin{array}{c}\text { Total } \\
\text { tocopherol }\end{array}$ \\
\hline \multicolumn{2}{|c|}{ Control } & $20.2^{\mathrm{a}} \pm 2.0$ & $23.3^{\mathrm{a}} \pm 2.3$ & Control & $46.2^{a} \pm 2.5$ & $53.2^{\mathrm{a}} \pm 2.9$ \\
\hline \multirow{4}{*}{ 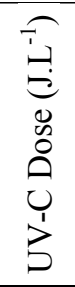 } & 7151 & $21.0^{\mathrm{a}} \pm 2.2$ & $24.2^{\mathrm{a}} \pm 2.5$ & 芹 31533 & $48.9^{\mathrm{a}} \pm 5.8$ & $56.2^{\mathrm{a}} \pm 6.6$ \\
\hline & 14303 & $20.4^{\mathrm{a}} \pm 2.0$ & $23.4^{\mathrm{a}} \pm 2.4$ & $\underset{\infty}{\stackrel{\Xi}{0}} 47299$ & $45.3^{\mathrm{a}} \pm 1.2$ & $52.1^{\mathrm{a}} \pm 1.4$ \\
\hline & 28606 & $21.7^{\mathrm{a}} \pm 1.2$ & $25.0^{\mathrm{a}} \pm 1.4$ & 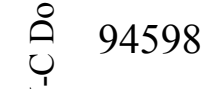 & $48.1^{\mathrm{a}} \pm 3.2$ & $55.3^{\mathrm{a}} \pm 3.7$ \\
\hline & 32181 & $20.6^{\mathrm{a}} \pm 0.9$ & $23.7^{\mathrm{a}} \pm 1.0$ & 3 115619 & $47.1^{\mathrm{a}} \pm 2.6$ & $54.2^{\mathrm{a}} \pm 3.0$ \\
\hline \multicolumn{2}{|c|}{ Pasteurized } & $13.1^{\mathrm{b}} \pm 0.18$ & $15.4^{\mathrm{b}} \pm 1.3$ & Pasteurized & $30.6^{b} \pm 4.3$ & $34.8^{\mathrm{b}} \pm 7.1$ \\
\hline
\end{tabular}

\subsubsection{Vitamin C}

Vitamin $\mathrm{C}$ is an essential nutrient for humans. The ascorbate acts as an antioxidant by protecting the body against oxidative stress, and it is also a cofactor in at least eight enzymatic reactions including several collagen synthesis reactions that, when dysfunctional, cause the most severe symptoms of scurvy (Padayatti et al., 2003).

The recommended daily intake of vitamin $\mathrm{C}$ for adults is between $75-120$ mg (USDA, 2010). Due to their low contents, eggs are not considered an important source of vitamin C. However, basic knowledge about the behavior of this vitamin in different matrices if submitted to UV-C, is 
specially relevant due to possible side reactions of the degradation products. The content of ascorbic acid on untreated egg white and whole egg were $3.06,1.20 \mu \mathrm{g} . \mathrm{g}^{-1}$, respectively. These values are close to the reference values of $3 \mu \mathrm{g} . \mathrm{g}^{-1}$ of egg white (Souci, Fachmann and Kraut, 2008)

When submitted to UV-C light, the level of ascorbic acid in the samples significantly decreased $(\mathrm{P}<0.05)$, and an effect even more pronounced was observed in the egg white (Figure 5.44). Vitamin $\mathrm{C}$ is well known to be sensitive to light (Kitzawa, 1997). At the highest studied doses, 20,133 J.L-1 for egg white and $32,181 \mathrm{~J} . \mathrm{L}^{-1}$ for whole egg, the final values of ascorbic acid decreased by 66 and 45\% respectively, reaching the final values of 1.03 and $0.65 \mu \mathrm{g} . \mathrm{g}^{-1}$. The presence of different protecting egg components could be a possible explanation for the lower reduction observed in liquid whole egg. In fact, the influence of food components is a non-negligible factor. For example, in the study of Kitazawa (1997) the rate of ascorbic acid oxidation in the presence of tocopherol was enhanced by a photosentisizer (riboflavin), and the inhibition of singlet oxygen $\left({ }^{1} \mathrm{O}_{2}\right)$ by carotenoids did not stabilize the ascorbic acid in model matrices.

On the case of the whole egg the lipid fraction protected the albumen protecting the vitamin from the light and diminishing the degradation. Sancho et al. (1999) studied the effect of ultra-high hydrostatic pressure on water-soluble vitamins and compared the vitamins retention to that induced by pasteurization or sterilization, and observed that the ascorbate levels in strawberry coulis decreased with high pasteurization and with sterilization as well as ultra-high pressure process; but none of the processes induced 
Results and discussion

significant changes of ascorbate retention in egg yolk. Sensitivity of vitamin $\mathrm{C}$ to heat varies with $\mathrm{pH}$ (Morris et al., 2004), and by the results presented by Sancho et al. (1999) is possible to deduce that the sensitivity also depends on the food matrix. In microwave processing of infant formulas also were observed an exponential degradation of vitamin C (Laguerre et al., 2011).

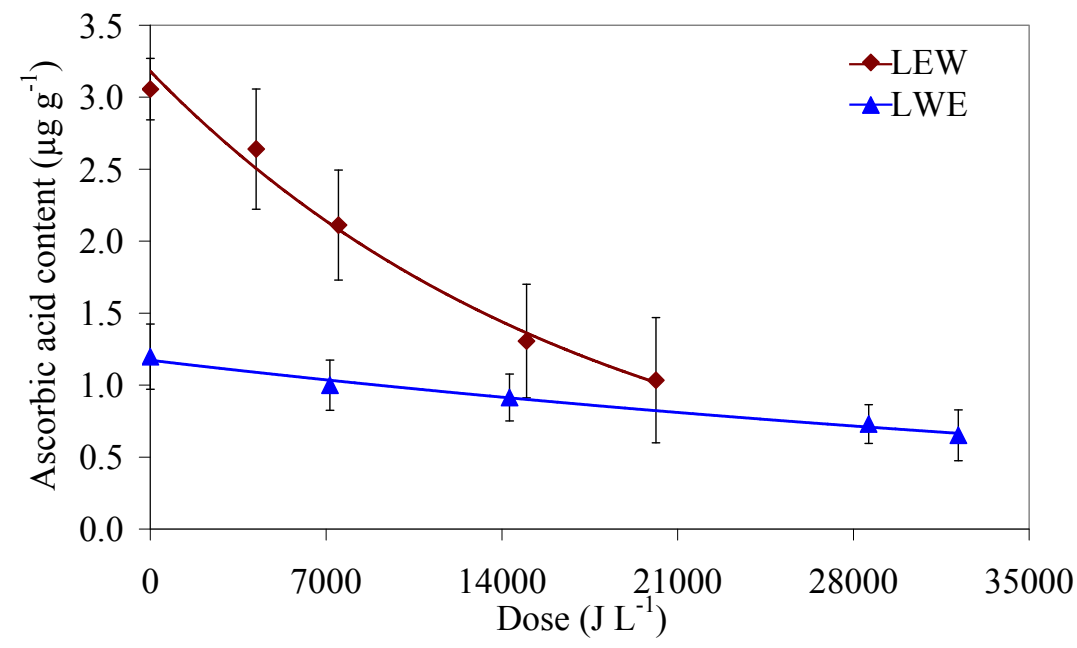

Figure 5.44 - Effect of UV-C irradiation on ascorbic acid (vitamin C) content of LEW and LWE. Results are the mean of triplicate \pm standart deviation.

\subsubsection{Vitamin $B_{5}$}

Pantothenic acid participates in heme synthesis to hemoglobin and cytochromes, and also in regeneration of skin cells and mucous membranes, and participates in antibody production. The recommended daily intake of vitamin $\mathrm{B}_{5}$ for adults is between 4-7 $\mathrm{mg}$ (USDA, 2010). The content of 
pantothenic acid in untreated egg white, whole egg and egg yolk were $1 \mu \mathrm{g} . \mathrm{g}^{-1}, 16 \mu \mathrm{g} . \mathrm{g}^{-1}$ and $37 \mu \mathrm{g} . \mathrm{g}^{-1}$, respectively. These values are close to the reference values of 1.4, 1.6 and $3.7 \mu \mathrm{g} . \mathrm{g}^{-1}$ (Souci, Fachmann and Kraut, 2008). No significant changes in pantothenic acid contents could be measured after the eggs' exposure to UV-C (Table 5.37). Rivas et al. (2007) also obtained stable vitamin $\mathrm{B}_{5}$ content mixed orange juice and milk treated with pulsed electric fields, showing that this vitamin is highly stable to light or electric fields in different food matrices.

Table 5.37 - Influence of UV-C exposure on panthotenic acid content of LEPs.

\begin{tabular}{|c|c|c|c|c|c|}
\hline \multicolumn{6}{|c|}{ Pantothenic acid $\left(\mu \mathrm{g} . \mathrm{g}^{-1}\right)$} \\
\hline \multicolumn{2}{|c|}{ Egg white } & \multicolumn{2}{|c|}{ Whole egg } & \multicolumn{2}{|c|}{ Egg yolk } \\
\hline Treatment & Vit. $B_{5}$ & Treatment & Vit. $B_{5}$ & Treatment & Vit. $B_{5}$ \\
\hline Control & $1.42^{\mathrm{a}} \pm 0.22$ & Control & $16.0^{\mathrm{a}} \pm 1.4$ & Control & $37.2^{\mathrm{a}} \pm 6.2$ \\
\hline 皃 4214 & $1.45^{\mathrm{ab}} \pm 0.15$ & 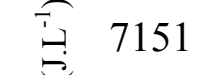 & $15.3^{\mathrm{a}} \pm 2.7$ & 今 31533 & $36.0^{\mathrm{a}} \pm 6.0$ \\
\hline $\begin{array}{ll}0 \\
0 \\
0\end{array}$ & $1.37^{\mathrm{ab}} \pm 0.27$ & $\begin{array}{ll}\underbrace{}_{0} & 14303 \\
\text { d }\end{array}$ & $15.0^{\mathrm{a}} \pm 3.0$ & 总 47299 & $35.2^{a} \pm 5.9$ \\
\hline 14982 & $1.26^{\mathrm{abc}} \pm 0.16$ & ب̂. & $14.2^{\mathrm{a}} \pm 3.8$ & 94598 & $33.0^{\mathrm{ab}} \pm 3.9$ \\
\hline 20133 & $1.17^{\mathrm{bc}} \pm 0.13$ & S 32181 & $13.9^{\mathrm{a}} \pm 1.2$ & D 115619 & $32.2^{\mathrm{ab}} \pm 5.4$ \\
\hline Pasteurized & $0.91^{\mathrm{c}} \pm 0.22$ & Pasteurized & $9.6^{\mathrm{b}} \pm 1.8$ & Pasteurized & $26.0^{b} \pm 4.2$ \\
\hline
\end{tabular}

\subsubsection{Carotenoids: Lutein and Zeaxanthin}

Lutein and zeaxanthin are powerful antioxidants, and lutein is widely known as the primary nutrient for protecting ocular function. It has long been 
Results and discussion

thought that carotenoid intake also reduces the risk of certain forms of cardiovascular disease, stroke, and cancer. Lutein and zeaxanthin may prevent cellular damage in these conditions by quenching singlet oxygen or neutralizing photosensitizers. Lutein and zeaxanthin inhibit lipid peroxidation, a likely factor in the aetiology of both retinal and cardiovascular disease.

Lutein and zeaxanthin belong to the xanthophyll family of carotenoids. Lutein and zeaxanthin differ from other carotenoids in that they each have two hydroxyl groups, one on each side of the molecule. Zeaxanthin is a stereoisomer of lutein, differing only in the location of a double bond in one of the hydroxyl groups. The hydroxyl groups appear to control the biological function of these two xanthophylls.

The cooking of lutein/zeaxanthin-containing foods may increase bioavailability by disrupting the cellular matrix and the carotenoid-protein complexes. Lutein is relatively sensitive to thermal degradation in food matrices containing a high amount of fatty acids (Aparicio-Ruiz et al., 2011) and it isomerizes. The effect of the UV-C on lutein and zeaxanthin of whole egg and egg yolk samples is represented on Figure 5.45. A highly oxidizing effect of UV-C is likely responsible for the loss in both antioxidants at doses necessary to achieve pasteurization. A significant decrease is observed in both fractions for both carotenoids, which is comparable to the loss of $\beta$ carotene and lutein in oil after $20 \mathrm{~h}$ at $120{ }^{\circ} \mathrm{C}$, reported by Aparicio-Ruiz et al. (2011). 


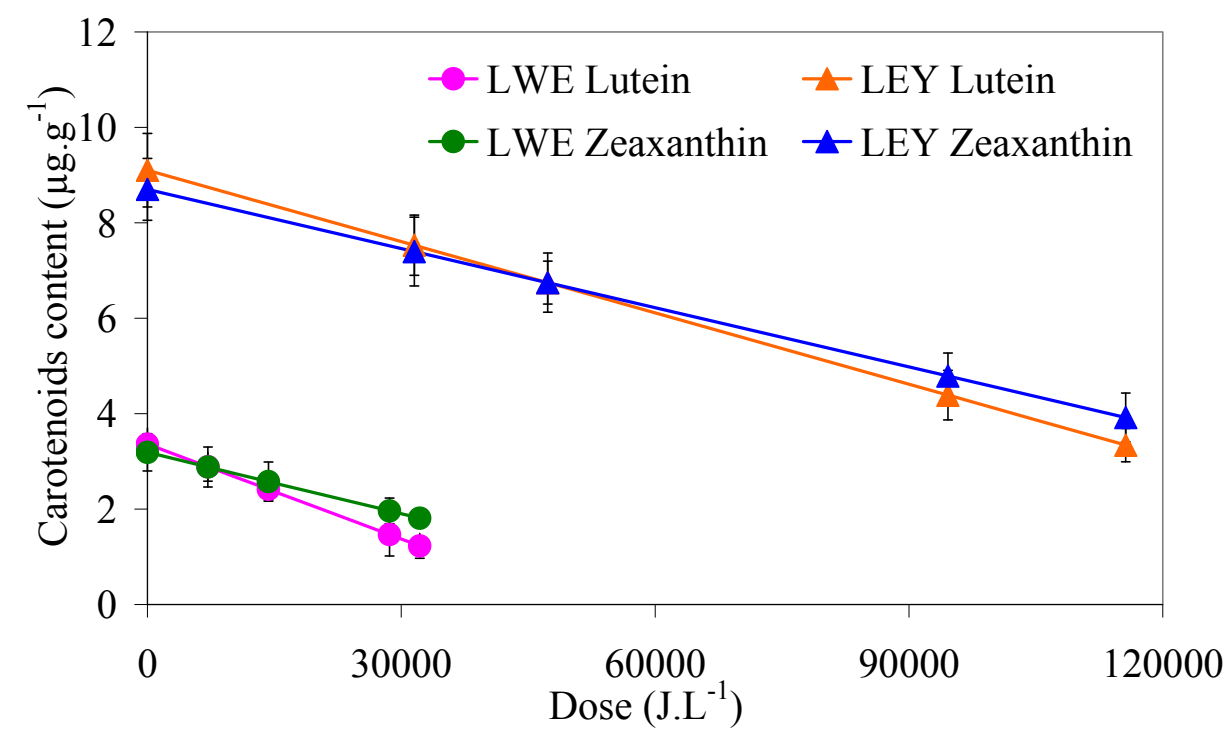

Figure 5.45 - Influence of UV-C exposure on Luthein and Zeaxanthin content of LWE and LEY. Results are the mean of triplicate \pm standart deviation.

\subsubsection{Micronutrients}

The macronutrient and vitamin content of foods are more likely to be affected by processing than the mineral content. Just like vitamins, minerals help body to grow, to develop, and to stay healthy. The body uses minerals to perform many different functions, from building strong bones to transmitting nerve impulses. Some minerals are even used to make hormones or maintain a normal heartbeat. Eggs supply a great part of the mineral needs of humans. The recommended ingestion of $\mathrm{P}$ and $\mathrm{Fe}$ are 800 $\mathrm{mg}$ and $10 \mathrm{mg}$ (NRC, 1989), and $100 \mathrm{~g}$ of whole egg can provide alone 25 $\%$ of $\mathrm{P}$ and $20 \%$ of $\mathrm{Fe}$. 
Results and discussion

Minerals are more resistant to manufacturing processes than vitamins. However, they do undergo changes when exposed to heat, air, or light. Minerals such as copper, iron, and zinc are also affected by moisture, and may react with other food components such as proteins and carbohydrates. Minerals can be also lost through leaching into cooking/processing water, as in the case of fortified rice, where the rice grain is coated with iron as fortificant (Anonymous, 2011).

In this work, the effects of short wave ultraviolet treatments (UV-C) in the most relevant egg micronutrients have been evaluated. All tests were performed in triplicate and showed relative standard deviations around $2 \%$. The content of each element was calculated from the construction of calibration curves with at least 5 points, and presenting a linear regression coefficient greater than 0.998 .

The quantitative determinations of $\mathrm{K}, \mathrm{Ca}, \mathrm{Mg}$ and $\mathrm{Zn}$ for the LEW, LWE and LEY are reported in Table 5.38.

All minerals were maintained after UV-C exposure to dose sufficient to reduce $5 \mathrm{D}$ on microbial eggs load (section 5.2.1.1) and no significant differences were observed between applied doses. Total ash of untreated egg white, whole egg and egg yolk (373 mg, $665 \mathrm{mg}$ and $1.23 \mathrm{~g}$, respectively), were stable after UV processing. 
Table 5.38 - Mineral content in UV-C treated LEPs.

\begin{tabular}{|c|c|c|c|c|c|}
\hline \multirow{2}{*}{\multicolumn{2}{|c|}{ Dose $\left(J . L^{-1}\right)$}} & \multicolumn{4}{|c|}{ Minerals (mg.g $\left.{ }^{-1}\right)$} \\
\hline & & $\mathbf{K}$ & $\mathrm{Ca}$ & Mg & $\mathbf{Z n}$ \\
\hline \multirow{5}{*}{ 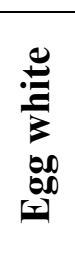 } & 0 & $154.3^{\mathrm{a}} \pm 10.8$ & $11.2^{\mathrm{a}} \pm 1.1$ & $12.4^{\mathrm{a}} \pm 1.8$ & $20.5^{\mathrm{a}} \pm 3.3$ \\
\hline & 4214 & $115.6^{\mathrm{a}} \pm 11.5$ & $10.8^{\mathrm{a}} \pm 1.6$ & $13.1^{\mathrm{a}} \pm 1.6$ & $19.7^{\mathrm{a}} \pm 2.6$ \\
\hline & 7491 & $149.8^{\mathrm{a}} \pm 12.6$ & $12.4^{\mathrm{a}} \pm 1.3$ & $12.3^{\mathrm{a}} \pm 1.2$ & $18.4^{\mathrm{a}} \pm 3.8$ \\
\hline & 14982 & $151.5^{\mathrm{a}} \pm 11.4$ & $11.5^{\mathrm{a}} \pm 1.7$ & $12.8^{\mathrm{a}} \pm 2.1$ & $18.9^{\mathrm{a}} \pm 2.9$ \\
\hline & 20133 & $156.9^{\mathrm{a}} \pm 14.3$ & $11.9^{\mathrm{a}} \pm 2.1$ & $13.6^{\mathrm{a}} \pm 1.9$ & $19.3^{\mathrm{a}} \pm 3.2$ \\
\hline \multirow{5}{*}{ 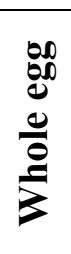 } & 0 & $147.5^{\mathrm{a}} \pm 11.3$ & $51.6^{\mathrm{a}} \pm 2.6$ & $11.23^{\mathrm{a}} \pm 0.71$ & $1.34^{\mathrm{a}} \pm 0.16$ \\
\hline & 7151 & $163.4^{\mathrm{a}} \pm 9.4$ & $52.4^{\mathrm{a}} \pm 3.4$ & $11.16^{\mathrm{a}} \pm 0.97$ & $1.27^{\mathrm{a}} \pm 025$ \\
\hline & 14303 & $135.9^{\mathrm{a}} \pm 8.9$ & $55.1^{\mathrm{a}} \pm 5.1$ & $10.94^{\mathrm{a}} \pm 1.18$ & $1.41^{\mathrm{a}} \pm 0.17$ \\
\hline & 28606 & $122.1^{\mathrm{a}} \pm 6.7$ & $50.9^{\mathrm{a}} \pm 4.8$ & $11.55^{\mathrm{a}} \pm 0.84$ & $1.38^{\mathrm{a}} \pm 0.22$ \\
\hline & 32181 & $152.6^{\mathrm{a}} \pm 10.2$ & $53.3^{\mathrm{a}} \pm 1.7$ & $12.08^{\mathrm{a}} \pm 0.91$ & $1.49^{\mathrm{a}} \pm 0.14$ \\
\hline \multirow{5}{*}{ 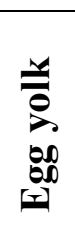 } & 0 & $126.5^{\mathrm{a}} \pm 6.8$ & $140.3^{\mathrm{a}} \pm 9.3$ & $16.13^{\mathrm{a}} \pm 1.22$ & $3.84^{\mathrm{a}} \pm 0.32$ \\
\hline & 31533 & $121,8^{\mathrm{a}} \pm 7.7$ & $138.9^{\mathrm{a}} \pm 8.6$ & $18.15^{\mathrm{a}} \pm 2.16$ & $3.73^{\mathrm{a}} \pm 0.55$ \\
\hline & 47299 & $142.5^{\mathrm{a}} \pm 9.4$ & $144.5^{\mathrm{a}} \pm 5.7$ & $17.22^{\mathrm{a}} \pm 1.54$ & $3.66^{\mathrm{a}} \pm 0.46$ \\
\hline & 94598 & $133.6^{\mathrm{a}} \pm 7.3$ & $136.5^{\mathrm{a}} \pm 6.3$ & $16.35^{\mathrm{a}} \pm 2.55$ & $3.51^{\mathrm{a}} \pm 0.28$ \\
\hline & 115619 & $138.9^{\mathrm{a}} \pm 8.1$ & $141.2^{\mathrm{a}} \pm 8.1$ & $17.55^{\mathrm{a}} \pm 3.84$ & $3.99^{a} \pm 0.43$ \\
\hline
\end{tabular}




\subsection{Cyto and genototoxicity}

\subsubsection{Effects on the vitality of the intestinal Caco-2 cells}

Ultraviolet radiations at oxidizing wavelengths increase the oxidative stress due to the formation of ions and free radicals, and might also accelerate the oxidation of important food components. Regarding the oxidative damage in liquid egg products, the impact of dynamic UV-C treatments is relatively low, but oxidized residues might have physiological implications which can be assessed in vitro.

The production of furan in other food systems, such as UV-C treated apple juice and cider (Fan and Geveke, 2007; Bule et al., 2010) is of main concern, it being mandatory to discard cytotoxic effects in UV-C decontaminated food products.

The viability of Caco-2 cells decreased at increasing egg concentrations. Cell viability was however not significantly affected by incubation for $24 \mathrm{~h}$ with $10 \%, 5 \%$ and $2.5 \%(\mathrm{v} / \mathrm{v})$ (Figure 5.46), and statistically significant differences were only found when the Caco- 2 cells were incubated with egg preparations at a concentration of $20 \%(\mathrm{v} / \mathrm{v})$. 
Egg yolk showed a slightly higher effect on cell viability than the other liquid egg fractions, probably due to the high lipid concentration. Therefore, egg components increasingly affected cell metabolism, resulting in cellular death. Several mechanisms could be implied. For example, raw egg white contains conalbumin which binds iron when the consumption is over 20 eggs per day for several weeks. Additionally, avidin binds to biotin and can impair the metabolism of B-vitamins (Pollack, 1958). Low cytotoxic effects have also been reported for pork meat patties in contact with Caco-2 cells after a simulated gastric digestion (Kenny, Callaghan and O'Brien, 2008), in agreement with the modest effects observed for liquid egg products.

Notably, differences in cytotoxicity between non-treated and UV-C-treated egg preparations were not statistically significant $(\mathrm{P}<0.05)$. Consequently, the presence of new cytotoxic compounds, or variations in the concentration of essential food components, cannot be confirmed at the investigated treatment levels in in vitro systems.

This is in agreement with the low oxidative defects found for lipids and proteins after dynamic UV-C treatments, confirming the UV-C decontamination of liquid egg products as a feasible application. Further chemical analyses are however recommended to completely discard the presence of contaminants. 
Results and discussion
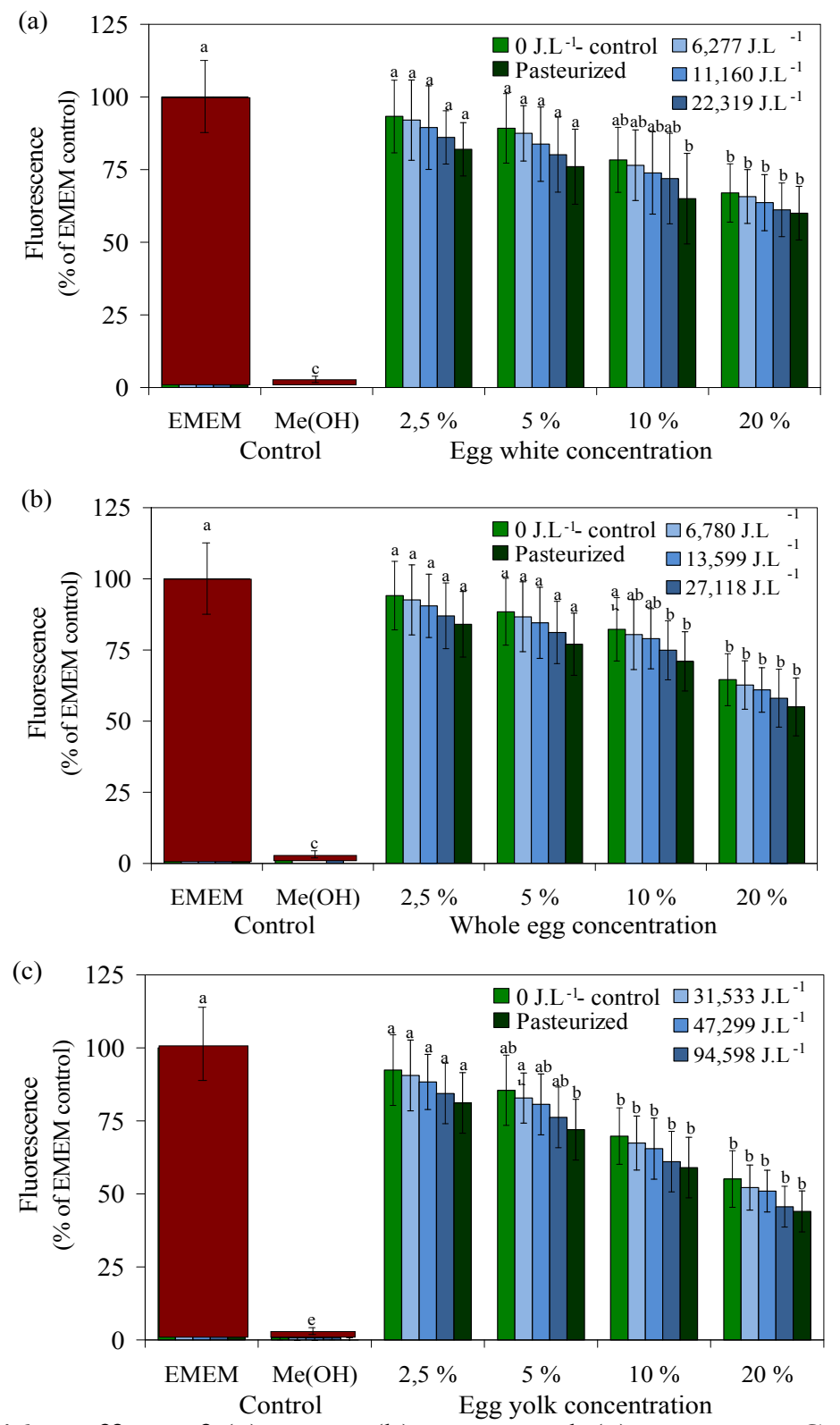

Figure 5.46 - Effect of (a) LEW (b) LWE and (c) LEY UV-C treated on viability of Caco-2 cells. Control cells were incubated in medium only (EMEM). Results are the mean of triplicate \pm standart deviation. Different superscripts for each concentration and control indicate difference statiscally significant at $95 \%$ confidence level. 


\subsubsection{Effects on DNA damage}

The influence of diet on carcinogenesis is complex; the comet assay is a relatively simple biomarker to evaluate DNA damage and repair which has been used to study the role of micronutrients and food components, nutrients and secondary metabolites, in carcinogenesis (Wasson et al., 2008). The antioxidant or prooxidant effects of whole foods have been exhaustively evaluated (Puddey, Zilkens and Croft, 2003; Palozza et al., 2003; Aruoma, 1994). Some food components, such as the heterocyclic amines and polycyclic aromatic hydrocarbons generated in cooked meat, increase the levels of strand breaks in a variety of cell types (Wasson et al., 2008; Kenny, Callaghan and O'Brien, 2008). The Comet assay is a standard method to identify food genotoxic effects and can provide useful data on the effects of UV-C treatments in food.

For liquid egg products, the incubation of cells with non-treated or UVtreated $\left(20,133 \mathrm{~J} . \mathrm{L}^{-1}\right.$ for egg white, $32,181 \mathrm{~J}^{-L^{-1}}$ for whole egg and 115,619 J.L $\mathrm{L}^{-1}$ for egg yolk) egg preparations at a concentration of $5 \%(\mathrm{v} / \mathrm{v})$ for $24 \mathrm{~h}$ did not significantly increase DNA strand breaks in Caco-2 cells. Confirming the low effects of UV-C on liquid egg matrices, UV-C-treated egg preparations are not significantly different $(\mathrm{P}<0.05)$ from non-treated (Figure 5.47).

However, a number of biologically active compounds are responsible for antioxidant or prooxidant effects, also in eggs. UV-C increased slightly the amount of peroxides and the TBARS values. 


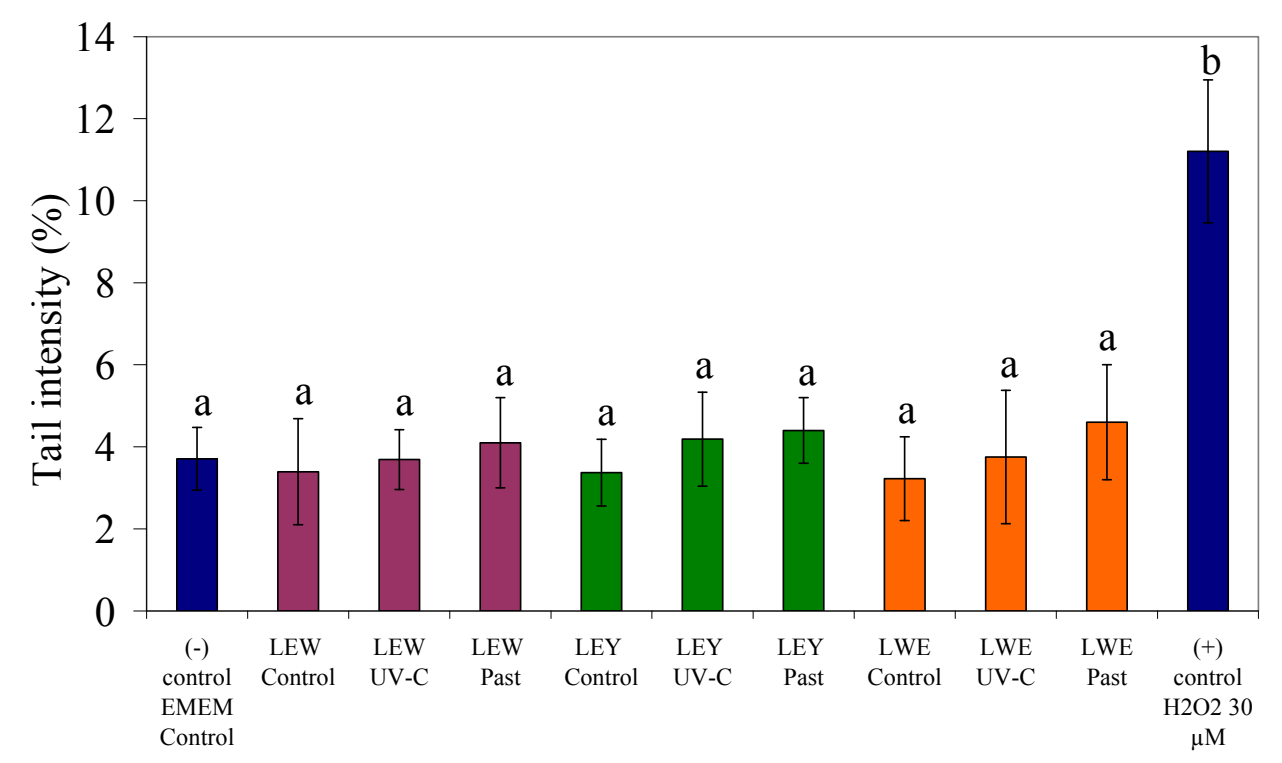

Figure 5.47 - Effect of LEPs on DNA strand breaks in Caco-2 cells. LEW UV-C 20,133 J.L L $^{-1}$ LWE UV-C 32,181 J.L L $^{-1}$ and LEY UV-C 115,619 J.L. ${ }^{-1}$. Results are the mean of triplicate \pm standart deviation. Different superscripts for bar indicate difference statiscally significant at $95 \%$ confidence level.

Consequently, a complete chemical characterization is advisable to discard genotoxic effects of potentially modified individual components in different cell lines, but results in food matrices already suggest that UV-C decontamination treatments produce negligible cyto or genotoxic effects in Caco-2 cells. In agreement with Sommers et al. (2009) who found no UV-C induced mutagenesis in Frankfurters containing potassium lactate and sodium diacetate.

UV-C is able to modify a number of chemical food constituents leading to formation of new compounds with unknown biological activities. Not all 
products of such chemical modifications are known. In fact taking into consideration a huge number of food compounds and possible reaction products of them, it seems to be hardly possible. In vitro tests for cytotoxicity and genotoxicity allow investigating whether new compounds with cytotoxic/genotoxic properties at considerable concentration are generated during UV-C treatment of food. Here we showed that UV-C treatment of egg preparations treated with high UV-C doses up to 115,619 J.L $L^{-1}\left(10,693{\mathrm{~J} . \mathrm{cm}^{-2}}^{-2}\right.$ did not cause any changes in the cytotoxic and genotoxic effects of egg preparations with respect to the indicator tests studied. 


\subsection{Sensorial analysis}

Safety, health and taste are important quality issues for producers and consumers. The rase in the demand for foodstuffs that keep for a longer period, their specific nutritious and taste characteristics, has imposed the development of adequate methods of preservation that are able to meet a number of up to date requirements. For the consumers, the food quality is related with validity date of product and with sensorial characteristics, like color and taste (Biscaro and Brazaca, 2006).

Heat treatments are traditionally applied to pasteurize or sterilize food, generally at the expense of its sensory and nutritional qualities. As consumers increasingly perceive fresh food as healthier than heat treated food, the industry is now looking for alternative technologies to maintain most of the fresh attributes, safety and storage stability of food (Ahvenainen, 1996).

Since actual consumers prefer minimally processed and preservative-free products, the need for alternative non-thermal pasteurisation technologies, which do not compromise product quality, is important. Contrary to the limitations of thermal treatments, UV-C radiation is known to be extremely effective against most vegetative microorganisms, suggesting that this technology can be an alternative non-thermal process for liquid egg products in order to achieve microbiologically safe products (Donahue, Canitez and Bushway, 2004; Bintsis et al., 2000). The use of ultraviolet 
light at germicidal wavelengths has been approved to treat food surfaces and clear fruit juices (US-FDA, 2002).

Sensory and functional properties of eggs are relatively radiation sensitive (Farkas, 1998). But for irradiation Serrano et al. (1997) showed that doses of $1.5 \mathrm{kGy}$ would be sufficient to eliminate the Salmonella from whole shell eggs and liquid whole eggs without significant adverse effects on the egg quality. In the heat pasteurization of shell eggs no exterior changes can be noted, but the exposures to high temperatures can denaturate the albumen's heat-sensitive proteins. As a result, the albumen appears more opaque and cloudier than those from unpasteurized eggs (Hou et al., 1996; Shuman et al., 1997; Rodriguez-Romo, 2004). If heat exposure is prolonged, the proteins begin to coagulate and viscosity increases.

In sections 5.1.2.2 and 5.2.2.2 the color changes on the liquid egg products were studied and it was concluded that lower UV-C doses did not affect this parameter, while high doses produced significant changes on the CIELAB characteristics, resulting in darker samples.

Even if these results show the good perspectives of the UV-C treatment by the sensorial point of view they do not guarantee that the UV-C treated food will be well accepted by consumers. Therefore, the objective of this section was to investigate the potential of UV-C irradiation on sensorial qualities of liquid egg products and on products produced with UV-C treated liquid egg products. 
Results and discussion

\subsubsection{Sensory evaluation: difference}

Cross results for the highest UV-C dose $\left(4.176 \mathrm{~J}_{\mathrm{cm}} \mathrm{cm}^{-2}\right.$ equivalent to $30 \mathrm{~min}$ at $2.32 \mathrm{~mW} . \mathrm{cm}^{-2}$ ), heat treatments and controls are reported on Table 5.39. When fresh products were evaluated, the lowest differences were found in egg whites. The sensory panel did not find significant differences up to the 99.9\% confidence level when untreated and UV-C treated egg whites were compared in the entire UV dose range studied (from $0.696 \mathrm{~mJ} . \mathrm{cm}^{-2}$ to 4.176 $\mathrm{J} . \mathrm{cm}^{-2}$ ); a similar result was found when heat treated and UV-C treated samples were compared. The panel was however able to differentiate the untreated from the heat treated egg white samples at the $95 \%$ confidence level, pointing out only small differences in the general appearance, which are more evident if individually color or aroma are considered. Heat treated samples were graded as having a cooked flavor by some panelists. More remarkable are the effects on egg yolk and whole egg. The panel could identify differences between the untreated and UV-C treated samples after $3.480{\mathrm{~J} . \mathrm{cm}^{-2}}^{-}$(from $0.696 \mathrm{~J} . \mathrm{cm}^{-2}$ to $3.480 \mathrm{~J} . \mathrm{cm}^{-2}$, no significant differences at the $99.9 \%$ confidence level was discribed).

Whole egg samples were significantly different at the $95 \%$ confidence level after the exposure to $4.176 \mathrm{~J} . \mathrm{cm}^{-2}$, while yolk samples showed stronger differences, being data significantly different up to the $99.9 \%$ confidence level. Those results indicate a remarkable effect of UV-C radiation on sensory parameters for the egg fractions containing fat, in accordance with previously published data on the effects of UV-C on the evolution of the TBARS index in UV-C treated whole egg and egg yolk samples (section 
5.1.3.1). Remarkably, heat treated whole egg and egg yolk samples were significantly different from the control and the UV-C treated samples up to $3.480{\mathrm{~J} . \mathrm{cm}^{-2}}^{2}$, confirming the stronger similarities between the UV-C treated samples and the control. Such effects are also found when color and aroma are evaluated individually, and only the samples treated with $4.176{\mathrm{~J} . \mathrm{cm}^{-2}}^{-2}$ wew not significantly different from the heat treated ones for both parameters at the $99.9 \%$ confidence level.

Table 5.39 - Correct answers in a triangle test by treatment comparison at the highest UV dose (4.176 J.cm ${ }^{-2}$ or 30 min with fluence of $2.32 \mathrm{~mW} . \mathrm{cm}^{-2}$ ).

\begin{tabular}{|c|c|c|c|c|c|c|c|}
\hline \multirow{3}{*}{$\begin{array}{l}\text { Type of } \\
\text { product }\end{array}$} & \multirow{3}{*}{$\begin{array}{l}\text { Treatment } \\
\text { comparison }\end{array}$} & \multicolumn{6}{|c|}{ Sensory parameters } \\
\hline & & \multicolumn{2}{|c|}{$\begin{array}{c}\text { General } \\
\text { impression }\end{array}$} & \multicolumn{2}{|c|}{ Color } & \multicolumn{2}{|c|}{ Aroma } \\
\hline & & Nat & Past & Nat & Past & Nat & Past \\
\hline \multirow{2}{*}{ Egg white } & UV & $24^{\prime}$ & 16 & $27^{\prime \prime}$ & 21 & $23^{\prime}$ & 18 \\
\hline & Nat & - & $41^{\prime \prime \prime}$ & - & $44^{\prime \prime \prime}$ & - & $42^{\prime \prime \prime}$ \\
\hline \multirow[b]{2}{*}{ Whole egg } & UV & 16 & 17 & 18 & 14 & 20 & 16 \\
\hline & Nat & - & $23^{\prime}$ & - & $26^{\prime \prime}$ & - & $29^{\prime \prime \prime}$ \\
\hline \multirow{2}{*}{ Egg yolk } & UV & $32 "$ & 21 & $33^{\prime \prime \prime}$ & 20 & $34^{\prime}$ & 22 \\
\hline & Nat & - & $39 " '$ & - & $39 " '$ & - & $40^{\prime \prime \prime}$ \\
\hline \multirow{2}{*}{$\begin{array}{l}\text { Cooked egg } \\
\text { white }\end{array}$} & UV & 13 & 16 & 12 & 18 & 12 & 18 \\
\hline & Nat & - & 22 & - & 14 & - & 14 \\
\hline \multirow{2}{*}{$\begin{array}{l}\text { Cooked whole } \\
\text { egg }\end{array}$} & UV & 8 & 14 & 15 & 16 & 17 & 15 \\
\hline & Nat & - & 17 & - & 21 & - & 16 \\
\hline \multirow{2}{*}{$\begin{array}{c}\text { Cooked egg } \\
\text { yolk }\end{array}$} & UV & 18 & 19 & 22 & 18 & 17 & 15 \\
\hline & Nat & - & $23^{\prime}$ & - & 20 & - & 20 \\
\hline \multirow{2}{*}{ Mayonnaise } & UV & $24^{\prime}$ & 16 & 17 & 17 & 22 & 18 \\
\hline & Nat & - & 19 & - & 22 & - & 20 \\
\hline \multirow{2}{*}{ Pudding } & UV & 16 & 16 & 17 & 15 & 19 & 16 \\
\hline & Nat & - & 18 & - & 20 & - & 19 \\
\hline \multirow{2}{*}{ Angel cake } & UV & 13 & 16 & 18 & 13 & 15 & 14 \\
\hline & Nat & - & 17 & - & 20 & - & 20 \\
\hline
\end{tabular}


Results and discussion

Egg cooking or baking are processes where egg protein denaturation takes place, and therefore affected by $\mathrm{pH}$ (Davis and Willians, 1998), protein quality (degree of oxidation), and egg functional properties (foaming and emulsifying properties). Sensory results indicate that cooking or baking of UV-C treated or heat treated egg fractions minimized the differences in all investigated parameters. Remarkably, the panel did not find significant differences in the quality of the cooked products, and the general appearance of heat or UV-C treated egg fractions, and more specifically color and aroma, were not found different to the control. Only a significant effect was observed for the general appearance of the heat treated egg yolk compared to the control. In a similar way, the baked products (pudding and angel cake) did not shown significant differences up to the $99.9 \%$ confidence level regarding the general appearance, the color or the aroma. Consequently, the similarities found between the processed egg fractions point out for a minimal effect of UV-C treatments on the egg foaming and emulsifying properties. UV light at germicide wavelengths is known to generate small changes in physicochemical properties and should not alter, for example, the $\mathrm{pH}$ of food (section 5.1.2.1 and 5.2.2.1; Torkamani and Niakousari, 2011), but could be oxidizing (Muruganandham and Swaminathan, 2004; Wang, Hsieh, and Hong, 2000). Therefore more specific tests about hedonic markers might provide a further insight into potential quality changes in preparations containing UV-C treated egg products.

Regarding mayonnaise, significant differences ( $95 \%$ confidence level) were reported between the natural and the $4.176 \mathrm{~J} . \mathrm{cm}^{-2} \mathrm{UV}-\mathrm{C}$ treated samples. 
Panelists indicated that the UV-C treated sample was firmer than the natural, even if they could not find differences in the color or the aroma.

\subsubsection{Consumer acceptance test}

Color and aroma are probably the most relevant quality attributes for fresh eggs and liquid egg products because they are simple indicators of microbiological spoilage. A green color or a sulphur smell are related to the characteristic appearance of rotten eggs, and indicate the end of shelf-life. Changes in egg rheological behavior are also typically associated to protein denaturation, and may occur during pasteurization (Douglas, Greenberg, Farrell and Edmondson, 1981) and egg irradiation with ionizing sources (Min et al., 2005). Consequently, in the present study, the consumer acceptance of egg fractions treated with different methods was evaluated by asking the degree of liking on 9-point hedonic scales for 5 different parameters: color, aroma, viscosity, appearance and general acceptance.

When fresh egg white, whole egg and egg yolk were evaluated, the acceptance scores for all treatments were fairly similar in all the investigated categories (Figure 5.48), giving slightly lower scores only for heat treated egg whites.

Discrimination tests also demonstrated previously that consumers were able to differentiate only scarce effects of processing on the egg fractions, confirming that heat treated samples were the most different to the control. 
Results and discussion
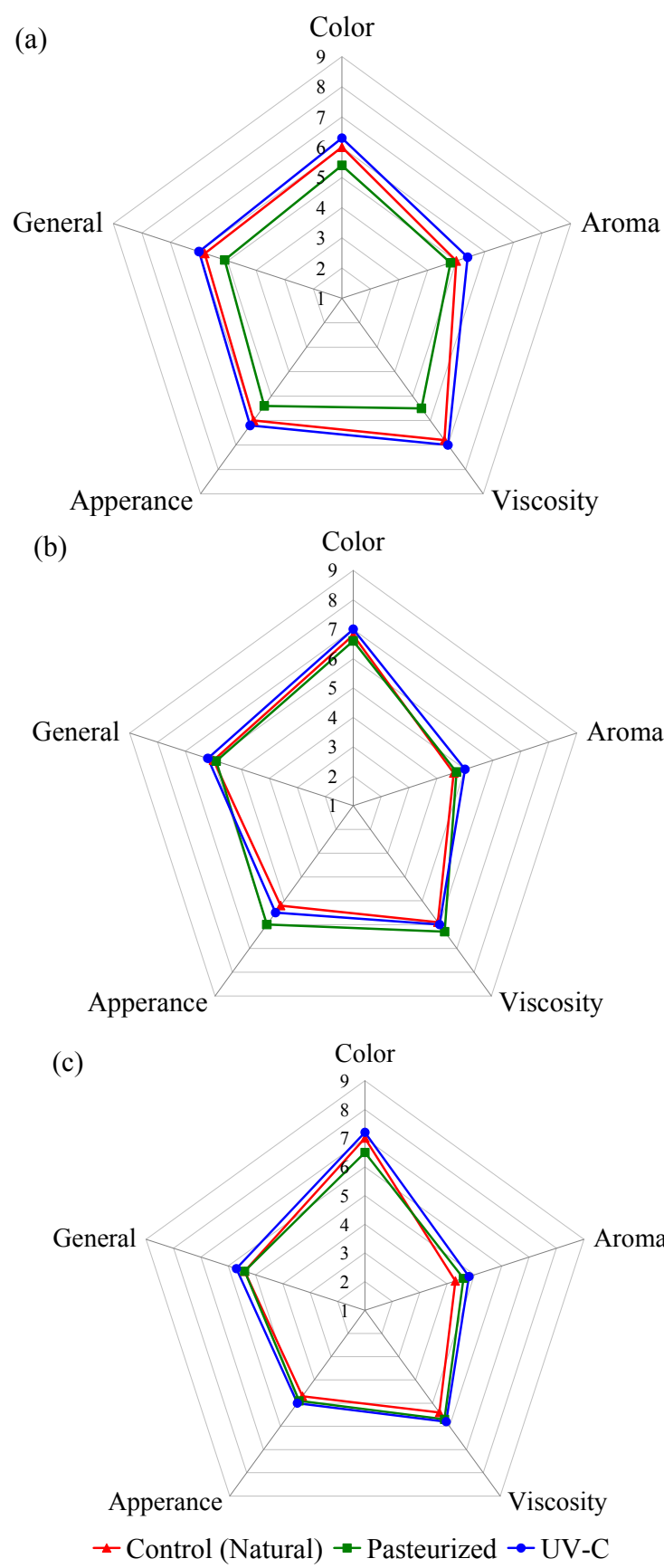

Figure 5.48 - Hedonic scale grades attained by (a) LEW, (b) LWE, and (c)

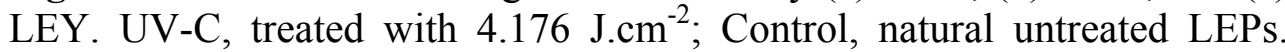
Results are the mean of triplicate. Standart deviation is bellow $5 \%$. 
Consumers seem to have a similar degree of acceptability for all the products, which obtained rather low scores in the "like slightly" range of the scale because fresh egg products are relatively flat in odor and flavor, and they are not consumed raw. But the panelists seem not to have distinguished any particular discolorations or off-flavor after the samples exposure to $4.176 \mathrm{~J} . \mathrm{cm}^{-2}$ or regular heat treatments, being the color scores the highest in this group. The most pronounced difference, which still was not significant $(\mathrm{P}>0.05)$, was observed on the egg white viscosity after heating, where heat could have promoted a certain degree of protein coagulation. Protein coagulation could be then responsible for an apparently different viscosity, and the lower scores generally found for the heat treated egg whites.

For cooked LEPs, color, aroma, appearance, flavor, after taste and general acceptance were analyzed (Figure 5.49). The reported scores show no discrepancy between treated products and the controls, and results again point out for a minimization in the differences after cooking. The parameters analyzed confirm that the taste of cooked LEPs sanitized by heat or UV-C is as acceptable as that from natural eggs. Flavor and color received the highest scores, while in general, the aroma was scored rather low ("dislike moderately" to "dislike slightly") for all the products. These low aroma scores are likely due to the fact that the cooked egg products were served without added ingredients (oil, salt, pepper, etc.), contrary to the usual way of consumption, not individually but as part of a meal. The off-flavor average score observed in all samples (Table 5.40) indicates that treatments did not induced the formation of any particular off-flavor. Sensory defects in UV-C treated food products are mainly attributed to the 
oxidation of sulphur containing amino acids, but off-flavors typically fade during time. Results for mayonnaise, pudding and angel cake are represented on Figure 5.50, and its appereance are show on Figure 5.51.

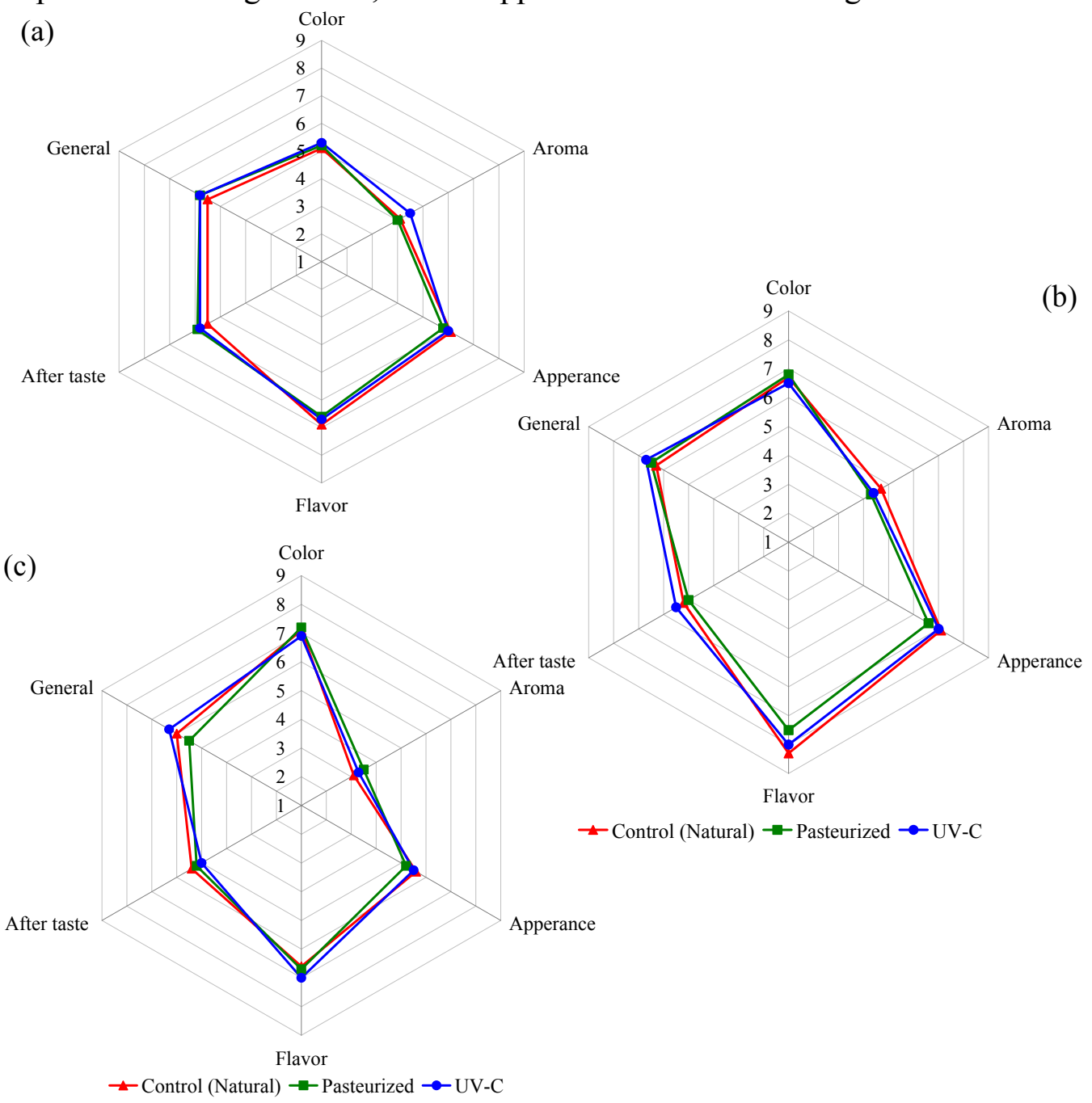

Figure 5.49 - Hedonic scale grades attained by (a) cooked LEW, (b) cooked

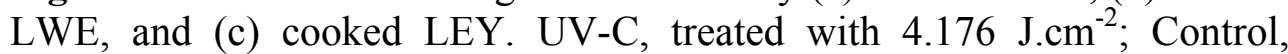
natural untreated LEPs. Results are the mean of triplicate. Standart deviation is bellow $5 \%$. 
Here, color, flavor, aroma, texture, after flavor, and especially for mayonnaise, creaminess and firmness, were evaluated. Acceptance scores were comparable in all attribute categories $(P \geq 0.05)$, and in overall liking, with responses being in the "like moderately" to the "like very much" range of the scale.

Remarkably, the general acceptance attained for the preparations was considerably higher than the scores attained for plain cooked liquid egg fractions.

Regarding mayonnaise, consumers showed a certain degree of preference for the samples prepared using UV-C treated whole egg, also reflected on the overall quality scores (Table 5.40), even if not statiscally significant. The scores obtained by texture and firmness considerably higher than in controls and in heat treated samples.

Egg functional properties are highly related to the texture, creaminess, and firmness achieved in preparations. Consequently, results would indirectly confirm that the foaming and emulsifying properties of UV-C treated samples were not negatively affected by the treatment.

Only a few studies deal with the organoleptic attributes of UV-C treated food, and to our knowledge, no consumer acceptance studies have been carried out on UV-treated eggs. 
Results and discussion

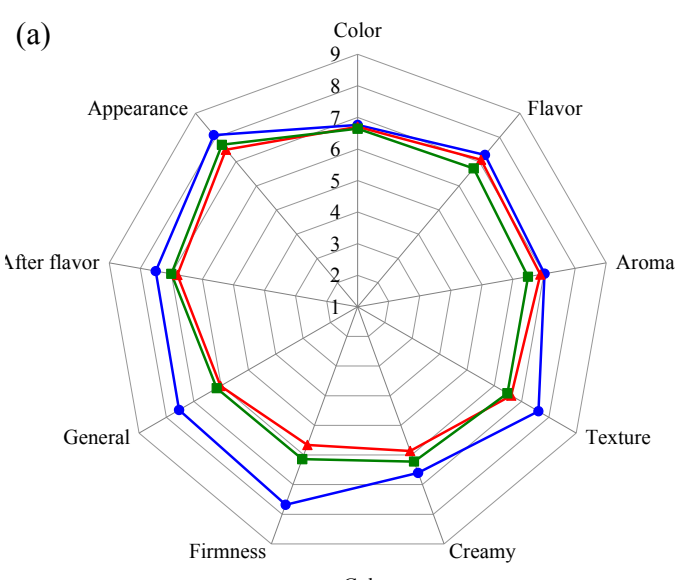

(b)

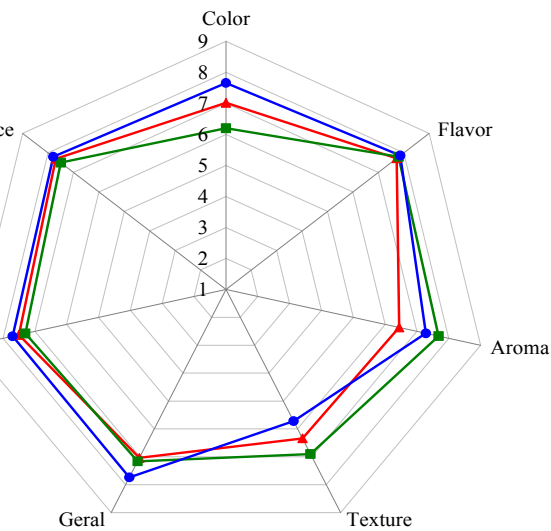

(c)

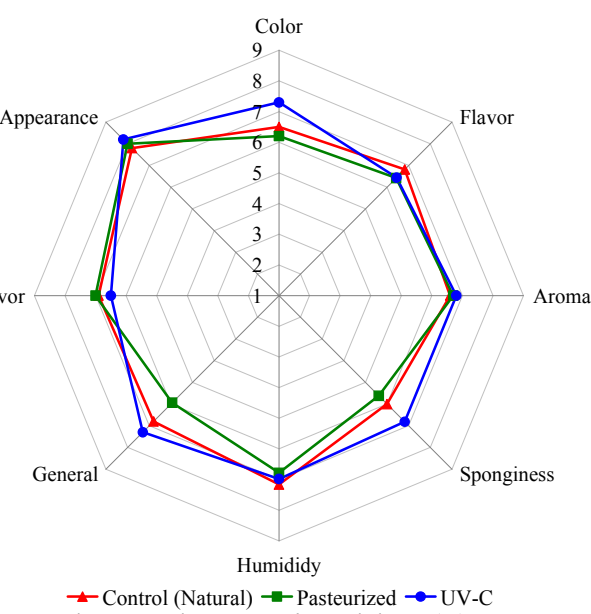

Figure 5.50 - Hedonic scale grades attained by (a) mayonnaise, (b) pudding,

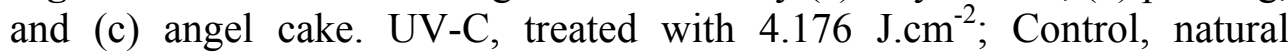
untreated LEPs. Results are the mean of triplicate. Standart deviation is bellow $5 \%$. 
Table 5.40 - Consumer acceptance ratings specifically for off-flavor on cooked egg white, cooked whole egg, cooked egg yolk, mayonnaise, pudding and angel cake; and overall quality calculated from the aroma, flavor, color and harmony (general acceptance).

\begin{tabular}{|c|c|c|c|}
\hline \multicolumn{2}{|c|}{ Samples } & Off-flavor & Overall quality \\
\hline \multirow{3}{*}{$\begin{array}{c}\text { Cooked egg } \\
\text { white }\end{array}$} & Natural & $5.1^{\mathrm{a}} \pm 2.1$ & $5.7^{\mathrm{a}} \pm 1.2$ \\
\hline & Pasteurized & $5.0^{\mathrm{a}} \pm 1.2$ & $5.6^{\mathrm{a}} \pm 1.7$ \\
\hline & UV $4.176 \mathrm{~J} . \mathrm{cm}^{-2}$ & $5.3^{\mathrm{a}} \pm 2.3$ & $5.8^{\mathrm{a}} \pm 1.6$ \\
\hline \multirow{3}{*}{$\begin{array}{c}\text { Cooked } \\
\text { whole egg }\end{array}$} & Natural & $4.8^{\mathrm{a}} \pm 1.0$ & $6.8^{\mathrm{a}} \pm 1.7$ \\
\hline & Pasteurized & $4.4^{\mathrm{a}} \pm 1.6$ & $6.4^{\mathrm{a}} \pm 1.6$ \\
\hline & UV $4.176 \mathrm{~J} . \mathrm{cm}^{-2}$ & $5.0^{\mathrm{a}} \pm 1.1$ & $6.6^{\mathrm{a}} \pm 1.4$ \\
\hline \multirow{3}{*}{$\begin{array}{c}\text { Cooked egg } \\
\text { yolk }\end{array}$} & Natural & $5.2^{\mathrm{a}} \pm 1.3$ & $5.7^{\mathrm{a}} \pm 1.5$ \\
\hline & Pasteurized & $4.9^{\mathrm{a}} \pm 1.6$ & $5.7^{\mathrm{a}} \pm 1.5$ \\
\hline & UV $4.176 \mathrm{~J} . \mathrm{cm}^{-2}$ & $5.0^{\mathrm{a}} \pm 1.4$ & $5.9^{\mathrm{a}} \pm 1.4$ \\
\hline \multirow{3}{*}{ Mayonnaise } & Natural & $5.0^{\mathrm{a}} \pm 0.7$ & $6.8^{\mathrm{a}} \pm 1.8$ \\
\hline & Pasteurized & $4.2^{\mathrm{a}} \pm 1.1$ & $6.5^{\mathrm{a}} \pm 2.0$ \\
\hline & UV $4.176 \mathrm{~J} . \mathrm{cm}^{-2}$ & $5.1^{\mathrm{a}} \pm 0.8$ & $7.2^{\mathrm{a}} \pm 1.6$ \\
\hline \multirow{3}{*}{ Pudding } & Natural & $4.9^{a} \pm 1.5$ & $7.2^{\mathrm{a}} \pm 1.6$ \\
\hline & Pasteurized & $5.2^{\mathrm{a}} \pm 2.1$ & $7.4^{\mathrm{a}} \pm 1.4$ \\
\hline & UV $4.176 \mathrm{~J} . \mathrm{cm}^{-2}$ & $5.4^{\mathrm{a}} \pm 1.3$ & $7.7^{\mathrm{a}} \pm 1.3$ \\
\hline \multirow{3}{*}{ Angel cake } & Natural & $5.5^{\mathrm{a}} \pm 1.2$ & $6.7^{\mathrm{a}} \pm 1.6$ \\
\hline & Pasteurized & $5.0^{\mathrm{a}} \pm 1.4$ & $6.4^{\mathrm{a}} \pm 1.7$ \\
\hline & UV $4.176 \mathrm{~J} . \mathrm{cm}^{-2}$ & $5.2^{\mathrm{a}} \pm 1.6$ & $6.8^{\mathrm{a}} \pm 1.8$ \\
\hline
\end{tabular}

The impact of UV-C radiation on the volatile profile is matrix dependent. In the work of Manzoco et al. (2011), a sensory panel discarded the presence of off-flavors attributed to UV-C treatment during the storage of apple slices, and the light seem not to have induced differences in the 
Results and discussion

physiological ripening of the fruit. Similarly to our results, in apple cider, triangle tests revealed no significant differences between the control and the treated samples (heat, UV-C, PEF) at day 0 (Valappil et al., 2009). However, on the Valappil et al. (2009) study significant differences (P $\leq$ 0.05 ) were observed after 4 weeks storage, the control being preferred over the UV-C treated sample probably due to the loss in hexanal and the increase in 1-hexanol, together with some sensory notes associated to microbial growth.

Therefore, the variety of results available point out for the necessity of individualized analysis for each product, and the studies ought to be extended up to the end of product shelf-life.

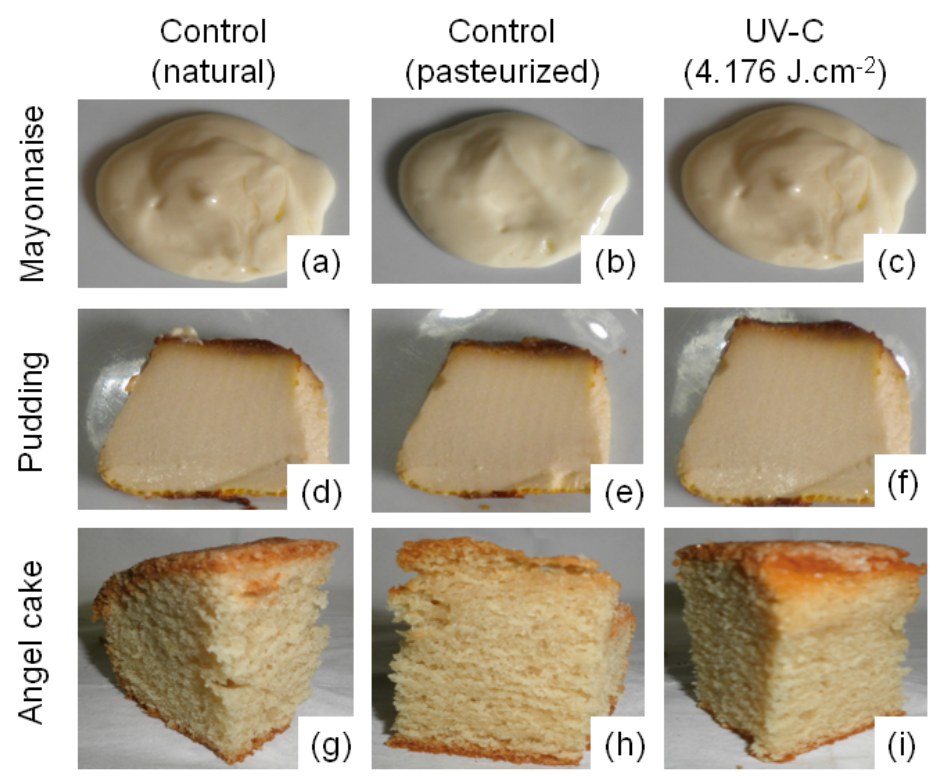

Figure 5.51 - Products prepared with LEPs. (a) (b) (c) Mayonnaise; (d) (e) (f) Pudding; (g) (h) (i) Angel cake. (a) (d) (g) Preparations with untreated LEPs; (b) (e) (h) Preparations with pasteurized LEPs; (c) (f) (i) Preparations with UV-C treated LEPs. 


\subsection{MRI2010 UV-C reactor}

Treating opaque liquids with UV-C is a challenge, and the scale up of the process includes the analysis of variables like flow and sample optical density. The characteristics of the UV-light source and flow pattern need to be considered as critical in the scale-up process.

The suspensions of microorganism that are irradiated with UV-C can be considered as dense packages of absorbing molecules separated from each other by the suspension liquid. The presence of dissolved organic solutes and compounds leads to strong UV-attenuation. Suspended solids might also attenuate the light through light scattering, and provide with space for aggregation of microorganisms.

Under laminar flows and at high optical densities, light will be absorbed and microorganisms flowing through the centre of an UV transparent glass tube will not be necessarily inactivated. Extreme thin-film reactors are recommended to achieve adequate inactivation under lamina flows. Providing a highly turbulent flow, however, could allow sufficient treatment uniformity, as all particles would be better mixed. As turbulence increases, the pressure drops across the reactor, and the residence time diminishes, which can lead to complications in the scale-up (Koutchma, 2009). Additionally, Dean Vortices would induce the mass-transfer and improve the mixing during process in turbulent devices (Müller et al., 2011). 
Results and discussion

A critical component of UV-C process validation is the selection and qualification of scale-up models/prototypes. Important aspects to be considered to process scale-up are devices design and performance, and the final product quality.

In this study, a UV-C reactor described in section 4.2.4 was used to increase the volume of treated LEPs and to confirm the possibility of scale-up the UV-C process. In this reactor, a flow of $20 \mathrm{~L}^{-\mathrm{h}^{-1}}$ was achieved under turbulent conditions $(\operatorname{Re}>2500)$. This device slightly improves the $\operatorname{Re}$ and of the UVIvatec ${ }^{\circledR}$ reactor, following the estimated numbers presented in Table 4.2.

\subsubsection{Microbiology: Effects on inoculated microorganisms}

Figure 5.52 presents the inactivation kinetics for the Salmonella subterranea, Escherichia coli and Listeria innocua treated on the MRI reactor for the whole egg. The volume flow achieved in the device was 20 $\mathrm{L}^{-1} \mathrm{~h}^{-1}$, which is the double of the flow achieved in the laboratory device (UVivatec $\AA$ ). The study was carried out only in whole egg due its dual characteristics, high protein content as in the egg white, and high viscosity. With this equipment, a 5 Log reduction was achieved at approx. 16,000 $18,000 \mathrm{~J} . \mathrm{L}^{-1}$.

The kinetic parameters obtained for the Salmonella subterranea, Escherichia coli and Listeria innocua are comparable to the kinetics 
obtained for the same microorganisms on the lab-scale device. Table 5.41 show the Weibull fitting parametersAround 6,000 and 8,000 J.L $\mathrm{L}^{-1}$ the tailing phenomena started. Likely due to the improved flow characteristics achieved in this reactor, fewer cycles are needed to reach inactivation rates similar to the UVivatec ${ }^{\circledR}$.

The difference in efficacy is probably caused by the higher flows achieved and the better mixing due to the Dean numbers and the turbulence. But further improvements must be carried out to optimize the inactivation process based on Dean Vortex technology at an industrial scale.

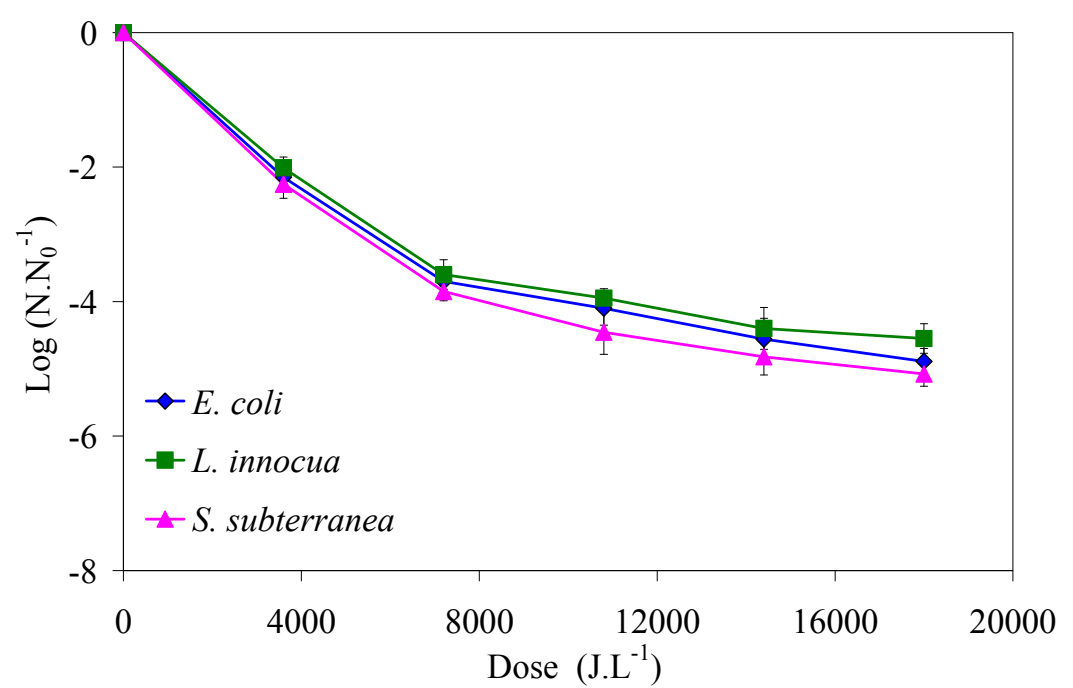

Figure 5.52 - UV-C inactivation of Escherichia coli DH5a, Listeria innocua WS 2258 and Salmonella subterranea DSM 16208 in LWE treated at the MRI2010 UV-C reactor, as a function of the volumetric dose. Results are the mean of triplicate \pm standart deviation. 
Results and discussion

Table 5.41 - Weibull fitting from inactivation kinetics of LWE at the MRI 2010 reactor

\begin{tabular}{lccc}
\hline \multirow{2}{*}{ Parameters } & \multicolumn{3}{c}{ Weibull } \\
\cline { 2 - 4 } & $\begin{array}{c}\text { Salmonella } \\
\text { subterranea }\end{array}$ & $\begin{array}{c}\text { Escherichia } \\
\text { coli }\end{array}$ & $\begin{array}{c}\text { Listeria } \\
\text { innocua }\end{array}$ \\
\hline $\mathrm{RMSE}^{\mathrm{a}}$ & 0.8767 & 0.7258 & 0.8156 \\
$\mathrm{R}^{2}$ & 0.8788 & 0.9076 & 0.8718 \\
$\mathrm{Log} \mathrm{N}_{0}\left(\mathrm{CFU} . \mathrm{mL}^{-1}\right)^{\mathrm{b}}$ & 6.26 & 6.69 & 6.42 \\
$\delta\left(\mathrm{J} . \mathrm{L}^{-1}\right)^{\mathrm{c}}$ & 3095.15 & 2676.40 & 3391.44 \\
$\mathrm{p}(-)^{\mathrm{d}}$ & 0.84 & 0.79 & 0.84 \\
$5 \mathrm{D}\left(\mathrm{J} . \mathrm{L}^{-1}\right)$ & 20475 & 18000 & 22275 \\
\hline
\end{tabular}

${ }^{\text {a }}$ RMSE: Root mean sum of squared error.

${ }^{\mathrm{b}} \log \left(\mathrm{N}_{0}\right)$ : predicted logarithm of initial count.

${ }^{\mathrm{c}} \delta$ : fluence for the first decimal reduction.

${ }^{\mathrm{d}} \mathrm{p}$ : dimensionless parameter describing concavity or convexity of the curve. 
6. Conclusions 



\section{Conclusions}

Short wave ultraviolet (UV-C) is a promising technology to pasteurize liquid egg products. The most limiting factor is the optical density of the product. Other parameters, such as the fluence rate, the viscosity, the Reynolds number and the Dean number are also relevant. The main conclusions of this work are:

1. In batch, Gram(-) microorganisms are more sensitive to UV-C than Gram(+). 5 Log reductions of Salmonella enteritidis and Escherichia coli are achieved with 3.39 and $4.25{\mathrm{~J} . \mathrm{cm}^{-2}}^{-}$in liquid egg white (LEW). Doses of 10.14 and $6.54{\mathrm{~J} . \mathrm{cm}^{-2}}^{-2}$ are required to achieve a comparable reduction for, respectively, Listeria innocua and Staphylococcus aureus. Significantly lower effects are recorded in liquid egg yolk (LEY) and whole egg (LWE) for the same microorganisms, mainly due to the higher absorbance at 254 nm.

2. Under continuous processing (UVivatec ${ }^{\circledR} L a b$ device), differences within vegetative microorganisms are minimized. 5 Log reductions are achieved in the populations of Salmonella subterranea, Escherichia coli and Listeria innocua in all liquid egg fractions. Doses required are approx. $8000 \mathrm{~J} . \mathrm{L}^{-1}$, $16,000 \mathrm{~J} . \mathrm{L}^{-1}, 63,000 \mathrm{~J} . \mathrm{L}^{-1}$ for, respectively, liquid egg white, liquid whole egg and liquid egg yolk with optical densities LEW $<$ LWE $<$ LEY. 
Conclusions

3. UV-C treatments are able to ensure a microbial inactivation enough to prolong the shelf-life of liquid egg products. Significant decreases are recorded in the endogenous microbial groups, most of them related to eggspoilage microorganisms, and Salmonella. In batch, $4.12 \mathrm{~J} . \mathrm{cm}^{-2}$ provide values comparable to heat pasteurizations. In particular, the shelf-life of liquid egg white and liquid whole egg goes up to 8 weeks at $4{ }^{\circ} \mathrm{C}$, and 15 days at $20{ }^{\circ} \mathrm{C}$, without the addition of preservatives. In egg yolk, microbiological counts exceed the legal requirements after 6 weeks cold storage.

4. At doses necessary to achieve 5 Log reductions, UV-C treatments do not cause relevant changes in physicochemical parameters and sensory attributes of liquid egg products. $\mathrm{pH}$ remains stable after UV-C treatments. Perceptible browning in egg yolk and whole egg is stated due to Maillard, but total color differences are acceptable at pasteurization doses, in batch and under continuous treatments. TBARS and peroxide values increased as the radiation dose increased, but final values are better than after heat pasteurization. The content of cholesterol is considerably reduced due to UV-C.

5. UV-C treatments at doses necessary to reduce $5 \mathrm{Log}$ do not alter the flow behavior, temperature-dependent viscosity, thermodynamic properties and electrophoretic pattern of liquid egg products. A certain degree of protein cross-linking originates however an enhancement in the instrumental 
emulsifying and foaming properties, in particular, of liquid egg white, in batch and in continous treatments.

6. Changes in egg functional properties are minimal and do not cause a different perception of UV-C treated liquid egg products. Triangle and acceptance tests revealed that consumers can not differentiate the UV-C treated liquid egg products from the fresh ones when exposure is below 3.48 $\mathrm{J}_{\mathrm{cm}}{ }^{-2}$. And no difference can be detected when UV-C processed egg products are cooked or used in egg preparations, such as mayonnaise, pudding or angel cakes. Products containing UV-C treated egg samples are perceived as comparable to or, in some cases, better than the heat treated. Remarkably, no off-flavors due to UV-C treatments are detected.

7. To decrease the residence time necessary to achieve pasteurization, especially the mixing system and light sources need to be optimized. Under the studied conditions, a significant decay in the concentration of vitamins $\mathrm{A}$ and $\mathrm{C}$, and in relevant secondary metabolites such as lutein and zeaxanthin, has been stated. Vitamins $\mathrm{B}_{2}, \mathrm{~B}_{5}$ and $\mathrm{E}$ were stable.

8. And remarkably, UV-C does not cause changes in the cytotoxic and the genotoxic effects of liquid egg products at doses necessary to achieve pasteurization values. 


\subsection{Recommendations for future studies}

Non-ionizing radiation, namely short-wave ultraviolet (UV-C) wavelengths (220-300 nm with 90\% emission at $253.7 \mathrm{~nm}$ ) has been approved as a non thermal technology by the U.S. Food and Drug Administration (FDA) for the pasteurization of clarified fruit juices and surface sterilization. This technique has been extensively used to decontaminate food surfaces or materials which come in contact with food. The main industrial application of UV-C in liquid foods is in the disinfection of drinking water. The mechanism of action of UV light involves the interruption of bacterial replication due to the formation of pyrimidine dimmers and is highly effective against spoilage-related microorganisms, spores and viruses.

High expectations exists for adopting short-wave ultraviolet based technologies in small or large scale processing units for liquid foods and aseptic packaging lines. Results obtained in this $\mathrm{PhD}$ Thesis would confirm UV-C treatment as a promising alternative to extend the shelf-life of liquid egg products. After UV-C, safety levels would be comparable to traditional thermal pasteurizations, while the flow behavior and the egg functional properties are preserved, and sensory acceptance is maintained. Toxic compounds seem not be generated, but losses in nutritional were repported. Face to this, extend research need to be done about the nutritional aspects.

Also further research needs to be done on the modeling of UV irradiation 
kinetics of egg related microorganisms other than Listeria, Salmonella, Staphylococcys and Eschericia coli. And also studies need to be done considering the phenomenon of photo-regeneration in UV-C treated liquid egg products. Extensive research is also highly recommended under continuous treatments, and analysis of the most important quality parameters during storage is necessary. The scale-up of the technology will require an optimization of the light sources, the mixing procedure, and complete studies in combination with natural preservatives.

Future research should also asses the re-design of the UV reactor, the effects of the placement of the sample in relation to the UV-C source. And scale up the process to an industrial level. Therefore, for the future, more studies should be carried out to determine the synergistic effects of combining technologies, like heat pasteurizing (UV-C as pre-treatment), hight pressure etc. And combination treatments of UV-C with chemical treatments such as hydrogen peroxide or ozone. 



\section{References}





\section{References}

Adams, M. R.; Moss MO. (1999). Food Microbiology. Royal Society of Chemistry, Cambridge. p. $255-274$.

Afify, A. E. M.; Rashed, M. M.; Mahmoud, E. A.; Beltagi, H. S. (2011). Effect of Gamma Radiation on Protein Profile, Protein Fraction and Solubility's of Three Oil Seeds: Soybean, Peanut and Sesame. Not Bot Horti Agrobo, v. 39, i.2, p.90-98.

Aguiar, A.M.S.; Brito, L. L. A.; Fernandes-Neto, M. L. (2002). Avaliação do emprego da radiação ultravioleta na descontaminação de águas com turbidez e or moderadas. Engenharia Sanitária e Ambiental, v. 7, n. 1, p. $38-47$.

Ahvenainen, R. (1996). New approaches in improving the shelf life of minimally processed fruit and vegetables. Trends in Food Science and Technology, v.7, n. 6, p. 179-197.

Albert, I.; Mafart, P. (2005). A modified Weibull model for bacterial inactivation. International Journal of Food Microbiology, v. 100, p. 197211.

Ali, N. A.; Ahmed, S. H.; Mohamed, E. A.; Mohamed Ahmed, I. A.; Babiker, E. (2011). Effect of transglutaminase cross-linking on the functional properties as a function of $\mathrm{NaCl}$ concentration of legumes protein isolate. International Journal of biological and life sciences, v.7, p. $8-13$. 
References

Almazara, S. M. (2007). La radiación ultravioleta: una alternativa "no térmica" para la pasteurización de jugos. Ingeniería Alimentaria, v. 68, p. 103-108.

Altic, L. C.; Rowe, M. T.; Grant, I. R. (2007). UV light inactivation of Mycobacterium avium subsp. paratuberculosis in milk as assessed by FASTPlaque TB phage assay and culture. Applied and Environmental Microbiology, v. 73. p. 3728-3733.

Alvarez I.; Niemira B. A.; Fan, X.; Sommers, C. H. (2007). Modeling the irradiation followed by heat inactivation of Salmonella inoculated in liquid whole egg. Journal of Food Science, v. 72. p. 145-52.

Alvarez, I.; Niemira, B. A.; Fan, X.; Sommers, C. H. (2006). Inactivation of Salmonella serovars in liquid whole egg by heat following irradiation treatments. Journal of Food Protection, v. 69, n. 9, p. 2066-2074.

American Egg Board. (2007). Egg facts. Available from: http://www. incredibleegg.org/egg_facts.html. Accessed in Feb 26 ${ }^{\text {th }}, 2009$.

Amiali, M.; Ngadi, M. O.; Raghavan, V. G. S.; Smith, J. P. (2004). Inactivation of Escherichia coli $\mathrm{O} 157: \mathrm{H} 7$ in liquid dialyzed egg using pulsed electric fields. Food and Bioproducts Processing, v. 82. p. 151156.

Antoniou, M. G.; Dionysius, D. D. (2007). Investigation of the photocatalytic degradation pathway of creatinine: effect of $\mathrm{pH}$. National Meeting Proceedings of the 234th American Chemical Society. C. Ellen Gonter Environmental Chemistry Awards Session, Division of Environmental Chemistry, v. 47, n. 2.

Anonymous. (2011). Health nutrition guide. Classification of vitamins, functions, food sources, nutritional requirements, interesting facts Available on: http://www.healthynutritionguide.info/vitamins.htm Accessed in Oct, $26^{\text {th }}, 2011$. 
AOAC. (1995). Association of Official Analytical Chemists. Official methods of analysis of AOAC International. 14th ed. Washington, 1141p. AOAC (method 33.2.09/A, AOAC, 1995).

AOAC. (1998). Association of Official Analytical Chemists. Methods and Recommended Practices of the American Oil Chemists' Society, 5th ed., AOCS Press, Champaign. AOAC method Cd 8-53.

Aparicio-Ruiz, R.; Mínguez-Mosquera, M. I., Gandul-Rojas, B. (2011). Thermal degradation kinetics of lutein, $\beta$-carotene and $\beta$-cryptoxanthin in virgin olive oils. Journal of Food Composition and Analysis, v. 24, n. 6, p. 811-820.

Aruoma, O. I. (1994). Nutrition and health aspects of free radicals and antioxidants. Food and chemical toxicology, v. 32, n. 7, p. 671-683.

ASTM. (1968). American Society for Testing and Materials. STP 434 Manual on Sensory Testing Methods, ASTM, Philadelphia, Pennsylvania.

Badr, H. M. (2006). Effect of gamma radiation and cold storage on chemical and organoleptic properties and microbiological status of liquid egg white and yolk. Food Chemistry, v. 97, p. 285-293.

Ball, D.W. (2007). The electromagnetic spectrum: a history. Spectroscopy, v. 3, n. 22, p.14-17.

Bank, H.L.; Schmehl, J.L.; Dratch, R. J. (1990). Bacteriocidal Effectiveness of Modulated UV Light. Applied and Environmental Microbiology, v. 56, p. 3888-3889.

Banwart, G. J. (1989). Foodborne agents causing illness. In: Basic food microbiology. $2^{\text {nd }}$ ed. New York, NY: Chapman and Hall. p 195.

Barbosa-Cánovas, G.V.; Pothakamury, U.R.; Palou, E.; Swanson, B.G. (1998). Conservación No Térmica de Alimentos. Ed. Acribia, S.A., España, 248 p. 
References

Bari M.L.; Ukuku D.O.; Mori M.: Kawamoto S.; Yamamoto K. (2008). Effect of hydrostatic pressure pulsing on the inactivation of Salmonella enteritidis in liquid whole egg. Foodborne Pathogens Disease, v.5, p. $175-182$.

Basaran, N.; Quintero-Ramos, A.; Moake, M. M.; Churey, J. J.; Worobo, R. W. (2004). Influence of apple cultivars on inactivation of different strains of Escherichia coli O157:H7 in apple cider by UV irradiation. Applied and Environmental Microbiology, v. 70, p. 6061-6065.

Bazhal, M. I.; Ngadi, M. O.; Raghavan, G. S. V.; Smith, J. P. (2006). Inactivation of Escherichia coli $\mathrm{O} 157: \mathrm{H} 7$ in liquid whole egg using combined pulsed electric field and thermal treatments. LWT - Food Science and Technology, v. 39, p. 420-426.

Beaulieu, J. C. (2007). Effect of UV Irradiation on Cut Cantaloupe: Terpenoids and Esters. Journal of Food Science, v. 72, n. 4, p. S272S281.

Beeson, S.; Mayer, J. W. (2008). Patterns of light chasing the spectrum from Aristotle to LEDs - Springer New York Publisher.

Bell, C.; A. Kyriakides. (2002). Salmonella - a practical approach to the organism and its control in foods, p 84-98. Blackwell Science, Oxford.

Beveridge, T.; Arntfield, S. (1974). Heat Induced Changes in Sulphydryl Levels in Egg White. Journal Can. Inst. Food Sci. Technol., v. 197, n. 12, p. 173-176.

Bialka, K. L.; Demirci, A.; Puri, V. M. (2008). Modeling the inactivation of Escherichia coli O157:H7 and Salmonella enterica on raspberries and strawberries resulting from exposure to ozone or pulsed UV-light. Journal of Food Engineering, v. 85, p. 444-449.

Bigelow, W. D.; Esty, J. R. (1920). Thermal death point in relation to time of typical thermophylic organisms. J. of Infected Diseases, v. 27, p. 602617. 
Bintsis, T.; Litopoulou-Tzanetaki, E.; Robinson, R. K. (2000). Existing and potencial applications of ultraviolet light in the food industry - a critical revision. Journal of the Science of Food and Agriculture, v. 80, p. 637645.

Biscaro, L. M.; Caniatti-Brazaca, S.G. (2006). Cor, betacaroteno e colesterol em gema de ovos obtidos de poedeiras que receberam diferentes dietas. Ciência e Agrotecnologia, v. 30, n. 6, p. 1130-1134.

Bizzotto, C. S.; Capobiango, M.C.; Silvestre, M. P. C. (2005) Evaluation of functional properties of a blood protein. Pak. J. Nutr., v. 4, p. 11-16.

Blume, T.; Neis, U. (2004). Improved Wastewater Disinfection by Ultrasonic Pre- Treatment. Ultrasonics Sonochemistry, v.11, p. 333-336.

Board, R.G. (1964). The growth of Gram-negative bacteria in the hen's egg. J. Appl. Bacteriol., v. 27, n. 350.

Board, R.G. (1966). Review Article: The Course of Microbial Infection of the Hen's Egg. J. Appl. Bacteriol., v. 29, p. 319-341.

Board, R.G.; Fuller, R. (1974). Non-specific antimicrobial defences of the avian egg, embryo, and neonate. Biological Reviews 49:15-49.

Board, R.G.; Loseby, S.; Miles, V. R. (1979). A note on microbial growth on hen eggshells. Br. Poult. Sci. v. 20, p. 413-420.

Board, R.G., N.H.C. Sparks, and H.S. Tranter. 1986. Antimicrobial defense of avian eggs. In: Natural antimicrobial systems. (Gould, G.W., M.E. Rhodes Roberts, A.K. Charnley, Eds.) Bath University Press, Bath, UK pp. 82-96.

Bolton, J. R.; Linden, K.G. (2003). Standardization of methods for fluence UV dose determination in bench-scale UV experiments. Journal of Environmental Engineering, v. 129, p. 209-215. 
References

Boziaris, I. S.; Humpheson, L.; Adams, M. R. (1998). Effect of nisin on heat injury and inactivation of Salmonella enteritidis PT4. International Journal of Food Microbiology, v. 43, p. 7-13.

Boyer, R.; McKinney, J. (2009). Food Storage Guidelines for Consumers. Virginia Cooperative Extension. Available on: http://shelflifeadvice.com/daily/eggs-and-egg-whites. Acessed in: January $1^{\text {st }}, 2012$.

Braden, C. R. (2006). Salmonella enterica serotype Enteritidis and eggs: A national epidemic in the United States. Clin. Infect. Dis., v. 43, n. 4, p. 512-517.

Bringe, N.A.; Howard, D.B.; and Clark, D.R. (1996). Emulsifying properties of low-fat, low-cholesterol egg yolk prepared by supercritical $\mathrm{CO}_{2}$ extraction. J. Food Sci., v. 61, p. 19-23.

Britton, G. (1995). Structure and properties of carotenoids in relation to function. FASEB J., v. 9, p. 1551-1558.

Bule, M. V.; Desai, K. M.; Parisi, B.; Parulekar, S. J.; Slade, P.; Singhal, R. S.; Rodriguez, A. (2010). Furan formation during UV-treatment of fruit juices. Food Chemistry, v. 122, n. 4, p. 937-942.

Cabaj, A.; Sommer, R. (2000). Measurements of ultraviolet radiation with biological dosemeters. Radiation Protection Dosimetry, v. 91, n.1-3, p.139-142.

Caboni, M. F.; Boselli, E.; Messia, M. C. ; Velazco, V. ; Fratianni, A. ; Panfili, G. (2005). Effect of processing and storage on the chemical quality markers of spray-dried whole egg. Food Chemistry, v. 92. p. 293-303.

Cadet, J.; Sage, E.; Douki, T. (2005). Ultraviolet Radiation-Mediated Damage to Cellular DNA. Mutation Research, v. 571, p. 3-17.

Calderon-Miranda, M.L.; Barbosa-Canovas, G.V.; Swanson, B.G. (1999). Inactivation of Listeria innocua in liquid whole egg by pulsed electric 
fields and nisin. International Journal of Food Microbiology, v. 51, p. 717.

CDC. (2005). Centers for Disease Control and Prevention. Available on: http://www.cdc.gov/ Acessed in: September 13 $3^{\text {th }}, 2011$.

CDC. (2008). Centers for Disease Control and Prevention. Salmonella surveillance: Annual summary, 2006. Atlanta, Georgia.

Chang, Y. I.; Chen, T. C. (2000). Functional and gel characteristics of liquid whole egg as affected by $\mathrm{pH}$ alteration. Journal of Food Engineering, v. 45, p. 237-241.

Chavez, C.; Knape, K. D. ; Coufal, C. D.; Carey, J. B. (2002). Reduction of eggshell aerobic plate counts by ultraviolet irradiation. Poult. Sci., v. 81, p. 1132-1135.

Chevrefils, G.; Caron, E.; Wright, H.; Sakamoto, G.; Payment, P.; Barbeau, B. (2006). UV dose required to achieve incremental log inactivation of bacteriea, protozoa and viruses. IUVA News, v. 8, p. 38-45.

Chmiel, H.; Kaschek, M.; Blöcher, C.; Noronha, M.; Mavrov, V. (2002). Concepts for the Treatment of Spent Process Water in the Food and Beverage Industries. Desalination, v. 152, p. 307-314.

Chobert, J.M.; Bertrand-Harb, C.; Nicolas, M.G. (1988). Solubility and emulsifying properties of caseins and whey proteins modified enzymatically by trypsin. J. Agric. Food Chem., v, 36, p. 883-886.

Chun, H. H.; Kim, J. Y.; Lee, B. D.; Yu, D. J.; Song, K. B. (2010). Effect of UV-C irradiation on the inactivation of inoculated pathogens and quality of chicken breast during storage. Food Control, v. 21, p. 276-280.

Chung, S. L.; Ferrier, L. K. (1992). pH and sodium chloride effects on emulsifying properties of egg yolk phosphovitin. Journal of Food Science, v. 57, p. 40-42. 
References

Chung, R. A.; Stadelman, W. J. (1965). A study of variations in the structure of the hen's egg. British Poult. Sci., v. 6,p. 277-282.

Cieminis, K. G. K.; Ranelien, V. M.; Prijalgauskien, A. J.; Tiunaitien, N. V.; Rudzianskait, A. M.; Janys, Z. J. (1987). Chromosome and DNA Damage and Their Repair in Higher Plants Irradiated with Short-Wave Ultraviolet Light. Mutation Research/Fundamental and Molecular Mechanisms of Mutagenesis, v. 181, n. 1, p. 9-16.

Clark, D. C.; Kiss, I. F.; Wilde, P. J.; Wilson, D. R. (1992). The effect of irradiation on the functional properties of spray-dried egg white. Poult. Sci., v. 47, p. 1481-1487.

Clarkson, J. R.; Cui, Z. F. ; Darton, R. C. (1999). Protein denaturation in foam. Journal of Colloid and Interface Science, v. 215, p. 323-332.

Code of Federal Regulations.(2005).Title 9, volume 2, 590.570. U.S. Government Printing Office. Washington, DC.

Corrales, M.; Souza, P. M.; Stahl, M. R. ; Fernandez, A. (2012). Effects of the decontamination of a fresh tiger nuts' milk beverage (horchata) with short wave ultraviolet treatments (UV-C) on quality attributes. Innovative Food Science and Emerging Technologies, v. 13, p. 163-168

Cordobés, F.; Partal, P.; Guerrero, A. (2004). Rheology and microstructure of heat-induced egg yolk gels. Rheol Acta, v. 43, p.184-195

Coufal, C.; Chavez, C.; Knape, K.; Carey, J. (2003). Evaluation of a method of ultraviolet light sanitation of broiler hatching eggs. Poult. Sci., v. 82, p.754-759.

Croguennec, T.; Nau, F.; Brulé, G. (2002). Influence of pH and salts on egg white gelation. J. Food Sci., v. 67, p. 608-614.

Daughtry, B.; Sumner, J.; Hooper, G.; Thomas, C.; Grimes, T.; Horn, R.; Moses, A.;Pointon, A. (2005). National Food Safety Risk Profile of Eggs and Egg Product (A report for the Australian Egg Corporation Limited), AECL Publication, n.05/06, Australia. 
Davey, E. M.; Zabik, M.E. ; Dawson, L. E. (1969). Fresh and frozen egg yolk fractions; emulsion stabilizing power viscosity and electrophoretic patterns. Poult. Sci., v. 48, p. 251-260.

Davis, P. J.; Willians, S. C. (1998). Protein modification by thermal processing. Allergy, v. 53, n. 146, p. 102-105.

Dean, W. R. (1927). Motion of fluid in a curved pipe. Philosophical Magazine and Journal of Science, v. 4, p. 15.

Desert, C.; Guerin-Dubiard, C.; Nau, F.; Jan, G.; Val, F.; Mallard, J. (2001). Comparison of Different Electrophoretic Separations of Hen Egg White Proteins. Agriculture and Food Chemistry, v. 49, p. 4553-4561.

Dickinson, E. (1986). Emulsions. Annual Reports in the Progress of Chemistry, Royal Society of Chemistry, London. Section C. p. 31-58.

Dickinson, E. (1992). An Introduction to Food Colloids. Oxford University Press, Oxford.

Donahue, D. W.; Canitez, N.; Bushway, A. A. (2004). UV inactivation of $E$ coli $\mathrm{O} 157: \mathrm{H7}$ in apple cider: quality, sensory and shelf-life analysis. Journal of Food Processing and Preservation, v. 28, p. 368-387

Douglas, F. W.; Greenberg, R.; Farrell, H. M.; Edmondson, F. (1981). Effects of Ultra-High-Temperature Pasteurization on Milk Proteins. J. Agric. Food Chem., v. 29, p. 11-15.

Doulia, D.; Katsinis, G.; Mougin, B. (2000). Prolongation of the microbial shelf life of wrapped part baked baguettes. International Journal of Food Properties, v. 3, n. 3, p.447-457.

Dutcosky, S. D. (1996). Análise sensorial de alimentos. Curitiba: Champagnat, $126 \mathrm{p}$.

Dvorak, P.; Kunova, J.; Strakova, E.; Suchy, P.; Kunova, V. (2005). Changes in the color and the acidity number of egg yolk upon 
References

irradiation. European Food Research and Technology, v. 221, p. 348350 .

Ebel, E.; Schlosser, W. (2000). Estimating the annual fraction of eggs contaminated with Salmonella enteritidis in the United States. Int J Food Microbiol, v. 61, n. 1, p. 51-62.

EFSA. (2010). European Food Safety Authority. Analysis of the baseline survey on the prevalence of Campylobacter in broiler batches and of Campylobacter and Salmonella on broiler carcasses in the EU, 2008 Part A: Campylobacter and Salmonella prevalence estimates. EFSA Journal, v. 8,n. 3, p.1503.

Elliot, J. H.; Ganz, A. J. (1975). Gel characterization with the weissenberg rheogoniometer: Application to carrageenan gels. Journal of Food Science, v. 40, p. 394-398.

Elyasi, S.; Taghipour, F. (2006). Simulation of UV Photoreactor for Water Disinfection in Eulerian Framework. Chemical Engineering Science, v. 61, n.14. p. 4741-4749.

Emenhiser, C.; Sander, L.; Schwartz, S. (1995). Capability of a polymeric C30 stationary phase to resolve cis-trans carotenoid isomers in reversedphase liquid chromatography. Journal of Chromatography A, v. 707, n. 2, p. 205-216.

Egg Nutrition Center. 2004. Egg protein fact sheet. Available from: http://www.enc-online.org/factsheet/EggProtein.pdf. Accessed in: February $28^{\text {th }}, 2009$.

European Pharmacopoeia. (2005a). Ascorbic acid: vitamin C. 01/2005:0253 European Pharmacopoeia, 5th Edition.

European Pharmacopoeia. (2005b). Pantothenic acid: vitamin $\mathrm{B}_{5}$. 01/2005:0470 European Pharmacopoeia, 5th Edition.

European Pharmacopoeia (2005c). Riboflavin: vitamin B B $_{2}$ 01/2005:0292. European Pharmacopoeia, 5th Edition. 
Food Safety Autority. (2007). Microbiological criteria for foodstuffs. European Regulation CEE 1441/2007.

Falguera, J. P.; Garza, S.; Garvín, A.; Ibarz, A. (2011). Ultraviolet processing of liquid food: A review: Part 2: Effects on microorganisms and on food components and properties. Food Research International, v. 44 , n. 6 , p. $1580-1588$.

Fan, X.; Geveke, D. J. (2007). Furan Formation in Sugar Solution and Apple Cider upon Ultraviolet Treatment. J. Agric. Food Chem., v. 55, p. 7816-7821.

Farkas, J. (1998). Irradiation as a method for decontaminating food A review. International Journal of Food Microbiology, v. 44, p. 189-204.

Fauquet, C. M.; Mayo, M. A.; Maniloff, J.; Desselberger, U.; Ball, L.A. (2004). Virus taxonomy VIIIth report of the International Committee on Taxonomy of Viruses. San Diego: Academic Press. 1162 p.

Favier, G.; Escudero, M.; De Guzman, A. (2001). Effect of Clorine, Sodium Chloride, Trisodium Phosphate and Ultraviolet Radiation on the Reduction of Yersinia enterocolitica and Mesophilic Aerobic Bacteria from Eggshell Surface. Journal of Food Protection, v. 64, n.10, p. 16211623.

FDA. (2000a). Food labeling, safe handling statements, labeling of shell eggs; refrigeration of shell eggs held for retail distribution; Final rule. v. 65, n. 234, p. 76092-76110. Fed. Regist. Washington DC.

FDA. 2000b. Irradiation in the production, processing and handling of food; Final rule. v.65, n. 141, p. 45280-82. Fed. Regist. Washington, DC.

FDA. (2009). Food Code 2009: Annex 3 - Public Health Reasons / Administrative Guidelines - Chapter 3, Food

Ferreira, M.; Hofer, C.; Raemy, A. (1997). A calorimetric study of egg white proteins. Journal of thermal analysis, v. 48, p. 683-690. 
References

Fletouris, D.J.; Botsoglou, N.A.; Psomas, I.E.; Mantis, A.I. (1998). Rapid determination of cholesterol in milk and milk products by direct saponification and capillary gas chromatography. Journal of Daily Science,v. 81, p. 2833-2840.

Foregeding, E. A.; Luck, P.J.; Davis, J. P. (2006). Factors Determining the Physical Properties of Protein Foams. Food Hydrocolloids, v. 20, p. 284292.

Fonseca, J. M.; Rushing, J. W. (2006). Effect of ultraviolet-C light on quality and microbial population of fresh-cut watermelon. Postharvest Biol. Technol., v. 40,p. 256-261.

Forsythe, R. H. (1957). Some factors affecting the use of eggs in the food industry. Cereal Science Today, v.2, p. 211-216.

Forsyre, P. (1970) cited in Hamid-Samimi et al., (1984). Hamid-Samimi, M.H.; Swartzel, K.R.;Ball, H.R. (1984). Flow behavior of liquid whole egg during thermal treatments. Journal of Food Science, v. 49, p. 132136.

Franz, M. A. P. C.; Specht, I.; Cho, G. S.; Graef, V.; Stahl, M. (2009). UV$\mathrm{C}$-inactivation of microorganisms in naturally cloudy apple juice using novel inactivation equipment based on Dean vortex technology. Food Control, v. 20, p. 1103-1107.

Froning, G. W.; Peters, D.; Muriana, P.; Eskridge, K.; Travniceck, D.; Summer, S. S. (2001). International egg pasteurization manual. United Egg Association and American Egg Board. Available from: http://www.aeb.org/EggProducts/documents/EggPast.Manual.pdf. Acessed in: February 29 2012.

Froning, G. W.; Peters, D.; Muriana, P.; Eskridge, K.; Travnicek, D.; Sumner, S.S. (2002). International Egg Pasteurization Manual. United Egg Association, Alpharetta, p. 5-12.

Fucci, L.; Oliver, C. N.; Coon, M. J.; Stadtman, E. R. (1983). Inactivation of key metabolic enzymes by mixed-function oxidation reactions: 
Possible implication in protein turnover and ageing, Proc. Natl. Acad. Sci. USA, v. 80, p. 1521-1525.

Fuhrmann, H.; Rupp, N.; Buchner, A.; Braun,P. (2010). The effect of gaseous ozone treatment on egg components Journal of the Science of Food and Agriculture, v. 90, p. 593-598.

García, A. F.; Butz, P.; Bognàr, A.; Tauscher, B. (2001). Antioxidative capacity, nutrient content and sensory quality of orange juice and an orange-lemon-carrot juice product after high pressure treatment and storage in different packaging. European Food Research and Technology, v. 213, p. 290-296.

Gardner, D.W.M.; Shama, G. (1999). UV intensity measurement and modelling and disinfection performance prediction for irradiation of solid surfaces with UV light. Food Bioprod. Proc., v. 77, n. C3, p. 232242.

Garibaldi, J. A.; Straka, R. P.; Liichi, K. (1969). Heat resistance of Salmonella in various egg products. Applied Microbiology, v. 17, p. 491-496.

Garland, T. D. (1973). Studies on egg yolk myelin figures and granule lowdensity lipoproteins. PhD thesis, University of British Columbia (Canada).

Gast, R.K.; Beard, C.W. (1990). Production of Salmonella enteritidiscontaminated eggs by experimentally infected hens. Avian Dis., v.34, p. 438-446.

Gast, R. K.; Holt, P. S. (2001). Assessing the frequency and consequences of Salmonella enteritidis deposition on the egg yolk membrane. Poult Sci., v. 80, n.7, p. 997-1002.

Geeraerd, A. H.; Valdramidis, V. P.; Van Impe, J. F. (2005). GInaFiT, a freeware tool to assess non-log-linear microbial survivor curves. International Journal of Food Microbiology, v. 102, p. 95-105. 
References

Geeraerd, A.H.; Herremans, C.H.; Van Impe, J.F. (2000). Structural model requirements to describe microbial inactivation during a mild heat treatment. International Journal of Food Microbiology, v.59, p. 185209.

Geveke, D. J. (2005). UV inactivation of bacteria in apple cider. Journal of food protection, v. 68, p. 1739-1742.

Geveke, D. J. (2008). UV inactivation of E. coli in liquid egg white. Food Bioprocess Technology, 1, 201-206.

Giese, G. (1964) cited in Bintsis et al., (2000). Bintsis, T.; LitopoulouTzanetaki, E.; Robinson, R. (2000). Existing and potencial applications of ultraviolet light in the food industry - a critical review. Journal of the Science of Food and Agriculture, v. 80,p. 637-645.

Giese, N.; Darby, J. (2000). Sensitivity of Microorganisms to Different Wavelengths of UV Light: Implications on Modeling of Medium Pressure UV Systems. Water Resources, v. 34. p. 4007-4013.

Góngora-Nieto, M.M.; Pedrow, P.D.; Swanson, B.; Barbosa-Cánovas, G.V. (2003). Energy Analysis of Liquid Whole Egg Pasteurized by Pulsed Electric Fields. Journal of Food Engineering, v. 57, p. 209-216.

Gonzales, L.G.; Geeraerdc, A.H.; Elst, K.; Van Ginnekena, L.; Van Imped, J.F.; Devlieghere, F. (2009). Inactivation of naturally occurring microorganisms in liquid whole egg using high pressure carbon dioxide processing as an alternative to heat pasteurization. Journal of Supercritical Fluids, v. 51, p. 74-82.

Gossett, P. W.; Rizvi, S. S. H.; Baker, R. C. (1983). Selected rheological properties of $\mathrm{pH}$-adjusted or succinylated egg albumen. Journal of Food Science, v. 48, p. 1395-1399.

Graham, D. E.; Phillips, M. C. J. (1979). Colloid Interface Sci., v. 75, p. 403-414. 
Green, F.B.; Lundquist, T. J.; Oswald, W.J. (1995). Energetics of Advanced Integrated Wastewater Pond Systems. Water Science and Technology, v. 31, n. 12 , p. $9-20$.

Guedes, A. M. M.; Novello, D.; Mendes, G. M. P.; Cristianini, M. (2009). Tecnologia de ultravioleta para preservação de alimentos. B.CEPPA, Curitiba, v. 27, n. 1, p. 59-70.

Guerrero-Beltran, J. A.; Barbosa-Canovas, G. (2004). Review: advantages and limitations on processing foods by UV light. Food Science and Technology International, v.10, p. 137-147.

Guerrero-Beltran, J. A.; Barbosa-Canovas, G. V. (2005). Reduction of Saccharomyces cerevisiae, Escherichia coli and Listeria innocua in apple juice by ultraviolet light. Journal of Food Process Engineering, v. 28 , n. 5 , p. 437-452.

Guerrero-Beltran, J. A.; Barbosa-Canovas, G. V. (2006). Inactivation of Saccharomyces cerevisiae and polyphenoloxidase in mango nectar treated with UV light. Journal of Food Protection,v. 69, n. 2, p. 362-368.

Guevara, M.; Tapia, M. S.; Gómez-Lòpez, V. M. (2011). Microbial Inactivation and Quality of Guava and Passion Fruit Nectars Treated by UV-C Light. Food and Bioprocess Technology, v. 5, n. 2, p. 803-807.

Guilmineau, F.; Krause, I.; Kulozik, U. (2005). Efficient Analysis of Egg Yolk Proteins and Their Thermal Sensitivity Using Sodium Dodecyl Sulfate Polyacrylamide Gel Electrophoresis under Reducing and Nonreducing Conditions. J. Agric. Food Chem., v. 53, p. 9329-9336.

Günter, E.A.; Kapustina, O.M.; Popeyko, O.V.; Ovodov, S. (2007). Influence of ultraviolet-C on the compositions of cellwall polysaccharides and carbohydrase activities of Silene vulgaris callus. Carbohydrate Research, v. 342, p.182-189.

Gut, J.A.W.; Pinto, J.M.; Gabas, A.L.; Telis-Romero, J. (2005). Continuous Pasteurization of Egg Yolk: Thermophysical Properties and Process Simulation. Journal of Food Process Engineering, v. 28, p. 181-203. 
References

Haines, R.B. (1939). Microbiology in the preservation of the hen's egg. Rept. Food Invest. Bd, Lond. n. 47. London: H.M.S.O.

Hamid-Samimi, M.H.; Swartzel, K.R. (1985). Maximum Change in Physical and Quality Parameters of Fluid Foods During Continuous Flow Heating: Application to Liquid Whole Egg. Journal of Food Processing and Preservation, v. 8, p. 225-239.

Hanes, D. E.; Worobo, R. W. ; Orlandi, P. A. ; Burr, D. H. ; Miliotis, M. D.; Robl, M. G. (2002). Inactivation of Cryptosporidium parvum oocysts in fresh apple cider by UV irradiation. Applied and Environmental Microbiology, v. 68, p.4168-4172.

Harrington, W. O.; Hills, C. H. (1968). Reduction of the microbial population of apple cider by ultraviolet irradiation. Food Technology, v. 22. p. $117-120$.

Hassen, A., , Mahrouk, M., Ouzari, H., Cherif, M., Boudabous, A. and, Damelincourt, J.J. 2000. "UV Disinfection of Treated Wastewater in A Large-Scale Pilot Plant and Inactivation of Selected Bacteria in A Laboratory UV Device”, Bioresource Technology, Vol. 74, pp. 141-150.

Hermawan, N.; Dantzer, W.; Zhang, Q. H. (2004). Pulsed electric field treatment of liquid whole egg inoculated with Salmonella enteritidis. Journal of Food Safety, v. 24, p. 71-85.

Huang, E., Mittal, G. S., \& Griffiths, M. W. (2006). Inactivation of Salmonella enteritidis in liquid whole egg using combination treatments of pulsed electric field, high pressure and ultrasound. Biosystems Engineering, 4, 403-413.

Humphrey, T.J., A. Baskerville, S. Mawer, B. Rowe, and S. Hopper. 1989. Salmonella enteritidis phage type 4 from the contents of intact eggs: a study involving naturally contaminated hens' eggs. Epidemiol. Infect. 103:415-423. 
Humphrey, T.J., A. Whitehead, A.H.L. Gawler, A. Henley, and B. Rowe. 1991. Numbers of Salmonella enteritidis in the contents of naturally contaminated hens' eggs. Epidemiol. Infect. 106:489-496.

Humphrey, T.J. 1994. Contamination of egg shell and contents with Salmonella enteritidis: a review. Int. J. Food Micro. 21:31-40.

Hope BK, Baker R, Edel ED, Hogue AT, Schlosser WD, Whiting R, McDowell RM, Morales RA. 2002. An overview of the Salmonella Enteritidis risk assessment for shell eggs and egg products. Risk Anal 22(2):203-18.

Hsieh, Y. L.; Regenstein, J. M. (1992). Modeling.gelation of egg albumen and ovalbumin. J. Food Sci., 57, 856-861.

Hou H, Singh RK, Muriana PM, Stadelman WJ. 1996. Pasteurization of intact shell eggs. Food Microbiol 13(2):93-101.

Hutchinson, M.L., J. Gittins, A. Walker, A. Moore, C. Burton, and N. Sparks. 2003. Washing table eggs: a review of the scientific and engineering issues. World's Poult. Sci. J. 59:233-248.

Ibanoglu, E.; Erçelebi, E. A. (2007). Thermal denaturation and functional properties of egg proteins in the presence of hydrocolloid gums. Food Chemistry, v. 101, p. 626-633.

ICMSF. (2005). International commission on microbiological specifications for foods. Eggs and egg products. Microorganisms in Foods 6: Microbial Ecology of Food Commodities. Kluwer Academic/Plenum Publishers, New York, p. 597-632.

Ijichi, K.; Hammerle, O. A.; Lineweaver, H.; Kline, L. (1964). Effects of ultraviolet irradiation of egg liquids on Salmonella destruction and performance quality with emphasis on egg white. Food Technology, v. 10, p. 1628.

Isiker G.; Gurakan G.C.; Bayindirli A. (2003). Combined effect of high hydrostatic pressure treatment and hydrogen peroxide on Salmonella 
References

enteritidis in liquid whole egg. European Food Research and Technology, v. 217, p. 244-248.

Jaekel, T.; Ternes, W. (2009). Changes in rheological behavior and functional properties of hen's egg yolk induced by processing and fermentation with phospholipases. International Journal of Food Science and Technology, v. 44, p. 567-573.

Jambrak, A. R.; Lelas, V.; Mason, T. J.; Kresic, G.; Badanjak, M. (2009). Physical properties of ultrasound treated soy proteins. J. Food Eng., v. 93, p. 386-393.

Jin, T.; Zhang, H.; Hermawan, N.; Dantzer, W. (2009). Effects of pH and temperature on inactivation of Salmonella typhimurium DT104 in liquid whole egg by pulsed electric fields. International Journal of Food Science and Technology, v. 44, p. 367-372.

Joint FAO/WHO (1989). London: Food Standard Program Recommended International Standards.

Jones, D.R.; Curtis, P. A.; Anderson, K.E.; Jones, F.T. (2004). Microbial contamination in inoculated shell eggs: II. Effects of layer strain and egg storage. Poult. Sci., v. 83, p. 95-100.

Katusin-Razem, B.; Mihaljevic, B.; Razem, D. (1992). Radiation-induced oxidative chemical changes in dehydrated egg products. Journal of Agricultural and Food Chemistry, v. 40, p. 662-668.

Keller, L. H.; Benson, C. E.; Krotec, K.; Eckroade, R. J. (1995). Salmonella enteritidis colonization of the reproductive-tract and forming and freshly laid eggs of chickens. Infect Immun,v. 63, n.7, p. 2443-2449.

Kenny, O.; O’Callaghan, Y.; O'Brien. (2008). Effects of Ingredient Incorporation into Sausage Meat on the Micellarisation and uptake of $\alpha$ tocopherol by Caco-2 Human Intestinal Cells. Food Science and Technology International, v. 14, n. 1, p. 79-86. 
Keyser, M.; Müller, I. A.; Cilliers, F. P.; Nel, W.; Gouws, P. (2008). Ultraviolet radiation as a non-thermal treatment for the inactivation of microorganisms in fruit juice. Innovative Food Science and Emerging Technologies, v. 9, p. 348-354.

Kim, S. K.; Nawar, W. W. (1993). Parameters influencing colesterol oxidation. Lipids,v. 28, p. 917-921.

Kiosseoglou, V. D.; Sherman, P. (1983). The influence of egg yolk lipoproteins on the rheology and stability of $\mathrm{O} / \mathrm{W}$ emulsions and mayonnaise 2. Interfacial tension-time behavior of egg yolk lipoproteins at the groundnut oil-water interface. Colloid \& Polymer Sci., v. 261. p. 502-507.

Kitabatake, N.; Doi, E. (1987). Conformational change of hen egg ovalbumin during foam formation detected by 5, 5'-dithiobis (2nitrobenzoic acid). J. Agric. Food Chem., v. 35. p. 953-957.

Koivunen, J.; Heinonen-Tanski, H. (2005). Inactivation of enteric microorganisms with chemical disinfectants, UV irradiation and combined chemical/UV treatments. Water Res., v. 39, p. 1519-1526.

Koutchma, T.; Kellerb, S.; Chirtelc, S.; Paris, B. (2004). Ultraviolet disinfection of juice products in laminar and turbulent flow reactors. Innovative Food Science and Emerging Technologies, v. 5, p. 179-189.

Koutchma, T. B.; Parisi, B.; Patazca, E. (2007). Validation of a UV coiled tube reactor for fresh fruit juices. Journal of Environmental Engineering Science, v. 6, p. 319-328.

Koutchma, T. (2009). Advances in Ultraviolet Light Technology for Nonthermal Processing of Liquid Foods. Food and Bioprocess Technology, v. 22, p. 138-155.

Kuan, Y. H.; Bath, R.; Karim, A. A. (2011). Emulsifying and Foaming Properties of Ultraviolet-Irradiated Egg White Protein and Sodium Caseinate. J. Agric. Food Chem., v. 59, p. 4111-4118. 
References

Kuhn, H. J.; Braslavsky, S. E.; Schmidt, R. (2004). Chemical actinometry (IUPAC technical report). Pure and Applied Chemistry, v. 76, p. 21052146.

Kuo, F. L.; Ricke, S.C.; Carey, J. B. (1997). UV irradiation of shell eggs: effect on populations of aerobes, moulds, and inoculated Salmonella typhimurium. J Food Prot, v. 60, p. 639-643.

Kusunoki, T. (1983). Growth. In: The Reading Book of New Nutrition (ed by K. Hosoya), p. 150-155. Japan Review Company, Tokyo.

Laemmli, U.K. (1970). Cleavage of structural proteins during the assembly of the head of bacteriophage T4. Nature, v. 277, p. 680-685.

Lage, C.; Teixeira, P.C.N.; Leitao, A.C. (2003). Non-Coherent Visible and Infrared Radiation Increase Survival to UV (254 nm) in Escherichia coli K12. Journalof Photochemistry and Photobiology B: Biology, v. 54, p. 155-161.

Laguerre, J. C.; Widehem, P. G.; Marier, D.; Onillon, E.; Lamia, A. A.; Aragon, I. B. (2011). The impact of microwave heating of infant formula model on neo-formed contaminant formation, nutrient degradation and spore destruction. Journal of Food Engineering, v. 107, p. 208-213.

Lagunas-Solar M.C.; Zeng, N.X.; Essert, T. K.; Truong, T. D.; Piña, C. U. (2006). Radiofrequency power disinfects and disinfests foods, soils and wastewater. California Agriculture, v. 60,n. 4, p. 191-199.

Lai, L.S. (2006). Quality and Safety of Frozen Eggs and Egg Products. Handbook of Frozen Food Processing and Packaging. Taylor and Francis LLC, Boca Raton, p.503-516.

Lai, K. M.; Chuang, Y. S.; Chou , Y. C.; Hsu , Y. C.; Chenge, Y. C.; Shi , C. Y.; Chi , H. Y.; Hsu, K. C. (2010). Changes in physicochemical properties of egg white and yolk proteins from duck shell eggs due to hydrostatic pressure treatment. Poultry Science, v. 89, p. 729-737. 
Lamikanr, O. ; Kueneman, D.; Ukuku, D.; Bett-Garber, K. L. (2005). Effect of processing under ultraviolet light on the shelf life of fresh-cut cantaloupe melon. J. Food Sci., v. 70, p. $534-539$.

Lazarova, V.; Janex, M.L.; Fiksdal, L.; Oberg, C.; Barcina, I.;Pommepuy, M. (1998). Advanced Wastewater Disinfection Technologies: Short and Long Term Efficiency. Water Science and Technology, v. 38, n. 12, p. 109-117.

Lee, D. U.; Heinz, V.; Knorr, D. (2001). Biphasic inactivation kinetics of Escherichia coli in liquid whole egg by high hydrostatic pressure treatments. Biotechnology Progress, v. 17, p. 1020-1025.

Lee, D. U.; Heinz, V.; Knorr, D. (2003). Effects of combination treatments of nisin and high-intensity ultrasound with high pressure on the microbial inactivation in liquid whole egg. Innovative Food Science and Emerging Technologies, v. 4, p. 387-393.

Lee, D. U.; Heinz, Y.; Knorr, D. (1999). Evaluation of Processing Criteria for the High Pressure Treatment of Liquid Whole Egg: Rheological Study. Lebensm.-Wiss. u.-Technol., v. 32, p. 299-304.

Lehtola, M. J.; Miettinen, I.T.; Lampola, T.; Hirvonen, A.; Vartiainen, T.; Martikainen, P. J. (2004). Pipeline Materials Modify the Effectiveness of Disinfectants in Drinking Water Distribution Systems. Water Research, v. 39, p. 1962-1971.

Li-Chan, E. C. Y.; Powrie, W. D. ; Nakai, S. (1995). The chemistry of eggs and egg products. In: Egg science and technology. Stadelman, W. J. and Cotterill, O. J., editors. 2nd ed. Binghamton, NY: The Haworth Press, Inc. p 105-175.

Liltved, H.; Landfald, B. (2000). Effects Of High Intensity Light on Ultraviolet- Irradiated and Non-Irradiated Fish Pathogenic Bacteria. Water Research, v. 34, n. 2, p. 481-486. 
References

Liu, L.Y.; Yang, M. H.; Lin, J. H.; Lee, M. H. (2005). Lipid profile and oxidative stability of commercial egg products. Journal of Food and Drug Analysis, v. 13, p. 78-83.

Liu, X. D.; Han, R. X.; Yun, H.; Jung, K. C.; Jin, D. I.; Lee, B. D.; Min, T. S.; Jo, C. (2009). Effect of irradiation on foaming properties of egg white proteins. Poultry Science, v. 88. p. 2435-2441.

Little, C. L.; Surman-Lee, S.; Greenwood, M.; Bolton, F. J.; Elson, R.; Mitchell, R. T. (2007). Public health investigations of Salmonella enteritidis in catering raw shell eggs, 2002-2004. Letters in Applied Microbiology, v. 44, p. 595-601.

Li, B.; Logan, B. E. (2004). Bacterial adhesion to glass and metal-oxide surfaces. Colloids and Surfaces B: Biointerfaces, v. 36, p. 81-90.

Lopez-Malo, A.; Palou, E. (2002). Ultraviolet light and food preservation. In G. Barbosa-Cánovas, M. S. Tapia and P. Cano (Eds.), Novel food processing technologies (p. 405-422). Boca Raton, USA: CRC Press.

López-Malo, A.; Palou, E. (2005). Ultraviolet light and food preservation. In: Barbosa-Cánovas, G.; Tapia,M. S.; Cano, P. Novel food processing technologies. New York: CRC. Chap. 18.

Lowry, O. H. ; Rosenbrough, N. J.; Randall, R. J.(1951). Protein measurement with the folin phenol reagent. J. Biol. Chem., v. 193, p. 265-275.

Lucas, J. (2003). Integrating MAP with new germicidal techniques. In: Ahvenainen, R. Novel food packaging techniques. Boca Ratón, Flórida: CRC. Chap. 15.

Lyon, S. A. ; Fletcher, D. L. ; Berrang, M. E. (2007). Germicidal Ultraviolet Light to Lower Numbers of Listeria monocytogenes on Broiler Breast Fillets. Poult. Sci., v. 86, n. 5, p. 964-967.

Ma, C. Y.; Sahasrabundhe, M. R.; Poste, L. M.; Harwalkar, V. R.; Chambers, J. R. (1990). $\gamma$ irradiation of shell eggs: internal and sensory 
quality, physicochemical characteristics, and functional properties. Can. Inst. Food Sci. Technol. J., v. 23, p. 226-232.

Ma, L.; Chang, F. J.; Barbosa-Canovas, G.V.; Swanson, B. G. (1997). Inactivation of E.coli in Liquid Whole Eggs Using Pulsed Electric Fields Technology. In: Barbosa-Canovas (Ed.) New frontiers in food engineering. New York, AIChE.

Mafart, O. ; Couvert, S. ; Gaillard, O.; Leguerinel, I. (2002). On calculating sterility in thermal preservation methods: application of the Weibull frequency distribution model. International Journal of Food Microbiology, v. 72, p. 107-113.

Manzoco, L.; Pieve, S.; Bertolini, A.; Bartolomeoli, I.; Maifreni, M.; Vianello, A.; Nicoli, M. C. (2011). Surface decontamination of fresh-cut apple by UV-C light exposure: Effects on structure, color and sensory properties. Postharvest Biology and Technology, v. 61, p. 165-171.

Mañas, P.; Pagán, R.; Alvarez, I.; Usón, S.C. (2003). Survival of Salmonella senftenberg $775 \mathrm{~W}$ to Current Liquid Whole Egg Pasteurization Treatments. Food Microbiology, v. 20, n. 5, p. 593-600.

Marion, J. E.; Woodroof, J. G.; Cook, R. E. (1965). Some physical and chemical properties of eggs from hens of five different stocks. Poultry Science, v. 44, p. 522-534.

Marnett, L. J. (1999). Lipid peroxidation-DNA damage by malondialdehyde. Mutation research,v. 8, n. 424, i. 1-2, p. 83-95.

Masschelein, J.; Debacker, E.; Chebak, S. (1989). Laboratory investigations on the disinfection of water by UV-light. Rev. Sci. Eau., v. 2, p. 29-41.

Matak, K. E.; Churey, J. J.; Worobo, R. W.; Sumner, S. S.; Hovingh, E.; Hackney, C. R.; Pierson, M. D. (2005). Efficacy of UV Light for the Reduction of Listeria monocytogenes in Goat's Milk", Journal of Food Protection, v. 68, p. 2212-2216. 
References

Mayer-Miebach, E.; Spieß, W.E.L. (2003). Influence of cold storage and blanching on the carotenoid content of Kintoki Carrots. J. Food Eng., v. 56, p. 211-213.

McCormick, A. M.; Napoli, J. L.; DeLuca, H. F. (1980). High-pressure liquid chromatography of vitamin A metabolites and analogs. Methods in Enzymology, v. 67, part F. Edited by DB McCormick, LD Wright, New York, Academic Press, p. 220-233.

McKinney, J.M.; Willians, R.C.; Boardman, G.D.; Eifert, J.D.; Sumner, S.S. (2009). Effect of acid stress, antibiotic resistance, and heat shock on the resistance of Listeria monocytogenes to UV light when suspended in distilled water and fresh brine. Journal of food protection, v. 72, n. 8, p. 1634-1640.

Miller, R.; Jeffrey, W.; Mitchell, D.; Elasri, M. (1999). Bacterial Responses to Ultraviolet Light. ASM news, v. 65, p. 534-541.

Min, B.R.; Nam, K.C.; Lee, E.J.; Ko, G.Y.; Trampel D.W.; Ahn, D.U. (2005). Effect of irradiating shell eggs on quality attributes and functional properties of yolk and white. Poultry Science, v. 84, p. 17911796.

Mine, Y. (1995). Recent advances in the understanding of egg white protein functionally. Trends in Food Science and Technology, v. 6, p. 225- 231.

Morowitz, H. J. (1950). Absorption effects in volume irradiation of microorganisms. Science, v. 111, p. 229-230.

Morris, A.; Barnett, A.; Burrows, O. J. (2004). Effect of Processing on Nutrient Content of Foods. Pan American Health Organization, CFNI Caribbean Food and Nutrition Institute, v. 37, p. 3.

Moan, J. (1989). Effects of UV Radiation on Cells. Journal of Photochemistry and Photobiology B: Biology, v. 4., n. 1, p. 21-34. 
Monfort, S.; Gayan, E.; Raso, J.; Condon, S.; Alvarez, I. (2010). Evaluation of pulsed electric fields technology for liquid whole egg pasteurization. Food Microbiology, v. 27, p. 845-852.

Mousseron-Canet, M. (1979). Photochemical transformation of vitamin A. Methods in Enzymology, vol XVIII, part C. Edited by DB McCormick, LD Wright, New York, Academic Press, p. 591-615.

Muller, F. L.; Lustgarten, M. S.; Jang, Y.; Richardson, A.; Van Remmen, H. (2007). Trends in oxidative aging theories. Free Radic. Biol. Med., v. 43, p. 477-503.

Müller, A.; Stahl, M.; Graef, V.; Franz, C. M. A. P.; Huch, M. (2011). UV$\mathrm{C}$ treatment of juices to inactivate microorganisms using Dean vortex technology. Journal of Food Engineering, v. 107, p. 268-275.

Muriana, P. M. (1997). Effect of $\mathrm{pH}$ and hydrogen peroxide on heat inactivation of Salmonella and Listeria in egg white. Food Microbiology, v. 14, p. 11-19.

Mizutani, R.; Nakamura, R. (1984). Emulsifying properties of egg yolk low density lipoprotein (LDL)comparison with bovine serum albumin and egg lecithin Lebensmittel-Wissenschaft and Technology, v. 17, p. 213216.

Mizutani, R.; Nakamura, R. (1985). Physical state of the dispersed phases of emulsions prepared with egg yolk low density lipoprotein and bovine serum albumin Journal of Food Science, v. 50, p. 1621-1623.

Murakami, E. G.; Jackson, L.; Madsen, K.; Schickedanz, B. (2006). Factors affecting the ultraviolet inactivation of Escherichia coli K12 in apple juice and a model system. Journal of Food Process Engineering, v. 29, n. 1, p. 53-71.

Murcia, M. A.; Tomé, M. M.; Cerro, I.; Sotillo, F.; Ramirez, A. (1999). Proximate composition and vitamin E levels in egg yolk: losses by cooking in a microwave oven. J Sci Food Agric, v. 79, p. 1550-1556. 
References

Muruganandham, M.; Swaminathan, M. (2004). Photochemical oxidation of reactive azo dye with $\mathrm{UV}-\mathrm{H}_{2} \mathrm{O}_{2}$ process. Dyes and Pigments, v. 62, p. 269-275.

Nelis, H. J.; De Bevere, V. O. R. C.; De Leenheer, A. P. (1985). Vitamin E: tocopherols and tocotrienols, in Modern Chromatographic analysis of the Vitamins, Ch Ed by De Leeheer AP, Lambert WE and de Ruyter MGM, Marcel Dekker, New York. p. 129.

Németh, C.; Horváth, K. ; Drobecz, A. ; Friedrich, L.; Paztor-Huszar, K.; Balla, C. (2010). Calorimetric study of changes induced by preservatives in liquid egg products. Pol. J. Food Nutr. Sci., v. 60, n. 4, p. 347-352.

Ngati, M.; Smith, J.P.; Cayouette, B. (2006). Kinetics of ultraviolet light inactivation of Escherichia coli $\mathrm{O} 157: \mathrm{H} 7$ in liquid foods. Journal of the Science of Food and Agriculture, v. 83, p. 1551-1555.

Noci, F.; Riener, J.; Walking-Ribeiro, M.; Cronin, D. A.; Morgan, D. J.; Lyng, J. G. (2008). Ultraviolet irradiation and pulsed electric fields (PEF) in a hurdle strategy for the preservation of fresh apple juice. Journal of Food Engineering, v. 85, p. 141-146.

NRC. (1989). National Research Counsil (NRC). (1989). Recommended Dietary Allowances. National Academy of Science, Washington, $10^{\text {th }}$ edition.

Ohata, H; Yomogida, K.; Dohmae, K. (2000). Regulation of proliferation and differentiation in spermatogonial stem cells: the role of the c-kit and its ligant. SCF. Development, v. 127, p. 2125-2131.

Oppenheimer, J. A.; Montgomery, W.; Pasadena, C. A.; Hoagland, J. E.; Laine, J. M.; Jacangelo, J. G.; Bhamrah, A. (1993). Microbial Inactivation and Characterisation of Toxicity and by Products Occurring in Reclaimed Wastewater Disinfected with UV Radiation. Alit Water Environmental Federation Planning of Desalination Operations of Effluent Disinfection Systems, Whippany, NJ, 23-25 May, p. 13. 
Ovobel. (2012). Equipment and engineering for egg processing. Available on: http://www.ovobel.com/ Acessed in: December, $18^{\text {th }}, 2011$.

Padayatty, S. J.; Katz, A.; Wang, Y.; Eck, P.; Kwon, O.; Lee, J. H.; Chen, S.; Corpe, C. (2003). Vitamin C as an antioxidant: evaluation of its role in disease prevention. Journal of the American College of Nutrition, $\mathrm{v}$. 22, n. 1, p. $18-35$.

Palou, E.; Lopez-Malo, A.; Barbosa-Canovas, G. V.; Welti-Chanes, J.; Swanson, G. B. (1999). Polyphenoloxidase activity and color of blanched and high hydrostatic pressure treated banana puree. Journal of Food Science, v. 64, p. 42-45.

Palozza, P.; Serini,S.; Nicuolo, F. D.; Piccioni, E.; Calviello, G. (2003). Prooxidant effects of $\beta$-carotene in cultured cells Molecular. Aspects of Medicine, Fat Soluble Vitamins. Old Molecules with Novel Properties, v. 24 , n. 6 , p. 353-362.

Pearce, K. N.;Kinsella, J. E. (1978).. Emulsifying properties of proteins: evaluation of a turbidimetric technique. J. Agri. Food Chem., v. 26, p. 716-723.

Peldszus, S.; Andrews, S. A.; Souza, R.; Smith, F.; Douglas, I.; Bolton, J.; Huck, P. M. (2003). Effect of Medium-Pressure UV Irradiation on Bromate Concentrations in Drinking Water, A Pilot-Scale Study. Water Research, v. 38, p. 211-217.

Peleg, M. (2000). Microbial survival curves. The reality of flat shoulders and absolute thermal death times. Food Res. Int.,v. 33, p. 531.

Perez, O. E.; Pilosof, A. M. R. (2004). Pulsed electric fields effects on the molecular structure and gelation of b-lactoglobulin concentrate and egg white. Food Research International, v. 37, p. 102-110.

Peterson, G. L. (1977) A simplification of the protein assay method of Lowry et al. which is more generally applicable. Anal Biochem, v. 83, p. 346-356. 
References

PGO. (2011). Präzisions glas \& optik. Selected Float Glass, Transmission. Available on: http://www.pgoonline.com/intl/katalog/curves/whitefl_kurve.html Acessed in: March 13th, 2011.

Phillips, M. C. (1981). Protein conformation at liquid interfaces and its role in stabilizing emulsions and foams. Food Technol., v. 35, p. 50-57.

Philips. (2006). Ultraviolet purification application information. The Netherlands: Philips Lighting B.V. Available on: www.lighting.philips.com/gl_en/global_sites/application/water_purificat ion/pdfs/uvp_application_brochure.pdf Acessed in: March 1 ${ }^{\text {st }}, 2012$.

Pollack, O. J. (1958). Serum cholesterol levels resulting from various egg diets: experimental studies with clinical implications. J Am. Ger. Soc., v. 6 , p. 614-618.

Poggel, M.; Wübben, D. I. M.; Brod, H.; Jenne, M.; Schmidt, S. (2008). UVivatec ${ }^{\circledR}$ - a novel scalable reactor system for pathogenic virus inactivation by UV-C irradiation. In Viral safety for biopharmaceuticals conference, Prague, Czech Republic, 23-24 June.

Pottier, L.; Pruvost, J.; Deremetz, J.; Cornet, J.F.; Legrand, J.; Dussap, C. G. (2005). A Fully Predictive Model for One-Dimensional Light Attenuation by Chlamydomonas reinhardtii in A Torus Photobioreactor. Biotechnology and Bioengineering, v. 91, p. 569-582.

Powrie, W. D.; Nakai, S. (1986). The chemistry of eggs and egg products. In Egg science and technology, 3d ed.Westport, Conn: AVI Publishing Co. p. 97-139.

Puddey, I. B.; Zilkens, R. R.; Croft, K. D. (2003). Antioxidant and prooxidant effects of alcoholic beverages: relevance to cardiovascular disease. In Nutrition and Alcohol: Linking Nutrient Interactions and Dietary Intake. R. R. Watson and V. R. Preedy (Eds.), CRC Press, London, p. 19-40 (chapter 2). 
Punidadas, P.; McKellar, R.C. (1999). Selected Physical Properties of Liquid Egg Products at Pasteurization Temperatures. Journal of Food Processing and Preservation, v. 23, p. 153-168.

Reinemann, D. J.; Gouws, P.; Cilliers, T.; Houck, K.; Bishop, J. R. (2006). New methods for UV treatment of milk for improved food safety and product quality. St. Joseph, Michigan: American Society of Agricultural and Biological Engineers.

Rahn, R. O. (1997a). Potassium Iodide as a chemical actinometer for 254 $\mathrm{nm}$ radiation: use of iodate as an electron scavenger. Photochemistry and Photobiology, v. 66, p. 450-455.

Rahn, R. O. (1997b). Erratum Potassium Iodide as a chemical actinometer for $254 \mathrm{~nm}$ radiation: use of iodate as an electron scavenger. Photochemistry and Photobiology. Photochemistry and Photobiology, v. 66, n. 6, p. 885.

Ramanathan, L.; Das, N. P. (1992). Studies on the control of lipid oxidation in ground fish by some polyphenolic natural products. Journal of Agriculture and Food Chemistry, v. 40, p. 17-21.

Ren, Y. (2009). Oxidative stability of omega-3 polyunsaturated fatty acids enriched eggs. Master's thesis. Master of Science in Food Science and Technology. Department of Agricultural, Food and Nutritional Sciences. University of Alberta: Edmonton, Alberta, Canada.

Reu, K.; Grijspeerdt, K. ; Herman, L.; Heyndrickx, M.; Uyttendaele, M.; Debevere, J.; Putirulan, F. F.; Bolder, N. M. (2006). The effect of a commercial UV disinfection system on the bacterial load of shell eggs. Letters in Applied Microbiology, v. 42, p.144-148.

Ricke, S. C.; Birkjould, S. G.; Gast, R. K. (2001). Eggs and egg products. F.P. Downes, K. Ito (Eds.), Compendium of methods for the microbiological examination of foods, American Public Health Association, Washington, D.D., p. 473-482 
References

Rivas, A.; Rodrigo, D.; Company, B.; Sampedro, F.; Rodrigo, M. (2007). Effects of pulsed electric fields on water-soluble vitamins and ACE inhibitory peptides added to a mixed orange juice and milk beverage. Food Chemistry, v. 104, p. 1550-1559.

Rodriguez-Romo, L. A.; Yousef, A. (2005). Inactivation of Salmonella enterica Serovar enteritidis on shell eggs by ozone and UV radiation. Journal of Food Protection, v. 68, p. 711-717.

Rodriguez-Romo, L. A. (2004). Control of Salmonella enterica serovar Enteritidis in shell eggs by ozone, ultraviolet radiation, and heat. DPhil dissertation. Columbus, OH: The Ohio State University. 186 p. Available from: UMI Microform, Ann Arbor, MI: 3122605.

Romanoff, A. L.; Romanoff, A. J. (1949). The avian egg. John Wiley \& Sons, New York. Second Printing, 1963.

Rumbo, M.; Chirdo, F. G.; Fossati, C. A.; Anon, M. C. (1996). Analysis of structural properties and immunochemical reactivity of heat-treated ovalbumin. Journal of Agricultural and Food Chemistry, v. 44, p. 37933798 .

Rysstad, G.; Kolstad, J. (2006). Extended shelf life milk-advances in technology. International Journal of Daily Technology, v. 59, n. 2, p.8596.

Saeed, A. M.; Koons, C. W. (1993). Growth and heat resistance of Salmonella enteritidis in refrigerated and abused eggs. J Food Prot., v. 56, n. 11, p. 927-931.

Sakai, H.; Oguma, K.; Katayama, H.; Ohgaki, S. (2007). Effects of low- or medium-pressure ultraviolet lamp irradiation on Microcystis aeruginosa and Anabaena variabilis. Water Research, v. 41, n. 1, p. 11-18.

Sancho, F.; Lambert, Y.; Demazeau, G.; Larteau, A.; Bouvier, J. L.; Narbonne, J. F. (1999). Effect of ultra-high hydrostatic pressure on hydrosoluble vitamins. Journal of Food Engineering, v. 39, p. 247-253. 
Sands, J. A. (1981). Photochemical destruction of the virucidal activities of retinoids and unsaturated fatty acids. Antimicrob. Agents Chemother, v. 20, p. 699-701.

Sastry, S. K.; Datta, A. K.; Worobo, R. W. (2000). Ultraviolet light. JFS Supplement: kinetics of microbial inactivation for alternative food processing technologies, p. 90-92.

Schoeni, J. L.; Glass, K. A.; McDermott, J. L.; Wong, A. C. (1995). Growth and penetration of Salmonella enteritidis, Salmonella heidelberg and Salmonella typhimurium in eggs. Int J Food Microbiol., v. 24,n. 3, p. 385-396.

Schmidt, S.; Kauling, J. (2007). Process and Laboratory Scale UV Inactivation of Viruses and Bacteria Using an Innovative Coiled Tube Reactor. Chemical Engineering and Technology, v. 30, n. 7, p. 645-950.

Schuman, J. D.; Sheldon, B. W.; Vandepopuliere, J. M.; Ball, H. R. (1997). Immersion heat treatments for inactivation of Salmonella enteritidis with intact eggs. J Appl Microbiol., v. 83, n. 4, p. 438-444.

Schuerger, A. C.; Richards, J. T.; Newcombe, D. A.;Venkateswaran, K. (2005). Rapid Inactivation of Seven Bacillus spp. under Simulated Mars UV Irradiation. Icarus, v. 181, p. 52-62.

Schuman, J. D.; Sheldon, B. W. (2003). Inhibition of Listeria monocytogenes in $\mathrm{pH}$-adjusted pasteurised liquid whole egg. Journal of Food Protection, v. 66, p. 999-1006.

Schroeder, C. M.; Naugle, A. L.; Schlosser, W. D.; Hogue, A. T.; Angulo, F. J.; Rose, J. S.; Ebel, E. D.; Disney, W. T.; Holt, K. G.; Goldman, D. P. (2005). Estimate of illnesses from Salmonella enteritidis in eggs, United States, 2000. Emerg Infect Dis., v. 11, n. 1, p.113-5.

Schroeder, M.; Chang, J. S.; Kaufman, R. J. (2000). The unfolded protein response represses nitrogen-starvation induced developmental differentiation in yeast. Genes Dev., v. 14, p. 2962-2975. 
References

Schuerger, A.C.; Richards, J.T.; Hintze, P.E.; Kern, R.G. (2005). Surface characteristics of spacecraft components affect the aggregation of microorganisms and may lead to different survival rates of bacteria on Mars landers. Astrobiology, v. 5, p. 545-559.

Serrano L.E.; Murano, E.A.; Shenoy, K.; Olson, D.G. (1997). D Values of Salmonella enteritidis Isolates and Quality Attributes of Shell Eggs and Liquid Whole Eggs Treated with Irradiation. Poultry Science, v. 76, p. 202-205.

Severa, L.; Nedoma, S.; Buchar, J. (2010). Influence of storing time and temperature on the viscosity of an egg yolk. Journal of Food Engineering, v. 96, p. 266-269.

Severin, B ; Engelbrecht, M. S. R. (1983). . Kinetic modeling of U.V disinfection of water. Water. Res, v. 17, p. 1669-1678.

Shacter, E. (2000). Quantification and signification of protein oxidation in biological samples. Drug metabolism reviews, v. 32, n. 3-4, p. 307-326.

Shama, G.; Peppita, C.; Biguzzi, M. (1996). A novel thin film fotoreactor. Journal of Chemical Technology and Biotechnology, v. 65, p. 56-64.

Shama, G. (1999). Ultraviolet light. In: Robinson, R.K.; Batt, C.; Patel, P. (eds). Encyclopedia of food microbiology-3. London: Academic Press, p.2208-2214.

Shama, G. (2007). Process Challenges in Applying Low Doses of Ultraviolet Light to Fresh Produce for Eliciting BeneficiaL.hormetic Responses. Postharvest Biology and Technology, v. 44, p. 1-8.

Shebolina, E. S.; Sullivan, S. A.; O’Neill, K. R.; Nevin, K. P.; Lovley, D. R. (2004). Isolation, characterization, and U(VI)-Reduction Potential of a Facultatively, Anaerobic, Acid-Resitant Bacterium from Low-pH, Nitrate-and U(VI)- Comtaminated Subsurface Sediment and Description of Salmonella subterranea sp. nov. Applied and environmental microbiology, v. 70, n. 5, p. 2959-2965. 
Shenton, A. J. (1979). Membrane composition and performance of food emulsions. Ph.D. thesis, University of London.

Schuman, J. D.; Sheldon, B. W.; Vandepopuliere, J. M.; Ball Jr, H. R. (1997). Immersion heat treatments for inactivation of Salmonella enteritidis with intact eggs. Journal of Applied Microbiology, v. 83, p. $438-444$.

Sommer, R.; Cabaj, A. (1993). Evaluation of the efficiency of a UV plant for drinking water disinfection. Water Science and Technology, v. 27, p. 357-362.

Sommer, R., Cabaj, A, Pribil, W and, Haider, T. (1998). Influence of Lamp Intensity and Water Transmittance on the UV Disinfection of Water. Water Science andTechnology, v. 35, n. 11-12, p. 113-118.

Sommers, C. H. ; Geveke, D. J.; Pulsfus, S.; Lemmenes, B. (2009). Inactivation of Listeria innocua on Frankfurters by ultraviolet light and flash pasteurization. Journal of food science, v. 74, n. 3, p. 138-141.

Sommers, C. H.; Sites, J. E. ; Musgrove, M. (2010). Ultraviolet light $(254 \mathrm{~nm})$ inactivation of pathogens on foods and stainless steel surfaces. Journal of Food Safety, v. 30, p. 470-479.

Sosnin, E. A.; Oppenländer, T.; Tarasenko, V. F. (2006). Applications of Capacitive and Barrier Discharge Excilamps in Photoscience. Journal of Photochemistry and Photobiology C: Photochemistry Reviews, v. 7, p. 145-163.

Souci, S.W.; Fachmann, W.; Kraut, H. (2008). Food Composition and Nutrition Tables. Stuttgart, Germany: MedPharm Scientific Publishers, 7th Edition. 1364 p.

Souza, P. M.; Fernandez, A. (2011). Effects of UV-C on physicochemical quality attributes and Salmonella enteritidis inactivation in liquid egg products. Food Control, v. 22, p. 1385-1392.

Space Environment Technologies. (2004). ISO-DIS-21348 
References

Sparks, N. H. C.;Board, R. G. (1984). Cuticle, shell porosity and water uptake through hens' eggshells. Br. Poult. Sci., v. 25, p. 267-276.

Spikes, J. (1981). Photodegradation of foods and beverages. In K. C. Smith (Ed.), Photochemical and photobiological reviews (p. 29-81). New York: Plenum Press.

St. Louis, M. E.; Morse, D. L.; Potter, M. E.; DeMelfi, T. M.; Guzewich, J. J.; Tauxe, R. V.; Blake, P. A. (1988). The emergence of grade A eggs as a major source of Salmonella enteritidis infections: new implications for the control of salmonellosis. JAMA,v. 259, n. 14, p.2103-2107.

Stadtman, E. R. (1990). Metal ion-catalyzed oxidation of proteins: Biochemical mechanism and biological consequences. Free Radical Biol. Med., v. 9, p. 315-325.

Stadelman, W. J. (1995). Quality identification of shell eggs. In: Egg science and technology. Stadelman WJ and Cotterill OJ, editors. Binghamton, NY: The Haworth Press, Inc. p 39-66.

Stadelman W. J.; Cotteril O. J. (1990). Egg Science and Technology. 3rd Ed. Haworth Press, New York. p.289-315.

Steffe, J. F. (1996). Introduction to rheology. In: Rheological Methods in Food Process Engineering. Freeman Press, East Lansing, USA.

Sumner, S. S.; Wallner-Pendleton, E. A.; Froning, G.W.; Stetson, L. W. E. (1995). Inhibition of Salmonella typhimurium on Agar Medium and Poultry Skin by Ultraviolet Energy. Journal of Food Protection, v. 59, p. 319-321.

Szablewski, T.; Kijowski, J.; Cegielska-Radziejewska, R.; Kaczmarek, A.; Pytel, A. (2009). Promieniowanie UV jako metoda higienizacji skorupy jaj konsumpcyjnych zanieczyszczonych bakteriami Escherichia coli. Aparatura badawcza i dydaktyczna, v. 1, p. 36-41. 
Tang, Q.; Munro, P. A.; McCarthy, O. J. (1993). Rheology of whey protein concentrate solutions as a function of concentration, temperature, $\mathrm{pH}$ and salt concentration. Journal of Daily Research, v. 60, p. 349-361.

Tchobanoglous, G.L.F.; Darby, J.; Devries, M. (1996). UV Design: Comparison of Probabilistic and Deterministic Design Approaches. Water Science and Technology, v. 33, n. 10-11, p. 251-260.

Telis-Romero, J.; Thomas, C.E.P.; Bernardi, M.; Telis, V.R.N.; Gabas, A.L. (2006). Rheological Properties and Fluid Dynamics of Egg Yolk, Journal of Food Engineering, v. 74, p. 191-197.

Ternes, W.; Werlein, H. D. (1987). Viscosity of egg-yolk in a hightemperature range in correlation to salt, sugar, acid and alcohol. Archiv Für Geflügelkunde, v. 51, n. 5, p. 173-179.

Torkamani, A. E.; Niakousari, M. (2011). Impact of UV-C on orange juice quality and shelf life. International Food Research Journal, v. 18, n. 4, p. $1265-1268$.

Tornaletti, S. (2005). Transcription Arrest at DNA Damage Sites. Mutation Research, v. 577, p. 131-145.

Torrico, D. D.; No,H. K.; Sriwattana, S.; Ingram, D.; Prinyawiwatkul, W. (2011). Effects of initial albumen quality and mineral oil-chitosan emulsion coating on internal quality and shelf-life of eggs during room temperature storage. International Journal of Food Science and Technology, v. 46, i. 9, p. 1783-1792.

Tosa, K.; Hirata, T. (1999). Photoreactivation of enterohemorrhagic Escherichia coli following UV disinfection. Water Research, v. 33, n. 2, p. 361-366.

Triassi, M.; Di Popolo, A.; Ribera D'Alcalà, G. (2006). Clinical and Environmental Distribution of Legionella pneumophila in a University Hospital in Italy: Efficacy of Ultraviolet Disinfection. Journal of Hospital Infect, v. 6, n. 4, p.494-501. 
References

Trojan UV. (2012). UV Disinfection and Oxidation Treatment Systems TrojanUV. Available on: http://www.trojanuv.com/ Acessed on: January 13th,2012.

Ünlütürk, S.; Atilgan, M. R.; Baysal, H.; Tari, C. (2007). Use of UV-C radiation as non-thermal process for liquid egg products (LEP). Journal of Food Engineering, v. 85, p. 561-568.

Ünlütürk, S.; Atılgan, M. R.; Baysal, A. H.; Ünlütürk, M. S. (2010). Modeling inactivation kinetics of liquid egg white exposed to UV-C irradiation. International Journal of Food Microbiology, p. 341-347.

USDA U.S. (1969). Deptartment of Agriculture. Egg pasteurization manual. ARS 74-48. Washington, D.C: Agricultural Research Service.

USDA. (2010). National Academy of Sciences. Institute of Medicine. Food and Nutrition Board. Available on: http://www.iom.edu/Activities/Nutrition/SummaryDRIs/ /media/Files/A ctivity\%20Files/Nutrition/DRIs/5_Summary\%20Table\%20Tables\%2014.pdf Acessed on: June $2^{\text {nd }}, 2012$.

US-FDA. (2002). United States Food and Drug Administration Ultraviolet radiation for the processing and treatment of food. Code of Federal Regulations, 21. Part 179.39.

USDA-FSIS (2005) US Department of Agriculture. Risk assessments of Salmonella Enteritidis in shell eggs and Salmonella spp. in egg products. U.S. Department of Agriculture, Food Safety and Inspection Service, Washington, D.C.

US - FDA. (2000). Department of Agriculture. Egg-Grading Manual. Agriculture Marketing Division. Agriculture Handbook No. 75. U.S. Department of Agriculture, Washington, D.C.

US FDA. (2000). Food and Drug Administration. Code of Federal Regulations. Title 21, Part 179. Irradiation in the production, processing and handling of food. Federal Register, v. 65, p.71056-71058. 
US-FDA (2001). USA Food Drug and Administration. Federal Register Final Rule (July 9, 2009, 74 FR 33030): Prevention of Salmonella enteritidis in Shell Eggs During Production, Storage, and Transportation. http://www.fda.gov/Food/FoodSafety/ProductSpecificInformation/EggSafety/EggSafetyActionPlan/ucm170746.htm

USDA-AMS. (2000). USDA Egg.grading Manual. Agricultural Marketing Service, AgriculturaL.handbook (Volume 75), July, 2000.

Valappil, Z.A.; Fan, X.; Zhang, H.Q.; Rouseff, R.L. (2009). Impact of Thermal and Nonthermal Processing Technologies on Unfermented Apple Cider Aroma Volatiles. Journal of Agricultural and Food Chemistry, v. 57, p. 924-929.

Van der Plancken, I.; Van Remoortere M.; Van Loey, A.; Hendrickx, M. E. G. (2003). Heat-induced changes in the susceptibility of egg white proteins to enzymatic hydrolysis: A kinetic study. J. Agric. Food Chem, v. 51, p. 3819-3823.

Van der Plancken, I.; Delattre, M.; Van Loey, A.; Hendrickx, M. E. G. (2004). Kinetics study on the changes in the susceptibility of egg white proteins to enzymatic hydrolysis induced by heat and high hydrostatic pressure pretreatment. J. Agric. Food Chem, v. 52, p. 5621-5626.

Van der Plancken, I.; Van Loey, A.; Hendrickx, M. E. G. (2005). Combined effect of high pressure and temperature on selected properties of egg white proteins. Innov. Food Sci. Emerg. Technol., v. 6, p. 11-20.

Van der Plancken, I.; Van Loey, A.; Hendrickx, M. E. G. (2006). Effect of heat-treatment on the physico-chemical properties of egg white proteins: A kinetic study. J. Food Eng., v. 75, p. 316-326.

Van der Plancken, I.; Van Loey, A.; Hendrickx, M. (2007). Kinetic study on the combined effect of high pressure and temperature on the physicochemical properties of egg white proteins. Journal of Food Engineering, v. 78, p. 206-216 
References

Velázquez-Estrada, R. M.; Hernández-Herrero, M.M.; López-Pedemonte, T.; Guamis-López, B.; Roig-Sagués, A.X. (2008). Inactivation of Salmonella enterica serovar Senftenberg $775 \mathrm{~W}$ in liquid whole egg by ultrahigh pressure homogenization,J. Food Prot., v. 71, p. 2283-2288.

Verardo, V.; Pasini, F.; Iafelice, G.; Messia, M.C.; Marconi, E.;Caboni, M.F. (2010). Influence of storage conditions on cholesterol oxidation in dried egg pasta. Journal of Agricultural and Food Chemistry, v. 58, p. 3586-3590.

Vicenti, S. J. V.; Sampaio, G. R.; Ferrari, C. K. B. (2012). Oxidation of cholesterol in foods and its importance for human health. Food reviews international, v. 28, n. 1, p. 47-70.

Vynckel, W. (1970). Direct determination of the thiobarbituric acid value in tricloroacetic acid extracts of fish as a measure of oxidative rancidity. Fette Seifen Anstrichmittel, v. 72, p. 1084-1087.

Vuillemard, J.C.; Gauthier, S. F. ; Richard, J. P. ; Paquin, P. (1990). Development of a method for measurement of the maximum value of emulsifying capacity of milk proteins. Milchwissenschaft, v. 45, p. 572575 .

Wang, G.S.; Hsieh, S.T.; Hong, C. S. (2000). Destruction of humic acid in water by UV light - catalyzed oxidation with hydrogen peroxide. Water Research, v. 34, n. 15, p. 3882-3887.

Wang, H.; Slavik, M. (1998). Bacterial penetration into eggs washed with various chemicals and stored at different temperatures and times. J. Food Prot., v. 61, p. 276- 279.

Wasson, R. R. (2008). Complementary and alternative therapies and the aging population. San Diego: Academic press. 597p.

Watt Executive Guide to World Poultry. (2010). The statistical references for poultry executives. http://www.vniipp.ru/EG2010.pdf 
Watkins, B. A. (1995). The nutritive value of the egg. In: Egg science and technology. Stadelman WJ and Cotterill OJ, editors. Binghamton, NY: The Haworth Press, Inc. p 177-194.

Weiss, J. (1999). Effect of Mass Transport Processes on Physicochemical Properties of Surfactant- Stabilized Emulsions. Department of Food Science, University of Massachusetts, Amherst. 280 p.

Wong, E.; Linton, R. H.; Gerrard, D. E. (1998). Reduction of E.coli and S.seftenberg on Pork Skin and Pork Muscle Using Ultraviolet Light. Food Microbiology, p. 415- 423.

Wrigley, D. M.; Llorca, N. G. (1992). Decrease of Salmonella typhimurium in Skim Milk and Egg by Heat and Ultrasonic Wave Treatment. Journal of Food Protection, v. 55, p. 678-680.

Wright, J. R.; Sumner, S.S.; Hackney, C.R.; Pierson, M. D.; Zoecklein, B.W. (2000). Efficacy of Ultraviolet Light for Rreducing Escherichia coli O157:H7 in Unpasteurized Apple Cider. Journal of Food Protection, v. 63, p. $563-567$.

Yang, S. C.; Baldwin, R. E. (1995). Functional properties of eggs in foods. In: Stadelman, W. J. \& Cotterill, O. J. (Eds.). Egg Science and Technology, New York: Food Products Press., p. 405-453.

Yaun, B. Y.; Sumner, S. S.; Eifert, J. D.; Marcy, J. E. (2003). Response of Salmonella and Escherichia coli $\mathrm{O} 157: \mathrm{H7}$ to UV energy. Journal of Food Protection, v. 66, p. 1071-1073.

Zabielski, J.; Kijowski, J.; Fiszer, W.; Niewiarowicz, A. (1984). The effect of irradiation on technological properties and protein solubility of broiler chicken meat. Journal of the Science of Food and Agriculture, v. 35, i. 6, p. 662-670.

Zasgaevsky, J. S.;Lutikova, P O. (1944). Sanitary measures in the egg breaking plant. U.S. Egg Poult. Mag. 50. 17. 
References

Zayas, J. F. (1997). Introduction. In Functionality of Proteins in Food; Zayas, J. F., Ed.; Springer-Verlag: Berlin, Germany, p. 1-5.

Zeidler, G. (2002). Quality and functionality of egg products. In: Commercial chicken meat and egg production. Bell DD and Weaver WD, Jr., editors. New York, NY: Springer Science+Business Media, Inc. p. 1219-1228.

Zhao, W.; Yang, W.; Tang, Y.; Zhang, W.; Hua, X. (2009). Investigation of the Protein-Protein Aggregation of Egg White Proteins under Pulsed Electric Fields. J. Agric. Food Chem., v. 57, p. 3571-3577. 
Appendix 



\section{Appendix}

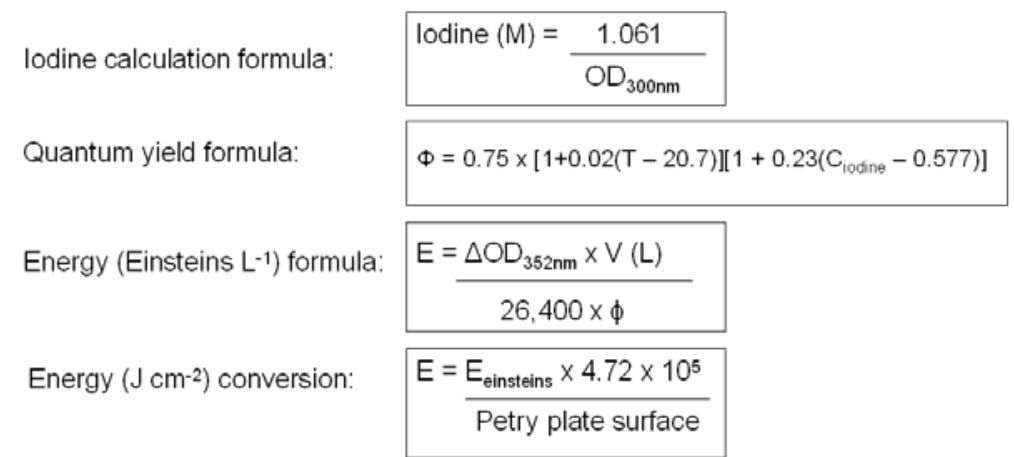

Figure A.1 - Scheme of dose calculation formulas - actinometry measurement.

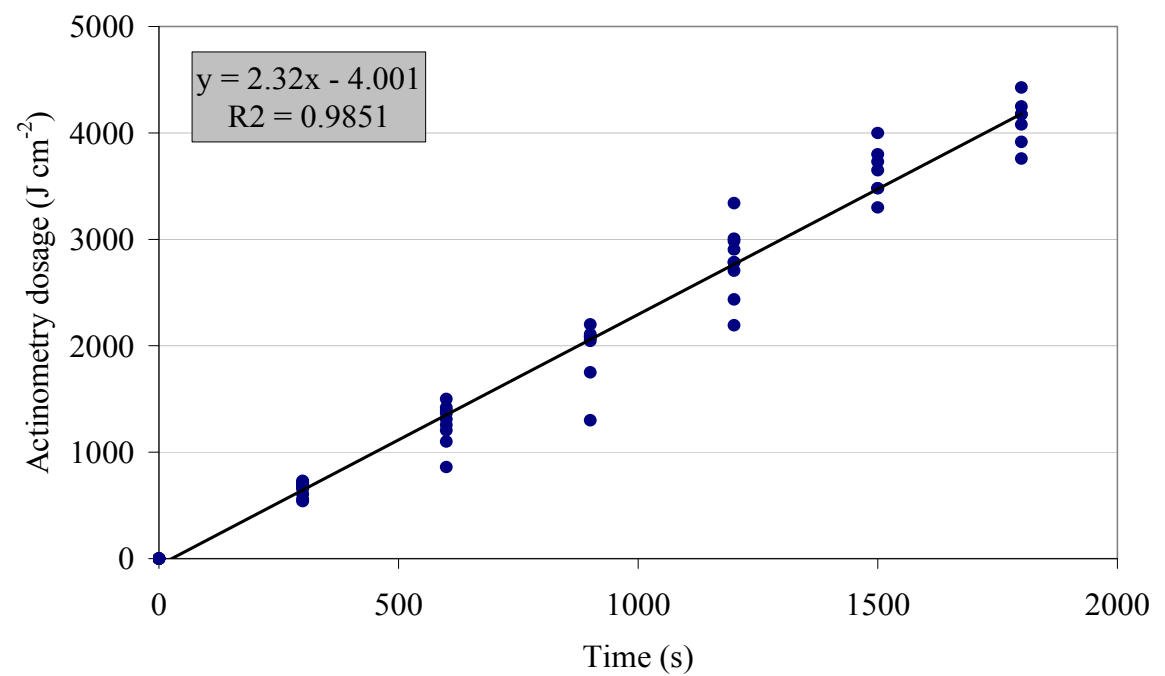

Figure A.2 - Actinometry calibration curbe. 
Appendix

Table A.1 - Log-linear fitting from inactivation kinetics of LEW treated on the IATA bench device.

\begin{tabular}{|c|c|c|c|c|}
\hline \multirow[b]{2}{*}{ Parameters } & \multicolumn{4}{|c|}{ Log-linear } \\
\hline & $\begin{array}{c}2 \mathrm{~mm} \\
\text { Dynamic }\end{array}$ & $\begin{array}{l}2 \mathrm{~mm} \\
\text { Static }\end{array}$ & $\begin{array}{c}5 \mathrm{~mm} \\
\text { Dynamic }\end{array}$ & $\begin{array}{l}5 \mathrm{~mm} \\
\text { Static }\end{array}$ \\
\hline \multicolumn{5}{|l|}{ Salmonella enteritidis } \\
\hline $\mathrm{RMSE}^{\mathrm{a}}$ & 11,075 & 0.6347 & 0.8727 & 0.4225 \\
\hline $\mathrm{R}^{2}$ & 0.5955 & 0.6603 & 0.6705 & 0.7135 \\
\hline $\log \mathrm{N}_{0}\left(\mathrm{CFUmL}^{-1}\right)^{\mathrm{b}}$ & $5.16 \pm 0.31$ & $6.67 \pm 0.18$ & $5.99 \pm 0.24$ & $7.26 \pm 0.12$ \\
\hline $\mathrm{K}_{\max }\left(\mathrm{cm}^{2} \mathrm{~J}^{-1}\right)^{\mathrm{c}}$ & $0.99 \pm 0.15$ & $0.65 \pm 0.09$ & $0.91 \pm 0.12$ & $0.49 \pm 0.06$ \\
\hline $\log N_{\text {res }}\left(\mathrm{CFUmL}^{-1}\right)^{\mathrm{d}}$ & - & - & - & - \\
\hline \multicolumn{5}{|l|}{ Escherichia coli } \\
\hline $\mathrm{RMSE}^{\mathrm{a}}$ & 0.9345 & 0.5043 & 0.5954 & 0.2537 \\
\hline $\mathrm{R}^{2}$ & 0.7145 & 0.7503 & 0.8193 & 0.8447 \\
\hline $\log \mathrm{N}_{0}\left(\mathrm{CFUmL}^{-1}\right)^{\mathrm{b}}$ & $5.60 \pm 0.26$ & $6.91 \pm 0.14$ & $6.29 \pm 0.16$ & $7.37 \pm 0.07$ \\
\hline $\mathrm{K}_{\max }\left(\mathrm{cm}^{2} \mathrm{~J}^{-1}\right)^{\mathrm{c}}$ & $1.08 \pm 0.13$ & $0.64 \pm 0.07$ & $0.93 \pm 0.08$ & $0.43 \pm 0.04$ \\
\hline $\log N_{\text {res }}\left(\mathrm{CFUmL}^{-1}\right)^{\mathrm{d}}$ & - & - & - & - \\
\hline \multicolumn{5}{|l|}{ Staphylococcus aureus } \\
\hline $\mathrm{RMSE}^{\mathrm{a}}$ & 0.7247 & 0.4996 & 0.7231 & 0.2905 \\
\hline $\mathrm{R}^{2}$ & 0.7389 & 0.5891 & 0.6780 & 0.7014 \\
\hline $\log \mathrm{N}_{0}\left(\mathrm{CFUmL}^{-1}\right)^{\mathrm{b}}$ & $6.03 \pm 0.20$ & $7.03 \pm 0.14$ & $6.50 \pm 0.20$ & $7.39 \pm 0.08$ \\
\hline $\mathrm{K}_{\max }\left(\mathrm{cm}^{2} \mathrm{~J}^{-1}\right)^{\mathrm{c}}$ & $0.89 \pm 0.10$ & $0.44 \pm 0.07$ & $0.77 \pm 0.10$ & $0.33 \pm 0.04$ \\
\hline $\log N_{\text {res }}\left(\mathrm{CFUmL}^{-1}\right)^{\mathrm{d}}$ & - & - & - & - \\
\hline \multicolumn{5}{|l|}{ Listeria innocua } \\
\hline RMSE $^{\mathrm{a}}$ & 0.5803 & 0.4611 & 0.5877 & 0.3344 \\
\hline $\mathrm{R}^{2}$ & 0.7236 & 0.4191 & 0.5935 & 0.4754 \\
\hline $\log \mathrm{N}_{0}\left(\mathrm{CFUmL}^{-1}\right)^{\mathrm{b}}$ & $6.43 \pm 0.16$ & $7.16 \pm 0.13$ & $6.63 \pm 0.16$ & $7.27 \pm 0.09$ \\
\hline $\mathrm{K}_{\max }\left(\mathrm{cm}^{2} \mathrm{~J}^{-1}\right)^{\mathrm{c}}$ & $0.69 \pm 0.08$ & $0.29 \pm 0.06$ & $0.52 \pm 0.08$ & $0.23 \pm 0.05$ \\
\hline $\log N_{\text {res }}\left(C F U m L^{-1}\right)^{d}$ & - & - & - & - \\
\hline
\end{tabular}


Table A.2 - Log-linear with tail fitting from inactivation kinetics of LEW treated on the IATA bench device.

\begin{tabular}{|c|c|c|c|c|}
\hline \multirow[b]{2}{*}{ Parameters } & \multicolumn{4}{|c|}{ Log-linear + tail } \\
\hline & $\begin{array}{c}2 \mathrm{~mm} \\
\text { Dynamic }\end{array}$ & $\begin{array}{l}2 \mathrm{~mm} \\
\text { Static }\end{array}$ & $\begin{array}{c}5 \mathrm{~mm} \\
\text { Dynamic }\end{array}$ & $\begin{array}{l}5 \mathrm{~mm} \\
\text { Static } \\
\end{array}$ \\
\hline \multicolumn{5}{|l|}{ Salmonella enteritidis } \\
\hline $\mathrm{RMSE}^{\mathrm{a}}$ & 0.6004 & 0.4299 & 0.5379 & 0.3518 \\
\hline $\mathrm{R}^{2}$ & 0.8854 & 0.8497 & 0.8793 & 0.8085 \\
\hline $\log N_{0}\left(C_{F U m L}^{-1}\right)^{b}$ & $6.85 \pm 0.27$ & $7.28 \pm 0.17$ & $7.08 \pm 0.22$ & $7.49 \pm 0.12$ \\
\hline $\mathrm{K}_{\max }\left(\mathrm{cm}^{2} \mathrm{~J}^{-1}\right)^{\mathrm{c}}$ & $6.65 \pm 0.97$ & $2.12 \pm 0.42$ & $3.94 \pm 0.56$ & $0.96 \pm 0.20$ \\
\hline $\log \mathrm{N}_{\text {res }}\left(\mathrm{CFUmL}^{-1}\right)^{\mathrm{d}}$ & $2.57 \pm 0.14$ & $4.81 \pm 0.12$ & $3.48 \pm 0.14$ & $5.72 \pm 0.14$ \\
\hline \multicolumn{5}{|l|}{ Escherichia coli } \\
\hline $\mathrm{RMSE}^{\mathrm{a}}$ & 0.6792 & 0.3275 & 0.4277 & 0.2346 \\
\hline $\mathrm{R}^{2}$ & 0.8546 & 0.8984 & 0.9101 & 0.8720 \\
\hline $\log \mathrm{N}_{0}\left(\mathrm{CFUmL}^{-1}\right)^{\mathrm{b}}$ & $6.68 \pm 0.28$ & $7.39 \pm 0.13$ & $6.69 \pm 0.15$ & $7.46 \pm 0.08$ \\
\hline $\mathrm{K}_{\max }\left(\mathrm{cm}^{2} \mathrm{~J}^{-1}\right)^{\mathrm{c}}$ & $4.02 \pm 0.66$ & $1.74 \pm 0.28$ & $1.68 \pm 0.21$ & $0.61 \pm 0.09$ \\
\hline $\log \mathrm{N}_{\text {res }}\left(\mathrm{CFUmL}{ }^{-1}\right)^{\mathrm{d}}$ & $2.63 \pm 0.18$ & $5.06 \pm 0.09$ & $3.49 \pm 0.14$ & $5.80 \pm 0.17$ \\
\hline \multicolumn{5}{|l|}{ Staphylococcus aureus } \\
\hline $\mathrm{RMSE}^{\mathrm{a}}$ & 0.5954 & 0.4841 & 0.6114 & 0.2873 \\
\hline $\mathrm{R}^{2}$ & 0.8300 & 0.6281 & 0.7780 & 0.7186 \\
\hline $\log \mathrm{N}_{0}\left(\mathrm{CFUmL}^{-1}\right)^{\mathrm{b}}$ & $6.82 \pm 0.24$ & $7.19 \pm 0.17$ & $7.12 \pm 0.25$ & $7.45 \pm 0.09$ \\
\hline $\mathrm{K}_{\max }\left(\mathrm{cm}^{2} \mathrm{~J}^{-1}\right)^{\mathrm{c}}$ & $3.12 \pm 0.59$ & $0.79 \pm 0.26$ & $2.39 \pm 0.59$ & $0.47 \pm 0.13$ \\
\hline $\log N_{\text {res }}\left(\mathrm{CFUmL}^{-1}\right)^{\mathrm{d}}$ & $3.61 \pm 0.15$ & $5.63 \pm 0.22$ & $4.37 \pm 0.16$ & $6.12 \pm 0.28$ \\
\hline \multicolumn{5}{|l|}{ Listeria inпосиа } \\
\hline $\mathrm{RMSE}^{\mathrm{a}}$ & 0.4606 & 0.4630 & 0.5252 & 0.3212 \\
\hline $\mathrm{R}^{2}$ & 0.8321 & 0.4352 & 0.6870 & 0.5331 \\
\hline $\log \mathrm{N}_{0}\left(\mathrm{CFUmL}^{-1}\right)^{\mathrm{b}}$ & $7.12 \pm 0.19$ & $7.26 \pm 0.16$ & $7.15 \pm 0.22$ & $7.46 \pm 0.14$ \\
\hline $\mathrm{K}_{\max }\left(\mathrm{cm}^{2} \mathbf{J}^{-1}\right)^{\mathrm{c}}$ & $2.81 \pm 0.19$ & $0.57 \pm 0.31$ & $2.16 \pm 0.62$ & $0.98 \pm 0.45$ \\
\hline $\log N_{\text {res }}\left(\mathrm{CFUmL}^{-1}\right)^{\mathrm{d}}$ & $4.48 \pm 0.12$ & $6.21 \pm 0.26$ & $5.22 \pm 0.14$ & $6.61 \pm 0.10$ \\
\hline
\end{tabular}


Appendix

Table A.3 - Weibull with tail fitting from inactivation kinetics of LEW treated on the IATA bench device.

\begin{tabular}{|c|c|c|c|c|}
\hline \multirow[b]{2}{*}{ Parameters } & \multicolumn{4}{|c|}{ Weibull + tail } \\
\hline & $\begin{array}{c}2 \mathrm{~mm} \\
\text { Dynamic }\end{array}$ & $\begin{array}{l}2 \mathrm{~mm} \\
\text { Static }\end{array}$ & $\begin{array}{c}5 \mathrm{~mm} \\
\text { Dynamic }\end{array}$ & $\begin{array}{l}5 \mathrm{~mm} \\
\text { Static }\end{array}$ \\
\hline \multicolumn{5}{|l|}{ Salmonella enteritidis } \\
\hline $\mathrm{RMSE}^{\mathrm{a}}$ & 0.4476 & 0.4221 & 0.4708 & 0.358 \\
\hline $\mathrm{R}^{2}$ & 0.9387 & 0.8605 & 0.9110 & 0.8091 \\
\hline $\log \mathrm{N}_{0}\left(\mathrm{CFU} \cdot \mathrm{mL}^{-1}\right)^{\mathrm{b}}$ & $7.53 \pm 0.26$ & $7.50 \pm 0.24$ & $7.56 \pm 0.27$ & $7.45 \pm 0.17$ \\
\hline$\delta\left(\mathrm{J} . \mathrm{cm}^{-2}\right)^{\mathrm{c}}$ & $0.03 \pm 0.03$ & $0.69 \pm 0.31$ & $0.14 \pm 0.09$ & $2.52 \pm 0.62$ \\
\hline $\mathrm{p}(-)^{\mathrm{d}}$ & $0.37 \pm 0.07$ & $0.63 \pm 0.18$ & $0.43 \pm 0.09$ & $1.13 \pm 0.44$ \\
\hline $\log \mathrm{N}_{\text {res }}\left(\mathrm{CFU} \cdot \mathrm{mL}^{-1}\right)^{\mathrm{e}}$ & $2.39 \pm 0.14$ & $4.75 \pm 0.15$ & $3.29 \pm 0.19$ & $5.74 \pm 0.14$ \\
\hline \multicolumn{5}{|l|}{ Escherichia coli } \\
\hline $\mathrm{RMSE}^{\mathrm{a}}$ & 0.4765 & 0.3209 & 0.2601 & 0.2326 \\
\hline $\mathrm{R}^{2}$ & 0.9311 & 0.9061 & 0.9680 & 0.8787 \\
\hline $\log \mathrm{N}_{0}\left(\text { CFU.mL }{ }^{-1}\right)^{\mathrm{b}}$ & $7.53 \pm 0.27$ & $7.54 \pm 0.18$ & $7.48 \pm 0.15$ & $7.56 \pm 0.12$ \\
\hline$\delta\left(\mathrm{J}^{\mathrm{c}} \mathrm{cm}^{-2}\right)^{\mathrm{c}}$ & $0.04 \pm 0.03$ & $1.00 \pm 0.32$ & $0.22 \pm 0.08$ & $3.39 \pm 0.74$ \\
\hline$p(-)^{d}$ & $0.32 \pm 0.05$ & $0.69 \pm 0.16$ & $0.42 \pm 0.04$ & $0.73 \pm 0.21$ \\
\hline $\log \mathrm{N}_{\text {res }}\left(\mathrm{CFU} \cdot \mathrm{mL}^{-1}\right)^{\mathrm{e}}$ & $1.90 \pm 0.55$ & $4.98 \pm 0.14$ & $3.08 \pm 0.07$ & $5.57 \pm 0.54$ \\
\hline Staphylococcus aureus & $*$ & $*$ & & $*$ \\
\hline $\mathrm{RMSE}^{\mathrm{a}}$ & 0.4108 & 0.4683 & 0.5588 & 0.2892 \\
\hline $\mathrm{R}^{2}$ & 0.9221 & 0.6648 & 0.8214 & 0.7253 \\
\hline $\log \mathrm{N}_{0}\left(\mathrm{CFU}_{\mathrm{m}} \mathrm{mL}^{-1}\right)^{\mathrm{b}}$ & $7.50 \pm 0.24$ & $7.51 \pm 0.27$ & $7.52 \pm 0.32$ & $7.54 \pm 0.16$ \\
\hline$\delta\left(\mathrm{J} \cdot \mathrm{cm}^{-2}\right)^{\mathrm{c}}$ & 0.08 & 1.70 & $0.36 \pm 0.38$ & 5.19 \\
\hline$p(-)^{d}$ & 0.31 & 0.42 & $0.44 \pm 0.13$ & 0.69 \\
\hline $\log N_{\text {res }}\left(\text { CFU.mL } L^{-1}\right)^{\mathrm{e}}$ & 2.11 & 2.96 & $3.95 \pm 0.45$ & 5.68 \\
\hline Listeria innocua & $*$ & $*$ & $*$ & \\
\hline $\mathrm{RMSE}^{\mathrm{a}}$ & 0.3657 & 0.4554 & 0.4775 & 0.3213 \\
\hline $\mathrm{R}^{2}$ & 0.8981 & 0.4738 & 0.7509 & 0.5503 \\
\hline $\log \mathrm{N}_{0}\left(\mathrm{CFU} \cdot \mathrm{mL}^{-1}\right)^{\mathrm{b}}$ & $7.52 \pm 0.21$ & $7.50 \pm 0.26$ & $7.51 \pm 0.27$ & $7.53 \pm 0.18$ \\
\hline$\delta\left(\mathrm{J} . \mathrm{cm}^{-2}\right)^{\mathrm{c}}$ & 0.20 & 4.45 & 0.38 & $3.87 \pm 3.90$ \\
\hline$p(-)^{d}$ & 0.33 & 0.39 & 0.31 & $0.55 \pm 0.39$ \\
\hline $\log \mathrm{N}_{\text {res }}\left(\mathrm{CFU} \cdot \mathrm{mL}^{-1}\right)^{\mathrm{e}}$ & 3.11 & 1.24 & 3.94 & $6.39 \pm 0.59$ \\
\hline
\end{tabular}

${ }^{a}$ RMSE: Root mean sum of squared error.

${ }^{\mathrm{b}} \log \left(\mathrm{N}_{0}\right)$ : predicted logarithm of initial count.

${ }^{\mathrm{c}} \delta$ : Model parameter

${ }^{\mathrm{d}} \mathrm{p}$ : Model parameter

${ }^{\mathrm{e}} \log \left(\mathrm{N}_{\mathrm{res}}\right)$ : predicted logarithm of residual count 
Table A.4 - Log-linear fitting from inactivation kinetics of LEW treated on IATA bench equipement.

\begin{tabular}{|c|c|c|c|c|}
\hline \multirow[b]{2}{*}{ Parameters } & \multicolumn{4}{|c|}{ Log-linear } \\
\hline & $\begin{array}{c}2 \mathrm{~mm} \\
\text { Dynamic }\end{array}$ & $\begin{array}{l}2 \mathrm{~mm} \\
\text { Static }\end{array}$ & $\begin{array}{c}5 \mathrm{~mm} \\
\text { Dynamic }\end{array}$ & $\begin{array}{l}5 \mathrm{~mm} \\
\text { Static }\end{array}$ \\
\hline \multicolumn{5}{|l|}{ Salmonella enteritidis } \\
\hline $\mathrm{RMSE}^{\mathrm{a}}$ & 0.6837 & 0.4564 & 0.5518 & 0.4389 \\
\hline $\mathrm{R}^{2}$ & 0.7464 & 0.7023 & 0.7992 & 0.6617 \\
\hline $\log \mathrm{N}_{0}\left(\mathrm{CFUmL}^{-1}\right)^{\mathrm{b}}$ & $6.43 \pm 0.19$ & $7.14 \pm 0.13$ & $6.94 \pm 0.15$ & $7.31 \pm 0.12$ \\
\hline $\mathrm{K}_{\max }\left(\mathrm{cm}^{2} \mathrm{~J}^{-1}\right)^{\mathrm{c}}$ & $0.86 \pm 0.09$ & $0.51 \pm 0.06$ & $0.81 \pm 0.08$ & $0.45 \pm 0.06$ \\
\hline $\log N_{\text {res }}\left(C F U m L L^{-1}\right)^{f}$ & - & - & - & - \\
\hline \multicolumn{5}{|l|}{ Escherichia coli } \\
\hline $\mathrm{RMSE}^{\mathrm{a}}$ & 0.5582 & 0.5306 & 0.4811 & 0.2276 \\
\hline $\mathrm{R}^{2}$ & 0.8063 & 0.6522 & 0.8074 & 0.8562 \\
\hline $\log \mathrm{N}_{0}\left(\mathrm{CFUmL}^{-1}\right)^{\mathrm{b}}$ & $6.31 \pm 0.15$ & $6.90 \pm 0.16$ & $6.53 \pm 0.13$ & $7.40 \pm 0.06$ \\
\hline $\mathrm{K}_{\max }\left(\mathrm{cm}^{2} \mathrm{~J}^{-1}\right)^{\mathrm{c}}$ & $0.84 \pm 0.08$ & $0.53 \pm 0.08$ & $0.72 \pm 0.07$ & $0.41 \pm 0.03$ \\
\hline $\log N_{\text {res }}\left(\mathrm{CFUmL}^{-1}\right)^{\mathrm{f}}$ & - & - & - & - \\
\hline \multicolumn{5}{|c|}{ Staphylococcus aureus } \\
\hline $\mathrm{RMSE}^{\mathrm{a}}$ & 0.6444 & 0.4796 & 0.5134 & 0.3604 \\
\hline $\mathrm{R}^{2}$ & 0.6681 & 0.4624 & 0.7462 & 0.5295 \\
\hline $\log \mathrm{N}_{0}\left(\mathrm{CFUmL}^{-1}\right)^{\mathrm{b}}$ & $6.45 \pm 0.18$ & $7.23 \pm 0.13$ & $6.79 \pm 0.14$ & $7.41 \pm 0.10$ \\
\hline $\mathrm{K}_{\max }\left(\mathrm{cm}^{2} \mathrm{~J}^{-1}\right)^{\mathrm{c}}$ & $0.67 \pm 0.09$ & $0.33 \pm 0.07$ & $0.65 \pm 0.07$ & $0.28 \pm 0.05$ \\
\hline $\log N_{\text {res }}\left(\mathrm{CFUmL}^{-1}\right)^{\mathrm{f}}$ & - & - & - & - \\
\hline \multicolumn{5}{|l|}{ Listeria innocua } \\
\hline $\mathrm{RMSE}^{\mathrm{a}}$ & 0.5856 & 0.5623 & 0.4048 & 0.3406 \\
\hline $\mathrm{R}^{2}$ & 0.5920 & 0.3204 & 0.6637 & 0.4279 \\
\hline $\log \mathrm{N}_{0}\left(\mathrm{CFUmL}^{-1}\right)^{\mathrm{b}}$ & $6.63 \pm 0.16$ & $7.27 \pm 0.16$ & $6.83 \pm 0.11$ & $7.41 \pm 0.09$ \\
\hline $\mathrm{K}_{\max }\left(\mathrm{cm}^{2} \mathrm{~J}^{-1}\right)^{\mathrm{c}}$ & $0.52 \pm 0.08$ & $0.28 \pm 0.08$ & $0.42 \pm 0.06$ & $0.22 \pm 0.05$ \\
\hline $\log N_{\text {res }}\left(\mathrm{CFUmL}^{-1}\right)^{\mathrm{f}}$ & - & - & - & - \\
\hline
\end{tabular}


Appendix

Table A.5 - Log-linear with tail fitting from inactivation kinetics of LWE treated on IATA bench equipement.

\begin{tabular}{|c|c|c|c|c|}
\hline \multirow[b]{2}{*}{ Parameters } & \multicolumn{4}{|c|}{ Log-linear + tail } \\
\hline & $\begin{array}{c}2 \mathrm{~mm} \\
\text { Dynamic }\end{array}$ & $\begin{array}{l}2 \mathrm{~mm} \\
\text { Static }\end{array}$ & $\begin{array}{c}5 \mathrm{~mm} \\
\text { Dynamic }\end{array}$ & $\begin{array}{l}5 \mathrm{~mm} \\
\text { Static }\end{array}$ \\
\hline \multicolumn{5}{|l|}{ Salmonella enteritidis } \\
\hline $\mathrm{RMSE}^{\mathrm{a}}$ & 0.5059 & 0.3432 & 0.3783 & 0.3875 \\
\hline $\mathrm{R}^{2}$ & 0.8661 & 0.8377 & 0.9090 & 0.7457 \\
\hline $\log \mathrm{N}_{0}\left(\mathrm{CFUmL}^{-1}\right)^{\mathrm{b}}$ & $7.02 \pm 0.20$ & $7.49 \pm 0.13$ & $7.34 \pm 0.13$ & $7.53 \pm 0.14$ \\
\hline $\mathrm{K}_{\max }\left(\mathrm{cm}^{2} \mathrm{~J}^{-1}\right)^{\mathrm{c}}$ & $2.21 \pm 0.43$ & $1.32 \pm 0.28$ & $1.56 \pm 0.20$ & $0.91 \pm 0.23$ \\
\hline $\log N_{\text {res }}\left(\mathrm{CFUmL}^{-1}\right)^{\mathrm{f}}$ & $3.98 \pm 0.14$ & $5.62 \pm 0.11$ & $4.52 \pm 0.13$ & $5.90 \pm 0.15$ \\
\hline \multicolumn{5}{|l|}{ Escherichia coli } \\
\hline RMSE $^{\mathrm{a}}$ & 0.4834 & 0.3758 & 0.3882 & 0.2181 \\
\hline $\mathrm{R}^{2}$ & 0.8600 & 0.8317 & 0.8790 & 0.8727 \\
\hline $\log \mathrm{N}_{0}\left(\mathrm{CFUmL}^{-1}\right)^{\mathrm{b}}$ & $6.59 \pm 0.16$ & $7.42 \pm 0.15$ & $6.77 \pm 0.13$ & $7.47 \pm 0.07$ \\
\hline $\mathrm{K}_{\max }\left(\mathrm{cm}^{2} \mathrm{~J}^{-1}\right)^{\mathrm{c}}$ & $1.35 \pm 0.20$ & $1.88 \pm 0.39$ & $1.15 \pm 0.16$ & $0.53 \pm 0.08$ \\
\hline $\log N_{\text {res }}\left(C F U m L ~ L^{-1}\right)^{f}$ & $3.74 \pm 0.18$ & $5.38 \pm 0.10$ & $4.23 \pm 0.16$ & $5.81 \pm 0.22$ \\
\hline \multicolumn{5}{|c|}{ Staphylococcus aureus } \\
\hline RMSE $^{\mathrm{a}}$ & 0.6205 & 0.4769 & 0.3621 & 0.4340 \\
\hline $\mathrm{R}^{2}$ & 0.7032 & 0.4851 & 0.5420 & 0.8251 \\
\hline $\log \mathrm{N}_{0}\left(\mathrm{CFUmL}^{-1}\right)^{\mathrm{b}}$ & $6.68 \pm 0.21$ & $7.32 \pm 0.16$ & $7.47 \pm 0.12$ & $7.14 \pm 0.16$ \\
\hline $\mathrm{K}_{\max }\left(\mathrm{cm}^{2} \mathrm{~J}^{-1}\right)^{\mathrm{c}}$ & $1.15 \pm 0.30$ & $0.55 \pm 0.25$ & $0.42 \pm 0.18$ & $1.42 \pm 0.30$ \\
\hline $\log N_{\text {res }}\left(C F U m L ~ L^{-1}\right)^{f}$ & $4.40 \pm 0.24$ & $6.08 \pm 0.32$ & $6.31 \pm 0.38$ & $4.91 \pm 0.14$ \\
\hline \multicolumn{5}{|l|}{ Listeria innocua } \\
\hline $\mathrm{RMSE}^{\mathrm{a}}$ & 0.5240 & 0.5694 & 0.3733 & 0.3434 \\
\hline $\mathrm{R}^{2}$ & 0.6850 & 0.3279 & 0.7244 & 0.4391 \\
\hline $\log \mathrm{N}_{0}\left(\mathrm{CFUmL}^{-1}\right)^{\mathrm{b}}$ & $7.13 \pm 0.22$ & $7.32 \pm 0.19$ & $7.21 \pm 0.16$ & $7.45 \pm 0.12$ \\
\hline $\mathrm{K}_{\max }\left(\mathrm{cm}^{2} \mathrm{~J}^{-1}\right)^{\mathrm{c}}$ & $2.03 \pm 0.60$ & $0.43 \pm 0.19$ & $1.67 \pm 0.46$ & $0.36 \pm 0.22$ \\
\hline $\log N_{\text {res }}\left(C F U m L ~ L^{-1}\right)^{f}$ & $5.22 \pm 0.14$ & $6.17 \pm 0.58$ & $5.71 \pm 0.10$ & $6.53 \pm 0.41$ \\
\hline
\end{tabular}

a RMSE: Root mean sum of squared error.

${ }^{\mathrm{b}} \log \left(\mathrm{N}_{0}\right)$ : predicted logarithm of initial count.

${ }^{\mathrm{C}}$ Model parameter

${ }^{\mathrm{d}} \log \left(\mathrm{N}_{\mathrm{res}}\right)$ : predicted logarithm of residual count. 
Table A.6 - Weibull with tail fitting from inactivation kinetics of LWE treated on IATA bench equipement.

\begin{tabular}{|c|c|c|c|c|}
\hline \multirow[b]{2}{*}{ Parameters } & \multicolumn{4}{|c|}{ Weibull + tail } \\
\hline & $\begin{array}{c}2 \mathrm{~mm} \\
\text { Dynamic }\end{array}$ & $\begin{array}{l}2 \mathrm{~mm} \\
\text { Static }\end{array}$ & $\begin{array}{c}5 \mathrm{~mm} \\
\text { Dynamic }\end{array}$ & $\begin{array}{l}5 \mathrm{~mm} \\
\text { Static }\end{array}$ \\
\hline \multicolumn{5}{|l|}{ Salmonella enteritidis } \\
\hline $\mathrm{RMSE}^{\mathrm{a}}$ & 0.4403 & 0.3494 & 0.3681 & 0.3948 \\
\hline $\mathrm{R}^{2}$ & 0.9023 & 0.8380 & 0.9170 & 0.7458 \\
\hline $\log \mathrm{N}_{0}\left(\mathrm{CFU} \cdot \mathrm{mL}^{-1}\right)^{\mathrm{b}}$ & $7.50 \pm 0.25$ & $7.52 \pm 0.18$ & $7.55 \pm 0.20$ & $7.51 \pm 0.19$ \\
\hline$\delta\left(\mathrm{J} \cdot \mathrm{cm}^{-2}\right)^{\mathrm{c}}$ & $0.34 \pm 0.19$ & $1.69 \pm 0.48$ & $0.99 \pm 0.34$ & $2.56 \pm 0.75$ \\
\hline$p(-)^{d}$ & $0.48 \pm 0.10$ & $0.92 \pm 0.32$ & $0.71 \pm 0.15$ & $1.05 \pm 0.48$ \\
\hline $\log N_{\text {res }}\left(\text { CFU.mL } L^{-1}\right)^{\mathrm{e}}$ & $3.67 \pm 0.27$ & $5.61 \pm 0.13$ & $4.42 \pm 0.17$ & $5.91 \pm 0.17$ \\
\hline Escherichia coli & $*$ & $*$ & $*$ & $*$ \\
\hline $\mathrm{RMSE}^{\mathrm{a}}$ & 0.2640 & 0.3806 & 0.2454 & 0.2192 \\
\hline $\mathrm{R}^{2}$ & 0.9598 & 0.8338 & 0.9531 & 0.8762 \\
\hline $\log \mathrm{N}_{0}\left(\mathrm{CFU} \cdot \mathrm{mL}^{-1}\right)^{\mathrm{b}}$ & $7.50 \pm 0.15$ & $7.50 \pm 0.21$ & $7.49 \pm 0.14$ & $7.54 \pm 0.11$ \\
\hline$\delta\left(\mathrm{J}_{\mathrm{cm}} \mathrm{cm}^{-2}\right)^{\mathrm{c}}$ & 0.16 & 1.10 & 0.33 & 4.16 \\
\hline$p(-)^{d}$ & 0.35 & 0.77 & 0.38 & 0.78 \\
\hline $\log N_{\text {res }}\left(C F U \cdot m^{-1}\right)^{\mathrm{e}}$ & 1.08 & 5.35 & 3.64 & 5.54 \\
\hline Staphylococcus aureus & $*$ & $*$ & & \\
\hline $\mathrm{RMSE}^{\mathrm{a}}$ & 0.5164 & 0.4798 & 0.3869 & 0.3676 \\
\hline $\mathrm{R}^{2}$ & 0.8020 & 0.4982 & 0.8661 & 0.5455 \\
\hline $\log \mathrm{N}_{0}\left(\mathrm{CFU} \cdot \mathrm{mL}^{-1}\right)^{\mathrm{b}}$ & $7.48 \pm 0.30$ & $7.50 \pm 0.27$ & $7.53 \pm 0.22$ & $7.53 \pm 0.20$ \\
\hline 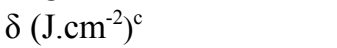 & 0.23 & 4.29 & $0.70 \pm 0.38$ & $6.27 \pm 5.57$ \\
\hline$p(-)^{d}$ & 0.32 & 0.51 & $0.47 \pm 0.12$ & $0.73 \pm 0.60$ \\
\hline $\log \mathrm{N}_{\text {res }}\left(\text { CFU.mL } L^{-1}\right)^{\mathrm{e}}$ & 0.00 & 5.13 & $4.51 \pm 0.46$ & $5.96 \pm 2.41$ \\
\hline Listeria innocua & $*$ & $*$ & $*$ & $*$ \\
\hline $\mathrm{RMSE}^{\mathrm{a}}$ & 0.4754 & 0.5742 & 0.3172 & 0.3488 \\
\hline $\mathrm{R}^{2}$ & 0.7503 & 0.3418 & 0.8083 & 0.4426 \\
\hline $\log \mathrm{N}_{0}\left(\mathrm{CFU} \cdot \mathrm{mL}^{-1}\right)^{\mathrm{b}}$ & $7.51 \pm 0.27$ & $7.50 \pm 0.33$ & $7.49 \pm 0.18$ & $7.51 \pm 0.19$ \\
\hline$\delta\left(\mathrm{J} \cdot \mathrm{cm}^{-2}\right)^{\mathrm{c}}$ & 0.39 & 6.03 & 0.94 & 9.23 \\
\hline$p(-)^{d}$ & 0.31 & 0.50 & 0.32 & 0.67 \\
\hline $\log \mathrm{N}_{\text {res }}\left(\text { CFU.mL } L^{-1}\right)^{\mathrm{e}}$ & 4.09 & 1.28 & 1.45 & 6.01 \\
\hline
\end{tabular}

${ }^{a}$ RMSE: Root mean sum of squared error.

${ }^{\mathrm{b}} \log \left(\mathrm{N}_{0}\right)$ : predicted logarithm of initial count.

${ }^{\mathrm{c}} \delta$ : Model parameter

${ }^{\mathrm{d}} \mathrm{p}$ : Model parameter

${ }^{\mathrm{e}} \log \left(\mathrm{N}_{\mathrm{res}}\right)$ : predicted logarithm of residual count 
Appendix

Table A.7 - Log-linear fitting from inactivation kinetics of LWE treated on IATA bench equipement.

\begin{tabular}{|c|c|c|c|c|}
\hline \multirow[b]{2}{*}{ Parameters } & \multicolumn{4}{|c|}{ Log-linear } \\
\hline & $\begin{array}{c}2 \mathrm{~mm} \\
\text { Dynamic }\end{array}$ & $\begin{array}{l}2 \mathrm{~mm} \\
\text { Static }\end{array}$ & $\begin{array}{c}5 \mathrm{~mm} \\
\text { Dynamic }\end{array}$ & $\begin{array}{l}5 \mathrm{~mm} \\
\text { Static }\end{array}$ \\
\hline \multicolumn{5}{|l|}{ Salmonella enteritidis } \\
\hline $\mathrm{RMSE}^{\mathrm{a}}$ & 0.5719 & 0.512 & 0.5539 & 0.3720 \\
\hline $\mathrm{R}^{2}$ & 0.7576 & 0.6187 & 0.6622 & 0.6240 \\
\hline $\log \mathrm{N}_{0}\left(\mathrm{CFU} \cdot \mathrm{mL}^{-1}\right)^{\mathrm{b}}$ & $6.56 \pm 0.16$ & $7.26 \pm 0.14$ & $6.76 \pm 0.15$ & $7.42 \pm 0.10$ \\
\hline $\mathrm{K}_{\max }\left(\mathrm{cm}^{2} \mathrm{~J}^{-1}\right)^{\mathrm{c}}$ & $0.74 \pm 0.08$ & $0.48 \pm 0.07$ & $0.57 \pm 0.08$ & $0.35 \pm 0.05$ \\
\hline $\log \mathrm{N}_{\text {res }}\left(\text { CFU.mL }{ }^{-1}\right)^{\mathrm{d}}$ & - & - & - & - \\
\hline \multicolumn{5}{|l|}{ Escherichia coli } \\
\hline RMSE $^{\mathrm{a}}$ & 0.6183 & 0.3231 & 0.3996 & 0.1814 \\
\hline $\mathrm{R}^{2}$ & 0.7470 & 0.7301 & 0.8507 & 0.8645 \\
\hline $\log \mathrm{N}_{0}\left(\mathrm{CFU} \cdot \mathrm{mL}^{-1}\right)^{\mathrm{b}}$ & $6.53 \pm 0.17$ & $7.15 \pm 0.09$ & $6.85 \pm 0.11$ & $7.49 \pm 0.05$ \\
\hline $\mathrm{K}_{\max }\left(\mathrm{cm}^{2} \mathrm{~J}^{-1}\right)^{\mathrm{c}}$ & $0.78 \pm 0.09$ & $0.39 \pm 0.04$ & $0.70 \pm 0.06$ & $0.34 \pm 0.03$ \\
\hline $\log N_{\text {res }}\left(\text { CFU.mL } L^{-1}\right)^{d}$ & - & - & - & - \\
\hline \multicolumn{5}{|l|}{ Staphylococcus aureus } \\
\hline $\mathrm{RMSE}^{\mathrm{a}}$ & 0.4941 & 0.3755 & 0.3168 & 0.2833 \\
\hline $\mathrm{R}^{2}$ & 0.7617 & 0.5466 & 0.8548 & 0.6019 \\
\hline $\log \mathrm{N}_{0}\left(\mathrm{CFU} \cdot \mathrm{mL}^{-1}\right)^{\mathrm{b}}$ & $6.87 \pm 0.14$ & $7.28 \pm 0.10$ & $7.07 \pm 0.09$ & $7.43 \pm 0.08$ \\
\hline $\mathrm{K}_{\max }\left(\mathrm{cm}^{2} \mathrm{~J}^{-1}\right)^{\mathrm{c}}$ & $0.65 \pm 0.07$ & $0.30 \pm 0.05$ & $0.56 \pm 0.04$ & $0.26 \pm 0.04$ \\
\hline $\log \mathrm{N}_{\mathrm{res}}\left(\mathrm{CFU} \cdot \mathrm{mL}^{-1}\right)^{\mathrm{d}}$ & - & - & - & - \\
\hline \multicolumn{5}{|l|}{ Listeria innocua } \\
\hline $\mathrm{RMSE}^{\mathrm{a}}$ & 0.5735 & 0.3920 & 0.5457 & 0.2451 \\
\hline $\mathrm{R}^{2}$ & 0.5046 & 0.3952 & 0.4364 & 0.3787 \\
\hline $\log \mathrm{N}_{0}\left(\mathrm{CFU} \cdot \mathrm{mL}^{-1}\right)^{\mathrm{b}}$ & $6.63 \pm 0.16$ & $7.30 \pm 0.11$ & $7.13 \pm 0.15$ & $7.46 \pm 0.07$ \\
\hline $\mathrm{K}_{\max }\left(\mathrm{cm}^{2} \mathrm{~J}^{-1}\right)^{\mathrm{c}}$ & $0.42 \pm 0.08$ & $0.23 \pm 0.05$ & $7.35 \pm 0.08$ & $0.14 \pm 0.03$ \\
\hline $\log \mathrm{N}_{\text {res }}\left(\text { CFU.mL } L^{-1}\right)^{\mathrm{d}}$ & - & - & - & - \\
\hline
\end{tabular}

${ }^{a}$ RMSE: Root mean sum of squared error.

${ }^{b} \log \left(\mathrm{N}_{0}\right)$ : predicted logarithm of initial count.

${ }^{\mathrm{C}}$ Model parameter

${ }^{\mathrm{d}} \log \left(\mathrm{N}_{\text {res }}\right)$ : predicted logarithm of residual count. 
Table A.8 - Log-linear with tail fitting from inactivation kinetics of LEY treated on the IATA bench device.

\begin{tabular}{|c|c|c|c|c|}
\hline \multirow[b]{2}{*}{ Parameters } & \multicolumn{4}{|c|}{ Log-linear + tail } \\
\hline & $\begin{array}{c}2 \mathrm{~mm} \\
\text { Dynamic }\end{array}$ & $\begin{array}{l}2 \mathrm{~mm} \\
\text { Static }\end{array}$ & $\begin{array}{c}5 \mathrm{~mm} \\
\text { Dynamic }\end{array}$ & $\begin{array}{l}5 \mathrm{~mm} \\
\text { Static }\end{array}$ \\
\hline \multicolumn{5}{|l|}{ Salmonella enteritidis } \\
\hline $\mathrm{RMSE}^{\mathrm{a}}$ & 0.4307 & 0.4377 & 0.4196 & 0.3529 \\
\hline $\mathrm{R}^{2}$ & 0.8674 & 0.7312 & 0.8131 & 0.6736 \\
\hline $\log \mathrm{N}_{0}\left(\mathrm{CFUmL}^{-1}\right)^{\mathrm{b}}$ & $7.13 \pm 0.17$ & $7.57 \pm 0.16$ & $7.33 \pm 0.17$ & $7.55 \pm 0.12$ \\
\hline $\mathrm{K}_{\max }\left(\mathrm{cm}^{2} \mathrm{~J}^{-1}\right)^{\mathrm{c}}$ & $2.18 \pm 0.41$ & $1.16 \pm 0.33$ & $2.15 \pm 0.45$ & $0.64 \pm 0.19$ \\
\hline $\log N_{\text {res }}\left(\mathrm{CFUmL}^{-1}\right)^{\mathrm{f}}$ & $4.49 \pm 0.12$ & $5.82 \pm 0.15$ & $5.18 \pm 0.11$ & $6.24 \pm 0.19$ \\
\hline \multicolumn{5}{|l|}{ Escherichia coli } \\
\hline $\mathrm{RMSE}^{\mathrm{a}}$ & 0.5319 & 0.3171 & 0.3178 & 0.1808 \\
\hline $\mathrm{R}^{2}$ & 0.8194 & 0.7494 & 0.9090 & 0.8702 \\
\hline $\log \mathrm{N}_{0}\left(\mathrm{CFUmL}^{-1}\right)^{\mathrm{b}}$ & $6.91 \pm 0.19$ & $7.24 \pm 0.10$ & $7.06 \pm 0.10$ & $7.52 \pm 0.06$ \\
\hline $\mathrm{K}_{\max }\left(\mathrm{cm}^{2} \mathrm{~J}^{-1}\right)^{\mathrm{c}}$ & $1.58 \pm 0.33$ & $0.57 \pm 0.14$ & $1.06 \pm 0.12$ & $0.40 \pm 0.07$ \\
\hline $\log N_{\text {res }}\left(C F U m L ~ L^{-1}\right)^{f}$ & $4.25 \pm 0.17$ & $5.76 \pm 0.23$ & $4.59 \pm 0.14$ & $5.93 \pm 0.37$ \\
\hline \multicolumn{5}{|c|}{ Staphylococcus aureus } \\
\hline $\mathrm{RMSE}^{\mathrm{a}}$ & 0.4685 & 0.3721 & 0.2639 & 0.2868 \\
\hline $\mathrm{R}^{2}$ & 0.7934 & 0.5708 & 0.9028 & 0.6064 \\
\hline $\log \mathrm{N}_{0}\left(\mathrm{CFUmL}^{-1}\right)^{\mathrm{b}}$ & $7.01 \pm 0.15$ & $7.36 \pm 0.13$ & $7.23 \pm 0.09$ & $7.46 \pm 0.09$ \\
\hline $\mathrm{K}_{\max }\left(\mathrm{cm}^{2} \mathrm{~J}^{-1}\right)^{\mathrm{c}}$ & $0.90 \pm 0.16$ & $0.51 \pm 0.20$ & $0.86 \pm 0.10$ & $0.33 \pm 0.14$ \\
\hline $\log N_{\text {res }}\left(\mathrm{CFUmL}^{-1}\right)^{\mathrm{f}}$ & $4.67 \pm 0.25$ & $6.20 \pm 0.27$ & $5.20 \pm 0.13$ & $6.23 \pm 0.61$ \\
\hline Listeria innocua & & & & $*$ \\
\hline $\mathrm{RMSE}^{\mathrm{a}}$ & 0.4922 & 0.3965 & 0.5265 & 0.2496 \\
\hline $\mathrm{R}^{2}$ & 0.6482 & 0.4033 & 0.4940 & 0.3787 \\
\hline $\log N_{0}\left(C_{F U m L}^{-1}\right)^{b}$ & $7.26 \pm 0.22$ & $7.35 \pm 0.13$ & $7.45 \pm 0.22$ & $7.46 \pm 0.08$ \\
\hline $\mathrm{K}_{\max }\left(\mathrm{cm}^{2} \mathrm{~J}^{-1}\right)^{\mathrm{c}}$ & $2.87 \pm 0.91$ & $0.36 \pm 0.23$ & $1.42 \pm 0.66$ & 0.14 \\
\hline $\log N_{\text {res }}\left(C F U m L ~ L^{-1}\right)^{f}$ & $5.53 \pm 0.12$ & $6.35 \pm 0.50$ & $6.16 \pm 0.14$ & 3.58 \\
\hline
\end{tabular}

${ }^{\text {a }}$ RMSE: Root mean sum of squared error.

${ }^{\mathrm{b}} \log \left(\mathrm{N}_{0}\right)$ : predicted logarithm of initial count.

${ }^{\mathrm{C}}$ Model parameter

${ }^{\mathrm{d}} \log \left(\mathrm{N}_{\text {res }}\right)$ : predicted logarithm of residual count. 
Appendix

Table A.9 - Weibull with tail fitting from inactivation kinetics of LEY treated on the IATA bench device

\begin{tabular}{|c|c|c|c|c|}
\hline \multirow[b]{2}{*}{ Parameters } & \multicolumn{4}{|c|}{ Weibull + tail } \\
\hline & $\begin{array}{c}2 \mathrm{~mm} \\
\text { Dynamic }\end{array}$ & $\begin{array}{l}2 \mathrm{~mm} \\
\text { Static }\end{array}$ & $\begin{array}{c}5 \mathrm{~mm} \\
\text { Dynamic }\end{array}$ & $\begin{array}{l}5 \mathrm{~mm} \\
\text { Static }\end{array}$ \\
\hline \multicolumn{5}{|l|}{ Salmonella enteritidis } \\
\hline $\mathrm{RMSE}^{\mathrm{a}}$ & 0.3634 & 0.4459 & 0.4022 & 0.3595 \\
\hline $\mathrm{R}^{2}$ & 0.9091 & 0.7314 & 0.8346 & 0.6739 \\
\hline $\log \mathrm{N}_{0}\left(\mathrm{CFU} \cdot \mathrm{mL}^{-1}\right)^{\mathrm{b}}$ & $7.52 \pm 0.21$ & $7.55 \pm 0.22$ & $7.54 \pm 0.23$ & $7.53 \pm 0.17$ \\
\hline$\delta\left(\mathrm{J} \cdot \mathrm{cm}^{-2}\right)^{\mathrm{c}}$ & $0.39 \pm 0.21$ & $2.02 \pm 0.66$ & $0.69 \pm 0.36$ & $3.62 \pm 1.07$ \\
\hline$p(-)^{d}$ & $0.44 \pm 0.08$ & $1.07 \pm 0.52$ & $0.51 \pm 0.15$ & $1.08 \pm 0.60$ \\
\hline $\log \mathrm{N}_{\text {res }}\left(\text { CFU.mL } L^{-1}\right)^{\mathrm{e}}$ & $4.06 \pm 0.33$ & $5.83 \pm 0.16$ & $5.00 \pm 0.21$ & $6.25 \pm 0.22$ \\
\hline Escherichia coli & & $*$ & $*$ & \\
\hline $\mathrm{RMSE}^{\mathrm{a}}$ & 0.4460 & 0.2926 & 0.2462 & 0.1842 \\
\hline $\mathrm{R}^{2}$ & 0.8777 & 0.7645 & 0.9474 & 0.8702 \\
\hline $\log \mathrm{N}_{0}\left(\mathrm{CFU} \cdot \mathrm{mL}^{-1}\right)^{\mathrm{b}}$ & $7.51 \pm 0.25$ & $7.51 \pm 0.17$ & $7.51 \pm 0.14$ & $7.51 \pm 0.09$ \\
\hline$\delta\left(\mathrm{J} \mathrm{cm}^{-2}\right)^{\mathrm{c}}$ & $0.34 \pm 0.23$ & 2.81 & 0.80 & $5.71 \pm 1.06$ \\
\hline $\mathrm{p}(-)^{\mathrm{d}}$ & $0.41 \pm 0.09$ & 0.46 & 0.50 & $1.03 \pm 0.36$ \\
\hline $\log N_{\text {res }}\left(C F U \cdot m^{-1}\right)^{\mathrm{e}}$ & $3.67 \pm 0.70$ & 0.33 & 4.19 & $5.97 \pm 0.55$ \\
\hline Staphylococcus aureus & $*$ & $*$ & $*$ & $*$ \\
\hline $\mathrm{RMSE}^{\mathrm{a}}$ & 0.4355 & 0.3730 & 0.2371 & 0.2905 \\
\hline $\mathrm{R}^{2}$ & 0.8281 & 0.5847 & 0.9245 & 0.6113 \\
\hline $\log \mathrm{N}_{0}\left(\mathrm{CFU} \cdot \mathrm{mL}^{-1}\right)^{\mathrm{b}}$ & $7.47 \pm 0.25$ & $7.50 \pm 0.21$ & $7.50 \pm 0.13$ & $7.51 \pm 0.16$ \\
\hline$\delta\left(\mathrm{J}^{\mathrm{cm}}{ }^{-2}\right)^{\mathrm{c}}$ & 0.93 & 5.08 & 1.60 & 8.67 \\
\hline $\mathrm{p}(-)^{\mathrm{d}}$ & 0.46 & 0.53 & 0.56 & 0.72 \\
\hline $\log \mathrm{N}_{\text {res }}\left(C F U \cdot \mathrm{mL}^{-1}\right)^{\mathrm{e}}$ & 2.02 & 5.39 & 4.81 & 2.63 \\
\hline Listeria innocua & $*$ & $*$ & $*$ & * \\
\hline $\mathrm{RMSE}^{\mathrm{a}}$ & 0.4669 & 0.3984 & 0.5294 & 0.2539 \\
\hline $\mathrm{R}^{2}$ & 0.6951 & 0.4197 & 0.5075 & 0.3809 \\
\hline $\log \mathrm{N}_{0}\left(\mathrm{CFU} \cdot \mathrm{mL}^{-1}\right)^{\mathrm{b}}$ & $7.51 \pm 0.27$ & $7.49 \pm 0.23$ & $7.55 \pm 0.30$ & $7.44 \pm 0.11$ \\
\hline$\delta\left(\mathrm{J} \cdot \mathrm{cm}^{-2}\right)^{\mathrm{c}}$ & 0.37 & 9.01 & 2.66 & 14.71 \\
\hline$p(-)^{d}$ & 0.26 & 0.5 & 0.40 & 1.22 \\
\hline $\log N_{\text {res }}\left(C F U \cdot m L^{-1}\right)^{\mathrm{e}}$ & 2.70 & 1.05 & 0.00 & 0.00 \\
\hline
\end{tabular}

${ }^{a}$ RMSE: Root mean sum of squared error.

${ }^{\mathrm{b}} \log \left(\mathrm{N}_{0}\right)$ : predicted logarithm of initial count.

${ }^{\mathrm{c}} \delta$ : Model parameter

${ }^{\mathrm{d}} \mathrm{p}$ : Model parameter

${ }^{\mathrm{e}} \log \left(\mathrm{N}_{\mathrm{res}}\right)$ : predicted logarithm of residual count 


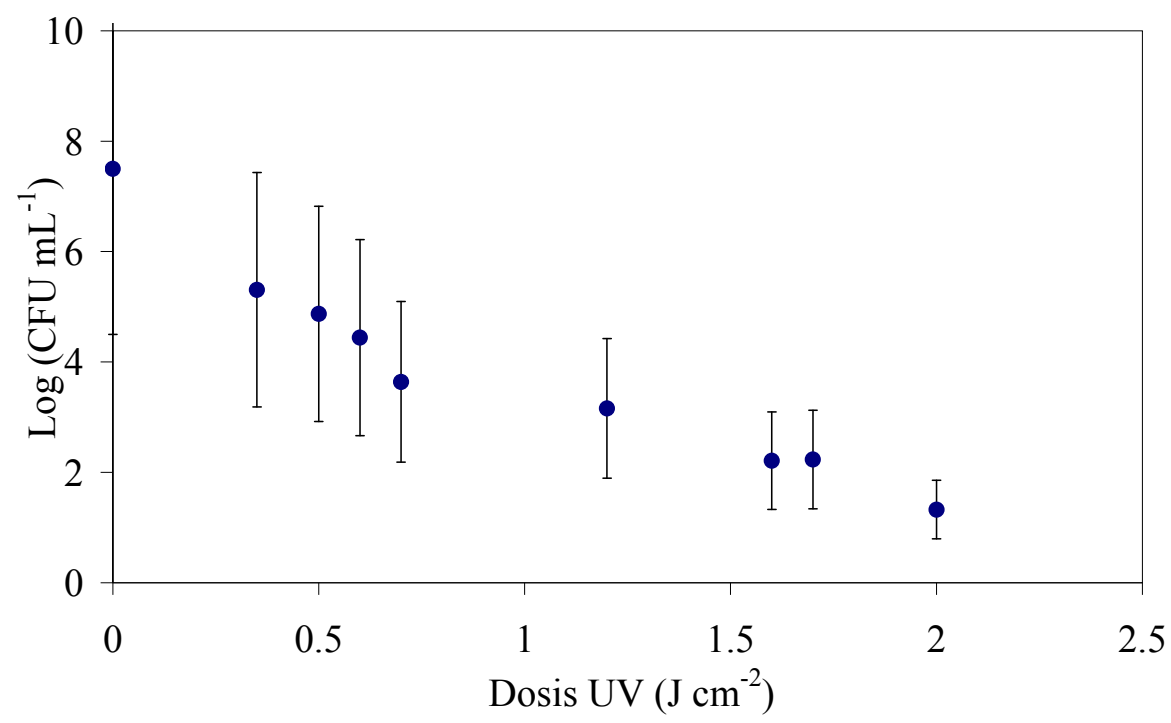

Figure A.3 - Inactivation kinetics of Salmonella enteritidis ATCC 13076 in LEW treated on the four lamps positive geometry device.

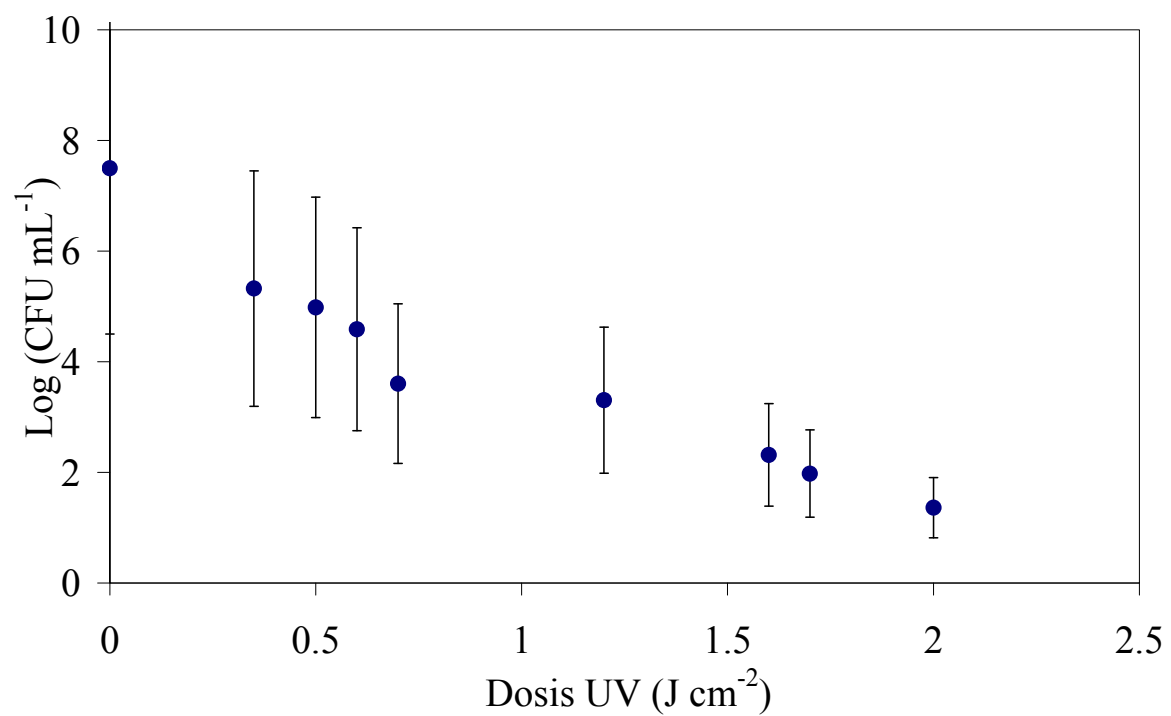

Figure A.4 - Inactivation kinetics of Escherichia coli ATCC 11775 in LEW treated on the four lamps positive geometry device. 



\section{Publications}

List of publications resulting from this $\mathrm{PhD}$ thesis:

\section{Published:}

Souza, P.M.; Fernandéz, A. (2011). Effects of UV-C on physicochemical quality attributes and Salmonella enteritidis inactivation in liquid egg products. Food Control, v. 22, p. 1385-1392.

Corrales, M.; Souza, P.M.; Stahl, M.; Fernández, A. (2012). Effects of the decontamination of a fresh tiger nuts' milk beverage (horchata) with short wave ultraviolet treatments (UV-C) on quality attributes. Innovative Food Science and Emerging Technologies, v. 13, p. 163-168.

Souza, P.M.; Fernandéz, A. (2012). Consumer acceptance of UV-C treated liquid egg products and preparations with UV-C treated eggs. Innovative Food Science and Emerging Technologies, v. 14, p. 107-114.

\section{Accepted:}

Souza, P.M.; Fernandéz, A. (2012). Rheological properties and protein quality of UV-C processed liquid egg products. Food Hydrocolloids. 
Publications

\section{Submitted:}

Souza, P.M.; Briviba, K. B.; Müller, A.; Fernández, A.; Stahl, M. (2012). Cyto-/ genotoxic and oxidative effects of a continuous UV-C treatment of liquid egg products. Food Chemistry.

Souza, P.M.; Müller, A.; Fernández, A.; Stahl, M. UV-C microbiological study in liquid egg products. Journal of Food Microbiology.

Souza, P.M.; Müller, A.; Mayer-Miebach, E.; Oehlke, K.; Stahl, M.; Greiner, R.; Fernández, A. UV-C effects on nutritional composition and functional properties of liquid egg products. Journal of Food Technology.

\section{In preparation:}

Souza, P.M.; Fernandéz, A. Effects of UV-C on physicochemical quality attributes and bacteria inactivation in liquid egg products using a novel 4 lamps bench reactor.

Souza, P.M.; Fernandéz, A. UV-C inactivation of Listeria innocua, Salmonella enteritidis, Staphylococcus aureus and Escherichia coli on liquid egg products.

Souza, P.M.; Fernandéz, A. Liquid egg products shelf life and inactivation kinetics of spoilage-related microorganisms UV-C treated.

Souza, P.M.; Fernandéz, A. Effects of UV-C treatements on functional properties of liquid egg products.

Souza, P.M.; Fernandéz, A. Lipid oxidation and choresterol reduction on liquid egg products treated by short-wave ultraviolet. 